Otto Roloff,

Sibylle Brander,

Ingo Barens,

Claudia Wesselbaum

\title{
Direktinvestitionen \\ und internationale \\ Steuerkonkurrenz
}


Otto Roloff, Sibylle Brander, Ingo Barens, Claudia Wesselbaum

\section{Direktinvestitionen und internationale Steuerkonkurrenz}

In der Arbeit wird untersucht, ob Steuern die räumliche Allokation von Kapital beeinflussen. Die vorliegenden Ergebnisse belegen, daß die beobachtbare internationale Steuer-Standort-Konkurrenz um grenzüberschreitende Investitionen und Investoren theoretisch und empirisch nicht begründet werden kann. Vor allem existieren keine verläßlichen Daten für Direktinvestitionen und effektive Steuersätze, um den Einfluß und das Gewicht der Besteuerung auf Standortentscheidungen statistisch erklären zu können. Mit Hilfe einer Veranlagungssimulation wird international vergleichend der Einfluß der Körperschaftsteuer auf das verwendbare Eigenkapitel einer Kapitalgesellschaft dargestellt.

Otto Roloff, Dr. rer. pol., Professor für Volkswirtschaftslehre, insbesondere Finanzwissenschaft an der Bergischen Universität-Gesamthochschule Wuppertal.

Ingo Barens, Dr. rer. pol., Privatdozent, z.Z. Lehrstuhlvertretung im Fachbereich Wirtschaftswissenschaft an der Bergischen Universität-Gesamthochschule Wuppertal.

Claudia Wesselbaum, Dr. rer. oec., Wissenschaftliche Mitarbeiterin im Fachbereich Wirtschaftswissenschaft der Bergischen Universität-Gesamthochschule Wuppertal.

Sibylle Brander, Dipl.-Volksw., Wissenschaftliche Mitarbeiterin im Fachbereich Wirtschaftswissenschaft der Bergischen Universität-Gesamthochschule Wuppertal. 
Direktinvestitionen und internationale Steuerkonkurrenz 


\section{FINANZWISSENSCHAFTLICHE SCHRIFTEN}

Herausgegeben von den Professoren

Albers, Krause-Junk, Littmann, Oberhauser, Pohmer, Schmidt

Band 58

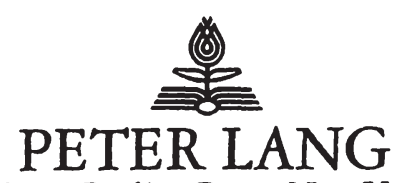

Frankfurt am Main - Berlin - Bern - New York - Paris - Wien

Otto Roloff, Sibylle Brander, Ingo Barens and Claudia Wesselbaum - 978-3-631-75210-4

Downloaded from PubFactory at 01/11/2019 07:04:40AM

via free access 


\section{Otto Roloff, Sibylle Brander, Ingo Barens, Claudia Wesselbaum}

\section{Direktinvestitionen und internationale Steuerkonkurrenz}

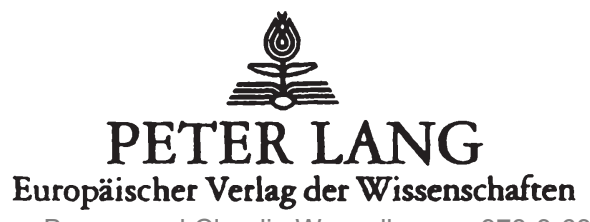


Die Deutsche Bibliothek - CIP-Einheitsaufnahme

Direktinvestitionen und internationale Steuerkonkurrenz / Otto Roloff ... - Frankfurt am Main ; Berlin ; Bern ; New York ; Paris ; Wien : Lang, 1994

(Finanzwissenschaftliche Schriften ; Bd. 58) ISBN 3-631-46832-6

NE: Roloff, Otto; GT

Open Access: The online version of this publication is published on www.peterlang.com and www.econstor.eu under the international Creative Commons License CC-BY 4.0. Learn more on how you can use and share this work: http://creativecommons. org/licenses/by/4.0.

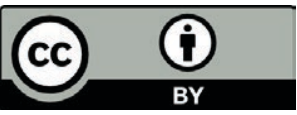

This book is available Open Access thanks to the kind support of ZBW - Leibniz-Informationszentrum Wirtschaft.

\author{
ISSN 0170-8252 \\ ISBN 3-631-46832-6 \\ ISBN 978-3-631-75210-4 (eBook) \\ (C) Peter Lang GmbH \\ Europäischer Verlag der Wissenschaften \\ Frankfurt am Main 1994 \\ Alle Rechte vorbehalten.
}

Das Werk einschließlich aller seiner Teile ist urheberrechtlich geschützt. Jede Verwertung außerhalb der engen Grenzen des Urheberrechtsgesetzes ist ohne Zustimmung des Verlages unzulässig und strafbar. Das gilt insbesondere für Vervielfältigungen, Übersetzungen, Mikroverfilmungen und die Einspeicherung und Verarbeitung in elektronischen Systemen.

Printed in Germany 134567 


\section{Vorwort}

Der Europäische Binnenmarkt wird die bestehenden nationalstaatlichen Finanzwirtschaften weiter verändern. Seit längerer Zeit diskutieren Finanzwissenschaftler und Steuerpolitiker über die Harmonisierung von Steuersystemen in den Mitgliedsländern der Europäischen Gemeinschaft. Die Vereinheitlichung bestimmter Steuern sei notwendig, um die Gemeinschaft mit eigenen Steuerquellen ausstatten und/oder um supranationale Effizienz erreichen zu können. Vereinheitlichung und Abgabe von Steuern mindern aber andererseits die nationale Finanzsouveränität und damit die politische Handlungsfähigkeit der Mitgliedsstaaten.

Wir halten die Frage, inwieweit Steuersystem. finanzföderalistische Organisationsstruktur und staatliches Ausgabengebaren im Europäischen Binnenmarkt eine effiziente Allokation interdependent bedingen, für eine noch weitgehend ungeklärte Frage, zu deren Erforschung wir mit dem gemeinsamen Forschungsprojekt „Finanzwirtschaftlicher Föderalismus im Europäischen Binnenmarkt unter besonderer Beachtung unternehmerischer Standortentscheidungen" beitragen möchten.

Als Ergebnis der ersten Arbeitsphase von 1990 - 1992 liegen die beiden Forschungsberichte „Direktinvestitionen und internationale Steuerkonkurrenz" und „Empirische Analyse der Autonomie dezentraler Finanzwirtschaften in der Europäischen Gemeinschaft" vor sowie zwei zugehörige Dissertationen „Internationale Steuerbelastungsvergleiche" (Claudia Wesselbaum-Neugebauer) und „Kommunale Finanzautonomie und ihre Bedeutung für eine effiziente lokale Finanzwirtschaft" (Hans-Georg Napp).

Wir danken der VW-Stiftung für die Förderung des Forschungsprojektes. Den anonymen Gutachtern der Stiftung sowie allen Kollegen, mit denen wir über unsere Arbeit diskutieren konnten, danken wir für die vielfältigen und hilfreichen Anregungen.

Bernd Rahmann, Paderborn

Otto Roloff. Wuppertal

Juli 1993 
Otto Roloff, Sibylle Brander, Ingo Barens and Claudia Wesselbaum - 978-3-631-75210-4 Downloaded from PubFactory at 01/11/2019 07:04:40AM via free access 


\section{Inhaltsverzeichnis}

Verzeichnis der Tabellen ................... XIII

Verzeichnis der Abbildungen .................. XVII

Verzeichnis der Abkürzungen $\ldots \ldots \ldots \ldots \ldots \ldots$ XIX

Verzeichnis der Symbole .................... XXIII

Kapitel $\ldots \ldots \ldots \ldots \ldots \ldots$ XXIII

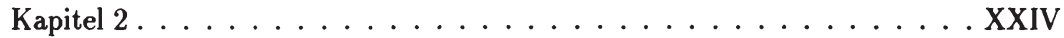

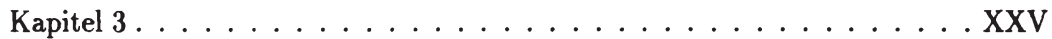

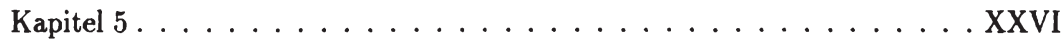

$\begin{array}{ll}\text { Einleitung } & 1\end{array}$

1 Investitionen und Steuern: einige theoretische Grundprobleme $\quad 9$

1.1 Die Analyse von Steuerwirkungen auf Direktinvestitionen in Investitionsmodellen .......................... 9

1.2 Investitionen ohne Anpassungskosten: das Jorgenson-Modell . . . . . . . 10

1.2.1 Darstellung ...................... 10

1.2.1.1 Der theoretische Ansatz .............. 10

1.2.1.2 Der empirische Ansatz . . . . . . . . . . . 12

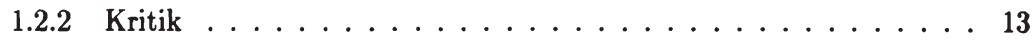

1.3 Investitionen mit Anpassungskosten: das $q$-Modell . . . . . . . . . . . 14

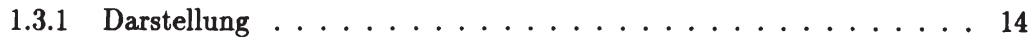


$1.3 .2 \quad$ Kritik . . . . . . . . . . . . . . . . 18

1.3.2.1 Das Problem der Anpassungskosten . . . . . . . . . 18

1.3.2.2 Das Problem der Identität von marginalem und durchschnittlichem q . . . . . . . . . . . . . . 19

1.4 Das kapitaltheoretische Grundproblem in der Investitionstheorie . . . . . 21

1.5 Eine neue Perspektive: der Einfluß asymmetrischer Informationen auf Investitionen . . . . . . . . . . . . . . . . 27

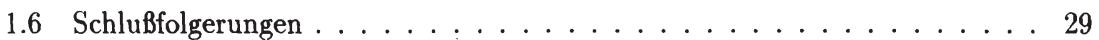

2 Steuerbelastung und verwendbares Eigenkapital: eine Veranlagungssimulation

2.1 Steuerliche Gewinnermittlung im jeweiligen Quellenstaat . . . . . . . 32

2.1.1 Steuerbelastung in der Bundesrepublik Deutschland, in Frankreich und in Großbritannien . . . . . . . . . . . . . 35

2.1.2 Rückführung des ausgewiesenen Gewinnes an eine bundesdeutsche Mutterkapitalgesellschaft unter Berücksichtigung der bestehenden Doppelbesteuerungsabkommen . . . . . . . . . . . . . 38

2.1.3 Resultate . . . . . . . . . . . . . . . . 44

2.2 Bestimmung der erforderlichen Rendite vor Unternehmensteuern für die Erzielung einer festgelegten Rendite nach Unternehmensteuern unter Berücksichtigung der Finanzierungsart sowie der bestehenden Doppelbesteuerungsabkommen . . . . . . . . . . . . . . . . 44

2.2.1 Mindestrendite einer bundesdeutschen Mutterkapitalgesellschaft vor Unternehmensteuern . . . . . . . . . . . . . . . . 48

2.2.2 Mindestrendite einer in- bzw. ausländischen Tochterkapitalgesellschaft vor Steuern . . . . . . . . . . . . . . . 50

2.2.3 Versteuerung eines über die Mindestrendite hinausgehenden Gewinnes bei einer bundesdeutschen Mutterkapitalgesellschaft . . . . . 56

2.2 .4 Resultate . . . . . . . . . . . . . . . 57 
3.1 Effiziente effektive Steuersätze . . . . . . . . . . . . 6 61

3.1.1 Annahmen zur Ermittlung effizienter effektiver Steuersätze . . . . . 61

3.1.2 Effiziente effektive Steuersātze bei Freistellung von im Ausland erwirtschafteten Erträgen im Inland (Source Principle) . . . . . . . 64

3.1.3 Effiziente effektive Steuersätze bei Freistellung von im Ausland erwirtschafteten Erträgen im Ausland (Residence Principle) . . . . 68

3.1.4 Effiziente effektive Steuersätze bei Vollanrechnung von im Ausland gezahlten Steuern im Inland (Vollanrechnungs- bzw. Erstattungsverfahren) ....................... 69

3.1.5 Effiziente effektive Steuersätze bei Teilanrechnung von im Ausland gezahlten Steuern im Inland (Teilanrechnungsverfahren) . . . . . 70

3.1.6 Zusammenfassung der Ergebnisse ............... 72

3.2 Internationale Steuerkonkurrenz . . . . . . . . . . . . . 74

3.2.1 Steuerkonkurrenz um grenzüberschreitende Investitionen . . . . . . 78

3.2.2 Steuerharmonisierung als Grundlage supranational optimaler Kapitalallokation .................. 80

4 Direktinvestitionen und ihre statistische Erfassung

4.1 Theoretische Abgrenzung der Direktinvestitionen von Portfolioinvestitionen 84

4.2 Methoden zur statistischen Erfassung von Direktinvestitionen - ein Überblick 86

4.2.1 Stromgrößen versus Bestandsgrößen . . . . . . . . . . 88

4.2.2 Abgrenzung von Inländern und Ausländern . . . . . . . . . . . 91

4.2.3 Statistische Abgrenzung von Direktinvestor, Direktinvestitionsunternehmen und Direktinvestitionskapital . . . . . . . . . 92

4.2.3.1 Direktinvestor. . . . . . . . . . . . . 93 


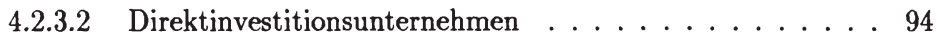

4.2.3.3 Direktinvestitionskapital . . . . . . . . . . 100

4.3 Bundesrepublik Deutschland . . . . . . . . . . . . 106

4.3.1 Direktinvestitionen in der Zahlungsbilanzstatistik der Deutschen Bundesbank . . . . . . . . . . . . . . . . . 108

4.3.2 Transferstatistik des Bundesministeriums für Wirtschaft $\ldots \ldots 118$

4.3.3 Bestandsstatistik der Deutschen Bundesbank . . . . . . . . . . . 127

4.3.4 Deutsche Direktinvestitionen im Ausland und ausländische Direktinvestitionen in der Bundesrepublik Deutschland - ein Vergleich der in den bundesdeutschen Statistiken ausgewiesenen Daten . . . . . 139

4.3.4.1 Zahlungsbilanzstatistik der Deutschen Bundesbank versus Transferstatistik des Bundesministeriums für Wirtschaft . 142

4.3.4.2 Veränderung des Bestands an Direktinvestitionen (Buchwerte) versus Zahlungsbilanzwerte . . . . . . . . 150

4.4 Direktinvestitionen in der US-amerikanischen Statistik $\ldots \ldots \ldots \ldots$

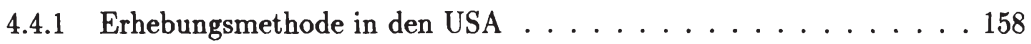

4.4.2 Abgrenzung von Direktinvestor und Direktinvestitionsunternehmen in $\operatorname{der}$ US-Statistik . . . . . . . . . . . . . 161

4.4.3 Direktinvestitionskapital in der US-Statistik $\ldots \ldots \ldots \ldots 7$

4.4.4 Bestand an Direktinvestitionen in der US-Statistik . . . . . . . 175

4.4.5 Schätzverfahren in den USA . . . . . . . . . . . 178

4.4.6 Direktinvestitionen der USA im Ausland und ausländische Direktinvestitionen in den USA in den Jahren 1982 bis 1991 (Transaktionswerte) . . . . . . . . . . . . . . . 185

4.4.7 Direktinvestitionen der Bundesrepublik Deutschland in den USA und Direktinvestitionen der USA in der Bundesrepublik Deutschland in bundesdeutscher und in US-amerikanischer Statistik . . . 190 
4.5 Weitere Argumente gegen quantitativ-empirische Studien mit aggregierten Daten für Direktinvestitionen . . . . . . . . . . . . . . . . . 192

5 Steuersätze im internationalen Vergleich

5.1 Berechnungen auf Basis der Daten der Volkswirtschaftlichen Gesamtrechnung

5.2 Tarifvergleich . . . . . . . . . . . . . . . . . 205

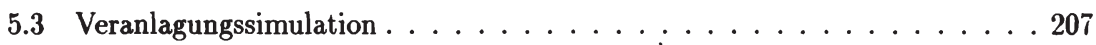

5.3.1 Durchschnittlicher effektiver Steuersatz . . . . . . . . . . 208

5.3.2 Effektiver Grenzsteuersatz anhand des Modells von King und Fullerton . . . . . . . . . . . . . . . . 217

5.3.2.1 Theoretische Grundlage $\ldots \ldots \ldots . \ldots 218$

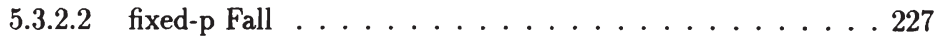

5.3.2.3 fixed-r Fall $\ldots \ldots \ldots \ldots \ldots \ldots \ldots \ldots \ldots$

5.3.2.4 Ökonomische Abschreibung . . . . . . . . . . . . 245

5.3.2.5 Investitionszulagen $\ldots \ldots \ldots \ldots \ldots \ldots$

5.3.2.6 Bewertung des Vorratsvermögens . . . . . . . . . . . . 251

5.3.2.7 Resümee und abschließende Bemerkungen . . . . . . . . 252

5.3 .3 OECD $\ldots \ldots \ldots \ldots \ldots \ldots \ldots \ldots \ldots \ldots \ldots \ldots \ldots \ldots$

Anhang Kapitel $5 \ldots \ldots$. . . . . . . . . . . . . . . . . . . . . 259

Literaturverzeichnis:

Quellenverzeichnis: 
Otto Roloff, Sibylle Brander, Ingo Barens and Claudia Wesselbaum - 978-3-631-75210-4 Downloaded from PubFactory at 01/11/2019 07:04:40AM via free access 


\section{Tabellenverzeichnis}

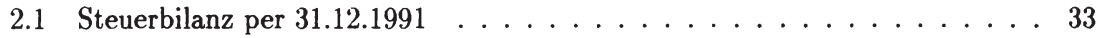

2.2 Steuerliche Gewinnermittlung vom 1.1.1991-31.12.1991 . . . . . . . . . 34

2.3 Steuerbelastung einer Kapitalgesellschaft in der Bundesrepublik Deutschland, in Frankreich bzw. in Großbritannien . . . . . . . . . . . . . . 37

2.4 Steuerbelastung unter Berücksichtigung der Doppelbesteuerungsabkommen 40

2.5 Zu versteuerndes Einkommen, verwendbares Eigenkapital und Zufluß bei einem deutschen Aktionär unter Berücksichtigung der Ausschüttung anhand des Handelsbilanzgewinns . . . . . . . . . . . . . . . . . 43

2.6 Finanzleistungen einer bundesdeutschen Mutterkapitalgesellschaft bei der Ausgabe neuer Aktien bzw. der Aufnahme von Fremdkapital bei Kapitaleinkünften aus einer Beteiligung bzw. der Vergabe von Fremdkapital . . . . 47

2.7 Mindestrendite einer Tochterkapitalgesellschaft vor Unternehmensteuern bei einer Zins- bzw. Dividendenleistung an eine bundesdeutsche Mutterkapitalgesellschaft in Höhe von $\mathrm{p}_{M} \ldots \ldots \ldots \ldots 3$

2.8 Rendite einer bundesdeutschen Mutterkapitalgesellschaft nach Unternehmensteuern bei einem zusätzlichen Gewinn einer Tochterkapitalgesellschaft in Höhe einer Einheit . . . . . . . . . . . . . . . . . . . . . 58

3.1 Entscheidungsrelevante effiziente effektive Steuersätze . . . . . . . . . . 73

3.2 Die Wirkung von Steuersatzsenkungen auf die Steuereinnahmen nach Direktinvestitionen und Zuzug von Geschäftssitzen . . . . . . . . . . . . . 75

3.3 Verteilung von Steuererträgen auf Wohnsitz- und Quellenland . . . . . . 76

4.1 Deutsche Direktinvestitionen in den EG-Mitgliedsstaaten, in den USA und in Japan sowie Direktinvestitionen der EG-Mitgliedsstaaten, der USA und Japans in der Bundesrepublik Deutschland im Jahr 1986 - Gegenüberstellung der Ergebnisse der Transferstatistik des Bundesministeriums für Wirtschaft nach bisheriger und neuer Erfassungsmethode . . . . . . . . . . . 126 
4.2 Deutsche Direktinvestitionen im Ausland und ausländische Direktinvestitionen in der Bundesrepublik Deutschland in Mio. DM (Transaktionswerte und Bestände), 1982 bis 1991 . . . . . . . . . . . . . . . . 140

4.3 Regionale Struktur des Bestands an deutschen Direktinvestitionen im Ausland und an ausländischen Direktinvestitionen in der Bundesrepublik Deutschland nach ausgewählten Ländern, Ende 1990 . . . . . . . . . 143

4.4 Deutsche Direktinvestitionen in den EG-Mitgliedsstaaten (Transaktionswerte) in Mio. DM und in \% aller deutschen Direktinvestitionen im Ausland, 1982 bis $1991 \ldots \ldots$. . . . . . . . . . . . . . . . 144

4.5 Direktinvestitionen der EG-Mitgliedsstaaten in der Bundesrepublik Deutschland (Transaktionswerte) in Mio. DM und in \% aller ausländischen Direktinvestitionen in der Bundesrepublik, 1982 bis $1991 \ldots . . \ldots 145$

4.6 Deutsche Direktinvestitionen im Ausland und ausländische Direktinvestitionen in der Bundesrepublik Deutschland - Gegenüberstellung von Zahlungsbilanzstatistik der Deutschen Bundesbank und Transferstatistik des Bundesministeriums für Wirtschaft, 1982 bis $1991 \ldots \ldots . \ldots 151$

4.7 US-amerikanische Direktinvestitionen im Ausland in Mio. US-\$ (Transaktionswerte) nach Komponenten und ausgewählte Transaktionen zwischen US-Muttergesellschaften und ihren Finanzierungstochtergesellschaften auf den Niederländischen Antillen, 1982 bis $1991 \ldots$. . . . . . . . . . . 176

4.8 US-amerikanische Direktinvestitionen im Ausland und ausländische Direktinvestitionen in den USA in Mio. US-\$ (Bestände nach Buchwert-, Wiederbeschaffungskosten- und Marktwertmethode), 1982 bis 1991 . . . 179

4.9 US-amerikanische Direktinvestitionen im Ausland und ausländische Direktinvestitionen in den USA in Mio. US-\$ (Transaktionswerte), 1982 bis 1991

4.10 Deutsche Direktinvestitionen in den USA und US-amerikanische Direktinvestitionen in der Bundesrepublik Deutschland in Mio. DM (Transaktionswerte), 1987 bis 1991

5.1 Steuern vom Gewinn, Ertrag und Vermögen insgesamt (Gesamtsteuerlast) im Verhältnis zum bereinigten Bilanzgewinn (cash flow) für Kapitalgesellschaften des Maschinenbaus und Bekleidungsgewerbes bei tatsächlichem Ausschüttungsverhältnis im internationalen Vergleich in v. H. . . . . . 209 
5.3 fixed-p Fall $\ldots \ldots \ldots \ldots \ldots \ldots \ldots \ldots \ldots \ldots \ldots \ldots \ldots$

5.4 Interner Kalkulationssatz $(\sigma=\mathrm{p})$ bei einer Ausschüttung in Höhe des Ka-

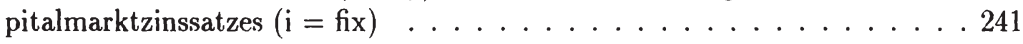

5.5 fixed-r Fall . . . . . . . . . . . . . . . . . . . . 244

5.6 Auswirkungen der ökonomischen und steuerlichen Abschreibung auf die Steuerzahllast eines Unternehmens während eines Wirtschaftsjahres . . . 248

5.7 Steuerliche Auswirkungen variierender ökonomischer und steuerlicher Abschreibungsbeträge auf die Steuerbelastung ohne Berücksichtigung von Inflation . . . . . . . . . . . . . . . . . . . 249

A 1 Vermögenssteuer- und Einkommensteuersatz in Abhängigkeit von der Finanzierungsart für Großbritannien, die Bundesrepublik Deutschland und die Vereinigten Staaten von Amerika laut King/Fullerton . . . . . . . 261 
Otto Roloff, Sibylle Brander, Ingo Barens and Claudia Wesselbaum - 978-3-631-75210-4 Downloaded from PubFactory at 01/11/2019 07:04:40AM via free access 


\section{Abbildungsverzeichnis}

4.1 Saldo der deutschen Direktinvestitionen im Ausland und der ausländischen Direktinvestitionen in der Bundesrepublik Deutschland in Mrd. DM (Transaktionswerte), 1982 bis $1991 \ldots \ldots \ldots 14 \ldots \ldots \ldots$

4.2 Saldo der deutschen Direktinvestitionen in Frankreich und der französischen Direktinvestitionen in der Bundesrepublik Deutschland in Mrd. DM (Transaktionswerte), 1982 bis $1991 \ldots \ldots \ldots$. . . . . . . . . . . . . . .

4.3 Saldo der deutschen Direktinvestitionen in Großbritannien und der britischen Direktinvestitionen in der Bundesrepublik Deutschland in Mrd. DM (Transaktionswerte), 1982 bis 1991

4.4 Saldo der deutschen Direktinvestitionen in den Niederlanden und der niederländischen Direktinvestitionen in der Bundesrepublik Deutschland in Mrd. DM (Transaktionswerte), 1982 bis $1991 \ldots \ldots$. . . . . . . . 148

4.5 Saldo der deutschen Direktinvestitionen in der Belgisch-Luxemburgischen Wirtschaftsunion und der belgisch-luxemburgischen Direktinvestitionen in der Bundesrepublik Deutschland in Mrd. DM (Transaktionswerte), 1982 bis 1991

4.6 US-amerikanische Direktinvestitionen im Ausland in Mrd. US-\$ (Transaktionswerte), 1982 bis $1991 \ldots \ldots \ldots . \ldots . \ldots 156$

4.7 Ausländische Direktinvestitionen in den USA in Mrd. US- \$ (Transaktionswerte), 1982 bis $1991 \ldots \ldots$. . . . . . . . . . . . . . . . . . . . . . .

4.8 Saldo der US-amerikanischen Direktinvestitionen im Ausland und der ausländischen Direktinvestitionen in den USA in Mrd. US-\$ (Transaktionswerte), 1982 bis $1991 \ldots \ldots$. . . . . . . . . . . . . . . . . . . . . .

4.9 Ausländische Direktinvestitionen in den USA - Beziehungen zwischen den Mitgliedern der „foreign parent group" und US-amerikanischer Tochtergesellschaft . . . . . . . . . . . . . . . . . . . 165

5.1 Kapitalgeber, Finanzierungsart, Investor, Anlageart . . . . . . . . . 221

A 1 Unternehmensteuerbelastungsvergleiche .............. . 260 
Otto Roloff, Sibylle Brander, Ingo Barens and Claudia Wesselbaum - 978-3-631-75210-4 Downloaded from PubFactory at 01/11/2019 07:04:40AM via free access 


\section{Verzeichnis der Abkürzungen}

Abg.

Abs.

Abschn.

Abt.

ADS

AfA

AHK

AIG

AktG

Anm.

AO

Art.

AStG

AVW

AWG

$\mathrm{BBk}$

BDI

BEA

BerlinFG

BGBl.

BLUE

BMWi

BStBl

Buchst.

DATEV

DB

DBA

DDR-IG

DIHT

DIW

DStR

EC

EG

EH

EntwLStG

ErfVO

EStDV

EStG

EStR

eurostat
Abgeordneter

Absatz

Abschnitt

Abteilung

Adler/Düring/Schmaltz

Absetzung für Abnutzung

Außenhandelskammer

Außeninvestitionsgesetz

Aktiengesetz

Anmerkung

Abgabenordnung

Artikel

Außensteuergesetz

Verordnung zur Durchführung des Außenwirtschaftsgesetzes/

Außenwirtschaftsverordnung

Außenwirtschaftsgesetz

Deutsche Bundesbank

Bundesverband der Deutschen Industrie

Bureau of Economic Analysis

Berlinförderungsgesetz

Bundesgesetzblatt

Belgisch-Luxemburgische Wirtschaftsunion

Bundesministerium für Wirtschaft

Bundessteuerblatt

Buchstabe

Datenverarbeitungsorganisation des steuerberatenden Berufes in der Bundesrepublik Deutschland

Der Betrieb

Doppelbesteuerungsabkommen

DDR-Investitionsgesetz

Deutscher Industrie und Handelstag

Deutsches Institut für Wirtschaftsforschung

Deutsches Steuerrecht

European Community

Europäische Gemeinschaft

Einheiten

Entwicklungsländer-Steuergesetz

Erfinderverordnung

Einkommensteuer-Durchführungsverordnung

Einkommensteuergesetz

Einkommensteuer-Richtlinie

Statistisches Amt der Europäischen Gemeinschaften 


\section{XX}

e. V.

EWG

FASB

FiFo

Fn.

Fördergebiets G

GBI.

GewStG

GWG

$\mathrm{HdJ}$

$\mathrm{HGB}$

$\mathrm{Hj}$.

ifo

IFS

IMF

Inv'uulG

InvZulV()

iW

JÜ

hapErhStC

KStG

KSt.R

LiFo

Mutterkapitalgesell.

OECD

SolZ(

Steuerpfl.

UN

UStG
hapESt

eingetragener Verein

Europäische Wirtschaftsgemeinschaft

Financial Accounting Standards Board Statements

First in - First out

Fußnote

Gesetz über Sonderabschreibungen und Abzugsbeträge im

Fördergebiet (Fördergebietsgesetz)

Cresetzblatt

Gewerbesteuergesetz

geringwertige Wirtschaftsgüter

Handbuch des Jahresabschlusses in Einzeldarstellungen

Handelsgesetzbuch

Halbjahr

Institut für Wirtschaftsforschung

The Institute for Fiscal Studies

International Monetary Fund

Investitionszulagengesetz

Investitionszulagenverordnung

Institut der deutschen Wirtschaft

Jahresüberschuß

Kapitalertragssteuer

Gesetz über steuerrechtliche Maßnahmen bei Erhöhung des

Nennkapitals aus Gesellschaftsmitteln

Körperschaftsteuergesetz

Körperschaftsteuer-Richtlinic

Last in - First out

Mutterkapitalgesellschaft

Organisation for Economic Co-operation and Development

Gesetz zur Einführung eines befristeten Solidaritätszuschlags und zur Änderung von Verbraucher- und anderen Gesetzen (Solidaritätszuschlagsgesetz)

Steuerpflichtiger

United Nations

Umsatzsteuergesetz

VermB(

Vermögensbildungsgesetz 


\section{XXI}

Versicherungsg. Versicherungsgesellschaft

VGR

VStG

Volkswirtschaftliche Gesamtrechnung

VZ

Vermögensteuergesetz

Veranlagungszeitraum

WiSt

Wirtschaftswissenschaftliches Studium

WoPG

Wohnungsbauprämiengesetz

WSI

Wirtschafts- und Sozialwissenschaftliches Institut des

Deutschen Gewerkschaftsbunds

ZEW

Zentrum für Europäische Wirtschaftsforschung

ZRFG

Zonenrandförderungsgesetz 
Otto Roloff, Sibylle Brander, Ingo Barens and Claudia Wesselbaum - 978-3-631-75210-4 Downloaded from PubFactory at 01/11/2019 07:04:40AM via free access 


\section{Verzeichnis der Symbole}

\section{Kapitel 1}

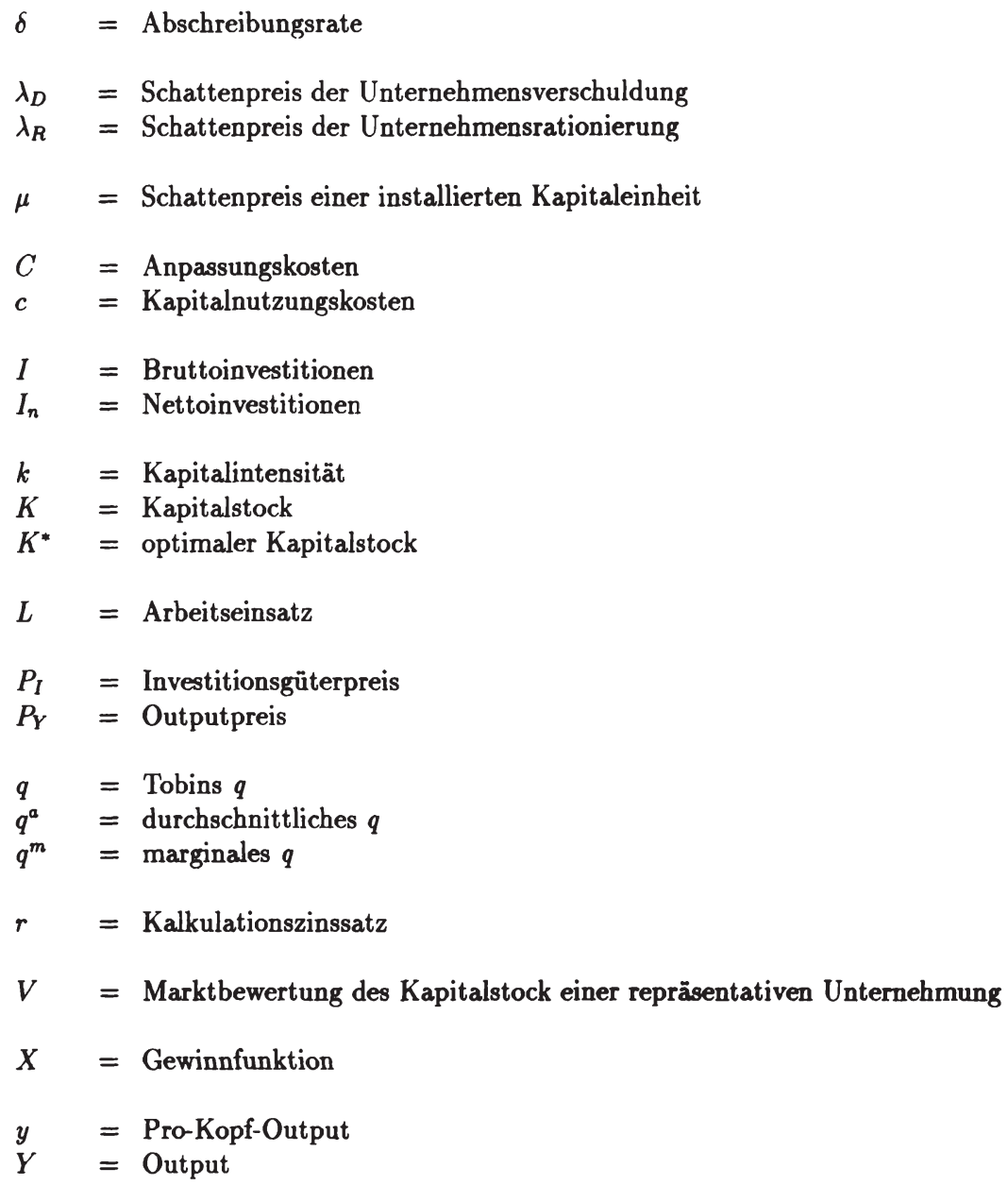




\section{XXIV}

\section{Kapitel 2}

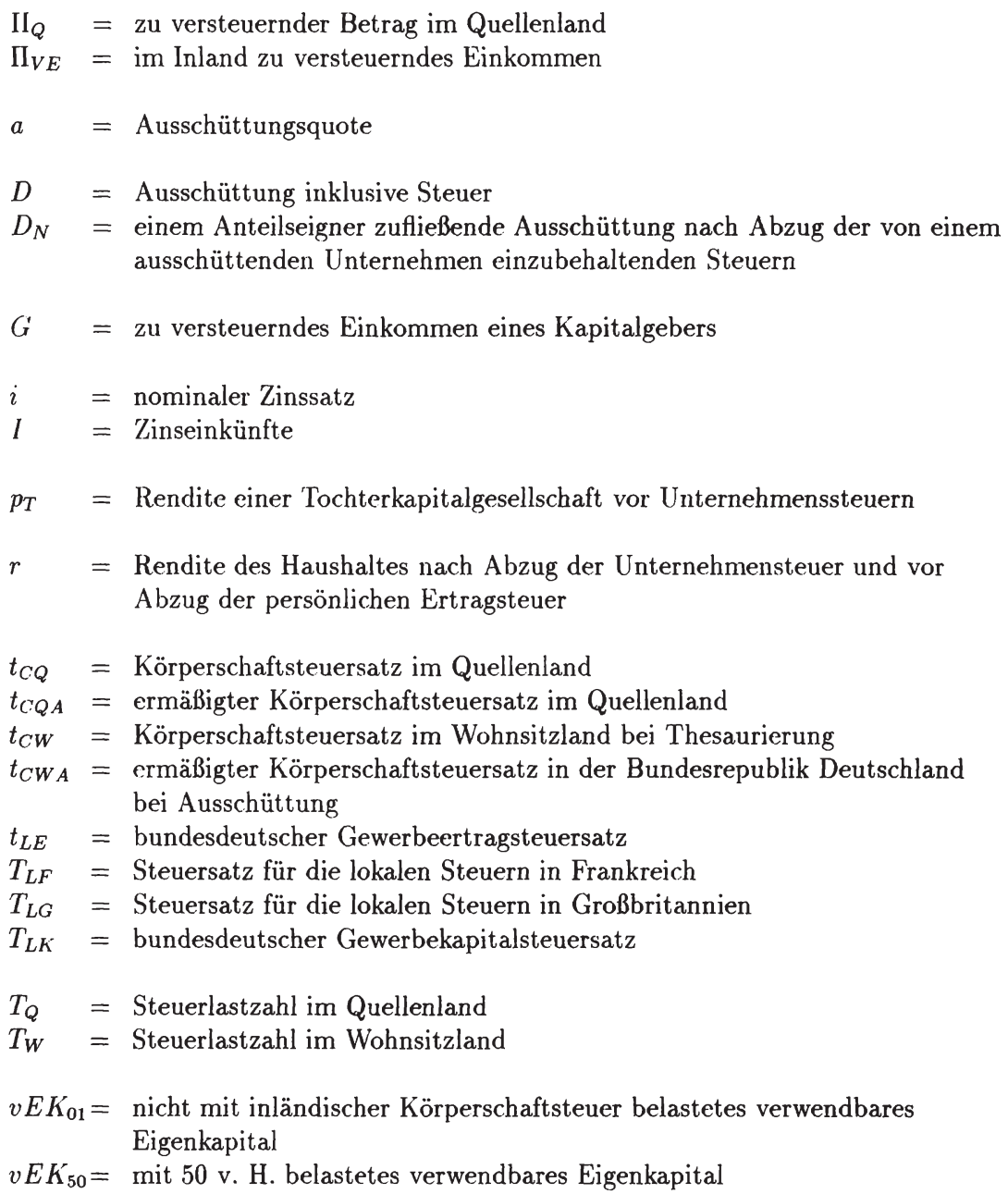




\section{Kapitel 3}

\begin{tabular}{|c|c|}
\hline$Q$ & $=$ Quellenland \\
\hline$W$ & $=$ Wohnsitzland \\
\hline$X_{W}, X_{Q}$ & $=$ Output im Wohnsitz- bzw. Quellenland \\
\hline$L_{W}, L_{Q}$ & $=$ Arbeitsinput im Wohnsitz- bzw. Quellenland \\
\hline$K_{W}, K_{Q}$ & $=$ Kapitaleinsatz im Wohnsitz- bzw. Quellenland \\
\hline$F_{W}, F_{Q}$ & $=$ Produktionsfunktionen im Wohnsitz- bzw. Quellenland \\
\hline$p_{W}, p_{Q}$ & $=$ Output-Preis im Wohnsitz- bzw. Quellenland \\
\hline$w_{W}, w_{Q}$ & $=$ Lohnsatz im Wohnsitz- bzw. Quellenland \\
\hline$p_{K W}, p_{K Q}$ & $=$ Kapitalgutpreis im Wohnsitz- bzw. Quellenland \\
\hline$i_{W}, i_{Q}$ & $=$ Zinssatz im Wohnsitz- bzw. Quellenland \\
\hline$t^{*}, t_{W}^{*}, t_{Q}^{*}$ & $\begin{aligned}= & \text { gesetzlicher Steuersatz bzw. gesetzlicher Steuersatz im } \\
& \text { Wohnsitz- bzw. Quellenland }\end{aligned}$ \\
\hline$t_{W}, t_{Q}$ & $=$ Durchschnittssteuersatz im Wohnsitz- bzw. Quellenland \\
\hline$t_{W}^{\prime}, t_{Q}^{\prime}$ & $=$ Grenzsteuersatz im Wohnsitz- bzw. Quellenland \\
\hline$\Pi_{W}, \Pi_{Q}$ & $=$ Bemessungsgrundlage im Wohnsitz- bzw. Quellenland \\
\hline$x_{W}, x_{Q}$ & $=$ Bemessungsfaktor im Wohnsitz- bzw. Quellenland \\
\hline$P, P_{W}, P_{Q}$ & $\begin{aligned}= & \text { Ökonomischer Gewinn bzw. ökonomischer Gewinn im } \\
& \text { Wohnsitz- bzw. Quellenland }\end{aligned}$ \\
\hline$t_{W}(P), t_{W}\left(P_{W}\right), t_{Q}\left(P_{Q}\right)$ & $\begin{aligned}= & \text { Steuerbetragsfunktion mit/ohne Progressionsvorbehalt im } \\
& \text { Wohnsitzland- bzw. Quellenland }\end{aligned}$ \\
\hline$t_{W}^{\prime}(P), t_{W}^{\prime}(P W), t_{Q}^{\prime}\left(P_{Q}\right)$ & $\begin{aligned}= & \text { Grenzsteuersatzfunktion mit/ohne Progressionsvorbehalt im } \\
& \text { Wohnsitzland bzw. Quellenland }\end{aligned}$ \\
\hline Ü & $=$ betrieblicher Überschuß \\
\hline$\beta$ & $=$ Anteil des ökonomischen Gewinns am betrieblichen Überschuß \\
\hline$T, T_{W}, T_{Q}$ & $=$ Steuerbetrag bzw. Steuerbetrag im Wohnsitz- bzw. Quellenland \\
\hline$r_{W}, r_{Q}$ & $=$ Durchschnittsrendite im Wohnsitz- bzw. Quellenland \\
\hline$r_{W}^{\prime}, r_{Q}^{\prime}$ & $=$ Rendite im Wohnsitz- bzw. Quellenland \\
\hline$r_{W}^{\prime \text { netto }}, r_{Q}^{\text {nnetto }}$ & $=$ Rendite nach Steuern im Wohnsitz- bzw. Quellenland \\
\hline$i_{W}^{\text {netto }}, i_{Q}^{\text {netto }}$ & $=$ Zinssatz nach Steuern im Wohnsitz- bzw. Quellenland \\
\hline$w, w^{e r w}$ & $=$ Devisenkurs bzw. erwarteter Devisenkurs \\
\hline$\epsilon_{t}$ & $=$ Durchschnittssteuersatzelastizität \\
\hline$\alpha_{w}, \alpha_{Q}, \epsilon_{T}$ & $=$ Steuerbetragselastizität im Wohnsitz- bzw. Quellenland \\
\hline$\mu$ & $=$ Anteil des ökonomischen Gewinns im Wohnsitzland \\
\hline & dite-Kapitaleinsatz-Elastizität \\
\hline
\end{tabular}




\section{XXVI}

\section{Kapitel 5}

$$
\begin{aligned}
& \pi \quad=\text { körperschaftsteuerpflichtiger Gewinn } \\
& \pi_{E}=\text { ökonomischer Gewinn } \\
& \alpha_{K} \quad=\text { Gewichtung des Anlagevermögens }
\end{aligned}
$$

$\tau=$ Grenzsteuersatz inklusive Körperschaftsteuer, Vermögensteuer sowie lokaler Ertrag- und Substanzsteuer für ein Unternehmen

$\sigma \quad=$ interner Kalkulationssatz

$\delta \quad=$ ökonomischer Abschreibungssatz

$\epsilon \quad=$ in der ersten Periode realisierter Gewinn bei einem Vermögenszuwachs um eine Einheit

$\mu \quad=$ Wertzuwachs einer Aktie bei Thesaurierung

$\Theta=$ Bruttodividende eines Kapitaleigners, wenn eine Einheit des Unternehmensgewinns nach Steuer ausgeschüttet würde

$a_{t} \quad=$ steuerlich zulässiger Abschreibungssatz

c $\quad=$ Anrechnungssatz

$\mathrm{D}=$ Ausschüttung inklusive Steuer

$D_{N} \quad=$ einem Anteilseigner zufließende Ausschüttung nach Abzug der von einem ausschüttenden Unternehmen einzubehaltenden Steuern

$\mathrm{G} \quad=\mathrm{zu}$ versteuerndes Einkommen eines Kapitalgebers

$\mathrm{i} \quad=$ nominaler Zinssatz

$i_{r} \quad=$ realer Zinssatz

I $\quad=$ Zinseinkünfte

$\mathrm{k} \quad=$ spezifische Kombination von Kapitalgeber, Finanzierungsart, Investor und Anlageart

$\mathrm{n} \quad=$ Periode

$\mathrm{p} \quad=$ abdiskontierte Rendite einer inländischen Grenzinvestition vor Steuern

$p_{D} \quad=$ gewichteter Kapitalwert einer Grenzinvestition vor Steuern

$p_{K} \quad=$ gewichtete Rendite einer Unternehmens vor Steuern

$p_{T} \quad=$ Rendite einer Tochterkapitalgesellschaft vor Unternehmensteuern 


\section{XXVII}

$\mathrm{r} \quad=$ Rendite des Haushalts nach Abzug der Unternehmensteuer und vor Abzug der persönlichen Einkommensteuer

$\mathrm{s} \quad=$ Grenzertrag des privaten Haushaltes nach Abzug der Ertrag- und Substanzsteuer

$s_{K} \quad=$ gewichtete Rendite des privaten Haushaltes nach Abzug der Steuern

$\mathrm{t}=$ effektiver Grenzsteuersatz

$t_{A}=$ Körperschaftsteuergrenzsatz auf Ausschüttungen

$t_{C}=$ Körperschaftsteuersatz des betrachteten Landes

$t_{C Q A}=$ ermäßigter Körperschaftsteuersatz im Quellenland

$t_{C W}=$ Körperschaftsteuersatz im Wohnsitzland bei Thesaurierung

$t_{C W A}=$ ermäßigter Körperschaftsteuersatz in der Bundesrepublik Deutschland bei Ausschüttung

$t_{D}=$ durchschnittlicher effektiver Grenzsteuersatz

$t_{I}=$ Einkommensteuersatz im Wohnsitzland

$t_{L}=$ Steuersatz lokal erhobener Ertragsteuern

$\mathrm{T}=$ Gesamtsteuerbelastung einer inländischen Mutterkapitalgesellschaft bzw. eines inländischen Kapitaleigners bei ausländischen Einkünften

$\mathbf{w} \quad=$ Gesamtsteuerbelastung mit Unternehmensteuer und der individuellen Steuer des privaten Haushaltes

$w_{C}=$ Vermögensteuersatz

$w_{D}=$ durchschnittliche effektive Grenzsteuerbelastung

$w_{H H}=$ Steuerbelastung des privaten Haushaltes

$w_{U N}=$ Steuerbelastung des Unternehmens

$\mathrm{z} \quad=$ effektiver Steuersatz auf aufgelaufene Vermōgenszuwächse (capital gains tax)

$z_{s} \quad=$ gesetzlicher Steuersatz auf Vermögenszuwächse 
Otto Roloff, Sibylle Brander, Ingo Barens and Claudia Wesselbaum - 978-3-631-75210-4 Downloaded from PubFactory at 01/11/2019 07:04:40AM via free access 


\section{Einleitung}

\section{Internationale Steuerkonkurrenz um Direktinvestitionen: Steuerpolitische}

Rahmengeschichte bei Fiskalillusion?

Die vorliegende Studie berichtet über erste Ergebnisse aus dem Forschungsprojekt „Finanzwirtschaftlicher Föderalismus im Europäischen Binnenmarkt unter besonderer Beachtung unternehmerischer Standortentscheidungen “. Dieses Projekt wurde von der VWStiftung gefördert und an den Universitäten - Gesamthochschulen Paderborn und Wuppertal durchgeführt. Die Antragsteller interessiert die Frage, ob der Fiskalföderalismus im Europäischen Binnenmarkt, der sich durch nationalstaatliche Standortkonkurrenz auszeichnet, eine Chance hat, und wenn ja, unter welchen Bedingungen diese Chance realisierbar ist.

Auf Anregung von Gutachtern bearbeitete die Wuppertaler Arbeitsgruppe vom Herbst 1990 bis zum Herbst 1992 zunächst das Thema „Das Gewicht der Besteuerung bei grenzüberschreitenden Standortentscheidungen. Methodische Fragen der empirischen Ermittlung und erste Ergebnisse“. Sie hatte somit zu prüfen, ob sich ein Zusammenhang zwischen Steuern und räumlicher Allokation von Kapital in methodisch vertretbarer Weise statistisch erklären läßt. Das Ergebnis dieser Prüfung ist negativ ausgefallen. Es gibt weder eine empirisch relevante Investitionstheorie noch verläßliche Daten über Direktinvestitionen und effektive Steuersätze. Es müssen also n eue Konzepte entwickelt werden, um den Einfluß von Steuern auf Direktinvestitionen (quantitativ-empirisch) erforschen zu können. Die Grundlagen eines derartigen Konzepts werden im ersten und zweiten Kapitel vorgestellt. Dem Einfluß von Steuersatzdifferentialen auf die Standortentscheidungen über den Geschäftssitz einer Muttergesellschaft wird in dieser Studie nicht nachgegangen.

Die von den Gutachtern gestellte Aufgabe schien uns keine besonderen Schwierigkeiten zu beinhalten. Die in der Literatur diskutierten Ansätze über Direktinvestitionen mußten sondiert und der tragfähigste Ansatz als Grundlage für ein geeignetes Schätzmodell herausgesucht werden. Sodann waren die Daten zu den Direktinvestitionen und die nationalen effektiven Steuersätze zusammenzustellen und mit dem gewählten Schätzmodell die Hypothese zu testen, ob Steuersatzdifferentiale einen signifikanten Einfluß auf Direktinvestitionen haben. Somit schien ein normales und erfolgversprechendes Arbeitsprogramm vor uns zu liegen. Tatsächlich erwies sich die Aufgabe mit den herkömmlichen ökonomischen und statistischen Methoden als undurchführbar. Die auftretenden Hemmnisse aber auch Versuche, mit Hilfe neuer Methoden den Einfluß von Steuern auf die unternehmerische Investitionstätigkeit zu beschreiben, werden im folgenden kurz dargestellt.

Parallel zu dem Forschungsprojekt untersuchte Ingo Barens die Tragfähigkeit neuerer In- 
vestitionstheorien (Akzeleratoransatz, Jorgenson-Modell, q-Ansatz), von denen sich das Jorgenson- und q- Modell als theoretische Grundlagen eignen, um die Abhängigkeit der Direktinvestitionen von Steuersatzdifferentialen zu beschreiben. Über die zusammengefaßten Ergebnisse dieser Untersuchung (Barens 1992) wird im Kapitel 1 „Investitionen und Steuern -- einige theoretische Grundprobleme" berichtet. Es gibt keine tragfähige empirisch relevante Investitionstheorie bzw. Theorie der Direktinvestitionen, aus der sich ein theoretisch fundiertes Schätzmodell ableiten ließe. Die Investitionsrate kann nur unter Berücksichtigung zeitlicher und räumlicher Anpassungskosten rigoros begründet werden. Allerdings muß man dann konvexe Anpassungskostenfunktionen unterstellen, die sich systematisch jedoch nicht begründen lassen, sondern ad hoc angenommen werden müssen. Plausibler erscheinen hingegen lineare Anpassungskostenfunktionen. In dem Fall läßt sich aber die Investitionsrate theoretisch nicht mehr bestimmen. Unterstellt man realistischerweise multiple Kapitalgüter und/oder Kreditrationierung, dann verliert die q-Theorie ihre empirische Relevanz, da sich das marginale q empirisch nicht beobachten läßt. Auch mit Hilfe makroökonomischer Produktionsfunktionen läßt sich zwischen Nettorendite und Investitionsrate kein konsistenter theoretischer Zusammenhang begründen. Wenn man für quantitativ-empirische Untersuchungen auf den Zusammenhang von Nettorendite und Direktinvestitionen rekurriert, dann gibt es dafür keine theoretische Basis. Von Bedeutung erscheint uns jedoch, daß neuerdings wieder empirische Untersuchungen die Bedeutung von internen Finanzierungsmitteln für die Investitionstätigkeit herausstellen. Im Falle von Kreditrationierung sind in der Tat interne Finanzierungsmittel eine notwendige Voraussetzung (Finanzierungsbedingung) für die Durchführung von geplanten Investitionen.

Im zweiten Kapitel „Steuerbelastung und verwendbares Eigenkapital: Eine Veranlagungssimulation" wird anhand der Daten einer real existierenden Unternehmung für die Bundesrepublik, Frankreich und Großbritannien eine Veranlagungssimulation durchgeführt. Zwar werden keine effektiven Grenzsteuersätze bzw. Durchschnittssteuersätze geschätzt, aber wenn man einmal davon ausgeht, daß der ökonomische Gewinn in allen drei Ländern denselben Anteil vom Umsatzerlös ausmacht, dann wäre der effektive Durchschnittssteuersatz in Großbritannien am höchsten, und zwar unabhängig von der Gewinnverwendung. Dieses Ergebnis resultiert aus dem Unstand, daß in Großbritannien zwar der Körperschaftsteuersatz mit $33 \%$ am niedrigsten, die Bemessungsgrundlage aber am breitesten ist, so daß die Steuerbelastung in Großbritannien absolut am höchsten ausfällt. Die Veranlagungssimulation demonstriert somit eindrucksvoll den Einfluß der Gewinnermittlungsvorschriften auf das steuerpflichtige Einkommen und die effektive Steuerbelastung. Der Fall Großbritannien zeigt, daß eine breite Bemessungsgrundlage einen niedrigen Steuersatz im Hinblick auf die steuerliche Belastung überkompensieren kann. Da Investoren, sofern sie nicht unter Steuersatzillusion leiden, ihre Entscheidungen an effektiven Steuersätzen orientieren, kann somit nicht erwartet werden, daß eine aufkommensneutrale Senkung der Spitzen- 
steuersätze bei der Einkommensteuer und Körperschaftsteuer von $53 \%$ bzw. $50 \%$ auf z. B. $44 \%$ die Attraktivität des Standortes Bundesrepublik Deutschland erhöht.

Nun sind die Informationsbeschaffungs- und -verarbeitungskosten derartiger Veranlagungssimulationen für Investoren, die nach dem günstigsten Standort Ausschau halten, vermutlich sehr hoch (zur Ermittlung der jeweiligen nationalen steuerlichen Gewinnermittlungsvorschriften sowie zu den Verfahren zur Vermeidung von Doppelbesteuerung vgl. Wesselbaum-Neugebauer 1992). Unterstellt man nun aus methodischen Gründen rationales Verhalten von Investoren, dann wird man Nettorenditen als $\mathrm{Maß}$ für die lokale Vorteilhaftigkeit von Investitionen zugrunde legen müssen. Die Frage ist jedoch, ob inan rationales Verhalten einfach unterstellen kann (zur Problematik der Annahme rationalen Verhaltens vgl. Vogt 1993). Selbst wenn man empirisch beobachten sollte, daß ein Investor keine Renditeberechnungen durchführt, kann man noch nicht auf irrationales Verhalten bzw. auf Steuersatzillusion schließen, denn es kann sich auch um rationale Informationsbeschränkung handeln. Unabhängig von diesen methodischen Einwänden werden im zweiten Kapitel exemplarisch Renditeberechnungen für die drei Länder Bundesrepublik Deutschland, Frankreich und Großbritannien vorgenommen. Diese Berechnungen lehren nämlich zweierlei. Erstens wird man vergleichbare und empirisch relevante Renditen nur dann schätzen können, wenn sich der ökonomische Gewinn theoretisch eindeutig definieren läßt. Dies ist jedoch nicht der Fall. Zweitens können lokal unterschiedliche Umsätze und Kosten zu übereinstimmenden oder abweichenden Renditen nach Steuern führen; die Steuerbelastung ist nur eine von mehreren Kostenfaktoren.

Im dritten Kapitel „Steuern als Standortfaktor“ werden die methodischen Grundlagen zur empirischen Ermittlung effektiver entscheidungsrelevanter Steuersätze besprochen. Dabei werden je zwei einschlägige Verfahren der Freistellung und der Anrechnung von Kapitalerträgen bzw. von Steuern auf Kapitalerträge zur Vermeidung von Doppelbesteuerung berücksichtigt. Es zeigt sich, daß internationale Steuersatzdifferentiale überhaupt keinen Einfluß auf Direktinvestitionen haben, wenn entweder Kapitalerträge im Quellenland dort von der Besteuerung freigestellt werden (Residence Principle bzw. Wohnsitzland-Prinzip), oder wenn Steuern auf Kapitalerträge im Quellenland im Wohnsitzland des Direktinvestors auf die dort anfallenden Steuern voll angerechnet bzw. erstattet werden. (Vollanrechnungsverfahren). National unterschiedliche Steuersysteme verzerren auch nicht die supranational effiziente Kapitalallokation, wenn eines dieser beiden Verfahren zur Vermeidung von Doppelbesteuerung zwischenstaatlich vereinbart wird. Wenn nun Steuersätze keinen Einfluß auf Direktinvestitionen ausüben, erübrigt sich auch eine (statistische) Erklärung über ihren Einfluß. Allerdings können niedrigere Durchschnittssteuersätze die Wahl des Wohn- resp. Geschäftssitzes von Direktinvestoren beeinflussen. 
In der Praxis spielen neben dem Wohnsitzland-Prinzip und dem Vollanrechnungsverfahren bei der Besteuerung von im Ausland erzielten Kapitalerträgen noch andere Verfahren eine Rolle. Deshalb werden die entscheidungsrelevanten Steuersätze im folgenden auch bestimmt für die Fälle, daß Kapitalerträge nur im Land ihrer Entstehung besteuert werden (Source Principle bzw. Quellenland-Prinzip), oder das Steuern auf Erträge im Quellenland im Wohnsitzland des Direktinvestors teilweise bis zu einer Höchstbetragsgrenze angerechnet werden (Teilanrechnungsverfahren). In beiden Fällen können effektive Steuersätze c. p. die räumliche Allokation des Kapitals beeinflussen. Im Falle des QuellenlandPrinzips orientiert sich ein rationaler Direktinvestor unabhängig von der Tarifform bzw. der Steuerbetragsfunktion theoretisch immer am effektiven Grenzsteuersatz, während er den effektiven Steuersatz beim Teilanrechnungsverfahren aus einer komplexen Formel, in die die effektiven Grenz- und Durchschnittssteuersätze vom Quellen- und Wohnsitzland eingehen, ermitteln muß.

In allen genannten Verfahren zur Vermeidung von Doppelbesteuerung ist auch noch der effektive vom formalen Steuersatz zu unterscheiden. Die effektiven Steuersätze entsprechen dem Verhältnis von faktisch gezahlten Steuern als Produkt aus formalem Steuersatz und national zulässiger Bemessungsgrundlage zu ökonomischem Gewinn. Diese effektiven Steuersätze sind in die Definition für die entscheidungsrelevanten Steuersätze einzufügen. Nach dieser theoretischen Definition effektiver Steuersätze scheint es u.E. methodisch nicht vertretbar zu sein, den Einfluß von Steuern auf aggregierte Direktinvestitionen statistisch zu bestimmen. Denn einen für alle Investoren gleichermaßen gültigen effektiven entscheidungsrelevanten Steuersatz gibt es überhaupt nicht.

Neben der theoretischen Bestimmung effektiver Steuersätze werden im Kapitel 3 auch noch die Voraussetzungen für eine fiskalisch erfolgreiche Steuer-Standort-Politik analysiert. Eine dieser notwendigen Voraussetzungen, nämlich ein ein-eindeutiger Zusammenhang von Rendite und Investitionsrate, ist - wie in Kapitel 1 erläutert - theoretisch nicht begründbar. Das heißt, man kann theoretisch nicht sagen, ob eine Steuersenkungspolitik fiskalisch erfolgreich ist bzw. sich selbst finanziert.

In seinem Werk „Kapitaleinkommensbesteuerung“ hat Hans-Werner Sinn (1985) den Einfluß von Steuern auf die räumliche Kapitalallokation im Rahmen eines allgemeinen dynamischen Gleichgewichtsmodells untersucht. Aber er geht in seiner herausragenden Studie nicht weiter auf die kontrovers diskutierten Fragen ein, ob eine empirisch relevante Investitionstheorie überhaupt konsistent formuliert werden kann und inwieweit staatliche Ausgaben in die öffentliche Infrastruktur den Einfluß von Steuern auf die Rendite des eingesetzten Kapitals neutralisieren können. Eindeutige Empfehlungen für die Steuerpolitik können somit aus diesem theoretischen Ansatz kaum abgeleitet werden. 
In der Literatur werden närnlich inzwischen auch empirische und theoretische Untersuchungen über den Einfluß von Staatsausgaben insbesondere in die örtliche lnfrastruktur auf die Kapitalproduktivität des privaten Sektors diskutiert (vgl. u.a. Munnel 1990). Relativ hohe Steuersätze sind danach weder hinreichende noch notwendige Voraussetzungen dafür, daß Direktinvestoren einen Standort meiden. Denn der Einfluß hoher Steuersätze auf die Rendite kann durch produktivitätssteigernde Staatsausgaben in die Infrastruktur neutralisiert werden. Schließlich muß auf die These hingewiesen werden, daß Fiskalföderalismus als Grundlage für fiskalische Standortkonkurrenz eine notwendige Voraussetzung ist für effiziente staatliche Ausgabentätigkeit (Richter 1992). Die Effizienzgewinne aufgrund einer Harmonisierung oder Egalisierung der Steuersysteme in den Ländern des Europäischen Binnenmarktes müßten somit mit den resultierenden Effizienzverlusten im öffentlichen Sektor saldiert werden, um zu einem ausgewogenen Urteil über die Wirkungen einer Steuerharmonisierung oder Steueregalisierung in den Ländern des Europäischen Binnenmarktes zu kommen (vgl. u.a. Devereux/Pearson 1989).

Nun könnte man der in den ersten drei Kapiteln vorgetragenen Kritik durchaus zustimmen, aber mit Hinweis auf eine Vielzahl empirischer Untersuchungen über den Zusammenhang von Steuern und Direktinvestitionen (vgl. u.a. Langkau 1989) antworten, einer Fiskalillusion unterliege man durchaus nicht; es sei auch unerheblich, daß man die theoretischen Zusammenhänge zwischen den beiden Variablen nicht genau kenne. Die folgenden Ergebnisse über die Empirie von Direktinvestitionen und Steuersätzen sprechen aber gegen einen derartigen Empirie-Optimismus.

In Kapitel 4 "Direktinvestitionen und ihre statistische Erfassung“ werden die in der Praxis angewandten Methoden zur Erfassung von Direktinvestitionen detailliert analysiert. Nach dem Versuch, Portfolioinvestitionen von Direktinvestitionen theoretisch abzugrenzen, werden die von der OECD entwickelten Definitionen zu den Begriffen Direktinvestor, Direktinvestitionsunternehmen und Direktinvestitionskapital sowie die Methoden ihrer Erfassung (Bewertung von Direktinvestitionen, Abgrenzung von Direktinvestitionen sowie deren Erhebung und Aufbereitung) beschrieben. Diese Definitionen und Erfassungsmethoden der OECD dienen als Referenz für die Analyse der Datenerhebungen in der Bundesrepublik Deutschland und den USA. Leider können die Ergebnisse dieser Datenanalyse hier nur in verkürzter Form ausgebreitet werden (vgl. den ausführlichen Bericht von Brander 1993). Im Ergebnis existieren weder in sich konsistente Zeitreihen (für Zwecke von Zeitreihenanalysen) noch untereinander vergleichbare konsistente Zeitreihen (für Zwecke der Querschnittsanalyse). Die z.T. erheblichen Abweichungen in den Statistiken (nicht nur im Niveau, sondern auch im Vorzeichen von Nettodirektinvestitionen) lassen sich auf institutionell und zeitlich unterschiedliche Abgrenzungen von Direktinvestoren, Direktinvestitionsunternehmen und des Direktinvestitionskapitals sowie auf unterschiedliche Auf- 
bereitungsmethoden des Datenmaterials zurückführen. Es gibt kein Kriterium für eine rationale Wahl bestimmter empirischer Daten für eine quantitativ-empirische Analyse. Vielmehr hängt es von der willkürlichen Entscheidung des Forschers ab, welche Direktinvestitionsdaten er für den Hypothesentest heranzieht, d.h. es gibt nur willkürliche statistische Erklärungen über den Zusammenhang von Steuern und Direktinvestitionen.

Im Kapitel 5 „Steuersätze im internationalen Vergleich“ wird schlieblich methoden-kritisch die Aussagekraft der vorliegenden internationalen Steuerbelastungsvergleiche (auf Basis der volkswirtschaftlichen Gesamtrechnung, auf Basis von Tarifvergleichen und aufgrund von Veranlagungssimulationen) überprüft.

Das aggregierte Einkommen aus Unternehmertätigkeit und Vermögen in der volkswirtschaftlichen Gesamtrechnung ist nicht identisch mit den einkommen- und körperschaftsteuerpflichtigen Gewinnen der Kapitalgesellschaften und Einzelunternehmen bzw. Personengesellschaften, sondern es enthält die Kapitaleinkommen aller Unternehmen und Vermögensbesitzer. Es ist deshalb zunächst zu bereinigen und auf die beiden Unternehmensformen aufzuteilen. Außerdem weichen die Gewinnermittlungsvorschriften der volkswirtschaftlichen Gesamtrechnung ab von denjenigen der Steuerbilanz, insbesondere bei der Feststellung der Abschreibungen und der Bewertung des Vorratsvermögens. Das aggregierte Steueraufkommen entspricht den kassenmäßig registrierten Steuereinnahmen der Gebietskörperschaften und nicht der nach der Veranlagung tatsächlich zu leistenden Steuer. Schlieflich können in Frankreich unter bestimmten Voraussetzungen Personengesellschaften wählen, ob sie zur Einkommensteuer oder Körperschaftsteuer veranlagt werden. Derartige Wahlmöglichkeiten verzerren zusätzlich die Aussagekraft der Daten zum Steueraufkommen. Ausländische Erträge sind entweder von der Besteuerung freigestellt oder können im Sitzland der Muttergesellschaft angerechnet werden. Das aggregierte Einkommen und das aggregierte Steueraufkommen in der volkswirtschaftlichen Gesamtrechnung sind somit nicht ohne weiteres zur Berechnung der durchschnittlichen Steuerbelastung von Kapitalgesellschaften oder Personengesellschaften bzw. Einzelunternehmen geeignet.

Beim Tarifvergleich wird von der Fiktion international identischer steuerlicher Bemessungsgrundlagen ausgegangen. Tatsächlich werden aber häufig gerade zur Förderung der Investitionstätigkeit besondere Finanzhilfen oder erhöhte Abschreibungen von den Nationalfiski gewährt. Thesaurierte Gewinne erhöhen das Eigenkapital. Als Bemessungsgrundlage für Steuern auf das Kapital dient der Einheitswert. In den verschiedenen Vergleichsrechnungen werden z.T. sehr unterschiedliche Relationen zwischen dem erwirtschafteten Gewinn und dem Einheitswert zugrunde gelegt, so daß die vorgelegten Belastungsrechnungen nicht mehr vergleichbar sind. Die Vergleichbarkeit wird ebenfalls dadurch einge- 
schränkt, daß die unterschiedlichsten Steuern als Unternehmenssteuern definiert werden.

Bei der Veranlagungssimulation werden zwei Verfahren zur Ermittlung effektiver Steuersätze angewandt. Effektive Durchschnittssteuersätze sind im ersten Fall definiert durch das Verhältnis der tatsächlichen Steuerschuld zum ökonomischen Gewinn, wobei die Steuerschuld das Produkt aus gesetzlichem Steuersatz und der jeweiligen Bemessungsgrundlage ist. Externe Beobachter werden den ökonomischen resp. richtigen Gewinn nicht exakt erfassen können, da sie die erforderlichen unternehmensinternen Informationen (u.a. Steuerbilanz) nicht erhalten werden. Denn die Unternehmen haben kein Interesse daran, der Öffentlichkeit, d.h. auch ihren Konkurrenten, den ökonomischen Gewinn mitzuteilen. Die entsprechenden Simulationen zum Modellunternehmen gehen deshalb von veröffentlichten Daten aus. Aus diesen Daten wird für verschiedene Branchen für sogenannte repräsentative Unternehmen der ökonomische Gewinn geschätzt. Methodisch ist es jedoch fragwürdig, sich auf das Konzept eines repräsentativen Unternehmens zu stützen, da die Einflüsse auf die faktische Steuerbelastung eines Unternehmens sehr vielfältig sein können. In der Regel wird in den bekannten Schätzverfahren der Cash- flow als Hilfsgröße für den ökonomischen Gewinn herangezogen. Da aber Abschreibungen und Rückstellungen für ein Unternehmen tatsächlich Aufwand sind, sollte der ökonomische Gewinn eher durch die Korrektur der handelsrechtlich gewählten Wertansätze durch ökonomisch richtige ermittelt werden. Für diese Wertberichtigungen fehlen aber, wie erwähnt, die erforderlichen Informationen.

King und Fullerton haben in einem international viel beachteten Simulationsverfahren versucht, die effektive Grenzsteuerbelastung bezüglich einer Nettoinvestition zu schätzen. Sie wollten mit ihren Berechnungen international vergleichend den möglichen Einfluß der Steuersysteme in Großbritannien, der Bundesrepublik Deutschland, Schweden und in den USA auf die Nettorendite bzw. auf das Investitionsverhalten von Unternehmen darstellen. In ihrem theoretischen Modell umgehen King und Fullerton die Schwierigkeiten zur Bestimmung des ökonomischen und steuerlichen Gewinns, indem sie einmal die Rendite des Unternehmens vor Steuern als gegeben und fix voraussetzen und zum anderen die Rendite des Kapitalgebers vor persōnlichen Steuern als gegeben und gleich dem Marktzinssatz annehmen. Diese Vorgehensweise scheint unüberwindliche Informationsbeschaffungsprobleme verblüffend einfach aus dem Wege zu räumen, aber tatsächlich gelingt es King und Fullerton auf der Grundlage ihrer Annahmen nicht, effektive Grenzsteuersätze auf Unternehmenserträge zu bestimmen. Denn im Fall der Bundesrepublik Deutschland werden z. B. unter den von King und Fullerton getroffenen Annahmen keine körperschaftsteuerpflichtigen Kapitalgesellschaften gegründet, weil es für die Anleger vorteilhafter wäre, bei gegebenem Steuersystem ihr gesamtes Geldvermögen in festverzinsliche Wertpapiere anzulegen; Kapitalgesellschaften fehlte deshalb die Finanzierungsbasis. In Großbritannien 
und den USA stellten die ertragsmaximierenden Geldvermögensbesitzer den Kapitalgesellschaften bei gegebenem Steuersystem lediglich Fremdkapital zur Verfügung; Erträge auf Fremdkapital werden aber in diesen beiden Ländern steuerlich nicht belastet. Zwar verwenden King und Fullerton zur empirischen Schätzung effektiver Grenzsteuersätze Daten aus offenen Volkswirtschaften (obwohl ihr Modell für geschlossene Volkswirtschaften konzipiert ist,), aber sie treffen keine Annahmen über den Wohnsitzstaat eines Kapitaleigners noch über die anzuwendenden Verfahren zur Vermeidung der Doppelbesteuerung. Deshalb sind die von King und Fullerton geschätzten effektiven Grenzsteuersätze für offene Volkswirtschaften, in denen Unternehmen international agieren, mit entsprechenden Schätzfchlern behaftet.

Fs existieren somit keine verläBlichen Daten über Direktinvestitionen und effektive Steuersätze. Methodisch abgesicherte quantitativ- empirische Analysen auf der Grundlage aggregierter Daten sind damit nicht durchführbar. Die vorliegenden Ergebnisse unterstützen somit die Vermutung, daß dic beobachtbare internationale Abgabenkonkurrenz um grenzüberschreitende Investitionen und Investoren mit einer möglicherweise wählerwirksamen, obgleich theoretisch nicht fundierten, Rahmengeschichte gerechtfertigt wird und außerdem die Steuerpolitiker der Illusion unterliegen, sie könnten mit dieser Steuerkonkurrenz nachhaltig fiskalische Gewinne errielen. 


\section{Kapitel 1:}

\section{Investitionen und Steuern: einige theoretische Grundprobleme}

\subsection{Die Analyse von Steuerwirkungen auf Direktinvestitionen in Investitions- modellen}

Empirische Untersuchungen über den Zusammenhang von Besteuerung und Direktinvestitionen verwenden für diese Fragestellung modifizierte theoretische Modelle zur Erklärung des Einflußes von Besteuerung auf die Investitionstätigkeit. Derartige Modelle lassen sich wiederum unterteilen in Modelle, die cinen Zusammenhang zwischen Investitionen und den Kapitalnutzungskosten (Jorgenson-Ansatz) konstruieren, und Modelle, die einen Zusammenhang zwischen Investitionen und dem Verhältnis der Marktbewertung von Internehmungen $z u$ den Wiederbeschaffungskosten ihres Kapitalbestandes ( $q$-Ansatz) konstruieren. Ein entscheidender Unterschied zwischen beiden Modellen liegt in der Berücksichtigung von Anpassungs- bzw. Installationskosten im Zusammenhang mit Veränderungen des Kapitalbestandes. Während der $q$-Ansatz Installationskosten in das Kalkül ciner repräsentativen Unternehmung integricrt, berücksichtigt der Jorgenson-Ansatz diese nicht. Beiden Klassen von Modellen ist gemeinsam, daß die Investitionstätigkeit aus der Perspektive der Grenzproduktivitätstheorie untersucht wird.

Im vorliegenden Kapitel sollen die grundlegenden Probleme von investitionstheoretischen Analysen, unabhänging von ihrer etwaigen Erweiterung z. B. um die Berücksichtigung von Steuervariablen, behandelt werden.

Die zentrale Fragestellung der Investitionstheorie besteht in der Bestimmung eines optimalen Investitionsniveaus $(I)$ bzw. einer optimalen Investitionsrate $(I / K)$. Zur Beantwortung dieser Frage reicht die Bestimmung eines optimalen Kapitalstocks nicht aus, denn die Kenntnis über eine etwaige Abweichung zwischen aktuellem und optimalem Kapitalbestand erlaubt noch keine Aussage über den dadurch initiierten AnpassungsprozeB (positive Nettoinvestitionen). Unter den üblichen Annahmen ist vielmehr davon auszugehen, daß die Lücke zwischen aktuellem und optimalem Kapitalstock ohne Kosten und ohne Zeitverzögerungen geschlossen werden kann. Das optimale Investitionsniveau (oder die optimale Investitionsrate) ist unter diesen Umständen allerdings unbestimmt. ${ }^{1}$

Unterschiedliche Investitionstheorien können danach unterschieden werden, wie dieses investitionstheoretische Grundproblem gelöst werden soll. Zunächst werden der JorgensonAnsatz und das $q$-Modell dargestellt und einige theoretische Probleme dieser Investitionsmodelle behandelt. Daraufhin soll ein grundlegendes kapitaltheoretisches Problem disku-

\footnotetext{
${ }^{1}$ S. Haavelmo (1960) und Junankar (1972)
} 
tiert werden, das allen investitionstheoretischen Modellen, die auf der Vorstellung einer neoklassischen aggregierten Produktionsfunktion basieren, gemeinsam ist. Den Abschluß bilden einige Bemerkungen zu neueren empirischen Arbeiten, die mit den verfügbaren internen Finanzierungsmitteln einen „neuen“ Einflußfaktor der Investitionstätigkeit in den Vordergrund rücken. ${ }^{2}$

\subsection{Investitionen ohne Anpassungskosten: das Jorgenson-Modell}

\subsubsection{Darstellung}

Das Jorgenson-Modell stellt einen der ersten Versuche dar, das Grundproblem der Investitionstheoric im Rahmen der neoklassischen Theorie rigoros zu lösen. Da sich dieser $\Lambda$ nsatz in cine theoretische und eine empirisch orientierte Variante unterschieden werden kann, sollen beide Varianten dargestellt werden.

\subsubsection{Der theoretische Ansatz}

Den Ausgangspunkt der Analyse von Jorgenson bildet eine repräsentative Unternehmung die in ciner friktionslosen Welt bei vollkommenem Wettbewerb das Ziel der Maximierung des (Gegenwartswerts ihrer erwarteten zukünftigen Nettoeinnahmen verfolgt. ${ }^{3}$ Die Zielfunktion einer repräsentativen Unternehmung lautet dann

$$
\max \quad V=\int_{0}^{\infty} e^{-r t}\left[p_{Y_{t}} F\left(K_{t}, L_{t}\right)-w_{t} L_{t}-p_{I t} I_{t}\right] d t
$$

mit dem Kalkulationszinssatz $r,{ }^{4}$ der Produktionsfunktion $F\left(K_{t}, L_{t}\right)$, dem Arbeitseinsatz $L_{t}$, den Bruttoinvestitionen $I_{t}$, dem Geldlohnsatz $w_{t}$, dem Produktpreis $p_{Y t}$ und dem Preis des Investitionsgutes $p_{I t}$. Weiterhin ist die $\Lambda$ kkumulationsgleichung

$$
I_{n t}=\dot{K}_{t}=I_{t}-\delta K_{t}
$$

mit $I_{n t}$ Nettoinvestitionen und $\delta$ ökonomische Abschreibungsrate als Nebenbedingung zu beachten.

${ }^{2}$ Natürlich ist die Bedeutung solcher Größen wie cash flow etc. bereits seit den frühesten empirischen Arbeiten zu den Bestimmungsgrïnden der Investitionstätigkeit bekannt. Allerdings sind diese empirischen Hinweise nicht theoretisch fruchtbar geworden, da zu jener Zeit noch keine anerkannte rigorose theoretische Begründung für einen solchen Einfluß existierte. Erst in jüngerer Zeit ist mit den Arbeit.en von Stiglitz und anderen (s. z. B. Jaffee/Stiglitz (1990)) mit der 'Theorie der Kreditrationierung die rigorose Analyse derartiger Phänomene möglich geworden.

${ }^{3}$ Vgl. zur folgenden Darstellung z. B. Jorgenson (1967) und Junankar (1972); die Notation ist gegenïber Jorgenson (1967) geändert.

4 Im folgenden wird Zeitinvarianz des Kalkulationszinssatzes $(r)$ angenommen. 
Zur Maximierung des Gegenwartswertes der zukünftigen Nettoeinnahmen verwendet Jorgenson die Lagrange-Funktion

$$
L=\int_{0}^{\infty}\left\{e^{-r t}\left[p_{Y t} F^{\prime}\left(K_{t}, L_{t}\right)-w_{t} L_{t}-p_{I t} I_{t}\right]+\lambda_{t}\left(I_{n t}-I_{t}-\delta K_{t}\right)\right\} d t
$$

mit $\lambda_{t}$ Lagrange-Multiplikator.

Als Bedingung für den optimalen Einsatz von Arbeit erhält er mit

$$
F_{L}\left(K_{t}, L_{t}\right)=\frac{w_{t}}{p_{Y t}}
$$

die übliche Grenzproduktivitätsregel: der Arbeitseinsatz ist dann optimal wenn der Reallohn $w_{t} / p_{Y t}$ mit der Grenzproduktivität des Faktors Arbeit $F_{L}\left(K_{t}, L_{T}\right)$ übereinstimmt.

Als Bedingung für den optimalen Einsatz von Kapital erhält man

$$
F_{K}\left(K_{t}, L_{t}\right)=\frac{p_{I t}(r+\delta)-\dot{p}_{I t}}{p_{Y t}}
$$

bzw.

$$
F_{K}\left(K_{t}, L_{t}\right)=\frac{c_{t}}{p_{Y t}}
$$

mit $c_{t}=p_{I t}(r+\delta)-\dot{p}_{I t}$ nuser costs" (Kapitalnutzungskosten, Opportunitätskosten der Kapitalnutzung oder interne Gebrauchskosten) ${ }^{5}$

Diese Gleichgewichtsbedingung besagt, daß der Kapitaleinsatz dann optimal ist, wenn die Kapitalnutzungskosten, dividiert durch den Outputpreis, mit der Grenzproduktivität des Kapitals übereinstimmen. Ein höherer Outputpreis wird dann verbunden sein mit einem höheren optimalen Kapitalbestand, während hingegen ein höherer Zinssatz (oder ein höherer Preis des Investitionsgutes) mit einem niedrigeren optimalen Kapitalstock verbunden sein wird.

Durch Gleichung (1.6) wird bislang allein der optimale Kapitalstock, d.h. die optimale Kapitalnachfrage bestimmt, nicht aber die optimale Investitionsnachfrage. Unter den von Jorgenson gemachten Annahmen würde eine z. B. durch eine Zinsänderung ceteris paribus verursachte Diskrepanz zwischen vorhandenem und optimalem Kapitalbestand in einer unendlich kurzen Zeitspanne beseitigt werden, die Veränderung des Kapitalstocks

${ }^{5}$ Die Kapitalnutzungskosten sind die durch den Kapitaleinsatz verursachten Kosten; sie setzen sich zusammen aus den Opportunitätskosten $p_{I} r$ der Anlage von $p_{I}$ Geldeinheiten in Realkapital, den Kosten der Kapitalabnutzung $p_{I} \delta$ und Kapitalgewinnen bzw. -verlusten $\left(\dot{p}_{I}>0 \mathrm{bzw}, \dot{p}_{I}<0\right)$. 
(Nettoinvestitionen) wäre unabhängig vom Ausmaß dieser Diskrepanz stets unendlich groß und eine Investitionfunktion nicht definiert.

Jorgenson (1967, S. 148) schließt in seiner Analyse derartige diskrete Veränderungen des Kapitalstocks aufgrund z. B. einer Zinssatzänderung aus und versucht eine Bestimmung der optimalen Investitionsnachfrage auf zwei verschiedenen Wegen. In der theoretischen Analyse verwendet er die Methode der „komparativen Dynamik“, 6 in empirischen Untersuchungen greift er zurück auf die Annahme von Lags, die eine verzögerungsfreie Anpassung des Kapitalstocks verhindern ( Jorgenson (1965)). ${ }^{7}$

In seiner theoretischen Analyse verhindert Jorgenson diskrete Änderungen des Kapitalstocks durch die Annahme, daß sich bei Änderungen des Zinssatzes in $t_{0}$ die Kapitalnutzungskosten $c_{t_{0}}$ nicht ändern. Diese Annahme impliziert gemäß Gleichung (1.5) eine kompensierende Änderung der erwarteten Änderungsrate des Investitionsgüterpreises bei Änderungen des Zinssatzes:

$$
\frac{d\left(r-\dot{p}_{I} / p_{I}\right)}{d t}=0
$$

Erhöht sich nun in $t_{0}$ der Zinssatz $r$, so bleibt $c_{0}$ aufgrund der kompensierenden Anpassung von $\dot{p}_{I 0} / p_{I 0}$ konstant. Damit ist auch der Kapitalstock $K_{0}$ weiterhin optimal ${ }^{8}$, allerdings werden alle zukünftigen $c_{t}$ höher sein. Für alle $t>t_{0}$ gilt somit, daß der optimale Kapitalbestand $K^{*}$ nun geringer sein wird als beim ursprünglichen Zinssatz. Damit gilt aber: ${ }^{9}$

$$
\frac{\partial I}{\partial r}<0
$$

Durch den Vergleich zweier alternativer gleichgewichtiger Wachstumspfade gelingt es Jorgenson, eine Investitionsfunktion abzuleiten.

\subsubsection{Der empirische Ansatz}

In empirischen Untersuchungen arbeitet Jorgenson mit einem Modell, das in zweierlei Hinsicht von seinem rigorosen investitionstheoretischen Modell abweicht. ${ }^{10}$

Zum einem macht er bei der Bestimmung des optimalen Kapitalstocks die Annahme, das

\footnotetext{
6 Vgl. Jorgenson (1967, S. 148).

7 Zeitverzögerungen werden im nächsten Abschnitt behandelt.

8 Jorgenson macht die Annahme, daß der aktuelle stets mit dem optimalen Kapitalbestand übereinstimmt.

9 Vgl. ausführlich Jorgenson (1967, S. 148ff.) und Ebel (1978, S. 270f.)

10 Vgl. z. B. Jorgenson (1963); in dieser Arbeit findet sich bereits eine Berücksichtigung von Steuervariablen, vgl. Jorgenson (1963, S. 249).
} 
Outputniveau sei der repräsentativen Unternehmung exogen vorgegeben. Bei Verwendung einer Cobb-Douglas-Produktionsfunktion

$$
Y_{t}=L_{t}^{\alpha} K_{t}^{\beta}
$$

führt diese Annahme zu folgender Bestimmung des optimalen Kapitalstocks $K^{*}$

$$
K^{*}=\frac{\beta p_{Y t} Y_{t}}{c_{t}}
$$

Der optimale Kapitalstock hängt positiv ab Outputniveau und -preis und negativ von den Kapitalnutzungskosten.

Zum anderen leitet Jorgenson die Investitionsnachfrage auf der Grundlage eines optimalen Kapitalstocks nicht rigoros ab, sondern er nimmt an, daß nicht näher analysierte Zeitverzögerungen (z. B. Lieferzeiten in der Investitionsgüterproduktion etc.) eine augenblickliche Anpassung des vorhandenen an den optimalen Kapitalstock verhindern. Die Annahme einer solchen zeitverzögerten Verringerung der Lücke zwischen aktuellem und gewünschten Kapitalbestand führt zu folgender Investitionsfunktion:

$$
I_{t}=\Psi(L)\left[K_{t}^{*}-K_{t-1}^{*}\right]+\delta K_{t-1}
$$

mit $\Psi(L)$ lag-Polynom.

\subsubsection{Kritik}

Im Rahmen der vorliegenden Fragestellung sind die folgenden Kritikpunkte von Bedeutung:

- Das in empirischen Untersuchungen verwendete Modell ist nicht konsistent mit der rigorosen Ableitung der Investitionsnachfrage im Ausgangmodell; denn unter Bedingungen vollkommenen Wettbewerbs ist auch das Outputniveau eine endogene, von den Input- und Outputpreisen abhängige Variable.

- Die Ableitung der Investitionsnachfrage auf der Grundlage eines optimalen Kapitalstocks kann in beiden Varianten des Jorgenson-Modells nicht überzeugen.

- Die von Jorgenson gemachte Annahme über die kompensierende Anpassung der zukünftigen Investitionsgüterpreise ist überaus restriktiv und wenig plausibel. ${ }^{11}$

- Die im empirischen Modell verwendeten Zeitverzögerungen beruhen auf ad hocAnnahmen.

11 Vgl. Tobin (1967); Jorgensons Vorgehensweise ist wegen ihrer geringen Plausibilität denn auch nicht weiter verfolgt worden; vgl. Ebel (1978, S. 271) 
Zusammenfassend ist somit festzustellen, daß der von Jorgenson entwickelte Ansatz keine tragfähige theoretische Grundlage für die empirische Untersuchung der Einfluffaktoren der Investitionstätigkeit zu liefern vermag. Insbesondere vermag er nicht das Problem der rigorosen, nicht auf ad hoc-Annahmen basierenden Ableitung einer Investitionsfunktion zu lösen.

\subsection{Investitionen mit Anpassungskosten: das q-Modell}

In jüngerer Zeit ist mit dem neoklassischen $q$-Modell ein investitionstheoretischer Ansatz entwickelt und in der empirischen Forschung angewandt worden, dem es durch die Integration von bei Veränderungen des Kapitalstocks anfallenden Anpassungskosten gelingt, den Anpassungspfad des vorhandenen an den optimalen Kapitalstock im Rahmen des Optimierungskalküls einer repräsentativen Unternehmung zu bestimmen und somit eine Investitionsfunktion rigoros abzuleiten.

\subsubsection{Darstellung}

Ausgehend von Tobins Hypothese, derzufolge die Investitionstätigkeit abhängt vom Verhältnis der empirisch beobachtbaren Marktbewertung $V$ eines gegebenen Kapitalstocks zu seinen Reproduktionskosten $p K$ (Tobins $q=V / p K$ ), ist ein neoklassischer investitionstheoretischer Ansatz entwickelt worden, der Anpassungskosten in das Optimierungskalkül einer repräsentativen Unternehmung intergiert. ${ }^{12}$

Die Vorstellung, die Änderung einer Bestandsgröße (Kapitalstock) verursache Kosten, stellt den entscheidenden Fortschritt auf dem Weg der Integration des Anpassungspfades in das Optimierungskalkül einer investierenden Unternehmung dar und erlaubt es zum ersten Mal ein optimales Investitonsniveau $(I)$ bzw. eine optimale Rate der Investition $(I / K)$ zu bestimmen.

Es wird dabei die Annahme gemacht, daß bei Änderungen des Kapitalstocks Anpassungskosten gemäß einer Anpassungskostenfunktion anfallen, die z. B. die folgende Form hat:

$$
C=C(I) \quad \text { mit } \quad C_{I}(I), C_{I I}(I)>0
$$

Eine solche konvexe Anpassungskostenfunktion beinhaltet zum einen die Vorstellung, daß der Investitionsprozeß mit Kosten verbunden ist $\left(C_{I}>0\right),{ }^{13}$ und zum anderen die Vorstel-

\footnotetext{
12 Tobins q-Theorie ist entwickelt worden in Tobin $(1961 ; 1963 ; 1971 ; 1978)$ sowie in Tobin/Brainard (1968;1977); s. auch Barens (1992) für eine genauere Darstellung des Zusammenhangs zwischen dem ursprünglichen $q$-Ansatz von Tobin und der neoklassischen $q$-Investitionstheorie.

13 Die Anpassungskosten können unterschieden werden in externe und interne Anpassungskosten und entweder in Einheiten des Investitionsgutes (wasted capital) oder in Einheiten des Outputgutes (lost 
lung, daß mit zunehmender Anpassungsgeschwindigkeit die Grenzkosten der Anpassung ansteigen werden $\left(C_{I I}>0\right){ }^{14}$

Bei Existenz von Anpassungs- bzw. Installationskosten lautet die Gewinnfunktion nun

$$
X_{t}=p_{Y t} F\left(K_{t}, L_{t}\right)-w_{t} L_{t}-p_{I t} I_{t}-p_{I t} C\left(I_{t}\right)
$$

und das Entscheidungsproblem einer repräsentativen Unternehmung kann formuliert werden als

$$
\max \quad W=\int_{0}^{\infty} e^{-r t}\left[p_{Y t} F\left(K_{t}, L_{t}\right)-w_{t} L_{t}-p_{I t} I_{t}-p_{I t} C\left(I_{t}\right)\right] d t
$$

unter Berücksichtigung der Nebenbedingung

$$
\dot{K}_{t}=I_{t}-\delta K_{t}
$$

Zur Lōsung dieses Entscheidungsproblems wird das „Maximumprinzip“ von Pontrjagin herangezogen. ${ }^{15}$ Man definiert die folgende Momentanwert-Hamiltonfunktion ${ }^{16}$

$$
H_{t}(L, I, K, \mu)=\left[p_{Y t} F\left(K_{t}, L_{t}\right)-w_{t} L_{t}-p_{I t} I_{t}-C\left(I_{t}, K_{t}\right)\right]+\mu_{t}\left(I_{t}-\delta K_{t}\right)
$$

Durch Differentation von $H_{t}$ nach $L_{t}$ und $I_{t}$ erhält man die folgenden Optimalitätsbedingungen für Arbeitseinsatz bzw. Investitionsniveau:

$$
F_{L}\left(K_{t}, L_{t}\right)=\frac{w_{t}}{p_{Y t}}
$$

output) gemessen werden. Im Folgenden werden die Installationskosten in Einheiten des Investitionsgutes gemessen.

14 Als Argument werden dabei entweder die Brutto- oder die Nettoinvestitionen gewählt. Dies führt zu folgenden Anpassungskostenfunktionen: $C=C(I)$ bzw. $C=(\dot{K})$. Anpassungskosten als Funktion der Bruttoinvestitionen werden z. B. von Lucas (1967b), Gould (1968) und Nickell (1978) angenommen, während Eisner/Strotz (1963), Lucas (1967a) und Treadway $(1969 ; 1970)$ eine Abhängigkeit von den Nettoinvestitionen annehmen. Weiterhin kann neben den Investitionen auch der Kapitalstock in die Anpassungskostenfunktion eingeführt werden, wobei die Annahme gemacht wird, daB in einer großen Unternehmung, gemessen an ihrem Kapitalbestand, bei einem gegebenen Investitionsprojekt geringere Anpassungskosten anfallen als in einer kleinen Unternehmung. Dies führt zu den folgenden Anpassungskostenfunktionen: $C=C(I / K)$ bzw. $C=C(\dot{K} / K)$ oder allgemein $C=C(I, K)$ mit $C_{K}<0$. Vgl. z. B. Abel (1979, S. 43). Da Anpassungskostenfunktionen dieses Typs in den unten behandelten Modellen Verwendung finden, werden weitergehende Literaturhinweise dort gegeben. Die unterschiedlichen Anpassungskostenfunktionen führen zu qualitativ gleichen Ergebnissen, allein die Gleichgewichtszustände werden im Detail unterschiedlich ausfallen.

15 Auf eine Darstellung des Maximumprinzips von Pontrjagin wird an dieser Stelle verzichtet; eine ausführliche Darstellung findet sich z. B. in Bolenz (1978), Feichtinger/Hartl (1986), Jochum (1991) und Seierstad/Sydsæeter (1987).

16 Zur Unterscheidung in Momentanwert- und Gegenwartswert-Hamiltonfunktion s. Feichtinger/Hartl (1986, S. 20). 


$$
\mu_{t}=p_{I t}+p_{I t} C_{I}\left(I_{t}, K_{t}\right)
$$

Gleichung (1.17) stellt die übliche Grenzproduktivitätsregel für den optimalen Arbeitseinsatz dar. In Gleichung (1.18) stellt $\mu_{t}$ den Schattenpreis einer zusätzlich installierten Einheit Kapital dar. Gleichung (1.18) besagt somit, daß die Höhe der Investitionen dann optimal ist, wenn der Schattenpreis einer zusätzlich installierten Einheit Kapital übereinstimmt mit der Summe aus Preis und Grenzkosten der Installation dieser zusätzlichen Einheit Kapital (= Grenzkosten der Investition). Anders ausgedrückt, läßt sich sagen, daß die Grenzkosten der Anpassung der Differenz zwischen dem Schattenpreis einer Einheit installierten Kapitals und dem Preis einer Einheit nicht-installierten Kapitals entsprechen.

Da der Schattenpreis $\mu_{t}$ gleich ist der Erhöhung des Wertes der repräsentativen Unternehmung aufgrund einer marginalen Erhöhung des Kapitalbestandes (marginale Nettoinvestition $)^{17}$

$$
\mu_{t}=\frac{d V_{t}}{d K_{t}}
$$

kann der Quotient aus $\mu_{t}$ und dem Preis des Investitionsgutes in Analogie zu Tobins q, das - wie bereits erwähnt - eine empirisch beobachtbare Durchschittsgröße darstellt, als marginales $q\left(q_{t}^{m}\right)$ interpretiert werden:

$$
q_{t}^{m}=\frac{\mu_{t}}{p_{I t}}=\frac{d V_{t}}{p_{I t} d K_{t}}
$$

Die Optimalitätsbedingung (1.18) weist eine weitere interessante Eigenschaft auf. Sie impliziert nämlich eine Investitionsfunktion, in der die Investitionen vom Schattenpreis $\mu_{t}$ abhängig sind. Um zu einer Investitionsfunktion zu gelangen, ist Gleichung (1.18) nach $I_{t}$ aufzulösen. Dies soll am Beispiel der folgenden, in der Literatur weitverbreiteten speziellen Anpassungskostenfunktion ${ }^{18}$

$$
C(I, K)=\frac{\beta}{2}\left(\frac{I}{K}-\gamma\right)^{2} K
$$

\footnotetext{
${ }^{17} \mathrm{Vgl}$. Klein (1992)

18 Diese Anpassungskostenfunktion ist von Summers (1981) eingeführt und hat in der Literatur weite Verbreitung gefunden; s. z. B. Salinger/Summers (1983), Poterba/Summers (1983), Devereux/Schiantarelli (1990), Mettelsiefen (1991) sowie Schiantarelli/Georgoutsos (1990). Ähnliche Anpassungskostenfunktionen verwenden z. B. Chirinko (1987), Fazzari et al. (1989), Hoshi/Kashyap (1990) und Klein (1992).
} 
dargestellt werden. ${ }^{19}$ Für die Grenzkosten der Anpassung ergibt sich

$$
C_{I}(I, K)=\beta\left(\frac{I}{K}-\gamma\right)
$$

Die Optimalitätsbedingung (1.18) lautet dann

$$
\mu_{t}=p_{I t}+p_{I t} \beta\left(\frac{I}{K}-\gamma\right)
$$

bzw. unter Berücksichtigung von (1.20)

$$
q_{t}^{m}-1=\beta\left(\frac{I}{K}-\gamma\right)
$$

Umformung führt zur linearen Investitionsfunktion

$$
I_{t}=\left(\gamma+\frac{1}{\beta}\left(q_{t}^{m}-1\right)\right) K
$$

Diese Investitionsfunktion enthält neben der Variablen $q_{t}^{m}$ ausschließlich die Parameter $\beta$ und $\gamma$ der Anpassungskostenfunktion (1.21); weiterhin ist hervorzuheben, daß die Investitionsfunktion keine zeitverzögerten Variablen enthält, die Akkumulationsrate $I / K$ hängt allein vom laufenden $q^{m}$-Wert ab. ${ }^{20}$

Die Investitionsfunktion (1.25) kann allerdings in dieser Form noch nicht für empirische Untersuchungen verwendet werden, denn der implizite Schattenpreis $q^{m}$ ist nicht direkt empirisch zu beobachten. Hayashi (1982) hat zeigen können, daß marginales $q$ und durchschnittliches $q$ übereinstimmen, sofern auf den Absatz- und Faktormärkten der repräsentativen Unternehmung vollkomener Wettbewerb herrscht und Produktions- und Anpassungskostenfunktion linear-homogen sind. Unter diesen Bedingungen kann in (1.25) $q^{m}$ durch das empirisch feststellbare durchschnittliche $q^{a}$ ersetzt werden und die sich ergebende Investitionsfunktion

$$
I_{t}=\left(\gamma+\frac{1}{\beta}\left(q_{t}^{a}-1\right)\right) K
$$

19 Zwei Interpretationen des Parameters $(\gamma)$ bieten sich an. Zum einen kann $(\gamma)$ gleichgesetzt werden mit der Abschreibungsrate des Kapitalstocks $(\delta)$. Die Anpassungskosten wären dann eine Funktion der Nettoinvestitionen (vgl. z.B. Chirinko (1987, S. 76). Zum anderen kann $(\gamma)$ als Ausdruck einer "normalen " Wachstumsrate (oder allgemeiner des Trends der Wachstumsrate) verstanden werden. In diesem Fall wären die Anpassungskosten eine Funktion der Differenz zwischen tatsächlicher und ${ }_{n}$ normaler" Wachstumsrate. Eine solche Annahme wird beispielsweise von Tobin (1982, S. 179) gemacht; s. auch Tobin/Brainard (1968, S. 105).

${ }^{20}$ Für die Berücksichtigung von Steuervariablen in $q$-Modellen s. z. B. Summers (1981) und Funke/Willenbockel (1991/92). 
oder allgemein

$$
I_{t}=I\left(q_{t}^{a}\right)
$$

ist einer empirischen Überprüfung zugänglich.

\subsubsection{Kritik}

Zwei Eigenschaften kennzeichnen das q-Modell und erlauben empirische Untersuchungen auf seiner Grundlage. Die Einführung von Anpassungs- oder Installationskosten ermöglicht die rigorose Bestimmung eines optimalen Niveaus der Investitionen, der Nachweis der Identität von nicht beobachtbaren marginalem und beobachtbaren durchschnittlichem $q$ ermöglicht die empirische Schätzung von Investitionsfunktionen allein auf der Grundlage von Zeitreihen der Variablen $q^{a}$. Allerdings haben die vielfältigen empirischen Arbeit zur q-Theorie bislang nicht zu befriedigenden Ergebnissen geführt. Darüberhinaus haben sich die für die Identităt von $q^{m}$ und $q^{a}$ notwendigen Bedingungen als überaus restriktiv und die analytischen Ergebnisse als überaus sensitiv gegenüber Abweichungen von diesen notwendigen Bedingungen erwiesen. Beide Problembereiche sollen in den folgenden Abschnitten näher behandelt werden.

\subsubsection{Das Problem der Anpassungskosten}

Zunächst ist darauf hinzuweisen, daß im Rahmen der $q$-Theorie die Annahme einer konvexen Anpassungskostenfunkion für die Bestimmung eines optimalen Investitionsniveaus unverzichtbar ist. Lineare oder konkave Anpassungskostenfunktionen implizieren hingegen ein unbestimmtes Investitionsniveau. ${ }^{21}$ Allerdings existieren keine theoretisch zwingenden Argumente für die Annahme konvexer Anpassungskosten, vielmehr erscheinen nicht-konvexe Anpassungskosten als wesentlich plausibler. ${ }^{22}$ Die vom $q$-Modell erzwungene Annahme konvexer Anpassungskosten erweist sich bei genauerer Betrachtung als eine ad hoc-Annahme, deren einzige Begründung in der Möglichkeit der Bestimmung eines optimalen Investitionsniveaus liegt.

Aber selbst wenn von diesen grundlegenden Einwänden abgesehen wird, ist festzustellen, daß die empirische Schätzung von Investitionsfunktionen auf der Grundlage von $q$-Modellen nicht zu befriedigenden Ergebnissen führt. ${ }^{23}$ Die von empirisch geschätzten

${ }^{21}$ In beiden Fällen ist es für eine Unternehmung lohnend die Diskrepanz zwischen aktuellem und optimalem Kapitalstock „sofort“ zu schließen. Damit stellt sich aber erneut das bereits aus der neoklassischen Investitionstheorie von Jorgenson bekannte Problem.

22 Vgl. Rothschild (1971) und Barens (1992).

${ }^{23}$ Die Schätzung von Investitionsfunktionen stellt nichts anderes dar als die Schätzung der Paramter der angenommenen Anpassungskostenfunktion, z. B. der Paramter $\beta$ und $\gamma$ in der Investitionsfunktion (1.25). 
Investitionsfunktionen implizierten Größenordnungen der Anpassungskosten erweisen sich als unplausibel. ${ }^{24}$ Ebenso unplausibel erscheint der Zeitbedarf des Anpassungsprozesses des aktuellen an den optimalen Kapitalbestand. ${ }^{25}$ Darüberhinaus, das sei an dieser Stelle ebenfalls erwähnt, kann der Erklärungswert empirischer Investitionsfunktionen durch die Berücksichtigung zusätzlicher Variablen, denen in der rigorosen Bestimmung optimaler Investitionen keine Bedeutung zukommt, wie z. B. Output, Gewinn, Umsätze u.ä. ${ }^{26,27}$ oder von zeitverzögerten Werten von $q^{a}$ teilweise erheblich verbessert werden. ${ }^{28}$

Zwar kann der Erklärungswert empirischer Investitionsfunktionen durch modifizierte Anpassungskostenfunktionen verbessert werden ${ }^{29}$, die ökonomische Begründung für derartige Modifikationen erscheint allerdings fraglich. ${ }^{30}$

Zusammenfassend ist somit festzustellen, daß die empirische Umsetzung der $q$-Investitionstheorie bislang nicht zu überzeugenden Ergebnissen geführt hat. ${ }^{31}$

\subsubsection{Das Problem der Identität von marginalem und durchschnittlichem} q

Die $q$-Investitionstheorie wurde durch den Nachweis der Identität von marginalem und durchschnittlichem $q$ empirisch überprüfbar. Neben den Bedingungen linear-homogener Produktions- und Anpassungkostenfunktion sowie vollkommenen Wettbewerbs hat sich aber herausgestellt, daß weitere Bedingungen erfüllt sein müßen, damit diese Identität existiert. Zum einen sind die Konsequenzen multipler Kapitalgüter, zum anderen einer endogenen Finanzierungspolitik der repräsentativen Unternehmung untersucht worden. Diese beiden Fragen sowie die Konsequenzen von Rationierung auf den Input- und Outputmärktenn sollen im folgenden behandelt werden.

\section{a) Multiple Kapitalgüter}

Wird die Annahme aufgegeben, der Kapitalstock bestehe allein aus einer Art von Kapitalgut, ergeben sich weitreichende Konsequenzen für die empirische Variante der $q$-Theorie.

\footnotetext{
${ }^{24}$ So implizieren die Ergebnisse von Summers (1981) durchschnittliche Anpassungskosten in Höhe von ca. $22 \%$ und Grenzkosten der Anpassung in Höhe von ca. $200 \%$ des Preises der installierten Investitionsgüter; vgl. Tobin/White (1981).

${ }^{25}$ Summers (1981, S. 106) kommt zu dem Ergebnis, daB nach 20 Jahren die Diskrepanz zwischen aktuellem und optimalem Kapitalstock noch $25 \%$ beträgt.

$26 \mathrm{Vgl}$. Abel/Blanchard (1986); Poterba (1990) verweist darauf, daß sich q-Modelle regelmäBig Modellen, die derartige Stromgrößen berücksichtigen, als unterlegen erweisen.

${ }^{27}$ Dieser Aspekt wird in Abschnitt 5.5 noch einmal aufgegriffen.

$28 \mathrm{Vgl}$. Chirinko (1988)

${ }^{29}$ So nimmt Sensenbrenner (1991, S. 784ff.) an, daB die Anpassungskosten im Zeitpunkt $t$ abhängen vom realisierten Investitionsniveau im Zeitpunkt $t-1$

30 Vgl. Campbell (1991) und König (1991).

31 Vgl. z. B. Chirinko (1992) und Coen/Eisner (1992, S. 512). 
Wird die Existenz multipler Kapitalgüter zugelassen ${ }^{32}$, dann ergibt sich analog zur Optimalitätsbedingung (1.18) für jedes Kapitalgut eine Optimalitätsbedingung ${ }^{33}$

$$
\mu_{i t}=p_{I_{i} t}+p_{I_{i} t} C_{I_{i}}\left(I_{i t}, K_{i t}\right) \quad i=1, \ldots, n
$$

und entsprechend ergibt sich für jedes Kapitalgut ein spezifisches $q^{m}$

$$
q_{i t}^{m}=\frac{\mu_{i t}}{p_{I_{i} t}}=\frac{d V_{i t}}{p_{I_{i}} d K_{t}}
$$

Damit kann auch für jedes Kapitalgut eine spezifische Investitionsfunktion

$$
I_{i}=G_{i}\left(q_{i}^{m}\right)
$$

abgeleitet werden. Eine Investitionsfunktion der Form (1.27) kann allerdings nicht mehr konstruiert werden, weil nun die Kenntnis von $q^{a}$ allein zur Schätzung einer empirischen Investitionsfunktion nicht länger ausreicht. Es ist nicht möglich, von $q^{a}$ auf die kapitalgutspezifischen $q_{i}^{m}$ zu schließen, eine Identität zwischen empirisch beobachtbarem durchschnittlichem $q$ und den investitionsbestimmenden marginalen $q_{i}^{m}$ ist nicht gegeben. Damit ist der Versuch einer empirischen Schätzung von Investitionsfunktionen erneut mit dem Problem konfrontiert, daß die theoretisch ermittelten Bestimmungsfaktoren der Investitionstätigkeit empirisch nicht beobachtet werden können.

\section{b) Endogene Finanzierungspolitik}

$\mathrm{Zu}$ einem ähnlichen Ergebnis gelangt man, wenn eine endogene Finanzierungspolitik der repräsentativen Unternehmung berücksichtigt wird. ${ }^{34}$ Hat die repräsentative Unternehmung die Wahlmöglichkeit zwischen Finanzierungsalternativen, ${ }^{35}$ ergibt sich folgende Modifikation der Optimalitätsbedingung (1.20):

$$
q_{t}^{m}=q_{t}^{a}-\left(1+\lambda_{D t}\right) \frac{D_{t}}{p_{I t} K_{t}}
$$

mit $D_{t}$ Unternehmensverschuldung und $\lambda_{D t}$ Schattenpreis der Unternehmensverschuldung. Wiederum zeigt sich, daß die Identität zwischen durchschnittlichem $q$ und investitionsbestimmendem marginalem $q^{m}$ nicht länger besteht.

\footnotetext{
32 Es ist der Versuch gemacht worden, mit dieser Annahme den Erklärungswert empirischer Investitionsfunktionen zu verbessern; vgl. Chirinko (1990).

$33 \mathrm{Vgl}$. zum folgenden Wildasin (1984)

34 Vgl. zum folgenden Chirinko (1987).

35 Die einfachste Art der Berücksichtigung von Finanzierungsalternativen besteht in der Annahme eines exogen vorgebenen Verschuldungsgrads; vgl. Summers (1981, S. 85) und Salinger/Summers (1983, S. 251.
} 


\section{c) Rationierung}

Wird die Möglichkeit zugelașsen, daß die repräsentative Unternehmung auf den für sie relevanten Märkten rationiert ist, muß dieser Umstand in der Modellierung ihres Entscheidungsproblem berücksichtigt werden. Die Konsequenzen sollen am Beispiel einer Rationierung auf dem Gütermarkt dargestellt werden. ${ }^{36}$

Ist die repräsentative Unternehmung auf dem Absatzmarkt rationiert, bedeutet dies, daß die tatsächliche Absatzmenge nicht größer sein kann als $\bar{Y}$. Somit ist als eine zusätzliche Nebenbedingung

$$
Y_{t} \leq \overline{Y_{t}}
$$

bei der Maximierung des Gegenwartswertes der repräsentativen Unternehmung zu beachten. Dies führt zu folgendem Ausdruck für $q^{m}$ :

$$
q_{t}^{m}=q_{t}^{a}-\frac{\int_{t}^{\infty} \lambda_{s} \bar{Y}_{s} e^{-r(s-t)} d s}{p_{I t} K_{t}}
$$

Durchschnittliches und marginales $q$ stimmen bei Rationierung auf dem Gütermarkt nicht überein. ${ }^{37}$ Mit $\lambda_{R t}$, dem Schattenpreis der Nebenbedingung (1.32), enthält (1.33) eine nicht beobachtbare Variable.

Zusammenfassend läßt sich somit festhalten, daß zum einen die bisherigen empirischen Untersuchungen auf der Grundlage der $q$-Theorie nicht zu befriedigenden Ergebnissen geführt haben und zum anderen Modellerweiterungen schwerwiegende Probleme bei der empirischen Implementation der $q$-Theorie mit sich bringen, da sie dazu führen, daß empirisch nicht beobachtbare Variablen in die Investitionsfunktion eingehen. ${ }^{38}$

\subsection{Das kapitaltheoretische Grundproblem in der Investitionstheorie}

Bislang sind jeweils spezifische Probleme behandelt worden, mit denen Jorgenson-Ansatz und $q$-Ansatz behaftet sind. In diesem Abschnitt soll ein grundlegendes Problem behandelt werden, das beiden Ansätzen gemeinsam ist und das darüberhinaus für jeden investitionstheoretischen Ansatz, der mit einer aggregierten Produktionsfunktion arbeitet, von Bedeutung sein wird.

\footnotetext{
36 Vgl. zum folgenden Precious (1985).

37 Für die Behandlung des allgemeinen Falls von Rationierung auf Output- und Inputmärkten s. Precious (1987) und Barens (1992).

38 Diese Ergebnisse führen z. B. Chirinko (1992, S. 247) zu der Feststellung, die Brauchbarkeit der $q$-Investitionstheorie sei überaus fragwürdig.
} 
Herzstück der aggregierten Version der neoklassischen Theorie ist eine gesamtwirtschaftliche Produktionsfunktion mit Arbeitseinsatz $L$ und Kapitaleinsatz (Kapitalstock) $K$ als Argumenten

$$
Y=F(L, K)
$$

Dabei werden der Produktionsfaktor Arbeit als homogen und der Kapitalstock als homogen und beliebig verformbar (malleable capital) angenommen.

Wird weiterhin lineare Homogenität der Produktionsfunktion angenommen, kann eine Produktionsfunktion in Pro-Kopf-Einheiten von Output $(y=Y / L)$ und Pro-Kopf-Kapitaleinsatz $(k=K / L)$ (Kapitalintensität) formuliert werden ${ }^{39}$

$$
y=y(k)
$$

Die Pro-Kopf-Produktionsfunktion hat die folgenden bekannten Eigenschaften:

$$
\begin{array}{r}
\frac{d y}{d k} \equiv y^{\prime}>0 \\
\frac{d^{2} y}{d k^{2}} \equiv y^{\prime \prime}<0
\end{array}
$$

Die Produktion steigt mit der Kapitalintensität, allerdings mit sinkenden Zuwächsen.

Gemäß der Grenzproduktivitätstheorie entspricht die Steigung (Gleichung (1.36)) der Produktionsfunktion (1.35) dem Entgelt des Produktionsfaktors Kapital, der Profitrate bzw. dem Zinssatz

$$
y^{\prime}=r
$$

Gemäß dem Eulerschen Theorem wird das Gesamtprodukt durch die Faktorentgelte genau ausgeschöpft

$$
y=w+r k
$$

mit $w$ Reallohn.

Profitrate und Kapitalintensität sind negativ miteinander korreliert

$$
\frac{d r}{d k}=y^{\prime \prime}<0
$$


Um den Zusammenhang von Reallohn und Kapitalintensität zu ermitteln wird zunächst Gleichung (1.39) unter Berücksichtigung von (1.38) umgeformt

$$
\begin{aligned}
& y=w+y^{\prime} k \\
& w=y-y^{\prime} k
\end{aligned}
$$

und nach der Kapitalintensität abgeleitet

$$
\frac{d w}{d k}=y^{\prime}-y^{\prime \prime} k-y^{\prime}=-y^{\prime \prime} k>0
$$

(1.40) und (1.42) entsprechen den üblichen Ergebnissen der Grenzproduktivitätstheorie: mit zunehmendem realtiven Faktoreinsatz sinken die Faktorgrenzproduktivitäten und damit die Faktorentlohnungen.

Entsprechend besteht eine inverse Beziehung zwischen Reallohn und Profitrate

$$
\frac{d w}{d r}=\frac{d w}{d k} \frac{d k}{d r}=\frac{-y^{\prime \prime} k}{y^{\prime \prime}}=-k<0
$$

Der Reallohn kann somit als eine Funktion der Profitrate betrachtet werden:

$$
w=\omega(r)
$$

Der Graph dieser Reallohnfunktion $\omega(r)$ wird als Lohnkurve bezeichnet. Die Ableitung der Reallohnfunktion mißt unter Vernachlässigung des Vorzeichens die Kapitalintensitäl.

$$
\omega^{\prime}=-k
$$

Die Kapitalintensität kann ebenfalls als eine Funktion der Profitrate dargestellt werden

$$
k=\kappa(r)
$$

mit

$$
\kappa^{\prime}=\frac{1}{y^{\prime \prime}}<0
$$

Hohe Profitraten sind verbunden mit niedriger Kapitalintensität und vice versa.

Mithilfe der beiden Funktionen $w=\omega(r)$ und $k=\kappa(r)$ kann der produktionstechnische Gehalt der Produktionsfunktion bzw. der neoklassischen Theorie deutlich gemacht werden. Ein bestimmter Wert der Kapitalintensität bedeutet ein ganz bestimmtcs Einsatzverhältnis von Kapital und Arbeit in der Produktion des Outputs $Y$. Eine bestimmte Kapitalintensität kann somit interpretiert werden als eine ganz bestimmte Technik zur 
Produktion von $Y$ und die Funktion $\kappa(r)$ gibt dann Auskunft über die Wahl der optimalen Produktionstechnik in Abhängigkeit von der Profitrate. Unter diesem Blickwinkel sind dann zwei Figenschaften der Funktion $\kappa(r)$ wichtig:

1. Bei einer hohen Profitrate wird eine Produktionstechnik mit niedriger Kapitalintensität gewählt und vice versa.

2. Fine Produktionstechnik, die einem bestimmten Wert der Profitrate zum Einsatz gekommen ist, wird bei anderen Werten der Profitrate nicht gewählt, es besteht eine ein-eindeutige /uordnung von Produktionstechnik und Profitrate.

Dieser produktionstechnische \%usammenhang kommt in der Reallohnfunktion $w=\omega(r)$ cbcnfalls zum Ausdruck. Thre zweite Ableitung lautet,

$$
\frac{d^{2} w}{d r^{2}} \equiv \omega^{\prime \prime}=-\frac{d k}{d r}=-\frac{1}{y^{\prime \prime}}=-\kappa^{\prime}>0
$$

Dies bedeutet, daß mit steigender Profitrate der absolute Wert der Steigung der Lohnkurve abnimmt. Der absolute. Wert der Steigung der Lohnkurve mißt aber (vgl. (1.43) b\%w. (1.44)) dic Kapitalintensität der zum Finsat/z kommenden Produktionstechnik. Fin Austicg der Profitrate geht somit einher zum einen mit einem Rückgang des Reallohns und zum anderen mit einem Rückgang der Kapitalintensität. ${ }^{40}$

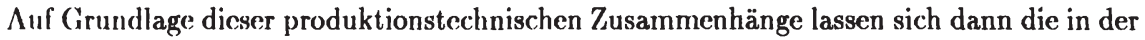
ncoklassischen Theorie üblichen Nachfragefunktionen für Arbeit und Kapital in Abhängigkeit von ihren jeweiligen Preisen (Reallohn b\%w. Profitrate) formulieren, wonach ein relativ billiger Faktor vermehrt nachgefragt und in der Güterproduktion eingesetzt wird.

Die Vorstellung einer aggregierten Produktionsfunktion setzt voraus, daß in der betrachteten Ökonomic allein ein einziges Gut produziert wird, daß sowohl konsumiert als auch als Kapital in der Produktion eingesetzt werden kann. In einer solchen Ökonomie gibt es kein Preissystem, Gesamtproduktion, Kapitalbestand, Reallohn und Profit werden in der gleichen physischen Finheit gemessen. Hine solche Fin-Gut-Ökonomie stellt aber offensichtlich kein realistisches $\Lambda$ bbild existierender Ökonomien dar. Besteht die Gesamtproduktion nicht allein aus einem Gut, sondern aus einem ganzen Güterbündel und ist der Kapitalbestand nicht homogen, sondern setzt sich zusammen aus einer Vielzahl heterogener Kapitalgüter, dann ist die Bewertung der einzelnen Güter mit Preisen notwendig, um zu die Aggregatgrößen Gesamtproduktion und Kapitalbestand zu ermitteln. Kapital und damit auch die Kapitalintensität können dann allein Wertgrößen sein und Veränderungen der Profitrate werden nicht allein zu physischen Veränderungen, zu Veränderungen in der

\footnotetext{
${ }^{40}$ Strenggenommen handelt sich hier allerdings allein um den Vergleich alternativer langfristiger
} Gleichgewichtspositionen. 
optimalen Produktionstechnik, sondern auch zu Veränderungen der relativen Güterpreise und damit in der Bewertung des Kapitalstocks führen. ${ }^{41}$

Damit taucht die Frage auf, ob die aus einer aggregierten Produktionsfunktion abzuleitenden Zusammenhänge ihre Gültigkeit für komplexere Ökonomien mit heterogenen Kapitalgütern behalten werden. Samuelson (1962) hat den Versuch unternommen, mit der Entwicklung einer Surrogat-Produktionsfunktion den Nachweis zu führen, daß auch in derartigen komplexeren Ökonomien diese Zusammenhänge Gültigkeit haben werden. Er versteht eine aggregierte Produktionsfunktion als eine drastisch vereinfachende und damit unrealistische Parabel, die aber dennoch „Grundwahrheiten“ zum Ausdruck bringe.

Im Zentrum seines Versuchs der Rettung der aggregierten Produktionsfunktion steht der Nachweis, daß auch in komplexeren Modellökonomien eine Reallohnfunktion $w=\omega(r)$ existiert, deren erste Ableitung die Kapitalintensität mißt.

Samuelson geht aus von einer zweisektoralen Wirtschaft, deren Technologie, die Gesamtheit aller verfügbaren Technikalternativen, von einem book of blueprints beschricben wird. Jede einzelne dieser Techniken wird definiert durch ein spezifisches Kapitalgut und fixen Inputkoeffizienten für den Arbeitseinsatz ${ }^{42}$ und den Einsatz des Kapitalgutes in der Produktion eines Konsumgutes und des technik-spezifischen Kapitalgutes. Unter der $\Lambda$ nnahme, daß in beiden Produktionssektoren Arbeit und Kapitalgut im gleichen Verhältnis eingesetzt werden, ${ }^{43}$ kann er zeigen, daß für jede Technik eine lineare Lohnkurve cxisticrt. ${ }^{44}$ Weiterhin kann er zeigen, daß die Umhüllende aller technik-spezifischen Lohnkurven eine Beziehung zwischen Reallohn und Profitrate $(w=\omega(r))$ wiedergibt, deren erste Ableitung ebenso wie in einer Ein-Gut-Ökonomie die Kapitalintensität, die nun den Quotienten aus dem Wert des Kapitalstocks und dem Arbeitseinsatz darstellt, mißt.

Aus diesem Ergebnis zieht Samuclson die Schlußfolgerung, daß die in einer Ein-Gut-Ōko-

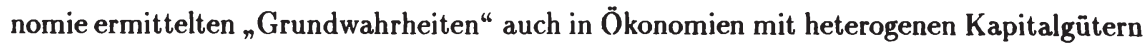
ihre Gültigkeit behalten, eine aggregierte Produktionsfunktion mithin eine zuverläßliche Beschreibung auch komplexerer Modellökonomien darstellt.

Die sog. Cambridge-Kontroverse ${ }^{45}$ hat allerdings deutlich gemacht, daß der Nachweis von Samuelson auf einem Spezialfall beruht, der gerade das entscheidende Problem der Abhängigkeit relativer Preise von der Profitrate eliminiert. Ist die „Kapitalgutintensitāt

\footnotetext{
41 Dieses Problem war bereits von Wicksell erkannt aber nicht weiter untersucht worden.

42 Arbeit wird dabei als homogen angenommen.

43 Da jede Technik allein über ein Kapitalgut verfügt, kann diese „Kapitalgutintensität* in physischen Einheiten gemessen werden.

44 Die Linearität der Lohnkurve bedeutet, daB $\omega^{\prime}=0$.

45 S. hierzu z.B Harcourt (1972)
} 
in allen Produktionssektoren identisch, sind die relativen Güterpreise unabhängig von der Profitrate durch den relativen Arbeitseinsatz bestimmt. ${ }^{46}$

Im allgemeinen Fall unterschiedlicher „Kapitalgutintensitäten“ führt der Einfluß der Profitrate aul die relativen Güterpreise aber zu Ergebnissen, die der neoklassischen Parabel widersprechen und somit die Gültigkeit der neoklassischen Theorie in Frage stellen. Im allgemeinen Fall können bei Variation der Profitrate zwei Phänomene auftreten:

1. Fine Erhöhung der Profitrate kann zum Einsatz einer kapitalintensiveren Technik führen (sog. Capital Reversing oder Negative Real Wicksell Effekt)

2. Fine Erhöhung der Profitrate kann zum Einsatz einer Technik führen, die bereits bei einer niedrigeren Profitrate eingesetzt, wurde (sog. Reswitching of Techniques)

Beide Phänomene stehen im Gegensatz zu den Aussagen der neoklassischen 'Theorie. Sie bedeuten somit, daß eine aggregierte Produktionsfunktion eben nicht komplexere Modellökonomien zuverlässig zu beschreiben vermag. In einer Mehr-Produkt-Welt ist es weder möglich, alternative Techniken eindeutig nach Maßgabe ihrer Profitabilität anzuordnen, noch is es im allgemeinen zutreffend, daß niedrigere Werte der Profitrate mit höheren Werten der Kapitalintensität einher gehen. Anders ausgedrückt: im Allgemeinen existiert cine aggregierte Produktionsfunktion nicht. ${ }^{47}$ Die Bedeutung dieser Schlußfolgerung ist weitreichend: die in einer Fin-Gut-Ökonomie abgeleiteten Aussagen der neoklassischen Parabel können nicht auf komplexere Modellökonomien und damit auch nicht auf die Wirklichkeit übertragen werden.

Die Reaktionen auf diese kapitaltheoretischen Ergebnisse sind vielfältig gewesen. Sie reichten (und reichen) vom Ignorieren dieser Frgebnisse - dies gilt insbesondere auch für die investitionstheoretische Literatur ${ }^{48}$ - über Versuche der Rettung der aggregierten Produktionsfunktion ${ }^{49}$ bis zu der Erwiderung, diese Ėrgebnisse seien zutreffend, aber entweder theoretisch oder empirisch irrelevant. Auf das Argument der Irrelevanz der Ergebnisse der Cambridge-Kontroverse kann an dieser Stelle nicht ausführlich eingegangen werden. ${ }^{50} \Lambda$ llein ein $\Lambda$ spekt soll hier näher behandelt werden.

${ }^{46}$ In diesem Fall gilt somit auch die Marrsche Arbeitswertlehre.

47 Darüber hinaus bedeuten sic, daB die Angebots-Nachfrage-Mechanik der neoklassischen Theorie zusammenbrechen muß, da sich für komplexere Modellökonomien keine Nachfragefunktionen für die Produktionsfaktoren Kapital und Arbeit bestimmen lassen; vgl. hierzu Garegnani (1989a,b).

48 Als ein besonders krasses Beispiel kann Junankar (1972, S.12-3) genannt werden: „Cambridge economists have argued very strongly that it is impossible to measure capital in value terms... For the purpose of this survey $I$ shall sidestep this controversy and assume that we can measure capital in value terms." S. ähnlich auch Galeotti (1984) und Wegener (1987, S. 7).

49 Derartige Versuche, Bedingungen für die Unmöglichkeit von Reswitching of Techniques und Capital Reversing in Mchr-Produkt-Ökonomien zu finden, sind entweder gescheitert (s. z. B. Gallaway/Shukla (1974) und die Erwiderung von (Garcgnani (1976)) oder haben zu extrem restriktiven Bedingungen geführt, deren ökonomische Relevanz ungeklärt ist (vgl. Burmeister (1987).

50 S. hierzu genauer Barens (1992) 
Aggregierte Produktionsfunktionen haben sich der hier behandelten kapitaltheoretischen Problematik zum Trotz empirisch als überaus erfolgreich erwiesen. Dies stellt möglicherweise einen Grund für den Umstand dar, daß auch nach der Cambridge-Kontroverse weiterhin mit aggregierten Produktionsfunktionen gearbeitet wird. Allerdings ist ein solcher Rückgriff auf den empirischen Erfolg von aggregierten Produktionsfunktionen nicht statthaft. Fisher $(1969 ; 1971)$ hat in Simulationsexperimenten festgestellt, daß beliebige Produktionstechnologien, damit auch solche, in denen die Existenzbedingungen einer aggregierten Produktionsfunktion nicht erfüllt sind, durch eine aggregierte Produktionsfunktion abgebildet werden können, sofern nur die Einkommensverteilung konstant ist. Damit aber kann aus einer aggregierten Produktionsfunktion keinerlei Information über die zugrumdeliegende Produktionstechnologie gewonnen werden. ${ }^{51}$ Insbesondere kann der empirische Erfolg von aggregierten Produktionsfunktionen nicht als Indiz für die Irrelevanz der hier dargestellten kapitaltheoretischen Ergebnisse angesehen werden. Denn die vermeintliche empirische Bestätigung beruht offensichtlich allein auf der zufälligen ${ }^{52}$ Konstanz der Einkommensverteilung in der untersuchten realen Ökonomie.

Das Konzept der aggregierten Produktionsfunktion erweist sich im Lichte einer kapitaltheoretischen Prüfung als eine theoretisch nicht fundierte Konstruktion, die allein für den empirisch völlig uninteressanten Fall einer Ein-Gut-Ökonomie zutreffende Aussagen erlaubt. Dieses Ergebnis entzieht, so muß die Schlußfolgerung im hier behandelten $\mathrm{Zu}$ sammenhang lauten, jedem investitionstheoretischen Ansatz, der mit diesem Konzept arbeitet, die theoretische Grundlage. Jorgenson-Ansatz und $q$-Theorie stellen keine theoretisch hinreichend fundierten investitionstheoretischen Ansätze dar und können somit auch keine verläßlichen Aussagen über den Einfluß von Besteuerung auf Investitionen bzw. Direktinvestitionen liefern.

\subsection{Eine neue Perspektive: der Einfluß asymmetrischer Informationen auf Investitionen}

Die bisherigen Überlegungen haben gezeigt, daß gegenwärtig keine tragfähige theoretische Grundlage zur Analyse des Einflußes von Besteuerung auf die Investitionstătigkeit existiert. In diesem Abschnitt soll eine weitere Möglichkeit der Wirkung von Besteuerung auf das Investitionsverhalten angesprochen werden, für die in neueren empirische Untersuchungen Hinweise gefunden worden sind.

Sind die Informationen über die Erfolgsaussichten von Investitionsprojekten asymmetrisch verteilt, wobei Kreditgeber im Gegensatz zu den Kredit nachfragenden Investo-

\footnotetext{
51 Vgl. hierzu auch Shaik $(1974 ; 1980 ; 1987)$

52 Zufällig in dem Sinn, daB die Konstanz der Einkommensverteilung eben nicht durch die Eigenschaften der Produktionsfunktion erklärt werden kann, somit theoretisch nicht erklärt ist.
} 
ren über systematisch unvollständige Informationen verfügen, entsteht die Möglichkeit der Kreditrationierung. ${ }^{53}$ Zwar bildet sich ein gleichgewichtiger Zinssatz heraus, dieser Gleichgewichtszins bringt allerdings nicht Kreditangebot und -nachfrage zum Ausgleich. Vielmehr werden die Kreditnachfrager in dem Sinne rationiert, daß entweder alle Nachfrager geringere Kredite als nachgefragt erhalten oder die Kreditnachfrage einiger Investoren vollständig befriedigt wird, während die restlichen Nachfrager keinerlei Kredite erhalten.

In einer solchen Situation können interne Finanzierungsmittel in zweifacher Hinsicht Bedeutung erlangen. Zum einen ermöglichen ausreichende interne Finanzierungsmittel eine Finanzierung der gewünschten Investitionen ohne Rückgriff auf den Versuch der Kreditaufnahme und die damit möglicherweise einhergehende Rationierung auf dem Kreditmarkt. Zum anderen kann die Höhe intern verfügbarer Finanzierungsmittel den über eine Kreditvergabe entscheidenden Banken als Indikator der Kreditwürdigkeit einer Unternehmung dienen und so die Wahrscheinlich der Krediterteilung erhöhen.

In beiden Fällen ist ceteris paribus ein positiver Zusammenhang zwischen internen Finanzierungsmitteln und Investitionstätigkeit zu erwarten. Neuere empirische Untersuchungen bestätigen diese Vermutung. ${ }^{54}$ Dieses Ergebnis ist allerdings weder überraschend noch neu; bereits in den frühestens empirischen Untersuchungen der Investitionstätigkeit wurden Variablen wie Cash Flow bzw. Profit erfolgreich berücksichtigt. ${ }^{55}$ Da aber zu jener Zeit keine befriedigende theoretische Fundierung für den Einfluß derartiger Variablen bekannt war, wurden sie unter dem Einfluß der Aussagen des Modigliani-Miller-Theorems zunehmend in den Hintergrund gedrängt um schließlich z. B. in den Arbeiten von Jorgenson gänzlich zu verschwinden. ${ }^{56}$ Es handelt sich also eher um eine empirische Wiederentdeckung von nun theoretisch wohlfundierten Einflußgrößen.

Auch wenn - wie dargelegt - gegenwärtig kein tragfähiges theoretisches und empirisches Investitionsmodell zur Verfügung steht, die Bestimmungsgründe der unternehmerischen Investitionstätigkeit somit weiterhin analytisch „im Dunklen“ bleiben, kann anhand der bisherigen empirischen Ergebnisse und der analytischen Aussagen der Theorie der Kreditrationierung wohl vermutet werden, daß die Verfügbarkeit interner Finanzierungsmittel sich stimulierend auf die Investitionstätigkeit auswirken wird. Der Umfang intern verfügbarer Finanzierungsmittel unterliegt aber steuerpolitischer Einflußnahme. Damit eröffnet sich möglicherweise eine Perspektive, aus der auch ohne eine genau fundierte Kenntnis der „wahren“ Bestimmungsgründe der Investitionstätigkeit der Einfluß von Besteuerung auf

\footnotetext{
${ }_{53}$ Zur Theorie der Kreditrationierung vgl. beispielhaft Jaffee/Stiglitz (1990) und Stiglitz (1992).

$54 \mathrm{Vgl}$. insbesondere die Arbeiten von Fazzari/Mott (1987), Fazzari/Athey (1987) und Fazzari et al. $(1988 ; 1989)$.

55 Vgl. Meyer/Kuh (1957)

56 S. hierzu Gertler (1988) und Stiglitz (1988).
} 
Investitionen bzw. Direktinvestitionen zumindest explorativ untersucht werden kann.

\subsection{Schlußfolgerungen}

Die Ausführungen dieses Kapitels haben deutlich gemacht, daß weder der JorgensonAnsatz noch der $q$-Ansatz, der im Vergleich zum Jorgenson-Ansatz durch die Berücksichtigung von Installationskosten einen entscheidenden Fortschritt in der Frage der Bestimmung optimaler Investitionen darzustellen schien, eine tragfähige Grundlage für die theoretische und empirische Untersuchung des Einflußes von Besteuerung auf Direktinvestitionen zu liefern vermögen. Allerdings finden sich in jüngster Zeit erneut interessante theoretische und empirische Hinweise auf einen möglichen Einfluß von Besteuerung auf die Investitionstätigkeit, insofern als die Investitionstätigkeit von intern verfügbaren Finanzierungsmittelen abhängig zu sein scheint, die ihrerseits wiederum von steuerpolitischen Maßnahmen beeinflußt werden (können). 
Otto Roloff, Sibylle Brander, Ingo Barens and Claudia Wesselbaum - 978-3-631-75210-4 Downloaded from PubFactory at 01/11/2019 07:04:40AM via free access 


\section{Kapitel 2:}

Steuerbelastung und verwendbares Eigenkapital: eine Veranlagungssimulation

Betrachtet man die Steuerpolitik eines Staates unter der Perspektive, daß neben der Förderung von Investitionen der im Staat ansässigen Unternehmen auch die Neuansiedlung von ausländischen Gesellschaften ihr Ziel ist, stellt sich für einen multinationalen Investor die Frage nach seiner effektiven Gesamtsteuerbelastung im Quellen- und Wohnsitzstaat an den alternativen Standorten in den EG-Mitgliedstaaten.

Bei Standortverlagerungen handelt es sich um langfristige Investitionen, die nur unter erheblichen finanziellen Verlusten revidierbar sind. Die Vorteilhaftigkeit des in dem betrachteten Land geltenden Steuersystems kann daher nicht anhand einer auf Modellannahmen und auf statistischen Daten beruhenden allgemeinen Kennziffer bewertet, sondern muß im Hinblick auf die spezielle Situation eines Unternehmens einzelwirtschaftlich ermittelt werden. Dies bedeutet, daß die alternativen Standorte in bezug auf die steuerliche Bemessungsgrundlage, der anzuwendenden Steuersätze sowie der daraus resultierenden Belastung im Belegenheitsstaat und die bei einer Rückführung der Rendite anzuwendende Methode zur Vermeidung der doppelten Besteuerung für ein Unternehmen analysiert werden müssen.

Eine Synopse der körperschaftsteuerlichen Gewinnermittlungsvorschriften ${ }^{1}$ verdeutlicht, daß sich durch das Rechtssystem der Bundesrepublik Deutschland, von Frankreich und von Großbritannien vielfältige Differenzen bei der Ermittlung der für die Körperschaftsteuer relevanten Bemessungsgrundlage ergeben. Im Rahmen einer Einzelbetrachtung mögen die diversen Abweichungen als geringfügig erachtet werden; aus der Addition dieser Differenzen ergeben sich indes Unterschiede, die einen spürbaren Einfluß auf die Höhe der Unternehmensteuerbelastung im Quellenland nehmen. Die aus den divergierenden Gewinnermittlungsvorschriften resultierenden Abweichungen bei der Berechnung der steuerlichen Bemessungsgrundlage sind dabei nicht so direkt ersichtlich, wie Differenzen bei den darauf anzuwendenden Körperschaftsteuersätzen.

Bei einer Rückführung der im Ausland erzielten Rendite an einen bundesdeutschen Kapitaleigner müssen zusätzlich zu den Gewinnermittlungsvorschriften und den Körperschaftsteuersätzen des Quellenlandes die anzuwendenden Methoden zur Vermeidung der Doppelbesteuerung im Wohnsitzland berücksichtigt werden. Die Analyse der in der Bun-

${ }^{1}$ Vgl. Wesselbaum-Neugebauer (1992, S. 61 ff. und $\left.192 \mathrm{ff}.\right)$. 
desrepublik Deutschland verwendeten Verfahren zeigt, daß durch die im Rahmen von Doppelbesteuerungsabkommen vereinbarte Freistellung von Einkünften bzw. durch das Quellenland-Prinzip, eine zweifache Erfassung vermieden wird. Bei Zinszahlungen wird dabei die Gesamtsteuerbelastung determiniert durch das Steuersystem des Wohnsitzlandes und bei Dividendenzahlungen durch die Steuergesetzgebung im jeweiligen Quellenstaat. Aufgrund der fehlenden Möglichkeit, die uni- und bilateralen Maßnahmen zur Beseitigung der doppelten Besteuerung auch auf die Aktionäre anzuwenden, wird bei einer Weiterausschüttung der empfangenen Dividenden die doppelte Besteuerung weder vermieden noch vermindert.

Um den Einfluß der steuerlichen Gewinnermittlungsvorschriften auf das steuerpflichtige Einkommen und die Steuerbelastung zu analysieren, wird im folgenden anhand der Daten einer real existierenden Kapitalgesellschaft eine Veranlagungssimulation für die alternativen Standorte Bundesrepublik Deutschland, Frankreich und Großbritannien durchgeführt.

\subsection{Steuerliche Gewinnermittlung im jeweiligen Quellenstaat}

Bei der Veranlagungssimulation wird davon ausgegangen, daß die Umsätze sowie die damit im Zusammenhang stehenden Ausgaben in allen Staaten identisch sind. Zudem wird angenommen, daß der Gewinn aus Gewerbebetrieb dem zu versteuernden Einkommen entspricht. Es wird davon ausgegangen, daß der nach Handelsrecht ermittelte Bilanzgewinn identisch ist mit dem steuerrechtlich ermittelten Gewinn. ${ }^{2}$

Aufgrund der vorgelegten Buchführung sowie des Rechtssystems in der Bundesrepublik Deutschland, in Frankreich und in Großbritannien ergibt sich folgende steuerliche Bilanz per 31.12.1991 sowie Gewinn- und Verlustrechnung von dem 1.1.1991 bis zu dem 31.12.1991 eines Unternehmens, das alternativ in der Bundesrepublik Deutschland, in Frankreich bzw, in Großbritannien veranlagt wird.

Die durchgeführte Veranlagungssimulation zeigt, daß die unterschiedlichen Gewinnermittlungsvorschriften zu einem je nach Nation variierenden Jahresüberschuß vor Steuern führen. Eine Analyse der Differenzen verdeutlicht, daß bei einem identischen Umsatz und übereinstimmenden Ausgaben Unterschiede resultieren aus:

- abweichenden Bewertungsvorschriften, z. B. unterschiedlichen Abschreibungssätzen,

- der späteren bzw. früheren Erfassung von Erträgen und Aufwendungen, z. B. Aktive bzw. Passive Rechnungsabgrenzung, Rückstellungen sowie

${ }^{2}$ Die für die Durchführung der Veranlagungssimulation zugrundegelegten Annahmen, die vorgenommenen Abschlußbuchungen, die HauptschluBübersicht sowie der Anlagenspiegel können bei WesselbaumNeugebauer (1992, S. $235 \mathrm{ff}$.) nachgeschlagen werden. 
Tabelle 2.1: Steuerbilanz per 31.12.1991

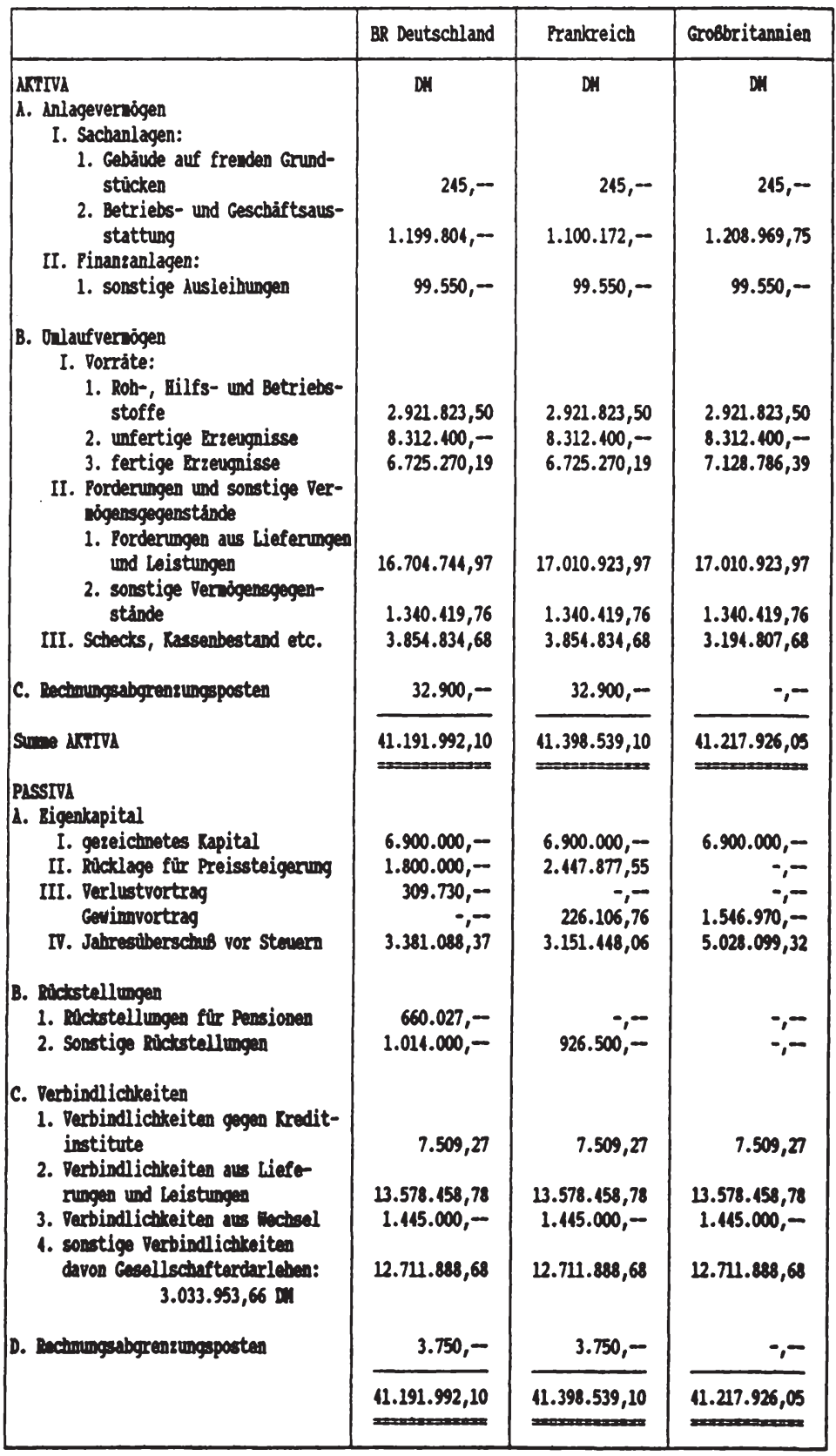


Tabelle 2.2: Steuerliche Gewinnermittlung vom 1.1.1991-31.12.1991

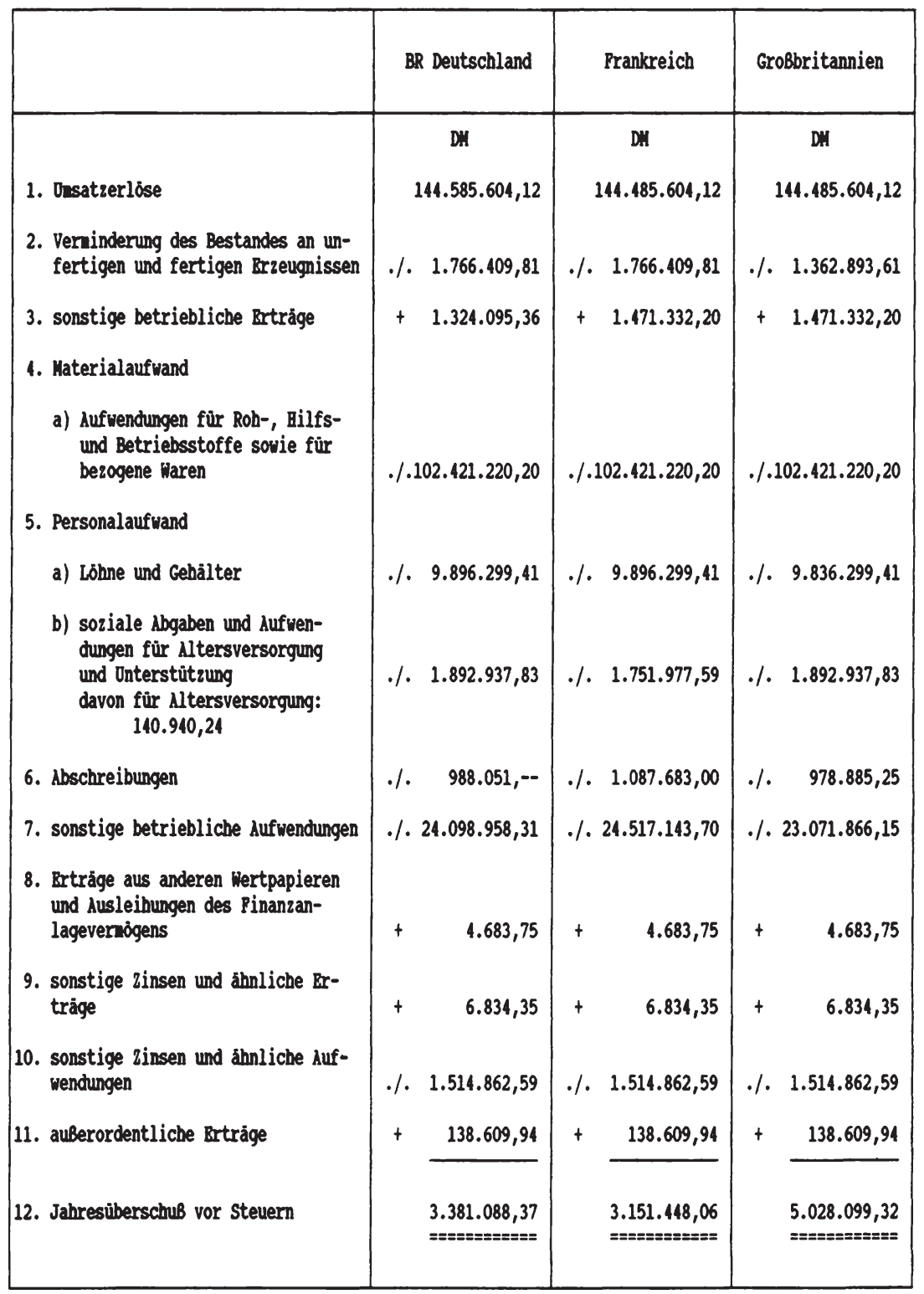


- der Nichtabzugsfähigkeit von Ausgaben bzw. der Belastung mit Kosten, die aufgrund nationaler Gegebenheiten anfallen, z. B. betriebliche Pensionsleistungen.

Bei den genannten Differenzen handelt es sich fast ausschließlich um temporäre Abweichungen, die sich mit der Zeit umkehren. Durch die Teilnahme am allgemeinen wirtschaftlichen Verkehr ergibt sich jedoch für ein Unternehmen in jedem Wirtschaftsjahr die Möglichkeit, Bewertungswahlrechte in Anspruch zu nehmen, welche zu temporären Differenzen führen. In Höhe des hieraus resultierenden ständigen Bestandes an temporären Abweichungen existiert eine quasi permanente Differenz zwischen den nationalen Bemessungsgrundlagen, welche eine dauerhafte Verschiebung der Steuerlast auf spätere Perioden bewirkt.

\subsubsection{Steuerbelastung in der Bundesrepublik Deutschland, in Frankreich und in Großbritannien}

Inwieweit unterschiedliche steuerliche Bemessungsgrundlagen bei voneinander abweichenden nominalen Steuersätzen auch zu einer ungleichen Steuerbelastung führen, wird im folgenden analysiert. Bei der Berechnung der Steuerlast wird dabei nur die Körperschaftsteuer des alternativen Standortes berücksichtigt. Sonstige Ertrag- und Substanzsteuer bleiben außer acht. Es wird angenommen, daß die Ausschüttungsquote (a) 70 v. H. beträgt und der laut Handelsbilanz ausgewiesene Gewinn mit dem steuerlichen Jahresüberschuß (JÜ) übereinstimmt. Das zu versteuerde Einkommen im Inland $\left(\pi_{V E}\right)$ und im Ausland $\left(\pi_{Q}\right)$ wird entsprechend der nationalen Bestimmungen ermittelt.

Bei einem gespaltenen Steuersatz variiert die an das Finanzamt abzuführende Körperschaftsteuer je nach Ausschüttungsverhalten eines Unternehmens. Auf ausgeschüttet Gewinne wird in der Bundesrepublik Deutschland ein ermäBigter Steuersatz $\left(\mathrm{t}_{C W A}\right)$ angewendet, während Thesaurierungen mit dem Normalsteuersatz $\left(\mathrm{t}_{C W}\right)$ belastet werden. Für die Berechnung der bundesdeutschen Körperschaftsteuerbelastung $\left(\mathrm{T}_{W}\right)$ gilt daher:

$$
\begin{aligned}
T_{W} & =\pi_{V E}(1-a) t_{C W}+\pi_{V E} a t_{C W A} \\
& =\pi_{V E}\left[(1-a) t_{C W}+a t_{C W}\right]
\end{aligned}
$$

In Frankreich wird demgegenüber ein ermäßigter Steuersatz $\left(\mathrm{t}_{C Q A}\right)$ auf thesaurierte Gewinne angewendet, während der Normalsteuersatz $\left(t_{C Q}\right)$ auf ausgeschüttete Dividenden erhoben wird. Für die Steuerbelastung $\left(\mathrm{T}_{Q}\right)$ bedeutet dies:

$$
\begin{aligned}
T_{Q} & =\pi_{Q}(1-a) t_{C Q A}+\pi_{Q} a t_{C Q} \\
& =\pi_{Q}\left[(1-a) t_{C Q A}+a t_{C Q}\right]
\end{aligned}
$$


In Großbritannien wird auf Ausschüttungen und Thesaurierungen ein einheitlicher Steuersatz $\left(t_{C Q}\right)$ angewendet. Die Steuerbelastung resultiert demnach aus:

$$
T_{Q}=\pi_{Q} t_{C Q}
$$

Unter Zugrundelegung dieser Gleichungen ergeben sich für die betrachteten Nationen die in der Tabelle 2.3 zusammengefaßten Resultate.

Die Ergebnisse der für ein tatsächlich existierendes Unternehmen durchgeführten Veranlagungssimulation nach deutschem, französischem und britischem Steuerrecht verdeutlichen, daß aufgrund der nationalen Bewertungsdifferenzen die bundesdeutsche körperschaftsteuerliche Bemessungsgrundlage lediglich 67,24 v. H. und die französische Bemessungsgrundlage nur 62,68 v. H. des in Großbritannien zu versteuernden Gewinns beträgt. Setzt man die unter Berücksichtigung der national differierenden Gesetzgebung ermittelte Steuerbelastung in bezug zu der britischen Bemessungsgrundlage, so ergibt sich bei einem Ausschüttungsverhalten von 70 v. H. des länderspezifischen Jahresüberschusses vor Steuern für die Bundesrepublik Deutschland ein effektiver durchschnittlicher Körperschaftsteuersatz in Höhe von 25,66 v. H., für Frankreich von 24,82 v. H. und für Großbritannien von $33 \mathrm{v}$. H.

Wird anstelle der britischen Bemessungsgrundlage der nach bundesdeutschem Steuerrecht ermittelte Jahresüberschuß vor Steuern als Bezugsgröße verwendet, so ergibt sich für Frankreich ein effektiver durchschnittlicher Körperschaftsteuersatz von 33,81 v. H., für Großbritannien in Höhe von 49,07 v. H. und für die Bundesrepublik Deutschland in Höhe von 38,15 v. H. Wird die absolute Belastung mit Körperschaftsteuer in den betrachteten Ländern gegenübergestellt, so weist unabhängig von dem Ausschüttungsverhalten die nach britischem Steuerrecht durchgeführte Veranlagung die höchste Steuerzahllast auf. In der Bundesrepublik Deutschland und in Frankreich variiert die Steuerlast je nach Ausschüttungsverhalten.

Für das betrachtete Unternehmen geht demnach der in der Bundesrepublik Deutschland relativ hohe nominale Tarifsatz mit einer niedrigen effektiven Durchschnittsteuerbelastung und der in Großbritannien relativ niedrige tarifliche Steuersatz mit einer hohen effektiven Durchschnittsteuerbelastung einher. Die niedrigste durchschnittliche effektive Körperschaftsteuerbelastung resultiert aus einer Direktinvestition in Frankreich, wenn der Gewinn entweder thesauriert oder zu weniger als 72,72 v. H. ausgeschüttet wird. Bei einer Vollausschüttung bzw. einer über 72,72 v. H. hinausgehenden Ausschüttung des Gewinnes weist die bundesdeutsche Tochterkapitalgesellschaft die geringste, absolute steuerliche Belastung auf. 
Tabelle 2.3: Steuerbelastung einer Kapitalgesellschaft in der Bundesrepublik Deutschland, in Frankreich bzw. in Großbritannien

\begin{tabular}{|c|c|c|c|}
\hline & $\begin{array}{l}\text { BR Deutschland } \\
\text { in DW }\end{array}$ & $\begin{array}{l}\text { Prankreich } \\
\text { in DH }\end{array}$ & $\begin{array}{l}\text { Grobbritannien } \\
\text { in DII }\end{array}$ \\
\hline $\begin{array}{l}\text { Ousatzerlöse } \\
\text { Jahresüberschuß vor Steuern }\end{array}$ & $\begin{array}{r}144.485 .604,12 \\
3.381 .088,37\end{array}$ & $\begin{array}{r}144.485 .604,12 \\
3.151 .448,06\end{array}$ & $\begin{array}{r}144.485 .604,12 \\
5.028 .099,32\end{array}$ \\
\hline $\begin{array}{l}\text { Steuersatz auf Ausschüttungen } \\
\text { Steuersatz bei Thesaurierung }\end{array}$ & $\begin{array}{l}36 \text { v. В. } \\
50 \text { v. В. }\end{array}$ & $\begin{array}{l}12 \text { v. } \text {. } \\
34 \text { v. } 8 .\end{array}$ & $\begin{array}{l}33 \text { v. B. } \\
33 \text { v. B. }\end{array}$ \\
\hline $\begin{array}{l}\text { Steuerbelastung absolut } \\
\text { a) Vollausschuittung } \\
\text { b) Vollthesaurierung } \\
\text { c) } 70 \text { v. H. Ausschuittung }\end{array}$ & $\begin{array}{l}1.105 .689,01 \\
1.535 .679,19 \\
1.289 .970,52\end{array}$ & $\begin{array}{l}1.323 .608,19 \\
1.071 .492,34 \\
1.247 .973,43\end{array}$ & $\begin{array}{l}1.659 .272,78 \\
1.659 .272,78 \\
1.659 .272,78\end{array}$ \\
\hline $\begin{array}{l}\text { Steuerquote in v. B. der nationalen } \\
\text { Benessungsgrundlage } \\
\text { a) Vollausschüttung } \\
\text { b) Vollthesaurierung } \\
\text { c) } 70 \text { v. H. Lusschüttung }\end{array}$ & $\begin{array}{r}36 \text { v. В. } \\
50 \text { v. В. } \\
38,15 \text { v. В. }\end{array}$ & $\begin{array}{l}42 \text { v. В. } \\
34 \text { v. Н. } \\
39,6 \text { v. Н. }\end{array}$ & $\begin{array}{l}33 \text { v. H. } \\
33 \text { v. . } \\
33 \text { v. Е. }\end{array}$ \\
\hline$\frac{j \dot{\delta} \text { vor Steuern in Land } 1 \cdot 100}{j \dot{\delta} \text { vor Steuern in Grobbritannien }}$ & 67,24 v. B. & 62,68 v. H. & 100 v. H. \\
\hline $\begin{array}{l}\text { Steverbelastumg in Land } 1 \cdot 100 \\
\text { Ji vor Steuern in Grobbritannien } \\
\text { a) Vollausschittung } \\
\text { b) Vollthesaurierung } \\
\text { c) } 70 \mathrm{v.} \mathrm{B.} \mathrm{Ausschüttumg}\end{array}$ & $\begin{array}{l}21,99 \text { จ. В. } \\
30,54 \text { У. В. } \\
25,66 \text { ข. В. }\end{array}$ & $\begin{array}{l}26,32 \text { v. В. } \\
21,31 \text { v. В. } \\
24,82 \text { v. В. }\end{array}$ & $\begin{array}{l}33 \text { v. H. } \\
33 \text { v. H. } \\
33 \text { v. H. }\end{array}$ \\
\hline $\begin{array}{l}\text { Steuerbelastung in Land } 1 \cdot 100 \\
\text { J0 vor Stevern in BR Deutschland } \\
\text { a) Vollausschittung } \\
\text { b) Vollthesauriermg } \\
\text { c) } 70 \text { v. B. Ausschittung }\end{array}$ & $\begin{array}{l}50 \text { v. Е. } \\
36 \text { v. В. } \\
38,15 \text { v. В. }\end{array}$ & $\begin{array}{l}39,15 \text { v. В. } \\
31,69 \text { v. .. } \\
33,81 \text { v. В. }\end{array}$ & 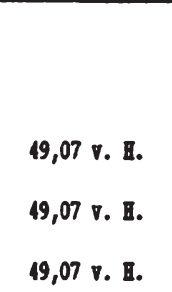 \\
\hline
\end{tabular}




\subsubsection{Rückführung des ausgewiesenen Gewinnes an eine bundesdeutsche Mutterkapitalgesellschaft unter Berücksichtigung der bestehenden Doppelbesteuerungsabkommen}

Wird in die Analyse die Rückführung des Gewinnes einer Tochterkapitalgesellschaft an die bundesdeutsche Mutterkapitalgesellschaft einbezogen, müssen die im Wohnsitzland angewendeten Methoden zur Vermeidung bzw. Verminderung der Doppelbesteuerung berücksichtigt werden. Die vorher getroffenen Annahmen werden bei der Untersuchung übernommen.

Die Bundesrepublik Deutschland hat sowohl mit Frankreich als auch mit Großbritannien ein Doppelbesteuerungsabkommen abgeschlossen, in dem das Schachtelprivileg vereinbart ist. Bezieht eine bundesdeutsche Mutterkapitalgesellschaft Dividendeneinkünfte von einer in Frankreich bzw. Großbritannien ansässigen Tochterkapitalgesellschaft, so sind diese demnach nur im Quellenland körperschaftsteuerpflichtig (Freistellungsverfahren bzw. Source Prinziple). Eine Besteuerung im Wohnsitzland der Mutterkapitalgesellschaft entfällt bis zu einer Weiterausschüttung der ausländischen Dividende an die Aktionäre. Zusätzlich zu der Körperschaftsteuer wird in Großbritannien und in Frankreich bei einer Ausschüttung der Dividende an eine ausländische Gesellschaft keine Kapitalertragsteuer erhoben. Die Körperschaftsteuerbelastung im Quellenland $\left(\mathrm{T}_{Q}\right)$ beläuft sich daher bei einer Vollausschüttung auf:

$$
T_{Q}=\pi_{Q} t_{C Q}
$$

Die einer bundesdeutschen Mutterkapitalgesellschaft nach Steuern zufließende Dividende $\left(D_{N}\right)$ beläuft sich bei den Einkünften aus Frankreich und Großbritannien auf:

$$
D_{N}=\pi_{Q}\left(1-t_{C Q}\right)
$$

In der Bundesrepublik Deutschland wird von der ausschüttenden Gesellschaft der ermäBigte Körperschaftsteuersatz $\left(\mathrm{t}_{C W A}\right)$ für einen Dividendenempfänger direkt einbehalten. Die Steuerbelastung $\left(\mathrm{T}_{W}\right)$ der inländischen Dividende beträgt somit:

$$
T_{W}=\pi_{V E} t_{C W A}
$$

Für die einer bundesdeutschen Mutterkapitalgesellschaft nach Steuern zufließende Dividende gilt bei inländischen Einkünften:

$$
D_{N}=\pi_{V E}\left(1-t_{C W A}\right) \text {. }
$$


Das im Inland zu versteuernde Finkommen $(G)$ beträgt für die I)ividendeneinkünfte aus einer bundesdeutschen 'Tochterkapitalgesellschaft:

$$
\begin{aligned}
G & =D_{N} \frac{1}{1-t_{C W A}} \\
& =\pi_{V E}
\end{aligned}
$$

Die inländischen Dividendeneinkünfte werden mit dem Normalsteuersatz belastet und sind in das mit 50 v. H. belastete Eigenkapital $\left(\mathrm{vEK}_{50}\right)$ einzustellen. Bei der Körperschaftsteuerabschlußzahlung an das Finanzamt wird die von der bundesdeutschen Tochterkapitalgesellschaft auf die Dividendeneinkünfte bereits einbehaltene Steuer in voller Höhe angerechnet, so daß lediglich der verbleibende Differenzbetrag noch zu leisten ist. Auf die ausländischen Einkünfte wird im Inland keine zusätzliche Steuer erhoben, da sie von der inländischen Besteuerung freigestellt werden. Die Einstellung der ausländischen Dividendeneinkünfte erfolgt daher in das mit inländischer Körperschaftsteuer nicht belastete Eigenkapital $\left(\mathrm{vFK}_{01}\right)$.

Werden die inländischen Einkünfte, welche mit dem Normalsteuersatz belastet sind, an die Anteilseigner weiter ausgeschüttet, so wird für die Herstellung der niedrigeren Ausschüttungsbelastung eine Körperschaftsteuerminderung in Höhe des Differenzbetrages vorgenommen. Erfolgt dahingehend eine Ausschüttung der bisher nicht mit inländischer Körperschaftsteuer belasteten Eigenkapitalanteile, so erfolgt eine Nachbesteuerung zu dem ermäßigten Ausßchüttungssatz. Aufgrund des in der Bundesrepublik Deutschland geltenden Vollanrechnungsverfahrens kann die von einer inländischen Mutterkapitalgesellschaft einbehaltene Ertragsteuer auf die persönliche Steuer eines inländischen Anteilseigners angerechnet werden. Dies bewirkt, daß lediglich ein Kapitaleigner ertragsteuerlich belastet wird, während ein Kapitalnehmer keine Körperschaftsteuer zu leisten hat.

Die bereits im Quellenland einbehaltene Körperschaftsteuer wird aufgrund der fehlenden Steuersubjekt- und Steuerobjektidentität nicht gutgeschrieben. Bei der im Quellenland einbehaltenen direkten Steuer handelt es sich somit um eine Definitivbelastung, welche die Rendite eines Anteilseigners verringert. Ein inländischer Kapitaleigner muß auf die von ihm erzielten Dividendeneinkünfte einen einheitlichen persönlichen Ertragsteuersatz leisten. Die von einem Aktionär zu zahlende Ertragsteuer wird daher nicht in die Analyse einbezogen, da voneinander abweichende Renditen nach Unternehmen- und vor persönlicher Steuer simultan unterschiedliche Renditen nach Abzug der Gesamtsteuerbelastung beinhalten und umgekehrt. Unter Zugrundelegung der bei der Veranlagungssimulation ermittelten Resultate ergeben sich somit für eine bundesdeutsche Mutterkapitalgesellschaft sowie einem inländischen Aktionär die in der Tabelle 2.4 zusammengestellten Ergebnisse.

Die Resultate zeigen, daß Großbritannien die umfassenste Bemessungsgrundlage, den 
Tabelle 2.4: Steuerbelastung unter Berücksichtigung der Doppelbesteuerungsabkommen

\begin{tabular}{|c|c|c|c|}
\hline & $\begin{array}{l}\text { BR Deutschland } \\
\text { in DII }\end{array}$ & $\begin{array}{c}\text { Prankreich } \\
\text { in DH }\end{array}$ & $\begin{array}{c}\text { Grobbritannien } \\
\text { in DH }\end{array}$ \\
\hline $\begin{array}{l}\text { Onsatzerlöse } \\
\text { Jahresüberschuß vor Steuern } \\
\text { Steuersatz bei Ausschüttung } \\
\text { Steuerbelastung bei vollausschüttung }\end{array}$ & $\begin{array}{c}144.485 .604,12 \\
3.381 .088,37 \\
36 \text { v. } 1 . \\
1.105 .689,01\end{array}$ & $\begin{array}{c}144.485 .604,12 \\
3.151 .448,06 \\
42 \text { v. 8. } \\
1.323 .608,19\end{array}$ & $\begin{array}{c}144.485 .604,12 \\
5.028 .099,32 \\
33 \text { v. H. } \\
1.659 .272,78\end{array}$ \\
\hline $\begin{array}{l}\text { ZufluB bei einer bundesdeutschen } \\
\text { Mutterkapitalgesellschaft } \\
\text { zu versteuerndes Binkonnen } \\
\text { inländische Gesantsteuerbelastung } \\
\text { in das jeweilige verwendbare Rigenkapi- } \\
\text { tal einzustellender Betrag } \\
\text { verwendbare Bigenkapital Land } 1 \cdot 100 \\
\text { verwendbare Rigenkapital GroBbritannien }\end{array}$ & $\begin{array}{c}1.965 .669,26 \\
3.071 .358,37 \\
1.535 .679,19 \\
1.535 .679,19 \\
45,585 \&\end{array}$ & $\begin{array}{r}1.827 .839,87 \\
-,-- \\
-,-- \\
1.827 .839,87 \\
54,257 \quad\end{array}$ & $\begin{array}{r}3.368 .826,54 \\
-,-- \\
-,-- \\
3.368 .826,54 \\
1008\end{array}$ \\
\hline $\begin{array}{l}\text { 2ufluß bei einen inländischen Aktionär } \\
\text { zu versteuerndes Binkomen } \\
\text { Gesantbelastung nit in- bzw. auslandi- } \\
\text { scher Rorperschaftsteuer bei einer } \\
\text { Weiterausschüttung an die Nktionäre }\end{array}$ & $\begin{array}{l}1.965 .669,26 \\
3.071 .358,37\end{array}$ & $\begin{array}{l}1.169 .817,52 \\
1.827 .839,87\end{array}$ & $\begin{array}{l}2.156 .048,99 \\
3.368 .826,54\end{array}$ \\
\hline
\end{tabular}


niedrigsten formalen Steuersatz, die höchste absolute Steuerbelastung und zugleich die höchste Ausschüttung an die Mutterkapitalgesellschaft aufweist. Bei einem identischen Umsatz und übereinstimmenden Ausgaben verfügt eine bundesdeutsche Mutterkapitalgesellschaft bei Dividendeneinkünften aus einer französischen Tochterkapitalgesellschaft lediglich über 54,257 \% der in Großbritannien erzielbaren Rendite nach Abzug der zu leistenden Körperschaftsteuer. Bei Einkünften aus einer bundesdeutschen Tochterkapitalgesellschaft verbleibt einer inländischen Kapitalgesellschaft cin verwendbares Eigenkapital in Höhe von 45,585 \% der bei britischen Einkünften erzielbaren Rendite. Ia in Großbritannien eine umfangreichere Bemessungsgrundlage für die Besteuerung herangezogen wird, übersteigt auch bei einer Weiterausschüttung der empfangenen ausländischen Dividenden die einem inländischen Aktionär nach Unternehmensteuern und vor persönlicher Ertragsteuer zufließende Rendite die der alternativen Standorte Bundesrepublik Deutschland und Frankreich. Das Land mit der höchsten absoluten Körperschaftsteucrbelastung, der umfangreichsten Bemessungsgrundlage und dem niedrigsten Tarifsteuersatz weist somit die höchste Rendite nach Steuern auf. Dies gilt allerdings nur unter der $\Lambda$ nnahme, daß der Steuerbilanzgewinn mit dem in der Handelsbilanz ausgewiesenen Gewinn übereinstimmt. In der Bundesrepublik Deutschland handelt es sich bei der Stcuerbilanz um eine nach steuerlichen Gesichtspunkten ${ }^{3}$ korrigierte Handelsbilanz. Dic gesetzlich geregelte Maßgeblichkeit der Handelsbilanz für die Steuerbilanz bzw. die Umkehrung des Maßgeblichkeitsprinzips führt dazu, daß bestimmte Bewertungswahlrechte (z. B. Sonderabschreibungen) nur wahrgenommen werden können, wenn sie sowohl in der Handels- als auch in der Steuerbilanz in Anspruch genommen werden. Das Interesse von Aktionären an einer hohen Dividendenzahlung sowie das dem gegenüberstehende Ziel der Geschäftsführung einer Kapitalgesellschaft, durch dic Inanspruchnahme von Bewertungswahlrechten und die Bildung stiller Reserven dic Stcuerlast zu minimicren, werden durch das Maßgeblichkeitsprinzip in einem starken Maße miteinander verbunden. Andererseits bewirkt die enge Verknüpfung von bundesdeutscher Handels- und Steuerbilanz, daß die in der Handelsbilanz gebildeten stillen Reserven nicht nur den Aktionären für eine Ausschüttung sondern auch dem Fiskus für die Besteuerung entzogen werden. Trotz des Maßgeblichkeitsprinzips wird es aufgrund steuerlicher Vorschriften (z. B. der nicht abzugsfähigen Betriebsausgaben ${ }^{4}$ ) selten vorkommen, daß Handels- und Steuerbilanz identisch sind.

In Frankreich ist die körperschaftsteuerliche Bemessungsgrundlage der nach den steucrli-

${ }^{3}$ Dem Handelsbilanzgewinn müssen gem. $§ 10 \mathrm{KStG}$ die Steuern vom Einkommen und vom Vermögen, festgesetzte Geldstrafen, die Hälfte der Vergütung an Mitglieder des Aufsichtsrats, verdeckte Gewinnausschüttungen etc. hinzugerechnet werden. Vgl. hierzu auch Wesselbaum-Neugebauer (1992, S. $62 \mathrm{ff}$.)

${ }^{4}$ So können z. B. Aufwendungen für Geschenke an Personen, die nicht Arbeitnehmer des Steuerpflichtigen sind steuerlich nicht geltend gemacht werden, wenn die Anschaffungskosten/Herstellungskosten 75 DM überschreiten. Aufwendungen für die Bewirtung von Personen aus geschäftlichem AnlaB sind steuerlich nur zu 80 v. h. abzugsfähig. In der Handelsbilanz können die entsprechenden Kosten in nachgewiesener Höhe abgesetzt werden. 
chen Vorschriften ${ }^{5}$ korrigierte Handelsbilanzgewinn. ${ }^{6}$ Das in der Bundesrepublik geltende Maßgeblichkeitsprinzip wird in Frankreich nicht angewendet, so daß steuerliche Vergünstigungen (z. B. Sonderabschreibungen) keinen Einfluß auf den Handelsbilanzgewinn nehmen. Auch in Frankreich führen steuerliche Vorschriften ${ }^{7}$ dazu, daß der nach Handelsrecht ermittelte Gewinn in der Regel von der steuerlichen Bernessungsgrundlage abweicht.

In Großbritannien wird die nach betriebswirtschaftlichen Vorschriften erstellte Überschußrechnung den einkommensteuerlichen Vorschriften angepaßt. ${ }^{8}$ Die zur Deckung ungewisser Verpflichtungen und möglicher Verluste gebildeten Posten (z. B. Rückstellungen) werden steuerlich nicht anerkannt. ${ }^{9}$ Dies führt dazu, daß Handels- und Steuerbilanzgewinn in einom starken Maße voneinander abweichen.

Der für Ausschüttungen verwendbare Bilanzgewinn wird durch das Handelsrecht bestimmt. Durch die Transformation der 4. EG-Richtlinie (Bilanzrichtlinie) in das nationale Recht der Bundesrepublik Deutschland, Frankreichs und Großbritanniens gelten im Zusammenhang mit der Ermittlung des Handelsbilanzgewinnes weitgehend identische Bewertungsansätze. ${ }^{10}$ Unter der Annahme, daß der Handelsbilanzgewinn für das betrachtete Unternehmen in der Bundesrepublik Deutschland, in Frankreich und in Großbritannien ceteris paribus identisch ist mit dem in der Bundesrepublik Deutschland ausgewiesenen Steuerbilanzgewinn, ${ }^{11}$ ergeben sich für das verwendbare Einkommen sowie dem einen Aktionär bei einer Weiterausschüttung verbleibenden Nettobetrag die in Tabelle $2.5 \mathrm{zu}$ sammengefaßten Kirgebnisse.

Die Frgebnisse zeigen, daß unter Berücksichtigung des für die Ausschüttung relevanten Handelsbilanzgewinnes eine bundesdeutsche Tochterkapitalgesellschaft die höchste Ausschüttung an eine Mutterkapitalgesellschaft vornehmen kann. Da Einkünfte aus Frankreich und Großbritannien aufgrund des bestehenden Doppelbesteuerungsabkommens von der inländischen Besteuerung freigestellt sind, resultiert der höchste in das verwendbare

5 Dem handelsrechtlichen Gewinn müssen z. B. überhöhte Vergütungen an Gesellschafter, Körperschaftsteuerzahlungen, Steuerstrafen etc. hinzugerechnet werden. Abzugfähig ist ein Verlustvortrag (auf fünf Jahre) sowie ein Verlustrückt.rag (drei Jahre). Vgl. Hidien (1991, S. 234) sowie WesselbaumNeugebauer (1992, S. $64 \mathrm{ff}$.)

6 Vgl. Ilidien (1991, S. 234), Kühn (1991, S. 201)

7 So können z. B. Abschreibungen auf PKWs steuerlich nicht abgezogen werden, soweit die Anschaffungskosten $65000 \mathrm{FF}$ übersteigen.

8 Vgl. Müssener (1991, S. 11; 1992, S. 277 f.), Seidel et al. (1989, S. 60), Whiteman et al. (1988, S. 146).

9 Vgl. Möllering/Mohr (1986, S. 35), Seidel et al. (1989, S. 61). Für weitergehende Ausführungen zu der Frmittlung der steuerpflichtigen Bemessungsgrundlage siehe Wesselbaum-Neugebauer (1992, S. $68 \mathrm{ff}$. und $195 \mathrm{ff}$.).

10 Im Rahmen der Ermittlung des Handelsbilanzgewinns ergeben sich nationale Differenzen bei der Aktivierung von Gründungs-, Ingansetzungs-, Erweiterungs,- Forschungs- und Entwicklungskosten, dem Geschäfts- oder Firmenwert sowie der Zulässigkeit vereinfachender Bewertungsmethoden. Vgl. Küting/Weber (1990, S. 22 ff.).

11 Bei der Durchführung der Veranlagungssimulation wurde davon ausgegangen, daB die Kosten in den betrachteten Ländern identisch sind und die erforderlichen Bedingungen der Abzugsfähigkeit erfüllen. Siche hierzu auch Wesselbaurn-Neugebauer (1992, S. 237). 
Tabelle 2.5: $Z u$ versteuerndes Einkommen, verwendbares Eigenkapital und Zufluß bei einem deutschen Aktionär unter Berücksichtigung der Ausschüttung anhand des Handelsbilanzgewinns

\begin{tabular}{|c|c|c|c|}
\hline & $\begin{array}{l}\text { BR Deutschland } \\
\text { in DII }\end{array}$ & $\begin{array}{l}\text { Prankreich } \\
\text { in DII }\end{array}$ & $\begin{array}{c}\text { Grobbritannien } \\
\text { in DAl }\end{array}$ \\
\hline Ousatrerlöse & $144.485 .604,12$ & $144.485 .604,12$ & $144.485 .604,12$ \\
\hline Gevinn vor Stevern - Bandelsbilanz & $3.071 .358,371)$ & $3.071 .358,371)$ & $3.071 .358,371$ \\
\hline Gevinn vor Steuern - Steverbilanz & $3.071 .358,371)$ & $3.151 .448,06$ & $5.028 .099,32$ \\
\hline Steverbelastung (vgl. Tabelle 4) & $1.105,689,01$ & $1.323 .608,19$ & $1.659 .272,18$ \\
\hline $\begin{array}{l}\text { Zuflub bei einer bundesdeutschen } \\
\text { Mutterkapitalgesellschaft }\end{array}$ & $1.965 .669,26$ & $1.747 .750,18$ & $1.412 .086,19$ \\
\hline ou versteuerndes Binkomen in Inland & $3.071 .358,37$ &,--- &,--- \\
\hline inländische cesantsteverbelastung & $1.535 .679,19$ & $\because, \cdots$ &,--- \\
\hline $\begin{array}{l}\text { in das jeweilige verwendbare Bigenkapi- } \\
\text { tal einzustellender Betrag }\end{array}$ & $1.535 .679,19$ & $1.747 .750,18$ & $1.412 .086,19$ \\
\hline Steverbelastung Land I & & & \\
\hline Handelsbilanzgetinn in Land 1 & & 80,078 & $\pi, 0<3$ \\
\hline zuflub bei einen inländischen Aktionär & $1.965 .669,26$ & $1.118 .560,12$ & $903.735,16$ \\
\hline su versteverndes Binkomen & $3.071 .358,37$ & $1.747 .750,18$ & $1.412 .086,19$ \\
\hline
\end{tabular}

1 Unter Berücksichtigung des Verlustvortrages

Eigenkapital einzustellende Betrag aus der Errichtung einer Tochterkapitalgesellschaft in Frankreich. Bei Einkünften aus Großbritannien verbleibt einer inländischen Kapitalgesellschaft dabei ein verwendbares Eigenkapital in Höhe von $80.79 \%$ und bei bundesdeutschen Einkünften in Höhe von $87,86 \%$ des aus Frankreich zufließenden Betrages.

Wird die Steuerbelastung des jeweiligen Landes auf den entsprechenden Handelsbilanzgewinn bezogen, so zeigt sich, daß Großbritannien mit 54,02\% den hōchsten und die Bundesrepublik Deutschland mit $36 \%$ den niedrigsten durchschnittlichen effektiven Steuersatz aufweist.

Werden die Dividendeneinkünfte eines inländischen Aktionärs in die Betrachtung einbezogen, so zeigt sich, daß die höchste Rendite nach Körperschaftsteuer und vor individueller Einkommensteuer aus einer Investition im Inland resultiert. Bei der Weiterausschūttung von in Frankreich realisierten Gewinnen verfügt ein Anteilseigner über 56,90\% und bei 
britischen Einkünften lediglich über 45,98 \% der bei einer bundesdeutschen Tochterkapitalgesellschaft zu erwartenden Bruttorendite, da die bereits im Quellenstaat einbehaltene Körperschaftsteuer nicht auf die Einkommensteuer eines Aktionärs angerechnet werden kann und somit eine Definitivbelastung darstellt.

\subsubsection{Resultate}

Die einzelwirtschaftliche Veranlagungssimulation für ein in der Bundesrepublik Deutschland, in Frankreich bzw. in Großbritannien ansässiges Unternehmen zeigt, daß die nationalen Steuergesetze bei identischen Umsätzen und übereinstimmenden Aufwendungen zu unterschiedlichen Bemessungsgrundlagen führen. Ein umfangreiches zu versteuerndes Einkommen kann dabei geringere nominale Steuersätze überkompensieren und zu einer höheren absoluten Steuerbelastung führen, als in einer Nation mit einer Vielzahl von Bewertungswahlrechten, die eine geringere Bemessungsgrundlage bewirken, auf die ein höherer nominaler Steuersatz anzuwenden ist. Die ausschließliche Betrachtung des nominalen Steuersatzes bzw. der absoluten Steuerbelastung beinhaltet keine Information über die Möglichkeit, stille Reserven zu bilden und diese sowohl den Aktionären für eine Ausschüttung als auch dem Fiskus für eine Besteuerung zu entziehen.

Stille Reserven bewirken eine Eigenkapitalbildung in einem Unternehmen und stärken so das Selbstfinanzierungspotential. Einem Unternehmen stehen die nach Handelsrecht gebildeten aber steuerlich nicht anerkannten stillen Reserven nur mit dem nach Unternehmensteuern verbleibenden Betrag zur freien Verfügung. Die handelsrechtlich gewährte Möglichkeit, das betriebliche Kapital real zu sichern und zu erhalten sowie die Selbstfinanzierungskraft eines Unternehmens zu stärken, wird durch die steuerliche Erfassung der stillen Reserven in Großbritannien stärker eingeengt als in der Bundesrepublik Deutschland oder Frankreich.

Die Analyse verdeutlicht, daß anstelle des formalen der effektive Steuersatz in die Standortentscheidung einbezogen werden muß. Hierfür ist es erforderlich, neben dem laut Handelsrecht auszuweisenden Gewinn den nach steuerlichen Vorschriften korrigierten Steuerbilanzgewinn in die Analyse einzubeziehen.

\subsection{Bestimmung der erforderlichen Rendite vor Unternehmensteuern für die Erzielung einer festgelegten Rendite nach Unternehmensteuern unter Berücksichtigung der Finanzierungsart sowie der bestehenden Doppel- besteuerungsabkommen}

Die in Kapitel 5 analysierten Untersuchungen zur Berechnung von internationalen Steuerbelastungen haben die steuerlichen Bemessungsgrundlage nicht bzw. nur spezielle Vorschriften zu ihrer Ermittlung eingeschlossen. Im Rahmen von Investitionsentscheidungen können die so ermittelten Daten aufgrund ihrer hohen Aggregation nicht verwendet werOtto Roloff, Sibylle Brander, Ingo Barens and Claudia Wesselbaum - 978-3-631-75210-4 
den. Einzelwirtschaftliche Veranlagungssimulationen sind sehr zeitaufwendig und erfordern einen hohen Informationsgrad über die Steuersysteme der alternativen Standorte. Die bei der durchgeführten Veranlagungssimulation getroffene Annahme identischer Umsätze und übereinstimmender Ausgaben muß bei einer konkreten Investitionsentscheidung aufgegeben werden, denn je nach Standortqualität variieren die Erträge und Aufwendungen. Unterschiedliche Umsätze und Kosten können dabei zu übereinstimmenden oder abweichenden Renditen nach Steuern führen. Die Steuerbelastung ist dabei nur eine von mehreren Kostenfaktoren, welche einen Einfluß auf die einem Unternehmen nach Abzug aller Aufwendungen verbleibende Rendite nimmt.

Im folgenden wird daher untersucht, wie hoch die Rendite einer Tochterkapitalgesellschaft vor Unternehmensteuern und sonstigen Aufwendungen mindestens sein muß, damit unter Berūcksichtigung der Körperschaftsteuer, der bei der Gewinnermittlung abzugsfähigen lokalen Steuern, der bestehenden Doppelbesteuerungsabkommen und der Finanzierungsart einer Mutter- sowie einer Tochterkapitalgesellschaft die hieraus resultierenden Steuer- und Finanzierungskosten erwirtschaftet werden.

Bei der Untersuchung wird von einer bundesdeutschen Mutterkapitalgesellschaft ausgegangen, die sich ausschließlich im Inland finanziert und zwar entweder durch die Vergabe neuer Aktien oder die Aufnahme von Fremdkapital. Es wird angenommen, dab die inländischen Kapitalgeber der Mutterkapitalgesellschaft unabhängig von der Deklaration der angelegten Mittel (Eigen- bzw. Fremdkapital) eine identische Rendite nach Unternehmensteuern und vor persönlicher Ertragsteuer (r) erzielen wollen, d. h.

$$
r=I=D=G,
$$

wobei I für die Zinseinkünfte, $\mathrm{D}$ für die Dividendeneinkünfte und $\mathrm{G}$ für das zu versteuernde Einkommen steht.

Geplant wird die Errichtung einer 100\%igen Tochterkapitalgesellschaft an den alternativen Standorten Bundesrepublik Deutschland, Frankreich oder Großbritannien. Bei den Direktinvestitionen bleiben Wechselkursschwankungen unberücksichtigt. Es wird angenommen, daß eine Tochterkapitalgesellschaft in voller Höhe durch eine Mutterkapitalgesellschaft finanziert wird und zwar entweder durch die Vergabe von Fremd- oder Eigenkapital. Eine Finanzierung einer Tochterkapitalgesellschaft im jeweiligen Quellenland unterbleibt. Bei der Analyse wird unterstellt, daß es sich bei dem Mutter-Tochter-Verhältnis nicht um eine Organschaft ${ }^{12}$ handelt. Des weiteren wird angenommen, daß die Rendite einer Tochterka-

${ }^{12}$ Ein Organverhältnis ist gegeben, wenn eine Kapitalgesellschaft, deren Sitz und Geschäftsleitung im Inland belegen ist, nach dem Gesamtbild der tatsächlichen Verhältnisse finanziell, wirtschaftlich und organisatorisch in ein anderes inländisches Unternehmen eingegliedert ist. Bei einer solchen Ein- 
pitalgesellschaft den an eine Muttergesellschaft zu leistenden Zins- bzw. Dividendenzahlungen entspricht.

Aufgrund der getroffenen Annahmen müssen bei der Finanzierungsart einer Mutter- bzw. Tochterkapitalgesellschaft folgende Konstellationen unterschieden werden:

1. Eine Mutterkapitalgesellschaft finanziert sich durch die Aufnahme von Fremdkapital und gewährt einer Tochterkapitalgesellschaft ein Darlehen in entsprechender Höhe (Fall 1).

2. Eine Mutterkapitalgesellschaft finanziert sich durch die Ausgabe von Aktien und gewährt einer Tochterkapitalgesellschaft ein Darlehen in entsprechender Höhe (Fall 2).

3. Eine Mutterkapitalgesellschaft finanziert sich durch die Aufnahme von Fremdkapital und stellt einer Tochterkapitalgesellschaft Eigenkapital in entsprechender Höhe bereit (Fall 3).

4. Eine Mutterkapitalgesellschaft finanziert sich durch die Ausgabe von Aktien und stellt einer Tochterkapitalgesellschaft Eigenkapital in entsprechender Höhe bereit (Fall 4).

Hieraus resultieren die in der Tabelle 2.6 dargestellten Einkünfte bzw. Zahlungen einer bundesdeutschen Mutterkapitalgesellschaft.

Die vorherigen Analysen haben gezeigt, daß die bei inländischen Ausschüttungen einzubehaltene Körperschaftsteuer aufgrund des Vollanrechnungsverfahrens lediglich einen inländischen Aktionär belastet. Die auf Dividendeneinkünfte einzubehaltene Körperschaftsteuer wird daher nicht als Unternehmensteuer betrachtet. In die Untersuchung wird die einem Aktionär nach persönlicher Ertragsteuer verbleibende Rendite nicht einbezogen, da das bundesdeutsche Steuerrecht inländische Kapitaleinkünfte (Zins- bzw. Dividendenerträge) identisch besteuert. Eine übereinstimmende Rendite nach Unternehmensteuern und vor persönlicher Ertragsteuer führt bei einem bundesdeutschen Aktionär daher zu einer identischen Rendite nach Abzug der individuellen Ertragsteuer und umgekehrt.

In die Betrachtung einbezogen werden die nationale Körperschaftsteuer sowie die lokal erhobenen Steuern, soweit sie bei der Berechnung der steuerlichen Bemessungsgrundlage abzugsfähig sind. ${ }^{13}$ Die Steuertatbestandsmerkmale, an welche die lokale Steuerpflicht knüpft, weichen in der Bundesrepublik Deutschland, in Frankreich und in Großbritannien

gliederung ist eine Tochterkapitalgesellschaft (Organ) den Entscheidungen einer Mutterkapitalgesellschaft (Organträger) derart untergeordnet, daß keine eigenen Beschlüsse gefaßt werden können. Vgl. KieBling/Pelikan (1991, S. 173 ff.).

${ }^{13}$ In der Bundesrepublik Deutschland zählt hierzu die Gewerbeertrag- sowie Gewerbekapitalsteuer. In Frankreich ist hier die Gewerbesteuer (taxe professionelle) zu nennen, die an das Anlagevermögen sowie die Lohnsumme anknüpft; die Lohnsummensteuer (taxe sur les salaires), welche auf die gezahlten Löhne und Gehälter erhoben wird; die Lehrlingsteuer (taxe d'apprentissage) bei gewerblichen Unternehmen; die Berufsausbildungsabgabe sowie die Wohnungsbauabgabe (participation des employeurs a l'effort de construction), welche von Unternehmen mit mindestens 10 Arbeitnehmen erhoben wird. 
Tabelle 2.6: Finanzleistungen einer bundesdeutschen Mutterkapitalgesellschaft bei der Ausgabe neuer Aktien bzw. der Aufnahme von Fremdkapital bei Kapitaleinkünften aus einer Beteiligung bzw. der Vergabe von Fremdkapital

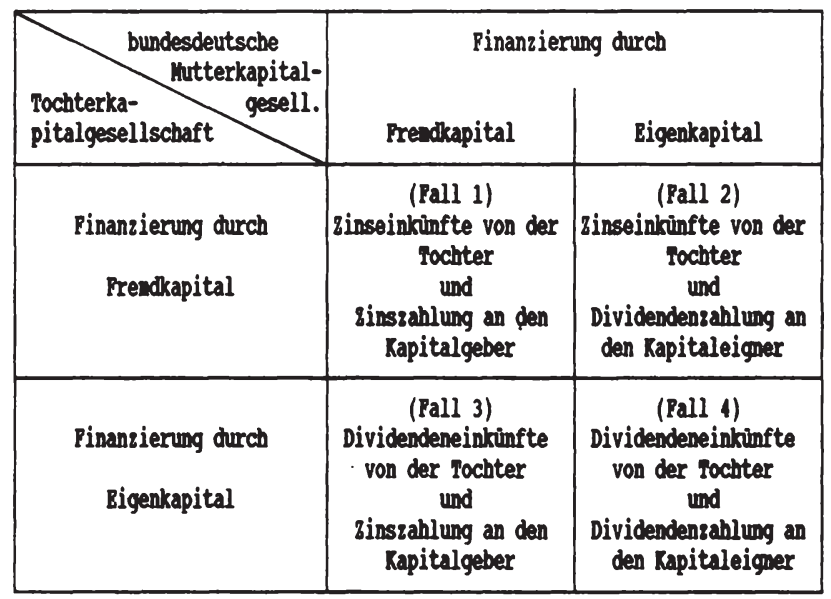

voneinander ab. In der Bundesrepublik Deutschland sind der durch Hinzurechnungen und Kürzungen bereinigte Steuerbilanzgewinn sowie der nach dem Gewerbesteuergesetz korrigierte Einheitswert eines Unternehmens Steuergegenstand für die lokale Steuer. In Frankreich wird als Steuergegenstand der Mietwert der körperlichen Anlagen sowie die gezahlten Löhne und Gehälter herangezogen. In Großbritannien ist Steuerobjekt der Mietwert unternehmerisch genutzter Grundstücke. Aufgrund der fehlenden Anknüpfung an die Ertragskraft eines Unternehmens bewirken die bundesdeutsche Gewerbekapitalsteuer sowie die in Frankreich und GroBbritannien erhobenen lokalen Abgaben insbesondere in Phasen, in denen ein Unternehmen keine Gewinne erwirtschaftet, z. B. in Rezessionszeiten, bei einer Umstrukturierung oder bei der Erschließung neuer Märkte, einen Liquiditätsabfluß, der aufgrund fehlender Gewinne die Substanz eines Unternehmens verringert. ${ }^{14}$

Unberücksichtigt bleiben die sonstigen, bei der steuerlichen Gewinnermittlung nicht abzugsfähigen Steuern. ${ }^{15}$ Es wird davon ausgegangen, daß Vergünstigungen in Form von Steuergutschriften, Steuererleichterungen bzw. Steuerbefreiungen weder von einer bun-

In Großbritannien zählt hierzu die Grundsteuer (national non-domestic rate), welche von dem Nutzenden auf dem Mietwert unternehmerisch genutzter Grundstücke erhoben wird. Vgl. Lenz/Meyer (1991, S. 187 ff.), Müssener (1989, S. 270; 1992, S. 286), Seidel et al. (1989, S. 63), Stawinoga (1987, S. 101).

14 Vgl. Tipke/Lang (1991, S. 172 f.).

15 Hierbei handelt es sich um die auf Betriebsvermögen erhobene bundesdeutsche Vermögensteuer, welche bei der Berechnung des steuerpflichtigen Gewinns nicht abzugsfähig ist. 
desdeutschen Mutterkapitalgesellschaft noch von einer Tochterkapitalgesellschaft in Anspruch genommen werden können.

Im folgenden wird zunächst analysiert, wie hoch die Rendite vor Unternehmensteuern einer Mutterkapitalgesellschaft in Abhängigkeit von der Finanzierungsart sein muß, um die Kosten für die inländische Finanzierung zu erwirtschaften. Daran anschliefend wird unter Berücksichtigung der bestehenden Doppelbesteuerungsabkommen untersucht, wie hoch die Rendite einer Tochterkapitalgesellschaft vor nationalen Steuern mindestens sein muB, um in Abhängigkeit von der Finanzierungsart die geforderte Zins- bzw. Dividendenzahlung an die Mutterkapitalgesellschaft leisten zu können.

\subsubsection{Mindestrendite einer bundesdeutschen Mutterkapitalgesellschaft vor Unternehmensteuern}

Da die auf Ausschüttungen einzubehaltene Körperschaftsteuer keine Steuerlast eines Unternehmens darstellt und durch die Abzugsfähigkeit der Zinszahlungen bei der Ermittlung des zu versteuernden Einkommens die Einkünfte ausschließlich bei einem Kapitaleigner ertragsteuerlich erfaßt werden, stellt in der Bundesrepublik Deutschland lediglich die lokale Gewerbesteuer eine Unternehmensteuer dar. ${ }^{16}$ Bevor auf die, für die Deckung der Finanzierungskosten erforderliche Mindestrendite einer bundesdeutschen Mutterkapitalgesellschaft eingegangen wird, wird zunächst untersucht, inwieweit die unterschiedlichen Kapitaleinkunftsarten (Zins- bzw. Dividendeneinkünfte) einen Einfluß auf die Unternehmensbesteuerung nehmen.

\section{a) Zinseinkünfte}

Die bei der Vergabe von Fremdkapital an eine inländische Tochterkapitalgesellschaft zu erzielenden Zinseinkünfte unterliegen in der Bundesrepublik Deutschland sowohl bei der leistenden als auch bei der empfangenen Gesellschaft der Gewerbesteuer. Bei einer französischen bzw. britischen Tochterkapitalgesellschaft wird eine lokale Steuer auf Zinszahlungen im Quellenstaat nicht erhoben. Im Inland unterliegen die im Ausland erzielten Zinseinkünfte aufgrund des Welteinkommensprinzip der laufenden Besteuerung. Inwieweit die Kapitaleinkünfte bei einer bundesdeutschen Mutterkapitalgesellschaft zu der Gewerbeertragsteuer herangezogen werden, ist wiederum abhängig von ihrer Finanzierungsart.

\section{aa) Fremdfinanzierung einer Mutterkapitalgesellschaft}

Bei der Fremdfinanzierung einer Mutterkapitalgesellschaft wird die Zinszahlung bei der Ermittlung des körperschaftsteuerpflichtigen Gewinns als Betriebsausgabe abgezogen. Für die Berechnung des Gewerbeertrages muß gem. $\S 8 \mathrm{Nr} .1 \mathrm{GewStG}$ die Hälfte der geleisteten Zinsen dem ermittelten steuerlichen Gewinn hinzugerechnet werden. Der betriebliche Ein-

${ }^{16}$ Die Vermögensteuer wird bei dieser Untersuchung nicht betrachtet. 
heitswert wird durch die Aufnahme und die gleichzeitige Vergabe von Fremdkapital nicht berührt, wenn die Beträge wertmäßig identisch sind. Bei der Berechnung des Gewerbekapitals einer Mutterkapitalgesellschaft müssen die bei der Ermittlung des Einheitswertes berücksichtigten Dauerschulden in Höhe des den Freibetrag ${ }^{17}$ übersteigenden Betrages gem. $§ 12$ Abs. 1 Nr. 1 GewStG zur Hälfte hinzugerechnet werden.

Aufgrund der Abzugsfähigkeit von Zinszahlungen sowie der Gewerbesteuerleistung bei der Ermittlung der körperschaftsteuerlichen Bemessungsgrundlage fällt eine Körperschaftsteuerzahlung auf diese Einkünfte nicht an. Die erforderliche Mindestrendite einer bundesdeutschen Spitzeneinheit vor Steuern ( $\mathrm{p}_{M_{1}}$ ) beträgt bei der Fremdfinanzierung einer Mutterkapitalgesellschaft und der Darlehensgewährung an eine Tochterkapitalgesellschaft in entsprechender Höhe, d. h. bei einer Konstellation entsprechend dem Fall 1:

$$
p_{M 1}=i\left(1+0,5 t_{L E}\right)+T_{L K}
$$

wobei i für den zu leistenden Zinssatz, $\mathrm{t}_{L E}$ für den bundesdeutschen Gewerbeertragsteuersatz und $\mathrm{T}_{L K}$ für die Gewerbekapitalsteuerbelastung steht.

\section{ab) Eigenkapitalfinanzierung einer Mutterkapitalgesellschaft bei Dividendenzahlung an einen Anteilseigner}

Die auf Beteiligungskapital zu zahlenden Dividenden an einen Aktionär stellen für ein leistendes Unternehmen keine abzugsfähige Betriebsausgabe sondern eine Gewinnverwendung dar. Die Gewerbeertragsteuer wird von dem nach Einkommen- bzw. Körperschaftsteuerrecht ausgewiesenen Gewinn berechnet, d. h. die Dividendenzahlung unterliegt in voller Höhe der lokalen Ertragsteuer. Der dem Gewerbekapital zugrundeliegende Einheitswert beinhaltet das Beteiligungskapital eines Aktionärs, welches bei der Gewerbekapitalbesteuerung in ungemilderter Höhe herangezogen wird. Damit eine Mutterkapitalgesellschaft einem Aktionär eine identische Rendite nach Unternehmensteuern wie im Falle einer Fremdfinanzierung leisten kann, muB die Mindestrendite aus der Vergabe von Fremdkapital an eine Tochterkapitalgesellschaft sich vor Steuern $\left(\mathrm{p}_{M_{2}}\right)$ für den 2. Fall belaufen auf:

$$
p_{M 2}=i\left(1+t_{L E}\right)+T_{L K}
$$

\section{b) Dividendeneinkünfte}

Erzielt eine Mutterkapitalgesellschaft bei der Vergabe von Eigenkapital Dividendeneinkünfte aus einer in- oder ausländischen Tochterkapitalgesellschaft, so ist der nach Ein-

${ }^{17}$ Der Freibetrag beläuft sich gem. $\S 12$ GewStG auf 50.000 DM. Bei der Analyse wird dieser Freibetrag außer acht gelassen. 
kommen- oder Körperschaftsteuergesetz ermittelte Gewinn gem. $\S 9$ Nr. 2 a und Nr. 8 GewStG um diese Erträge zu kürzen. Ebenso ist gem. $\S 12 \mathrm{Abs.} 3 \mathrm{GewStG}$ bei der Ermittlung des Gewerbekapitals der Einheitswert eines Unternehmens um den Wert einer in- bzw. ausländischen Beteiligung zu verringern. Eine zweifache Erfassung der Einkünfte bzw. der Beteiligung wird hierdurch vermieden. Inwieweit die Finanzierungsart einer Mutterkapitalgesellschaft sowie die bundesdeutsche Unternehmensteuer einen Einfluß auf die erforderliche Mindestrendite nimmt, wird im folgenden analysiert.

\section{ba) Fremdfinanzierung einer Mutterkapitalgesellschaft}

Finanziert sich eine Mutterkapitalgesellschaft durch die Aufnahme von Fremdkapital und stellt sie einer Tochterkapitalgesellschaft Eigenkapital in entsprechender Höhe zur Verfügung, so müssen die an einen Kapitaleigner zu leistenden Zinszahlungen zur Hälfte dem Gewerbeertrag hinzugerechnet werden. Bei der Berechnung des Gewerbekapitals müssen die bei der Ermittlung des Einheitswertes berücksichtigten Dauerschulden in Höhe des den Freibetrag übersteigenden Betrages ebenfalls zur Hälfte hinzuaddiert werden. Für die von einer bundesdeutschen Mutterkapitalgesellschaft zu realisierende Mindestrendite gilt demnach bei einer Fremdfinanzierung der Mutterkapitalgesellschaft und einer Beteiligungsfinanzierung einer Tochterkapitalgesellschaft $\left(\mathrm{p}_{M 3}\right)$, d. h. bei einer Konstellation entsprechend dem 3. Fall:

$$
p_{M 3}=i\left(1+0,5 t_{L E}\right)+T_{L K} .
$$

\section{bb) Eigenkapitalfinanzierung einer Mutterkapitalgesellschaft bei Dividendenzahlung an einen Anteilseigner}

Die Ausschüttung an einen Kapitaleigner stellt keinen gewerbesteuerpflichtigen Tatbestand dar. Finanziert sich eine Mutterkapitalgesellschaft durch die Ausgabe von Aktien und stellt sie einer Tochterkapitalgesellschaft Eigenkapital in entsprechender Höhe zur Verfügung, so beläuft sich die von einer Mutterkapitalgesellschaft zu erzielende Mindestrendite bei einer Dividendenausschüttung $\left(\mathrm{p}_{M_{4}}\right)$ daher im 4. Fall auf:

$$
p_{M 4}=i \text {. }
$$

\subsubsection{Mindestrendite einer in- bzw. ausländischen Tochterkapitalgesellschaft vor Steuern}

Im folgenden wird für eine Tochterkapitalgesellschaft an den alternativen Standorten Bundesrepublik Deutschland, Frankreich und Großbritannien untersucht, wie hoch die Rendite vor Unternehmensteuern sein muß, um einer bundesdeutschen Mutterkapitalgesellschaft

die geforderte Mindestrendite in Höhe ihrer Finanzierungskosten leisten zu können. Die Otto Roloff, Sibylle Brander, Ingo Barens and Claudia Wesselbaum - 978-3-631-75210-4 
Mindestrendite der Mutterkapitalgesellschaft wird zunächst mit $\mathbf{p}_{M}$ bezeichnet und nimmt je nach Finanzierungsart der Mutter den Wert von $\mathrm{p}_{M 1}, \mathrm{p}_{M 2}, \mathrm{p}_{M 3}$ oder $\mathrm{p}_{M_{4}}$ an. Die zuvor getroffenen Annahmen werden übernommen. Es wird davon ausgegangen, daß eine Tochterkapitalgesellschaft keine Zins- bzw. Dividendeneinkünfte erzielt.

a) Fremdfinanzierung

Bei einer Fremdfinanzierung muß eine bundesdeutsche Tochterkapitalgesellschaft neben der Zinsleistung an die Mutterkapitalgesellschaft in Höhe von $\mathrm{p}_{M}$ die darauf lastende lokale Gewerbesteuer erzielen. Aufgrund der Abzugsfähigkeit der Zinszahlung sowie der Gewerbesteuer wird in Höhe dieser Leistungen keine Körperschaftsteuer fällig. Für die Rendite einer Tochterkapitalgesellschaft vor Unternehmensteuer $\left(\mathrm{p}_{T}\right)$ gilt:

$$
p_{T}=p_{M}\left(1+0,5 t_{L E}\right)+T_{L K} .
$$

In Frankreich werden die lokalen Steuern unabhängig von dem erzielten Gewinn erhoben. Die Zinsleistung sowie die Zahlung der lokalen Steuern werden bei der Ermittlung der körperschaftsteuerlichen Bemessungsgrundlage berücksichtigt. Damit eine französische Tochterkapitalgesellschaft ihren Verpflichtungen nachkommen kann, muß sie demnach eine Rendite vor Steuern in Höhe von

$$
p_{T}=p_{M}+T_{L F}
$$

erzielen, wobei $\mathrm{T}_{L F}$ die lokalen Steuern determiniert.

In Großbritannien werden die lokalen Steuern $\left(\mathrm{T}_{L G}\right)$ ebenfalls nicht von dem erzielten Gewinn eines Unternehmens erhoben. Die Zins- sowie lokale Steuerzahlung ist bei der Berechnung des nach dem Körperschaftsteuergesetz zu versteuernden Einkommens abzugsfähig. Die Rendite einer britischen Tochterkapitalgesellschaft vor Unternehmensteuern muß demnach

$$
p_{T}=p_{M}+T_{L G}
$$

betragen.

b) Eigenkapitalfinanzierung bei einer Dividendenzahlung an eine bundesdeutsche Mutterkapitalgesellschaft

Wird eine Tochterkapitalgesellschaft durch Eigenkapital finanziert, so stellen die an eine bundesdeutsche Mutterkapitalgesellschaft zu leistenden Dividendenzahlungen in keiner der betrachteten Nationen eine den steuerlichen Gewinn mindernde Ausgabe dar.

Auf den Gewinn sowie das Vermögen einer bundesdeutschen Tochterkapitalgesellschaft 
wird zum einen die lokale Gewerbesteuer erhoben. Zum anderen muß bei einer Ausschüttung der verringerte Körperschaftsteuersatz einbehalten werden. Einer Mutterkapitalgesellschaft steht in diesem Fall nur der um die einbehaltene Steuer verringerte Betrag für die Kapitaldienstleistung zur Verfügung. Erwirtschaftet die Mutterkapitalgesellschaft keine weiteren Einkünfte, so resultiert aus der Abzugsfähigkeit von Zinszahlungen bei einer Fremdfinanzierung die Erstattung der von einer Tochtergesellschaft einbehaltenen Körperschaftsteuer von dem Fiskus. Weichen der Zeitpunkt der Zinszahlung sowie der Körperschaftsteuererstattung voneinander ab, kann in Höhe der einbehaltenen Steuer ein kurzfristiger Kapitalbedarf entstehen. Finanziert sich die bundesdeutsche Mutterkapitalgesellschaft demgegenüber durch die Ausgabe neuer Aktien, so handelt es sich bei der einbehaltenen Körperschaftsteuer um einen durchlaufenden Posten. ${ }^{18}$ Unabhängig von der Finanzierungsart, ist demnach weder eine bundesdeutsche Mutterkapitalgesellschaft noch eine Tochterkapitalgesellschaft mit inländische Körperschaftsteuer belastet. Die Mindestrendite einer inländischen Tochterkapitalgesellschaft muß daher betragen:

$$
p_{T}=\frac{p_{M}}{\left(1-t_{L E}\right)}+T_{L K}
$$

Handelt es sich bei einem ausschüttenden Unternehmen um eine französische Tochterkapitalgesellschaft, werden aufgrund des im Doppelbesteuerungsabkommens vereinbarten Schachtelprivilegs die ausländischen Dividendeneinkünfte von der bundesdeutschen Besteuerung freigestellt; eine Kapitalertragsteuer wird nicht erhoben. Die lokale Steuer wird in Frankreich ertragsunabhängig erhoben, d. h. für die Mindestrendite einer Tochterkapitalgesellschaft gilt:

$$
p_{T}=\frac{p_{M}}{\left(1-t_{C Q}\right)}+T_{L F}
$$

Bei dem mit Großbritannien abgeschlossenen Doppelbesteuerungsabkommen ist ebenfalls das Schachtelprivileg vereinbart. Die von einer britischen Tochterkapitalgesellschaft einbehaltene Körperschaftsteuer kann daher im Inland nicht angerechnet werden. Die lokale Grundsteuer wird ertragsunabhängig erhoben; eine Quellensteuer nicht einbehalten, d. h. für die zu erzielende Mindestrendite gilt:

$$
p_{T}=\frac{p_{M}}{\left(1-t_{C Q}\right)}+T_{L G}
$$

In der folgenden Tabelle 2.7 werden die in Abschnitt 2.2.1 sowie 2.2.2 ermittelten Resultate zusammengestellt.

Die Untersuchung zeigt, daß die bundesdeutsche Körperschaftbesteuerung keinen Einfluß

\footnotetext{
${ }^{18}$ Siehe obige Ausführungen.

Otto Roloff, Sibylle Brander, Ingo Barens and Claudia Wesselbaum - 978-3-631-75210-4 
Tabelle 2.7: Mindestrendite einer Tochterkapitalgesellschaft vor Unternehmensteuern bei einer Zins- bzw. Dividendenleistung an eine bundesdeutsche Mutterkapitalgesellschaft in Höhe von $p_{M}$

\begin{tabular}{|c|c|c|c|c|}
\hline \multicolumn{3}{|c|}{$\begin{array}{l}\text { bundesdeutsche } \\
\text { toch- } \\
\text { terkapital- } \\
\text { gesellischaft in }\end{array}$} & \multicolumn{2}{|c|}{ Pinanzierung durch } \\
\hline \multirow{2}{*}{$B R$} & \multirow{2}{*}{$\begin{array}{l}\text { Pinan- } \\
\text { zierung } \\
\text { curch }\end{array}$} & Frevaltapital & {$\left[i\left(1+0,5 t_{L B}\right)+m_{L R}\right]\left[\left(1+0,5 t_{L B}\right)+m_{L R}\right]$} & {$\left[i\left(1+t_{L B}\right)+2_{L X}\right]\left[\left(1+0,5 t_{L L B}\right)+t_{L R}\right]$} \\
\hline & & Bigenkapital & $\frac{i\left(1+0,5 t_{L B}\right)+t_{L R}}{\left(1-t_{L R}\right)}+t_{L_{R}}$ & $\frac{i}{\left(1-t_{L B}\right)}+T_{L X}$ \\
\hline \multirow{2}{*}{1} & \multirow{2}{*}{$\begin{array}{l}\text { Pinan- } \\
\text { zierung } \\
\text { durch }\end{array}$} & Prendkapital & $i\left(1+0,5 t_{L R}\right)+i_{L R}+m_{L P}$ & $i\left(1+t_{L R}\right)+I_{L R}+T_{L P}$ \\
\hline & & Bigenkapital & $\frac{i\left(1+0,5 t_{L R}\right)+i_{L R}}{\left(1-t_{C Q}\right)}+T_{L P}$ & $\frac{i}{\left(1-t_{\infty}\right)}+1+p$ \\
\hline \multirow{2}{*}{$G B$} & $\begin{array}{l}\text { Pinar } \\
\text { zierung }\end{array}$ & Freadkapital & $i\left(1+0,5 t_{L B}\right)+T_{L S}+r_{L C}$ & $i\left(1+t_{L B}\right)+T_{L R}+T_{L C}$ \\
\hline & durch & Bigentapital & $\frac{i\left(1+0,5 t_{L B}\right)+T_{L R}}{\left(1-t_{C Q}\right)}+T_{L C}$ & $\frac{i}{\left(1-t_{\infty}\right)}+T_{G}$ \\
\hline
\end{tabular}

auf die erforderliche Mindestrendite einer inländischen Mutterkapitalgesellschaft vor Unternehmensteuern nimmt. Demgegenüber führt die zu erhebende lokale Gewerbesteuer zu einer zusätzlichen Belastung, welche je nach Finanzierungsart variiert.

Die Finanzierung einer Mutterkapitalgesellschaft durch die Ausgabe neuer Aktien sowie die Weitergabe des Kapitals an eine inländische Tochterkapitalgesellschaft in Form ei- 
ner Beteiligungsfinanzierung (Fall 4) erfordert die niedrigste Rendite vor Steuern und weist daher die geringste Unternehmensteuerbelastung auf. In diesem Fall unterliegen die Einkünfte bzw. das Beteiligungskapital lediglich bei einer inländischen Tochterkapitalgesellschaft der Gewerbesteuer. Bei einer bundesdeutschen Mutterkapitalgesellschaft wird durch die Kürzung des Gewerbeertrages bzw. des Gewerbekapitals um die bei einer Tochtergesellschaft bereits erfaßten Beträge, die Freistellung der Schachteldividenden bzw. der Schachtelbeteiligung erreicht.

Bei der Fremdfinanzierung einer Tochterkapitalgesellschaft wird die Zinszahlung bzw. die Darlehensverbindlichkeit sowohl bei einem leistenden Unternehmen als auch bei einer empfangenen Gesellschaft steuerlich erfaßt. Die hieraus resultierende doppelte Belastung ist laut Gesetzgeber mit dem Zweck der Gewerbesteuer zu vereinbaren und enthält keinen Verstoß gegen den Gleichheitssatz. ${ }^{19}$ Da geleistete Zinszahlungen an einen Kapitaleigner bzw. die ihr zugrundeliegenden Dauerschulden bei der Gewerbesteuer nur zur Hälfte erfaßt werden, erfordert die Fremdfinanzierung einer Mutterkapitalgesellschaft bei der Vergabe eines Darlehens an eine inländische Tochterkapitalgesellschaft (Fall 1) eine geringere Mindestrendite als die Konstellationen entsprechend den Fällen 2 und 3. Wird eine bundesdeutsche Mutterkapitalgesellschaft demgegenüber durch die Ausgabe neuer Aktien finanziert und gewährt sie einer inländischen Tochterkapitalgesellschaft ein Darlehen in entsprechender Höhe (Fall 2), so übersteigt die Steuerbelastung die aus den Fall 4 und Fall 1 resultierende Last, da die Zinszahlungen bei der leistenden Gesellschaft einer verminderten Gewerbesteuer unterliegen. Da die Dividendenzahlung an einen Kapitaleigner keine Betriebsausgabe sondern eine Gewinnverwendung darstellt, unterliegen die von einer Mutterkapitalgesellschaft empfangenen Zinseinkünfte dabei in ungemilderter Höhe der Gewerbesteuer. Die höchste Mindestrendite vor Unternehmensteuern resultiert aus der Fremdfinanzierung einer Mutterkapitalgesellschaft bei der Beteiligungsfinanzierung einer inländischen Investition (Fall 3). In diesem Fall unterliegt zum einen die Dividendenzahlung einer Tochterkapitalgesellschaft in voller Höhe und zum anderen die Zinszahlung einer Mutterkapitalgesellschaft in verringerter Höhe der Unternehmensteuer. Die Gesamtsteuerbelastung übersteigt hierbei die Unternehmensteuerbelastung der übrigen Finanzierungskonstellationen.

Hinsichtlich des alternativen Standortes einer Tochterkapitalgesellschaft in Frankreich bzw. in Großbritannien ist aus Sicht einer bundesdeutschen Mutterkapitalgesellschaft eine differenziertere Betrachtung erforderlich. Während die bei einer Fremdfinanzierung zu erzielenden Zinserträge aus einer ausländischen Tochterkapitalgesellschaft bei einer bundesdeutschen Mutterkapitalgesellschaft einer Ertragsbesteuerung unterliegen, werden ausländische Schachteldividenden im Quellenstaat ertragsteuerlich erfaßt. Dies bedeutet

19 Vgl. Spangemacher/Spangemacher (1986, S. 263 f.).

Otto Roloff, Sibylle Brander, Ingo Barens and Claudia Wesselbaum - 978-3-631-75210-4 
nicht, daß einem bundesdeutschen Unternehmen die Einkünfte steuerfrei zur Verfügung stehen, denn im Belegenheitsstaat einer ausländischen Tochterkapitalgesellschaft unterliegt der realisierte Gewinn der nationalen Körperschaftsteuer. Zur Vermeidung einer kumulativen Belastung werden die im Ausland erwirtschafteten und bereits versteuerten Einkünfte im Sitzstaat einer Mutterkapitalgesellschaft aufgrund von Doppelbesteuerungsabkommen zwischen den betrachteten Staaten freigestellt. Die erhobene ausländische Ertragsteuer bleibt als Definitivbelastung bestehen und nimmt einen Einfluß auf die erforderliche Mindestrendite vor Steuern einer inländischen Mutterkapitalgesellschaft.

Neben der nationalen Körperschaftsteuer nehmen die in Frankreich, in Großbritannien und in der Bundesrepublik Deutschland erhobenen lokalen ertragsabhängigen sowie ertragsunabhängigen Steuern einen Einfluß auf die erforderliche Mindestrendite. In der Bundesrepublik Deutschland unterliegen dabei ausländische Zinserträge sowie die ihnen zugrundeliegenden Forderungen zusätzlich zu der im Quellenstaat bereits einbehaltenen lokalen Steuer der Gewerbesteuer. Beteiligungen an ausländischen Tochterkapitalgesellschaften und daraus bezogene Dividenden sind demgegenüber bei einer bundesdeutschen Mutterkapitalgesellschaft von der Gewerbesteuer freigestellt. ${ }^{20}$

Bei ausländischen Direktinvestitionen resultiert die niedrigste Mindestrendite aus der Fremdfinanzierung einer inländischen Mutterkapitalgesellschaft, welche das aufgenommene Kapital als Darlehen an eine französische bzw. britische Tochterkapitalgesellschaft weiterreicht (Fall 1). Wird eine bundesdeutsche Mutterkapitalgesellschaft durch die Ausgabe von Aktien finanziert und gewährt sie einer ausländischen Tochterkapitalgesellschaft ein Darlehen in entsprechender Höhe (Fall 2), so ist die für die Deckung der hieraus resultierenden Finanzierungskosten sowie der Unternehmensteuerbelastung erforderliche Mindestrendite höher als bei einer ausschließlichen Fremdfinanzierung. Diese Finanzierungsweise unterschreitet jedoch die bei der Ausgabe von Aktien einer bundesdeutschen Mutterkapitalgesellschaft benötigte Mindestrendite, wenn die inländische Spitzeneinheit einer französischen bzw. britischen Tochterkapitalgesellschaft Eigenkapital (Fall 4) zur Verfügung stellt. Die höchste Mindestrendite vor Steuern ist bei der Fremdfinanzierung einer bundesdeutschen Mutterkapitalgesellschaft erforderlich, welche einer französischen bzw. britischen Tochterkapitalgesellschaft Eigenkapital in entsprechender Höhe (Fall 3) zur Verfügung stellt.

Die Untersuchung verdeutlicht, daß in der Bundesrepublik Deutschland die Finanzierung einer Mutterkapitalgesellschaft durch die Ausgabe neuer Aktien bei der Vergabe von Eigenkapital an eine inländische Tochterkapitalgesellschaft eine geringere Rendite vor Steuern erfordert als die Fremdfinanzierung. Wird eine Direktinvestition im Ausland realisiert,

20 Vgl. Spangemacher/Spangemacher (1986, S. 324 ff.). 
so zeigt die Analyse, daß die ausschließliche Fremdfinanzierung sowohl einer Mutterkapitalgesellschaft als auch einer Tochterkapitalgesellschaft die niedrigste Rendite vor Steuern erfordert. Inwieweit die Errichtung einer ausländischen Tochterkapitalgesellschaft in Frankreich oder Großbritannien vorteilhafter ist, kann ohne weitergehende Analyse der zusätzlich zu der Körperschaftsteuer erhobenen lokalen Steuern nicht beurteilt werden.

\subsubsection{Versteuerung eines über die Mindestrendite hinausgehenden Gewinnes bei einer bundesdeutschen Mutterkapitalgesellschaft}

Ein Unternehmen hat bei der Realisierung einer Investition nicht nur ein Interesse daran, die Mindestrendite zu erzielen, sondern zusätzliche Gewinne zu realisieren, um frei verfügbares Kapital zu erwirtschaften und zusätzliches Eigenkapital zu bilden. Erwirtschaftet eine Tochterkapitalgesellschaft bei gleichbleibendem Betriebsvermögen und unveränderten Kosten über die Mindestrendite hinaus Gewinne, so führt dies bei einer Fremdfnanzierung zu keinem höheren Ertrag bei der bundesdeutschen Mutterkapitalgesellschaft sondern zu einer Eigenkapitalbildung bei einer Tochtergesellschaft. Denn bei einer Fremdfinanzierung ist ein Kapitalgeber weder am Gewinn noch an Verlust eines Unternehmens beteiligt; sein Forderungsanspruch begrenzt sich auf die Zahlung des im Kreditvertrag vereinbarten Zinses. ${ }^{21}$ Wird eine Tochterkapitalgesellschaft demgegenüber durch Eigenkapital finanziert, ist eine bundesdeutsche Mutterkapitalgesellschaft sowohl am Gewinn als auch am Verlust beteiligt. Im folgenden wird unter Zugrundelegung der zuvor getroffenen $\Lambda$ nnahmenen ${ }^{22}$ untersucht, in welcher Höhe einer Mutterkapitalgesellschaft die zusätzlich ausgeschütteten Gewinne einer Tochterkapitalgesellschaft für reinvestive Zwecke zur freien Verfügung stehen.

Die über die Mindestrendite hinausgehenden Gewinne unterliegen unabhängig von dem eingesetzten Kapital der Unternehmensteuerbelastung. Neben dem Regelkörperschaftsteuersatz wird bei einer bundesdeulschen Tochterkapitalgesellschaft keine weitere ertragsabhängige Steuer erhoben. ${ }^{23}$ Der nach Abzug der Gesamtsteucrbelastung verbleibende Bet.rag ist in das mit 50 v. II. belastete Figenkapital $\left(\mathrm{vEK}_{50}\right)$ einzustellen, d. $h$.

$$
v E K_{50}=1-\iota_{C W} .
$$

Schüttet eine französische Tochterkapitalgesellschaft zusätzliche Gewinne an die bundesdeutsche Mutterkapitalgesellschaft aus, so werden die Einkünfte aufgrund des Schachtelprivilegs von der inländischen Körperschaftsteuer und Gewerbesteuer freigestellt. Der zufließende Betrag muß daher in das nicht mit inländischer Körperschaftsteuer belastete

\footnotetext{
21 Vgl. Perridon/Steiner (1986, S. 207).

22 Siehe hierzu Abschnitte 2.2.1 und 2.2.2

23 Siehe obige Ausführungen.
} 
Eigenkapital ( $\mathrm{vEK}_{01}$ ) eingestellt werden. Eine Quellensteuer wird nicht einbehalten; eine ertragsabhängige lokale Steuer wird in Frankreich nicht erhoben. Einer bundesdeutschen Mutterkapitalgesellschaft verbleibt daher ein in das mit inländischer Körperschaftsteuer nicht belastetes Eigenkapitalanteil $\left(\mathrm{vEK}_{01}\right)$ einzustellendes, frei verfügbares Kapital in Höhe von:

$$
v E K_{01}=1-t_{C Q}
$$

Erwirtschaftet eine britische Tochterkapitalgesellschaft zusätzliche Gewinne, welche sie an eine bundesdeutsche Gesellschaft ausschüttet, so sind die zufließenden Einkünfte aufgrund des vereinbarten Schachtelprivilegs von der inländischen Körperschaftbesteuerung sowie Gewerbesteuer freigestellt. Eine Kapitalertragsteuer wird in Großbritannien auf ausgeschüttete Dividenden nicht einbehalten. Die lokalen Steuern werden ertragsunabhängig erhoben, so das hieraus keine zusätzliche Belastung resultiert. Für den in das mit inländischer Körperschaftsteuer unbelastete Kapital ( $\mathrm{vEK}_{01}$ ) einzustellende Betrag gilt:

$$
v E K_{01}=1-t_{C Q}
$$

Die obigen Ausführungen werden in der Tabelle 2.8 zusammengefaßt.

Die Analyse zeigt, daß lediglich bei einer Finanzierung durch Eigenkapital eine bundesdeutsche Mutterkapitalgesellschaft über die zusätzlichen Gewinne einer Tochterkapitagesellschaft verfügen kann. Die Höhe des verfügbaren Kapitals wird durch die Gewinnermittlungsvorschriften, dem für Ausschüttungen verfügbaren Bilanzgewinn, dem anzuwendenden nominalen Körperschaftsteuersatz, dem bestehenden Doppelbesteuerungsabkommen sowie den unilateralen Methoden zur Vermeidung bzw. Verminderung der Doppelbesteuerung determiniert.

\subsubsection{Resultate}

Die Analyse verdeutlicht, daß die für die Deckung der Finanzierungskosten sowie der Unternehmensteuerbelastung erforderliche Mindestrendite einer bundesdeutschen Mutterkapitalgesellschaft zum einen durch die Finanzierungsart und zum anderen durch den Standort einer Tochterkapitalgesellschaft bestimmt wird. Die bundesdeutsche Körperschaftsteuer nimmt dabei keinen Einfluß auf die erforderliche Rendite vor Leistung der Zins- bzw. Dividendenzahlung sowie in- und ausländische Unteruehmensteuern. Demgegenüber wirkt sich die im Ausland zu leistende Körperschaftsteuer einer Tochterkapitalgesellschaft sowie die zusätzlich zu erhebende lokale Steuer einen mittelbaren Einfluß auf die erforderliche Mindestrendite aus.

Unterschreitet der geplante Gewinn einer Direktinvestition die erforderliche Mindestren- 
Tabelle 2.8: Rendite einer bundesdeutschen Mutterkapitalgesellschaft nach Unternehmensteuern bei einem zusätzlichen Gewinn einer Tochterkapitalgesellschaft in Höhe einer Einheit

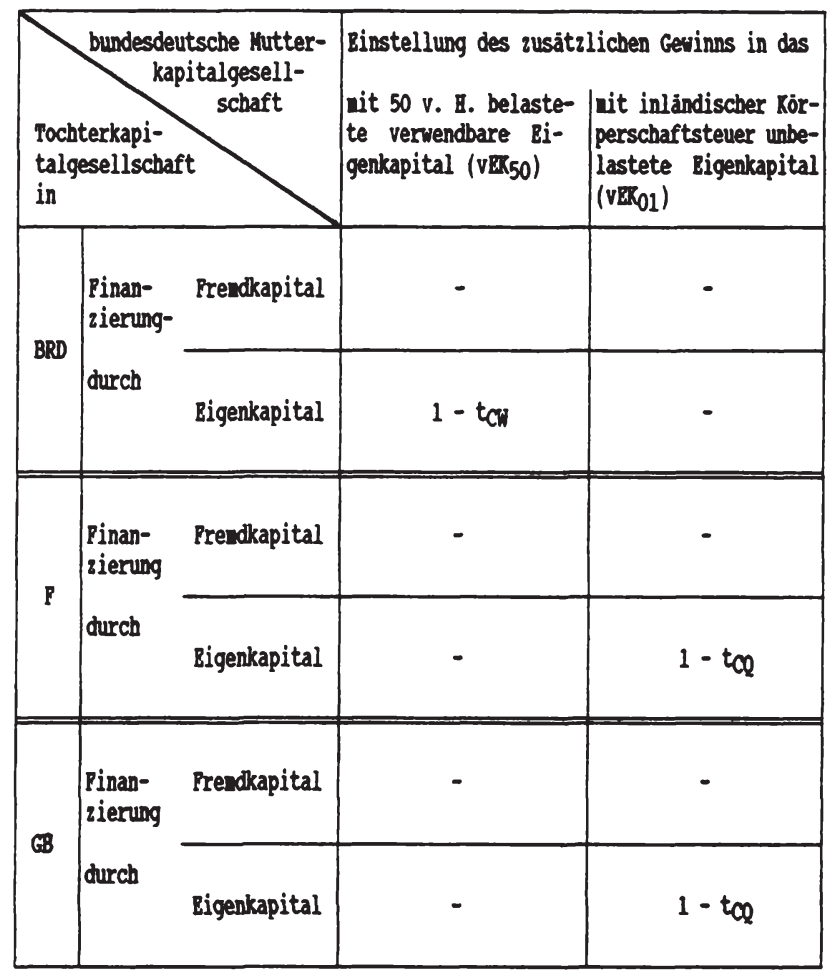

dite, so ist nicht die Unternehmensteuerbelastung Ursache für eine zu geringe Rendite nach Steuern sondern das Zusammenwirken einer Vielzahl von Faktoren. Dies kann z. B. ein im Vergleich zu alternativen Standorten zu geringer Umsatz, höhere Erschließungskosten, höhere Kosten für Infrastruktur etc. sein. Im Rahmen der komplexen Investitionsentscheidung und der Vielzahl der zu berücksichtigenden Komponenten ist es daher für die Beurteilung der Rentabilität einer Investition nicht durchführbar, aus dem Zusammenhang einen Faktor herauszugreifen und anhand dessen einen Beschluß zu fassen. Auch die je nach Nation variierende, erforderliche Mindestrendite ermöglicht es nicht, die Vorteilhaftigkeit eines Standortes zu beurteilen. Damit ein Standort beurteilt werden kann, ist es daher unvermeidbar, durch die Gegenüberstellung der zu erwartenden Erträge und aller im Zusammenhang anfallenden geplanten Aufwendungen die voraussichtliche Nettorendite eines Investitionsobjektes zu ermitteln und mit alternativen Anlageformen zu vergleichen. 
Die bei der Realisierung einer Investition zu wählende Finanzierungsart wird durch eine Vielzahl von Determinanten beeinflußt. In aller Regel wird eine Tochterkapitalgesellschaft allerdings weder in voller Höhe fremd noch vollständig eigenfinanziert. Entgegen der im Rahmen der Analyse getroffenen Annahme, haben Eigenkapitalgeber z. B. keinen Anspruch auf eine feste Verzinsung des eingesetzten Kapitals. Der für Dividendenleistungen verfügbare Bilanzgewinn ist zudem abhängig von der Inanspruchnahme handelsrechtlicher Bewertungsvorschriften sowie den national divergierenden, gesetzlich geregelten Gewinnverwendungsvorschriften. ${ }^{24}$ Dabei dürfte es im Interesse einer Tochterkapitalgesellschaft sein, die national gegebenen Möglichkeiten für die Bildung stiller Reserven weitestgehend in Anspruch zu nehmen, um die Selbstfinanzierungskraft zu stärken und eine finanzielle Unabhängigkeit von einer Mutterkapitalgesellschaft zu erlangen. Die steuerlichen Gewinnermittlungsvorschriften determinieren dabei, inwieweit der Gewinn lediglich den Aktionären für die Ausschüttung oder aber auch dem Fiskus für eine Besteuerung entzogen wird.

Bei einer Weiterausschüttung von Einkünften gilt das Eigenkapital in der Bundesrepublik Deutschland als in der Reihenfolge verwendet, in der die Tarifbelastung abnimmt (allgemeine Verwendungsfiktion gem. $§ 28$ Abs. $3 \mathrm{KStG}$ ). Dies bewirkt, daß vorrangig die hochbelasteten Eigenkapitalanteile ausgeschüttet werden, während nicht oder geringer belastete Anteile im Unternehmen verbleiben. ${ }^{25}$ Erzielt ein bundesdeutsches Unternehmen inländische Einkünfte sowie ausländische Zinserträge, so werden die nicht mit inländischer Körperschaftsteuer belasteten Dividenden ausländischer Tochterkapitalgesellschaften erst nach Ausschüttung der höher belasteten Eigenkapitalanteile an inländische Anteilseigner weiterausgeschüttet. ${ }^{26}$ Die im Ausland nach Abzug einer Unternehmensteuer realisierten Dividendeneinkünfte stärken die Finanzkraft sowie die Liquidität eines inländischen Unternehmens daher nachhaltig, solange für die Ausschüttung an die Aktionäre höher belastete Eigenkapitalanteile zur Verfügung stehen.

Über rein rechnerische Größen hinaus existieren weitere Faktoren, die auf die Vergabe von Eigen- bzw. Fremdkapital einen Einfluß nehmen. Die Ausstattung einer Tochterkapitalgesellschaft mit Eigenkapital stärkt z. B. die Selbstfinanzierungskraft einer Gesellschaft und ermöglicht es ihr, auch auf den internationalen Finanzmärkten Kapital aufzunehmen. Bei

\footnotetext{
${ }^{24}$ Laut bundesdeutschem Aktiengesetz ist $\mathrm{z}$. B. der zwanzigste Teil des um einen Verlustvortrag aus dem Vorjahr geminderten Jahresüberschusses in die gesetzliche Rücklage einzustellen, bis der Zehnte oder ein in der Satzung bestimmter Teil des Grundkapital erreicht ist ( $\$ 150$ Abs. 2 AktG). Darüber hinaus können Vorstand und Aufsichtsrat einen Teil des Jahresüberschusses, maximal jedoch die Hälfte, in andere Gewinnrücklagen einstellen ( $\$ 58 \mathrm{AktG}$ ). Die Aktionäre können bei der Hauptversammlung lediglich über die Verwendung des hiernach verbleibenden Bilanzgewinns entscheiden.

25 Vgl. Streck (1991, S. 381).

26 Vgl. Jacobs/Spengel (1992, S. 7).
} 
der Wahl der Finanzierungsart einer Gesellschaft ist die Gesamtsteuerbelastung daher nur ein Faktor von mehreren.

Um den europäischen Unternehmen die Entscheidung über Direktinvestitionen in Mitgliedsländern der Europäischen Gemeinschaft zu erleichtern, hat die EG-Kommission mehrere Richtlinienvorschläge erarbeitet, welche die Besteuerung von Unternehmen im Gemeinsamen Binnenmarkt vereinheitlichen soll. ${ }^{27}$ 


\section{Kapitel 3:}

\section{Steuern als Standortfaktor}

In der steuerpolitischen Debatte wird häufig auf die im internationalen Vergleich als zu hoch angesehene Belastung der Unternehmenserträge am Standort Deutschland hingewiesen und eine nachhaltige Steuerentlastung der Unternehmensgewinne gefordert. ${ }^{1}$ Deshalb wird hier zunächst erörtert, welche Steuersätze ein international tätiges Unternehmen seiner räumlichen Investitionsplanung und seinen Entscheidungen über den Standort seines Geschäftssitzes zugrunde legen muß, unter welchen Bedingungen sich eine Steuersenkungskonkurrenz der Nationalfiski, also auch für die Bundesrepublik Deutschland, lohnt, ob die supranational allokative Effizienz durch national unterschiedliche Steuersätze auf Unternehmensgewinne beeinträchtigt wird und inwieweit es vertretbar ist, für supranational allokative Effizienz die nationale Steuerhoheit aufzugeben.

\subsection{Effiziente effektive Steuersätze}

In diesem Abschnitt wird der Zusammenhang zwischen Steuersätzen und optimaler räumlicher Kapitalallokation eines privaten Investors in der Modellwelt der vollkommenen Konkurrenz analysiert, um die Anforderungen an das Datenmaterial für effektive Steuersätze theoretisch zu bestimmen (zur Empirie effektiver Steuersätze s. u. Kapitel 5). Die Einschränkung auf das Modell der vollkommenen Konkurrenz ist unerheblich, da die Berücksichtigung von Marktunvollkommenheiten keine zusätzlichen Erkenntnisse liefert. Der allgemeine Informationsbedarf eines Direktinvestors über die national verschiedenen Steuersysteme wird anhand eines mikroökonomischen statischen Optimierungskalküls dargestellt, wobei ein allgemeiner (nicht linearer) Tarif und die einschlägigen Verfahren zur Vermeidung von Doppelbesteuerung angenommen werden. Es soll verdeutlicht werden, daß kein einheitlicher für alle Investoren maßgeblicher effektiver Steuersatz existiert, der als erklärende Variable für das Verhalten aggregierter Direktinvestitionen oder für Untersuchungen über das Direktinvestitionsverhalten einer repräsentativen Unternehmung herangezogen werden kann.

\subsubsection{Annahmen zur Ermittlung effizienter effektiver Steuersätze}

Es existieren Investitionsstandorte in zwei Ländern. Im Wohnsitzland (W) residiere eine Muttergesellschaft und im Quellenland (Q) ihre 100\%ige Tochterkapitalgesellschaft oder eine Betriebsstätte. Die beiden Unternehmungen produzieren je ein homogenes Gut in den Mengen $X_{W}$ und $X_{Q}$ bei gegebener Technologie mit je zwei Produktionsfaktoren

1 Vgl. u. a. Sachverständigenrat (1992) 
Arbeit $\left(L_{W}\right.$ bzw. $\left.L_{Q}\right)$ und Kapital $\left(K_{W}\right.$ bzw. $\left.K_{Q}\right)$, d. h. $X_{W}=F_{W}\left(K_{W}, L_{W}\right)$ und $X_{Q}=F_{Q}\left(K_{Q}, L_{Q}\right)$.

Die Preise $p_{W}$ und $p_{Q}$ der Outputs und die Preise der Produktionsfaktoren, die Lohnsätze $\left(w_{W}, w_{Q}\right)$ und die Zinssätze $\left(i_{W}, i_{Q}\right)$ sind für die Investoren vorgegeben; die Preise für die Kapitalgüter werden gleich eins gesetzt.

Die Muttergesellschaft maximiere bei gegebenen Steuertarifen an den beiden Standorten den erwarteten Konzerngewinn nach Steuern $\left(P^{*}\right)$. Steuerrechtlich unterschiedlich definierte Bemessungsgrundlagen im Wohnsitz- und Quellenland seien ihr bekannt. Freiheit von Steuersatzillusion wird hier im Gewinnmaximierungskalkül durch effektive Steuersätze berücksichtigt. Sie sind definiert als Verhältnis der faktischen Steuerbelastung zum ökonomischen Gewinn.

Der Begriff des ökonomischen Gewinns läßt sich theoretisch nicht eindeutig bestimmen. Man kann ihn z. B. definieren als maximal ausschüttbaren Überschußbetrag bei unverändertem Wert des Kapitalstocks aus der laufenden inländischen Produktion (vgl. King 1975). Der Unternehmung sei die Differenz aus laufenden Erträgen und betrieblichen Aufwendungen (Ü) bekannt. Dann errechnet sich der ökonomische Gewinn nach Abzug der zu Wiederbeschaffungspreisen bewerteten Abschreibungen, der Scheingewinne bzw. -verluste aufgrund von Wertänderungen bei Vorräten sowie der Kapitalgewinne bzw. - verluste aufgrund von Neubewertungen bzw. Transaktionen von Anlagevermögen. Dieser ökonomische Gewinn kann (unter Berücksichtigung von Subventionen und Finanzhilfen für Investitionen) in Form von Steuern an den Staat und in Form von Dividenden an die Kapitaleigner abgeführt bzw. ausgeschüttet werden sowie zur Innenfinanzierung thesauriert bzw. gespart werden. Sei der ökonomische Gewinn $(\mathrm{P})$ ein bestimmter Anteil $(\boldsymbol{\beta})$ des betrieblichen Überschusses (Ü), dann kann man ihn auch schreiben als

$$
P=\beta \cdot \ddot{U}
$$

Wendet man auf diesen ökonomischen Gewinn den formalen Steuersatz $t^{*}$ an, dann erhält man einen theoretischen Steuerbetrag $T=t^{*} \cdot P$. Die faktische Steuerbelastung einer Unternehmung hängt aber unter Berücksichtigung von Subventionen und Finanzhilfen von den national unterschiedlichen Bewertungsvorschriften, Abschreibungsverfahren, Möglichkeiten des Verlustausgleichs bzw. Verlustvortrags und Verlustrücktrags und anderer Regelungen zur Ermittlung des steuerlichen Einkommens bzw. der Bemessungsgrundlage ab (vgl. u. a. Wesselbaum-Neugebauer 1992).

Sei die Bemessungsgrundlage im Wohnsitzland $\pi_{W}$, dann ist der effektive Steuersatz definiert durch $t_{W}=\left(t_{W}^{*} \pi_{W}\right) / P, \mathrm{~d}$. h. als Verhältnis der faktischen Steuerbelastung (immer 
unter Berücksichtigung von Subventionen und Finanzhilfen) zum ökonomischen Gewinn. Für das Wohnsitzland gilt dann für den Bemessungsfaktor $x_{W}=\pi_{W} / P$. Für das Quellenland gelte für den Bemessungsfaktor $x_{Q}=\pi_{Q} / P$. Sei $x_{Q} / x_{W}=z_{Q}=\pi_{Q} / \pi_{W}$, dann gilt für den effektiven Steuersatz im Quellenland

$$
t_{Q}=x_{W} \cdot z_{Q} \cdot t_{Q}^{*}=x_{Q} \cdot t_{Q}^{*}
$$

und im Wohnsitzland

$$
t_{W}=x_{W} \cdot t_{W}^{*}
$$

Die Regierungen bzw. Parlamente im Wohnsitz- und Quellenland bestimmen autonom, also unabhängig voneinander, die in ihrem Territorium geltenden Steuertarife und Bemessungsgrundlagen. Für das Wohnsitzland gilt somit der effektive Steuertarif $t_{W}\left(P_{W}\right)=$ $t_{W}^{*}\left(x_{W} \cdot P_{W}\right)$, wobei $t^{*}{ }_{W}$ für den formalen Steuersatz und $x_{W} \cdot P_{W}$ für die Bemessungsgrundlage steht. Ebenso gilt für den effektiven Steuertarif des Quellenlandes $t_{Q}\left(P_{Q}\right)=$ $t_{Q}^{*}\left(x_{Q} \cdot P_{Q}\right)$. Es wird nachfolgend unterstellt, daß Steuern nicht überwälzt werden können, und da $B$ die gewinnmaximierenden Unternehmen bei ihrer Ressourcenplanung diese effektiven Steuersätze berücksichtigen und deshalb nicht unter Steuersatzillussion leiden.

Zur Vermeidung von Doppelbesteuerung können die Nationalfiski zwischen dem Freistellungs- und dem Anrechnungsverfahren wählen. Das Freistellungsverfahren kann nach dem Source Principle oder dem Residence Principle angewandt werden. Werden im Ausland erwirtschaftete Erträge von der Besteuerung im Inland freigestellt, dann spricht man vom Source Principle. Werden im Ausland erwirtschaftete Erträge von der Besteuerung im Ausland freigestellt, dann spricht man vom Residence Principle. Für den Steuerpflichtigen, nicht aber für den Steuergläubiger, entspricht das Residence Principle dem Vollanrechnungsverfahren, bei dem die tatsächlichen im Ausland gezahlten Steuern auf die Steuerschuld im Inland angerechnet werden. Statt der vollen Anrechnung können und werden auch tatsächlich im Ausland gezahlte Steuern teilweise, d. h. maximal bis zur Höhe der im Wohnsitzland zu leistenden Steuer auf die Steuerschuld im Inland angerechnet. Man spricht dann vom Teilanrechnungsverfahren (zur steuerrechtlichen Praxis vgl. Wesselbaum-Neugebauer 1992).

In der Literatur wird in der Regel vorausgesetzt, daß die Unternehmenserträge nach dem Teilhaberprinzip besteuert werden. Da im Modell der vollkommenen Konkurrenz keine Extragewinne anfallen, werden danach Zinsen auf das Fremdkapital ohne Abzug an der Quelle an den Gläubiger ausgezahlt und von diesem nach seiner persönlichen Leistungsfähigkeit versteuert. Erträge auf das Eigenkapital werden nach der Teilhabersteuer mit dem Spitzensteuersatz der Einkommensteuer im Unternehmen auf Rechnung 
der Kapitaleigner belastet. Diese können die von der Gesellschaft bereits an den Fiskus abgeführte Steuer voll auf ihre persönliche Steuerschuld anrechnen. Die Unternehmenssteuer ist somit als durchlaufender Posten in die persönliche Steuer der Teilhaber nach deren Leistungsfähigkeit voll integriert (vgl. u. a. Blankart, 1991).

Unabhängig von der Finanzierungsart und der Verwendung von Erträgen auf das Eigenkapital zahlt das Unternehmen nach dem Konzept der Teilhabersteuer im Modell der vollkommenen Konkurrenz faktisch überhaupt keine Steuern. Der Sparer zahlt eine individuelle Einkommensteuer auf den Kapitaleinsatz, sofern er seine Ersparnisse als Fremd- oder Eigenkapital dem investierenden Unternehmen via Kapitalmarkt zur Verfügung stellt. Finanzintermediäre, die aufgrund gering verzinster Einlagen von Sparern via Kredit- und Geldschöpfung Finanzierungsmittel für die Durchführung von Investitionen kreieren, existieren in dieser Modellwelt nicht. Die Teilhabersteuer hat sich aber in der Praxis bisher nicht durchgesetzt. Hier sind vielmehr Zinsen auf das Fremdkapital bezüglich der Körperschaftsteuer in der Regel abzugsfähig, sie unterliegen in dem Fall im Unternehmen keiner Steuer. Für die ausgeschütteten Gewinne gilt in der Bundsrepublik Deutschland unter Berücksichtigung der Kapitalertragsteuer wegen der Vollanrechnung praktisch das Teilhaberprinzip. Die thesaurierten Gewinne von Kapitalgesellschaften dagegen werden im Unternehmen mit dem einheitlichen Thesaurierungssatz in Höhe von z. Zt. 50 \% belastet. Der Fiskus geht hierbei von der Vermutung aus, daß der Wert der Beteiligung durch die Thesaurierung entsprechend steigt, und weil diese Wertsteigerung beim Kapitaleigner nicht der Besteuerung unterliegt, erfolgt die Belastung der Reinvermögenstheorie folgend ersatzweise im Unternehmen. Im folgenden wird deshalb vorausgesetzt, daß der zu versteuernde Gewinn einer Kapital- oder Personengesellschaft vollständig thesauriert wird und infolgedessen dem jeweiligen Thesaurierungssatz unterliegt. Alternativ könnte man auch annehmen, daß der zu versteuernde Gewinn nach dem klassischen System der Körperschaftsteuer im Unternehmen und beim Kapitaleigner, also doppelt, besteuert wird.

\subsubsection{Effiziente effektive Steuersätze bei Freistellung von im Ausland erwirt- schafteten Erträgen im Inland (Source Principle)}

Unter dem effektiven efflizienten Steuersatz wird im folgenden der Satz verstanden, den eine Unternehmung unter den genannten Annahmen zugrunde legen muß, wenn sie bei optimalem Ressourceneinsatz den ökonomischen Gewinn nach Steuern weltweit zu maximieren beabsichtigt.

Es gelte das Freistellungsverfahren ohne Progressionsvorbehalt. Danach müssen Mutterund Tochterkapitalgesellschaft Steuern zahlen in Höhe von insgesamt

$$
T=t_{W}\left(P_{W}\right) P_{W}+t_{Q}\left(P_{Q}\right) P_{Q}
$$


Der zu maximierende Konzerngewinn errechnet sich unter der Annahme, daß zum herrschenden Zinssatz am jeweiligen Kapitalmarkt unbeschränkt Kapital aufgenommen werden kann, aus der Gleichung für den Gewinn nach Steuern.

$$
\begin{aligned}
P^{*}= & \left(1-t_{W}\left(P_{W}\right)\right)\left\{p_{W} F_{W}\left(K_{W}, L_{W}\right)-w_{W} \cdot L_{W}-i_{W} \cdot K_{W}\right\} \\
& +\left(1-t_{Q}\left(P_{Q}\right)\right)\left\{p_{Q} F_{Q}\left(K_{Q}, L_{Q}\right)-w_{Q} \cdot L_{Q}-i_{Q} \cdot K_{Q}\right\}
\end{aligned}
$$

Schreibt man für das Wertgrenzprodukt $p_{W} \cdot F_{W, K}=r_{W}^{\prime}=$ Rendite für $p_{K W}=1$, dann erhält man für die Nettorendite bzw. den Nettozinssatz als notwendige Bedingung für das Gewinnmaximum

$$
\begin{aligned}
r_{W}^{\prime \text { netto }} & =r_{W}^{\prime}\left\{1-t_{W}\left(P_{W}\right) \cdot\left(1+\epsilon_{t}\right)\right\}= \\
i_{W}^{\text {netto }} & =i_{W}\left\{1-t_{W}\left(P_{W}\right) \cdot\left(1+\epsilon_{t}\right)\right\}
\end{aligned}
$$

Diese notwendige Bedingung findet man aus der partiellen Ableitung des Gewinns nach Steuern nach dem Kapitaleinsatz

$$
\begin{aligned}
\frac{\partial P^{*}}{\partial K_{W}} & =\frac{\partial}{\partial K_{W}}\left\{1-t_{W}\left(P_{W}\right)\right\} P_{W}+\left(1-t_{W}\left(P_{W}\right)\right) \cdot \frac{\partial P_{W}}{\partial K_{W}} \\
& =-\frac{d t_{W}}{d P_{W}} \cdot \frac{\partial P_{W}}{\partial K_{W}} \cdot P_{W}+\frac{\partial P_{W}}{\partial K_{W}}-t_{W}\left(P_{W}\right) \cdot \frac{\partial P_{W}}{\partial K_{W}} \\
& =\left\{-\frac{d t_{W}}{d P_{W}} \cdot \frac{P_{W}}{t_{W}} \cdot t_{W}\left(P_{W}\right)-t_{W}\left(P_{W}\right)+1\right\} \cdot \frac{\partial P_{W}}{\partial K_{W}} \\
& =\left\{1-t_{W}\left(P_{W}\right)\left(1+\epsilon_{t}\right)\right\}\left(p_{W} \cdot F_{W, K}-i_{W}\right)=0
\end{aligned}
$$

Aus dieser Bedingungsgleichung wird unmittelbar ersichtlich, daß bei progressivem Tarif der effektive Durchschnittssteuersatz vom effektiven effizienten Grenzsteuersatz abweicht. Ersterer ist für die Entscheidung über den Standort des Unternehmenssitzes relevant und letzterer für Entscheidungen über die räumliche Allokation von Sachkapital (Direktinvestitionen).

Nun entspricht die Durchschnittssteuersatzelastizität $\epsilon_{t}$ dem Ausdruck $\left(t_{W}^{\prime} / t_{W}\right)-1$, mit $t_{W}^{\prime}=$ Grenzsteuersatz und $t_{W}=$ Durchschnittssteuersatz. Für die Nettorendite bzw. den Nettozinssatz im Wohnsitzland gilt somit für optimalen Kapitaleinsatz die notwendige Bedingung

$$
r_{W}^{\prime}\left(1-t_{W}^{\prime}\right)=i_{W}\left(1-t_{W}^{\prime}\right)
$$

Diese Bedingung besagt, daß die Zinserträge aus Geldvermögensanlagen im Optimum wie die Erträge aus in produktive Anlagen investiertes Kapital nach dem Source Prin- 
ciple besteuert werden müssen. Analog findet man für den optimalen Kapitaleinsatz im Quellenland die notwendige Bedingung

$$
r_{Q}^{\prime}\left(1-t_{Q}^{\prime}\right)=i_{Q}\left(1-t_{Q}^{\prime}\right)
$$

Für eine gewinnmaximierende international tätige Unternehmung (Investor) sind unter den oben genannten Voraussetzungen die effizienten effektiven Grenzsteuersätze für ihr Investitionskalkül relevant. Das Unternehmen alloziiert das eingesetzte Kapital räumlich optimal, wenn an den beiden Standorten gleiche Nettorenditen bzw. gleiche Nettozinssätze erzielt werden. Die Annahme identischer Zinssätze, d. h. $i_{W}^{\text {netto }}=i_{Q}^{\text {netto }}$, impliziert einen vollkommenen internationalen Kapitalmarkt, auf dem ein homogenes Kapitalmarktpapier gehandelt wird. Außerdem muß der aktuelle Devisenkurs dem erwarteten Kurs, d. h. $w=w^{\text {erw }}$, entsprechen (vgl. u. a. Jarchow/Rühmann 1991).

Sind die effizienten effektiven Grenzsteuersätze an den (beiden) Standorten verschieden, dann fallen dort auch unterschiedliche Bruttorenditen an. Für $t_{W}^{\prime} \neq t_{Q}^{\prime}$ gilt nämlich

$$
\begin{aligned}
r_{W}^{\prime} & \neq r_{Q}^{\prime} \text { wegen } \\
r_{W}^{\prime}\left(1-t_{W}^{\prime}\right) & =r_{Q}^{\prime}\left(1-t_{Q}^{\prime}\right) \text { und } \\
i_{W}\left(1-t_{W}^{\prime}\right) & =i_{Q}\left(1-t_{Q}^{\prime}\right)
\end{aligned}
$$

Ist z. B. die Bruttorendite (Bruttozinssatz) im Wohnsitzland größer als im Quellenland, dann wird hier aus steuerlichen Gründen zuviel Kapital eingesetzt. Bei einer Senkung des Grenzsteuersatzes im Wohnsitzland käme es c. p. zu einer räumlichen Reallokation von Kapital. Bei gleichen Bruttorenditen an den beiden Standorten wird von supranational effizienter Kapitalallokation gesprochen.

In der Praxis wird in der Regel auf Zinserträge zur Vermeidung von Doppelbesteuerung das Residence Principle angewandt, d. h. Zinserträge werden am Wohnsitz des Gläubigers versteuert und im Quellenland von der Steuer freigestellt. In dem Fall resultiert als Optimumbedingung für Sachanlagen

$$
\begin{aligned}
r_{W}^{\prime}\left(1-t_{W}^{\prime}\right) & =i_{W}\left(1-t_{W}^{\prime}\right) \\
r_{Q}^{\prime}\left(1-t_{Q}^{\prime}\right) & =i_{Q}\left(1-t_{W}^{\prime}\right)
\end{aligned}
$$

Da der Schuldner (Investor) bei international vollkommenen Kapitalmärkten Kredite in dem Land mit dem geringsten Bruttozinssatz aufnehmen wird, werden sich die Bruttozinssätze im Wohnsitz- und Quellenland angleichen. Denn falls der erwartete Devisenkurs dem faktischen Kurs entspricht $\left(w^{e r w}=w\right)$, lohnen sich via Kapitalimporte bzw. Kapital- 
exporte Arbitragegeschäfte, solange Zinssatzdifferenzen existieren. Es wird $i_{W}=i_{Q}$ gelten und somit die Gleichheit der Nettorenditen auf Sachanlagen

$$
r_{W}^{\prime}\left(1-t_{W}^{\prime}\right)=r_{Q}^{\prime}\left(1-t_{Q}^{\prime}\right)
$$

Sei der effektive Steuersatz im Quellenland geringer als im Wohnsitzland, gilt

$$
\frac{i_{Q}^{\text {netto }}}{1-t_{Q}^{\prime}}=r_{Q}^{\prime}=\frac{r_{Q}^{\prime} \text { netto }}{1-t_{Q}^{\prime}}<\frac{r_{W}^{\prime}{ }^{\text {netto }}}{1-t_{W}^{\prime}}=r_{W}^{\prime}
$$

Unterschiedliche Steuersätze in Verbindung mit unterschiedlichen Doppelbesteuerungsverfahren implizieren somit suboptimale Kapitalallokation: supranational, weil die Bruttorenditen an den verschiedenen nationalen Standorten voneinander abweichen bzw. weil in dem Land mit dem niedrigeren Steuersatz c. p. vergleichsweise zuviel Investitionen getătigt werden und national, weil die Bruttorendite (in jedem beliebigen Q-Land) kleiner ist als der Bruttozinssatz, bzw. weil das Anlagevermögen suboptimal strukturiert ist.

Die Möglichkeit, daß in der Praxis Zinserträge nach einem anderen Verfahren zur Vermeidung von Doppelbesteuerung behandelt werden als die Erträge aus Investitionen in Sachanlagen, wird in den folgenden Analysen nicht explizit berücksichtigt, da die Resultate den hier vorgestellten entsprechen. Außerdem erübrigen sich beim Residence Principle und Vollanrechnungsverfahren die oben angeführten Modifikationen für die Optimumbedingungen.

Bei einem proportionalen Tarif sind Grenz- und Durchschnittssteuersätze gleich und deshalb auch die marginale und durchschnittliche Steuerbelastung für den Investor. Für einen progressiven Tarif gilt jedoch allgemein

$$
\alpha=1+\epsilon_{t}>1
$$

Supranational effiziente effektive Grenzsteuersätze, d. h. $t_{W}^{\prime}=t_{Q}^{\prime}$, können in dem Fall mit einer unterschiedlichen durchschnittlichen steuerlichen Belastung der Kapitalerträge an den beiden Standorten verbunden sein. Denn für $\alpha_{W} \neq \alpha_{Q}$ gilt wegen

$$
\begin{aligned}
\alpha_{Q} \cdot t_{Q}=t_{Q}^{\prime} & =t_{W}^{\prime}=\alpha_{W} \cdot t_{W} \\
t_{Q} & \neq t_{W}
\end{aligned}
$$

Unabhängig von den räumlichen Investitionsentscheidungen, die nach obigem Gewinnmaximierungskalkül von den marginalen Steuersātzen beinflußt werden, wird die Muttergesellschaft (Investor) ihren Geschäftssitz in das Land mit dem niedrigeren Durchschnittssteuersatz legen - sofern die Mobilitätskosten geringer sind als die Steuerersparnisse -, um Steuern auszuweichen: 


\subsubsection{Effiziente effektive Steuersätze bei Freistellung von im Ausland erwirt- schafteten Erträgen im Ausland (Residence Principle)}

Die Tochterkapitalgesellschaft zahlt nach Voraussetzung im Quellenland keine Steuern. Die Muttergesellschaft zahlt im Wohnsitzland Steuern auf den weltweit erwirtschafteten Gewinn (unter Progressionsvorbehalt).

$$
T=t_{W}\left(P_{W}+P_{Q}\right) \cdot\left(P_{W}+P_{Q}\right)=t_{W}(P) \cdot P
$$

Der zu maximierende Konzerngewinn errechnet sich aus

$$
P^{*}=\left(1-t_{W}(P)\right)\left\{p_{W} F_{W}-w_{W} L_{W}-i_{W} K_{W}+p_{Q} F_{Q}-w_{Q} L_{Q}-i_{Q} K_{Q}\right\}
$$

Aus den notwendigen Bedingungen für den maximalen Gewinn findet man (weil unabhängig von der Anlageform das Wohnsitzlandprinzip gilt, ist $i_{W}=i_{Q}$ )

$$
\begin{aligned}
& r_{W}^{\prime \text { netto }}=r_{W}^{\prime}\left\{1-t_{W}(P)\left(1+\epsilon_{t}\right)\right\} \\
& r_{Q}^{\prime \text { netto }}=r_{Q}^{\prime}\left\{1-t_{W}(P)\left(1+\epsilon_{t}\right)\right\}
\end{aligned}
$$

Da der effektive Grenzsteuersatz $t_{W}^{\prime}(\mathrm{P})$ dem Ausdruck $t_{W}(P)\left(1+\epsilon_{t}\right)$ entspricht, resultiert aus dem beschriebenen Gewinnmaximierungskalkül, daB die Netto- und Bruttorenditen an beiden Standorten für optimale Kapitalallokation identisch sein müssen. Die Anwendung des Residence Principles ist somit unabhängig von den nationalen Steuersystemen mit supranational effizienter Kapitalallokation vereinbar. Da die Tochterkapitalgesellschaft im Quellenland nicht zur Steuer herangezogen wird, spielen Differenzen der effektiven Steuersätze für die Entscheidungen über die räumliche Verteilung der Investitionen der Muttergesellschaft keine Rolle; sie muß sich bei ihrer Investitionsplanung nur an dem Steuersystem in Wohnsitzland orientieren. Eine Veränderung des Steuertarifs oder steuerliche Vorschriften zur Ermittlung der Bemessungsgrundlagen im Quellenland würden ihr Investitionskalkül nicht berühren; möglicherweise aber die Entscheidung über den Standort des Geschäftssitzes.

Steuerentlastungen im Quellenland entlasten die Investoren, die dort ihren Gesellschaftssitz haben. Es kann deshalb nicht ausgeschlossen werden, daB Investoren aus anderen Ländern ihre Gesellschaftssitze dorthin verlagern, sofern die Wanderungskosten geringer sind als die Steuerersparnisse. In dem Fall würde das steuersenkende Quellenland Fiskalgewinne realisieren, wenn die Mehreinnahmen der zugezogenen Muttergesellschaften größer sind als die Mindereinnahmen aus der geringeren Belastung der bereits ortsansässigen Zensiten. Die anderen Länder erlitten auf jeden Fall Fiskalverluste. Bei Anwendung des Residence Principles berührt also Steuersenkungskonkurrenz der Nationalfiski die räumli- 
che Verteilung der Investitionen nicht, wohl aber die Standortwahl für die Geschäftssitze. Man kann nun davon ausgehen, daß die Verlagerung von Geschäftssitzen nicht mit weitreichenden Verlusten oder Gewinnen an Arbeitsplätzen und Investitionen verbunden sind, so daß eine Steuersenkungskonkurrenz auf jeden Fall beschäftigungs- und wachstumspolitisch und unter Umständen auch einnahmepolitisch ins Leere läuft.

\subsubsection{Effiziente effektive Steuersätze bei Vollanrechnung von im Ausland ge- zahlten Steuern im Inland (Vollanrechnungs- bzw. Erstattungsverfah- ren)}

Für die weltweite Steuerschuld von Mutter- und Tochterkapitalgesellschaft gilt beim Vollanrechnungsverfahren

$$
\begin{aligned}
T & =\left\{t_{W}(P) \cdot\left(P_{W}+P_{Q}\right)-t_{Q}\left(P_{Q}\right) P_{Q}\right\}+t_{Q}\left(P_{Q}\right) P_{Q} \\
& =t_{W}(P) P
\end{aligned}
$$

Hinsichtlich der effizienten effektiven Steuersätze findet man das gleiche Ergebnis wie im Fall des Residence Principles: Steuersatzdifferentiale spielen für die räumliche Kapitalallokation keine Rolle, da nur das Steuersystem im Wohnsitzland die Investitionsentscheidungen beeinflußt.

Das Vollanrechnungsverfahren müßte wie das Residence Principle in der steuerpolitischen Diskussion als ernstzunehmende Option für die Vereinbarkeit eines supranational effizienten und zugleich dezentralen Steuersystems in den Ländern des Europäischen Binnenmarktes betrachtet werden. Gegen die Anwendung des direkten Vollanrechnungsverfahrens sprechen jedoch juristische und vor allem fiskalpolitische Argumente. Steuerrechtlich handelt es sich bei der Mutter- und Tochterkapitalgesellschaft um jeweils unterschiedliche Steuersubjekte. Die Muttergesellschaft kann deshalb nicht die Steuern eines anderen Steuersubjekts, nämlich der Tochterkapitalgesellschaft, direkt anrechnen. Außerdem subventionieren Niedrigsteuerländer Investitionen in Hochsteuerländern, so daß Bestrebungen, die Steuern zu senken, blockiert werden. Eher besteht ein Anreiz, die Steuersätze zu erhöhen.

Angenommen Land W und Land Q hätten in einer fiktiven Ausgangssituation den gleichen Steuertarif sowie gleiche Bemessungsgrundlagen. Land $\mathrm{W}$ beabsichtige nun, die Steuern zu senken, um Investoren ins Land zu ziehen und sich zusätzliche Fiskalressourcen zu erschließen. Aufgrund der Steuersenkung würden die beschränkt und unbeschränkt steuerpflichtigen Unternehmen im Land W weniger Steuern zahlen. Beide trifft ein niedrigerer Satz und die international tätige Muttergesellschaft erhielte Steuerzahlungen der Tochterkapitalgesellschaft im Hochsteuerland Q angerechnet. Das Land W kann mit Recht 
erwarten, daß unter sonst gleichen Bedingungen Zensiten ihren Geschäftssitz vom Land $\mathrm{Q}$ nach Land $\mathrm{W}$ verlagern. Diese neuen Zensiten sind auch tatsächlich zusätzliche Steuerzahler. Aber das Land W muß ihnen ihre Steuern im Land $Q$ anrechnen, weil dort der Steuersatz höher ist. Land W realisierte somit gerade wegen des Zuzugs neuer Zensiten Fiskalverluste. Außerdem ist kaum zu erwarten, daß die neuen Schreibtischunternehmen in erheblichem Maße zusätzliche Arbeitsplätze schaffen. Eine Steuersenkungspolitik ist somit fiskal- und wirtschaftspolitisch nicht attraktiv. Andererseits ist eine Steuererhöhung erfolgversprechender. Denn die vorhandenen bzw. verbleibenden Zensiten (Mutter- und Tochterkapitalgesellschaften bzw. Betriebsstätten) im Steuererhöhungsland zahlten jetzt höhere Steuern auf in- und ausländische Einkünfte. Aber die Investoren (Muttergesellschaften) hätten auch einen Anreiz, ihren Geschäftssitz in das benachbarte Niedrigsteuerland zu verlagern. Dieses müßte den neuen Zensiten die Steuerdifferenz ihrer Tochterkapitalgesellschaft bzw. Betriebsstätte zum Hochsteuerland erstatten, so daß es Fiskalverluste erlitte und deshalb einen Anreiz hätte, ebenfalls die Steuern zu erhöhen. Es würde somit unseres Erachtens eine Steuersatzkonkurrenz mit steigenden Sätzen ausgelöst.

\subsubsection{Effiziente effektive Steuersätze bei Teilanrechnung von im Ausland ge- zahlten Steuern im Inland (Teilanrechnungsverfahren)}

Es gelte das Teilanrechnungsverfahren unter Progressionsvorbehalt, d. h. für $t_{W}(P)<$ $t_{Q}\left(P_{Q}\right)$ wird die ausländische Steuer maximal bis zur Höhe der im Wohnsitzland zu leistenden Steuer angerechnet (Höchstbetragsgrenze). Die Muttergesellschaft kann somit von den Steuern auf den Gesamtgewinn, die Steuern, die im Wohnsitzland auf die im Quellenland erwirtschafteten Gewinne angefallen wären, anrechnen. Die Steuerbelastung des Konzerns errechnet sich für $t_{W}(P)<t_{Q}\left(P_{Q}\right)$ aus

$$
\begin{aligned}
T & =t_{W}(P) \cdot\left(P_{W}+P_{Q}\right)-t_{W}(P) P_{Q}+t_{Q}\left(P_{Q}\right) P_{Q} \\
& =t_{W}(P) P+\left\{t_{Q}\left(P_{Q}\right)-t_{W}(P)\right\} \cdot P_{Q} \\
& =t_{W}(P) P_{W}+t_{Q}\left(P_{Q}\right) P_{Q}
\end{aligned}
$$

Für $t_{W}(P)=t_{Q}\left(P_{Q}\right)$ gilt $T=t_{W}(P) \cdot P$ bzw. Vollanrechnung. Die folgenden Resultate gelten somit nur für den Fall $t_{W}(P)<t_{Q}\left(P_{Q}\right)$, d. h. für den Fall der echten Teilanrechnung. Die Steuerbelastung bei Teilanrechnung unterscheidet sich von der Belastung bei Anwendung des Source Principles (Freistellung von im Quellenland erwirtschafteten Gewinnen von der Besteuerung im Wohnsitzland) durch den anzuwendenden effektiven Steuersatz im Wohnsitzland; im ersten Fall bezieht er sich wegen des Progressionsvorbehalts auf das weltweit erwirtschaftete Einkommen $t_{W}=t_{W}(P)$ und im zweiten Fall auf 
die im Wohnsitzland erzielten Erträge $t_{W}=t_{W}\left(P_{W}\right)$. Bei einem progressiven Tarif muß dann für $P_{Q}>0$ gelten

$$
t_{W}(P)>t_{W}\left(P_{W}\right)
$$

Der zu maximierende Gewinn nach Steuern errechnet sich aus der Gleichung für den Konzerngewinn nach Steuern

$$
\begin{aligned}
P^{*}= & \left(1-t_{W}(P)\right)\left\{p_{W} F_{W}\left(K_{W}, L_{W}\right)-w_{W} L_{W}-i_{W} K_{W}\right\} \\
& +\left(1-t_{Q}\left(P_{Q}\right)\right)\left\{p_{Q} F_{Q}\left(K_{Q}, L_{Q}\right)-w_{Q} L_{Q}-i_{Q} K_{Q}\right\}
\end{aligned}
$$

Aus den notwendigen Bedingungen für optimalen Kapitaleinsatz erhält man wiederum die Bedingungsgleichung für die Nettorenditen

$$
\begin{aligned}
r_{W}^{\prime \text { netto }} & =r_{W}^{\prime}\left\{1-t_{W}(P)-\mu\left[t_{W}^{\prime}(P)-t_{W}(P)\right]\right\} \\
r_{Q}^{\prime}{ }^{\text {netto }} & =r_{Q}^{\prime}\left\{1-t_{Q}^{\prime}\left(P_{Q}\right)-\mu\left[t_{W}^{\prime}(P)-t_{W}(P)\right]\right\} \\
\text { für } \mu=\frac{P_{W}}{P} &
\end{aligned}
$$

Falls im Wohnsitzland ein proportionaler Tarif existiert, so daß $t_{W}^{\prime}(P)=t_{W}(P)$ ist, lautet die Bedingung für die optimale Kapitalallokation

$$
r_{W}^{\prime \text { netto }}=r_{W}^{\prime}\left(1-t_{W}(P)\right)=r_{Q}^{\prime}\left(1-t_{Q}^{\prime}\left(P_{Q}\right)\right)=r_{Q}^{\prime}{ }^{\text {netto }}
$$

Supranational effiziente Kapitallokation erforderte die Egalisierung der effizienten effektiven Steuersätze $t_{W}(P)=t_{Q}^{\prime}\left(P_{Q}\right)$, damit die Allokation steuerlich nicht verzerrt wird und $r_{W}^{\prime}=r_{Q}^{\prime}$ gilt. Im Falle eines nicht linearen Tarifs gestaltet sich die Frmittlung der Nettorenditen für den Konzern komplizierter. Sie müßten simultan mit den Steuersătzen $t_{W}^{\prime}(P), t_{W}(P), t_{Q}^{\prime}\left(P_{Q}\right)$ sowie dem Gewinnverteilungsfaktor $\mu$ simultan aus den folgenden Gleichungen ermittelt werden

$$
\begin{aligned}
r_{W}^{\prime}{ }^{\text {netto }} & =r_{W}^{\prime}\left\{1-t_{W}(P)-\mu\left[t_{W}^{\prime}(P)-t_{W}(P)\right]\right\} \\
r_{Q}^{\prime}{ }^{\text {netto }} & =r_{Q}^{\prime}\left\{1-t_{Q}^{\prime}\left(P_{Q}\right)-\mu\left[t_{W}^{\prime}(P)-t_{W}(P)\right]\right\} \\
T_{W} & =T_{W}(P) \\
T_{Q} & =T_{Q}\left(P_{Q}\right) \\
\mu & =\frac{P_{W}}{P}=\frac{r_{W} \cdot K_{W}}{r_{W} \cdot K_{W}+r_{Q} \cdot K_{Q}^{\prime}}
\end{aligned}
$$

wobei $r_{W}$ und $r_{Q}$ Durchschnittsrenditen sind. Sofern also ein international tätiger Investor die räumlich optimale Verteilung des Kapitals anstrebt und zu einem nicht linearen Tarif zur Steuer herangezogen wird und in seinem Wohnsitzland der Teilanrechnung unterliegt, benötigt er umfangreiche Informationen und erhebliche Informationsverarbeitungskapa-
oloft, Sigylle Brander, ngo Barens and Claudla Wesselbaum -978-3-635-75210-4 
zitäten. Falls er die erforderlichen Informationen nicht erwirbt und entsprechend verarbeitet. komnit es unter den Annahmen des obigen Kalküls zu einem suboptimalen, d. h. nicht gewinnmaximierenden Kapitaleinsatz.

\subsubsection{Zusammenfassung der Ergebnisse}

International tätige Unternehmen treffen in der beschriebenen Modellwelt Entscheidungen ïber die räumliche Verteilung von Investitionen und über den Standort ihres Geschäftssitzes. Sie müssen sich dabei je nach Tarifgestaltung und je nach den zwischenstaatlich vercinbarten Verfahren zur Vermeidung von Doppelbesteuerung an unterschiedlichen Steuersätzen orientieren. In der herkömmlichen Theorie optimaler Steuersätze wird in der Regel davon gesprochen, daß effektive effiziente Grenzsteuersätze für Investitionsentscheidungen maßgeblich sind. Aus der folgenden Tabelle 3.1 ist ersichtlich, daß diese Unterstellung lediglich im Falle des Source Principles plausibel ist. Sofern nun Unternehmungen mit ihren Erträgen je nach Unternehmesverfassung der progressiven Einkommensteuer oder der proportionalen Körperschaftsteuer unterliegen, müssen auch im Falle des Source Principles die Direktinvestitionen in entsprechende Teilaggregate gruppiert werden, wenn man den Finfluß von nationalen Steuersatzdifferentialen bzw. deren Veränderungen auf die räumliche Verteilung von Investitionen statistisch erklären will.

In den Fällen des Residence Principles und der Vollanrechnung spielen internationale Steuersatzdifferentiale für Entscheidungen über die räumliche Verteilung des produktiven Kapitals überhaupt keine Rolle. Denn falls zwischenstaatlich das Residence Principle vereinbart ist, verzichtet das Quellenland auf die Besteuerung von Erträgen aus Direktinvestitionen, und falls (unilateral) Vollanrechnung gilt, erhält der Investor die im Quellenland von der Tochterkapitalgesellschaft gezahlten Steuern in voller Höhe angerechnet. In beiden Fällen muß er sich somit nur an den heimischen Grenz- bzw. Durchschnittssteuersätzen orientieren; unterschiedliche Steuersysteme beeinflussen das Verhalten von Direktinvestitionen überhaupt, nicht.

Den höchsten Informationsbedarf und die höchsten Informationsverarbeitungskosten hat ein Investor, der bei vereinbarter oder unilaterial angewandter echter Teilanrechnung an beiden Standorten nach nicht linearen Tarifen veranlagt wird. Er muß bei erwarteten alternativen Erträgen an den verschiedenen Standorten simultan die effektiven Grenz- und Durchschnittssteuersätze im Wohnsitzland, den effektiven Grenzsteuersatz im Quellenland sowie die optimale örtliche Verteilung der ökonomischen Gewinne bei ausgeglichenen Nettorenditen ermitteln. Im Falle der Veranlagung nach linearen Tarifen entsteht der gleiche Informationsbedarf wie bei Anwendung des Source Principles.

7wischenstaatlich werden in der Praxis in der Regel verschiedene Doppelbesteuerungs- 
Tabelle 3.1: Entscheidungsrelevante effiziente effektive Steuersätzc

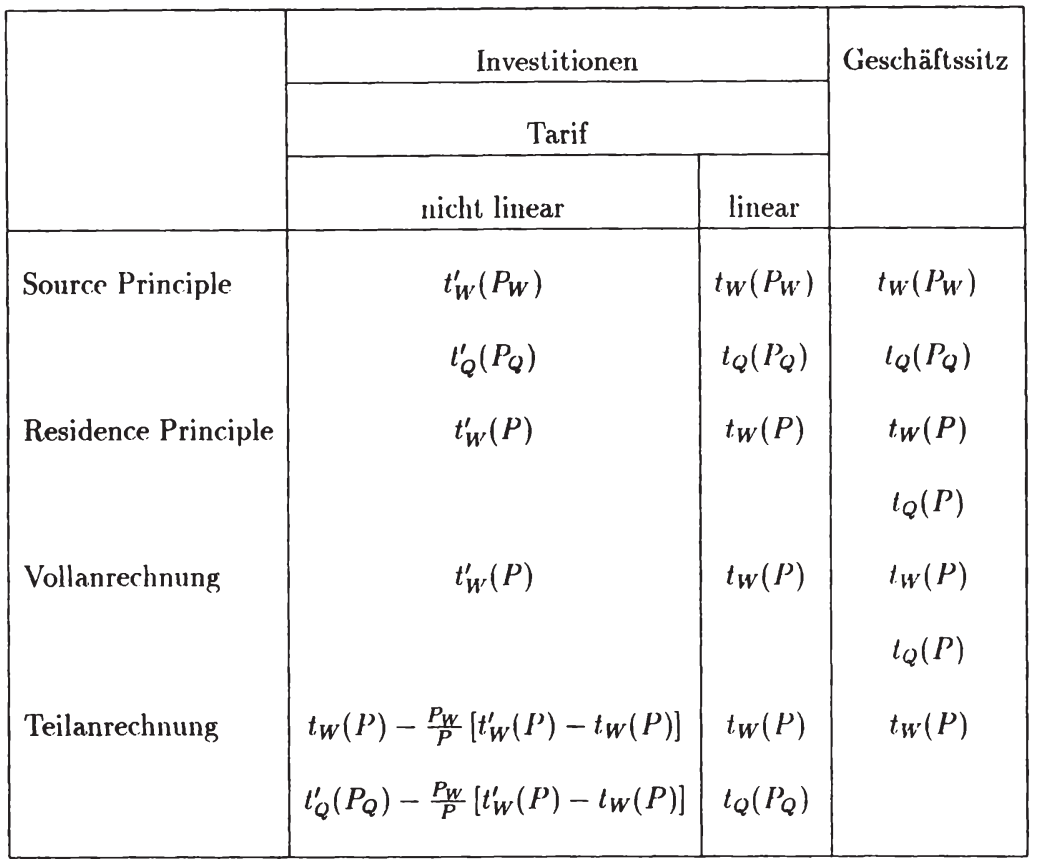

verfahren und/oder national und international unterschiedliche (lineare bzw. progressive) Steuertarife angewandt. Es existiert somit für einen bestimmten Zeitraum kein einheitlicher für alle Direktinvestoren gleichermaßer entscheidungsrelevanter effektiver Steuersatz, mit dessen Hilfe der Einfluß von internationalen Steuersatzdifferentialen auf das Verhalten aggregierter Direktinvestitionen statistisch erklärt werden kann. Außerdem ist es unrealistisch anzunehmen, daß alle Investoren zu allen Zeiten von einer einheitlichen Definition des ökonomischen Gewinns als Bezugsbasis zur Ermittlung effektiver Steuersätze ausgehen. Aus methodischen Gründen wäre somit eine entsprechende Gruppierung von Teilaggregaten der Direktinvestitionen für quantitativ-empirische Untersuchungen erforderlich. Im nächsten Kapitel der Studie wird gezeigt, daß die notwendigen Informationen für die Abgrenzung derartiger Teilaggregate $z$. Zt. nicht vorliegen. Und im fünften Kapitel wird herausgearbeitet, daß empirische Daten für die verschiedenen effektiven Steuersätze ebenfalls nicht verfügbar sind. 


\subsection{Internationale Steuerkonkurrenz}

Im vorhergehenden Abschnitt wurden die effizienten effektiven Steuersätze für Direktinvestitionen theoretisch definiert. In diesem Abschnitt sollen nun die Bedingungen dargestellt werden, unter denen sich Steuerkonkurrenz der Nationalfiski wachstums- und beschäftigungspolitisch oder fiskalpolitisch lohnen kann. Die Konkurrenz um arbeitsplatzschaffende Investitionen muß dabei getrennt von der Konkurrenz um die Ansiedlung von Geschäftssitzen betrachtet werden. Im ersten Kapitel der Studie wird bereits die Frage erörtert, ob sich die hier herausgearbeiteten Bedingungen theoretisch konsistent begründen lassen und in den folgenden Kapiteln inwieweit anhand der verfügbaren Daten über Direktinvestitionen und Steuersätze die Wirkung von Steuersatzdifferentialen auf Direktinvestitionen empirisch-quantitativ getestet werden kann. Auch soll im weiteren Verlauf des Forschungsprojektes dem Hinweis nachgegangen werden, daß Steuern schließlich nur ein Kostenfaktor im Kalkül eines Investors darstellen. Diesen Kosten stehen in der Regel Kostenersparnisse aufgrund staatlicher Infrastrukturausgaben gegenüber. Die Rendite eines Investors ist somit $u$. a. bestimmt von der Höhe der Steuern - sofern diese nicht überwälzt werden - und der Höhe der Ausgaben für öffentliche Güter. Beide Bestimmungsfaktoren beeinflussen die Nettorendite gegenläufig. Hohe Steuern senken sie und Staatsausgaben in die Infrastruktur erhöhen sie. A priori kann nicht gesagt werden, welcher Faktor den dominierenden Einfluß ausübt.

In der folgenden Tabelle 3.2 wird qualitativ die Wirkung einer Steuersenkung auf die Steuereinnahmen eines Landes angezeigt. Die. Wirkungen aus der Reallokation von Kapital in Form von Direktinvestitionen können unter bestimmten Voraussetzungen, die im folgenden analysiert werden, eindeutig markiert werden. Die Wirkungen aus der Verlagerung von Geschäftssitzen sind unbestimmt. Denn die bereits ortsansässigen Zensiten zahlen weniger Steuern, während die hinzugezogenen Zensiten zusätzliche Steuern zahlen. Per Saldo können sich aus dem Bestands- und Wanderungseffekt Mehr- oder Mindercinnahmen ergeben, oder die Mehreinnahmen gleichen die Mindereinnahmen gerade aus. Über die Gesamtwirkung auf die Steuereinnahmen aus der Reallokation von Kapital und dem Zuzug von Zensiten kann a priori nichts gesagt werden.

Im Falle des Source Principles (Quellensitzland-Prinzip) können Investitions- und Entscheidungen über den Standort des Gesellschaftssitzes nicht getrennt werden. Die Erträge des Konzerns werden am Ort ihrer Fntstehung besteuert unabhängig vom Standort der Muttergesellschaft. In allen anderen Fällen kann die Muttergesellschaft durch die Wahl eines Niedrigsteuerlandes, d. h. eines Landes mit der geringsten durchschnittlichen Steuerlast gemessen am Durchschnittssteuersatz, Steuern sparen. Wird eine Unternehmung progressiv besteuert, dann steigen diese Ersparnisse mit steigenden weltweiten Erträgen, weil im Wohnsitzland durch Progressionsvorbehalte der Durchschnittssteuersatz mit stei- 
Tabelle 3.2: Die Wirkung von Steuersatzsenkungen auf die Steuereinnahmen nach Direktinvestitionen und Zuzug von Geschäftssitzen

\begin{tabular}{|l|c|c|}
\hline & Direktinvestitionen & Geschäftssitz \\
\hline Wohnsitzland-Prinzip & 0 & $\sim$ \\
\hline Quellenland-Prinzip & + & $\sim$ \\
\hline Vollanrechnungs-Verfahren & 0 & - \\
\hline Teilanrechnungsverfahren & + & $\sim$ \\
\hline
\end{tabular}

0 = keine Wirkung

$+=$ Mehreinnahmen

- $=$ Mindereinnahmen

$\sim$ unbestimmt

gender Bemessungsgrundlage ebenfalls ansteigt. Die Muttergesellschaft kann durch die Verlagerung ihres Geschäftssitzes in das Niedrigsteuerland ihr Finanzierungspotential für Investitionen erhöhen, was bei Kreditrationierung nicht unerheblich sein mag. Somit sind bei Kreditrationierung Entscheidungen über den Gesellschaftssitz der Muttergesellschaft steuerlich relevant; diese Entscheidungen orientieren sich unabhängig von der jeweiligen Tarifform an effektiven durchschnittlichen Steuersätzen. Es ist jedoch insbesondere wieder im Hinblick auf quantitativ-empirische Studien zu beachten, daß dieser Satz nur bei proportionalen Tarifen konstant ist.

Falls unter Berücksichtigung von Umzugskosten und Steuerersparnissen Geschäftsleitungen international tätiger Unternehmungen mobil sind, wurde bereits dargelegt, daß sich im Falle der Vollanrechnung eine Steuersenkungspolitik fiskalpolitisch nicht lohnt sowie beschäftigungs- und wachstumspolitisch bedeutungslos ist. In den anderen Fällen sind die Wirkungen von Geschäftssitzverlagerungen bei einer Steuersenkung ungewiß. Einerseits werden neue Zensiten angezogen, andererseits zahlen die anwesenden Zensiten weniger Steuern. Per Saldo können somit die Einnahmen zunehmen, sinken oder konstant bleiben. 
Tabelle 3.3: Verteilung von Steucrerträgen auf Wohnsitz- und Quellenland

\begin{tabular}{|l|c|c|}
\hline & $\begin{array}{c}\text { Steuererträge } \\
\text { im Wohnsitzland }\end{array}$ & $\begin{array}{c}\text { Steuererträge } \\
\text { im Quellenland }\end{array}$ \\
\hline Freistellungsverfahren & $T_{W}$ & $T_{Q}$ \\
1. Source Principle & $T_{W}=t_{W}\left(P_{W}\right) P_{W}$ & \\
2. Residence Principle & $T_{W}=t_{W}(P) P$ & $T_{Q}=t_{Q}\left(P_{Q}\right) P_{Q}$ \\
Anrechnungsverfahren & $T_{W}=0$ \\
1. Vollanrechnung & $T_{W}=t_{W}(P) P-t_{Q}\left(P_{Q}\right) P_{Q}$ & $T_{Q}=t_{Q}\left(P_{Q}\right) P_{Q}$ \\
2. Teilanrechnung & $t_{W}(P) P_{W}+\left\{t_{W}(P)-t_{Q}\left(P_{Q}\right)\right\} P_{Q}$ & \\
Halbanrechnung/ & $T_{W}=t_{W}(P) P_{W}$ \\
Halbfreistellung & $=t_{W}(P) P_{W}+\left\{t_{W}(P)-\frac{1}{2} t_{Q}\left(P_{Q}\right)\right\} P_{Q}$ & \\
im Quellenland & & \\
\hline
\end{tabular}

1 Vorschlag von Krause-Junk, Gerold, Überlegungen zu einem künftigen europäischen Körperschaftsteuersystem, in Konjunkturpolitik, Heft 5/6 (1988), S. 268 ff.

Zur Vorbereitung der Fragestellung, ob sich Steuerkonkurrenz um Direktinvestitionen lohnt, soll die Verteilung der Steuererträge in Abhängigkeit der vereinbarten Doppelbesteuerungsverfahren dargestellt werden. Aus folgender Tabelle 3.3 wird diese Verteilung ersichtlich.

Betrachtet man zunächst die Steuererträge des Quellenlandes, dann wird ersichtlich, daß bei Anwendung des Residence Principles im Quellenland keine Steuern anfallen, weil dieses Land auf die Besteuerung von Erträgen aus Vermögen (Sachanlagen oder Finanzanlagen bzw. Direktinvestitionen oder Portfolioinvestitionen) im Eigentum von Ausländern verzichtet. In den anderen einschlägigen Doppelbesteuerungsverfahren müssen Erträge im Quellenland unabhängig vom Wohn- oder Gesellschaftssitz des Vermögensbesitzers voll versteuert werden.

Was die Steuererträge des Wohnsitzlandes anbetrifft, erhält dieses alle Steuern auf Erträ- 
ge aus Kapitalvermögen unabhängig vom Ort der Ertragsentstehung bei Anwendung des Residence Principles. Nach dem Source Principle erhält es lediglich Steuern aus Erträgen, die auch im Land selbst erwirtschaftet werden. Dies gilt auch für das Teilanrechnungsverfahren. Allerdings fallen hierbei im Falle von Steuerprogression höhere fiskalische Erträge aufgrund des Progressionsvorbehaltes an. Bei Teilanrechnung wird somit bei progressivem Tarif die Muttergesellschaft schlechter gestellt als beim Source Principle, und zwar nicht nur wegen einer höheren steuerlichen Belastung, sondern auch aufgrund höherer Informationsbeschaffung und Informationsverbeitungskosten. Bei Anwendung der Vollanrechnung ist das Ergebnis nicht eindeutig. Ist das Wohnsitzland im Vergleich zum Quellenland ein Hochsteuerland $\left(t_{W}(P)>t_{Q}\left(P_{Q}\right)\right)$, dann greift das Wohnsitzland auch noch auf die im Quellenland erwirtschafteten Erträge bei der Besteuerung der Muttergesellschaft teilweise durch. Im umgekehrten Fall (das Wohnsitzland ist Niedrigsteuerland) verzichtet es wegen der Vollanrechnung auf Steuererträge. Der Vorschlag von Krause-Junk stellt das Wohnsitzland im Vergleich zur Vollanrechnung besser und das Quellenland schlechter.

Wie bereits dargestellt, lohnt sich im Falle des Residence Principles und der Vollanrechnung Steuerkonkurrenz um grenzüberschreitende Investitionen nicht. Denn unabhängig von der Höhe des effektiven Steuersatzes im Quellenland wird ein Direktinvestor dort im ersten Fall überhaupt nicht besteuert und im zweiten Fall kann er alle dort gezahlten Steuern auf seine Steuerschuld im Wohnsitzland anrechnen. Die Entscheidungen über Investitionen resp. die räumliche Verteilung von Direktinvestitionen werden unabhängig von der Höhe der effektiven Steuersätze in allen anderen Ländern getroffen. Steuerkonkurrenz lohnt sich fiskalisch auch nicht um den Sitz von Geschäftsleitungen, oder sie ist wegen der Gefahr eines Steuer-Dumpings um Schreibtischstandorte nutzlos, weil dieses Steuer-Dumping keinem Land Vorteile bringen wird. Das Residence Principle und das Verfahren der Vollanrechnung sind beide kapitalexportneutral, d. h. sie sind beide auch bei unterschiedlichen Steuersystemen mit supranationaler Effizienz, nicht aber mit national effizienter Kapitalallokation vereinbar.

Steuerkonkurrenz um grenzüberschreitende Investitionen (Direktinvestitionen) lohnt sich also nur im Falle des Source Principles und der echten Teilanrechnung. In beiden Fällen nämlich werden die Erträge aus Kapitalanlagen am Ort ihrer Entstehung besteuert, wobei das Teilanrechnungsverfahren wegen des Progressionsvorbehaltes für das Wohnsitzland fiskalisch ergiebiger ist. In beiden Fällen wird importiertes Kapital steuerlich gleich behandelt, nicht aber die Erträge aus dem am Wohnsitz der Muttergesellschaften investierten Kapital. Steuersatzdifferentiale zwischen den Ländern sind unvereinbar mit supranational effizienter Kapitalallokation. 


\subsubsection{Steuerkonkurrenz um grenzüberschreitende Investitionen}

Es sollen die Bedingungen dargestellt werden, unter denen sich Steuerkonkurrenz um grenzüberschreitende Investitionen lohnt. Nach dem Source Principle gilt für das Steueraufkommen im Wohnsitzland

$$
T_{W}=t_{W}\left(P_{W}\right) \cdot P_{W}=t_{W}\left(P_{W}\right) \cdot r_{W} \cdot K_{W}
$$

mit $r_{W}=$ Durchschnittsrendite.

Da $P_{W}=r_{W} \cdot K_{W}$ ist, gilt für die Wachstumsrate der Gewinne im Wohnsitzland

$$
\hat{P}_{W}=\hat{r}_{W}+\hat{K}_{W}=\hat{K}_{W}\left(1+\frac{\hat{r}_{W}}{\hat{K}_{W}}\right)=\left(1-\epsilon_{r}\right) \hat{K}_{W}
$$

Bei kontinuierlicher Entwicklung entspricht die Wachstumsrate des steuerlichen Einkommens im Wohnsitzland der Summe der Wachstumsraten aus der durchschnittlichen Bruttorendite und dem Kapitalstock. Falls die Bruttorendite mit gleicher Rate abnimmt wie der Kapitalstock wächst, d. h. die Rendite-Kapital-Elastizität ist absolut gleich eins, steigt mit wachsendem Kapitalstock das zu versteuernde Einkommen nicht. Reagiert die Durchschnittsrendite auf Veränderungen des Kapitalstocks unelastisch, sei also $\left|\epsilon_{r}\right|<1$, dann nimmt das zu versteuernde Einkommen mit wachsendem Kapitalstock zu; es gilt

$$
\hat{P}_{W}>0 \text { für } \quad \hat{K}_{W}>0
$$

Nun ist die Steueraufkommenselastizität definiert durch

$$
\epsilon_{T}=\frac{t_{W}^{\prime}}{t_{W}}=\frac{\hat{T}_{W}}{\hat{P}_{W}}
$$

Diese Elastizität ist bei proportionalem Tarif gleich eins und bei progressivem Tarif größer eins, so daB in beiden Fällen mit wachsendem steuerpflichtigen Einkommen auch das Steueraufkommen wächst. Senkt das Wohnsitzland den Grenzsteuersatz oder den Durchschnittssteuersatz, dann steigt c. p. die Nettorendite des eingesetzten Kapitals. Denn es gilt ja

$$
\begin{aligned}
& r_{W}^{\text {netto }}=\left(1-t_{W}^{\prime}\left(P_{W}\right)\right) \cdot r_{W} \\
& r_{W}^{\text {netto }}=\left(1-t_{W}\left(P_{W}\right)\right) \cdot r_{W}
\end{aligned}
$$

für progressiven bzw. proportionalen Tarif. Nach obigem Gewinnmaximierungskalkül werden international tätige Investoren vermehrt Kapital im Wohnsitzland einsetzen, wenn dort die Nettorendite steigt, so daß unter den obigen Annahmen die Steuererträge zunehmen werden. 
Die Reform der Unternehmenssteuern in Form von effektiven Steuersatzsenkungen finanziert sich von selbst, weil durch diese steuerliche Entlastung der Unternehmenserträge grenzüberschreitende Investitionen attrahiert werden. Die Steuerreform zielt nicht auf die Grenzinvestitionen, sondern auf die grenzüberschreitenden Investitionen. Die gleichen Ergebnisse gelten auch für das Teilanrechnungsverfahren, da

$$
T_{W}=t_{W}(P) \cdot P_{W}=t_{W}(P) \cdot r_{W} \cdot K_{W}
$$

ist. Zusammengefaßt lohnt sich c. p. internationale Steuerkonkurrenz um Direktinvestitionen, wenn die Nationalfiski das Source Principle oder das echte Teilanrechnungsverfahren anwenden, wenn der Tarif proportional oder progressiv ist, wenn die Investoren frei sind von Steuersatzillusion und wenn die Zinssatz-Investitionsraten-Elastizität absolut kleiner als eins ist. Aber ceteris ist nicht paribus, wenn die Ausgaben der offentlichen Haushalte in die Infrastruktur die durchschnittliche Bruttorendite beeinflussen.

Durch diese Steuerkonkurrenz werden nach verbreiteter Ansicht dem Leviathan „SteuerStaat" nicht nur die Flügel gestutzt, so daß er zu effizienter, mindestens aber sparsamer Haushaltsführung gezwungen werde, sondern durch die Konkurrenz der Nationalfiski um die Fiskalquellen, d. h. um die ertragbringenden Sachanlagen, werde auch eine Angleichung der Steuersysteme erreicht, und damit eine supranational effiziente Kapitalallokation im privaten Sektor. Diese Angleichung der Steuersysteme entspränge letztlich den Präferenzen der Bürger, die unter den gegebenen Rahmenbedingungen von internationaler Steuerkonkurrenz und international mobilen Kapitals ihre Entscheidungen über das nationale Steuersystem rational treffen. Eine Harmonisierung oder gar Egalisierung der Steuern und die Aufgabe der nationalstaatlichen Steuersouveränität zugunsten einer - aus der Sicht der Bundesrepublik Deutschland - vierten Ebene im Europäischen Binnenmarkt müßte nicht einmal als Preis einer derartigen Reformstrategie gezahlt werden. Die zu problematisierende Frage ist jedoch, ob dieses optimistische Theorie-Szenario plausibel und realistisch ist.

Die Plausibilitätsprüfung muß an zwei zentralen Gliedern der obigen Argumentationskette ansetzen. Zum einen ist die empirische Relevanz der investitionstheoretischen Grundlage, d. h. der Zusammenhang zwischen Rendite und Kapitalakkumulation zu prüfen, wobei u. a. die Annahmen über konvexe Anpassungskosten in Zeit und Raum, unbeschränkte Finanzierungsmöglichkeiten, über die Homogenität von Kapitalgütern sowie über aggreggierte Produktionsfunktionen eingehend erörtert werden müssen. Die Kritik der modernen Investitionstheorie in Kapitel 1 des Berichts zeigt, daß eine systematisch und konsistent begründete mikro- und makroökonomische Investitionstheorie nicht existiert bzw. die vorherrschende Theorie empirisch irrelevant ist (Vgl. Barens 1992). Zweitens ist die Annahrne, daß die Bruttorendite privater Kapitalanlagen unabhängig ist von der Bereit- 
stellung öffentlicher Güter, zu problematisieren. Eine entsprechende Problemstudie ist in Arbeit und soll in nächster Zeit abgeschlossen werde. (Vgl. u. a. auch Munnell 1992). Außerdem kann gezeigt werden, daß effiziente Allokation bei Steuer-Ausgaben-Konkurrenz der Nationalfiski wesentlich von ihrer Fiskalautonomie abhängt. Kommt man schließlich zu dem Ergebnis, daß in der Realität die Finanzintermediäre die Investitionsmöglichkeiten durch Kreditrationierung maßgeblich beeinflussen, dann müssen die Wirkungen der Steuersysteme auf die Finanzierungspotentiale der privaten Investoren weitergehend untersucht werden. Die in Kapitel 2 exemplarisch vorgestellte international vergleichende Veranlagungssimulation einer real existierenden Unternehmung bestärkt die Vermutung, daß die national unterschiedlichen Steuersysteme einen merklichen Einfluß auf die Finanzierungspotentiale multinationaler Gesellschaften haben.

\subsubsection{Steuerharmonisierung als Grundlage supranational optimaler Kapita- lallokation}

Im Falle des Source Principles und des Teilanrechnungsverfahrens findet man - wie bereits dargestellt - für gewinnmaximierende Muttergesellschaften folgende Ausdrücke für die Nettorenditen im Wohnsitz- und Quellenland.

Source Principle:

$$
\begin{aligned}
& r_{W}^{\prime \text { netto }}=r_{W}^{\prime}\left\{1-t_{W}\left(P_{W}\right)\left(1+\epsilon_{t}\right)\right\}=r_{W}^{\prime}\left(1-t_{W}^{\prime}\left(P_{W}\right)\right) \\
& r_{Q}^{\prime}{ }^{\text {netto }}=r_{Q}^{\prime}\left\{1-t_{Q}\left(P_{Q}\right)\left(1+\epsilon_{t}\right)\right\}=r_{Q}^{\prime}\left(1-t_{Q}^{\prime}\left(P_{Q}\right)\right)
\end{aligned}
$$

Teilanrechnung:

$$
\begin{aligned}
& r_{W}^{\prime \text { netto }}=r_{W}^{\prime}\left\{1-t_{W}(P)-\frac{P_{W}}{P}\left[t_{W}^{\prime}(P)-t_{W}(P)\right]\right\} \\
& r_{Q}^{\prime \text { netto }}=r_{Q}^{\prime}\left\{1-t_{Q}^{\prime}\left(P_{Q}\right)-\frac{P_{W}}{P}\left[t_{W}^{\prime}(P)-t_{W}(P)\right]\right\}
\end{aligned}
$$

Die Muttergesellschaft maximiert ihren Gewinn, wenn die notwendigen Bedingungen für ein Maximum erfüllt sind, $d$. h. es muß gelten

$$
\begin{aligned}
& r_{W}^{\prime \text { netto }}=i_{W}^{\text {netto }} \\
& r_{Q}^{\prime \text { netto }}=i_{Q}^{\text {netto }}
\end{aligned}
$$

Bei international gleichen Nettozinssätzen auf vollkommenen Kapitalmärkten resultiert somit die Gleichheit der Nettorenditen als notwendige Voraussetzung für die betrieblich optimale räumliche Kapitalallokation. Aus obigen Gleichungen ist nun ersichtlich, daß die Otto Roloff, Sibylle Brander, Ingo Barens and Claudia Wesselbaum - 978-3-631-75210-4 
Bruttorenditen bei unterschiedlichen effektiven Steuersätzen an den beiden Standorten voneinander abweichen. In dem Land mit der höheren Bruttorendite bzw. mit dem höheren effektiven Steuersatz wird ein höherer Ertrag vor Steuern pro eingesetzte Kapitaleinheit erwirtschaftet. Bei gleichen effektiven Steuersätzen könnte also durch die Reallokation des Kapitals in das Land mit der höheren Bruttorendite ein insgesamt höherer Ertrag erzielt werden. Aber Steuerharmonisierung ist nicht - wie bereits erwähnt - in jedem Fall notwendige Voraussetzung für supranational effiziente Kapitalallokation, wie z. B. beim Residence Principle und Vollanrechnungsverfahren. Auch im Fall der echten Teilanrechnung ist Harmonisierung nicht notwendig für supranational effiziente Allokation, falls in den Vergleichsländern nicht lineare Tarife gelten. Denn bei progressivem Tarif ist es hinreichend, wenn der durchschnittliche effektive Steuersatz im Wohnsitzland c. p. dem effektiven Grenzsteuersatz im Quellenland entspricht. Die Angleichung der Steuersysteme ist somit nur im Fall des Source Principles c. p. notwendig für supranational effiziente Kapitalallokation. Aber der Preis für diese Angleichung ist der Verlust an Steuersouverānitāt der Nationalfiski.

Zu hinterfragen ist bei dieser Argumentation die c. p. Klausel. Denn sie besagt, daß die Bruttorendite unabhängig vom Steuersatz ist. Diese Annahme ist aber nicht plausibel. Die Muttergesellschaft vergleicht in ihrer Investitionsrechnung Kosten und Erträge aus dem zusätzlichen Kapitaleinsatz an den verschiedenen Standorten. Ein steigender Steuersatz erhöht zwar die Kosten des Investors, aber wenn aufgrund zusätzlicher Staatsausgaben in die öffentliche Infrastruktur die Grenzproduktivität des eingesetzten privaten Kapitals zunimmt, dann können die höheren Steuerlasten durch steigende Erträge überkompensiert werden. Ein hoher (niedriger) Steuersatz ist somit weder hinreichende noch notwendige Voraussetzung für eine geringere (höhere) Investitionsneigung.

Im Gegensatz zum privaten Investor sind für den Fiskus Steuern Erträge. Wenn ein öffentlicher Haushalt durch zusätzliche Ausgaben für die Standortpflege zusätzliche Einnahmen erzielt, weil die Erträge der Unternehmungen bei verbesserter Infrastruktur steigen, und wenn diese zusätzlichen Einnahmen ihm auch tatsächlich zufließen, dann wird er grundsätzlich bestrebt sein, Steuermehreinnahmen wachstums- oder produktivitätssteigernd einzusetzen. Voraussetzung für eine derartige Politik ist jedoch die Einnahmen- und Ausgabenautonomie dezentraler öffentlichen Haushalte. Denn anderenfalls haben sie kein Interesse an einer Ertragsteigerung der örtlich ansässigen Unternehmungen, und deshalb auch nicht an der pfleglichen Behandlung von Standorten. Wenn also die nationalen oder regionalen Fiski durch die Angleichung oder Harmonisierung von Unternehmenssteuern ihre Finanzautonomie verlieren, dann verlieren sie auch das Interesse an einer wachstumsoder produktivitätsfördernden Infrastrukturausstattung der Standorte in ihrem Hoheitsoder Verwaltungsbereich. Öffentliche Ressourcen werden in dem Fall vermutlich weniger effizient und eher verschwenderisch verausgabt, so daß die gesamtwirtschaftliche Produk- 
tivität und das gesamtwirtschaftliche Wachstum beeinträchtigt werden. Die Aufgabe der nationalstaatlichen Steuerhoheit zugunsten von supranational effizienter Kapitalallokation kann sich dann in ihr Gegenteil kehren.

Nun könnte man dieses Argument noch verstärken, weil ja oben bereits gezeigt wurde, daß bei unelastischer Reaktion der Durchschnittsrendite auf vermehrten Kapitaleinsatz Steuersenkungen vermehrte Fiskaleinnahmen hervorbringen. Trotz geringerer Steuerbelastung der Investoren könnte dann auch der Fiskus ggf. mehr Mittel für die Pflege der Standorte und die Steigerung der Produktivität des privaten Kapitals einsetzen. Diese Argumentation ist aber nur dann stichhaltig, wenn sich theoretisch ein eindeutiger und stabiler Zusammenhang von Zinssatz und Kapitalakkumulation nachweisen läßt, und die Steuermehreinnahmen aus der Reallokation des Kapitals nicht unter Berücksichtigung neu hinzugezogener Zensiten per saldo durch die Mindereinnahmen aus der Entlastung der ansässigen Zensiten neutralisiert werden. Dieser Nachweis konnte jedoch bis heute nicht erbracht werden, was häufig in der steuertheoretischen Diskussion übersehen wird. Deshalb wird hier eher der begründeten Vermutung gefolgt, daß Steuern c. p. zwar auch die Investitionsneigung (Rentabilitätsbedingung), aber vor allem nachhaltig die Investitionsfähigkeit (Finanzierungsbedingung) beeinflussen. Außerdem können Ausgaben dezentraler Gebietskörperschaften zum Ausbau, zur Pflege und zur Modernisierung der Infrastruktur eher die Rentabilität des privaten und öffentlichen Kapitaleinsatzes verbessern als Steuersenkungen. Diese Thesen müßten selbstverständlich ausführlicher begründet werden, und zwar muß die Bedeutung öffentlicher Ausgaben in die Infrastruktur auf die gesamtwirtliche Produktivität in einem finanzföderalistischen Model der Steuer-Ausgaben-Konkurrenz theoretisch fundiert werden. 


\section{Kapitel 4:}

\section{Direktinvestitionen und ihre statistische Erfassung}

In fast keiner quantitativ-empirischen Arbeit zu Direktinvestitionen fehlt die Bemerkung, daß die bei der statistischen Erfassung von Direktinvestitionen zugrunde gelegten Konzeptionen und Methoden zum Teil von Land zu Land unterschiedlich sind und die für Direktinvestitionen ausgewiesenen Daten deshalb im allgemeinen nicht bzw. nur begrenzt international vergleichbar sind. Da ökonometrische Untersuchungen zu den Determinanten von grenzüberschreitenden Standortentscheidungen ${ }^{1,2}$ ebenso wie alle deskriptiven Darstellungen der internationalen Kapitalverflechtungen von Unternehmen oder der Direktinvestitionsströme auf verfügbare Daten angewiesen sind, beschränken sich die meisten Autoren auf diese Feststellung. Wo diese Unterschiede liegen, wird jedoch entweder gar nicht aufgezeigt oder es werden einzelne, sehr „globale“ Abweichungen herausgegriffen.

Die Kenntnis darüber, wie sich die Methoden zur statistischen Erfassung von Direktinvestitionen zwischen den Ländern unterscheiden, trägt zum einen zur Verbesserung der Interpretation der Direktinvestitionsstatistiken bei; zum anderen zeigt sie aber auch, daß die Datenlage es nicht erlaubt, aussagefähige quantitativ-empirische Untersuchungen durchzuführen. Dies gilt nicht nur für internationale Querschnittsuntersuchungen. In einigen Ländern sind die nationalen Daten nicht einmal intertemporär vergleichbar - mit der

${ }^{1}$ Einen Überblick über die verschiedenen theoretischen Erklärungsansätze für Direktinvestitionen geben u. a. Agarwal (1980), Agarwal et al. (1991, S. 5 ff.), Braun (1988), Casson (1987, ch. 1 und 2), Caves (1982, ch. 1 und 2), Dunning (1988a; 1988b, ch. 1 und 2; 1988c), Jahrreiß (1984), McClintock (1988), Rugman (1986) und Stehn (1992, S. 17 ff.). Die empirischen Studien zu den Determinanten von Direktinvestitionen werden z. B. von Caves (1982, ch. 1 und 2), Buckley (1985), JahrreiB (1984), Krist (1985, S. 115 ff.) und Stehn (1992, S. 17 ff.) zusammengefaßt; zur Branchenstruktur der deutschen Direktinvestitionen im Ausland vgl. Wagner (1991, S. 118 ff.). Nur wenige ökonometrische Studien untersuchen den EinfluB der Besteuerung auf grenzüberschreitende Standortentscheidungen; vgl. hierzu die Zeitreihenanalysen von Hartman (1981; 1984), Boskin/Gale (1987), Newlon (1987), Young (1988), Murthy (1989), Slemrod (1990) und Jun (1990), die Querschnittsanalysen von Snoy (1975, ch. 26 und 27) und Langkau et al. (1989, S. 56 ff.) sowie die bei Kopits (1976, S. 641 ff.) und Caves (1982, ch. 8) angegebene Literatur. Die Zeitreihenanalysen sind fast ausschließlich Modifikationen von Hartmans Modell; vgl. auch Hartman (1985).

2 Einige Autoren versuchen, die Determinanten von Direktinvestitionen mittels Unternehmensbefragungen zu erforschen. Die Ergebnisse von Unternehmensbefragungen zu den Motiven von Direktinvestitionen, die in Form von Fragebogenaktionen und/oder Interviews durchgeführt werden und meist auf einer sehr geringen Anzahl von Antworten beruhen, sollten wegen der mit dieser Art von empirischer Studie verbundenen, hinreichend bekannten Problemen mit Vorsicht interpretiert werden. Einen Überblick über die Ergebnisse dieser Unternehmensbefragungen, in denen selten explizit nach dem Einfluß der Besteuerung gefragt wird - anders z. B. BeyfuB/Kitterer (1990) -, sondern meist nur neben einer Vielzahl anderer Motive das Gewinnmotiv erscheint, geben Jahrreiß (1984, S. $48 \mathrm{ff}$. und $278 \mathrm{ff}$.), Pott (1983, S. $33 \mathrm{ff}$.) und Snoy (1975, ch. 28). Zur Kritik an empirischen Studien, die mittels Unternehmensbefragungen die Determinanten von Direktinvestitionen erforschen wollen, vgl. z. B. Kallen (1987, S. 139 ff.). 
Folge, daß für diese Länder auch Zeitreihenanalysen problematisch erscheinen.

In diesem Kapitel wird der Frage nachgegangen, was die in den amtlichen Statistiken verschiedener Länder ausgewiesenen Daten für Direktinvestitionen eigentlich messen. Ziel ist also nicht die Entwicklung eines Verfahrens zur „idealen“ statistischen Erfassung von Direktinvestitionen, denn „Datenschutzbestimmungen, monopolistisches Verhalten von Datensatzbesitzern und Budgetrestriktionen des Untersuchenden [lassen] jegliches Nachdenken über den idealerweise zu verwendenden Datensatz ('tief disaggregierte Daten für einen langen Zeitraum, die alle theoretischen Konstrukte fehlerfrei messen' usw.) schnell zu wenig sinnvollen Spekulationen werden“3. Auf die theoretische Abgrenzung der Direktinvestitionen von Portfolioinvestitionen wird nur kurz eingegangen, da die internationale Terminologie hier relativ einheitlich ist (Abschnitt 4.1). Problematischer als die theoretische Abgrenzung von Direktinvestitionen ist die Umsetzung von deren Definition in Zahlen. An den Überblick über die vielfältigen Unterschiede in den nationalen Erhebungs- und Datenaufbereitungsmethoden zur statistischen Erfassung von Direktinvestitionen (Abschnitt 4.2) schließt sich eine Darstellung der in der Bundesrepublik Deutschland und in den USA verwendeten Erfassungsmethoden an (Abschnitt 4.3 und 4.4). ${ }^{4}$ Den Abschluß bildet eine Zusammenstellung weiterer Argumente gegen quantitativ-empirische Studien mit aggregierten Daten für Direktinvestitionen (Abschnitt 4.5).

\subsection{Theoretische Abgrenzung der Direktinvestitionen von Portfolioinvesti- tionen}

Der International Monetary Fund (IMF) definiert in seinem Balance of Payments Manual eine Direktinvestition als ,investment that is made to acquire a lasting interest in an enterprise operating in an economy other than that of the investor, the investor's purpose being to have an effective voice in the management of the enterprise. ${ }^{\text {"5 }}$ Wesentliches Merkmal einer Direktinvestition ist also, daß dieser Typ von Kapitalanlage im Ausland „mit einem unmittelbaren Einfluß auf die Geschäftstätigkeit des kapitalnehmenden Unternehmens “6 verbunden ist bzw. dazu dient, "to acquire control of the companies in question"7.

Portfolioinvestitionen werden in der Regel nicht durchgeführt mit der Absicht, Einfluß

3 Wagner (1991, S. 16).

${ }^{4}$ Die hierbei als Referenz dienenden Definitionen von IMF und OECD sowie die Ergebnisse der Datenanalyse für die Bundesrepublik Deutschland und für die USA können an dieser Stelle nur in verkürzter Form wiedergegeben werden. Zu einer ausführlichen Darstellung vgl. Brander (1993).

5 IMF (1977, Ziff. 408). In der 3. Ausgabe seines Balance of Payments Manual verwendet der IMF (1960, S. 175) den Begriff Direktinvestition für "investment made to create or expand some kind of permanent interest in an enterprise; it implies a degree of control over its management."

6 Deutsche Bundesbank (1978, S. 31 Fn. 1); ähnlich auch Deutsche Bundesbank (1965, S. 19; 1990f, S. 80) und eurostat (1983a, S. 29; 1984a, S. 152; 1985, S. 98).

7 eurostat (1984b, S. 82). 
auf die Geschäftsführung cines anderen Unternehmens zu nehmen. Vielmehr spielen bei diesem Typ von grenzüberschreitender Kapitalanlage Überlegungen in bezug auf „marketability, income yield, possibilities for capital appreciation, tax advantages, exchange rate prospects, and safety of principal" ${ }^{8}$ eine Rolle. Verglichen werden die erwarteten Erträge verschiedener Anlageformen und -arten. Ändern sich die erwarteten Erträge, wird das Portfolio umgeschichtet. ${ }^{9}$ Direktinvestitionen dagegen reagieren kaum auf kurzfristige Änderungen von Zinssätzen und von Wechselkursen. ${ }^{10}$ Während bei Portfolioinvestitionen das Ertragsmotiv im Vordergrund steht, tritt bei Direktinvestitionen neben das Ertragsmotiv das Kontrollmotiv.

Auffällig an der Literatur ist, daß zwar für Direktinvestitionen stets das Kontrollmotiv betont wird, aber der Frage, was dem Direktinvestor eigentlich sein Einfluß auf die Geschäftstätigkeit des ausländischen Unternehmens bringt, wird kaum nachgegangen. Eine der wenigen Ausführungen zu diesem Thema findet sich beim IMF (1977, Ziff. 409): „From the viewpoint of the direct investors, enterprises often represents units in a multinational operation, the overall profitability of which depends on the advantages to be gained by deploying the various resources available to the investors in units located in different economies. Direct investors are thereby in a position to derive benefits in addition to the property income that may accrue on the capital that they invest, e.g., the opportunity to earn management fees or other sorts of income."

Fin weiterer Unterschied zwischen Direkt- und Portfolioinvestitionen besteht darin, daß letztere auf den Transfer von Kapital beschränkt sind. Direktinvestitionen dagegen können auch in Form von nicht-monetären Leistungen, z. B. Transfer von technischem know-how, in Form von physischem Kapital oder Humankapital oder in Form von Thesaurierung der in Ausland erzielten Gewinne durchgeführt werden. Im Gegensatz zu Portfolioinvestitionen setzen Direktinvestitionen ein längerfristiges Engagement des Investors voraus. Dies drückt sich teilweise auch in den Definitionen für Direktinvestitionen aus: Schaffung oder Erweiterung „of permanent"11 bzw. "lasting interest in an enterprise ${ }^{\text {"12 }}$. Für den Fall, daß die Direktinvestition die Form der Gründung eines neuen Unternehmens im Ausland hat, ist erst langfristig mit einem Gewinn zu rechnen. Infolge der „Startkosten “ dürften kurzfristig die Erträge relativ niedrig sein. Darüber hinaus sind die meisten Direktinvestitionen kaum reversibel. Eine einmal getroffene Entscheidung, die auch umgesetzt wurde,

\footnotetext{
${ }^{8}$ IMF (1960, S. 175).

9 Vgl. IMF (1977, Ziff. 409).

10 Änderungen der Kapitalmarktzinssätze können aber einen Einfluß auf die Art der Finanzierung von Direktinvestitionen - und damit auf die Höhe der statistisch ausgewiesenen Direktinvestitionen haben.

11 IMF $(1960$, S. 175).

12 eurostat (1984a, S. 152). Ähnlich auch $\S 55$ Abs. 1 und $\S 57$ Abs. 1 Außenwirtschaftsverordnung. 
ist, wenn sie kurzfristig wieder rückgängig gemacht wird, in der Regel mit sunk cost verbunden.

Einigkeit besteht zwar in der theoretischen Abgrenzung der Direktinvestitionen von Portfolioinvestitionen. Aber die Umsetzung der mehr oder weniger allgemein akzeptierten Definition einer Direktinvestition bringt zahlreiche Probleme mit sich.

\subsection{Methoden zur statistischen Erfassung von Direktinvestitionen - ein Über- blick}

Alle Versuche von IMF, UN und OECD, international vergleichbare Statistiken für Direktinvestitionen $\mathrm{zu}$ erstellen, waren (bisher) wenig erfolgreich. ${ }^{13}$ Aufgrund national unterschiedlicher Abgrenzungskriterien in bezug auf Direktinvestoren, Direktinvestitionsunternehmen und Direktinvestitionskapital sowie wegen unterschiedlicher Erhebungs- und Datenaufbereitungsmethoden lassen sich keine international vergleichbaren Statistiken für Direktinvestitionen erstellen. Die sogenannten „vergleichbaren" Statistiken können nur so gleichartig sein, wie es das primäre Datenmaterial zuläßt.

Deutlich zeigt sich dies z. B. an den von der OECD (1987, S. 58 ff.) veröffentlichten Daten, über die sie schreibt: „Nevertheless, they [the statistics] are on a quite comparable basis. " ${ }^{14}$ Bei näherer Betrachtung dieser Statistiken stellt man fest, daß die angekündigte Ergänzung fehlender Angaben durch nationale Veröffentlichungen oder aus den Zahlungsbilanzstatistiken des IMF nur zum Teil stattgefunden hat - oder eben nicht möglich war. Den Zweifel an der internationalen Vergleichbarkeit bestärken insbesondere die Daten für Japan und für die USA; beide Statistiken werden auch auf nationaler Ebene in US-\$ ausgewiesen. Die Daten für Japan beziehen sich auf am 1. April beginnende Fiskaljahre; reinvestierte Gewinne sind nicht enthalten; für die japanischen Direktinvestitionen im Ausland basieren die für die 70er Jahre ausgewiesenen Daten auf Genehmigungssummen, die für die 80er Jahre auf Notifikationswerten; die für ausländische Direktinvestitionen in Japan ausgewiesenen Daten basieren auf Zahlungsbilanzwerten (bis einschließlich 1974) bzw. auf den mit dem Ziel der Einflußnahme auf die Unternehmensleitung durchgeführten Käufen von Aktien. Die Daten für die USA sind Zahlungsbilanzwerte, sie beziehen sich auf Kalenderjahre, und sie schließen reinvestierte Gewinne ein.

Die Richtlinien des IMF (1977) für die Frstellung von Zahlungsbilanzstatistiken enthalten zwar zu verschiedenen Aspekten der Direktinvestitionen weitergehende Ausführungen,

13 Auch das Statistische Amt der Europäischen Gemeinschaften hat die zuständigen Behörden in den Mitgliedsländern gebeten, Inhalt und Methode ihrer Zahlungsbilanzstatistiken in einer von ihm vorgegebenen Form, die an die 4. Ausgabe des Balance of Payments Manual des IMF anknüpft, darzustellen. Vgl. hierzu z. B. eurostat (1983a; 1983b; 1984a; 1984b; 1985; 1986).

14 OECD (1987, S. 57). 
aber es bleiben viele praktische Probleme im Zusammenhang mit der statistischen Frfassung von Direktinvestitionen offen. ${ }^{15}$ Diese Lücke versucht die OECD (1983) zu schließcı. Mit ihrer „benchmark definition of foreign direct investment." will die OECI) "provide a detailed and precise operational or benchmark definition of direct investment against. which each country can compare its present system and say exactly how it differs ... [and] set a standard towards which it is hoped that individual countries will endeavour to move as they develop and change their statistical systems.“ ${ }^{16}$ Dieser Standard deckt sowohl Strom- als auch Bestandsgrößen ab. Die Empfehlungen der OECD für die Lösung technischer Probleme unterstellen, daß Erhebungen bei Unternehmen durchgeführt werden. Einen Bezug zu vorhandenen Direktinvestitionsstatistiken stellt die OECD (1983) jedoch nicht her. ${ }^{17}$

Sinnvoll erscheint zunächst, die in den EG-Mitgliedsstaaten, in den USA und in Japan verwendeten Erfassungsmethoden den Empfehlungen von IMF und OFC.I) zur statistischen Erfassung von Direktinvestitionen gegenüberzustellen. Die Analyse der deutschen und der US-amerikanischen Statistiken zeigt jedoch, daß dieses Vorhaben einen außcrordentlich hohen Zeitaufwand erfordert, denn hierfür ist das Studium der Primärliteratur unerläßlich. Die Sekundärliteratur, die sich mit der statistischen Erfassung von Direktinvestitionen in einem Land auseinandersetzt, auch diejenige von OECD und dem Statistischen Amt der Europäischen Gemeinschaften, berücksichtigt zahlreiche der im folgenden dargestellten Aspekte nicht. ${ }^{18}$ Darüber hinaus sind diese fast ausschließlich zeitpunktbezogenen Darstellungen meist älteren Datums; in früheren Jahren oder seither eingetretene Änderungen der Erfassungsmethoden können auf diese Weise nicht berücksichtigt werden. Schließlich bleibt noch festzustellen, daß in der Sekundärliteratur zum Teil einander widersprechende Aussagen zu finden sind. Wenn im folgenden zur Verdeutlichung der internationalen Nicht-Vergleichbarkeit der nationalen Statistiken für Dircktinvestitionen dennoch teilweise auf diese Sekundärliteratur zurückgegriffen wird, geschieht dies stets unter Vorbehalt.

15 Ziel des Balance of Payments Manual, is to recommend the standard concepts, rules, definitions, guidelines, conventions, and classification scheme that are to be employed by member countries in assembling uniform statistics for a balance of payments statement, as well as ... to assist compilers in collecting and organizing their underlying data in a systematic manner that will serve both to facilitate the analysis of countries' international economic relationships and to maximize intercountry comparability." (IMF 1977, Ziff. 2). Die 5. Ausgabe des Balance of Payments Manual ist in Vorbereitung.

16 OFCD (1983, Ziff. 7).

17 Eine überarbeitete Version der "benchmark definition of foreign direct investment" unter Einbeziehung der nationalen Erfassungsmethoden ist in Vorbereitung.

18 Für die EG-Länder und für Japan vgl. z. B. Bedford/von Saldern (1972), Boeck (1972), Ernst/Hilpert $(1990$, S. $35 \mathrm{ff}$. und $165 \mathrm{ff}$.), eurostat (1983a; 1983b; 1984a; 1984b; 1985; 1986), Holthus (1972), Joseph (1988), Julius (1990, S. 109 ff.), Julius/Thomsen (1988), Krägenau (1972; 1975; 1979; 1982; 1987), Laurin (1990), OECD (1987, S. 71 ff.), Olle/Oesterheld (1985) und Scharrer (1972). 


\subsubsection{Stromgrößen versus Bestandsgrößen}

Der Begriff Direktinvestitionen wird in der Literatur zum einen sowohl für inländische Direktinvestitionen im Ausland als auch für ausländische Direktinvestitionen im Inland verwendet, zum anderen sowohl für Bestands- als auch für Stromgrößen. Da man bei den Stromgrößen zwischen Transaktionswerten und Genehmigungssummen unterscheiden muß, können mit dem Begriff Direktinvestitionen - unabhängig von allen Meßproblemen und von den Erhebungsmethoden - völlig verschiedene Sachverhalte bezeichnet sein:

- Transaktionswerte: Direktinvestitionen, die Inländer ( $\Lambda$ usländer) während eines bestimmten Zcitraumes, in der Regel ein Kalenderjahr, im Ausland (Inland) getätigt haberl:

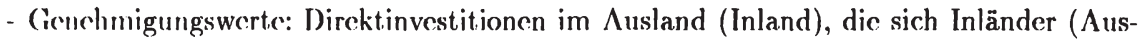
länder) während eines bestimmten Zcitraumes von den dafür zuständigen staatlichen Stellen haben genchmigen lassen; oder

- Bestandswerte: das Vermögen. das inländischen (ausländischen) Direktinvestoren im Ausland (Inland) an cinem bestimmten Stichtag, in der Regel am Jahresende, zuzurechnen ist.

Im folgenden wird - soweit es nicht der Findeutigkeit wegen erforderlich ist - nur von Direktinvestitionen gesprochen; gemeint sind damit sowohl die inländischen Direktinvestitionen im Ausland als auch die ausländischen Direktinvestitionen in Inland.

'Transaktionswerte für Direktinvestitionen sind in den meisten laändern als Unterposition der Kapitalbilanz, in der Regel der Bilanz des langfristigen Kapitalverkehrs, den Zahlungsbilanzstatistiken zu entnehmen. Ausnahmen hiervon bestehen insofern, als es zum cinen Länder gibt, deren Zahlungsbilanzstatistik keine Direktinvestitionen ausweist, ${ }^{19} \mathrm{zum}$ anderen führen einzelne Iänder verschiedene, unabhängig voneinander ermittelte Statistiken für Transaktionswerte ${ }^{20}$. Wieder andere Länder erstellen nationale und internationale Versionen ihrer Zahlungsbilanzstatistiken, in denen die Direktinvestitionen unterschiedlich erfaßt werden. ${ }^{21}$ Die ausgewiesenen 'Transaktionswerte für Direktinvestitionen sind in der Regel Nettowerte, $d$. h. Neuanlagen abzüglich Liquidationen ${ }^{22}$; manche Länder veröffentlichen nur Bruttowerte.

Die statistischen Quellen für die in den Zahlungsbilanzstatistiken ausgewiesenen Iirektinvestitionen sind nicht einheitlich. Finige länder verwenden hauptsächlich dic Infor-

\footnotetext{
19 So werden 7. B. weder in der irischen noch in der griechischen Zahlungshilanzstatistik inländische Direktinvestitionen im Ausland ausgewiesen.

20 7. B. dic Bundesrepublik Deutschland.

21 Z. B. Dänemark.

22 Der Begriff Liquidation wird im folgenden als Oberbegriff für die Veräußerung von Unternehmen(sbeteiligungen), Unternehmensauflösungen, Rückzahlungen von Krediten u. ä. verwendet.
} 
mationen, welche die für die Erstellung der Zahlungsbilanzstatistik zuständigen Stellon von inländischen Banken und anderen Finanzintermediären über dic monctären Transfers zwischen Inländern und Ausländern erhalten. Diese $\Lambda$ ufzcichnungen von Zahılungssilrömc’u werden zum Teil noch korrigiert, um nicht nur Zahlungen, sondern Transaktionen zu erfassen und um eine zeitgerechtere Zuordnung zu erreichen. ${ }^{23}$ Transaktionen müssen nicht unbedingt mit Zahlungen oder mit Zahlungen derselben Periode verbunden sein. Die durch die Erhebungsmethode bedingten statistischen Erfassungslücken können groß sein. ${ }^{24}$ In anderen Ländern finden zu den Transaktionen - mehr oder weniger regelmäßig und mehr oder weniger vollständig - Unternehmensbefragungen statt. Teilweise basicren dic ausgewiesenen Direktinvestitionen auf einander ergänzenden, aber auf unterschiedlicher rechtlicher Grundlage und von verschiedenen Institutionen durchgeführten Erhebungen. ${ }^{25}$ Einzelne Länder ${ }^{26}$ ermitteln Zahlungsbilanzwerte für Direktinvestitionen auf der Grundlage der Veränderung der jährlich bei einer Auswahl von Unternehmen erhobenen Buchwerten.

Genehmigungswerte für Direktinvestitionen sind wenig aussagekräftig. Sic geben Auskunft, über die potentiellen genehmigungspflichtigen Direktinvestitionen, die von den zuständigen Stellen genehmigt wurden. Unberücksichtigt bleiben also sowohl die Direktinvestitionen, die keiner Genehmigungspflicht unterliegen, als auch potenticlle Direktinvestitionen, für die keine Genehmigung erteilt wurde. Bei den Genehmigungswerten einer Periode bleibt zudem offen, ob die statistisch erfaßten Direktinvestitionen auch tatsächlich durchgeführt werden, und wenn ja, in welcher Periode und in welcher Höhc. ${ }^{27}$

Bej der Ermittlung von Bestandsgrößen für Direktinvestitionen kann man grundsät.zlich zwei Methoden unterscheiden: die Buchwertmethode ${ }^{28}$ und die Kumulierung von Stromgrößen. Bestandswerte, soweit sie auf den Angaben von Unternehmen über dic Buchwert. ihres Direktinvestitionskapitals beruhen, geben Auskunft über die zu historischen Anschaffungs- bzw. Herstellungkosten gemessene Kapitalverflechtung inländischer Unternehme॥ mit dem Ausland an einem Stichtag, in der Regel am Jahresende. Da Buchwerte in den meisten Fällen niedriger sind als Marktwerte und als Wiederbeschaffungskosten, stellen

${ }^{23}$ Der IMF (1977, Ziff. $30 \mathrm{ff}$.) empfichlt, in der Zahlungsbilanzstatistik ökonomische Transaktionen zu erfassen. Zur Unterscheidung zwischen transaction-based und cash-based balances vgl. eurostat (1984a, S. 135).

24 Durch die Erhebungsinethode bedingt können in der Bclgisch-Luxemburgischen Wirtschaftsunion (BLUE) beispielsweise im allgemeinen alle Transaktionen, die außerhalh des Bankensystems der BLUE stattfinden, wegen Datenmangels nicht erfaßt werden; vgl. eurostat (1984a, S. 134 f.).

25 Z. B. Großhritannicn.

${ }^{26}$ Z. B. Dänemark; Bewertungsänderungen und Änderungen infolge von Umklassifikation bleiben soweit wic möglich unberïcksichtigt.

27 Dänemark, Japan und Spanien weisen für Dircktinvestitionen sowohl Zahlungsbilanzwerte als auch Genehmigungswerte aus.

28 Bestandsstatistiken nach der Buchwertmethode werden in der Bundesrepublik Deutschland (seit. 1976), in Dänemark, in Großbritannien und in den USA erstellt; auch Frankreich (seit 1987), Italien (seit 1971) und die Niederlande (seit 1973) führen Bestandsstatistiken. 
diese Daten Mindestwerte für den Bestand an Direktinvestitionen dar. Für die USA wurden erstmals im Jahre 1991 auch $\Lambda$ ngaben über den Bestand an Direktinvestitionen in Preisen der laufenden Periode und zwar alternativ zu Wiederbeschaffungskosten und zum Marktwert veröffentlicht.

Dic Kumulierung von Stromgrößen zu einer Bestandsgröße für Direktinvestitionen kann entweder auf Transaktionswerten oder auf Genehmigungssummen bzw. Notifikationswerten basieren. ${ }^{29}$ Kumulierte Genehmigungssummen sind noch weniger aussagekräftig als aggregierte Transaktionswerte, da bei jenen nur bestimmte potentielle Direktinvestitionen berïcksichtigt werden. Bei der Interpretation kumulierter Transaktionswerte muß man insbesondere darauf achten, ob Brutto- oder Nettowerte aggregiert werden und ob der Begriff Transaktion auch fiktive Transaktionen - z. B. für die reinvestierten Gewinne - umfaßt. ${ }^{30}$ Bestandswerte für Direktinvestitionen, die durch Kumulierung von Stromgrößen ermittelt wcrden, berücksichtigen im Gegensatz zur Buchwertmethode keine Bestandsänderungen infolge von Wechselkursänderungen, Höherbewertungen, (Teil-) $\Lambda$ bschreibungen, Konkurs und Enteignung. ${ }^{31}$ Beim schrittweisen Aufbau einer Tochtergesellschaft findet keine Umklassifizierung von Portfolioinvestitionen zu Direktinvestitionen statt. Auch stellt sich anders als bei der Buchwertmethode - bei der Kumulierung von Stromgrößen das Problem der "Stunde Null": Die $\Lambda$ ggregation über alle verfügbaren Daten für die Stromgröße Dircktinvestitionen bedeutet, daß in der so crmittelten Bestandsgröße das Unternehmensvermögen, das vor Einführung einer Statistik für Direktinvestitionen gebildet wurde, nicht enthalten ist. ${ }^{32}$ Diese statistischen Erfassungslücken sind nicht quantifizierbar. Sie erst.recken sich in den verschiedenen nationalen Statistiken über unterschiedliche Zeiträume: In der Belgisch-Luxemburgischen Wirtschaftsunion (BLUE) stehen Stromgrößen für Direktinvestitionen seit dem Jahr 1965 zu Verfügung, in der Bundesrepublik Deutschland seit 1952 (für deutsche Dircktinvestitionen im $\Lambda$ usland) bzw. seit September 1961 (für ausländische Direktinvestitionen in der Bundesrepublik), in Dänemark seit 1957, in Frankreich ${ }^{33}$ scit 1960 b\%w. 1967, in Spanien seit 1960 und in Japan seit 1951.

\footnotetext{
29 Angaben ïber den Bestand an Direktinvestitionen werden in Japan durch Kurnulierung von Genehmigungswerten hzw. seit 1980 Notifikationswerten ermitt.telt.

30 In der Bundesrepublik Dentschland (bis 1976) und in Frankreich (bis 1986) werden Nettowerte, in Belgien/Luxemburg Bruttowerte - jeweils ohne reinvestierte Gewinne - aggregiert.

31 Dies gilt bei der Kumulicrung von Transaktionswerten nur insowcit, als Bewertungsänderungen nicht ïber dic reinvestierten Gewinne teilweise doch enthalten sind.

32 Werden diese statistisch noch nicht erfaßten Direktinvestitionen in einem Jahr, für das Daten für Djrektinvestitionen zur Verfügung st.chen, liquidiert, dann ist dieser Vorgang im Falle der Kumulierung von Nettot.ransaktionswerten im Bestand an Direktinvestitionen enthalten.

33 Die 'Transaktionen zwischen Frankreich (einschlicßlich ïbcrsceischer Départements und Gebiete) und den I,ändern der Franc-Zone werden in der französischen Zahlungshilanzstatistik erst seit 1967 erfaßt; vgl. hierzu curostat (1981b, S. 67), Bedford/von Saldern (1972, S. 326 ff.) und von Saldern (1973, S. $17 \mathrm{ff}$.).
} 


\subsubsection{Abgrenzung von Inländern und Ausländern}

Im Zusammenhang mit der Abgrenzung von Inländern und Ausländern verwendet der IMF den Begriff „Wirtschaft”: „(A)n economy comprises the economic entities - the government, individuals, private nonprofit bodies, and enterprises - that have a closer association with the territory in question than with any other territory. "34 Der IMF definiert Inländer also durch ihre Beziehung zum Territorium einer Wirtschaft. ${ }^{35}$ Die öffentlichen Stellen eines Landes auf allen Verwaltungsebenen, einschließlich diplomatischer, konsularischer und militärischer Agenturen des Inlands im Ausland, gelten stets als Inländer. Internationale Organisationen zählen in keinem Land als Inländer. Alle natürlichen Personen, die den Mittelpunkt ihres wirtschaftlichen Interesses im Inland haben, sind unabhängig von ihrer Nationalität als Inländer zu betrachten; in der Regel genügt ein Aufenthalt von mehr als einem Jahr in dem betreffenden Land. Private Organisationen ohne Erwerbscharakter mit Sitz im Inland gelten ebenfalls als Inländer. Gemäß dem IMF sind unabhängig von den Eigentumsverhältnissen alle tatsächlichen oder fiktiven Einheiten, die auf dem Territorium dieser Wirtschaft einer geschäftlichen Tätigkeit nachgehen, Inländer: „Resident enterprises are the actual or notional units that engage in (i) production of goods and services on the territory of a given economy, (ii) transactions in land located within the territory of that economy, or (iii) transactions in leases, rights, concessions, patents, copyrights, and similar nonfinancial intangible assets issued by the government of that economy. ${ }^{\text {36 }}$ Eine rechtliche Einheit (z. B. Muttergesellschaft mit Betriebsstätte im Ausland) oder eine Einrichtung, die sich auf mehrere Wirtschaftsgebiete erstreckt (z. B. Pipeline), sind Inländer verschiedener Länder. Agenturen zählen nicht zu den Inländern.

In allen nationalen Statistiken knüpft die Abgrenzung des Inländers vom Ausländer nicht an der Nationalität einer Person oder den Eigentumsverhältnissen eines Unternehmens an, sondern am Wohnsitz oder dem gewöhnlichen Aufenthalt bzw. am Sitz oder dem Ort der Leitung. Für natürliche Personen werden zum Teil kürzere Fristen (z. B. sechs Monate in der Bundesrepublik Deutschland), zum Teil längere Fristen (z. B. zwei Jahre in Frankreich) festgesetzt. ${ }^{37}$ Größere Abweichungen vom IMF-Konzept sind in bezug auf die Erfassung von tatsächlichen oder fiktiven Einheiten, die im Inland geschäftlich tätig sind, festzustellen. Nicht in allen Lāndern werden Grundbesitz, Erwerb von Patenten und anderen Schutzrechten, Finanzierungs-Leasing, bewegliche Ausrüstungsgüter, bestimmte Montagen u. a. m. als fiktive inländische Einheiten behandelt. Bei der Abgrenzung der Direktinvestitionsunternehmen wird hierauf zurückgekommen.

\footnotetext{
${ }^{34}$ IMF (1977, Ziff. 5); vgl. auch IMF (1977, Ziff. 26).

35 Zum folgenden vgl. auch IMF (1977, Ziff. $52 \mathrm{ff}$.).

36 IMF (1977, Ziff. 63).

${ }^{37}$ Auch die Behandlung der bei diplomatischen, konsularischen und militärischen Vertretungen des Inlands im Ausland Beschäftigten und deren Angehörigen folgt nicht in allen Ländern dem Konzept des IMF, der für diese Personen eine Sonderregelung vorsieht.
} 
Im Zusammenhang mit Erforschung und Ausbeutung von Naturschätzen des Meeres(unter)grundes ist es von Bedeutung, daß zum Inland in der Regel auch der einem Land zuzurechnende Anteil des Festlandsockels zählt.

Die Abgrenzung des Inlands vom Ausland, die ein bestimmtes Land in seiner Direktinvestitionsstatistik zugrunde legt, ist nicht immer identisch mit der in der Volkwirtschaftlichen Gesamtrechnung (VGR) dieses Landes verwendeten Abgrenzung. Gebiete und Besitzungen in Übersee werden in den Zahlungsbilanzstatistiken der meisten Länder als Inland und in der VGR als Ausland (Rest der Welt) behandelt. ${ }^{38}$ Dies ist zu beachten, wenn man - wie in allen ökonometrischen Studien zu den Determinanten vọn Direktinvestitionen - Daten für Direktinvestitionen mit Daten der VGR kombiniert. So zählen beispielsweise in der französischen Zahlungsbilanzstatistik seit dem Jahre 1967 zum Inland die Départements des Mutterlands (einschließlich Départements in Übersee), das Fürstentum Monaco, die überseeischen Gebietskörperschaften und die überseeischen Territorien mit beschränkter Selbstverwaltung; in der VGR Frankreichs dagegen ist das Inland auf das Mutterland (ohne die Départements in Übersee) und Monaco beschränkt. ${ }^{39}$ Beim Vergleich der in den jeweiligen nationalen Statistiken ausgewiesenen Direktinvestitionen zwischen zwei Ländern ist $\mathrm{zu}$ beachten, daß die Länder national unterschiedlich abgegrenzt sein können. In der deutschen Zahlungsbilanzstatistik beispielsweise ist Frankreich enger definiert als in der französischen Zahlungsbilanzstatistik; Frankreich umfaßt in der deutschen Zahlungsbilanzstatistik - ebenso wie in der französischen VGR - nur das Mutterland (ohne die Départements in Übersee) und das Fürstentum Monaco.

\subsubsection{Statistische Abgrenzung von Direktinvestor, Direktinvestitionsunter- nehmen und Direktinvestitionskapital}

Die statistische Umsetzung der Definition von Direktinvestitionen erfordert - unabhängig von der Erhebungsmethode und unabhängig davon, ob Strom- oder Bestandsgrößen ermittelt werden - eine möglichst exakte Abgrenzung der Begriffe Direktinvestor, Direktinvestitionsunternehmen und Direktinvestitionskapital. Der Kreis der Wirtschaftssubjekte, deren Investitionen in einem anderen Land potentiell Direktinvestitionen sein können, ist zu beschreiben. Es ist aufzuzeigen, wann das Kriterium der Einflußnahme des Direktinvestors auf die Geschäftstätigkeit eines Unternehmens in einem anderen Land als erfüllt anzusehen ist, wann also ein Investor zu einem Direktinvestor und ein Unternehmen zu einem Direktinvestitionsunternehmen wird. Dabei geht es auch um die Frage, inwieweit Gruppen von Unternehmen oder Privatpersonen als ein Wirtschaftssubjekt betrachtet werden und inwieweit mittelbare Unternehmensbeteiligungen berücksichtigt werden. Die Kapitalströme zwischen Direktinvestor und Direktinvestitionsunternehmen bzw. die ei-

\footnotetext{
38 Der IMF (1977, Ziff. 52) stellt es frei, diese Gebiete als eigene Volkswirtschaften zu behandeln.

39 Vgl. eurostat (1984b, S. 67, 72 und 93).
} 
nem Direktinvestor zuzurechnenden Vermögensbestände einer Tochtergesellschaft, die als Direktinvestitionen zu betrachten sind, also das zu erfassende Direktinvestitionskapital, sind abzugrenzen.

\subsubsection{Direktinvestor}

Die OECD (1983, Ziff. 12) definiert einen Direktinvestor ${ }^{40}$ als „an individual, an incorporated or unincorporated public or private enterprise, a government, a group of related individuals, or a group of related incorporated and/or unincorporated enterprises which has a direct investment enterprise - that is, a subsidiary, associate or branch - operating in a country other than the country or countries of residence of the direct investment investor or investors." Als Direktinvestoren kommen also alle Wirtschaftssubjekte sowie Gruppen verbundener Privatpersonen und verbundener Unternehmen in Betracht. So weit ist der Kreis der potentiellen Direktinvestoren in keiner nationalen Statistik gefaßt.

Die Auslandsinvestitionen inländischer öffentlicher Stellen zählen in vielen Ländern ${ }^{41}$ a priori nicht zu den Direktinvestitionen, mit der Begründung, daß deren Investitionen im Ausland meist aus anderen Motiven als dem der Einflußnahme auf die Geschäftstätigkeit eines anderen Unternehmens erfolgen. Der Kreis der potentiellen Direktinvestoren ist also häufig auf den privaten Sektor beschränkt. Inwieweit hierzu neben privaten Unternehmen und Privatpersonen auch öffentliche Unternehmen zählen, ist international unterschiedlich. So zählen beispielsweise in der Bundesrepublik ${ }^{42}$, in Großbritannien ${ }^{43}$ und in den USA auch die öffentlichen Unternehmen zu den potentiellen Direktinvestoren, nicht aber in der BLUE und in Griechenland. In Dänemark und m. E. in Großbritannien werden durch die Erhebungsmethode bedingt, Auslandsinvestitionen inländischer Privatpersonen nicht erfaßt.

In einzelnen Ländern bleiben - durch die statistischen Erhebungsmethoden bedingt - die Direktinvestitionen einzelner Wirtschaftszweige generell unberücksichtigt. Die in der britischen Zahlungsbilanzstatistik ausgewiesenen Direktinvestitionen enthalten keine Ölgesellschaften, und in der britischen Bestandsstatistik werden Ölgesellschaften, Banken und Versicherungsunternehmen nicht erfaßt. ${ }^{44}$

\footnotetext{
40 Die Definition des IMF (1977, Ziff. 408) ist wenig hilfreich zur Abgrenzung des Kreises der potentiellen Direktinvestoren: „The foreign entity or group of associated entities that makes the investment".

41 Z. B. in der BLUE, der Bundesrepublik, Frankreich, GroBbritannien, Griechenland und den USA.

42 Ausgenommen öffentliche Unternehmen ohne eigene Rechnungslegung.

43 Ohne Commonwealth Development Corporation.

44 Vgl. z. B. eurostat (1983a, S. 35) und OECD (1987, S. 159 ff.).
} 


\subsubsection{Direktinvestitionsunternehmen}

Ausgehend vom deutschen Außenwirtschaftsrecht, das zwischen Unternehmen, Zweigniederlassungen und Betriebsstätten unterscheidet, ist für alle Unternehmen, unabhängig von deren Rechtsform (mit Ausnahme der Einzelunternehmen) zu operationalisieren, wann das Kriterium der Einflußnahme eines Investors auf die Geschäftstätigkeit eines Unternehmens in einem anderen Land als erfüllt anzusehen ist, wann also ein Wirtschaftssubjekt, das in einem anderen Land investiert, als Direktinvestor und das kapitalnehmende Unternehmen als Direktinvestitionsunternehmen zu betrachten ist. ${ }^{45}$ Die in gewissem Umfang selbständigen Zweigniederlassungen und die Betriebsstätten sind Teile der Muttergesellschaft und gehören dieser damit definitionsgemäß zu $100 \%$. Die angelsächsische Literatur unterscheidet zwischen körperschaftlich organisierten und nicht-körperschaftlich organisierten Direktinvestitionsunternehmen. Zu letzteren zählen Einzelunternehmen, Personengesellschaften (darunter auch joint ventures), Zweigniederlassungen, Betriebsstätten oder Geschäftsstellen. Diese Unterscheidung läuft auf eine Differenzierung zwischen Unternehmen mit und Unternehmen ohne eigene Rechtspersönlichkeit hinaus. Obwohl im folgenden häufig von körperschaftlich und nicht-körperschaftlich organisierten Direktinvestitionsunternehmen die Rede sein wird, erscheint diese Trennung im Zusammenhang mit der Abgrenzung von Direktinvestitionen nicht besonders geeignet, denn die nicht-körperschaftlich organisierten Direktinvestitionsunternehmen umfassen zum einen Unternehmen, an denen ein (Direkt-)Investor mit weniger als $100 \%$ beteiligt sein kann, also nicht-körperschaftlich organisierte Unternehmen, bei denen zu entscheiden ist, ob sie als Direktinvestitionsunternehmen gelten oder nicht, zum anderen Zweigniederlassungen, Betriebsstätten oder Geschäftsstellen, die definitionsgemäß in 100\%igem Eigentum der Muttergesellschaft sind.

Der Begriff Direktinvestitionsunternehmen (Synonyme: Tochtergesellschaft und Tochterunternehmen) wird im folgenden als Oberbegriff für alle Betriebe verwendet, auf deren Geschäftsleitung ein Wirtschaftssubjekt eines anderen Landes Einfluß nehmen kann, d. h. sowohl für Unternehmen mit oder ohne eigene Rechtspersönlichkeit als auch für Zweigniederlassungen und Betriebsstätten, die wegen ihrer rechtlichen Eingliederung in das Mutterunternehmen keine Tochtergesellschaften im engeren Sinne sind. Die hier als Synonyme benutzten Begriffe Direktinvestor und Muttergesellschaft werden für alle Investoren verwendet, deren Vermögensanlage in einem anderen Land als Direktinvestition gilt. Direktinvestor und Direktinvestitionsunternehmen bzw. Mutter- und Tochtergesellschaft sind also stets Inländer verschiedener Länder.

45 Einen Überblick über die Rechtsformen von Unternehmen in der Bundesrepublik Deutschland gibt z. B. Wöhe (1986, S. 256 ff.). Personengesellschaften besitzen im Gegensatz zu juristischen Personen (v. a. Kapitalgesellschaften) keine eigene Rechtspersönlichkeit. Da sie jedoch einige für juristische Personen typische Merkmale aufweisen, spricht "man von einer 'relativen Rechtsfähigkeit' der Personengesellschaften. " (Wöhe 1986, S. 268). Diese zeigt sich im Handels- und im Steuerrecht. 
Das Kriterium der Einflußnahme des Direktinvestors auf die Geschäftstätigkeit des kapitalnehmenden Unternehmens wird in den meisten Ländern durch die Höhe der Beteiligung des Investors am Kapital dieser Gesellschaft quantifiziert. Ein Unternehmen in einem anderen Land zählt als Direktinvestitionsunternehmen, wenn der einem (Direkt)Investor zuzurechnende Anteil am Kapital oder an den Stimmrechten dieses Unternehmens mindestens so groß ist wie ein bestimmter vorgegebener Wert. Wird die Mindestbeteiligungshöhe, bei deren Erreichen bzw. Überschreiten ein Unternehmen als Direktinvestitionsunternehmen klassifiziert wird, als einziges Abgrenzungskriterium verwendet, dann besteht der Vorteil dieses Verfahrens in der leichten Handhabbarkeit. Eine aufwendige Einzelfallprüfung durch die Institution, welche die Daten für Direktinvestitionen sammelt und aufbereitet, entfällt.

Unabhängig von der genauen Höhe für die Mindestbeteiligung ist gegen diese pragmatische Vorgehensweise, der viele Länder folgen, einzuwenden, daß damit nur die juristische Dimension von Kontrolle, nicht aber deren ökonomische Dimension Berücksichtigung findet. ${ }^{46}$ Ein tatsächliches Mitspracherecht in der Geschäftsleitung wird zwar in der Regel durch eine Kapitalbeteiligung erreicht, einen allgemein gültigen Grenzwert für die Beteiligungsquote, ab der das Kriterium der Kontrolle bzw. der Einflußnahme als erfüllt anzusehen ist, kann es aber nicht geben. Denn zum einen spielt auch die Verteilung der übrigen Anteile eine Rolle. Im Prinzip ist der Aktienanteil, den man braucht, um das Management eines Unternehmens kontrollieren zu können, um so geringer, je weiter der Aktienbestand gestreut ist. Werden die sich im Streubesitz befindlichen Aktien jedoch Kreditinstituten zur Verwahrung und Verwaltung ins Depot gegeben, dann können die Banken über die Ausübung des Depotstimmrechts Einfluß in der Hauptversammlung einer Aktiengesellschaft nehmen. Zum anderen kann die Einflußnahme eines Investors auf ein anderes Unternehmen auch auf der vertraglichen Einräumung bestimmter wichtiger Kompetenzen beruhen, der Vertretung im Vorstand, im Aufsichtsrat oder in der Geschäftsführung, auf materiellen Transaktionen zwischen den Unternehmen, dem Austausch von Führungskräften, der Bereitstellung von technischen Informationen oder der Gewährung eines langfristigen Kredits zu Konditionen, die in keinerlei Beziehung zu Marktzinssätzen stehen. ${ }^{47}$ Solange die - bis zu einem gewissem Grad letztlich immer irgendwie willkürlich - festgelegte Mindestbeteiligungsquote nicht absolute Kontrolle bedeutet, kann der Direktinvestor - je nach Einzelfall - sowohl bei einer höheren als auch bei einer niedrigeren Kapitalbeteiligung als der Mindestbeteiligung (bzw. Mindestanteil am Kapital, das der Direktinvestor kontrolliert) die Möglichkeit haben, Einfluß auf das Management eines anderen Unternehmens zu nehmen oder an den Entscheidungen mitzuwirken.

${ }^{46}$ Zur Unterscheidung zwischen der juristischen und der ökonomischen Dimension von Kontrolle vgl. Eckert (1978, S. 107 ff.).

$47 \mathrm{Zu}$ den Gründen, warum nicht an einem starren Grenzwert festgehalten werden sollte, vgl. Adebahr (1981, S. 10) und OFCD (1983, Ziff. 17; 1987, S. 71). 
Im Extremfall muß der Direktinvestor überhaupt nicht an dem anderen Unternehmen beteiligt sein. ${ }^{48}$

Die OECD (1983, Ziff. 13 ff.) empfiehlt als Abgrenzungskriterium für Direktinvestitionsunternehmen die Kontrolle von $10 \%$ oder mehr der Stammaktien oder der Stimmrechte körperschaftlich organisierter Unternehmen bzw. bei nicht-körperschaftlich organisierten Unternehmen entsprechendes. ${ }^{49}$ Diese Quote sollte jedoch nur als Richtschnur dienen. ${ }^{50}$ Entscheidend ist, daß der Direktinvestor ein tatsächliches Mitspracherecht in der Geschäftsleitung des anderen Unternehmens hat. Mit anderen Worten: Kontrolliert ein Investor $10 \%$ oder mehr der Kapitalanteile eines Unternehmens in einem anderen Land, aber es ist erwiesen, daß ihm dies kein tatsächliches Mitspracherecht im Management erlaubt, dann gilt dieser nicht als Direktinvestor und jenes nicht als Direktinvestitionsunternehmen. Ein Investor, der weniger als $10 \%$ der Kapitalanteile eines Unternehmens in einem anderen Land kontrolliert, aber einen effektiven Einfluß auf die Geschäftstätigkeit dieses Unternehmens hat, ist dagegen als Direktinvestor zu behandeln und das Unternehmen in dem anderen Land als Direktinvestitionsunternehmen.

Die in den nationalen Statistiken zugrunde gelegten Untergrenzen für die Kapitalbeteiligung bzw. für den Mindestanteil an den Stimmrechten, die einem Investor zuzurechnen sein müssen bzw. die ein Investor kontrollieren muß, um als Direktinvestor zu gelten, werden von den Ländern individuell festgelegt. Für die EG-Mitgliedsländer, die USA und Japan ist festzustellen:

- Die Untergrenzen schwanken zwischen mindestens $10 \%$ und über $50 \%$.

- In einzelnen Ländern wurden die Mindestbeteiligungsquoten im Zeitablauf gesenkt.

- Für inländische Direktinvestitionen im Ausland und für ausländische Direktinvestitionen im Inland gelten nicht immer dieselben Untergrenzen.

- Zum Teil haben die festgelegten Untergrenzen nur für körperschaftlich organisierte Tochtergesellschaften bzw. nur für Aktiengesellschaften Gültigkeit, nicht aber für Direktinvestitionsunternehmen in anderer Rechtsform.

- Teilweise wurden Mindestbeteiligungsquoten erst in jüngster Zeit eingeführt.

- Einige Länder verzichten ganz auf die Festlegung einer Mindestbeteiligungsquote. Es wird in das Ermessen des meldenden Unternehmens gestellt, eine grenzüberschreitende Kapitalanlage als Direktinvestition zu qualifizieren.

- Manchmal ist die Mindestbeteiligungshöhe kein starres Kriterium, sondern es wird

48 In der Transferstatistik der Bundesministeriums für Wirtschaft war bis einschließlich dem Berichtsjahr 1989 dieser Fall mit Einschränkung berücksichtigt, denn es wurden auch Kredite erfaßt, deren Gewährung zu einem erheblichen Einfluß auf die Geschäftstätigkeit des kapitalnehmenden Unternehmens in einem anderen I,and fïhrten.

49 Die 4. Ausgabe des Balance of Payments Manual des IMF legt im Gegensatz zur 3. Ausgabe keine bestimmte Untergrenze für den Anteil des Investors am Kapital oder an den Stimmrechten fest; vgl. hierzu IMF (1960, S. $177 \mathrm{ff}$.; 1977, Ziff. $411 \mathrm{ff}$.).

$50 \mathrm{Vgl}$. OECD (1983, Ziff. 17). 
ergänzt durch das Kriterium der Schaffung oder Erweiterung dauerhafter Wirtschaftsbeziehungen. $\mathrm{Zu}$ beobachten ist auch, daß die festgelegte Mindestbeteiligungshöhe ersetzt werden kann durch die Kontrolle über das kapitalnehmende Unternehmen, was theoretisch auch bei einer Kapitalbeteiligung von $0 \%$ möglich ist.

- Gruppen verbundener Unternehmen oder Privatpersonen, die gemeinsam in einem anderen Land investieren, werden nur in einigen Ländern berücksichtigt. Festzustellen ist dabei, daß teilweise nur bei den ausländischen Direktinvestitionen im Inland wirtschaftlich verbundene Investoren als ein Wirtschaftssubjekt behandelt werden. Die Abgrenzung des Tatbestandes, wann Wirtschaftssubjekte als wirtschaftlich verbunden gelten, ist nicht einheitlich.

- Sind zwei nicht miteinander verbundene Wirtschaftssubjekte an dem selben Unternehmen in einem anderen Land beteiligt und erfüllt nur einer der beiden Investoren das Kriterium für einen Direktinvestor, der andere dagegen nicht, dann wird in einigen nationalen Statistiken letzterer auch als Direktinvestor (zum Teil aus Informationsmangel) behandelt, in anderen nationalen Statistiken dagegen als Investor, der eine Portfolioinvestition tătigt.

- Unterschiede bestehen auch in bezug darauf, wie inländische Unternehmen in ausländischem Streubesitz behandelt werden.

In einigen Ländern wurde das Verfahren zur statistischen Abgrenzung eines Direktinvestors bzw. eines Direktinvestitionsunternehmens im Zeitablauf geändert.

Der quantitative Einfluß des Abgrenzungskriteriums „Mindestbeteiligung am Stimmkapital $^{\star}$ auf die Höhe der ausgewiesenen Direktinvestitionen läßt sich nur schwer abschätzen. Aus einer durchschnittlich hohen Beteiligung der Direktinvestoren an den statistisch erfaßten Direktinvestitionsunternehmen kann man nicht auf die Höhe des nicht erfaßten Direktinvestitionskapitals schließen. Es ist dem IMF (1977, Ziff. 414) aber darin zuzustimmen, daß die Höhe der Mindestbeteiligung nicht das zentrale Problem im Zusammenhang mit der fehlenden internationalen Vergleichbarkeit der Statistiken für Direktinvestitionen ist $^{51}$ - sofern statistisch nicht ausschließlich Mehrheitbeteiligungen erfaßt werden.

Mittelbare Unternehmensbeteiligungen haben an Bedeutung gewonnen, insbesondere weil zunehmend Holdinggesellschaften als Verwaltungszentralen eingeschaltet werden. Eine mittelbare Beteiligung besteht, wenn ein (inländischer) Direktinvestor die Beteiligung an einem Unternehmen in einem anderen Land über eine andere ausländische Gesellschaft hält; dabei kann das ausländische Unternehmen, an dem die direkte Beteiligung besteht, an dem anderen ausländischen Unternehmen wiederum entweder unmittelbar oder mittelbar über andere ausländische Gesellschaften beteiligt sein. Bei mittelbaren Unter-

51 Ähnlich Julius (1990, S. 16). 
nehmensbeteiligungen ist es möglich, daß der Direktinvestor über mehrere gebietsfremde Gesellschaften, an denen er (direkt oder indirekt) beteiligt ist, Kapitalanteile an einer nachgeordneten Gesellschaft im Ausland hält. Die internationalen Kapitalverflechtungen multinationaler Unternehmen können sehr komplex sein. Da die Eigentumsverhältnisse bei Gruppen verbundener international tätiger Unternehmen nicht unbedingt die Managementverantwortlichkeiten widerspiegeln, empfiehlt die OECD (1983, Ziff. 21), alle Unternehmen, auf deren Geschäftsleitung der Direktinvestor unmittelbar oder mittelbar Einfluß nehmen kann, zu berücksichtigen. ${ }^{52}$ Das von der OECD vorgeschlagene Konzept zur Abgrenzung mittelbarer Direktinvestitionsunternehmen bedeutet, daß auch ein Unternehmen, dessen Stimmrechte die Muttergesellschaft zu weniger als $10 \%$ indirekt kontrolliert, ein mittelbares Direktinvestitionsunternehmen sein kann. Denn die OECD unterstellt, daß ein Direktinvestor, der ein tatsächliches Mitspracherecht in der Geschäftsleitung eines ihm direkt untergeordneten Unternehmens im Ausland hat, über dieses unmittelbare Direktinvestitionsunternehmen auch Einfluß auf die Geschäftsleitung mittelbarer Direktinvestitionsunternehmen nehmen kann, sofern die jeweils übergeordnete Gesellschaft Einfluß auf das ihr direkt untergeordnete Unternehmen nehmen kann. Das „Fully Consolidated System" der OECD ist symmetrisch, denn sowohl bei den inländischen Direktinvestitionen im Ausland als auch bei den ausländischen Direktinvestitionen im Inland werden sämtliche unmittelbaren und mittelbaren Direktinvestitionsunternehmen erfaßt. Es setzt jedoch Informationen über die mittelbar kontrollierten Tochtergesellschaften voraus, die nur weltweit konsolidierten Unternehmensbilanzen zu entnehmen sind.

In sehr vielen Ländern bleiben bei den Transaktionswerten für Direktinvestitionen mittelbare Beteiligungen unberücksichtigt. Da die meisten Kapitaltransaktionen zwischen Direktinvestor und dem von diesem unmittelbar kontrollierten Direktinvestitionsunternehmen stattfinden, führt die Nichtberücksichtigung der Transaktionen zwischen Direktinvestor und seinen mittelbar kontrollierten Tochterunternehmen v. a. zu einer Unterschätzung der Kapitalerträge aus Direktinvestitionen, der reinvestierten Gewinne ${ }^{53}$ und der Rentabilität von Direktinvestitionen. Mit der Einschränkung, daß das Kriterium der Einflußnahme auf die Geschäftsleitung eines anderen Unternehmens erst bei einer mindestens $20 \%$ igen Kapitalbeteiligung als erfüllt angesehen wird, wird das „Fully Consolidated System" in Großbritannien angewendet. ${ }^{54}$ In der US-Statistik (Zahlungsbilanz- und Bcstandsstatistik) gelten als Direktinvestitionsunternehmen alle Unternehmen, an denen ein Wirtschaftssubjekt (einschließlich Gruppen von Investoren) eines anderen Landes unmittelbar oder mittelbar mindestens $10 \%$ der Stimmrechte bzw. bei nicht-körperschaftlich organisierten Unternehmen eine entsprechende Beteiligung hält oder kontrolliert. In der

52 Der IMF (1977) spricht keine Empfehlung zur Abgrenzung mittelbarer Beteiligungen aus.

53 Vgl. OECD (1983, Ziff. 25).

54 Vgl. OECD (1983, Ziff. 26).

Otto Roloff, Sibylle Brander, Ingo Barens and Claudia Wesselbaum - 978-3-631-75210-4 
Bestandsstatistik der Deutschen Bundesbank werden als mittelbare Direktinvestitionsunternehmen deutscher Direktinvestoren im Prinzip alle Gesellschaften erfaßt, deren Anteile oder Stimmrechte zu mehr als $20 \%$ (vor dem Berichtsjahr 1989: mindestens $25 \%$ ) einem im Mehrheitsbesitz des Gebietsansässigen stehenden gebietsfremden Unternehmen zuzurechnen sind; mittelbare Beteiligungen Gebietsfremder im Inland werden nur berücksichtigt, wenn einer gebietsansässigen Gesellschaft, die im Mehrheitsbesitz eines Gebietsfremden steht, mehr als $20 \%$ (vor dem Berichtsjahr 1989: mindestens $25 \%$ ) der Anteile oder Stimmrechte an einem weiteren gebietsansässigen Unternehmen zuzurechnen sind, Beteiligungen gebietsansässiger Unternehmen an weiteren gebietsansässigen oder gebietsfremden Unternehmen bleiben unberücksichtigt. Weder in der Bestandsstatistik der Deutschen Bundesbank noch in der US-Statistik ist die Erfassungsmethode für inländische Direktinvestitionen im Ausland symmetrisch mit derjenigen für ausländische Direktinvestitionen im Inland, denn mittelbare Beteiligungen, die ein ausländischer Direktinvestor über eine inländische Gesellschaft an einem Unternehmen in einem Drittland hält, werden nicht sowohl bei den inländischen Direktinvestitionen im Ausland als auch bei den ausländischen Direktinvestitionen im Inland berücksichtigt. ${ }^{55}$

Da die statistische Abgrenzung der Direktinvestitionen von Portfolioinvestitionen mit Hilfe eines Mindestwerts für die Beteiligungshöhe impliziert, daß eine Kapitalanlage im Ausland bzw. des Auslands in der Statistik erst mit Erreichen oder Überschreiten dieses Grenzwertes von einer Portfolioinvestition zu einer Direktinvestition wird, erscheint diese Methode im Zusammenhang mit der Erfassung von Stromgrößen für Direktinvestitionen problematisch. Erstreckt sich der sukzessive Aufkauf einer ausländischen Aktiengesellschaft über die Börse oder die schrittweise Übernahme eines ausländischen Unternehmens über mehrere Jahre, dann werden die Zahlungen der Jahre, in denen der Anteil des Investors an dem ausländischen Unternehmen noch unter der Mindestbeteiligungshöhe war, als Portfolioinvestition ausgewiesen und in den Jahren nach Erreichen der Mindestbeteiligung als Direktinvestition. Diese Portfolioinvestitionen früherer Jahre werden - den Empfehlungen von IMF (1977, Ziff. 374(ii)) und OECD (1983, Ziff. 61) entsprechend - in der Regel nicht als Direktinvestitionen umklassifiziert, d. h., eine Umbuchung in Form von Portfolio-Disinvestition und Neuanlage von Direktinvestitionen findet nicht statt. Bei der Interpretation von Bestandsdaten, die durch die Kumulierung von Stromgrößen ermittelt werden, muß dies berücksichtigt werden. Bei der Erfassung von Direktinvestitionsbeständen mittels Buchwertmethode dagegen spielt dies keine Rolle. denn bei Überschreiten der Mindestbeteiligungsquote werden alle Kapitalanlagen im Ausland, egal in welchem Jahr sie erworben wurden, als Direktinvestitionen erfaßt.

55 Zu dieser Art von Asymmetrie vgl. OECD (1983, Ziff. 30). In der Bestandsstatistik der Deutschen Bundesbank kommt eine zweite Art von Asymmetrie hinzu: Die Abgrenzung des Direktinvestors ist für deutsche Direktinvestitionen im Ausland und für ausländische Direktinvestitionen im Inland unterschiedlich. 
Nationale Unterschiede bestehen auch in bezug darauf, inwieweit bestimmte wirtschaftliche Aktivitäten, die in einem anderen Land durchgeführt werden, als ausländische Unternehmen angesehen und damit als (fiktive) Direktinvestitionsunternehmen behandelt werden. ${ }^{56}$ Ferien- und Zweitwohnungen im Ausland (bzw. im Inland), die Inländern (bzw. Ausländern) gehören, sind in der Regel keine Direktinvestitionsunternehmen. Wenn überhaupt, dann wird nur kommerziell genutzter Grundbesitz als Direktinvestitionsunternehmen betrachtet. Mobile Anlagegüter wie Schiffe, Flugzeuge, Gas- und Ölbohrplattformen, die Inländern (bzw. Ausländern) gehören und die im Ausland (bzw. Inland) für mindestens ein Jahr eingesetzt werden, gelten teilweise als fiktive Direktinvestitionsunternehmen. Bauausführungen und Montagen, die inländische (bzw. ausländische) Unternehmen im Ausland (bzw. Inland) durchführen, zählen teils in Abhängigkeit ihrer Dauer, teils unabhängig von ihrer Dauer als fiktive Direktinvestitionsunternehmen. Erwerben Inländer (bzw. Ausländer) im Ausland (bzw. Inland) erteilte Patente oder ähnliche nicht-finanzielle immaterielle Rechte, dann wird dies meist nicht als Investition in ein Direktinvestitionsunternehmen erfaßt.

\subsubsection{Direktinvestitionskapital}

Bei Stromgrößen empfiehlt die OECD (1983, Ziff. 50), folgende Anlageformen als Direktinvestitionskapital zu berücksichtigen: ${ }^{57}$

(a) körperschaftlich organisierte Direktinvestitionsunternehmen:

- Erwerb abzüglich Veräußerung von Kapitalanteilen an dem Direktinvestitionsunternehmen (einschließlich Einbringung von Sachen und Rechten);

- Anteil des Direktinvestors an den reinvestierten Gewinnen des Direktinvestitionsunternehmens;

- Gewährung abzüglich Tilgung von Krediten; und

- Nettoveränderung der Handelskredite und anderer kurzfristiger Kredite, die der Direktinvestor dem Direktinvestitionsunternehmen gewährt hat.

(b) nicht-körperschaftlich organisierte Direktinvestitionsunternehmen:

- Zunahme der einbehaltenen Gewinne; und

- Nettozunahme an Mitteln, die der Direktinvestor zur Verfügung stellt.

Vom Volumen her sind die Unterschiede in den nationalen Statistiken insbesondere auf die abweichende Erfassung der reinvestierten Gewinne und der Kreditbeziehungen zurückzuführen. Die Literatur beschränkt sich in diesem Zusammenhang in der Regel auf die Feststellung, ob die reinvestierten Gewinne überhaupt berücksichtigt und ob neben

$56 \mathrm{Zu}$ den Empfehlungen von IMF und OECD vgl. IMF (1977, Ziff. 50, $63 \mathrm{ff}$. und 363a) und OECD (1983, Ziff. 21 (iii) und $68 \mathrm{ff}$ ).

57 Vgl. hierzu auch IMF (1977, Ziff. 416). 
langfristigen Krediten auch kurzfristige Kredite und IIandelskredite erfaßt werden. Der Empfehlung von IMF und OECD, für die Anteile der Direktinvestoren an den nichtausgeschütteten Gewinnen ihrer Direktinvestitionsunternehmen fiktive Transaktionen zu unterstellen, folgen nur wenige Länder: Bundesrepublik Deutschland ${ }^{58}$, Dänemark (seit 1974), Großbritannien und die USA. Die reinvestierten Gewinne der Tochtergesellschaften bleiben $\mathbf{u}$. a. in den amtlichen Statistiken der BLUE, von Dänemark (bis einschließlich 1973), Frankreich, Italien, Japan, den Niederlanden, Portugal und Spanien unberücksichtigt. ${ }^{59}$ In einer Reihe von Ländern zählen zum Direktinvestitionskapital nur langfristige Kredite, nicht aber kurzfristige Kredite und Handelskredite. In den USA dagegen spielt die Fristigkeit der Forderungen und Verbindlichkeiten keine Rolle. In einigen Ländern bleiben sogar die langfristigen Kredite unberücksichtigt. Die genauere Untersuchung der nationalen Erfassungsmethoden für Direktinvestitionen zeigt, daß die Feststellung, ob die amtliche Statistik eines Landes die reinvestierten Gewinne berücksichtigt oder nicht und ob neben langfristigen Krediten auch kurzfristige Kredite und Handelskredite erfaßt werden, unvollständig ist zur Charakterisierung der nationalen Erfassungsmethode.

Für die Höhe der ausgewiesenen reinvestierten Gewinne ist u. a. entscheidend, ob neben den thesaurierten Gewinnen körperschaftlich organisierter Tochtergesellschaften auch die nicht ausgeschütteten Gewinne nicht-körperschaftlich organisierter Direktinvestitionsunternehmen erfaßt werden und ob, und wenn ja, in welchem Umfang, realisierte und nicht-realisierte Vermögenszuwächse bzw. -verluste bei der als Residualgröße ermittelten reinvestierten Gewinne berücksichtigt werden. Darüber hinaus können die reinvestierten Gewinne entweder, der Empfehlung des IMF folgend, der Periode der Gewinnentstehung - z. B. US-Statistik und Bestandsstatistik der Deutschen Bundesbank - oder dem Folgejahr, dem Jahr der Gewinnverwendung - z. B. Zahlungsbilanzstatistik der Deutschen Bundesbank - zugeordnet werden. ${ }^{60}$

Im Zusammenhang mit den Kreditbeziehungen zwischen Direktinvestor und Direktinvestitionsunternehmen sind die nationalen Statistiken auch darauf hin zu prüfen, ob Kredite der Direktinvestitionsunternehmen an den Direktinvestor als Disinvestitionen oder als Portfolioinvestitionen erfaßt werden, in welchem Ausmaß die Kreditbeziehungen zwischen Direktinvestitionsunternehmen oder anderen Tochter- oder Enkelgesellschaften desselben Direktinvestors enthalten sind, in welcher Weise Kreditbürgschaften, die ein Direktinvestor für sein Direktinvestitionsunternehmen übernimmt, berücksichtigt werden und ob

\footnotetext{
58 Nur in der Zahlungsbilanzstatistik der Deutschen Bundesbank werden die reinvestierten Gewinne als Direktinvestitionskapital erfaßt, nicht aber in der Transferstatistik des Bundesministeriums für Wirtschaft.

${ }^{59}$ Für diese Länder weisen auch die Zahlungsbilanzstatistiken des IMF, zuletzt IMF (1991), keine reinvestierten Gewinne aus.

60 Vgl. hierzu auch IMF (1977, Ziff. 103, 299, 304 und 416) und OECD (1983, Ziff. 38 (a) (ii), 38 (b) (ii) und 43-49). Die Bedeutung der beiden ersten Aspekte zeigt die US-Statistik sehr deutlich.
} 
Finanzierung-Leasing sowie Operational-Leasing zwischen Direktinvestor und Direktinvestitionsunternehmen als Kredit des Leasinggebers an den Leasingnehmer und damit als Direktinvestitionskapital erfaßt werden. ${ }^{61}$

Für Kreditinstitute gilt es festzustellen, inwieweit die von IMF und OECD empfohlene Beschränkung des Direktinvestitionskapitals für diese Tochtergesellschaften auf langfristiges Kapital beachtet wird. ${ }^{62}$ In einigen Ländern umfassen die Stromgrößen für das Direktinvestitionskapital von Kreditinstituten nur Beteiligungskapital und reinvestierte Gewinne; d. h. kurz- und langfristige Verbindlichkeiten von Kreditinstituten gegenüber ihren Anteilseignern bleiben unberücksichtigt. Zu beobachten ist auch, daß sowohl die Verbindlichkeiten von Kreditinstituten als auch die Verbindlichkeiten gegenüber Kreditinstituten nicht als Direktinvestitionen erfaßt werden, also Kreditbeziehungen nur einbezogen werden, wenn Kreditgeber und Kreditnehmer Nichtbanken sind. In anderen Ländern enthält das Direktinvestitionskapital zwar die langfristigen, nicht aber die kurzfristigen Kreditbeziehungen zwischen Kreditinstituten und ihren Tochterinstituten. Die in den jeweiligen Sitzländern verwendeten Kriterien zur Abgrenzung der Kreditinstitute von Nichtbanken sind international nicht einheitlich. ${ }^{63}$

Zum Teil durch die Erhebungsmethode bedingt umfaft der Begriff Transaktion nicht in allen Ländern Verrechnung und Aufrechnung sowie Einbringung von Sachen und Rechten. Nationale Unterschiede bestehen auch in bezug darauf, inwieweit in bestimmten Fällen fiktive Transaktionen einbezogen werden. ${ }^{64} \mathrm{Da}$ es sich bei Direktinvestitionen um Transaktionen zwischen verbundenen Unternehmen handelt, besteht das Problem der Verrechnungspreise. Der Empfehlung des IMF, alle Transaktionen zu Marktpreisen zu bewerten, kann nur teilweise gefolgt werden. ${ }^{65}$

Weitere Abweichungen zwischen den nationalen Statistiken sind auf die bei der Umrechnung von Fremdwährungsbeträgen zugrunde gelegten Wechselkurse zurückzuführen. Von wenigen Ausnahmen ${ }^{66}$ abgesehen werden die Angaben für Direktinvestitionen in nationa-

${ }^{61}$ Zu den Empfehlungen vgl. IMF (1977, Ziff. 193, 415 und 363 (c)) sowie OECD (1983, Ziff. 53 f. und 56-58).

62 Als Begründung für diese Empfehlung führen IMF (1977, Ziff. 417) und OECD (1983, Ziff. 65 f.) an, $\mathrm{daB}$ Einlagen, Wechsel und kurzfristige Kredite zwischen einem Kreditinstitut und seiner Tochtergesellschaft bzw. Zweigniederlassung normale Geschäftsaktivitäten und keine Direktinvestitionen sind.

${ }^{63}$ In der Bundesrepublik ist der Kreis der Unternehmen, die als Kreditinstitute gelten, weiter als in anderen Ländern; vgl. z. B. Deutsche Bundesbank (1989a, S. 28; 1990f, S. 36).

$64 \mathrm{Vgl}$. hierzu die Empfehlung des IMF (1977, Ziff. $361 \mathrm{ff}$.).

$65 \mathrm{Vgl}$. hierzu IMF (1977, Ziff. $75 \mathrm{ff}$. und $421 \mathrm{f}$.). „Market price ... is conceived as the amount of money that a willing buyer pays to acquire something from a willing seller, when such an exchange is one between independent parties into which nothing but commercial considerations enter." (IMF 1977, Ziff. 76).

${ }^{66}$ Die japanische Statistik wird in US-\$ veröffentlicht. Mit welchem Wechselkurs die Umrechnung erfolgt, 
ler Währung veröffentlicht. ${ }^{67}$

In den meisten Statistiken für Transaktionswerte werden inländische Direktinvestitionen im Ausland und ausländische Direktinvestitionen im Inland jeweils netto, d. h. Neuanlagen abzüglich Liquidationen, ausgewiesen. ${ }^{68}$ Dabei werden aber jeweils auch dic Transaktionen von Direktinvestoren mit Nettoinvestitionen und mit Nettodisinvestitionen saldiert. ${ }^{69}$

Zur Ermittlung des Bestands an Direktinvestitionen empfiehlt die OECD ausschließlich aus praktischen Erwägungen die Buchwertmethode, denn die von ihr präferierten Wiederbeschaffungswerte für das Anlagevermögen und Marktwerte für die gehaltenen Wertpapiere sind nicht verfügbar. ${ }^{70}$ Für körperschaftlich organisierte Direktinvestitionsunternehmen sollte das Direktinvestitionskapital die Anteile der Direktinvestoren an den Buchwerten des Grund- bzw. Stammkapitals und der Rücklagen (einschließlich reinvestierter Gewinne) sowie die Nettoverbindlichkeiten der Direktinvestitionsunternehmen gegenüber ihren Direktinvestoren aus lang- und kurzfristigen Krediten, Handelskrediten und sonstigen Verbindlichkeiten ${ }^{71}$ umfassen. ${ }^{72}$ Bei nicht-körperschaftlich organisierten Direktinvestitionsunternehmen sollte sich das dem Direktinvestor zuzurechnende Nettovermögen zusammensetzen aus den Buchwerten des Anlagevermögens (nach Abschreibungen), zuzüglich den Buchwerten der Wertpapiere des Anlagevermögens und des Umlaufvermögens (ohne Forderungen an den Direktinvestor), abzüglich Verbindlichkeiten gegenüber Dritten, Rückstellungen und dem Teil des Reinvermögens, das auf andere Beteiligte entfällt. ${ }^{73}$

Bei den für den Bestand an Direktinvestitionen ausgewiesenen Daten gilt es insbesondere zu prüfen, in welcher Weise Kredite der Direktinvestitionsunternehmen an den Direktinvestor, Kredite zwischen Schwesterunternehmen und Kredite von anderen zum Konzernverbund gehörenden Unternehmen berücksichtigt werden, inwieweit das Direktinvestitionskapital für Kreditinstitute neben Eigenkapital (einschließlich reinvestierter Gewinne) auch kurz- und langfristige Kredite von Kreditinstituten und Forderungen an Kreditinstitute umfaßt und mit welchen Wechselkursen Fremdwährungsbeträge in die nationale Währung umgerechnet werden. ${ }^{74}$

\footnotetext{
ist nicht ersichtlich; vgl. Ernst/Hilpert (1990, S. 41 f.).

${ }^{67}$ Zur Währungsumrechnung vgl. auch IMF (1977, Ziff. 155 ff.) und OECD (1983, Ziff. 42 und 52).

${ }^{68}$ Dies entspricht der Enpfehlung des IMF (1977, Ziff. 419).

69 Vgl. hierzu auch die Empfehlung der OECD (1983, Ziff. 51).

70 Vgl. OECD (1983, Ziff. 33 f.).

${ }^{71}$ Einschlieblich der zur Dividendenausschüttung an den Direktinvestor bereitgestellten Beträge.

72 Grund- bzw. Stammkapital und Rücklagen der Tochtergesellschaften sollten gemessen werden als Buchwerte des Anlagevermögens (nach Abschreibungen) zuzüglich Buchwerte des Beteiligungsvermögens und sonstiger Aktiva abzüglich Verbindlichkeiten und Rückstellungen. Vgl. OECD (1983, Ziff. 31 (a)).

73 Vgl. OECD (1983, Ziff. 31 (b)).

74 Zur Währungsumrechnung vgl. OECD (1983, Ziff. 35 f.).
} 
Sowohl bei Transaktionswerten als auch bei Bestandsgrößen haben die nationalen Rechnungslegungspraktiken einen Einfluß auf die ausgewiesenen Daten für Direktinvestitionen. Das Direktinvestitionskapital kann entweder den Büchern des Direktinvestors oder den Büchern der Direktinvestitionsunternehmen entnommen werden. Nur zum Teil werden konsolidierte Bilanzen zugrunde gelegt.

Wenn die Daten für Direktinvestitionen auf der Grundlage von Unternehmensbefragungen crmittelt werden, dann ist für die Zuverlässigkeit der veröffentlichten Daten auch von Bedentung, wie häufig Unternehmensbefragungen durchgeführt werden, ob es sich dabei um Total- oder um Stichprobenerhebungen handelt, wie hoch die Meldefreigrenzen sind und auf welche $\Lambda$ rt und Weise nicht meldende Unternehmen berücksichtigt werden; die Teilnahme an den Erhebungen kann entweder freiwillig sein, oder es kann gesetzliche $\Lambda$ uskunftspflicht bestehen. In der Bundesrepublik werden die Zahlungsbilanzwerte für Direktinvestitionen und die Nettotransferleistungen grundsätzlich monatlich, die Buchwerte jährlich bei allen meldepflichtigen Unternehmen und Privatpersonen erhoben. Es besteht gesetzliche Auskunftspflicht; die Meldefreigrenzen sind im internationalen Vergleich relativ gering. In Großbritannien werden nebeneinander mehrere Erhebungen durchgeführt, die jeweils andere, einander ergänzende Tatbestände abdecken. Der Bestand an britischen Direktinvestitionen im Ausland und seit 1982 auch der Bestand an ausländischen Direktinvestitionen in britischen nicht-körperschaftlich organisierten Direktinvestitionsunternehmen (jeweils ohne Ölgesellschaften, Banken und Versicherungswesen) basiert auf in regelmäßigen Abständen - in der Regel alle drei Jahre - durchgeführten Totalerhebungen; es besteht Meldepflicht. Der Bestand an ausländischen Direktinvestitionen in britischen körperschaftlich organisierten Unternehınen sowie Transaktionswerte für Dircktinvestitionen werden mittels Frhebungen auf freiwilliger Basis ermittelt. In den USA finden in unregelmäßigen Abständen Totalerhebungen für Strom- und Bestandsgrößen statt. Für die dazwischen liegenden Jahre werden Transaktions- und Bestandswerte unter Verwendung der Ergebnisse vierteljährlicher Stichprobenerhebungen mit relativ hohen Meldefreigrenzen u. a. durch Extrapolation der Ergebnisse der jeweils jüngsten Totalerhebung ermittelt.

Schließlich ist noch darauf zu achten, ob sich die Daten auf Kalender- oder Fiskaljahre beziehen. Wenn es den Unternehmen gestattet ist, auf der Grundlage von Wirtschaftsjahren zu melden und diese vom Kalenderjahr abweichen, dann sind Unterschiede in den nationalen Statistiken auch darauf \%urückzuführen, daß in einigen Ländern die gemeldeten Daten auf Kalenderjahre umgerechnet werden (z. B. USA) und in anderen Ländern die Daten für Wirtschaftsjahre als Schätzgrößen für die Kalenderjahre übernommen werden.

Infolge der zunehmenden Konzentration von Vermögen in Holdinggesellschaften und der damit einhergehenden großen Bedeutung dieser Unternehmen als Direktinvestoren einer- 
seits und als Direktinvestitionsunternehmen, die eigene. Tochtergesellschaften haben, andererseits, ist die Aussagekraft von nach Ländern und/oder nach Wirtschaftszweigen disaggregierten Dircktinvestitionen eingeschränkt. Der Bestand an Direktinvestitionen kann entweder den unmittelbaren oder den tatsächlichen $\Lambda$ nlage- bzw. Kapitalgeberländern ' ugeordnet werden. Für Transaktionswerte dagegen ist nur eine Klassifikation nach den unmittelbaren Empfänger- bzw. Herkunftsländern möglich; „(a)ny figures in respect of the ultimate host or controlling country would be artificial. " ${ }^{75}$ Unterschiede in den nationalen Statistiken bestehen auch in bezug auf dic Erfassung von Dircktinvestitionsunternehmen, dic Bricfkastenfirmen sind. ${ }^{76}$

Den sektoral disaggregierten Direktinvestitionen können entweder die Wirtschaftszweige der Direktinvestoren oder die der Direktinvestitionsunternehmen zugrunde liegen. Die Gliederung der Direktinvestitionen nach Herkunftsbranchen ist nur dann unabhängig von konzerninternen organisatorischen Veränderungen, wenn bei der Ermittlung des Schwerpunkts der wirtschaftlichen Tätigkeit nicht nur die Aktivitäten des Direktinvestors, sondern auch die aller in dessen Sitzland ansässigen Gesellschaften, die dem Direktinvestor untergeordnet sind, berücksichtigt werden bzw. wenn - wic in der US-Statistik für inländische Direktinvestitionen im Ausland - die Muttergesellschaft als vollständig konsolidiertes Unternehmen definiert ist und über die einzelnen im selben Land ansässigen Untergesellschaften unabhängig von deren Branchenzugehörigkeit aggregiert wird. Bei dem in der deutschen Statistik verwendeten Zuordnungsverfahren nach dem wirtschaftlichen Schwerpunkt des (nicht-konsolidierten) inländischen Direktinvestors kann ein Strukturwandel auch das Ergebnis der Umstrukturierung eines im Zusammenhang mit Direktinvestitionen bedeutenden Konzerns sein. Entsprechend wird bei Dircktinvestitionsunternehmen, die eigene Niederlassungen haben, die Gliederung der Direktinvestitionen nach dem Wirtschaftszweig der Investitionsobjekte davon beeinflußt, ob die Zuordnung auf der Grundlage der jeweiligen Hauptaktivitäten des unmittelbaren Direktinvestitionsunternehmens und der einzelnen mittelbaren Tochtergesellschaften erfolgt oder ob die Branchenzugehörigkeit bestimmt wird vom Schwerpunkt der wirtschaftlichen Tätigkeit des unmittelbaren Direktinvestitionsunternehmen einschließlich aller mittelbaren Tochtergesellschaften. ${ }^{77}$

Stromgrößen für Direktinvestitionen berücksichtigen in der Regel nur Transaktionen, an

75 OFCD (1983, Ziff. 82). Die meisten Länder folgen bei den Transaktionswerten für Direktinvestitionen dieser Empfehlung der OECD; vgl. hierzu aber auch die regionale Disaggregation der ausländischen Direktinvestitionen in den ISA vor dem Berichtsjahr 1974. In der Zahlungsbilanzstatistik der BLUE werden Transaktionen, bei denen unmittelbare und tatsächliche Empfänger- bzw. Herkunftsländer offensichtlich voneinander abweichen - z. B. Transaktionen zwischen Inländern und in Steueroasen errichteten Holdinggesellschaften -, entgegen der sonstigen Vorgehensweise nicht den unmittelbaren Anlage- bzw. Kapitalgeberländern zugeordnet, sondern als „regional nicht aufteilbar“ ausgewiesen; vgl. eurostat (1984a, S. 163).

${ }_{76}$ Zur regionalen Disaggregation der Direktinvestitionen vgl. auch OECD (1983, Ziff. 77-86).

77 Zur sektoralen Gliederung der Direktinvestitionen vgl. auch OECD (1983, Ziff. 87-90). 
denen sowohl Inländer als auch $\Lambda$ usländer beteiligt sind. Wenn Liquidationen von Kapitalanlagen statistisch mit den Transaktionswerten erfaßt werden, ist die Nichtberücksichtigung dieser Transaktionen weder für die ausgewiesenen inländischen Nettodirektinvestitionen im Ausland insgesamt, nach Anlageländern und nach Zielbranchen noch für die ausländischen Nettodirektinvestitionen im Inland insgesamt und nach Branchen der inländischen Investitionsobjekte von Bedeutung. Die inländischen Nettodirektinvestitionen im Ausland nach Herkunftsbranchen werden jedoch verzerrt wiedergegeben, wenn ein Inländer cine Beteiligung an cinem ausländischen Unternehmen von einem anderen Inländer erwirbt und die beiden beteiligten Inländer den Schwerpunkt ihrer wirtschaftlichen Tätigkeit in verschiedenen Branchen haben. Veräußert ein $\Lambda$ usländer seine Beteiligung an einem inländischen Unternehmen an einen anderen $\Lambda$ usländer, dann werden die ausländischen Nettodirektinvestitionen im Inland nach Herkunftsländern bzw. nach Herkunftsbranchen nur in dem Fall korrekt ausgewiesen, wenn die beiden Ausländer im selben Land ansässig sind bzw. ihren wirtschaftlichen Schwerpunkt in derselben Branche haben.

\subsection{Bundesrepublik Deutschland}

In der Bundesrepublik Deutschland gibt es für Direktinvestitionen drei verschiedene Statistiken: Transaktionswerte werden erfaßt in der Zahlungsbilanzstatistik der Deutschen Bundesbank und in der vom Bundesministerium für Wirtschaft veröffentlichten Transferstatistik, Vermögensbestände in der Bestandsstatistik der Deutschen Bundesbank. Gemeinsam ist diesen drei Statistiken, daß ihnen Totalerhebungen bei gebietsansässigen Wirtschaftssubjekten zugrunde liegen; dic Daten werden jeweils von den Landeszentralbanken erfaßt und von der Deutschen Bundesbank aufbereitet. Rechtliche Grundlage für die Erhebung der Daten bilden die Meldevorschriften der Verordnung zur Durchführung des $\Lambda$ ußenwirtschaftsgesetzes (Außenwirtschaftsverordnung - AWV) für den Kapitalverkehr und für den Zahlungsverkehr in Verbindung mit § 26 Außenwirtschaftsgesetz ( $\Lambda \mathrm{WG}){ }^{78}$ Es besteht gesetzliche $\Lambda$ uskunftspflicht. Die in den drei Statistiken ausgewiesenen Direktinvestitionen beruhen jedoch jeweils auf einer anderen Datengrundlage. Diese unterscheiden sich zurn Teil in bezug auf die Abgrenzung von Direktinvestor, Direktinvestitionsunternehmen und Direktinvestitionskapital.

\footnotetext{
${ }^{78}$ Außenwirtschaftsgesetz vorn 28. April 1961, zuletzt geändert durch das Gesetz zur Änderung des Finanzverwaltungsgesetzes und anderer (Gesetze vom 7. Juli 1992 und Verordnung zur Durchführung des Außenwirtschaftsgesetzes (Außenwirtschaftsordnung - AWV) vom 22. August 1961, zuletzt geändert durch die Neunundfünfzigste. Verordnung zur Änderung der AuBenwirtschaftsverordnung vom 10. September 1986 sowie Verordnung zur Durchführung des Außenwirtschaftsgesetzes (Außenwirtschaftsverordnung - AWV) vom 18. Dezember 1986, zuletzt geändert durch die Sechsundzwanzigste Verordnung zur Änderung der Außenwirtschaftsverordnung vom 8. Oktober 1992. Die Meldevorschriften nach § 26 AWV für den Kapital- und Zahlungsverkehr gelten nach Inkrafttreten des Gemeinsamen Binnenmarktes am 1.1.1993 weiterhin, „auch soweit der Außenwirtschaftsverkehr mit EG-Mitgliedsstaaten betroffen ist.“ (Der Bundesminister für Wirtschaft 1992c, S. 9506)
} 
Das deutsche Außenwirtschaftsrecht verwendet nicht die Begriffspaare Inland/Ausland und Inländer/Ausländer, sondern Wirtschaftsgebiet/fremde Wirtschaftsgebiete und Gebietsansässige/Gebietsfremde. Im folgenden werden die Begriffspaare Inland/Wirtschaftsgebiet, Ausland/fremde Wirtschaftsgebiete, Inländer/Gebietsansässige und Ausländer/Gebietsfremde als Synonyme verwendet.

Wirtschaftsgebiet ist seit dem 3. Oktober 1990 die Bundesrepublik Deutschland in ihren Staatsgrenzen ohne die badischen Zollausschlüsse, aber einschließlich der Zollanschlüsse und dem der Bundesrepublik zustehenden Teil des Festlandsockels; als fremde Wirtschaftsgebiete gelten alle Gebiete außerhalb des Wirtschaftsgebiets. Vor der Einheit Deutschlands zählte das Währungsgebiet der Mark der Deutschen Demokratischen Republik weder zum Wirtschaftsgebiet noch zu den fremden Wirtschaftsgebieten. Seit dem 1. Juli 1990, also seit Inkrafttreten der Währungs-, Wirtschafts- und Sozialunion zwischen Bundesrepublik und DDR, sind die Transaktionen des Gebiets der ehemaligen DDR mit dem Ausland in den in Zahlungsbilanz- und Transferstatistik ausgewiesenen Daten für deutsche Direktinvestitionen im Ausland bzw. für ausländische Direktinvestitionen in der Bundesrepublik enthalten; in der Bestandsstatistik für Direktinvestitionen schließen die Angaben zum Jahresende 1990 das Gebiet der ehemaligen DDR mit ein. ${ }^{79}$

Die Abgrenzung von gebietsansässigen Privatpersonen und Unternehmen ${ }^{80} \mathrm{knüpft} \mathrm{-} \mathrm{wie}$ international üblich - nicht an die Nationalität einer Person oder an die Eigentumsverhältnisse eines Unternehmens an, sondern an den Wohnsitz oder den gewöhnlichen Aufenthalt bzw. den Sitz. Als Gebietsansässige gelten „natürliche Personen mit Wohnsitz oder gewöhnlichem Aufenthalt im Wirtschaftsgebiet, juristische Personen und Personenhandelsgesellschaften mit Sitz oder Ort der Leitung im Wirtschaftsgebiet; Zweigniederlassungen Gebietsfremder im Wirtschaftsgebiet gelten als Gebietsansässige, wenn sie hier ihre Leitung haben und für sie eine gesonderte Buchführung besteht; Betriebsstätten Gebietsfremder im Wirtschaftsgebiet gelten als Gebietsansässige, wenn sie hier ihre Verwaltung haben ${ }^{\text {} 81}$. Gebietsfremde sind entsprechend abgegrenzt. ${ }^{82}$ Abweichend vom Konzept

${ }^{79}$ Zur Begriffsbestimmung von "Wirtschaftsgebiet" und ${ }_{\text {fremde Wirtschaftsgebiete }}$ " siehe $\$ 4$ Abs. 1 Nr. 1 und 2 AWG vom 28. April 1961, geändert durch das Dritte Gesetz zur Änderung des Außenwirtschaftsgesetzes vom 29. März 1976 und durch Art. 8 in Verbindung mit Anlage I, Kapitel V, Sachgebiet F, Abschnitt II, Ziff. 1 Nr. 1 des Gesetzes zu dem Vertrag vom 31. August 1990 zwischen der Bundesrepublik Deutschland und der Deutschen Demokratischen Republik über die Herstellung der Einheit Deutschlands - Einigungsvertragsgesetz - und der Vereinbarung vom 18. September 1990 vom 23. September 1990.

${ }^{80}$ In der Bundesrepublik ist der Kreis der Unternehmen, die als Kreditinstitute gelten, weiter gefaBt als international üblich. Zur Definition von Kreditinstituten vgl. $\$ 1$ des Gesetzes über das Kreditwesen (KWG).

81 § 4 Abs. 1 Nr. 3 AWG vom 28. April 1961, geändert durch das Fünfte Gesetz zur Änderung des Außenwirtschaftsgesetzes vom 20. Juli 1990.

82 Vgl. § 4 Abs. 1 Nr. 4 AWG vom 28. April 1961, geändert durch das Fünfte Gesetz zur Änderung des Außenwirtschaftsgesetzes vom 20. Juli 1990. 
des IMF genügt bei Privatpersonen bereits cin Aufenthalt von mehr als sechs Monaten im Wirtschaftsgebiet, um als Gebietsansässiger angesehen zu werden. ${ }^{83}$ Das Außenwirtschaftsrecht behandelt gebietsansässige (gebietsfremde) Zweigniederlassungen und Betriebsstätten Gebietsfremder (Gebietsansässiger) seit 1976 als rechtlich selbständig. ${ }^{84} \mathrm{Als}$ inländische Einheiten gelten auch in Inland gelegene bebaute und unbebaute Grundstücke, die Gebietsfremden gehören, und von Ausländern betriebene Baustellen, Pipelines, Bohrstellen und andere Explorationsvorhaben im Wirtschaftsgebiet. Agenturen gebietsfremder Unternehmen im Wirtschaftsgebiet werden als ausländische Einheiten betrachtet. Die öffentlichen Stellen der Bundesrepublik auf allen Verwaltungsebenen, einschließlich der Sozialversicherung, den öffentlichen Unternehmen ohne selbständige Rechnungslegung, den deutschen diplomatischen Vertretungen im Ausland sowie den militärischen Agenturen im Ausland, gelten stets als Gebietsansässige; die selbständigen Unternehmen im öffentlichen Eigentum zählen zu den gebietsansässigen Unternehmen. ${ }^{85}$

An die Darstellung der statistischen Erfassung von Direktinvestitionen in der Zahlungsbilanzstatistik der Deutschen Bundesbank, in der Transferstatistik des Bundesministeriums für Wirtschaft und in der Bestandsstatistik der Deutschen Bundesbank schließt sich eine Gegenüberstellung der in diesen drei Statistiken ausgewiesenen Direktinvestitionen in den Jahren 1982 bis 1991 an, und es werden die wesentlichen Unterschiede zwischen den drei Statistiken aufgezeigt.

\subsubsection{Direktinvestitionen in der Zahlungsbilanzstatistik der Deutschen Bun- desbank}

Die Definition der Deutschen Bundesbank für Direktinvestitionen stellt ab auf die Möglichkeit des Direktinvestors, Einfluß auf die Geschäftsleitung des Direktinvestitionsunternehmens zu nehmen: „Eine Direktinvestition liegt vor, wenn ein Unternehmen ('Muttergesellschaft') oder ein Investor bzw. eine Gruppe verbundener Unternehmen oder Investoren einen spürbaren Einfluß auf die Geschäftspolitik eines anderen Unternehmens ('Tochterge-

83 Die Angehörigen ausländischer diplomatischer und konsularischer Vertretungen in der Bundesrepublik und ihre im Wirtschaftsgebiet wohnenden Familienangehörigen werden in der Regel als Inländer angesehen, die Mitglieder ausländischer Truppeneinheiten einschlieblich zivilen Gefolges, die im Inland stationiert sind, sowie deren Familienangehörigen dagegen als Ausländer. Zur Auslegung der Begriffe „Gebietsansässige“ und „Gebietsfremde“ bei natürlichen Personen vgl. Der Bundesminister für Wirtschaft (1983). Zur Abgrenzung Gebietsansässiger vgl. auch eurostat (1983b, S. 20 f.); zur Abgrenzung von Wirtschaftsgebiet und fremde Wirtschaftsgebiete sowie Gebietsansässige und Gebietsfremde im Außenwirtschaftsrecht vgl. auch Gramlich (1991, S. 12 ff. und 40 ff.).

84 Zur Begriffsbestimmung von „Zweigniederlassungen und Betriebsstätten“ siehe den mit dem Dritten Gesetz zur Änderung des Außenwirtschaftsgesetzes vom 29. März 1976 eingefügten § 4a AWG. Zur rechtlichen Verselbständigung von Zweigniederlassungen und Betriebsstätten vgl. auch Deutsche Bundesbank (1976b).

85 Zur Abgrenzung der gebietsansässigen inländischen Sektoren vgl. auch Deutsche Bundesbank (1990f, S. $24 \mathrm{f}$. und $36 \mathrm{f}$.). Internationale Organisationen, die ihren Sitz in der Bundesrepublik haben, werden als selbständige gebietsfremde Einheiten behandelt. 
sellschaft') ausüben kann."86 Das Kriterium der Einflußnahme auf dic Geschäftsführung eines anderen Unternehmens wird in der Zahlungsbilanzstatistik als erfüllt angesehen, wenn einem Investor mehr als $20 \%$ (vor dem Berichtsjahr 1990: mindestens $25 \%$ ) der Kapitalanteile an einem anderen Unternehmen zuzurechnen sind. In Ausnahmefällen, beispielsweise bei sehr großen Beträgen oder einer anderen Art von Einflußnahme, genügt auch eine geringere Beteiligung, um einen Investor als Direktinvestor bzw. als Muttergesellschaft und das Unternehmen in einem anderen Land als Direktinvestitionsunternehmen bzw. als Tochtergesellschaft zu qualifizieren. ${ }^{87}$ Dieses Konzept der statistischen Abgrenzung der Direktinvestitionen von Portfolioinvestitionen kann die Deutsche Bundesbank allerdings erst seit dem Berichtsjahr 1990 auch verwirklichen. Direktinvestitionen werden als Unterposition des langfristigen ${ }^{88}$ Kapitalverkehrs mit dem Ausland ausgewiesen. ${ }^{89}$

Der Kreis der potentiellen Direktinvestoren ist bei den deutschen Kapitalanlagen im Ausland auf den privaten Sektor, also auf private Unternehmen, öffentliche Unternehmen mit selbständiger Rechnungslegung, private Organisationen ohne Erwerbscharakter und Privatpersonen beschränkt. ${ }^{90}$ Bei den ausländischen Direktinvestitionen im Inland werden dagegen auch die Kapitalanlagen ausländischer öffentlicher Stellen in der Bundesrepublik Deutschland als Direktinvestitionen erfaßt.

Die in der Zahlungsbilanzstatistik der Deutschen Bundesbank ausgewiesenen Direktinvestitionen basieren mit Ausnahme der reinvestierten Gewinne auf den monatlichen bzw. halbjährlichen Meldungen Gebietsansässiger über den Zahlungsverkehr mit dem Ausland. Rechtliche Grundlage für die Statistik der Deutschen Bundesbank über den Auslandszahlungsverkehr bilden $\S \S 59$ ff. AWV (Meldungen von Zahlungen) in Verbindung mit $§ 26$ Abs. 2 AWG. Es besteht gesetzliche Auskunftspflicht.

"Gebietsansässige haben Zahlungen, die sie 1. von Gebietsfremden oder für deren Rechnung von Gebietsansässigen entgegennehmen (eingehende Zahlungen) oder 2. an Gebietsfremde oder für deren Rechnung an Gebietsansässige leisten (ausgehende Zahlungen), zu melden."91 Meldepflichtig ist der die Zahlung tatsächlich leistende oder empfangende Inländer. ${ }^{92}$ Ausgenommen von der Meldepflicht sind seit August 1991 alle Zahlungen, die den Betrag von (umgerechnet) 5000 DM (für September 1961 bis Januar 1974: 500 DM;

\footnotetext{
86 Deutsche Bundesbank (1990f, S. 80); ähnlich, aber ohne Hinweis auf Gruppen von Investoren auch Deutsche Bundesbank (1965, S. 19; 1978, S. 31 Fn. 1).

$87 \mathrm{Vgl}$. Deutsche Bundesbank (1987b, S. 80 f.; 1990 f, S. 80 f.).

88 Langfristig bedeutet eine ursprüngliche Laufzeit oder Kündigungsfrist von mehr als einem Jahr oder keine Laufzeitbegrenzung; vgl. z. B. Deutsche Bundesbank (1990f, S. 15 f.).

$89 \mathrm{Zu}$ den methodischen Grundlagen der Zahlungsbilanzstatistik der Deutschen Bundesbank vgl. Deutsche Bundesbank $(1987 \mathrm{~b} ; 1990 \mathrm{f})$ und eurostat $(1983 \mathrm{~b})$.

$90 \mathrm{Vgl}$. Deutsche Bundesbank (1990f, S. 83) und eurostat (1983b, S. 63).

$91 \S 59$ Abs. 1 AWV.

92 Vgl. Deutsche Bundesbank (1990f, S. 43).
} 
für Februar 1974 bis August 1982: 1000 DM; für September 1982 bis Juli 1991: 2000 DM) nicht übersteigen. ${ }^{93}$ Der Begriff Zahlungen beinhaltet auch die Aufrechnung und die Verrechnung sowie die Einbringung von Sachen und Rechten in Unternehmen, Zweigniederlassungen und Betriebsstätten. ${ }^{94}$ Erfaßt werden jedoch nur tatsächlich geleistete Zahlungen in diesem Sinne, nicht schon Vertragsabschlüsse. ${ }^{95}$ Es sind Bruttobeträge zu melden. ${ }^{96}$ Bei Zahlungen über konzerninterne Verrechnungskonten sowie für Sacheinbringungen sind als Transaktionswerte die in den Büchern des Gebietsansässigen ausgewiesenen Beträge zu melden. ${ }^{97}$ Mit Ausnahme der reinvestierten Gewinne werden alle Transaktionen zum Zahlungszeitpunkt erfaßt. ${ }^{98}$ Die Umrechnung von Fremdwährungsbeträgen in DM erfolgt bei Zahlungen über Kreditinstitute zu dem am Tag der Zahlungsgutschrift oder -ausführung durch die Bank geltenden Brief- oder Geldkurs. Andere Zahlungen sowie nicht auf DM lautende Forderungen und Verbindlichkeiten werden von den meldepflichtigen Gebietsansässigen meist zu den in ihren internen Rechnungswesen verwendeten Kursen umgerechnet. ${ }^{99}$

Um die gemeldeten Zahlungen den verschiedenen Positionen der Zahlungsbilanzstatistik zuordnen zu können, haben die berichtenden Gebietsansässigen bei der Meldung ihrer Transaktionen durch verbale Beschreibung und durch Angabe einer der im Leistungsverzeichnis (Anlage LV zur AWV) aufgeführten Kennzahlen den Zweck der Zahlung anzugeben. ${ }^{100}$ Gesonderte Kennzahlen für Direktinvestitionen wurden mit dem Ziel, die Datengrundlage für Direktinvestitionen in der Zahlungsbilanzstatistik zu verbessern, erst mit Wirkung zum 1.1.1990 eingeführt. Gemäß dem seither gültigen Leistungsverzeichnis, in dem der Begriff Direktinvestitionen erstmals explizit erscheint, sind folgende Transaktio-

93 Vgl. $\$ 59$ Abs. 2 Nr. 1 AWV vom 22. August 1961, geändert durch die EinunddreiBigste Verordnung zur Änderung der Außenwirtschaftsverordnung vom 30. Januar 1974, geändert durch die Zweiundfünfzigste Verordnung zur Änderung der Außenwirtschaftsverordnung vom 13. August 1982 und AWV vom 18. Dezember 1986, geändert durch die Sechzehnte Verordnung zur Änderung der Außenwirtschaftsverordnung vom 18. Juli 1991. In Sammelmeldungen dürfen auch Zahlungen unterhalb der Meldefreigrenzen berücksichtigt werden. Zur Erhöhung der Meldefreigrenze im Zahlungsverkehr vgl. auch Der Bundesminister für Wirtschaft (1982c; 1991) und Deutsche Bundesbank (1982b; 1991c). Darüber hinaus sind von der Meldepflicht ausgenommen Ausfuhrerlöse, Zahlungen im Zusammenhang mit kurzfristigen Krediten und Zahlungen natürlicher Personen für Güter zum persönlichen Gebrauch; vgl. § 59 Abs. 2 Nr. 2 bis 4 AWV vom 22. August 1961, geändert durch die Vierte Verordnung zur Änderung der Außenwirtschaftsverordnung vom 17. Dezember 1963 und AWV vom 18. Dezember 1986.

$94 \S 59$ Abs. 3 AWV.

$95 \mathrm{Vgl}$. eurostat (1983b, S. 63).

96 Vgl. hierzu auch Deutsche Bundesbank (1991c).

97 Vgl. Deutsche Bundesbank (1990f, S. 30 und 45) sowie eurostat (1983b, S. 11 und 22).

98 Vgl. Deutsche Bundesbank (1990f, S. 33) und eurostat (1983b, S. 24).

99 Vgl. Deutsche Bundesbank (1990f, S. 31) und eurostat (1983b, S. 22 f.).

100 Vgl. $\S 60$ Abs. 4 AWV, die Meldevordrucke für den Zahlungsverkehr (Anlagen Z 1, Z 2, Z 3 und Z 4 zur AWV) und Deutsche Bundesbank (1990f, S. 44). 
nen als Direktinvestitionen in fremden Wirtschaftsgebieten (bzw. als Direktinvestitionen im Wirtschaftsgebiet) zu melden: ${ }^{101}$

- Anteile am gezeichneten Kapital und an den Rücklagen von gebietsfremden (bzw. gebietsansässigen) Unternehmen, Zweigniederlassungen und Betriebsstätten, wenn dem gebietsansässigen (bzw. dem gebietsfremden) Kapitalgeber mehr als $20 \%$ des Nennkapitals des betreffenden Unternehmens zuzurechnen sind. Unter der Voraussetzung, daß dem Gebietsansässigen (bzw. Gebietsfremden) nach der Transaktion - bzw. bei Auflösung von Vermögen in fremden Wirtschaftsgebieten (bzw. im Wirtschaftsgebiet) vor der Transaktion - mehr als $20 \%$ der Anteile am Nominal- ${ }^{102}$ oder Geschäftskapital des gebietsfremden (bzw. gebietsansässigen) Unternehmens, zuzurechnen sind, zählen hierzu Zahlungen für Erwerb und Veräußerung von Unternehmensbeteiligungen, Zahlungen für Gründung oder Erwerb sowie für Auflösung oder Veräußerung von Unternehmen (einschließlich Unternehmen, deren Geschäftstätigkeit die gewerbliche Nutzung von Grundstücken und Gebäuden ist, z. B. Hotels), Zahlungen für Kapitalerhöhungen oder Rückzahlungen infolge Kapitalherabsetzungen, Zahlungen zur Ausstattung von Zweigniederlassungen und Betriebsstätten (einschließlich Bohrstellen) mit Dotations- oder Betriebskapital und Zahlungen zur Erhöhung der freien Rücklagen sowie zur Abdeckung von Verlustvorträgen. Als Ausstattung einer Betriebsstätte mit Betriebskapital gelten auch Zahlungen, die gebietsansässige Firmen in eigener Rechnung oder für Rechnung anderer Gebietsansāssiger (bzw. gebietsansässige Baufirmen) für Bauleistungen, Montagen, Ausbesserungen und Bohrtätigkeiten in fremden Wirtschaftsgebieten (bzw. im Wirtschaftsgebiet) an Gebietsfremde leisten (bzw. von Gebietsfremden für deren Rechnung oder für Rechnung anderer Gebietsfremder erhalten), einschließlich Zahlungen für Aufschließungsarbeiten bei Erdöl-, Erdgas- und anderen Mineralvorkommen. Zuschüsse ${ }^{103}$ von Muttergesellschaften an Tochtergesellschaften (Unternehmen, Zweigniederlassungen und Betriebsstätten) zur Finanzierung des laufenden Geschäftsbetriebs zählen nicht zum Direktinvestitionskapital.

- Zahlungen für Gewährung oder Rückzahlung langfristiger ${ }^{104}$ Kredite an gebietsfremde (bzw. gebietsansässige) Unternehmen, Zweigniederlassungen und Betriebsstätten, wenn dem inländischen (bzw. ausländischen) Kreditgeber oder einem von ihm abhängigen inländischen oder ausländischen Unternehmen im Zeitpunkt der Zahlung mehr als $20 \%$ des Nennkapitals des betreffenden Unternehmens zustehen und sowohl Kreditgeber als auch Kreditnehmer Nichtbanken sind (Direktinvestitionskredite). Die Abgrenzung der Abhängigkeit eines Unternehmens folgt nach Auskunft der Deutschen Bundesbank in der Zahlungsbilanzstatistik - ebenso wie in der Transferstatistik - $§ 17$ AktG. ${ }^{105}$ Danach

$\overline{101} \mathrm{Vgl}$. zum folgenden Deutsche Bundesbank (1990e, insb. S. 59 ff.).

102 Das Nominalkapital umfaBt Stamm-, Vorzugs- und andere Aktien mit Stimmrecht.

$103 \mathrm{Vgl}$. Deutsche Bundesbank (1990e, S. 35; 1990f, S. 67).

${ }^{104}$ Kredite mit einer Laufzeit von mehr als 12 Monaten.

105 Im folgenden beruhen einige Angaben auf mündlichen Informationen von Experten der Deutschen Otto Roloff, Sibylle Brander, Ingo Barens and Claudia Wesselbaum - 978-3-631-75210-4 
gilt ein Unternehmen als abhängig, wenn ein anderes Unternehmen auf dieses unmittelbar oder mittelbar einen herrschenden Einfluß ausüben kann; von einem Unternehmen, dessen Anteile oder Stimmrechte zu über $50 \%$ einem übergeordneten Unternehmen zuzurechnen sind, wird vermutet, daß es abhängig ist. ${ }^{106}$

Die Untergrenze für die Kapitalbeteiligung bezieht sich auf einzelne Unternehmen. Grenzüberschreitende Kapitalanlagen wirtschaftlich verbundener Investoren, die jeweils höchstens $20 \%$, zusammen aber mehr als $20 \%$ der Kapitalanteile an einem Unternehmen in einem anderen Land halten, werden nach Auskunft der Deutschen Bundesbank nicht als Direktinvestitionen erfaßt.

Wechselseitige Beteiligungen zwischen Mutter- und Tochtergesellschaft werden nicht saldiert. Die Investitionen einer gebietsansässigen (bzw. gebietsfremden) Tochtergesellschaft in ihre gebietsfremde (bzw. gebietsansässige) Muttergesellschaft werden als inländische Direktinvestitionen im Ausland (bzw. als ausländische Direktinvestitionen im Inland) erfaßt, wenn dem Tochterunternehmen mehr als $20 \%$ des Nennkapitals an seiner Muttergesellschaft zustehen, und als Portfolioinvestitionen, wenn die Tochtergesellschaft höchstens $20 \%$ des Nennkapitals der Muttergesellschaft hält.

Zahlungen für Erwerb und Veräußerung von im Ausland gelegenen Grundstücken und Gebäuden sowie von Rechten an Grundstücken (bzw. für Veräußerung und Rückerwerb von im Inland gelegenen Grundstücken und Gebäuden sowie von Rechten an Grundstücken an Ausländer bzw. von Gebietsfremden) sind - wie schon vor dem Berichtsjahr 1990 - unter der Kennziffer „Grundstücke und Rechte an Grundstücken in fremden Wirtschaftsgebieten (bzw. im Wirtschaftsgebiet) “ zu melden. In den Meldungen ist anzugeben, ob die Grundstücke und Gebäude gewerblich oder privat genutzt werden.

Vor Einführung gesonderter Kennzahlen für Direktinvestitionen im Leistungsverzeichnis $^{107}$ klassifizierte die Deutsche Bundesbank die Vermögensanlagen Gebietsansässiger im Ausland bzw. die Vermögensanlagen Gebietsfremder im Inland als Direktinvestitionen auf der Grundlage der verbalen Beschreibung des von den Meldepflichtigen angegebenen Zwecks der Zahlung und unter Verwendung zusätzlicher, nicht im Rahmen der Meldungen über den Auslandszahlungsverkehr erhobenen Informationen. ${ }^{108}$ Wegen Informationsman-

\section{Bundesbank.}

106 Der in Zahlungsbilanz- und Transferstatistik verwendete Abhängigkeitsbegriff ist nicht identisch mit. demjenigen in der Bestandsstatistik der Deutschen Bundesbank. Zum Abhängigkeitsbegriff im AktG vgl. Wirtschaftsprüfer-Handbuch (1992, Abschnitt R Tz. 109 ff.).

${ }^{107} \mathrm{Zu}$ dem bis Ende 1989 gültigen Leistungsverzeichnis vgl. z. B. Anlage LV zur AWV vom 22. August 1961.

108 Auch nach Einführung gesonderter Kennzahlen für Direktinvestitionen im Leistungsverzeichnis werden die Meldungen im Zahlungsverkehr mit dem Ausland u. a. mit den Meldungen über Vermögen(sanlagen) Gebietsansässiger in fremden Wirtschaftsgebieten und über Vermögen(sanlagen) Ge- 
gels konnte die Deutsche Bundesbank das oben beschriebene Konzept zur statistischen Erfassung von Direktinvestitionen nur zum Teil verwirklichen: Bis einschließlich dem Berichtsjahr 1989 war die Behandlung von Erwerb oder Veräußerung von Unternehmensbeteiligungen von der Rechtsform des Direktinvestitionsunternehmens abhängig, und Direktinvestitionen in Form von Gewährung und Tilgung langfristiger Kredite und Darlehen konnten nur sehr approximativ bestimmt werden.

Vor dem Berichtsjahr 1990 galt ein ausländisches körperschaftlich organisiertes Unternehmen (bzw. eine inländische Aktiengesellschaft) als Direktinvestitionsunternehmen, wenn einem Gebietsansässigen oder einer verbundenen Gruppe von Gebietsansässigen (bzw. einem Gebietsfremden oder einer verbundenen Gruppe von Gebietsfremden) mindestens $25 \%$ des Nominalkapitals dieses Unternehmens zuzurechnen waren. In Ausnahmefällen genügte auch ein geringerer Kapitalanteil. War ein Unternehmen erst einmal als Direktinvestitionsunternehmen klassifiziert, dann wurden aus Mangel an zusätzlichen Informationen auch alle anderen inländischen (bzw. ausländischen) Kapitalanlagen in dieses gebietsfremde (bzw. gebietsansässige) Unternehmen in der Zahlungsbilanzstatistik als Direktinvestitionen erfaßt, und zwar unabhängig davon, welche Kapitalanteile den anderen inländischen (bzw. ausländischen) Kapitaleignern zuzurechnen waren und ob diese anderen Investoren verbundene Wirtschaftssubjekte waren oder nicht. Ausländische nicht-körperschaftlich organisierte Unternehmen (bzw. inländische Unternehmen in anderer Rechtsform als einer Aktiengesellschaft), an denen Gebietsansässige (bzw. Gebietsfremde) beteiligt waren, galten unabhängig von der Höhe der inländischen (bzw. ausländischen) Beteiligung als Direktinvestitionsunternehmen; entsprechend wurden in der Zahlungsbilanzstatistik alle Kapitalanlagen in solche Unternehmen als Direktinvestitionskapital erfaßt. Zweigniederlassungen und Betriebsstätten wurden ebenso wie kommerziell genutzte Grundstücke stets als Direktinvestitionsunternehmen behandelt. ${ }^{109}$

Da bei Gewährung, Aufnahme und Tilgung langfristiger Kredite und Darlehen das ausländische Unternehrnen, das die gemeldete Zahlung empfing bzw. leistete, häufig nicht zu ermitteln war, wurden in der deutschen Zahlungsbilanzstatistik vor dem Berichtsjahr 1990 unabhängig von den tatsächlichen Empfängern alle langfristigen Kredite, die inländische Unternehmen Gebietsfremden gewährten, als Direktinvestitionen erfaßt, wenn der meldende Gebietsansässige (allein oder als Teil einer verbundenen Gruppe) im Bestimmungsland der Zahlung eine Tochtergesellschaft hatte; alle langfristigen Kredite, die

bietsfremder im Wirtschaftsgebiet abgestimmt, also mit den Daten, welche die Grundlage für die Transferstatistik des Bundesministeriums für Wirtschaft und für die Bestandsstatistik der Deutschen Bundesbank bilden. Fine nachträgliche Umklassifizierung von Direktinvestitionen zu Portfolioinvestitionen oder umgekehrt wird nicht vorgenommen.

$109 \mathrm{Vgl}$. Deutsche Bundesbank (1976a, S. 336; 1987b, S. 80 ff.; 1990f, S. 82) und eurostat (1983b, S. 49 und $61 \mathrm{f}$.). Die Kosten von Bohrungen wurden nur dann als Direktinvestitionen ausgewiesenen, wenn die Suche erfolgreich war; vgl. eurostat (1983b, S. 62). 
inländische Direktinvestitionsunternehmen in den Sitzländern ihrer ausländischen Kapitaleigner aufnahmen, wurden unabhängig von der tatsächlichen Herkunft der Mittel als Direktinvestitionen klassifiziert. ${ }^{110}$ Welche Unternehmen und Investoren als verbundene Gruppe galten, ist nicht definiert.

Die Deutsche Bundesbank weist Direktinvestitionen in der Zahlungsbilanzstatistik stets mit dem Zusatz „soweit erkennbar“ aus. Das Direktinvestitionskapital ist gegliedert nach: Anlagen in Dividendenwerten, Anlagen in sonstigen Kapitalanteilen und übrige Anlagen (langfristige Kredite, reinvestierte Gewinne und kommerzieller Grundbesitz).

Die Anlagen in Dividendenwerten beinhalten Erwerb und Veräußerung von Anteilen am Nominalkapital gebietsfremder körperschaftlich organisierter Unternehmen (deutsche Direktinvestitionen im Ausland) bzw. Erwerb und Veräußerung von Beteiligungen an gebietsansässigen Aktiengesellschaften (ausländische Direktinvestition in der Bundesrepublik), ohne Kapitalerhöhungen aus Gesellschaftsmitteln u. ä. Vorgängen. Die Anlagen in sonstigen Kapitalanteilen umfassen Erwerb und Veräußerung von Anteilen am Geschäftskapital gebietsfremder nicht-körperschaftlich organisierter Unternehmen bzw. Erwerb oder Veräußerung von Anteilen an gebietsansässigen Unternehmen in anderer Rechtsform als Aktiengesellschaften, einschließlich Zuführung externer Mittel zur Abdeckung von Verlustvorträgen oder zur Rücklagenbildung (bei den rechtlich unselbständigen Zweigniederlassungen und Betriebsstätten, die stets als Direktinvestitionsunternehmen behandelt werden: Ausstattung mit Dotationskapital oder Zuschüsse der Muttergesellschaft).

Die langfristigen Kredite der Direktinvestitionsunternehmen an ihre Muttergesellschaften und die Kredite zwischen in- und ausländischen Schwesterunternehmen sind nach Auskunft der Deutschen Bundesbank bis einschließlich Dezember 1992 nicht im ausgewiesenen Direktinvestitionskapital enthalten; seit Januar 1993 werden diese Kredite allerdings als Direktinvestitionen erfaßt. Die langfristigen Forderungen an Kreditinstitute und die langfristigen Verbindlichkeiten gegenüber Kreditinstitute zählen nicht zum Direktinvestitionskapital. Für Kreditinstitute ist das Direktinvestitionskapital also auf Anlagen in Kapitalanteilen (bei unselbständigen Tochtergesellschaften von Banken: Dotationskapital) und reinvestierte Gewinne beschränkt. ${ }^{111}$ Infolge der Nichtberücksichtigung langfristiger Forderungen und Verbindlichkeiten inländischer (bzw. ausländischer) Kreditinstitute gegenüber ihren gebietsfremden (bzw. gebietsansässigen) Tochterinstituten ist das Direktinvestitionskapital für Kreditinstitute in der Zahlungsbilanzstatistik enger definiert als in den Empfehlungen von IMF und OECD.

Den Empfehlungen von IMF und OECD entsprechend umfaßt das ausgewiesene Direk-

$\overline{110 \text { Vgl. Deutsche Bundesbank (1990f, S. }}$ 82) oder eurostat (1983b, S. 62 f.).

111 Vgl. Deutsche Bundesbank (1990f, S. 82 f.) und eurostat (1983b, S. 63).

Otto Roloff, Sibylle Brander, Ingo Barens and Claudia Wesselbaum - 978-3-631-75210-4 
tinvestitionskapital auch die Anteile der Direktinvestoren an den reinvestierten Gewinnen/Verlusten ihrer Tochtergesellschaften; dabei werden alle Direktinvestitionsunternehmen, also Unternehmen, Zweigniederlassungen und Betriebsstätten, berücksichtigt. Diese fiktiven Transaktionen werden jedoch im Gegensatz zu der Empfehlung des IMF nicht dem Entstehungsjahr, sondern erst dem Folgejahr zugeordnet. ${ }^{112}$ Reinvestierte Gewinne sind nicht meldepflichtig. Seit der Einführung der Bestandsstatistik der Deutschen Bundesbank für Direktinvestitionen basiert die Schätzung der reinvestierten Gewinne auf den gemeldeten Angaben über Stand und Zusammensetzung des Vermögens Gebietsansässiger in fremden Wirtschaftsgebieten sowie des Vermögens Gebietsfremder im Wirtschaftsgebiet und damit auf den Bilanzen bzw. Vermögensaufstellungen von Direktinvestitionsunternehmen, deren Bilanzsumme bzw. Bruttobetriebsvermögen 500000 DM übersteigt. Die reinvestierten Gewinne werden geschätzt unter Berücksichtigung der den Direktinvestoren zuzurechnenden Anteile an den Veränderungen von Rücklagen und Gewinn- bzw. Verlustvorträgen und des Teils des Gewinns, der im Folgejahr ausgeschüttet wurde. ${ }^{113}$ Auch in den Berichtsjahren vor 1977 waren die reinvestierten Gewinne in dem in der Zahlungsbilanzstatistik ausgewiesenen Direktinvestitionskapital enthalten; sie mußten jedoch auf wesentlich unsicherer Datengrundlage geschätzt werden und waren regional nicht aufteilbar. ${ }^{114}$

Erwerb und Veräußerung von kommerziell genutztem Grundbesitz zählen stets zum Direktinvestitionskapital. Nicht im Einklang mit den Empfehlungen von IMF und OECD stehend gelten privater Grundbesitz - bebaut oder unbebaut - als „übrige Anlagen“ und nicht als Direktinvestitionen. ${ }^{115}$

Das Direktinvestitionskapital enthält entgegen den Empfehlungen von IMF und OECD weder kurzfristige finanzielle Kreditbeziehungen noch lang- und kurzfristige Handelskredite zwischen verbundenen Unternehmen. Die von IMF und OECD vorgesehenen fiktiven Transaktionen für Finanzierungs-Leasing, für Operating-Leasing für länger als ein Jahr, für Geschäfte mit nicht-finanziellen immateriellen Vermögenswerten - insbesondere Patente, Copyrights und andere Schutzrechte - u. a. m. können wegen Informationsmangels meist nicht berücksichtigt werden. ${ }^{116}$

112 In der Bestandsstatistik der Deutschen Bundesbank werden die reinvestierten Gewinne dagegen im Jahr der Gewinnentstehung erfaßt; vgl. z. B. Deutsche Bundesbank (1990f, S. 33 und 70).

113 Zur Ermittlung der reinvestierten Gewinne vgl. Deutsche Bundesbank (1990f, S. 70 und 83) sowie eurostat (1983b, S. 49 f. und 63).

$114 \mathrm{Vgl}$. Deutsche Bundesbank (1978, S. 32). Die reinvestierten Gewinne werden erstmals für das Berichtsjahr 1977 getrennt ausgewiesen. Vgl. Deutsche Bundesbank (1984b, S. 20 Tab. 3e). In früheren Jahren waren die reinvestierten Gewinne nicht in den "übrigen Kapitalanlagen“ sondern in den "Anlagen in sonstigen Kapitalanteilen" enthalten.

115 Vgl. Deutsche Bundesbank (1976a, S. 336; 1987b, S. 82; 1990f, S. 81 und 86) und eurostat (1983b, S. 65).

116 Vgl. Deutsche Bundesbank (1990f, S. 27) und eurostat (1983b, S. 20). 
Mit Ausnahme der reinvestierten Gewinne sind in der Zahlungsbilanzstatistik Änderungen des Bestands, die nicht mit Zahlungen im weiteren Sinne verbunden sind, also z. B. Bestandsänderungen des Vermögens infolge von Wechselkursänderungen, Höherbewertungen, (Teil-)Abschreibungen, Konkurs oder Enteignung, nicht enthalten. ${ }^{117}$ Wechselkursänderungen gehen jedoch über die reinvestierten Gewinne teilweise in das Direktinvestitionskapital ein. Beim schrittweisen Erwerb eines Unternehmens in einem anderen Land werden die früher geleisteten bzw. entgegengenommenen Beträge nach Erreichen einer Kapitalbeteiligung, die den Kapitalanleger als Direktinvestor und gleichzeitig das Unternehmen in dem anderen Land als Direktinvestitionsunternehmen qualifiziert, nicht von Portfolio- zu Direktinvestitionen umklassifiziert. ${ }^{118}$

Für deutsche Kapitalanlagen im Ausland und für ausländische Kapitalanlagen in der Bundesrepublik Deutschland getrennt werden für die Positionen Anlagen in Dividendenwerten, Anlagen in sonstigen Kapitalanteilen, übrige Anlagen insgesamt und langfristige Kredite jeweils Neuanlagen, Liquidationen und Nettowerte ausgewiesen. Eine regionale Gliederung des Direktinvestitionskapital nach tatsächlichen Anlageländern bzw. nach tatsächlichen Herkunftsländern ist nicht möglich. Die in der Zahlungsbilanzstatistik erfaßten Transaktionen werden deshalb den unmittelbaren Anlageländern (deutsche Direktinvestitionen im Ausland) bzw. den Ländern der unmittelbaren ausländischen Investoren (ausländische Direktinvestitionen in der Bundesrepublik Deutschland) zugeordnet; nur die von deutschen Direktinvestoren in gebietsfremden Tochtergesellschaften reinvestierten Gewinne können den Sitzländern der unmittelbaren Direktinvestitionsunternehmen zugerechnet werden. ${ }^{119}$ Angaben über die Direktinvestitionen nach Ländern sind jedoch nur für die Nettokapitalanlagen im Ausland bzw. im Inland verfügbar; Neuanlagen und Liquidationen nach Ländern werden - außer für die USA - nur für Ländergruppen ausgewiesen. Zahlungsbilanzwerte für Direktinvestitionen nach Wirtschaftszweigen stehen nicht zur Verfügung, ${ }^{120}$ sondern nur Netto-Transaktionswerte nach inländischen Gläubigern bzw. Schuldnern, wobei nach Kreditinstituten und nach Unternehmen sowie Privatpersonen differenziert wird.

In der Zahlungsbilanzstatistik werden nur Transaktionen erfaßt, an denen sowohl Inländer als auch Ausländer (direkt oder über Gebietsansässige, die auf Rechnung von Gebietsfremden handeln) beteiligt sind, nicht aber Transaktionen zwischen Inländern bzw. zwischen Ausländern. Auf die Höhe der deutschen Nettokapitalanlagen im Ausland ins-

\footnotetext{
117 Vgl. Deutsche Bundesbank (1990f, S. 26 und 79) und eurostat (1983b, S. 19 und 59).

118 Vgl. Deutsche Bundesbank (1990f, S. 26) und eurostat (1983b, S. 62 Fn. 4)

119 Zur regionalen Gliederung der Direktinvestitionen vgl. Deutsche Bundesbank (1990f, S. 100 f.) und eurostat (1983b, S. 79).

120 Die Deutsche Bundesbank zieht deshalb im Zusammenhang mit der Branchenstruktur der Direktinvestitionen die Angaben der Transferstatistik des Bundesministeriums für Wirtschaft heran; vgl. Deutsche Bundesbank (1978, S. 33 f.). Zu den Zahlungsbilanzwerten für Direktinvestitionen nach inländischen Wirtschaftszweigen vgl. aber auch Deutsche Bundesbank (1989a, S. 32 f.).
} 
gesamt und nach Empfängerländern sowie auf die Summe der ausländischen Nettokapitalanlagen in der Bundesrepublik hat dies keinen Einfluß, denn die für Neuanlagen und für Liquidationen ausgewiesenen Daten sind jeweils um den selben Betrag zu niedrig. Auf die Nettokapitalanlagen nach Herkunftsländern hat die Nichtberücksichtigung des Eigentumswechsels zwischen Ausländern dann einen Einfluß, wenn die beiden Gebietsfremden Inländer verschiedener Länder sind. Veräußert beispielsweise ein Direktinvestor aus Land A seine Kapitalanteile, die er an einer Tochtergesellschaft in der Bundesrepublik hält, an einen Investor aus Land B, dann erscheint diese Transaktion nicht in der deutschen Zahlungsbilanzstatistik; da weder die Liquidation von Land A noch die Neuanlage von Land $B$ erfaßt wird, werden die in der deutschen Zahlungsbilanzstatistik für Direktinvestitionen von Land A in der Bundesrepublik zu hoch und die für Direktinvestitionen von Land B in der Bundesrepublik zu niedrig ausgewiesen.

Ein Beispiel aus jüngster Zeit verdeutlicht dies: Im Februar 1993 verkaufte die Bernard Tapie Finance S.A., Paris, für 615 Mio. DM ihre $78 \%$ ige Beteiligung an der Bernard Tapie Finance GmbH, Essen, (jetzt: adidas International Holding GmbH) - diese hält $95 \%$ der Aktien an dem Sportartikelhersteller adidas AG, Herzogenaurach - an drei französische Staatsunternehmen (Kreditinstitut Crédit Lyonnais und die beiden Versicherungsunternehmen Assurances Générales de France sowie, über ihre Tochtergesellschaft Banque Worms, die Union des Assurances de Paris), die ihren Anteil damit von $17 \%$ auf $42,1 \%$ aufstockten, an die von der in Luxemburg ansässigen Gruppe Euroknights kontrollierte Coatbridge Holdings Ltd. (15\%), an die Omega Ventures Limited (19,9\%) mit Sitz auf Jersey, an Ricesa (15\%) und an die derzeitige Vorstandsvorsitzende der adidas AG, Gilberte Beaux, die ihren Anteil um $3 \%$ auf $8 \%$ erhöhte. Der Verkauf von Tapies Beteiligung erscheint nicht in der Zahlungsbilanz, denn an den Transaktionen sind keine Inländer beteiligt. Das Beispiel zeigt auch, daß Direktinvestitionen nicht ausschließlich mit dem Kapitalanteil abgegrenzt werden sollten. Zum einen erwies sich der französische Stadtentwicklungsminister Bernard Tapie schon bald nach dem Kauf von $95 \%$ der Anteile an adidas im Sommer 1990 als Spekulant; da er die zum Erwerb der Beteiligung aufgenommenen Kredite nicht zurückzahlen konnte, verkaufte er bereits im folgenden Jahr einen Teil seiner Anteile gewinnbringend. Zum anderen erfüllen von den Käufern von Tapies Anteilen nur die drei Staatsunternehmen zusammen das Kriterium eines Direktinvestors. Im April 1993 wird der französische Geschäftsmann Robert Louis-Dreyfus, der über Ricesa mit $15 \%$ an der adidas-Holding beteiligt ist und eine Option auf Übernahme des gesamten Unternehmens hat, neuer Vorstandsvorsitzender der adidas AG; Gilberte Beaux, die $8 \%$ der Anteile an der Holding hält, wird dann Aufsichtsratsvorsitzende. ${ }^{121}$

Mittelbare Beteiligungen werden - soweit erkennbar - in der Zahlungsbilanzstatistik nicht

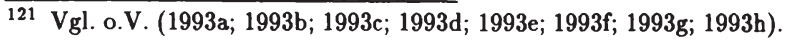


berücksichtigt. Ausgenommen hiervon sind nur die direkten Kredite an mittelbare Direktinvestitionsunternehmen. Investitionen der Adam Opel AG, Rüsselsheim, in Eisenach werden also beispielsweise in der deutschen Zahlungsbilanzstatistik nicht als Direktinvestitionen von General Motors, Detroit/Michigan, erfaßt; in der US-amerikanischen Zahlungsbilanzstatistik dagegen erscheinen diese Investitionen als US-amerikanische Direktinvestitionen in der Bundesrepublik.

Die Einführung gesonderter Kennzahlen für Direktinvestitionen hat zur Folge, daß die Daten für die Berichtsjahre ab 1990 zuverlässiger ermittelt werden können. Vor dem Berichtsjahr 1990 wurden zum Teil auch Transaktionen mit nicht-verbundenen Unternehmen einbezogen; seit 1990 ist die statistische Erfassung der Direktinvestitionen in Form von Erwerb und Veräußerung von Unternehmensbeteiligungen, ${ }^{122}$ insbesondere aber die der Direktinvestitionen in Form von langfristigen Krediten wesentlich genauer. Die verbesserte statistische Aufbereitung des Datenmaterials, aber auch die Herabsetzung der zur Unterscheidung der Direktinvestitionen von den Portfolioinvestitionen verwendeten Beteiligungsgrenze von mindestens $25 \%$ auf über $20 \%$ der Kapitalanteile, haben einen qualitativen Sprung in den Zeitreihen für Direktinvestitionen in der Zahlungsbilanzstatistik der Deutschen Bundesbank zur Folge. Auch im Jahr 1977 ist ein Bruch zu verzeichnen: Seit Einführung der Bestandsstatistik für Direktinvestitionen (Buchwertmethode) ist die Schätzung der Direktinvestitionen in Form von reinvestierten Gewinnen zuverlässiger und die unverteilten Gewinne sind regional aufteilbar.

\subsubsection{Transferstatistik des Bundesministeriums für Wirtschaft}

Ebenfalls auf Transaktionswerten beruht die Transferstatistik ${ }^{123}$, die das Bundesministerium für Wirtschaft (BMWi) jährlich im Bundesanzeiger ${ }^{124}$ veröffentlicht. Geführt wird diese Statistik seit dem 1.1.1952 für „Vermögensanlagen Gebietsansässiger in fremden Wirtschaftsgebieten“ bzw. seit dem 1.9.1961 für „Vermögensanlagen Gebietsfremder im Wirtschaftsgebiet ${ }^{\star}$. Nach $\S \S 55,56,57$ und 58 AWV in Verbindung mit $\S 26$ Abs. 2

$\overline{122}$ eurostat (1983b, S. 63) vermutet, daß die von der Beteiligungshöhe unabhängige Erfassung von Erwerb und Veräußerung von Beteiligungen an inländischen Unternehmen in anderer Rechtsform als einer Aktiengesellschaft bzw. von Beteiligungen an ausländischen nicht-körperschaftlich organisierten Unternehmen kaum Einfluß auf die Höhe des ausgewiesenen Direktinvestitionskapitals hat.

123 Die Deutsche Bundesbank spricht im Zusammenhang mit dieser Statistik von Spezialstatistik, Krägenau $(1972 ; 1979 ; 1982 ; 1987)$ von K-1- bzw. K-2-Statistik und Seifert (1967) von AWV-Statistik.

124 Zuletzt Der Bundesminister für Wirtschaft (1992a; 1992b). Die Transferstatistik wurde in früheren Jahren halbjährlich im Bundesanzeiger veröffentlicht. Bis einschließlich dem Berichtsjahr 1980 wurden seit dem 1.1.1952 (deutsche Direktinvestitionen im Ausland) bzw. seit dem 1.9.1961 (ausländische Direktinvestitionen in der Bundesrepublik) kumulierte Nettotransferwerte ausgewiesen; seither werden Stromgrößen veröffentlicht. Vgl. Der Bundesminister für Wirtschaft (1981a; 1981b; 1982a; 1982b). Die Transferstatistik wird auch in Bundesministerium für Wirtschaft: Leistung in Zahlen, zuletzt Bundesministerium für Wirtschaft (o.J.), ausgewiesen. 
AWG besteht gesetzliche Auskunftspflicht. ${ }^{125}$ Die Meldungen sich grundsātzlich monatlich abzugeben. Die Meldevorschriften wurden mehrfach geändert, teils zur Erweiterung der Meldepflicht, größtenteils aber zur Verringerung des statistischen Melde- und Aufbereitungsaufwandes. Die Neufassung der $\S \S 55,56,57$ und 58 AWV im September 1989 - die Änderungen traten zum 1.1.1990 in Kraft - brachte zahlreiche Änderungen in der Erfassungsmethode mit sich; ${ }^{126}$ deshalb muß wie schon bei der Zahlungsbilanzstatistik der Deutschen Bundesbank auch bei der Transferstatistik in weiten Teilen zwischen vor und seit dem Berichtsjahr 1990 unterschieden werden.

Meldepflichtig ist der eine Leistung an das Ausland erbringende bzw. vom Ausland empfangende Gebietsansässige; vor dem Berichtsjahr 1990 waren darüber hinaus Transaktionen zwischen Gebietsansässigen auf eigene Rechnung zu melden. ${ }^{127}$ Bereits im Jahre 1963 wurde die Meldepflicht bei Vermögensanlagen Gebietsansässiger in fremden Wirtschaftsgebieten erweitert auf den Fall, daß ,sich der Gebietsansässige beim Erbringen seiner Leistung eines Gebietsfremden, insbesondere eines von ihm abhängigen Unternehmens, bedient. ${ }^{\star 128}$ Mit Wirkung vom 1.1.1990 erstreckt sich dic Meldepflicht für deutsche Direktinvestitionen im Ausland und für ausländische Direktinvestitionen in der Bundesrepublik auch auf die Leistungen, die Gebietsansässige auf Rechnung von Gebietsfremden an Gebietsansässige erbringen bzw. auf Rechnung von Gebietsfremden von Gebietsansässigen entgegennehmen. ${ }^{129}$

Unter Brutto-Direktinvestitionen im Ausland werden in der Transferstatistik Leistungen verstanden, die Gebietsansässige ,an Gebietsfremde oder für deren Rechnung an Gebietsansässige erbringen und welche die Anlage von Vermögen in fremden Wirtschaftsgebieten zur Schaffung dauerhafter Wirtschaftsverbindungen (Direktinvestitionen) bezwecken“130. Für ausländische Direktinvestitionen in der Bundesrepublik Deutschland gilt entsprechen-

125 Zur Entwicklung der rechtlichen Grundlagen für die Ermittlung der deutschen Direktinvestitionen im Ausland nach dem Zweiten Weltkrieg bis zum Inkrafttreten des AWG vgl. Seifert (1967, S. 45 ff.).

${ }^{26}$ Zur Neufassung der $§ \S 55,56,57$ und 58 siehe Fünfte Verordnung zur Änderung der Außenwirtschaftsverordnung vom 20. September 1989.

$127 \mathrm{Vgl}$. $56 \mathrm{Abs} .1$ und $\S 58 \mathrm{Abs} .1 \mathrm{AWV}$ vom 22 . August 1961 und AWV vom 18. Dezember 1986, neugefaßt durch die Fünfte Verordnung zur Änderung der Außenwirtschaftsverordnung vom 20. September 1989 .

$128 \S 55$ Abs. 1 Satz 2 AWV vom 22. August 1961, geändert durch die Vierte Verordnung zur Änderung der Außenwirtschaftsverordnung vom 17. Dezember 1963; zu dieser Erweiterung der Meldepflicht vgl. auch Der Bundesminister für Wirtschaft (1964) und Seifert (1967, insb. S. 62). Welche Unternehmen als abhängig gelten, ist nicht spezifiziert. - Diese Meldebestimmung ist im neugefaBten $\S 55$ AWV nicht mehr enthalten.

129 Vgl. $§ 55$ Abs. 1 Nr. 1 und 2 und $\S 57$ Abs. 1 Nr. 1 und 2 AWV vom 18. Dezember 1986, neugefaßt durch die Fünfte Verordnung zur Änderung der Außenwirtschaftsverordnung vom 20. September 1989 .

$130 § 55$ Abs. 1 Nr. 1 AWV vom 18. Dezember 1986, neugefaßt durch die Fünfte Verordnung zur Änderung der Außenwirtschaftsverordnung vom 20. September 1989. 
des. ${ }^{131}$ Explizit crscheint der Begriff Direktinvestitionen in den für dic Transferstatistik relevanten Meldebestimmungen erstmals in der AWV in der Fassung vom 20. September 1989. ${ }^{132} \Lambda$ bgestellt wird nit dieser Definition auf die Dauerhaftigkeit der Wirtschaftsbezichungen. Daucrhaftigkeit zu qualifizicren und damit - unabhängig ${ }^{133}$ von dem Kriterium der Finflußnahme eines Direktinvestors auf die Geschäftsleitung eines Unternehmens in cinem anderen Land - bestimmte inländische (bzw. ausländische) Kapitalanlagen im Ausland (bzw. Inland) als Direktinvestitionen zu klassifizieren, lag vor dem Berichtsjahr 1990 zunächst, ausschlicßlich im Frmessen des meldenden Gebietsansässigen. Frst die Neufassuug der $§ \S 55$ und 57 AWV enthält eine Regelung, die dauerhafte Wirtschaftsbeziehungen und damit. Direktinvestitionen durch eine Mindestbeteiligung des Investors am Kapital eines anderen Unternehmens abgren\%t.

Die in der Transferstatistik als Direktinvestitionskapital erfaßten Vermögensanlagen im $\Lambda$ usland bzw. im Inland ergeben sich im wesentlichen aus den Meldevorschriften. Danach haben Gebictsansässige Kapitalanlagen in (bzw. aus) fremden Wirtschaftsgebieten sowie deren $\Lambda$ ufösung zu melden, wenn diese der Schaffung oder $\Lambda$ uflösung dauerhafter Wirtschaftsbezichungen dienen und in folgenden Formen vollzogen werden: ${ }^{134}$

- Gründung oder Erwerb sowie $\Lambda$ uflösung oder Veräußerung von gebietsfremden (bzw. gebietsansässigen) Unternchmen;

- Erwerb oder Veräußerung von Beteiligungen an gebietsfremden (bzw. gebietsansässigen) Unternehmen;

- Errichtung oder Erwerb sowie Aufhebung oder Veräußerung von gebietsfremden (bzw. gebictsansässigen) Zwcignicderlassungen oder Betricbsstättcn;

- Zuführung von Kapital zu gebietsfremden (bzw. gebietsansässigen) Unternehmen, Zweigniederlassungen oder Betricbsstätten, die dem gebietsansässigen (bzw. gebictsfremden) Kapitalgeber gehören oder an denen er beteiligt, ist, - beispielsweise Kapitalerhöhung,

131 Vgl. $\S 57$ Abs. 1 Nr. 1 AWV vom 18 . Dezember 1986, neugefaßt durch die Fünfte Verordnung zur Änderung der Außenwirtschaftsverordnung vom 20. September 1989.

132 In den früheren Fassungen der $\$ \$ 55$ und 57 AWV fehlte der Zusatz „Direktinvestitionen“. Vgl. hierzu auch Gramlich (1991, S. 172 ff.).

${ }^{133}$ Fïr Kredite bestand bis zur Neufassung der $§ \S 55,56,57$ und 58 AWV im September 1989 eine Ausnahme; siche unten.

134 Zurn folgenden vgl. $\S 55 \Lambda$ bs. 1 und 2 sowie $\S 57 \Lambda$ bs. 1 und $2 \Lambda$ WV vom 22 . $\Lambda$ ugust $1961, \S 55 \Lambda$ bs. 1 und $\$ 57 \Lambda$ bs. 1 AWV vom 18. Dezemher 1986, neugefabt, durch die Fünfte Verordnung zur Änderung der AuBenwirtschaftsverordnung vom 20 . September 1989, die mehrfach angepaBten bzw. neugefaBten Meldevordrucke für „Vermögensanlagen Gebietsansässiger in fremden Wirtschaftsgebieten“ (Anlage K 1 \%ur AWV) und „Vermögensanlagen Gebietsfremder im Wirtschaftsgebiet“" (Anlage K 2 zur AWV) sowic dic erstmals 1989 auf den Rïckseiten der Meldevordrucke K 1 und K 2 abgedruckten Erläuterungen der Deutschen Bundesbank (1990a; 1990h). Die Meldevordrucke sind ohne Frläuterungen abgedruckt als Anlagen zur AWV vom 22. August 1961, zur Bekanntmachung der Neufassung der Verordnung zur Durchfiihrung des AuBenwirtschaftsgesetzes (AuBenwirtschaftsverordnung - AWV) vom 31. August 1973, zur Zweiundfiinfzigsten Verordnung zur Änderung der Außenwirtschaftsverordnung vom 13. August 1982 und zur AWV vom 18. Dezember 1986, neugefabt durch die Fünft.e Verordnung zur Änderung der $\Lambda$ ußenwirtschaftsverordnung vom 20. September 1989. 
Rücklagenzuführung oder Zahlungen zur Abdeckung von Verlustvorträgen - sowie Rückführung von solchem Kapital,

bzw. vor dem Berichtsjahr 1990: Ausstattung dieser gebietsfremden (bzw. gebietsansässigen) Unternehmen, Zweigniederlassungen und Betriebsstätten mit Anlagemitteln oder Zuschüssen; und

- Gewährung von langfristigen ${ }^{135}$ Krediten an gebictsfremde (bzw. gebietsansässige) Unternehmen, Zweigniederlassungen oder Betriebsstätten, die dem gebietsansässigen (bzw. dem gebietsfremden) Kreditgeber oder einem von ihm abhängigen inländischen oder ausländischen Unternehmen gehören oder an denen der gebietsansässige (bzw. der gebietsfremde) Kreditgeber oder ein von ihın abhängiges inländisches oder ausländische's Unternehmen mit mehr als $20 \%$ der Anteile beteiligt ist, sofern beide an der Transaktion Beteiligte Nichtbanken sind, sowie Rückführung solcher Kredite; dic Abgrenzung der Abhängigkeit ${ }^{136}$ eines Unternehmens folgt - wie in der Zahlungsbilanzstatistik der Deutschen Bundesbank - §17 AktG;

bzw. vor dem Berichtsjahr 1990: Gewährung von Darlehen an gebietsfremde (bzw. gebietsansässige) Unternehmen, die dem gebietsansässigen (bzw. dem gebietsfremden) Darlehensgeber gehören oder an denen er unmittelbar oder mittelbar beteiligt ist oder auf deren Geschäftsführung er infolge der Gewährung des Darlehens erheblichen Finfluß hat, sowie Entgegennahme der Darlehensrückzahlung. Wann das Kriterium des erheblichen Einflusses als erfüllt anzusehen war und welche Beteiligungen als mittelbare zu behandeln waren, war nicht präzisiert.

Der Begriff Leistung umfaßt neben Zahlungen auch Verrechnung und Aufrechnung sowie Einbringung von Sachen und Rechten. Für nicht auf Dauer angelegte Betriebsstätten, also beispielsweise zur Durchführung eines speziellen Auftrags für eine begrenzte Zeit eingerichtete Montagestätten und Baustellen, sind keine Meldungen abzugeben.

Die Zahl der Leistungen, die erst seit dem Berichtsjahr 1990 nicht mehr der Meldepflicht unterliegen, ist so groß, daß die in der Transferstatistik ausgewiesenen Daten für Direktinvestition intertemporal nur eingeschränkt vergleichbar sind. Das bis bzw. seit 1990 statistisch erfaßte Direktinvestitionskapital unterscheidet sich insbesondere in folgenden Punkten: ${ }^{137}$

135 Ein Kredit mit einer ursprünglich vereinbarten Laufzeit oder Kündigungsfrist von mehr als zwölf Monaten gilt als langfristig; vgl. $§ 55$ Abs. 2 Nr. 3 und $\S 57$ Abs. 2 Nr. 3 AWV vom 18. Dezember 1986, neugefaßt durch die Fünfte Verordnung zur Änderung der Außenwirtschaftsverordnung vom 20. September 1989.

${ }^{136}$ Anders als bei der Bestandsstatistik für ausländische Direktinvestitionen in der Bundesrepublik Deutschland enthalten nur die Erläuterungen zu den Meldevordrucken K 1 und K 2 eine Regelung zur Abgrenzung abhängiger Unternehmen; vgl. Deutsche Bundesbank (1990a; 1990b).

137 Vgl. hierzu auch Der Bundesminister für Wirtschaft (1989, S. 4622) und Deutsche Bundesbank (1989b). 
- Seit dem Berichtsjahr 1990 sind nur noch Einzeltransaktionen von (umgerechnet) über 50000 DM meldepflichtig. In früheren Jahren unterlagen die von einem Gebietsansässigen erbrachten oder entgegengenommenen Leistungen der Meldepflicht, wenn sie in einem Kalenderjahr insgesamt (umgerechnet) 10000 DM (für September 1961 bis August bzw. Dezember 1982), 20000 DM (für September 1982 bzw. Januar 1983 bis Dezember 1987) bzw. 50000 DM (für 1988 und 1989) überstiegen; die Meldefreigrenzen galten jedoch weder für Veräußerung, Auflösung bzw. Aufhebung von Unternehmen, Zweigniederlassungen und Betriebsstätten noch für die Veräußerung von Beteiligungen, d. h., sie galten zwar für alle Neuanlagen, bei der Aufösung von Vermögensanlagen jedoch nur für die Entgegennahme von Darlehensrückzahlungen. ${ }^{138}$ Bei Fremdwährungsbeträgen ist der Gegenwert in DM im Zeitpunkt der Vermögensanlage anzugeben.

- Seit dem Berichtsjahr 1990 sind Anlage oder Auflösung von Vermögen in Unternehmen nur noch meldepflichtig, wenn dem Gebietsansässigen (Gebietsfremden) oder einem von ihm abhängigen Unternehmen mehr als $20 \%$ der Anteile am gezeichneten Kapital dieses Unternehmens zuzurechnen sind. Erwerb und Veräußerung von Unternehmensbeteiligungen müssen nur noch dann gemeldet werden, wenn dem Gebietsansässigen (Gebietsfremden) nach dem Erwerb bzw. vor der Veräußerung unmittelbar mehr als $20 \%$ des Nennkapitals dieses gebietsfremden (gebietsansässigen) Unternehmens zuzurechnen sind bzw. waren. ${ }^{139}$ Vor dem Berichtsjahr 1990 war keine Mindestbeteiligung als Untergrenze für die statistische Erfassung festgelegt.

- Vor dem Berichtsjahr 1990 wurden Darlehen als Direktinvestitionskapital erfaßt, wenn sic eine Laufzeit von über einem Jahr und Beteiligungscharakter hatten. ${ }^{140}$ Seit 1990 sind langfristige Kredite nur noch dann meldepflichtig, wenn sie einer unmittelbaren oder mittelbaren Tochtergesellschaft des Kreditgebers gewährt werden (einschließlich Kredite inländischer/ausländischer Gesellschaften an eine gebietsfremde/gebietsansässige Tochtergesellschaft eines vom Kreditgeber abhängigen inländischen/ausländischen Unternehmens) und weder Kreditgeber noch Kreditnehmer ein Geldinstitut sind; welche Unternehmen als Tochtergesellschaften zu behandeln sind, wird durch Festlegung einer Mindestbeteiligungsquote geregelt. Die Neuregelung bedeutet u. a., daß für Kre-

$\overline{138} \mathrm{Zu}$ den Meldefreigrenzen siehe $\S 55 \mathrm{Ab}$ s. 3 und $\S 57$ Abs. 3 AWV vom 22. August 1961, geändert durch die Zweiundfünfzigste Verordnung zur Änderung der Außenwirtschaftsverordnung vom 13. August 1982 , geändert durch dic Vicrundfünfzigste Verordnung zur Änderung der Außenwirtschaftsverordnung vom 17. Januar 1983 und $\S 55$ Abs. $2 \mathrm{Nr} .1$ und $\S 57$ Abs. 2 Nr. 1 AWV vom 18. Dezember 1986, geändert durch die Frste Verordnung zur Änderung der Außenwirtschaftsverordnung vom 14. Dezember 1987 und durch die. Fünfte. Verordnung zur Änderung der AuBenwirtschaftsverordnung vom 20. September 1989. Der Bundesminister für Wirtschaft (1982c) erwartete, daß durch die Verdoppelung der Meldefreigrenzen von 10000 DM auf 20000 DM zwar rund $20 \%$ der Meldungen, aber weniger als $1 \%$ des Wertes der getätigten Vermögensanlagen entfallen.

139 Vgl. $§ 55$ Abs. 2 Nr. 2 und $\S 57$ Abs. 2 Nr. 2 AWV vom 18. Dezember 1986, neugefaßt durch die Fünfte Verordnung zur Änderung der Außenwirtschaftsverordnung vom 20. September 1989.

140 Vgl. auch Seifert (1967, S. 51). 
ditinstitute das Direktinvestitionskapital seit 1990 auf Beteiligungskapital beschränkt ist und daß ein Unternehmen nicht mehr ausschließlich aufgrund einer Kreditvergabe bzw. -aufnahme an ein bzw. bei einem Wirtschaftssubjekt in einem anderen Land zu einem Direktinvestor bzw. zu einem Direktinvestitionsunternehmen werden kann. Handelskredite werden unabhängig von ihrer Fristigkeit nicht als Direktinvestitionskapital erfaßt.

- Seit dem Berichtsjahr 1990 sind Transaktionen zwischen Gebietsansässigen für eigene Rechnung und Transaktionen, die keinerlei Meldung auslösen, nicht mehr meldepflichtig.

- Seit dem Berichtsjahr 1990 zählen Zuschüsse an Tochtergesellschaften nicht mehr zum Direktinvestitionskapital.

Weder bei Vermögensanlagen Gebietsansässiger in fremden Wirtschaftsgebieten noch bei Vermögensanlagen Gebietsfremder im Wirtschaftsgebiet gelten wirtschaftlich verbundene Investoren als ein Wirtschaftssubjekt.

Grundsātzlich nicht erfaßt werden in der Transferstatistik Leistungen, die von der Meldepflicht ausgenommen sind, darunter kurzfristige Kredite, Kredite der Tochtergesellschaften an ihre Muttergesellschaften und Kredite zwischen in- und ausländischen Schwesterunternehmen, sowie alle transaktionsunabhängigen Wertänderungen der Vermögensanlagen wie Vermōgenszuwächse bzw. -verluste infolge Wechselkursänderungen, Höherbewertungen oder (Teil-)Abschreibungen. Für die Anteile der Direktinvestoren an den reinvestierten Gewinnen ihrer Tochterunternehmen werden - anders als in der Zahlungsbilanzstatistik der Deutschen Bundesbank - keine fiktiven Transaktionen unterstellt; $d$. h., reinvestierte Gewinne sind nicht im in der Transferstatistik ausgewiesenen Direktinvestitionskapital enthalten. Weder kommerzieller noch privater Grundbesitz zählen zum Direktinvestitionskapital.

Bei der statistischen Aufbereitung der Daten für die Transferstatistik zieht die Deutsche Bundesbank noch weitere Quellen heran. Es ist nicht festzustellen, welche der gemeldeten Leistungen auch tatsächlich berücksichtigt werden. Für die Berichtsjahre vor 1990 ist nicht auszuschließen, daß bei der Auswertung der gemeldeten Kapitalanlagen in Form von Unternehmensgründungen und von Erwerb von Unternehmensbeteiligungen nicht doch eine Mindestbeteiligungshöhe zur Abgrenzung der Direktinvestitionen zugrunde gelegt wurde, denn in den Meldevordrucken waren für Kapitalanlagen in diesen beiden Formen - und nur für diese - neben dem aufgewendeten bzw. entgegengenommenen Betrag oder Wert der Leistung auch der Anteil des Investors am Gesamtkapital anzugeben.

Seit dem Berichtsjahr 1990 ist der Umfang der zu meldenden Leistungen also geringer insbesondere wegen der Erhöhung der Meldefreigrenzen, der Beschränkung der Meldepflicht 
bei Beteiligungen auf direkte Beteiligungen, die $20 \%$ des Nennkapitals überschreiten, der Beschränkung der Meldepflicht auf bestimmte langfristige Kredite zwischen Nichtbanken sowie des Verzichts auf die Meldung von Zuschüssen und von Transaktionen zwischen Gebietsansässigen auf eigene Rechnung.

Als weiterer Grund, warum die Angaben über Direktinvestitionen in der Transferstatistik des BMWi intertemporär nur sehr bedingt vergleichbar sind, ist zu nennen, daß im Jahr 1987 die Erfassungsmethode geändert wurde: ${ }^{141}$

- Die Zuordnung der Transferleistungen erfolgt zeitgerechter.

- Die wertgerechte Erfassung der Transfers wurde verbessert. So werden beispielsweise Liquidationen nicht mehr in Höhe der ursprünglichen Neuanlage rückgebucht, sondern zum tatsächlichen Wert.

- Die Meldeergebnisse sind vollständiger.

Ziel der Umstellung der Erfassungsmethode war die qualitative Verbesserung der Transferstatistik und eine bessere Vergleichbarkeit mit der Bestandsstatistik der Deutschen Bundesbank. Nur für das Berichtsjahr 1986 stehen sowohl nach der bisherigen als auch nach der neuen Erfassungsmethode ermittelte Daten zur Verfügung. Bei identischer Datengrundlage ergeben sich in Abhängigkeit der Erfassungsmethode relativ große Unterschiede für das in der Transferstatistik ausgewiesene Direktinvestitionskapital. Für Vermögensanlagen Gebietsansässiger in fremden Wirtschaftsgebieten betragen die nach der neuen (alten) Methode erfaßten Bruttokapitalleistungen für Direktinvestitionen 23,8 Mrd. DM (21,2 Mrd. DM); für die Rückflüsse, d. h. für Rückzahlungen von Darlehen, Liquidationen, Veräußerungen von Beteiligungen und Umbuchungen, werden 7,3 Mrd. DM (10,0 Mrd. DM) ausgewiesen. Für Vermögensanlagen Gebietsfremder im Wirtschaftsgebiet werden nach der neuen (alten) Erfassungsmethode für Bruttodirektinvestitionen 10,7 Mrd. DM (11,1 Mrd. DM) und für Rückflüsse 8,4 Mrd. DM (5,3 Mrd. DM) ermittelt. Die Nettotransferleistungen für Vermögensanlagen Gebietsansässiger in fremden Wirtschaftsgebieten wurden also um 46,6 \% von 11,2 Mrd. DM auf 16,4 Mrd. DM ${ }^{142}$ nach oben und die Nettotransferleistungen für Vermögensanlagen Gebietsfremder im Wirtschaftsgebiet um $60 \%$ von 5,8 Mrd. DM auf 2,3 Mrd. DM nach unten revidiert. Der Saldo der Direktinvestitionen, d. h. die Differenz zwischen Nettotransferleistungen für deutsche Direktinvestitionen im Ausland und Nettotransferleistungen für ausländische Direktinvestitionen in der Bundesrepublik, beträgt nach der bisherigen Erfassungsmethode 5,4 Mrd. DM, auf der Grundlage der revidierten Daten dagegen 14,1 Mrd. DM.

Tabelle 4.1 zeigt am Beispiel der EG-Mitgliedsstaaten, Japans und der USA den großen Einfluß der mit dem Berichtsjahr 1986 geänderten Erfassungsmethode auf das für einzelne

\footnotetext{
141 Vgl. hierzu z. B. Der Bundesminister für Wirtschaft (1988a, Fn. 2; 1988b, Fn. 2).

142 Differenz in der Summe durch Runden der Zahlen.
} 
Ziel- bzw. Herkunftsländer ausgewiesene Volumen an Nettotransferleistungen. Die in absoluten Zahlen größten Revisionen sind für die deutschen Direktinvestitionen in Italien $(+1,4 \mathrm{Mrd}$. DM) und in den USA $(+3,6 \mathrm{Mrd}$. DM) sowie für britische bzw. japanische Direktinvestitionen in der Bundesrepublik (- 1,2 Mrd. DM bzw. -1,0 Mrd. DM) zu beobachten. In einzelnen Ländern weisen die nach alter bzw. neuer Methode erfaßten Nettotransferleistungen unterschiedliche Vorzeichen auf; je nach Berechnungsmethode sind für diese Länder die Bruttodirektinvestitionen entweder größer oder kleiner als die Rückflüsse.

Die regionale Zuordnung der Nettotransferleistungen erfolgt nach den Ländern, in denen die Tochtergesellschaften ihren Sitz haben, bzw. nach den Ländern der gebietsfremden Beteiligten. ${ }^{143}$ Die Transferstatistik des BMWi stellt auch nach Wirtschaftszweigen disaggregierte Nettotransferleistungen zur Verfügung. Die deutschen Direktinvestitionen im Ausland werden den Branchen der deutschen Investoren (Herkunftsbranchen) zugeordnet, die ausländischen Direktinvestitionen in der Bundesrepublik den Branchen der Direktinvestitionsunternehmen (Zielbranchen); bei diversifizierenden Unternehmen ist der Schwerpunkt der wirtschaftlichen Tätigkeit maßgebend. Die Gliederung der Nettotransferleistungen nach Wirtschaftszweigen folgt jedoch einer anderen Grundsystematik als andere amtliche Statistiken. ${ }^{144}$ Infolge der zunehmend zu beobachtenden Zusammenfassung von Vermögen in Holdinggesellschaften und der damit einhergehenden großen Bedeutung des Wirtschaftszweigs „Beteiligungsgesellschaften und sonstige Vermögensverwaltung “ als Herkunftsbranche deutscher Direktinvestitionen im Ausland, aber auch als Zielbranche ausländischer Vermögensanlagen in der Bundesrepublik, ist die Aussagekraft der Direktinvestitionen nach den Wirtschaftszweigen inländischer Investoren bzw. deutscher Investitionsobjekte stark eingeschränkt. Bruttokapitalleistungen und Rückflüsse nach Ländern oder nach Wirtschaftszweigen sowic Nettotransferleistungen nach Ländern und Wirtschaftszweigen weist die Transferstatistik nicht aus.

Sowohl bei der regionalen als auch bei der sektoralen Gliederung der Direktinvestitionen ist zu berücksichtigen, daß die Transferstatistik - ebenso wie die Zahlungsbilanzstatistik der Deutschen Bundesbank - Transaktionen zwischen Gebietsfremden nicht berücksichtigt; Transaktionen zwischen Gebietsfremden auf eigene Rechnung sind seit dem Berichtsjahr 1990 nicht mehr meldepflichtig. Verkauft ein Inländer seine Beteiligung an einem Unternehmen im Ausland an einen anderen Gebietsässigen bzw. veräußert ein Ausländer seine Beteiligung, die er an einem deutschen Unternehmen hält, an einen anderen Gebietsfremden, dann werden seit dem Berichtsjahr 1986, also seitdem die Liquidatio-

143 Belgien und Luxemburg weist die Transferstatistik nur in den Berichtsjahren 1984 bis 1986 (alte Erfassungsmethode) getrennt aus; vgl. hierzu Der Bundesminister für Wirtschaft (1985a; 1985b; 1987a; 1987b; 1988a; 1988b). In Zahlungsbilanzstatistiken wird häufig nur die BLUE ausgewiesen; vgl. hierzu z. B. die deutsche und die belgisch-luxemburgische Zahlungsbilanzstatistik.

144 Hierauf weist die Deutsche Bundesbank (1981a, S. 34) hin. 
Tabelle 4.1: Deutsche Direktinvestitionen in den EG-Mitgliedsstaaten, in den USA und in Japan sowie Direktinvestitionen der EG-Mitgliedsstaaten, der USA und Japans in der Bundesrepublik Deutschland im Jahr 1986 - Gegenüberstellung der Ergebnisse der Transferstatistik des Bundesministeriums für Wirtschaft nach bisheriger und neuer Erfassungsmethode

\begin{tabular}{|c|c|c|c|c|}
\hline \multirow{3}{*}{$\begin{array}{l}\text { Ziel- bzw. } \\
\text { Berkunftsland }\end{array}$} & \multicolumn{2}{|c|}{$\begin{array}{l}\text { Vernogensanlagen Cebiets- } \\
\text { ansassiger in frenden } \\
\text { Wirtschaftsgebieten }\end{array}$} & \multicolumn{2}{|c|}{$\begin{array}{l}\text { Venoggensanlagen Cebiets- } \\
\text { frender in Dirtschafts- } \\
\text { gebiet }\end{array}$} \\
\hline & $\begin{array}{l}\text { bisherige } \\
\text { Rrfassungs- } \\
\text { nethode }\end{array}$ & $\begin{array}{l}\text { neue } \\
\text { Erfassungs- } \\
\text { nethode }\end{array}$ & $\begin{array}{l}\text { bisherige } \\
\text { Rrfassungs- } \\
\text { nethode }\end{array}$ & $\begin{array}{l}\text { neue } \\
\text { Brfassungs- } \\
\text { wethode }\end{array}$ \\
\hline & \multicolumn{4}{|c|}{ in Mio. Dn } \\
\hline $\begin{array}{l}\text { alle Länder } \\
\text { darunter: }\end{array}$ & 11206,8 & 16429 & 5833,0 & 2332 \\
\hline $\begin{array}{l}\text { BG-Länder zusamen } \\
\text { davon: }\end{array}$ & 4427,6 & 6107 & 2919,2 & 1759 \\
\hline Belgien und Luxenburg & 394,5 & 290 & 67,3 & -178 \\
\hline Dänezark & $-2,3$ & 18 & 78,1 & 68 \\
\hline Irankreich & 495,7 & 486 & 424,3 & 356 \\
\hline Griechenland & 75,7 & 138 & 1,3 & $x$ \\
\hline Grobbritannien & 806,5 & 985 & 1724,8 & 518 \\
\hline Irland & 41,6 & 41 & 1,0 & $x$ \\
\hline Italien & $-238,5$ & 1151 & 146,3 & 84 \\
\hline niederlande & 2009,3 & 1745 & 445,3 & 898 \\
\hline Portugal & 32,1 & 30 & $-2,3$ & $x$ \\
\hline Spanien & 813,0 & 1223 & 33,2 & 17 \\
\hline Japan & 201,2 & 140 & 1256,6 & 246 \\
\hline OSA & 4414,3 & 8003 & 549,8 & -412 \\
\hline
\end{tabular}

$x$ Aus Gründen der Geheimhaltung von Einzelangaben nicht veröffentlicht.

Quelle: Der Bundesminister für Wirtschaft (1987a; 1987b; 1988a; 1988b); eigene Berechnungen.

nen von Kapitalanlagen mit den Transaktionswerten erfaßt werden bzw. für deutsche Direktinvestitionen im Ausland seit dem Berichtsjahr 1990, die Bruttokapitalleistungen für Direktinvestitionen und die Rückflüsse jeweils um denselben Betrag zu niedrig ausgewiesen. Die Nichtberücksichtigung dieser Transaktionen hat also keinen Einfluß auf die Höhe der Nettotransferleistungen insgesamt, nach Empfängerländern und nach inländischen Investitionsobjekten. Die deutschen Nettodirektinvestitionen im Ausland nach Herkunftsbranchen werden jedoch verzerrt wiedergegeben, wenn die beiden an der Trans- 
aktion beteiligten Inländer den Schwerpunkt ihrer wirtschaftlichen Tätigkeit in verschiedenen Branchen haben; die Nettotransferleistungen des Wirtschaftszweigs, dem das die Unternehmensbeteiligung verkaufende Unternehmen angehört, werden überschätzt und die des Wirtschaftszweigs, dem der die Unternehmensbeteiligung an dem ausländischen Unternehmen erwerbende Investor zugeordnet ist, unterschätzt. Entsprechendes gilt für die Nettotransferleistungen nach Herkunftsländern, wenn die Eigentumsrechte an einer Tochtergesellschaft in der Bundesrepublik Deutschland zwischen zwei Gebietsfremden, die Inländer verschiedener Länder sind, wechseln. Die Nettodirektinvestitionen des Landes, in dem das die Unternehmensbeteiligung verkaufende (erwerbende) Wirtschaftssubjekt ansāssig ist, werden zu hoch (niedrig) ausgewiesen.

\subsubsection{Bestandsstatistik der Deutschen Bundesbank}

Der Bestand an Direktinvestitionen auf der Basis von Buchwerten wurde in der Bundesrepublik Deutschland erstmals für das Berichtsjahr 1976 erhoben. ${ }^{145}$ Diese Statistik basiert auf den Meldungen über das „Vermögen Gebietsansässiger in fremden Wirtschaftsgebieten“ und über das „Vermögen Gebietsfremder im Wirtschaftsgebiet“, die inländische Unternehmen und Privatpersonen der Deutschen Bundesbank nach den Vorschriften der $\S \S 56 \mathrm{a}$ und $56 \mathrm{~b}$ sowie $58 \mathrm{a}$ und $58 \mathrm{~b} \mathrm{AWV}$ in Verbindung mit $\S 26 \mathrm{Abs} .3 \mathrm{AWG}$ einmal jährlich zu erstatten haben. Die Deutsche Bundesbank kommentiert regelmäßig auf der Grundlage dieser nach der Buchwertmethode erhobenen Statistik die Kapitalverflechtung der Unternehmen mit dem Ausland. ${ }^{146}$ Die von der Deutschen Bundesbank im Jahre 1993 geänderte Darstellung der statistischen Ergebnisse bleibt hier unberücksichtigt; die Begriffe mittelbar und indirekt werden deshalb im folgenden als Synonyme verwendet. ${ }^{147}$

Ein Gebietsansässiger hat Stand und Zusammensetzung seines Vermögens in fremden

$\overline{145}$ Bis zur Einführung dieser Statistik wurde der Bestand an Direktinvestitionen durch kumulierte Nettotransferleistungen (Transferstatistik des BMWi) approximiert.

146 Vgl. hierzu Deutsche Bundesbank (1979; 1980; 1981a; 1981b; 1982a; 1983b; 1984a; 1985; 1987a; 1989a; 1991a; 1993). Bis zur Ergänzung des Außenwirtschaftsrechts um die zur Erstellung der Bestandsstatistik relevanten Meldebestimmungen erlaubten die zur Verfügung stehenden Daten der Deutschen Bundesbank zwar eine Schätzung der ausländischen Beteiligungen an Unternehmen in der Bundesrepublik Deutschland, die Beteiligungen deutscher Unternehmen an Gesellschaften im Ausland konnten aber nicht ermittelt werden; vgl. hierzu z. B. Deutsche Bundesbank $(1972 ; 1974)$.

147 Seit April 1993 unterscheidet die Deutsche Bundesbank innerhalb der indirekten Kapitalbeziehungen zwischen mittelbaren Direktinvestitionen und sonstigem Unternehmensvermögen aus indirekter Kapitalbeteiligung. Als mittelbare deutsche Direktinvestitionen im Ausland (bzw. als mittelbare ausländische Direktinvestitionen in der Bundesrepublik) werden seither nur noch die indirekten Kapitalbeziehungen aus Beteiligungen von Inländern (bzw. Ausländern) an ausländischen (bzw. inländischen) Unternehmen über im Ausland (bzw. Inland) ansässige abhängige Holdinggesellschaften ausgewiesen; alle meldepflichtigen indirekten Kapitalbeziehungen, die nicht über abhängige Holdinggesellschaften, sondern z. B. über abhängige Produktionsunternehmen bestehen, werden statistisch als sonstiges Vermögen aus indirekten Kapitalbeziehungen erfaßt. Zur neuen Darstellung der statistischen Ergebnisse vgl. Deutsche Bundesbank (1993). 
Wirtschaftsgebieten zu melden, ${ }^{148}$

- wenn ihm am Meldestichtag unmittelbar oder mittelbar mehr als $20 \%$ (vor dem Berichtsjahr 1989: mindestens $25 \%$ ) der Anteile oder der Stimmrechte an einem gebietsfremden Unternehmen, dessen Bilanzsumme (umgerechnet) 500000 DM übersteigi, zuzurechnen sind; oder

- wenn er am Meldestichtag in fremden Wirtschaftsgebieten Zweigniederlassungen oder auf Dauer angelegte Betriebsstätten unterhält, deren Bruttobetriebsvermögen jeweils mehr als 500000 DM beträgt. Die Zusammenfassung mehrerer Zweigniederlassungen oder Betriebsstätten desselben Gebietsansässigen in einem Land zu einer Einheit ist möglich. Montagestätten, Baustellen u. ä., die zur Durchführung eines bestimmten Auftrags für eine begrenzte Zeit eingerichtet werden, gelten nicht als auf Dauer angelegte Betriebsstätten.

Meldestichtag ist der Bilanzstichtag des Gebietsansässigen bzw. bei nicht bilanzierenden Meldepflichtigen der 31. Dezember. ${ }^{149}$

Eine mittelbare Beteiligung eines Gebietsansässigen an einem gebietsfremden Unternehmen - im Sinne der Meldevorschriften - liegt vor, wenn einem von dem Gebietsansässigen abhängigen gebietsfremden Unternehmen mehr als $20 \%$ (vor 1989: mindestens $25 \%$ ) der Anteile oder der Stimmrechte an einem weiteren gebietsfremden Unternehmen zuzurechnen sind. Ein gebietsfremdes Unternehmen gilt als von einem Gebietsansässigen abhängig, wenn der Gebietsansässige mit mehr als $50 \%$ der Anteile oder der Stimmrechte an diesem gebietsfremden Unternehmen beteiligt ist. Hält ein von einem Gebietsansässigen abhängiges gebietsfremdes Unternehmen alle Anteile oder Stimmrechte an einem weiteren gebietsfremden Unternehmen, so gilt auch dieses gebietsfremde Unternehmen - und unter der Voraussetzung der 100\%igen Beteiligung jedes weitere Unternehmen - als Unternehmen, das von einem Gebietsansässigen abhängig ist. D. h., mittelbare Beteiligungen an ausländischen Gesellschaften über im Ausland ansässige, nicht im Mehrheitsbesitz des deutschen Direktinvestors stehenden Gesellschaften, werden in der Bestandsstatistik nicht erfaßt.

${ }_{148}$ Zum folgenden vgl. § 56a AWV vom 22. August 1961, eingefügt durch die FünfunddreiBigste Verordnung zur Änderung der Außenwirtschaftsverordnung vom 3. April 1976 und AWV vom 18. Dezember 1986, geändert durch die Fünfte Verordnung zur Änderung der Außenwirtschaftsverordnung vom 20. September 1989, $\S 56 \mathrm{~b}$ AWV vom 22 . August 1961, eingefügt durch die Fünfunddreißigste Verordnung zur Änderung der Außenwirtschaftsverordnung vom 3. April 1976 und AWV vom

18. Dezember 1986 und Deutsche Bundesbank (1976c; 1976d; 1979, S. 38 ff.; 1989b; 1990c).

149 Für die erstmalige Meldung des Vermögens Gebietsansässiger in fremden Wirtschaftsgebieten bzw. des Vermögens Gebietsfremder im Wirtschaftsgebiet war der erste Bilanzstichtag, der auf den 31. Dezember 1975 folgt, bzw. bei nicht bilanzierenden Meldepflichtigen der 31. Dezember 1976 maBgeblich; vgl. Fünfunddreißigste Verordnung zur Änderung der Außenwirtschaftsverordnung vom 3. April 1976. Die herabgesetzte Untergrenze für meldepflichtige Beteiligungen gilt für alle zu einem Meldestichtag bzw. Bilanzstichtag nach dem 29. September 1989 zu erstellenden Meldungen. 
Bei den gemeldeten mittelbaren deutschen Beteiligungen an gebietsfremden Unternehmen unterscheidet die Deutsche Bundesbank jedoch in der Praxis drei Gruppen: ${ }^{150}$

- Eine Beteiligung an einer ausländischen Enkelgesellschaft, die über eine im Ausland ansässige von einem deutschen Direktinvestor abhängige Holdinggesellschaft besteht, wird in der Bestandsstatistik auch als mittelbare Direktinvestition erfaßt. Der ausgewiesene Wert des mittelbaren Unternehmensvermögens im Ausland setzt sich zusammen aus dem Anteil solcher Holdinggesellschaften am Kapital und an den Verbindlichkeiten der Enkelgesellschaft sowie den darüber hinaus gehenden, weder regional noch scktoral ${ }^{151}$ aufteilbaren Krediten solcher Holdinggesellschaften, von denen unterstellt wurde, daß sie anderen, ihnen nicht direkt nachgeordneten ausländischen verbundenen Unternehmen gewährt wurden.

- Besteht die Beteiligung an einer ausländischen Enkelgesellschaft nicht über eine im Ausland ansässige abhängige Holdinggesellschaft, sondern über ein anderes abhängiges gebietsfremdes Unternehmen und ist das gebietsfremde Unternehmen, an dem der Direktinvestor unmittelbar beteiligt ist, im selben Land ansässig wie das Unternehmen, an dem der Direktinvestor mittelbar beteiligt ist, dann wird diese mittelbare Beteiligung in der Bestandsstatistik als unmittelbares deutsches Unternehmensvermögen im Ausland ausgewiesen, wobei über- und untergeordnetes gebietsfremdes Unternehmen durch Konsolidierung zusammengefaßt werden.

- Mittelbare Beteiligungen über abhängige Nicht-Holdinggesellschaften in Drittländern bleiben unberücksichtigt.

Die in der Bestandsstatistik ausgewiesenen Werte für mittelbare deutsche Direktinvestitionen im Ausland umfassen also nur die Beteiligungen an ausländischen Enkelgesellschaften, die über im Ausland ansässige von deutschen Investoren abhängige Holdinggesellschaften bestehen.

Da Beteiligungsgesellschaften nicht nur über die Mittel verfügen, die ihnen von den (Direkt-)Investoren direkt übertragen werden, sondern selbst Fremdmittel zum Erwerb von Beteiligungen an weiteren Unternehmen aufnehmen können, ist die Summe aus unmittelbaren und mittelbaren Direktinvestitionen aussagekräftiger als das unmittelbare Unternehmensvermögen; dies gilt sowohl in bezug auf das Volumen an Direktinvestitionen insgesamt als auch in bezug auf die regionale und die sektorale Gliederung. Zur Vermeidung von Doppelzählungen muß bei der Aggregation von unmittelbaren und mittelbaren Direktinvestitionen das unmittelbare Vermögen, das deutsche Investoren in von ihnen abhängigen Holdinggesellschaften im Ausland halten, subtrahiert werden. ${ }^{152}$

\footnotetext{
150 Vgl. Deutsche Bundesbank (1979, S. 39). Diese Darstellungsweise wurde jüngst geändert; vgl. Deutsche Bundesbank (1993).

151 Nach dem Wirtschaftszweig des ausländischen Investitionsobjekts.

152 Ende 1990 (Ende 1976) entfielen mit 58,6 Mrd. DM (8,2 Mrd. DM) 27,8\% (19,0\%) des unmittelbaren
} 
Die unmittelbaren deutschen Direktinvestitionen im Ausland sowie die Summe der unmittelbaren und mittelbaren deutschen Direktinvestitionen im Ausland werden nach Anlageländern, nach Wirtschaftszweigen der deutschen Investoren und nach Wirtschaftszweigen der ausländischen Investitionsobjekte disaggregiert ausgewiesen; für das unmittelbare und mittelbare deutsche Unternehmensvermögen im Ausland stehen auch nach ausgewählten Anlageländern und Herkunfts- bzw. Zielbranchen disaggregierte Daten zur Verfügung. ${ }^{153}$ Darüber hinaus werden die unmittelbaren Direktinvestitionen bei gebietsfremden abhängigen Holdingsgesellschaften und die mittelbaren Direktinvestitionen im Ausland nach Anlageländern veröffentlicht. Der regionalen Zuordnung liegen die Sitzländer der einzelnen unmittelbaren bzw. mittelbaren Direktinvestitionsunternehmen zugrunde; für die sektorale Zuordnung ist der Schwerpunkt der wirtschaftlichen Tätigkeit des deutschen Direktinvestors ${ }^{154}$ bzw. des jeweiligen unmittelbaren bzw. mittelbaren Direktinvestitionsunternehmen maßgeblich.

Die Statistik über den Bestand an ausländischen Direktinvestitionen in der Bundesrepublik beruht auf den Meldungen gebietsansässiger Unternehmen über Stand und Zusammensetzung des Vermögens Gebietsfremder im Wirtschaftsgebiet. Der Meldepflicht unterliegen: ${ }^{155}$

- Gebietsansässige Unternehmen mit einer Bilanzsumme von über 500000 DM, sofern

deutschen Unternehmensvermögens im Ausland auf Direktinvestitionen im Wirtschaftszweig „Beteiligungsgesellschaften und sonstige Vermögensverwaltung“, davon 45,5 Mrd. DM (5 Mrd. DM) auf Holdinggesellschaften, die im Mehrheitsbesitz eines deutschen Investors standen. Mit 18,1 Mrd. DM waren Ende 1990 (Ende 1976: 3,7 Mrd. DM) jedoch nur 7,8 \% (7,6 \%) des unmittelbaren und mittelbaren deutschen Unternehmensvermögens im Ausland in gebietsfremden Beteiligungsgesellschaften zusammengefaßt. Vgl. Deutsche Bundesbank (1983a, S. 4 und 19; 1992a, S. 4 und 19).

153 Bei den mittelbaren deutschen Direktinvestitionen im Ausland - und damit auch bei der Summe der unmittelbaren und mittelbaren Direktinvestitionen - sind die Kredite, die von deutschen Direktinvestoren abhängige Holdinggesellschaften ihnen nicht direkt nachgeordneten ausländischen verbundenen Unternehmen gewährt haben, und die Differenzen zwischen den Werten der Beteiligungen, den die Holdinggesellschaften ausweisen, und den Werten der auf die Holdinggesellschaften entfallenden Anteile am Eigenkapital der mittelbaren Direktinvestitionsunternehmen weder regional noch sektoral nach Zielbranchen aufteilbar (Ende 1990: 15,3 Mrd. DM). Vgl. z. B. Deutsche Bundesbank (1992a, S. 12 f. Anm. 1)

154 Bei der Interpretation der Direktinvestitionen nach den Wirtschaftszweigen der deutschen Investoren muß berücksichtigt werden, daß ein beobachteter Wandel der Branchenstruktur auch das Ergebnis der Umstrukturierung eines großen Konzerns oder der Änderung des wirtschaftlichen Schwerpunkts eines im Zusammenhang mit Direktinvestitionen wichtigen Unternehmens sein kann. So ist beispielsweise die im Jahr 1989 zu beobachtende Strukturverschiebung der deutschen Direktinvestitionen im Ausland nach dem Wirtschaftszweig des inländischen Investors vom Wirtschaftszweig Straßenfahrzeugbau zugunsten der Branche „Beteiligungsgesellschaften und sonstige Vermögensverwaltung“ weitgehend auf die Konzernumstrukturierung bei der Daimler-Benz AG zurückzuführen.

155 Zum folgenden vgl. § 58a AWV vom 22. August 1961, eingefügt durch die Fünfunddreißigste Verordnung zur Änderung der Außenwirtschaftsverordnung vom 3. April 1976, geändert durch die Zweiundfünfzigste Verordnung zur Änderung der Außenwirtschaftsverordnung vom 13. August 1982 und AWV vom 18. Dezember 1986, geändert durch die Fünfte Verordnung zur Änderung der Außenwirtschaftsverordnung vom 20. September $1989, \S 58 \mathrm{~b}$ AWV vom 22 . August 1961, eingefügt durch die Fünfunddreißigste Verordnung zur Änderung der Außenwirtschaftsverordnung vom 3. April 1976 und AWV vom 18. Dezember 1986 und Deutsche Bundesbank (1976c; 1976e; 1979, S. 40; 1989b; 1990d). 
einem Gebietsfremden oder mehreren wirtschaftlich verbundenen Gebietsfremden zusammen am Bilanzstichtag des Gebietsansässigen mehr als 20 \% (vor dem Berichtsjahr 1989: mindestens $25 \%$ ) der Anteile oder der Stimmrechte an diesem Unternehmen zuzurechnen sind; und

- gebietsansässige Zweigniederlassungen und auf Dauer angelegte Betriebsstätten ${ }^{156}$ von Gebietsfremden mit einem Bruttobetriebsvermögen von über 500000 DM (Bilanzstichtag des Gebietsfremden). Mehrere Zweigniederlassungen und Betriebsstätten desselben Gebietsfremden sind zu einer Einheit zusammenzufassen.

Als wirtschaftlich verbunden gelten natürliche und juristische gebietsfremde Personen, wenn sie gemeinsam - auch zusammen mit Gebietsansässigen - wirtschaftliche Interessen verfolgen, insbesondere Gebietsfremde, die sich in bezug auf das gebietsansässige Unternehmen zusammengeschlossen haben, die durch Beteiligungen an einem oder mehreren Unternehmen gemeinsam wirtschaftliche Interessen verfolgen, die in engen familienrechtlichen Beziehungen zueinander stehen oder die im Sinne des $§ 15$ AktG miteinander verbunden sind. ${ }^{157}$

Meldepflichtige Unternehmen haben auch über mittelbare Beteiligungen Gebietsfremder im Wirtschaftsgebiet zu berichten. Eine mittelbare Beteiligung - im Sinne der Meldevorschriften - liegt vor, wenn einem von einem Gebietsfremden oder von mehreren wirtschaftlich verbundenen Gebietsfremden zusammen abhängigen gebietsansässigen Unternehmen mit einer Bilanzsumme von mehr als 500000 DM am Bilanzstichtag mehr als $20 \%$ (vor dem Berichtsjahr 1989: mindestens $25 \%$ ) der Anteile oder der Stimmrechte an einem weiteren gebietsansässigen Unternehmen mit einer Bilanzsumme von über $500000 \mathrm{DM}$ zuzurechnen sind. Ein gebietsansässiges Unternehmen gilt als abhängig, wenn dem Gebietsfremden oder den wirtschaftlich verbundenen Gebietsfremden zusammen mehr als $50 \%$ der Anteile oder Stimmrechte an diesem Unternehmen zuzurechnen sind. Anders als bei den deutschen Direktinvestitionen im Ausland werden Beteiligungen Gebietsfremder an inländischen Unternehmen, die über in ausländischem Mehrheitsbesitz stehende gebietsansässige Nicht-Holdinggesellschaften bestehen, als mittelbares (und nicht als un-

156 Zur Abgrenzung von „auf Dauer angelegten Betriebsstätten“ vgl. oben.

$157 \mathrm{Vgl}$. 58a Abs. 2 AWV vom 22. August 1961, eingefügt durch die Fünfunddreißigste Verordnung zur Änderung der Außenwirtschaftsverordnung vom 3. April 1976, geändert durch die Zweiundfünfzigste Verordnung zur Änderung der Außenwirtschaftsverordnung vom 13. August 1982 und AWV vom 18. Dezember 1986. Erst mit der Zweiundfünfzigsten Verordnung zur Änderung der AWV wird ausschließlich auf die wirtschaftliche Verbundenheit Gebietsfremder im Sinne gemeinsamer Verfolgung wirtschaftlicher Interessen abgestellt. Der früher in § 58a AWV anstelle von "mehrere wirtschaftlich verbundene Gebietsfremde zusammen“ verwendete Begriff "Gruppe wirtschaftlich verbundener Gebietsfremder" führte in Einzelfallen zu Fehlinterpretationen; vgl. hierzu auch Der Bundesminister für Wirtschaft (1982c) und Deutsche Bundesbank (1982b). § 58a Abs. 4 Nr. 3 AWV schränkt die Meldepflicht auf die Fälle ein, in denen das (abhängige) gebietsansässige Unternehmen erkennen kann, daB es sich bei den Gebietsfremden um mehrere wirtschaftlich verbundene Gebietsfremde handelt. 
mittelbares) ausländisches Unternehmensvermögen in der Bundesrepublik ausgewiesen. Die inländischen Tochtergesellschaften der mittelbaren Direktinvestitionsunternehmen, also die inländischen Enkelgesellschaften des Meldepflichtigen, sowie alle ausländischen Tochtergesellschaften inländischer Direktinvestitionsunternehmen bleiben beim Bestand an ausländischen Direktinvestitionen in der Bundesrepublik unberücksichtigt.

Auf die Konsolidierung der über Nicht-Holdinggesellschaften bestehenden mittelbaren Beteiligungen mit den jeweils übergeordneten inländischen Unternehmen verzichtet die Deutsche Bundesbank, da - anders als bei den mittelbaren Beteiligungen deutscher Investoren im Ausland - „[d]er größere Teil der mittelbaren Auslandsbeteiligungen in der Bundesrepublik ... nicht ... über Holdinggesellschaften gehalten [wird], sondern über andere Produktions- und Handelsfirmen in unmittelbarer ausländischer Hand. "158 Die Zusammenfassung von Unternehmen mit unterschiedlicher Branchenzugehörigkeit würde zu einer Verzerrung der relativen Bedeutung der Kapitalverflechtung inländischer Direktinvestitionsunternehmen mit dem Ausland in den einzelnen Wirtschaftszweigen führen. Für die jüngere Zeit trifft diese Aussage allerdings nicht mehr zu. Insbesondere seit Ende der 80er Jahre wird vermehrt ausländisches Unternehmensvermögen in der Bundesrepublik in Beteiligungsgesellschaften zusammengefaßt. ${ }^{159}$ Eine Aggregation von unmittelbaren und mittelbaren ausländischen Direktinvestitionen in der Bundesrepublik Deutschland unter Vermeidung von Doppelzählungen ist nicht möglich. ${ }^{160}$

Die unmittelbaren ausländischen Direktinvestitionen in der Bundesrepublik Deutschland werden nach Kapitalgeberländern, nach Wirtschaftszweigen der inländischen Investitionsobjekte sowie nach Zielbranchen und ausgewählten Herkunftsländern disaggregiert ausgewiesen. Regional nicht aufteilbar sind zum einen die als unmittelbare Direktinvestitionen in der Bundesrepublik erfaßten direkten Kredite ausländischer Muttergesellschaften an

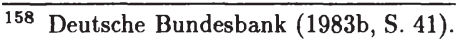

159 Ende 1990 (Ende 1976) entfielen vom Gesamtbestand an unmittelbaren ausländischen Vermögensanlagen in der Bundesrepublik in Höhe von 139,6 Mrd. DM (63,5 Mrd. DM) mit 46,3 Mrd. DM (5,8 Mrd. DM) $33,1 \%(9,1 \%)$ auf Direktinvestitionen im Wirtschaftszweig „Beteiligungsgesellschaften und sonstige Vermögensverwaltung"; insbesondere die unmittelbaren Direktinvestitionen bei abhängigen Holdingunternehmen im Inland haben an Bedeutung gewonnen.

160 Bei den von der Deutschen Bundesbank (1989a, S. 28; 1991a, S. 35) ausgewiesenen zusammengefaßten unmittelbaren und mittelbaren ausländischen Direktinvestitionen in der Bundesrepublik nach Kapitalgeberländern bzw. nach Wirtschaftszweigen der Investitionsobjekte bleiben wegen Datenmangels die mittelbaren Direktinvestitionen, die nicht über vom Ausland abhängige inländische Holdinggesellschaften, sondern über andere auslandsbeherrschte inländische Unternehmen bestehen, unberücksichtigt. Die von der Deutschen Bundesbank (1993, S. 41) veröffentlichten zusammengefaBten unmittelbaren und mittelbaren Direktinvestitionen nach Kapitalgeberländern bzw. nach Zielbranchen enthalten ebenfalls die über von Ausländern abhängige inländische Nicht-Holdingunternehmen bestehenden mittelbaren Beteiligungen nicht; seit der geänderten Darstellung der statistischen Ergebnisse werden diese indirekten, weder regional noch sektoral aufteilbaren Vermögensanlagen jedoch nicht mehr als mittelbare Direktinvestitionen, sondern als sonstiges Vermögen aus indirekter Kapitalbeteiligung bezeichnet. 
ihre inländischen Enkelgesellschaften (Ende 1990: 2,3 Mrd. DM), zum anderen dic mittelbaren Direktinvestitionen in der Bundesrepublik. ${ }^{161}$ Das mittelbare ausländische Unternehmensvermögen im Inland steht nach Zielbranchen gegliedert zur Verfügung. Die regionale Zuordnung erfolgt auf der Grundlage der Sitzländer der einzelnen gebietsfremden Beteiligten; sind die Direktinvestoren selbst abhängige Unternehmen, dann ist auch das Sitzland der Obergesellschaft zu melden. Für die sektorale Zuordnung ist der Schwerpunkt der wirtschaftlichen Tätigkeit des unmittelbaren bzw. mittelbaren Direktinvestitionsunternehmens maßgeblich.

Mit der im internationalen Vergleich relativ hohen Mindestbeteiligungsquote zur Abgrenzung der Direktinvestitionen von Portfolioinvestitionen in Höhe von mindestens $25 \%$ der Anteile am Nominalkapital oder der Stimmrechte - sie entspricht der sog. "Sperrminorität" des deutschen Aktiengesetzes - wollte die Deutsche Bundesbank ausschließen, daß Kapitalwerte, die nicht mit der Absicht einer Unternehmensbeteiligung erworben werden, als Direktinvestitionen erfaßt werden. ${ }^{162}$ In Anpassung an den neuen $\S 271$ HGB wurde die Mindestbeteiligungsquote mit dem Berichtsjahr 1989 auf mehr als $20 \%$ des Nennkapitals oder der Stimmrechte gesenkt. ${ }^{163}$ Wirtschaftlich verbundene Investoren werden nur bei den ausländischen Direktinvestitionen in der Bundesrepublik, nicht aber bei den deutschen Direktinvestitionen im Ausland als ein Wirtschaftssubjekt behandelt.

Sind einer gebietsfremden Tochtergesellschaft mehr als $20 \%$ der Anteile oder der Stimmrechte an ihrer deutschen Muttergesellschaft zuzurechnen, dann werden in der Bestandsstatistik der Deutschen Bundesbank das der Muttergesellschaft zuzurechnende Unternehmensvermögen im Ausland als deutsche Direktinvestitionen im Ausland und das der Tochtergesellschaft zuzurechnende Unternehmensvermögen im Inland als ausländische Direktinvestitionen in der Bundesrepublik erfaßt. Für ein inländisches Direktinvestitionsunternehmen, das an seiner gebietsfremden Muttergesellschaft beteiligt ist, gilt entsprechendes. Erfüllt die Tochtergesellschaft dagegen nicht das Kriterium eines Direktinvestors, ist sie z. B. nur mit genau $20 \%$ an ihrer Muttergesellschaft beteiligt, dann erscheint diese Kapitalbeteiligung weder bei den deutschen Direktinvestitionen im Ausland noch bei den ausländischen Direktinvestitionen im Inland, denn wechselseitige Beteiligungen zwischen Mutter- und Tochtergesellschaft werden nicht saldiert.

Die Bestandsstatistik für deutsche Direktinvestitionen im Ausland basiert auf den Meldungen der Direktinvestoren. Datengrundlage sind die nach den Vorschriften der jeweiligen

161 Vgl. Deutsche Bundesbank (1979, S. 36 Fn. 12; 1992a, S. 24 Anm. 4).

162 Vgl. Deutsche Bundesbank (1979, S. 38). Gleichzeitig folgt die Deutsche Bundesbank damit der Empfehlung des IMF in dessen 3. Ausgabe des Balance of Payments Manual; vgl. IMF (1960, S. 178).

$163 \mathrm{Vgl}$. § 56a und § 58a AWV vom 18. Dezember 1986, geändert durch die Fünfte Verordnung zur Änderung der Außenwirtschaftsverordnung vom 20. September 1989; vgl. hierzu auch Der Bundesminister für Wirtschaft (1989) und Deutsche Bundesbank (1989b). 
Sitzländer erstellten Bilanzen der Direktinvestitionsunternehmen, an denen die unmittelbare oder mittelbare Beteiligung besteht, sowie die vom Direktinvestor gemeldeten, ihm direkt oder indirekt zuzurechnenden Anteile an den Aktiva und Passiva dieser Bilanzen bzw. für gebietsfremde Zweigniederlassungen und Betriebsstätten deren Vermögensaufstellungen. In der Regel sind Fremdwährungsbeträge zu melden. Der Bestandsstatistik für ausländische Direktinvestitionen in der Bundesrepublik liegen bei unmittelbaren Beteiligungen die Meldungen der Direktinvestitionsunternehmen und bei mittelbaren Beteiligungen die Meldungen der Unternehmen, an denen die Gebietsfremden unmittelbar beteiligt sind, zugrunde. Datenbasis sind die Handelsbilanzen bzw. bei Zweigniederlassungen und Betriebsstätten die Vermögensaufstellungen der unmittelbaren und mittelbaren Direktinvestitionsunternehmen in der Bundesrepublik. Zu melden sind DM-Beträge.

Erst seit der Anpassung der Meldevordrucke an die durch das Bilanzrichtlinien-Gesetz geänderten Vorschriften für die Bilanzierung von Unternehmen sind die zu meldenden (aggregierten) Bilanzposten für „Vermögen Gebietsansässiger in fremden Wirtschaftsgebieten" (Anlage K 3 zur AWV) und für "Vermögen Gebietsfremder im Wirtschaftsgebiet" (Anlage K 4 zur AWV) einheitlich. ${ }^{164}$ Die neuen Vordrucke sind für alle zu einem Meldestichtag bzw. Bilanzstichtag des Meldepflichtigen nach dem 29. September 1989 zu erstellenden Meldungen zu verwenden. ${ }^{165}$

Innerhalb des Direktinvestitionskapitals unterscheidet die Bestandsstatistik der Deutschen Bundesbank zwischen Beteiligungskapital und konzerninternen Krediten. Das unmittelbare Beteiligungskapital setzt sich seit dem Berichtsjahr 1989 zusammen aus den Anteilen der Direktinvestoren am Nominalkapital (gezeichnetes oder eingefordertes Kapital, Dotationskapital, Einlagen von Gesellschaftern) ihrer unmittelbaren Direktinvestitionsunternehmen, zuzüglich der den Direktinvestoren unmittelbar zuzurechnenden Anteile an den Kapital- und Gewinnrücklagen, an den Gewinnvorträgen und Jahresüberschüssen bzw. Bilanzgewinnen ihrer Tochtergesellschaften, abzüglich der den Direktinvestoren unmittelbar zuzurechnenden Anteile an den Verlustvorträgen, Jahresfehlbeträgen bzw. Bilanzverlusten, an den nicht durch Eigenkapital gedeckten Fehlbeträgen und an den ausstehenden Einlagen auf das gezeichnete Kapital der Direktinvestitionsunternehmen. Für Nominalkapital und für ausstehende Einlagen auf das gezeichnete Kapital haben die Meldepflichtigen neben dem Gesamtbetrag die auf die Direktinvestoren entfallenden Beträge anzugeben. Für die anderen Bestandteile des Beteiligungskapitals ist jeweils nur der Gesamtbetrag zu melden; die den Direktinvestoren unmittelbar zuzurechnenden Anteile werden auf der

164 Die Meldevordrucke sind ohne Erläuterungen abgedruckt als Anlagen zur FünfunddreiBigsten Verordnung zur Änderung der Außenwirtschaftsverordnung vom 3. April 1976 und zur Fünften Verordnung zur Änderung der Außenwirtschaftsverordnung vom 20. September 1989.

165 Siehe Art. 5 Abs. 1 der Fünften Verordnung zur Änderung der Außenwirtschaftsverordnung vom 20. September 1989. 
Grundlage der unmittelbaren Anteile der Direktinvestoren am nominellen Figenkapital des Direktinvestitionsunternehmens ermittelt. ${ }^{166}$ Rücklagen und Gewinnvorträge spiegeln nicht nur die Gewinnthesaurierung der Tochtergesellschaften wider, sondern sie sind u. a. auch das Ergebnis von Zuschreibungen infolge der - insbesondere in Ländern mit hohen Inflationsraten üblichen - Neubewertung von Anlagegütern oder von Aktienemissionen über pari; Reservekapital kann auch beim Kauf neuer Beteiligungen an Direktinvestitionsunternehmen erworben werden. ${ }^{167}$ Das für die Berichtsjahre vor 1989 ausgewiesene Beteiligungskapital unterscheidet sich in mehrfacher Hinsicht von dem seither erfaßten Unternehmensvermögen. Vor 1989 wurden bei Vermögensanlagen Gebietsansässiger in fremden Wirtschaftsgebieten die ausstehenden Einlagen auf das Grund-, Stamm- bzw. Dotationskapital nicht erhoben. Der nicht für die Gewinnausschüttung im Folgejahr bcstimmte Teil des Jahresgewinns der Direktinvestitionsunternehmen war bei den deutschen Direktinvestitionen im Ausland von den Meldepflichtigen der Bilanzposition „Rücklagen, Gewinnvorträge“ zuzuordnen. ${ }^{168}$ Die Direktinvestitionsunternehmen in der Bundesrepublik dagegen hatten vor dem Berichtsjahr 1989 den Bilanzgewinn bzw. -verlust zu melden; die unmittelbar den Direktinvestoren zuzurechnenden Anteile an dem Teil des Bilanzgewinns, der im Folgejahr nicht ausgeschüttet wurde, ermittelte die Deutsche Bundesbank approximativ als Differenz zwischen dem Teil des gesamten Bilanzgewinns, der unmittelbar Direktinvestoren zuzurechnen war, und den in der Zahlungsbilanzstatistik ausgewicsenen Gewinnzahlungen an die ausländischen Kapitaleigner. ${ }^{169}$ Seit der Anpassung der Gliederung des Direktinvestitionskapitals an die neuen Vorschriften des BilanzrichtlinienGesetzes ist der gesamte anteilige Jahresüberschuß bzw. Bilanzgewinn im Beteiligungskapital enthalten; die für die Gewinnausschüttung an die Muttergesellschaften bereitgestellten, aber noch nicht transferierten Dividendenbeträge, die den Direktinvestitionsunternehmen bis zur Auszahlung noch als Finanzierungsmittel zur Verfügung stehen, wurden vor dem Berichtsjahr 1989 den (kurzfristigen) Krediten der Kapitaleigner an die Tochtergesellschaften zugerechnet. ${ }^{170}$

Zum unmittelbaren Direktinvestitionskapital in Form von konzerninternen Krediten zählen seit dem Berichtsjahr 1989 nicht nur die direkten Kredite der Direktinvestoren an ihre unmittelbaren und mittelbaren Direktinvestitionsunternehmen, sondern auch die direkten Kredite anderer verbundener Unternehmen sowic von Unternehmen, mit denen ein Beteiligungsverhältnis besteht, sofern diese Unternehmen ihren Sitz im Inland (deutsche Direktinvestitionen im Ausland) bzw. im Ausland (auslāndische Direktinvestitionen in

\footnotetext{
166 Vgl Deutsche Bundesbank (1979, S. 39; 1993, S. 48).

167 Vgl. Deutsche Bundesbank (1979, S. 30; 1981b, S. 41; 1983b, S. 34; 1984a, S. 23; 1989a, S. 25 f.).

168 Vgl. Deutsche Bundesbank (1976d, S. 4).

169 Vgl. Deutsche Bundesbank (1979, S. 40).

170 Vgl. Deutsche Bundesbank (1980, S. 26; 1981a, S. 30; 1981b, S. 41; 1991a, S. 30).
} 
der Bundesrepublik) haben. ${ }^{171}$ Vor dem Berichtsjahr 1989 erlaubte das Meldeverfahren uur dic Frfassung der direkten Kredite der Direktinvestoren an ihre unmittelbaren Tochtergesellschaften und der direkten Kredite der gebietsfremden Beteiligten an ihre mittelbaren Direktinvestitionsunternehmen in Inland. Die Kredite anderer zum Konzernverbund gehörender Unternehmen an die Direktinvestitionsunternehmen konnten nicht crfaßt werden. In den Krediten sind alle kurz- und langfristigen Verbindlichkeiten der Direktinvestitionsunternehmen enthalten, u. a. also auch „'Intercompany Accounts', Handelskredite, betciligungsähnliche Darlehen [und] Gesellschafterdarlehen von Kommanditisten" ${ }^{\text {172 }}$. Sowohl Verbindlichkeiten gegenüber Kreditinstituten als auch Forderungen an Kreditinstitute bleiben unberücksichtigt; das bedeutet u. a., daß für Kreditinstitute das Direktinvestitionskapital auf Beteiligungskapital (cinschließlich reinvestierter Gewinne) beschränkt ist, also enger definiert ist, als bei IMF und OECD. Dic Forderungen der Direktinvestitionsunternehmen an ihre Muttergesellschaften werden - im Gegensatz zu den Empfehlungen von IMF und OECD und zur Vorgehensweise einiger anderer Länder, z. B. den USA - „[w]egen des besonderen Charakters mancher dieser Forderungspositionen "173 nicht mit den Verbindlichkeiten der Torhtergesellschaften gegenüber den Direktinvestoren saldiert. Sic werden bei der Ermittlung des Direktinvestitionskapitals nicht berücksichtigt.

Die mittelbaren Direktinvestitionen werden nach der gleichen Methode wie die unmittelbaren Direktinvestitionen berechnet; an die Stelle des Direktinvestors tritt das von diescm abhängige, unmittclbar beteiligte gebictsfremde (deutsche Direktinvestitionen im

171 Kredite, die Direktinvestitionsunternehmen deutscher Dircktinvestoren von Schwesterunternchmen, die in cinem Drittland ihren Sitz haben, erhalten, müssen wegen Datenmangels unberücksichtigt hlcihen; vgl. Deutsche Bundeshank (1993, S. 39 Fn. 4). - Seit 1989 sind die Verhindlichkeiten der unmit,telharen und mittclharen Direktinvestitionsunternehmen, für die der Direktinvestor Garantien und Bürgschaften übernommen hat, nicht mehr meldepflichtig. - Das für die Rechnungslegung gelt.ende Handelsrecht definiert. Beteiligungen ( $\$ 271$ Abs. 1 HGB) und verbundene Unternehmen ( $\$ 271$ Abs. 2 H(GB). Die Definition verbundener Unternehmen in $\S 271$ Abs. 2 HGB ist grundsätzlich enger als die in $\$ 15$ AktG. Zum Verhältnis des aktien- und des handelsrechtlichen Begriffs verbundener Unternehmen vgl. Wirtschaftsprïfer-Handbuch (1992, Abschnit.t R. Tz. 9-11). Zum aktienrechtlichen Begriff verbundener Unternehmen vgl. Wirtschaftsprïfer-Handbuch (1992, Abschnitt R. Tz. 39 ff.), auch Wöhe (1992, S. 928 ff.). Der Wortlaut des $§ 271$ Abs. 2 HGB wirft eine Vielzahl von $\Lambda$ uslegungsproblemen, insbesondere in bezug auf dic Bedeutung der Verweise auf die (mögliche) Finbeziehung der Unternchmen in cinen KonzernabschluB, auf; vgl. ADS (1992, § 271 HGB, Tz. 26 ff.), Biener/Berneke (1986, § 271 HCB, S. 186 ff.) und Wirtschaftsprüfer-Handbuch (1992, Abschnitt F Tz. 83 f. und Abschnit.t. R. Tz. 336 ff.). Nach der über den Wortlaut hinausgehenden, Art. 41 der 7. EG-Richtlinie sowie den Sinn und Zweck der Vorschrift. berücksichtigenden Auslegung des $§ 271$ Abs. 2 IIGB ist für dic Verbundenheit von Unternchmen nur entscheidend, ob zwischen den Unternehmen ein Mutter-/ Tochterverhältnis im Sinne des $§ 290$ HGB besteht; Muttergesellschaft kann jedes Unternehmen unabhängig von seiner Rechtsform, seiner Größe und seinem Sitz sein. Fin Mutter-/Tochterverhältnis zwischen Unternehmen wird begründet, wenn ein Unternehmen über ein anderes Unternehmen, an dem es eine Beteiligung im Sinne des $§ 71$ Abs. 1 HGB hält, eine einheitliche I,eitung ausiibt (vgl. $\S 290$ Abs. 1 HCB) oder wenn zwischen zwei Unternehmen ein Control-Verhältnis vorliegt (vgl. $§ 290$ Abs. 2 HGB).

172 Deutsche Bundesbank (1979, S. 30); ähnlich auch Deutsche Bundesbank (1981b, S. 11; 1984, S. 23).

173 Deutsche Bundesbank (1979, S. 30); vgl. hierzu auch Deutsche Bundeshank (1983b, S. 34 ff.). 
Ausland) bzw. gebietsansässige (ausländische Dircktinvestitionen in der Bundesrepublik) Unternehmen.

Bei der Umrechnung des deutschen Unternehmensvermögens im Ausland von Fremdwährungsbeträgen in DM legt die Deutsche Bundesbank die am Bilanzstichtag geltenden Kassakurse zugrunde. ${ }^{174}$ In Perioden, in denen der Außenwert der DM stark, aber nur vorübergehend schwankt - so z. B. in den $80 \mathrm{cr}$ Jahren insbesondere gegenüber dem US- $\$$ - geben die jährlichen Ānderungen des Bestands an deutschen Direktinvestitionen im $\Lambda$ usland dic Wertentwicklung des Auslandsvermögens nur unzureichend wieder. Denn Aufwertungen der DM gegenüber einer anderen Währung führen ceteris paribus zu einem Rückgang des in dieser Währung bilanzierten, in DM umgerechneten deutschen Unternehmensvermögens im Ausland; entsprechend sind Abwertungen der DM mit Vermögenszuwächsen verbunden. Die Deutsche Bundesbank rechtfertigt die Umrechnung von Fremdwährungsbeträgen in DM mit den am Bilanzstichtag geltenden Kassakursen damit, das so ermittelte deutsche Unternehmensvermögen im Ausland sage aus, „welcher DM-Wert des ausgewicsenen Vermögens, wenn es zum aktuellen Stichtag zum Erwerb oder Verkauf gestanden hätte, bei den Kaufverhandlungen zugrunde zu legen gewesen wäre. Eine Alternative zu der Währungsumrechnung ist daher nicht gegeben. Jedoch empfiehlt es sich, die Wechselkurseinflüsse zumindest näherungsweise zu quantifizieren, um sie bei der Beurteilung der Vermögensentwicklung mit in Rechnung stellen zu können. “175 Diese Rechtfertigung der Deutschen Bundesbank übersieht allerdings ein von ihr an mehreren anderen Stellen, aber stets im Zusammenhang mit Direktinvestitionen genanntes $\Lambda$ rgument: Die Verkaufserlöse von Unternehmen(sbeteiligungen) sind u. a. wegen stiller Reserven und immaterieller nicht bilanzjerter Vermögenswerte in der Regel höher als die Buchwerte.

Insoweit, als der Bilanzstichtag von Direktinvestoren und Direktinvestitionsunternehmen vom 31. Dezember abweicht, spiegeln die ausgewiesenen Daten für den Bestand an Direktinvestitionen am Jahresende eine Mischung aus Bestand am Ende eines Kalenderjahres und Bestand am Ende des Wirtschaftsjahres der Direktinvestitionsunternehmen bzw. der Direktinvestoren wider. Denn für deutsche Direktinvestitionen im Ausland wird der Bestand nach dem Stand am Meldestichtag, also nach dem Stand am Bilanzstichtag des Direktinvestors bzw. bei nicht bilanzierenden Direktinvestoren nach dem Stand am

${ }^{174}$ Direktinvestoren, die eine interne oder veröffentlichte Weltbilanz erstellen, sollen die auf ihre Tochtergesellschaften entfallenden Beträge dieser Weltbilanz entnehmen und DM-Beträge melden; vgl. hierzu auch Deutsche Bundesbank (1976d, S. 4; 1982a, S. 43 Fn. 2). Da das HGB für die Fremdwährungsumrechnung im Konzernabschluß kein bestimmtes Verfahren festlegt, haben die Unternehmen die Wahl zwischen Umrechnung mit einheitlichem Stichtagskurs oder mit differenzierten Kursen. Zur Währungsumrechnung im KonzernabschluB vgl. z. B. Buchner (1990, S. 444 ff.).

175 Deutsche Bundesbank (1989a, S. 30); ähnlich auch Deutsche Bundesbank (1980, S. 25). Zur Bewertung des Unternehmensvermögens im Ausland mit den jeweils aktuellen Wechselkursen vgl. aber aurh Deutsche Bundesbank (1981a, S. 30; 1985, S. 31). - Zur Höhe der geschätzten Bewertungsverlust.e vgl. S. 152 
31. Dezember erfaßt; weicht der Bilanzstichtag des Direktinvestitionsunternehmens vom Meldestichtag ab, kann bei der Meldung der diesem Zeitpunkt unmittelbar vorausgegangene Bilanzstichtag des gebietsfremden Unternehmens zugrunde gelegt werden. ${ }^{176}$ Für ausländische Direktinvestitionen in der Bundesrepublik Deutschland wird der Bestand nach dem Stand am Bilanzstichtag des Direktinvestitionsunternehmens, an dem der Gebietsfremde unmittelbar beteiligt ist, bzw. bei nicht bilanzierenden Direktinvestitionsunternehmen nach dem Stand am Bilanzstichtag des Direktinvestors erhoben; ${ }^{177}$ stimmt der Bilanzstichtag cines mittelbaren Direktinvestitionsunternehmens nicht mit dem des unmittelbaren Direktinvestitionsunternehmens übercin und liegt keine Zwischenbilanz vor, „so sind die Angaben nach dem letzten Bilanzstichtag dieses Unternehmens vor dem Bilanzstichtag des Meldepflichtigen zu machen." ${ }^{178}$ Im Unterschied zu dem in den USA verwendeten Schätzverfahren werden für Wirtschaftsjahre gemeldete Daten nicht auf Kalenderjahre umgerechnet.

Dic ausgewiesenen Daten unterschätzen den tatsächlichen Bestand an Direktinvestitionen tendenziell. Als Gründe hicrfür sind insbesondere zu nennen:

- Investitionen in Unternehmen mit einer Bilanzsumme bzw. in Zweigniederlassungen oder Betriebsstätten mit einem Betriebsvermögen von höchstens 500000 DM sind nicht meldepflichtig. ${ }^{179}$

- Erfaßt wird das Unternehmensvermögen nur, wenn cinem inländischen Investor (bzw. einem ausländischen oder mehreren wirtschaftlich verbundenen ausländischen Investoren zusammen) an cincm gebietsfremden (bzw. gebietsansässigen) Unternehmen unmittelbar oder mittelbar mehr als $20 \%$ (vor 1989: mindestens $25 \%$ ) der Anteile am Nominalkapital oder an den Stimmrechten zuzurechnen sind. Das durch die Herabsetzung der Mindestbeteiligungsquote zusätzlich erfaßte Direktinvestitionskapital beträgt bei den deutschen Direktinvestitionen im Ausland und bei den ausländischen Direktinvestitionen in der Bundesrepublik Deutschland jeweils nur 0,5 Mrd. DM. ${ }^{180}$ Die durchschnittliche Beteiligungsquote der deutschen und der ausländischen Direktinvestoren ist hoch. ${ }^{181}$ Rückschlüsse darüber, wie hoch das nicht erfaßte Direktinvestitionskapital (Kapitalbeteiligungen bis zu $20 \%$ ) ist, kann man aus der durchschnittlich hohen Beteiligung jedoch nicht zichen. Mittelbare Beteiligungen an gebietsfremden (bzw. gebietsansässigen) Unternehmen werden nur dann erfaßt, wenn sic über im $\Lambda$ usland (im Inland) ansässige, im

176 Vgl. § 56b AWV vom 22. August 1961, eingefügt durch die Fünfunddreibigste Verordnung zur Änderung der AuBenwirtschaftsverordnung vom 3. April 1976 und AWV vom 18. Dezember 1986.

177 Vgl. § 58b AWV vom 22. August 1961, eingefügt durch die Fünfunddreißigste Verordnung zur Änderung der AuBenwirtschaftsverordnung vom 3. April 1976 und AWV vom 18. Dezember 1986.

178 Deutsche Bundesbank (1976c, S. 1); auch Deutsche Bundesbank (1990d).

179 Den Einfluß der Nichtberücksichtigung sog. Bagatellefälle auf dic Höhe des ausgewiesenen Bestands an Direktinvestitionen schätzt die Deutsche Bundesbank gering ein; vgl. Deutsche Bundesbank (1979, S. 38 Fn. 13).

180 Vgl. Deutsche Bundesbank (1991a, S. 28 Fn. 1).

181 Vgl. hierzu auch Deutsche Bundesbank (1981a, S. 31 f.; 1983b, S. 35; 1985, S. 33; 1989a, S. 25). 
Mehrheitsbesitz des Gebietsansässigen (bzw. des Gebietsfremden oder mehrerer wirtschaftlich verbundener Gebietsfremden zusammen) stehenden Unternehmen bestehen. Unberücksichtigt bleiben darüber hinaus bei den deutschen Vermögenanlagen im Ausland mittelbare Beteiligungen über von deutschen Investoren abhängige gebietsfremde Nicht-Holdinggesellschaften in Drittländern ${ }^{182}$ und bei den ausländischen Direktinvestitionen in der Bundesrepublik die inländischen Tochtergesellschaften der mittelbaren Direktinvestitionsunternehmen.

- Erst seit dem Berichtsjahr 1989 erlaubt das Meldeverfahren auch die Erfassung der Kredite anderer zum Konzernverbund gehörender inländischer (bzw. ausländischer) Unternehmen.

- Bei den deutschen Direktinvestitionen im Ausland bleiben wirtschaftlich verbundene Gebietsansässige als Direktinvestoren außer acht.

- Da die Meldungen der Unternehmen auf Buchwerten beruhen, stellen sie in der Regel Mindestwerte dar. Stille Reserven bleiben unberücksichtigt.

Aus den genannten Gründen werden auch die Anzahl der Direktinvestoren und der Direktinvestitionsunternehmen, ${ }^{183}$ Bilanzsummen und Jahresumsätze von Direktinvestitionsunternehmen sowie Beschäftigte ${ }^{184}$ bei Direktinvestitionsunternehmen zu niedrig ausgewiesen.

\subsubsection{Deutsche Direktinvestitionen im Ausland und ausländische Direktin- vestitionen in der Bundesrepublik Deutschland - ein Vergleich der in den bundesdeutschen Statistiken ausgewiesenen Daten}

Die öffentliche Diskussion über den Produktionsstandort Bundesrepublik Deutschland beruht in bezug auf die Entwicklung der Direktinvestitionen meist auf der Transferstatistik des BMWi. ${ }^{185}$ Eine ausschließlich auf diese Daten gestützte Argumentation übersieht, daß Transfer-, Zahlungsbilanz- und Bestandsstatistik (Veränderung des Bestands an unmittelbaren Direktinvestitionen gegenüber dem Vorjahr) für das Niveau und für die Dynamik der Direktinvestitionen kein einheitliches Bild zeigen. Tabelle 4.2 zeigt die Entwicklung der deutschen Direktinvestition im Ausland bzw. die Entwicklung der ausländischen Direktinvestition in der Bundesrepublik Deutschland, wie sie in den drei bundesdeutschen Statistiken für die Jahre 1982 bis 1990 bzw. 1991 (Bestandsdaten stehen nur bis 1990 zur Verfügung) ausgewiesen werden.

\footnotetext{
182 Dieser Typ von mittelbaren Beteiligungen spielt dem Volumen nach eine geringe Rolle; vgl. Deutsche Bundesbank (1979, S. 39).

183 Vgl. hierzu auch Deutsche Bundesbank (1979, S. 38 Fn. 13; 1983b, S. 33; 1991a, S. 35).

184 Diese Angabe ist nicht obligatorisch, jedoch erwünscht.

185 Nicht in allen Fällen ist die verwendete Datengrundlage ersichtlich. So wird beispielsweise in einer vom Handelsblatt (1992) angefertigten und veröffentlichten Grafik für Direktinvestitionsströme als Quelle sowohl die Deutsche Bundesbank als auch das Bundesministerium für Wirtschaft genannt; verwendet wurden ausschließlich Zahlungsbilanzdaten.
} 
Tabelle 4.2: Deutsche Direktinvestitionen im Ausland und ausländische Direktinvestitionen in der Bundesrepublik Deutschland in Mio. DM (Transaktionswerte und Bestände), 1982 bis 1991

\begin{tabular}{|c|c|c|c|c|c|c|c|c|}
\hline \multirow[b]{2}{*}{$\begin{array}{l}\text { Jahr } \\
\text { bzw. } \\
\text { Stand } \\
\text { an } \\
\text { Jahres- } \\
\text { ende }\end{array}$} & \multicolumn{3}{|c|}{$\begin{array}{l}\text { Transferstatistik des } \\
\text { Bundesninisteriuns für Wirtschaft }\end{array}$} & \multicolumn{3}{|c|}{$\begin{array}{l}\text { 2ahlungsbilanzstatistik der } \\
\text { Deutschen Bundesbank }\end{array}$} & \multicolumn{2}{|c|}{$\begin{array}{l}\text { Bestandsstatistik der } \\
\text { Deutschen Bundesbank }\end{array}$} \\
\hline & Meuanlagen & Rúckflüsse & $\begin{array}{l}\text { Metto- } \\
\text { transfer- } \\
\text { leistungen }\end{array}$ & Neuanlagen & $\begin{array}{l}\text { Liquida- } \\
\text { tionen }\end{array}$ & $\begin{array}{l}\text { Netto- } \\
\text { kapital- } \\
\text { anlagen }\end{array}$ & $\begin{array}{l}\text { unnittel- } \\
\text { bare } \\
\text { Direkt- } \\
\text { investi- } \\
\text { tionen }\end{array}$ & $\begin{array}{l}\text { Verände- } \\
\text { rung der } \\
\text { unnittel- } \\
\text { baren } \\
\text { Direkt- } \\
\text { investi- } \\
\text { tionen } \\
\text { gegenüber } \\
\text { den } \\
\text { Vorjahr }\end{array}$ \\
\hline & \multicolumn{8}{|c|}{ deutsche Direktinvestitionen in dusland in Mio. Du } \\
\hline 1982 & 13158,2 & 3396,5 & 9761,7 & 13097 & 7077 & 6020 & 95400 & 6971 \\
\hline 1983 & 13697,4 & 5859,8 & 7837,6 & 14366 & 6272 & 8095 & 106573 & 11173 \\
\hline 1984 & 14970,1 & 5704,3 & 9265,8 & 19020 & 6528 & 12492 & 125875 & 19302 \\
\hline 1985 & 21165,5 & 7522,9 & 13642,6 & 20977 & 6835 & 14142 & 130512 & 4637 \\
\hline 1986 & 23754 & 7325 & 16429 & 29586 & 8701 & 20885 & 135791 & 5279 \\
\hline 1987 & 19881 & 7080 & 12801 & 24843 & 8479 & 16364 & 141031 & 5240 \\
\hline 1988 & 25080 & 7236 & 17844 & 28233 & 8159 & 20074 & 167205 & 26174 \\
\hline 1989 & 29801 & 8511 & 21290 & 36585 & 9260 & 27326 & 185288 & 18083 \\
\hline 1990 & 44324 & 12618 & 31706 & 50316 & 13306 & 37010 & 210898 & 25610 \\
\hline \multirow[t]{2}{*}{1991} & 39551 & 10377 & 29174 & 47737 & 12000 & 35737 & $\ldots$ & $\ldots$ \\
\hline & \multicolumn{8}{|c|}{ ausländische Direktinvestitionen in der Bundesrepublik Deutschland in Mio. Du } \\
\hline 1982 & 6428,7 & 2310,6 & 4118,1 & 9398 & 7410 & 1988 & 76359 & 1620 \\
\hline 1983 & 7333,0 & 4263,6 & 3069,4 & 10480 & 5948 & 4533 & 81106 & 4747 \\
\hline 1984 & 7930,7 & 4867,3 & 3063,4 & 8343 & 6770 & 1573 & 84791 & 3685 \\
\hline 1985 & 7831,8 & 4271,0 & 3560,8 & 8159 & 6432 & 1727 & 90885 & 6094 \\
\hline 1986 & 10707 & 8375 & 2332 & 12739 & 10154 & 2585 & 95637 & 1752 \\
\hline 1987 & 9402 & 8893 & 509 & 12478 & 9061 & 3417 & 102345 & 6708 \\
\hline 1988 & 12261 & 10028 & 2233 & 13913 & 11799 & 2114 & 109534 & 7189 \\
\hline 1989 & 20576 & 12640 & 7937 & 26714 & 13558 & 13155 & 127076 & 17542 \\
\hline 1990 & 19086 & 13578 & 5508 & 20945 & 17208 & 3737 & 139624 & 12548 \\
\hline 1991 & 12587 & 10707 & 1880 & 17065 & 12221 & 4844 & .. & $\ldots$ \\
\hline
\end{tabular}

Differenzen in den Summen durch Runden der Zahlen.

Quelle: Deutsche Bundesbank (1988a, S. \& und 24; 1992a, S. \& und 24; 1992b, S. 34 ff.) und Presse- und Informationsamt der Bundesregierung (1992, S. 2) sowie eigene Berechnungen. 
Abbildung 4.1: Saldo der deutschen Direktinvestitionen im Ausland und der ausländischen Direktinvestitionen in der Bundesrepublik Deutschland in Mrd. DM (Transaktionswerte), 1982 bis 1991

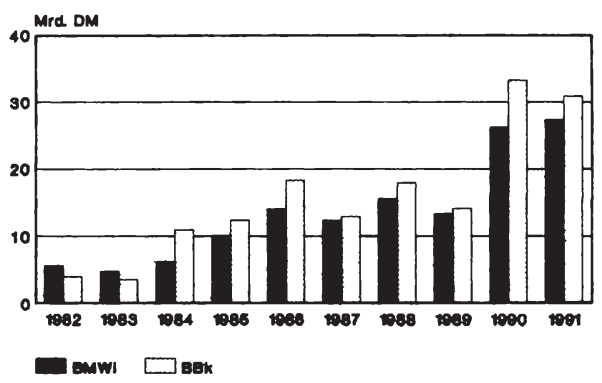

Quelle: Tabelle 4.2; eigene Berechnungen.

Sowohl Transferstatistik als auch Zahlungsbilanzstatistik zeigen für die Jahre 1982 bis 1991, daß der Saldo der deutschen Direktinvestitionen im Ausland und der ausländischen Direktinvestitionen in der Bundesrepublik Deutschland in jedem Jahr positiv ist (vgl. Abbildung 4.1) und daß das Volumen der deutschen Direktinvestitionen im Ausland wesentlich schneller zugenommen hat als das Volumen der ausländischen Direktinvestitionen in der Bundesrepublik. ${ }^{186}$ Die absoluten Zahlen weichen jedoch im Beobachtungszeitraum erheblich voneinander ab: Für die deutschen Nettodirektinvestitionen im Ausland ist die größte absolute Abweichung mit 6,6 Mrd. DM im Jahr 1991 und die größte prozentuale Abweichung mit über $62 \%$ im Jahr $1982 \mathrm{zu}$ beobachten; für die ausländischen Nettokapitalanlagen in der Bundesrepublik beträgt die größte absolute Abweichung 5,2 Mrd. DM (im Jahr 1989), im Jahr 1987 ist der in der Zahlungsbilanzstatistik ausgewiesene Wert um das 6,7fache größer als der Wert in der Transferstatistik. Für die Veränderungen der ausländischen Direktinvestitionen in der Bundesrepublik gegenüber dem Vorjahr weisen die beiden Statistiken in den Jahren 1983, 1986, 1987, 1988 und 1991 unterschiedliche Vorzeichen aus.

Die Bestandsänderungen (Buchwertmethode) zeigen zwar auch, daß das Volumen der deutschen Direktinvestitionen im Ausland im Berichtszeitraum 1982 bis 1990 stärker zugenommen hat als das der ausländischen Direktinvestitionen in der Bundesrepublik. Dies gilt jedoch nicht für die Jahre 1985 und 1987. Die abweichende Entwicklung in diesen beiden Jahren ist nur teilweise mit den im deutschen Unternehmensvermögen im Ausland enthaltenen Bewertungsverlusten infolge der Aufwertung der DM gegenüber den meisten

186 Häufig wird der Saldo der Direktinvestitionen als Indiz für die Standortschwäche der Bundesrepublik Deutschland interpretiert; anders DIW (1992). 
Währungen zu erklären, denn auch im Jahr 1986 stieg der Außenwert der DM gegenüber den Währungen wichtiger Anlageländer. Für die ausländischen Direktinvestitionen in der Bundesrepublik Deutschland liegen die Bestandsänderungen seit 1983 regelmäßig über den entsprechenden Transaktionswerten von Transferstatistik und von Zahlungsbilanzstatistik.

Tabelle 4.3 zeigt für Ende 1990 die regionale Struktur des Bestands an unmittelbaren sowie an unmittelbaren und mittelbaren deutschen Direktinvestitionen im Ausland (210,9 Mrd. bzw. 231,8 Mrd. DM) und des Bestands an unmittelbaren ausländischen Direktinvestitionen in der Bundesrepublik Deutschland (139,6 Mrd. DM). Die USA sind für die Bundesrepublik sowohl das wichtigste Anlageland als auch das bedeutendste Kapitalgeberland. Ende 1990 sind den sechs wichtigsten Kapitalgeberländern (USA, Schweiz, Niederlande, Großbritannien ${ }^{187}$, Japan und Frankreich) zusammen knapp $80 \%$ des gesamten Bestands an unmittelbaren ausländischen Direktinvestitionen in der Bundesrepublik zuzurechnen; Japan überholte im Jahre 1986 in seiner Bedeutung als Kapitalgeber Frankreich.

Am Beispiel ausgewählter EG-Mitgliedsstaaten wird im folgenden gezeigt, daß aus Transfer- und Zahlungsbilanzstatistik teilweise recht unterschiedliche Aussagen in bezug auf das Niveau der Direktinvestitionen in bzw. von einzelnen Ländern und in bezug auf die relative Bedeutung einzelner Länder als Zielland deutscher Direktinvestitionen bzw. als Herkunftsland ausländischer Direktinvestitionen in der Bundesrepublik abzuleiten sind. Daran anschließend werden die wichtigsten Ursachen für die abweichenden Angaben über die Entwicklung der Direktinvestitionen in Transfer- und Zahlungsbilanzstatistik einerseits und in Zahlungsbilanz- und Bestandsstatistik andererseits aufgezeigt.

\subsubsection{Zahlungsbilanzstatistik der Deutschen Bundesbank versus Transfer- statistik des Bundesministeriums für Wirtschaft}

Für die EG-Länder insgesamt zeigen Transfer- und Zahlungsbilanzstatistik die große Bedeutung der EG als Zielland deutscher Direktinvestitionen; beide Statistiken zeigen auch, daß die EG „im Zuge der Vorbereitung deutscher Unternehmen und Finanzinstitute auf den Gemeinsamen Binnenmarkt"188 seit 1989 stark an Bedeutung gewonnen hat (vgl. Tabelle 4.4). In bezug auf die relative Bedeutung der Bundesrepublik als Zielland von Direktinvestitionen aus EG-Ländern zeigen Transfer- und Zahlungsbilanzstatistik dagegen ein weniger einheitliches Bild; in den Jahren 1982 und 1983 stimmen nicht einmal

$\overline{187}$ Das Vereinigte Königreich Großbritannien und Nordirland ist sowohl in der britischen als auch in der deutschen Zahlungsbilanzstatistik definiert einschließlich der britischer Kanalinseln, der Insel Man und dem britischen Teil des Festlandsockels. Im folgenden werden die Begriffe Vereinigtes Königreich und Großbritannien als Synonyme verwendet.

188 Deutsche Bundesbank (1991b, S. 32). 
Tabelle 4.3: Regionale Struktur des Bestands an deutschen Direktinvestitionen im Ausland und an ausländischen Direktinvestitionen in der Bundesrepublik Deutschland nach ausgewählten Ländern, Ende 1990

\begin{tabular}{|c|c|c|c|}
\hline \multirow{3}{*}{$\begin{array}{l}\text { Anlage- bzw. } \\
\text { Rapitalgeberland }\end{array}$} & \multicolumn{2}{|c|}{ deutsche Direktinvestitionen in Ausland } & \multirow{2}{*}{$\begin{array}{l}\text { umittelbare } \\
\text { ausländische Direkt- } \\
\text { investitionen in der } \\
\text { Bundesrepublik } \\
\text { Deutschland }\end{array}$} \\
\hline & $\begin{array}{l}\text { umittelbare } \\
\text { Direkt- } \\
\text { investitionen }\end{array}$ & $\begin{array}{l}\text { umittelbare und } \\
\text { nittelbare Direkt- } \\
\text { investitionen }\end{array}$ & \\
\hline & \multicolumn{3}{|c|}{ in 8 aller Direktinvestitionen } \\
\hline $\begin{array}{l}\text { BG-Länder zusanen } \\
\text { darunter: }\end{array}$ & 48,6 & 45,4 & 35,2 \\
\hline Belgien & 6,1 & 6,0 & 1,6 \\
\hline Prankreich & 7,6 & 8,6 & 6,6 \\
\hline Grobbritannien & 9,2 & 7,3 & 8,2 \\
\hline Lureaburg & 3,9 & 3,5 & 0,6 \\
\hline Miederlande & 8,3 & 6,0 & 13,5 \\
\hline sonstige BG-Länder & 13,5 & 14,0 & 4,7 \\
\hline Scheiseis & 6,1 & 4,6 & 13,6 \\
\hline Japan & 1,7 & 1,9 & 7,1 \\
\hline OSA & 25,6 & 23,0 & 30,0 \\
\hline ibrige Lànder & 18,0 & 25,1 & 13,8 \\
\hline
\end{tabular}

Quelle: Deutsche Bundesbank (1992a, S. \& ff. und 24); eigene Berechnungen.

die Vorzeichen überein (vgl. Tabelle 4.5). ${ }^{189}$ In beiden Statistiken ist der Saldo der deutschen Direktinvestitionen in den EG-Ländern und der Direktinvestitionen der EG-Länder in der Bundesrepublik in allen Jahren des Berichtszeitraumes positiv, d. h., es sind mehr deutsche Direktinvestitionen in die EG-Länder geflossen als die Bundesrepublik Direktinvestitionen aus den anderen EG-Ländern erhalten hat.

${ }^{189}$ Die EG-Mitgliedsstaaten umfassen in der Zahlungsbilanzstatistik - anders als in der Transferstatistik - auch die zu den EG gehörenden internationalen Organisationen. Die in der Zahlungsbilanzstatistik für alle Länder zusammen ausgewiesenen Transaktionswerte für das Jahr 1982 (deutsche Direktinvestitionen im Ausland) sowie für die Jahre 1982 und 1983 (ausländische Direktinvestitionen in der Bundesrepublik) wurden nachträglich korrigiert; revidierte Daten für die Direktinvestitionen nach Empfänger- bzw. Herkunftsländern stehen jedoch nicht zur Verfügung. Die Angaben für die Anteile an allen deutschen Direktinvestitionen im Ausland (bzw. an allen ausländischen Direktinvestitionen in der Bundesrepublik) basieren in bezug auf die regionale Verteilung der Direktinvestitionen auf den nicht-revidierten Daten und in bezug auf die Direktinvestitionen insgesamt auf den revidierten Daten. 


\begin{tabular}{|c|c|c|c|c|c|c|c|c|c|c|c|c|c|c|c|c|c|c|c|c|}
\hline \multirow[b]{5}{*}{ Jahr } & \multicolumn{20}{|c|}{ deutsche Direktinvestitionen in den BG-Mitgliedsstaaten 1} \\
\hline & \multirow{2}{*}{\multicolumn{4}{|c|}{ zusamen }} & \multicolumn{16}{|c|}{ darunter: } \\
\hline & & & & & \multicolumn{4}{|c|}{ Belgien/Luxenburg } & \multicolumn{4}{|c|}{ Prankreich } & \multicolumn{4}{|c|}{ Grobbritannien } & \multicolumn{4}{|c|}{ Miederlande } \\
\hline & \multicolumn{2}{|c|}{$\mathrm{Bumi}^{2}$} & \multicolumn{2}{|c|}{ Bak $^{3}$} & \multicolumn{2}{|c|}{ Bni ${ }^{2}$} & \multicolumn{2}{|c|}{ BBK $^{3}$} & \multicolumn{2}{|c|}{ Buwi 2} & \multicolumn{2}{|c|}{$B k^{3}$} & \multicolumn{2}{|c|}{$\mathrm{Bnini}^{2}$} & \multicolumn{2}{|c|}{$\operatorname{sen}^{3}$} & \multicolumn{2}{|c|}{$\mathrm{Bawi}^{2}$} & \multicolumn{2}{|c|}{$B_{B K}{ }^{3}$} \\
\hline & Mio. Din & 1 & Mio. DII & 1 & Mio. DN & 8 & Mio. DH & 8 & Mio. DN & 1 & Mio. Dan & 1 & Mio. DN & 8 & Mio. DI & 1 & Mio. DM & 1 & Mio. DH & 8 \\
\hline 1982 & 3036,6 & 31,1 & 1865 & 31,0 & 749,4 & 7,7 & 936 & 15,5 & 304,4 & 3,1 & 117 & 1,9 & 1050,9 & 10,8 & 477 & 7,9 & 556,1 & 5,7 & -199 & $-3,3$ \\
\hline 1983 & 1511,1 & 19,3 & 2413 & 29,8 & 621,7 & 7,9 & 312 & 3,9 & 383,2 & 1,9 & 735 & 9,1 & 1058,0 & 13,5 & 587 & 7,3 & $-836,2$ & $-10,7$ & 345 & 4,3 \\
\hline 1984 & 2891,8 & 31,2 & 1294 & 31,1 & 474,8 & 5,1 & 168 & 3,7 & 494,1 & 5,3 & 789 & 6,3 & 1091,1 & 11,8 & 304 & 2,4 & 579,5 & 6,3 & 1104 & 8,8 \\
\hline 1985 & 1813,3 & 35,3 & 3655 & 25,8 & 562,3 & 4,1 & 584 & 1,1 & 494,5 & 3,6 & 804 & 5,7 & 2615,6 & 19,2 & 801 & 5,7 & $-33,7$ & $-0,2$ & 744 & 5,3 \\
\hline 1986 & 6107 & 37,2 & 7840 & 37,5 & 290 & 1,8 & 660 & 3,2 & 186 & 3,0 & 771 & 3,7 & 985 & 6,0 & 1296 & 6,2 & 1745 & 10,6 & 2207 & 10,6 \\
\hline 1987 & 2812 & 22,0 & 1475 & 27,3 & 127 & 1,0 & 782 & 1,8 & 758 & 5,9 & 983 & 6,0 & 1141 & 8,9 & 1069 & 6,5 & 116 & 0,9 & 624 & 3,8 \\
\hline 1988 & 6446 & 36,1 & 7086 & 35,3 & 935 & 5,2 & 1295 & 6,5 & 898 & 5,0 & 908 & 4,5 & 1508 & 8,5 & 1602 & 8,0 & 1021 & 5,7 & 984 & 4,9 \\
\hline 1989 & 13342 & 62,7 & 16315 & 59,7 & 1977 & 9,3 & 2957 & 10,8 & 1729 & 8,1 & 2397 & 8,8 & 4531 & 21,3 & 5181 & 19,0 & 1657 & 7,8 & 1689 & 6,2 \\
\hline 1990 & 21700 & 68,4 & 24622 & 66,5 & 1569 & 14,1 & 5169 & 14,0 & 1907 & 6,0 & 2118 & 5,7 & 5682 & 17,9 & 5852 & 15,8 & 2523 & 8,0 & 3632 & 9,8 \\
\hline 1991 & 19479 & 66,8 & 22936 & 64,2 & 3716 & 12,7 & 1242 & 11,9 & 3756 & 12,9 & 1315 & 12,1 & 1757 & 6,0 & 2767 & 7,7 & 876 & 3,0 & 1609 & 1,5 \\
\hline
\end{tabular}

1 Ab 1986 einschlieblich Spanien und Portugal. In der Zahlungsbilanzstatistik der Deutschen Bundesbank einschlieblich der su den BG geboreaden Internationalen Organisationen.

2 Transferstatistik des Bundesninisteriuns für Wirtschaft.

3 Zahlungsbilanzstatistik der Deutschen Bundesbank (Kapitalausfuhr: + ).

Quelle: Bundesninisteriun für Wirtscbaft (1990, S. 79 Tab. 5.52.12.3; 0.J., S. 101 Tab. 5.5.2.1.2.3) und Deutsche Bundesbank (1986, S. $6 \mathrm{ff} . ; 1987 \mathrm{c}$, S. 6 ff.; 1988b, S. 6 ff.; $1990 \mathrm{~g}$, S. 6 ff.; 1992b, S. 6 ff.); eigene Berechnungen. 


\begin{tabular}{|c|c|c|c|c|c|c|c|c|c|c|c|c|c|c|c|c|c|c|c|c|}
\hline \multirow[b]{5}{*}{ Jahr } & \multicolumn{20}{|c|}{ Direktiavestitionen der BG-Mitgliedestaaten ${ }^{l}$ in der Bundesrepublik Deutschland } \\
\hline & \multirow{2}{*}{\multicolumn{4}{|c|}{ zusamen }} & \multicolumn{16}{|c|}{ darunter: } \\
\hline & & & & & \multicolumn{4}{|c|}{ Belgien/Luxeaburg } & \multicolumn{4}{|c|}{ Prankreich } & \multicolumn{4}{|c|}{ Grosbritannien } & \multicolumn{4}{|c|}{ Miederlande } \\
\hline & \multicolumn{2}{|c|}{$\mathrm{monit}^{2}$} & \multicolumn{2}{|c|}{ Bear ${ }^{3}$} & \multicolumn{2}{|c|}{$\mathrm{Buwi}^{2}$} & \multicolumn{2}{|c|}{$\operatorname{Bat}^{3}$} & \multicolumn{2}{|c|}{ Bumil ${ }^{2}$} & \multicolumn{2}{|c|}{$\mathrm{BBK}^{3}$} & \multicolumn{2}{|c|}{ Buninit } & \multicolumn{2}{|c|}{$\operatorname{Bat}^{3}$} & \multicolumn{2}{|c|}{ Buni ${ }^{2}$} & \multicolumn{2}{|c|}{$\mathrm{BBK}^{3}$} \\
\hline & Mio. D & 1 & Mio. Din & 1 & Mio. DN & 8 & Mio. DH & 1 & Mio. Dn & 1 & Mio. DN & 1 & Mio. m & 1 & Mio. DH & 1 & Mio. DW & 8 & Mio. DM & 8 \\
\hline 1983 & $-115,2$ & $-3,8$ & 1916 & 42,3 & 121,3 & 1,0 & 747 & 16,5 & 352,7 & 11,5 & 210 & 5,3 & 223,3 & 7,3 & 116 & 2,6 & $-753,9$ & $-24,6$ & 824 & 18,2 \\
\hline 1981 & 2454,1 & 80,1 & 1677 & 106,6 & $-21,6$ & $-0,8$ & 181 & 11,5 & 359,0 & 11,7 & 370 & 23,5 & 1591,4 & 51,9 & 202 & 12,8 & 86,0 & 2,8 & 730 & 16,1 \\
\hline 1985 & 1700,5 & 17,8 & 1263 & 73,1 & $-18,0$ & $-0,5$ & 127 & 7,4 & 93,4 & 2,6 & 36 & 2,1 & 618,8 & 17,4 & 462 & 26,8 & 773,1 & 21,7 & 563 & 32,6 \\
\hline 1986 & 1759 & 75,1 & 2778 & 107,5 & -178 & $-7,6$ & -121 & $-1,7$ & 356 & 15,3 & 347 & 13,4 & 518 & 22,2 & 572 & 22,1 & 898 & 38,5 & 1671 & 64,6 \\
\hline 1987 & 128 & 84,1 & 811 & 23,7 & -32 & $-6,3$ & 58 & 1,7 & 156 & 30,6 & 14 & 1,3 & 131 & 25,7 & 379 & 11,1 & 217 & 42,6 & 373 & 10,9 \\
\hline 1988 & 2423 & 108,5 & 3084 & 145,9 & 63 & 2,8 & 106 & 5,0 & 626 & 28,0 & 733 & 34,7 & 494 & 22,1 & 695 & 32,9 & 908 & 40,7 & 1117 & 52,8 \\
\hline 1990 & 1195 & 21,7 & 1553 & 41,6 & -1470 & $-26,7$ & -1519 & $-10,6$ & 945 & 17,2 & 1147 & 30,7 & -252 & $-1,6$ & -75 & $-2,0$ & 950 & 17,2 & 893 & 23,9 \\
\hline 1991 & 1379 & 73,4 & 2853 & 58,9 & 377 & 20,1 & 583 & 12,0 & 983 & 52,3 & 1259 & 26,0 & -417 & $-22,2$ & -145 & $-3,0$ & -281 & $-14,9$ & 215 & 1,4 \\
\hline
\end{tabular}

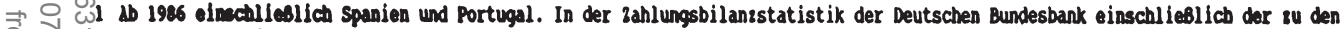
W gendreade internationales Organieationen.

2 Transforstatistik dundealnisterius für Hirtschaft.

ก)

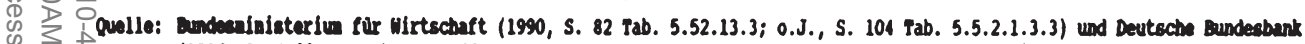

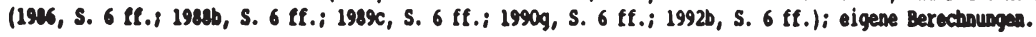


Vergleicht man jedoch die regionale Verteilung der in Transfer- und Zahlungsbilanzstatistik ausgewiesenen Daten für Direktinvestitionen innerhalb der EG, dann kommt man in bezug auf einzelne Länder in einzelnen Jahren, aber auch im Vorjahresvergleich teilweise zu sehr unterschiedlichen Aussagen über die relative Bedeutung eines bestimmten Landes als Zielland deutscher Direktinvestitionen bzw. als Herkunftsland ausländischer Direktinvestitionen in der Bundesrepublik Deutschland. Die Tabellen 4.4 und 4.5 zeigen dies exemplarisch für die im Zusammenhang mit grenzüberschreitenden Kapitalanlagen - am Bestand an Direktinvestitionen gemessenen - wichtigsten EG-Länder BelgischLuxemburgische Wirtschaftsunion (BLUE), Frankreich, Großbritannien und die Niederlande. Große Einzeltransaktionen zwischen der Bundesrepublik und irgendeinem Land schlagen sich sowohl auf den für dieses Land als auch für die insgesamt ausgewiesenen Transaktionswerte nieder. Deshalb ist davor zu warnen, die Bedeutung einzelner Länder als Zielländer bzw. als Herkunftsländer für Direktinvestitionen auf der Grundlage von Stromgrößen an der absoluten Höhe der Direktinvestitionen oder am Anteil der deutschen Direktinvestitionen in einem bestimmten Land an allen deutschen Direktinvestitionen im Ausland bzw. am Anteil der Kapitalanlagen eines bestimmten Landes an allen ausländischen Direktinvestitionen in der Bundesrepublik Deutschland in einem einzelnen Jahr zu messen. Auf der Grundlage von Transaktionswerten ist beispielsweise im Jahre 1991 Irland mit 6,5 Mrd. DM (Zahlungsbilanzstatistik) bzw. 6,6 Mrd. DM (Transferstatistik) mit großem Abstand das wichtigste Empfängerland deutscher Direktinvestitionen im Ausland. ${ }^{190}$

Die Abweichungen der absoluten Zahlen in Transfer- und Zahlungsbilanzstatistik für die wechselseitigen Direktinvestitionen zwischen Frankreich und der Bundesrepublik Deutschland sind relativ gering. Die starke Zunahme der französischen Direktinvestitionen in der Bundesrepublik im Jahre 1989 steht ausschließlich im Zusammenhang mit der Übernahme der Aktienmehrheit an der Colonia Versicherung AG durch die französische Versicherungsgruppe Victoire S. A., Paris, vom Kölner Privatbankhaus Sal. Oppenheim jr. \& Cie. ${ }^{191}$ Der Anteil der französischen Direktinvestitionen an allen Direktinvestitionen in der Bundesrepublik wird in beiden Statistiken jedoch recht unterschiedlich ausgewiesen. Der Saldo der Direktinvestitionen ist außer in den Jahren 1982 und 1989 positiv (vgl. Abbildung 4.2).

Die absoluten Werte für die bilateralen Direktinvestitionen zwischen Großbritannien und der Bundesrepublik in Transfer- und Zahlungsbilanzstatistik unterscheiden sich insbesondere bei den für deutsche Direktinvestitionen in Großbritannien ausgewiesenen Daten. Der große Unterschied in den für das Jahr 1984 ausgewiesenen britischen Direktinvestitionen in der Bundesrepublik führt allerdings dazu, daß laut Transferstatistik Großbritannien in

190 Zu den deutschen Direktinvestitionen in Irland Anfang der 90er Jahre vgl. auch Deutsche Bundesbank (1993, S. 40).

191 Zu dieser Großtransaktion im Versicherungswesen vgl. o.V. (1989).

Otto Roloff, Sibylle Brander, Ingo Barens and Claudia Wesselbaum - 978-3-631-75210-4 
Abbildung 4.2: Saldo der deutschen Direktinvestitionen in Frankreich und der französischen Direktinvestitionen in der Bundesrepublik Deutschland in Mrd. DM (Transaktionswerte), 1982 bis 1991

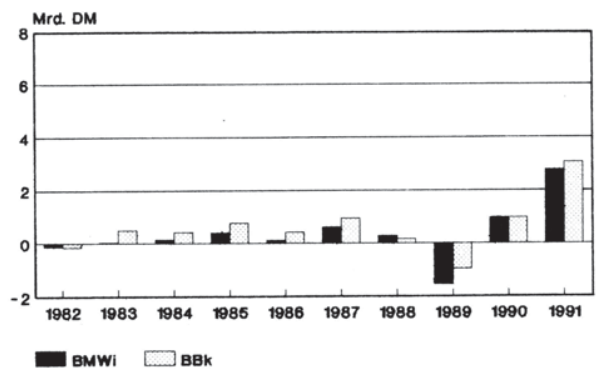

Quelle: Tabellen 4.4 und 4.5; eigene Berechnungen.

Abbildung 4.3: Saldo der deutschen Direktinvestitionen in Großbritannien und der britischen Direktinvestitionen in der Bundesrepublik Deutschland in Mrd. DM (Transaktionswerte), 1982 bis 1991

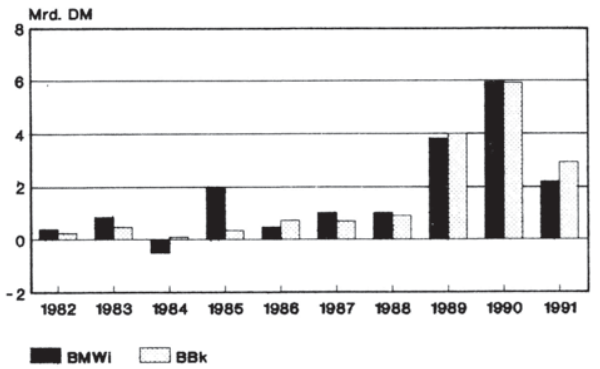

Quelle: Tabellen 4.4 und 4.5; eigene Berechnungen.

diesem Jahr per Saldo mehr in Deutschland investiert hat als Deutschland in Großbritannien, nach den Angaben der Zahlungsbilanzstatistik dagegen ist Deutschland auch in diesem Jahr Nettokapitalexporteur (vgl. Abbildung 4.3).

In den Niederlanden haben ähnlich wie in Großbritannien einige bedeutende multinationale Unternehmen ihren Sitz. Die Angaben für die wechselseitigen Direktinvestitionen zwischen den Niederlanden und der Bundesrepublik zeigen in fast allen Jahren ein völlig unterschiedliches Bild. In den Jahren 1982, 1983 und 1985 (deutsche Direktinvestitionen in den Niederlanden) und in den Jahren 1982, 1983, 1989 und 1991 (niederländische Direktinvestitionen in der Bundesrepublik) ist anhand von Transfer- und Zahlungsbilanzstatistik 
Abbildung 4.4: Saldo der deutschen Direktinvestitionen in den Niederlanden und der niederländischen Direktinvestitionen in der Bundesrepublik Deutschland in Mrd. DM (Transaktionswerte), 1982 bis 1991

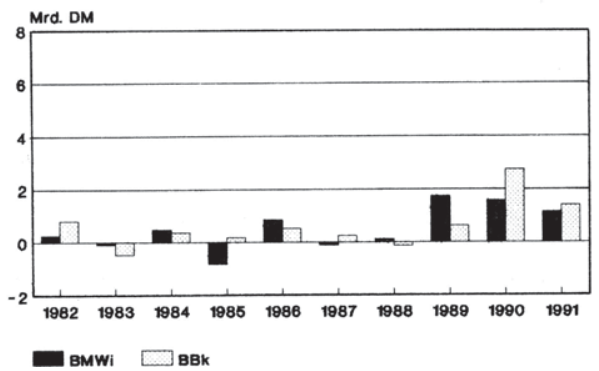

Quelle: Tabellen 4.4 und 4.5; eigene Berechnungen.

nicht einmal festzustellen, ob die Neuanlagen im jeweils anderen Land die entsprechenden Liquidationen übersteigen oder nicht. Für die niederländischen Kapitalanlagen in der Bundesrepublik im Jahre 1989 beispielsweise weist die Transferstatistik -85 Mio. DM aus, die Zahlungsbilanzstatistik dagegen +1075 Mio. DM. In den Jahren 1985, 1987 und 1988 ist zudem offen, ob Deutschland im Zusammenhang mit Direktinvestitionen Nettokapitalexporteur oder -importeur ist (vgl. Abbildung 4.4).

Auch bei den bilateralen Direktinvestitionen zwischen der BLUE und der Bundesrepublik weichen die Angaben von Transfer- und Zahlungsbilanzstatistik in vielen Jahren voneinander ab. Im Jahre 1983 hängt das Vorzeichen des Saldos der Direktinvestitionen von der zugrunde gelegten Statistik ab (vgl. Abbildung 4.5). Die starke Zunahme der deutschen Direktinvestitionen in Belgien in den Jahren 1990 und 1991 führt die Deutsche Bundesbank darauf zurück, daß „mit der Errichtung sogenannter Koordinationszentren für international tätige Unternehmen steuerliche Vorteile genutzt werden ${ }^{\iota 192}$ konnten.

Diese Beispiele zeigen, daß die Abweichungen in den Angaben über die absolute Höhe, die zeitliche Entwicklung und die regionale Struktur der Direktinvestitionen zwischen Transfer- und Zahlungsbilanzstatistik erheblich sein können. Die Analyse der Entwicklung der Direktinvestitionen anhand von Stromgrößen sollte sich deshalb nicht ausschließlich auf Daten der Transferstatistik stützen, sondern es sollten zugleich die Daten der Zahlungsbilanzstatistik herangezogen werden. Dann aber ist es nicht mehr möglich, eindeutig zu sagen, in welche Länder mit welchem Volumen die deutschen Direktinvestitionen fließen und welche Ländern in welcher Höhe Direktinvestitionen in der Bundesrepublik tätigen.

192 Deutsche Bundesbank (1993, S. 40). 
Abbildung 4.5: Saldo der deutschen Direktinvestitionen in der Belgisch-Luxemburgischen Wirtschaftsunion und der belgisch-luxemburgischen Direktinvestitionen in der Bundesrepublik Deutschland in Mrd. DM (Trarisaktionswerte), 1982 bis 1991

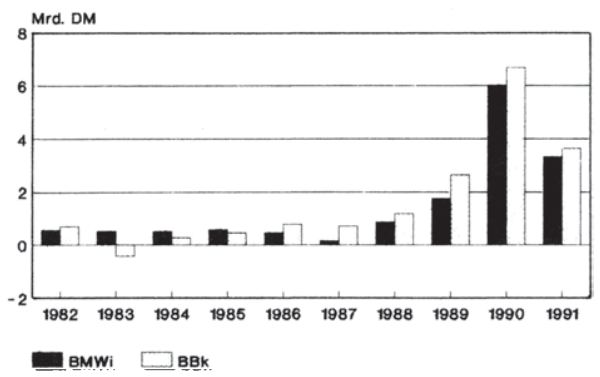

Quelle: Tabellen 4.4 und 4.5; eigene Berechnungen.

Sowohl die Angaben für Direktinvestitionen in der Zahlungsbilanzstatistik der Deutschen Bundesbank als auch die in der Transferstatistik des BMWi sind Transaktionswerte, die auf Totalerhebungen bei gebietsansässigen meldepflichtigen Unternehmen und Privatpersonen beruhen. In beiden Statistiken beinhalten Transaktionen auch die Verrechnung und Aufrechnung sowie die Einbringung von Sachen und Rechten. Abweichungen zwischen den Angaben für Direktinvestitionen in diesen beiden Statistiken sind zurückzuführen auf eine unterschiedliche statistische Abgrenzung des Direktinvestors, des Direktinvestitionsunternehmens, des Direktinvestitionskapitals, auf unterschiedliche Meldefreigrenzen und auf eine unterschiedliche Aufbereitung des Datenmaterials. Die für Direktinvestitionen der Bundesrepublik im Ausland in der Zahlungsbilanzstatistik ausgewiesenen Nettotransaktionswerte liegen in den Jahren 1983 bis 1991 über denjenigen der Transferstatistik; die Angaben der Zahlungsbilanzstatistik für Neuanlagen bzw. für Liquidationen übersteigen außer in den Jahren 1982 und 1985 bzw. im Jahr 1985 die entsprechenden Werte der Transferstatistik. Die für ausländische Direktinvestitionen in der Bundesrepublik in der Zahlungsbilanzstatistik ausgewiesenen Neuanlagen und Liquidationen sind während des gesamten Beobachtungszeitraums größer als diejenigen der Transferstatistik; die für Nettokapitalanlagen bzw. Nettotransferleistungen ausgewiesenen Werte zeigen jedoch kein einheitliches Bild (vgl. Tabelle 4.2).

Seit dem Berichtsjahr 1990, also seit der Neufassung der $\S \S 55,56,57$ und 58 AWV und der Einführung von Kennzahlen für Direktinvestitionen im Leistungsverzeichnis (Anlage LV der AWV), die zu einer Angleichung der Erfassungsmethoden führten, sind die unterschiedlichen Werte für Nettotransferleistungen bzw. für Nettokapitalanlagen trotz unterschiedlicher Meldefreigrenzen in den beiden Statistiken ausschließlich darauf zurück- 
zuführen, daß nur die Zahlungsbilanzstatistik kommerziell genutzten Grundbesitz und reinvestierte Gewinne als Direktinvestitionskapital erfaßt (vgl. Tabclle 4.6). Die für Neuanlagen und für Liquidationen in Transfer- und Zahlungsbilanzstatistik ausgewiesenen Werte (vgl. Tabelle 4.2) weichen aber weiterhin, auch nach Berücksichtigung der unterschiedlichen statistischen Abgrenzung des Direktinvestitionskapitals, erheblich voneinander ab. In früheren Jahren sind die unterschiedlichen Angaben in den beiden Statistiken neben der unterschiedlichen Erfassung von reinvestierten Gewinnen und kommerziell genutztem Grundbesitz insbesondere zurückzuführen auf cine abweichende Abgrenzung des Direktinvestors bzw. des Direktinvestitionsunternehmens, auf dic unterschiedliche Ermittlung der langfristigen Kredite, auf die nur in der Transferstatistik enthaltenen Zuschüsse, auf die bis zum Berichtsjahr 1986 abweichende zeitliche Zuordnung einzelner Transaktionen und darauf, daß Liquidationen von Vermögensanlagen in der Transferstatistik bis einschließlich dem Berichtsjahr 1985 nicht wie in der Zahlungsbilanzstatistik zum Transaktionswert, sondern mit dem ursprünglichen $\Lambda$ nschaffungswert erfaßt wurden. Darüber hinaus wurden in der Transferstatistik vor dem Berichtsjahr 1990 auch Transaktionen zwischen Gebietsansässigen auf eigene Rechnung berücksichtigt.

Da nur Transfer- und Bestandsstatistik, nicht aber die Zahlungsbilanzstatistik, disaggregierte Angaben für die Direktinvestitionen nach Herkunfts- bzw. Zielbranchen zur Verfügung stellen, ist eine Analyse der Determinanten von Direktinvestitionen auf der Ebene von Wirtschaftszweigen ausschließlich mittels Nettotransferleistungen oder mittels den im Zusammenhang mit der Bestandsstatistik erhobenen Daten möglich.

\subsubsection{Veränderung des Bestands an Direktinvestitionen (Buchwerte) versus Zahlungsbilanzwerte}

Die Abweichungen zwischen den in der Zahlungsbilanzstatistik ausgewiesenen Direktinvestitionen und den Veränderungen des auf der Grundlage von Buchwerten ermittelten Bestands an unmittelbaren Direktinvestitionen gegenüber dem Vorjahr sind zum einen darauf zurückzuführen, daß die Bestandsstatistik Vermögensänderungen enthält, die nicht mit Transaktionen im Sinne der Zahlungsbilanzstatistik verbunden sind, zum anderen auf Unterschiede in der statistischen Abgrenzung von Direktinvestoren, Direktinvestitionsunternehmen und Direktinvestitionskapital sowic auf unterschiedliche Erhebungs- und Datenaufbereitungsmethoden. ${ }^{193}$ Die verschiedenen Effekte kompensieren einander teilweise.

\footnotetext{
${ }^{193}$ Zur Höhe der Abweichungen zwischen den Veränderungen des Bestands an unmittelbaren Direktinvestition und den in der Zahlungsbilanzstatistik ausgewiesenen Transaktionswerten für Direktinvestitionen sowie zu den Vermögensänderungen, die keine Transaktionen im Sinne der Zahlungsbilanzstatistik sind, vgl. Deutsche Bundesbank (1981a, S. 29 f.; 1981b, S. 41 f.; 1982a, S. 43 f.; 1985, S. 30 f.; 1987a, S. 22 f.; 1989a, S. 28 ff.; 1991a, S. 29 f.).
} 
Tabelle 4.6: Deutsche Direktinvestitionen im Ausland und ausländische Direktinvestitionen in der Bundesrepublik Deutschland - Gegenüberstellung von Zahlungsbilanzstatistik der Deutschen Bundesbank und Transferstatistik des Bundesministeriums für Wirtschaft. 198: bis 1991

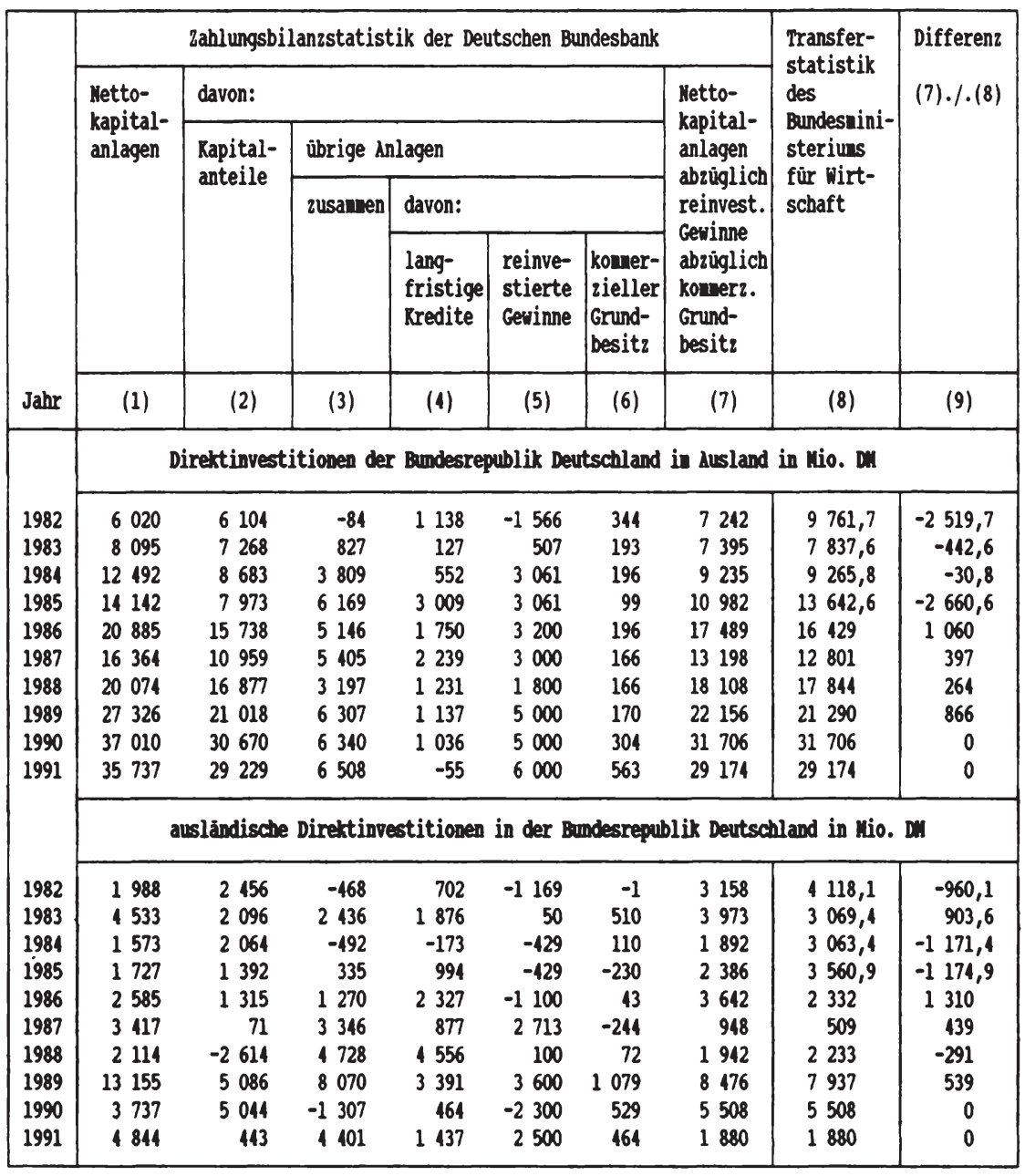

Differenzen in den Summen durch Runden der Zahlen.

Quelle: Bundesministerium für Wirtschaft (1990, S. 76 Tab. 5.52.11; o.J.. S. 98 Tab. 5.5.2.1.1). Deutsche Bundesbank (1990h, S. 22 f. Tab. 3e. S. 28 f. Tab. $5 a$ und S. 32 f. Tab. 5c: 1992d, S. 22 f. Tab. 3e, S. 28 f. Tab. 5a und S. 32 f. Tab. 5c); eigene Berechnungen. 
Die Transaktionswertc für Erwerb oder Veräußerung von Unternehmen(sbeteiligungen), also die Kauf- b/w. Verkaufspreise, enthalten auch den Preis für immaterielle, nicht in den Büchern crscheinende Vermögenswerte - beispielsweise den Geschäfts- oder Firmenwert oder das technische know how. Deshalb liegen sie in der Regel wesentlich über den bilanzierten Buchwerten der Unternehmen(sbetciligungen). D. h., die in der Zahlungsbilanzstatistik ausgewiesenen Daten für Neuanlagen in und für Liquidationen von Kapitalanteilen übersteigen dic entsprechenden Veränderungen des nach den Buchwerten ermitfelten Direkt investitionsbestands. Überwiegen die Unternehmenskäufe die Unternehmensverkäufe - dies gilt insbesondere für dic deutschen Dircktinvestitionen im Ausland seit dem Jahr 1986 -, dann licgen die Transaktionswerte über den Veränderungen der Buchwerte. Dircklinvestitionen, dic durch Aufösung der stillen Reserven von Direktinvestitionsunfornchmen finamiert werden, erscheinen nur in der Bestandsstatistik, nicht aber in der Zahlungsbilanzstatistik. ${ }^{194}$ Erwirbt und veräußert ein Investor eine (mehr als $20 \%$ ige) Belciligung an cinem Untcrnehmen in einem anderen Land in derselben Periode, dann wird in der Zahlıngsbilanzstatistik als Nettokapitalanlage die Differenz zwischen Kaufsumme und Verkaufserlös ausgewiesen, in der Bestandsstatistik erscheint diese Transaktion nicht.

In der Bestandsstatistik werden die reinvesticrten Gewinne im Jahr der Gewinnentstehung, also im Bilanzjahr, ausgewiesen; in der Zahlungsbilanzstatistik erscheinen sie erst im Folgejahr, dem .Jahr der Gewinnverwendung. Die Veränderung der für dic Gewinnausschïttung an die Dircktinvestoren bereitgestellten Dividendenbeträge wird nur in der Veränderung der Buchwerte, nicht, aber in der Zahlungsbilanzstatistik erfaßt.

Da das in Fremdwährungen bilanzicrte Vermögen Gebietsansässiger im $\Lambda$ usland in DM umgerechnet werden muß, spiegelt der in der Bestandsstatistik ausgewiesene Zuwachs des deutschen Untcrnehmensvermögens im $\Lambda$ usland auch dic Fintwicklung des $\Lambda$ uBenwerts der DM wider. Dic Deutsche Bundesbank schätzt, die Bewertungsverluste beim Beteiligungskapital von Ende 1977 bis Fude 1985 auf 5 Mrd. DM, von Ende 1985 bis Ende 1987 auf 15 Mrd. DM, darunter $10 \mathrm{Mrd}$. I)M für die deutschen Direktinvestitionen in den US $\Lambda$ infolge der IÏ̈herbewertung der DM gegenüber dem US-\$, und für Ende 1987 bis Ende 1989 auf $0,5 \mathrm{Mrd}$. 1)M; ${ }^{195}$ die wechselkursbedingten Wertminderungen bei den - meist auf DM lautenden - Forderungen der deutschen Kapitalcigner an ihre ausländischen Tochtergesell-

\footnotetext{
194 In den Ietzlen Jahıren war "\# beohachten, daß Direktinvestoren Beteiligungsgesellschaften in der Bundesrepublik Deutschland grïndeten und in diese ihre deutschen Tochtergesellschaften, an denen sic bisher unmittelbar beteiligt waren, zu üher den Buchwerten liegenden (fiktiven) VeräuBerungsbet.rägen cinbrachten. Disse neue: Finbindung der Tochtergesellschaften innerhalb des ausländischen multinationalen Unt.ernchmens erhöht infolge der Auflösung der stillen Reserven des vorher unmitt.clbaren, danach mitt.clbaren Direktinvestitionsunternehmens den nach der Buchwertmethode ermittelt.en Bestand an ausländischen Direktinvestition in der Bundesrepublik Deutschland, schlägt. sich aber nicht. in der Zahlungshilanzstatistik nieder. Zur Finanzierung von Direkt.investitionen durch Auflösung stiller Reserven vgl. auch Deutsche Bundesbank (1991a, S. 31).

195 Vgl. Deutsche Bundeshank (1987a, S. 25; 1989a, S. 29 f.; 1991a, S. 30).
} 
schaften lassen sich nicht beziffern. ${ }^{196} \mathrm{Da}$ Wertänderungen des Vermögens aufgrund der Wechselkursentwicklung keine Transaktionen in Sinne der Zahlungsbilanzstatistik darstellen, sind die für deutsche Direktinvestitionen im $\Lambda$ usland ausgewiesenen Stromgrößen bei $\Lambda$ ufwertungen ( $\Lambda$ bwertungen) der DM gegenüber den Währungen wichtiger $\Lambda$ nlageländer ceteris paribus höher (niedriger) als dic Bestandsänderungen.

Nur die Bestandsänderungen spiegeln auch Wertberichtigungen des Vermögens wider. Im Gegensatz zu den Transaktionswerten der Zahlungsbilanzstatistik enthalten dic Bestandsdaten auch den Effekt der Imklassifizicrung von Portfolio- zu Dircktinvestitionen.

Sowohl in Zahlungsbilanz- als auch in Bestandsstatistik werden Dircktinvestitioncon von Portfolioinvestitionen statistisch im Prinzip durch die Festlegung ciner Untergrenze für dic Beteiligung des Kapitalgebers an dem kapitalnchmenden Unternchmen abgegren\%t. In der Bestandsstatistik beträgt diese Mindestbeteiligung seit dem Berichtsjahr 1989 mchr als $20 \%$ (vorher: mindestens $25 \%$ ) der hapitalanteile; wirtschaftlich verbundene Investoren gelten nur im Zusammenhang mit ausländischen Direktinvestitionen in der Bundesrepublik als ein Wirtschaftssubjekt. In der Zahlungsbilanzstatistik erfolgt dic statistische (1)grenzung des Direktinvestors bzw. des Direktinvestitionsunternehmens scit dem Berichtsjahr 1990 durch cine Mindestbeteiligung von mehr als $20 \%$ der $\Lambda$ nteile: in Ausnahnncfälen genügt auch eine geringere Beteiligung; Gruppen von Investoren werden weder bei den Dircktinvestitionen der Bundesrepublik im $\Lambda$ usland noch bei den ausländischen Dirck1investitionen in der Bundesrepublik berücksichtigt. Vor dem Berichtsjahr 1990 wurden in der Zahlungsbilanzstatistik sämtliche inländischen (ausländischen) Kapitalanlagen in cin gebictsfremdes körperschaftlich organisiertes Unternchmen (cine gebictsansässige $\Lambda$ kticngescllschaft), dessen (deren) Nominalkapital zu mindestens $25 \%$ cinem Cebietsansässigen oder ciner verbundenen Gruppe von Gebictsansässigen (einem Gebietsfremden oder ciner verbundenen Gruppe von Gebictsfremden) zuzurechnen waren, als Direktinvestitionen crfaßt, und zwar unabhängig davon, welche Kapitalanteile den anderen inländischen (ausländischen) Kapitaleignern zuzurechnen waren und ob die anderen Investoren verbundene Wirtschaftssubjekte waren oder nicht; alle inländischen (ausländischen) Kapitalanlagen in gebietsfremde nicht-körperschaftlich organisierte Unternchmen (gebietsansässige $\Lambda \mathrm{k}$ tiengescllschaften) wurden in der Zahlungsbilanzstatistik unabhängig von der IIöhı der Beteiligung des Kapitalgebers als Direktinvestitionen erfaßt.

In der Bestandsstatistik werden sowohl langfristige als auch kurzfristige Kredite sowie säıntliche Handelskredite der Direktinvestoren an ihre Direktinvestitionsunternchmon als Direktinvestitionskapital erfaßt; seit dem Berichtsjahr 1989 umfassen die Kredite in der Bestandsstatistik auch die Kredite von anderen verbundenen Unternehmen. In der Zah-

196 Vgl. Deutsche Bundesbank (1981b, S. 42 Fn. 5; 1985, S. 31 Fn. 5). 
lungsbilan̋statistik dagegen bleiben die kur\%fristigen Kredite sowie alle Handelskredite umberücksichtigt; es werden nur bestimmte langfristige Kredite einbezogen. Vor dem Berichtsjahr 1990 konnten wegen Informationsmangels die Transaktionen im Zusammenhang mit Gewährung, $\Lambda$ ufnahme und Tilgung langfristiger Kredite und Darlehen jedoch nur näherungsweise ermittelt werden; das in der Zahlungsbilanzstatistik ausgewiesene Direktinvestitionskapital in Form von langfristigen Krediten wurde tendenziell überschätzt.

In Zahhungsbilanz- und Bestandsstatistik gelten unterschiedliche Meldefreigrenzen: In der Zahlungsbilanzstatistik sind alle Leistungen über 5000 DM meldepflichtig (vor Juli 1991 galten niedrigere Meldefreigrenzen); in der Bestandsstatistik werden nur Tochtergesellschaften mit cincr Bilaszsumme bzw. einem Bruttobetriebsvermögen von über 500000 D)M crfaBt.

Dir Daten für den Bestand an unmittelbaren deutschen Direktinvestitionen im Ausland umfassen teilweise auch mittelbare Direktinvestitionen, nämlich die Beteiligungen deutscher Investoren an ausländischen Fnkelgesellschaften, die über im Ausland ansässige von deutschen Kapitalgebern abhängige Direktinvestitionsunternehmen, die keine Holdinggesellschaften sind und die im selben Iand wie die Fnkelgesellschaften ansässig sind, gehalten werden.

Dic Daten der Zahlungsbilanzstatistik bezichen sich auf ein Kalenderjahr. Dies gilt für dic Bestandsdaten nur insoweit, als die Bilanzstichtage von Direktinvestoren und Direktinvestitionsunternehmen auf den 31. Dezember fallen.

Dic Zahlungsbilanzstatistik erfaßt nur Transaktionen, an der sowohl Inländer als auch $\Lambda$ usländer betciligt sind. Dic Bestandsstatistik erfaßt dagegen auch $\Lambda$ nderungen des Vermögens, dic auf Transaktionen zwischen Inländern bzw. zwischen Ausländern zurückzuführen sind. Dies hat $\Lambda$ uswirkungen auf die Dircktinvestitionen nach Zielländern bzw. nach Herkunftsländern und - vorausgesetzt Transaktions- und Buchwerte weichen voneinander ab - auch auf den Gesamtbestand an Direktinvestitionen. Wird ein ausländisches Unternehmen, das in der Bundesrepublik ein Direktinvestitionsunternehmen hat, von einem anderen ausländischen Unternehmen übernommen, dann schlägt sich diese Transaktion zwischen Ausländeru nicht in der Zahlungsbilanzstatistik nieder; entsprechendes gilt für den Fall, daß ein $\Lambda$ usländer (Land $\Lambda$ ) die Beteiligungen an cincm inländischen Direktinvestitionsunternehmen von cincm $\Lambda$ usländer (Land $\Lambda$ oder B) crwirbt. In der Bestandsstatistik ändert sich die regionale Vertcilung der ausländischen Direktinvestitionen in der Bundesrepublik, wenn die beiden $\Lambda$ usländer Inländer verschiedener Länder sind; wenn die Transaktionswerte über den Buchwerten liegen und die Neuanlagen mit höheren Buchwerten in die Bestandsstatistik eingehen, ändert sich auch der Bestand an ausländischen Direktinvestitionen in der Bundesrepublik insgesamt, und zwar unabhängig davon, 
ob dic beiden Ausländer in dem selben Land ansässig sind oder nicht. Verkauft ein deutscher Direktinvestor seine ausländische Tochtergesellschaft an ein anderes inländischen Wirtschaftssubjekt, dann erscheint diese Transaktion nicht in der Zahlungsbilanzstatistik; die Bestandsstatistik zeigt dagegen eine Änderung des Bestands, wenn Transaktionsund Buchwert der Beteiligung voneinander abweichen.

\subsection{Direktinvestitionen in der US-amerikanischen Statistik}

Es mag überraschen, warum in einer Arbeit über Fiskalföderalismus im Europäischen Binnenmarkt die statistische Erfassung von Direktinvestitionen in den USA so ausführlich dargestellt werden muß. Der wichtigste Grund hierfür ist, daß sich die US-Statistik besonders eignet, die Aussagekraft von Statistiken für Direktinvestitionen aufzuzeigen. Die US-Statistik stellt das umfangreichste und das am besten dokumentierte Datenmaterial im Zusammenhang mit grenzüberschreitenden Investitionen zur Verfügung. ${ }^{197}$ Darüber hinaus sind die USA sowohl das größte Herkunfts- als auch Ziclland von Direktinvestitionen. Die Mehrzahl der bisher durchgeführten empirischen Studien über den Einfluß von Steuersatzdifferentialen auf Direktinvestitionen beruhen auf US-Daten. Ferner erscheinen - zumindest auf den ersten Blick - die in der Bundesrepublik Deutschland und in den USA verwendeten Methoden zur statistischen Erfassung von Direktinvestitionen miteinander vergleichbar.

Mitte der 70er Jahre wurde in den USA auf neuer gesetzlicher Grundlage cin neues Verfahren zur Erhebung von Daten im Zusammenhang mit Direktinvestitionen eingeführt; zugleich wurde auch teilweise die Erfassungsmethode für Direktinvestitionen geändert. Da hier die Aussagekraft von Statistiken für Direktinvestitionen im Mittelpunkt steht, beschränken sich die folgenden Ausführungen im wesentlichen auf die Berichtsjahre ab 1982. Herausgestellt werden einige wichtige, insbesondere durch das Schätzverfahren, durch Ānderungen des Schätzverfahrens oder durch definitorische Änderungen bedingte Brüche in den Zeitreihen für Direktinvestitionen in der US-Statistik. Die Abbildungen 4.6 bis 4.8 zeigen die jeweils neuesten, zwischen Juni 1990 und August 1992 vom U.S. Department of Commerce für die Berichtsjahre 1982 bis 1991 veröffentlichten Stromgrößen für US-amerikanische Direktinvestitionen im Ausland (Abbildung 4.6), für auslāndische Direktinvestitionen in den USA (Abbildung 4.7) und für den Saldo der Direktinvestitionen (Abbildung 4.8). Die Abgrenzung des Inlands und die des Inländers sowie die Definition von Direktinvestition, Direktinvestor und Direktinvestitionsunternehmen wurde in diesem Zeitraum nicht geändert. Die Unterschiede in den für ein bestimmtes Jahr ausgewiesenen

$\overline{197}$ Die Revisionen der US-Zahlungsbilanzstatistik, die das U.S. Department of Commerce-BEA regelmäBig durchführt, um definitorische, konzeptionelle und statistische Änderungen sowie neue Informationen in den ausgewiesenen Daten zu berücksichtigen, werden jeweils in der Juni-Ausgabe des Survey of Current Business dokumentiert. 
Abbildung 4.6: US-amerikanische Direktinvestitionen im Ausland in Mrd. US-\$ (Transaktionswerte), 1982 bis 1991

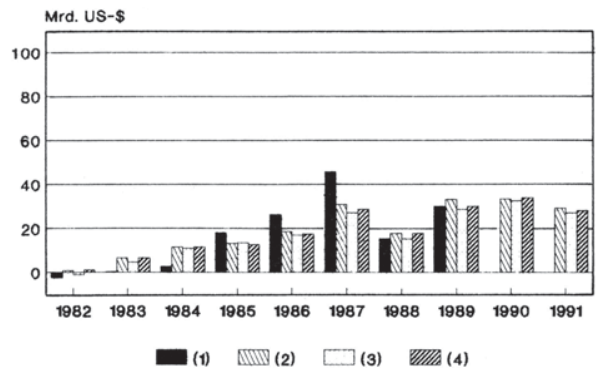

(1) Einschließlich Vermögenszuwächse bzw. -verluste, ohne Marktpreisberichtigung der Gewinne (1982-1989).

(2) Ohne Fremdwährungsumrechnungsgewinne bzw. -verluste, einschl. sonstiger Vermögenszuwächse bzw. -verluste, ohne Marktpreisberichtigung der Gewinne.

(3) Ohnє Vermögenszuwächse bzw. -verluste, mit Marktpreisberichtigung der Gewinne.

(4) Ohne Vermögenszuwächse bzw. -verluste, ohne Marktpreisberichtigung der Gewinne.

Quelle: Tabelle 4.9.

Daten sind zum einen zurückzuführen auf das in den USA verwendete Schätzverfahren. Zum anderen wurde das Verfahren zur Ermittlung der reinvestierten Gewinne in den beiden letzten Jahren mehrfach modifiziert; damit verbunden war jeweils eine rückwirkende Revision der Stromgrößen für Direktinvestitionen für die Berichtsjahre ab 1982. Die für die Jahre bis einschließlich 1981 ausgewiesenen Daten wurden nicht revidiert.

Der Beschreibung des in den USA seit Mitte der 70er Jahre angewendeten Erhebungsverfahrens für Direktinvestitionen und der Abgrenzung der Direktinvestitionen von Portfolioinvestitionen, des Direktinvestors, des Direktinvestitionsunternehmens und des Direktinvestitionskapitals folgt ein Überblick über die alternativen Maße für den Bestand an Direktinvestitionen. ${ }^{198}$ Im Anschluß an die Darstellung des in den USA verwendeten Schätzverfahrens werden die wichtigsten Ursachen für die Unterschiede in den für ein bestimmtes Jahr ausgewiesenen Stromgrößen für Direktinvestitionen aufgezeigt. Schließlich werden die Stromgrößen für deutsche Direktinvestitionen in den USA und für USamerikanische Direktinvestitionen in der Bundesrepublik Deutschland, wie sie in bundes-

198 Zur Erfassung der Direktinvestitionen in der US-Statistik bis Mitte der 70er Jahre vgl. Haubold (1972a, S. 23 ff.; 1972b, S. 92 f. und 208) sowie die dort angegebene Literatur. Wichtige, Mitte der 70er Jahre eingeführte und teilweise rückwirkend geltende Änderungen der Erfassungsmethode faBt Krägenau (1979, S. 108-113) zusammen. Die seit Mitte der 70er Jahre verwendeten Methoden zur Erfassung der Direktinvestitionen werden u. a. auch in U.S. Department of Commerce (1976, vol. 1) sowie U.S. Department of Commerce-Bureau of Economic Analysis (1981; 1983; 1985b; 1990a) beschrieben. 
Abbildung 4.7: Ausländische Direktinvestitionen in den USA in Mrd. US-\$ (Transaktionswerte), 1982 bis 1991

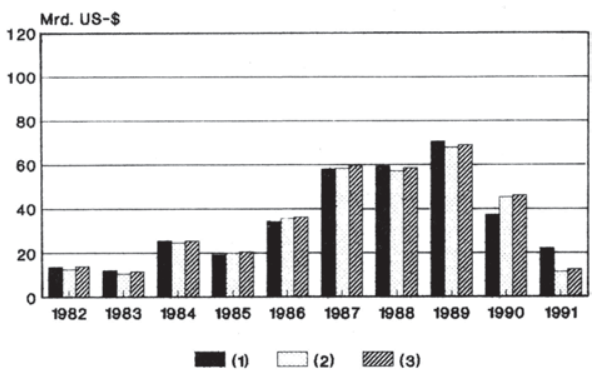

(1) Einschließlich Vermögenszuwächse bzw. -verluste, ohne Marktpreisberichtigung der Gewinne.

(2) Ohne Vermögenszuwächse bzw. -verluste, mit Marktpreisberichtigung der Gewinne.

(3) Ohne Vermögenszuwächse bzw. -verluste, ohne Marktpreisberichtigung der Gewinne.

Quelle: Tabelle 4.9.

Abbildung 4.8: Saldo der US-amerikanischen Direktinvestitionen im Ausland und der ausländischen Direktinvestitionen in den USA in Mrd. US-\$ (Transaktionswerte), 1982 bis 1991

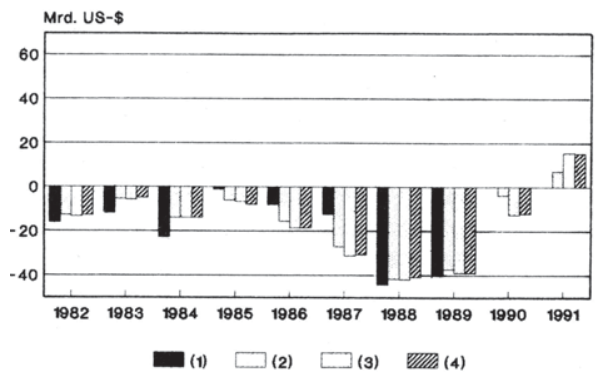

(1) Einschließlich Vermögenszuwächse bzw. -verluste, ohne Marktpreisberichtigung der Gewinne (1982 bis 1989).

(2) Direktinvestitionen der USA: Ohne Fremdwährungsumrechnungsgewinne bzw. -verluste, einschl. sonstiger Vermögenszuwächse bzw. -verluste; ohne Marktpreisberichtigung der Gewinne. Direktinvestitionen in den USA: Einschl. Vermögenszuwächse bzw. -verluste; ohne Marktpreisberichtigung der Gewinne.

(3) Ohne Vermögenszuwächse bzw. -verluste, mit Marktpreisberichtigung der Gewinne.

(4) Ohne Vermögenszuwächse bzw. -verluste, ohne Marktpreisberichtigung der Gewinne.

Quelle: Tabelle 4.9; eigene Berechnungen. 
deutscher und US-amerikanischer Statistik ausgewiesen werden, gegenübergestellt.

\subsubsection{Erhebungsmethode in den USA}

Stromgrößen für Direktinvestitionen werden in der US-Zahlungsbilanzstatistik als Unterposition von „U.S. private assets“ bzw. als Unterposition von "other foreign assets in the U.S.“ ausgewiesen. Bestandsgrößen für Direktinvestitionen sind der Nettoauslandsposition der USA zu entnehmen. Anders als beispielsweise in der Bundesrepublik Deutschland werden in den USA Strom- und Bestandsgrößen für Direktinvestitionen nicht unabhängig voneinander ermittelt. Vielmehr basieren die Bestandsgrößen in den meisten Jahren auf der Fortschreibung mittels Stromgrößen zuzüglich Wertberichtigungen.

Die Erhebung von Daten über die Aktivitäten multinationaler Unternehmen, die über die vom Bretton Woods Agreements Act of 1945 abgedeckten Zahlungsbilanzaspekte hinausgehen, ist erst seit der Verabschiedung des International Investment Survey Act of 1976 möglich. ${ }^{199}$ Nach Ergänzung um den Trade and Tariff Act of 1984 und Umbenennung in International Investment and Trade in Services Survey Act bildet dieses Gesetz heute die rechtliche Grundlage für die Erhebung umfangreicher Daten über die Aktivitäten multinationaler Unternehmen. Das für Erhebung und Aufbereitung der Daten für Direktinvestitionen zuständige U.S. Department of Commerce/Bureau of Economic Analysis (BEA) führt zum einen in unregelmäßigen ${ }^{200}$ Abständen Totalerhebungen, zum anderen in jedem Quartal Stichprobenerhebuugen durch. ${ }^{201}$ Alle privaten Organisationen, v. a. Unternehmen, die entweder im eigenen Namen oder auf Rechnung Dritter Transaktionen mit Ausländern tätigen, sind, sofern sie nicht unter die Meldefreigrenzen fallen, meldepflichtig.

Totalerhebungen (benchmark surveys) wurden bisher für Direktinvestitionen der USA für die Berichtsjahre 1977, 1982 und 1989 und für Direktinvestitionen in den USA für die Berichtsjahre 1974, 1980 und 1987 durchgeführt. ${ }^{202}$ In den Totalerhebungen werden detaillierte Informationen über sämtliche Beziehungen zwischen Direktinvestoren und ih-

199 Der Bretton Woods Agreements Act bildete in den Berichtsjahren 1950 bis 1976 (ohne Direktinvestitionen in den USA im Jahre 1974) die rechtliche Grundlage für die Erhebung von Daten für die US-amerikanische Zahlungsbilanzstatistik; es bestand Meldepflicht. Die Verabschiedung des Foreign Investment Study Act of 1974 ermöglichte für das Berichtsjahr 1974 die Durchführung einer einmaligen, obligatorischen Totalerhebung für ausländische Direktinvestitionen in den USA.

200 Im International Investment Survey Act bzw. im International Investment and Trade in Services Survey Act sind Totalerhebungen im Abstand von fünf Jahren vorgesehen.

201 Die Daten für Portfolioinvestitionen sammelt und verarbeitet das U.S. Treasury Department und die Federal Reserve Bank of New York; vgl. U.S. Department of Commerce-Bureau of Economic Analysis (1990b, S. 84).

202 Auf anderer gesetzlicher Grundlage und vom Umfang der erhobenen Daten - v. a. im Sinne von Datenvielfalt - weniger umfangreich wurden Totalerhebungen für Direktinvestitionen der USA auch für die Berichtsjahre 1957 und 1966 bzw. für Direktinvestitionen in den USA für das Berichtsjahr 1959 durchgeführt. 
ren Tochtergesellschaften erhoben. Neben Daten über den Bestand an Direktinvestitionen und über die Transaktionen zwischen Direktinvestoren und Tochtergesellschaften, d. h. Direktinvestitionskapitalströme, Kapitalerträge aus Direktinvestitionen, Lizenzen sowie Tantiemen und anderen Dienstleistungen zwischen Mutter- und Tochtergesellschaften, sind für die US-amerikanischen Muttergesellschaften und jede ihrer Tochtergesellschaften im Ausland sowie für die US-amerikanischen Tochtergesellschaften ausländischer Direktinvestoren u. a. auch Bilanzen, Gewinn- und Verlustrechnungen, Umsätze, Ausgaben für Sachanlagevermögen, Beschäftigung und Entlohnung sowie US-Warenexporte und -importe zu melden; darüber hinaus wird die Struktur der Außenfinanzierung der Tochtergesellschaften erhoben. ${ }^{203}$ Im Vergleich mit der Bundesrepublik sind die Meldefreigrenzen bei den Totalerhebungen in den USA seit Anfang der 80er Jahre relativ hoch: Bei den Direktinvestitionen der USA werden alle Tochtergesellschaften im Ausland mit einer Bilanzsumme, Umsatzerlösen oder Gewinnen von mindestens 3 Mio. US-\$ im entsprechenden Wirtschaftsjahr erfaßt; ${ }^{204}$ bei den Direktinvestitionen in den USA sind alle US-amerikanischen Tochtergesellschaften meldepflichtig, deren Bilanzsumme, Umsatzerlöse oder Gewinne im entsprechenden Wirtschaftsjahr 1 Mio. US-\$ oder mehr betragen oder die mindestens 200 Morgen US-Land besitzen. Ist bei einer dieser drei bzw. vier genannten Positionen die Meldefreigrenze überschritten, dann hat dieses Unternehmen zu berichten. ${ }^{205}$

In den vierteljährlichen Stichprobenerhebungen des U.S. Department of Commerce/BEA zu den für die Erstellung der US-Zahlungsbilanzstatistik und für den Ausweis der Nettoauslandsposition der USA relevanten Aspekten von Direktinvestitionen werden $u$. a. erhoben: ${ }^{206}$ Transaktionen zwischen Mutter- und Tochtergesellschaften oder anderen Wirtschaftssubjekten, die den Bestand an Eigenkapital, den die Direktinvestoren an ihren

$\overline{203} \Lambda \mathrm{m}$ detailliertesten ist für US-beherrschte ausländische Nicht-Banken-Tochtergesellschaften zu berichten, $d$. h. für ausländische Tochtergesellschaften, an denen die unmittelbaren und mittelbaren Beteiligungen aller US-Muttergesellschaften 50 \% übersteigen. Im Berichtsjahr 1982 waren $84,1 \%$ aller meldepflichtiger Nicht-Banken-Tochtergesellschaften im Ausland US-beherrschte Unternehmen (majority owned foreign affiliates); vgl. Whichard/Shea (1985, S. 37 und 48).

204 In der Totalerhebung für das Berichtsjahr 1977 betrug die Meldefreigrenze mindestens 0,5 Mio US-\$; vgl. z. B. Lowe/Mataloni (1991, S. 31 Fn. 7).

$205 \mathrm{Zu}$ den Meldefreigrenzen vgl. z. B. Whichard/Shea (1985, S. 38), Lowe/Mataloni (1991, S. 31 Fn. 7 und S. 45), Belli (1984, S. 32), Scholl (1991, S. 33 f.) und Howenstine (1989, S. 131). In der Totalerhebung für das Berichtsjahr 1987 waren von 12913 Tochtergesellschaften in den USA 8577, also 66,4 \%, meldepflichtig; vgl. Scholl (1991, S. 34 Fn. 11). Von insgesamt 33650 Tochtergesellschaften im Ausland waren in der Totalerhebung für das Berichtsjahr 1982 nur 18339, also 54,5\%, und ihre 2245 US-Muttergesellschaften meldepflichtig; vgl. Whichard/Shea $(1985$, S. 37 f. $)$. Gemessen an den $\Lambda$ ktiva und den Umsätzen aller Tochtergesellschaften haben die nicht meldepflichtigen Unternehmen eine sehr geringe Bedeutung; vgl. z. B. Belli (1984, S. 32), Whichard/Shea (1985, S. 38 Fn. 1), Scholl (1991, S. 34 Fn. 11) und Lowe/Mataloni (1991, S. 45).

206 Einen Überblick über die Erhebungen im Zusammenhang mit der Erstellung der USZahlungsbilanzstatistik gibt U.S. Department of Commerce-Bureau of Economic Analysis (1990b, S. 11-13). 
Tochtergesellschaften halten, ändern; der Bestand an Eigenkapital, das Direktinvestoren an ihren Tochtergesellschaften zuzurechnen ist; der Bestand an und Transaktionen im Zusammenhang mit Forderungen und Verbindlichkeiten der Muttergesellschaften gegenüber ihren Tochtergesellschaften; sowie die Anteile der Direktinvestoren an den Gewinnen, an den Vermögenszuwächsen bzw. -verlusten, an den ausgeschütteten und an den thesaurierten Gewinnen ihrer Tochtergesellschaften. Die Meldefreigrenzen wurden im Zeitablauf sukzessive erhöht, und sie sind für Direktinvestitionen der USA und für Direktinvestitionen in den USA teilweise unterschiedlich hoch. So werden beispiclsweise US-amerikanische Tochtergesellschaften ausländischer Gesellschaften mit einer jährlichen Bilanzsumme, Umsatzerlösen oder Gewinnen von mindestens 5 Mio. US- $\$$ (1981-83) bzw. mindestens 10 Mio. US-\$ (seit 1984) bzw. über 20 Mio. US-\$ (seit 1988) erfaßt; eine Meldepflicht besteht außerdem für US-Tochtergesellschaften, die mindestens 200 Morgen US-Land besitzen. Seit Mitte der $80 \mathrm{er}$ Jahre beträgt die Meldefreigrenze für ausländische Tochtergesellschaften von US-Gesellschaften 15 Mio. US- $\${ }^{207}$

Für Direktinvestitionen der USA haben die vollständig konsolidierten US-Muttergesellschaften (vgl. unten) über sich selbst und über jede einzelne ihrer Tochtergesellschaften im Ausland zu berichten; dabei dürfen Tochtergesellschaften im selben Land, wenn sie in demselben Wirtschaftszweig tätig sind oder wesentlicher Bestandteil derselben Geschäftstätigkeit sind, in Ausnahmefällen konsolidiert werden. ${ }^{208}$ Für Direktinvestitionen in den USA muß jede US-Tochtergesellschaft auf der Grundlage vollständiger Konsolidierung für sich selbst melden; in dic Konsolidierung eingeschlossen sind „all other U.S. affiliates of its foreign parent in which it directly or indirectly owns more than 50 percent of the outstanding voting interest. Any U.S. subsidiaries of a given affiliate that are not U.S. affiliates of its foreign parent are excluded from the consolidation, even if they are owned more than 50 percent by the given affiliate. " 209

$\overline{207} \mathrm{Zu}$ den Meldefreigrenzen in den vierteljährlichen Stichprobenerhebungen vgl. z. B. Belli $(1984$, S. 33), Stone Tice/Moczar (1986, S. 33) sowie U.S. Department of Commerce-Bureau of Economic Analysis (1990b, S. 11 und 87). - Zu anderen Aspekten der Aktivitäten multinationaler Nicht- BankenUnternehmen führt das U.S. Department of Commerce/BEA weitere, meist jährliche Stichprobenerhebungen mit jeweils unterschiedlichen, z. T. im Zeitablauf angehohenen Meldefreigrenzen und teilweise auch höheren Mindestbeteiligungsquoten zur Ahgrenzung der Direktinvestitionen von den Portfolioinvestitionen durch. $\mathrm{Zu}$ den jüngsten Veröffentlichungen der Ergebnisse dieser Stichprobenerhebungen vgl. für Direktinvestitionen der USA im Ausland Fahim-Nader (1991a; 1992a; 1992b), Mataloni (1990a; 1990b; 1991; 1992) und U.S. Department of Commerce-Bureau of Ficonomic Analysis (1991f; 1991g; 1992f) sowie für Direktinvestitionen in den USA Bezirganian (1991; 1992), FahimNader (1991b; 1992c), Howenstine/Zeile (1992) und U.S. Department of Commerce-Bureau of Fconomic Analysis (1992b; 1992c; 1992d). Einen Überblick über die verschiedenen Erhebungen des U.S. Department of Commerce/BEA fïr Direktinvestitionen in den USA geben Quijano (1990) sowie Graham/Krugman (1989, S. 145 ff.).

208 Vgl. U.S. Department of Commerce-Bureau of Economic Analysis (1990b, S. 86) oder Lowe/Mataloni (1991, S. 45 Fn. 17).

209 U.S. Department of Commerce-Bureau of Economic Analysis (1990b, S. 86). Ausländische Muttergesellschaften sind nicht meldepflichtig. 
Zum Inland im Sinne der US-Zahlungsbilanzstatistik zählen neben den 50 Bundesstaaten der District of Columbia, Puerto Rico, Samoa-Inseln, Guam, Midway-Inseln, Jungferninseln, Wake-Inseln sowie alle anderen US-Territorien und Besitzungen. Militärische, diplomatische, konsularische und andere nicht-militärische US-Einrichtungen im Ausland werden dem Inland zugerechnet. ${ }^{210}$

Mls US-Inländer zählen unabhängig von der Staatsangehörigkeit alle Wirtschaftssubjekte, die den Mittclpunkt ihres wirtschaftlichen Interesses im Inland haben und sich (voraussichtlich) für mindestens ein Jahr in den USA aufhalten. Dazu zählen natürliche Personen mit ständigem Aufenthalt in den USA, ${ }^{211}$ alle nach US-Gesetzen gegründeten gewerblichen Unternehmen ${ }^{212}$ und Organisationen ohne Erwerbscharakter sowie die Gebietskörperschaften cinschlicßlich deren im In- und Ausland tätigen Vertretungen und Unterabteilungen. ${ }^{213}$ Agenturen ausländischer Unternehmen im Inland gelten ebenfalls als US-Inländer. Briefkastenfirmen in den USA, d. h. in den USA gegründete, aber vollständig im Ausland tätige Unternehmen, werden in der US-Statistik nur dann als US-Inländer betrachtet, wenn sie von US-Interessen kontrolliert werden; gehören die Briefkastenfirmen dagegen Ausländern, dann gelten sie als Inländer der Länder, in denen diese Gesellschaften tätig sind. ${ }^{214}$

\subsubsection{Abgrenzung von Direktinvestor und Direktinvestitionsunternehmen in der US-Statistik}

Grenzüberschreitende Investitionen werden in der US-Statistik als Direktinvestitionen erfaßt, wenn der Investor an dem Unternehmen in einem anderen Land ein dauerhaftes Interesse hat und cinen Einfluß auf die Geschäftsführung dieses Unternehmens ausüben kann: „Direct investment implies that a person in one country has a lasting interest in, and a degree of influence over the management of, a business enterprise in another

$\overline{210}$ Vgl. U.S. Department of Commerce-Bureau of Economic Analysis (1990b, S. 3). Im Doppelbesteuerungsabkommen zwischen den USA und der Bundesrepublik Deutschland umfassen die USA dagegen nur die 50 Bundesstaaten und den District of Columbia; vgl. Debatin/Endres (1990, S. 190). Ähnlich eng ist das Inland in den Volkswirtschaftlichen Gesamtrechnungen der USA definiert. Dort zählen zu den USA nur die 50 Bundesstaaten, der District of Columbia sowie militärische, diplomatische und konsularische US-Finrichtungen im Ausland; vgl. Stone Tice/Moczar (1986, S. 28).

211 Ausgenommen hiervon sind u. a. Beschäftigte der US-Bundesregierung, die sich im Ausland aufhalten, also heispielsweise Mitglieder der bewaffneten Streitkräfte und Angehörige von diplomatischen und konsularischen Vertretungen einschlieBlich deren Familien; vgl. U.S. Department of Commerce-Bureau of Fronomic Analysis (1990h, S. 3).

212 Einen Überblick über das US-amerikanische Gesellschaftsrecht, das nicht einheitlich auf Bundesebene geregelt ist, sondern in den Hoheitsbereich der US-Bundesstaaten fält, geben z. B. von SamsonHimmelstjerna (1983), Roehm (1990) oder Flsing (1990, S. 8 ff.).

213 Zur Abgrenzung des US-Inländers vgl. U.S. Department of Commerce-Bureau of Economic Analysis $(1990 \mathrm{~h}, \mathrm{~S} .3 \mathrm{f}$.). Internationale Organisationen werden als Inländer keines Landes betrachtet und zusammen mit den regional nicht aufteilbaren Posten ausgewiesen.

214 Vgl. U.S. Department of Commerce-Burcau of Economic Analysis (1990b, S. 3 f.). 
country. This interest - in some instances, control - generally makes direct investment a long-term relationship, in which the operation of the enterprise is linked with the real output of the country in which it operates." ${ }^{215}$ Das Kriterium der Einflußnahme wird in der US-Statistik als erfüllt angesehen, wenn ein einzelnes inländisches (bzw. ausländisches) Wirtschaftssubjekt, der Direktinvestor, entweder unmittelbar oder mittelbar mindestens $10 \%$ der Stimmrechte einer ausländischen (bzw. inländischen) Körperschaft ${ }^{216}$ bzw. bei nicht-körperschaftlich organisierten Unternehmen eine entsprechende Beteiligung besitzt oder kontrolliert. ${ }^{217}$ Bei der Bestimmung des Anteils an den Stimmrechten, dic einem inländischen (bzw. ausländischen) Wirtschaftssubjekt an einem ausländischen (bzw. inländischen) Unternehmen zuzurechnen sind, werden alle unmittelbaren und über andere ausländische (bzw. inländische) Gesellschaften gehaltenen mittelbaren Beteiligungen berücksichtigt. $^{218}$

Der Begriff Wirtschaftssubjekt ist in der US-Statistik weit gefaßt. Zu den potentiellen Direktinvestoren zählen u. a. natürliche Personen, Zweigniederlassungen, Personengesellschaften, Nachlässe, Treuhandvermögen (trusts), ${ }^{219}$ Körperschaften (corporation) und sonstige Organisationen, verbundene Wirtschaftssubjekte sowie alle Gebietskörperschaften einschließlich deren Vertretungen, Körperschaften, Geldinstitute oder sonstigen Gebilde. ${ }^{20}$ Investitionen der US-Bundesregierung in Unternehmen im Ausland zählen jedoch selbst dann, wenn das Kriterium für Direktinvestitionen erfüllt ist, nicht als Direktinvestitionen. Dagegen werden Investitionen ausländischer Regierungen in US-Unternehmen bei mindestens 10\%iger Beteiligung als ausländische Direktinvestitionen in den USA erfaßt.

Zwei oder mehr Wirtschaftssubjekte, die ihre Stimmrechte durch den Anschein ihrer Handlungen, durch Absprachen oder durch Übereinkunft als Einheit ausüben, werden wegen ihrer Verbundenheit als ein einziges Wirtschaftssubjekt behandelt (associated group). Als verbunden gelten natürliche Personen, dic derselben Familie angehören; ein gewerbliches Unternehmen und mindestens eines seiner Vorstandsmitglieder oder einer seiner

\footnotetext{
215 U.S. Department of Commerce-Bureau of Economic Analysis (1990b, S. 84).

216 Unter den Begriff Körperschaften (corporations) fallen nicht nur Kapitalgesellschaften, sondern auch Vermögensmassen, Vereinigungen (associations) und Versicherungsgesellschaften; vgl. Debatin/Korn $(1989$, S. 541).

217 Vgl. z. B. U.S. Department of Commerce-Bureau of Economic Analysis (1990b, S. 84). De facto wurden auch schon vor 1977 bzw. 1974 Direktinvestitionen statistisch mittels einer mindestens 10\%igen Beteiligung abgegrenzt. Denn Unternehmen, deren stimmberechtigtes Kapital zwischen 10 und $25 \%$ einem Wirtschaftssubjekt eines anderen Landes zuzurechnen war (associated enterprises), wurden genauso behandelt wie Tochtergesellschaften, an denen ein Investor eines anderen Landes mindestens $25 \%$ der Anteile hielt oder kontrollierte. Vgl. Haubold (1972a, S. 27 f.).

218 Vgl. hierzu U.S. Department of Commerce-Bureau of Economic Analysis (1990b, S. 85).

${ }^{219}$ Im deutschen Recht gibt es für die in den USA weit verbreiteten Trusts keine direkte Parallele; vgl. Debatin/Korn (1989, S. 543).

220 Vgl. U.S. Department of Commerce-Bureau of Economic Analysis (1990b, S. 84). 
Geschäftsführer; Mitglieder eines joint venture oder eines Konsortiums; sowie eine Körperschaft und ihre inländischen Untergesellschaften. Auch wenn jedes einzelne dieser verbundenen Wirtschaftssubjekte an einem Unternehmen in einem anderen Land mit weniger als $10 \%$ beteiligt ist, gilt die Gruppe insgesamt als Direktinvestor und ihre grenzüberschreitenden Investitionen werden als Direktinvestitionen erfaßt, wenn die verbundenen Wirtschaftssubjekte zusammen mindestens $10 \%$ der Anteile an einem Unternehmen in einem anderen Land halten. ${ }^{221}$

Nicht als Direktinvestitionen zählen folglich in der US-Statistik Investitionen in Unternehmen, an denen das Eigentum so weit gestreut ist, daß kein Wirtschaftssubjekt eines anderen Landes eine mindestens $10 \%$ ige Beteiligung hält oder kontrolliert, und die Eigentümer nicht zusammenarbeiten können oder wollen, um Einfluß auf die Geschäftsführung zu nehmen. ${ }^{222}$ Sind zwei nicht miteinander verbundene Wirtschaftssubjekte an demselben Unternehmen in einem anderen Land beteiligt und zwar das eine Wirtschaftssubjekt mit mindestens $10 \%$, das andere mit weniger als $10 \%$, dann gilt die Beteiligung des ersteren als Direktinvestition, die des letzteren als Portfolioinvestition. ${ }^{223}$

Bei den Direktinvestitionen der USA im Ausland ist der Direktinvestor, im folgenden auch als US-Muttergesellschaft bezeichnet, im Falle einer Körperschaft der vollständig konsolidierte US-Konzern. In die Konsolidierung eingeschlossen sind alle US-Körperschaften, die mit Mehrheit, also zu über $50 \%$, an anderen US-Körperschaften beteiligt sind und die im Mehrheitsbesitz von US-Körperschaften stehen. ${ }^{24}$ Alle anderen US-Körperschaften und alle ausländischen Unternehmen, an denen die US-Muttergesellschaft beteiligt ist, sind von der Konsolidierung ausgeschlossen.

Bei den ausländischen Direktinvestitionen in den USA ist die ausländische Muttergesellschaft das in einer Eigentümerkette der US-Tochtergesellschaft erste Wirtschaftssubjekt außerhalb der USA, das an dem US-amerikanischen Unternehmen mindestens $10 \%$

$\overline{{ }^{221} \mathrm{Zu} \text { verbundenen Wirtschaftssubjekten }}$ vgl. U.S. Department of Commerce-Bureau of Economic Analysis (1990b, S. 84).

222 Vor dem Berichtsjahr 1974 (für Direktinvestitionen in den USA) bzw. 1977 (für Direktinvestitionen der USA) wurden auch Beteiligungen an Unternehmen in einem anderen Land als Direktinvestitionen erfabt, wenn nicht verbundene Wirtschaftssubjekte eines Landes zwar einzeln nicht das Kriterium des Direktinvestors erfüllten, aber zusammen über $50 \%$ des stimmberechtigten Kapitals hiclten. Vgl. Haubold (1972a, S. 27; 1972b, S. 208) oder U.S. Department of Commerce-Bureau of Economic Analysis (1990b, S. 84 f.).

223 Vgl. U.S. Department of Commerce-Bureau of Economic Analysis (1990b, S. 85).

224 "If incorporated, the U.S. parent is the fully consolidated domestic U.S. enterprise that consists of (1) the U.S. corporation whose voting securities are not owned more than $\mathbf{5 0}$ percent by another U.S. corporation, and (2) proceeding down each ownership chain from that U.S. corporation, any U.S. corporation whose voting securities are more than 50 percent owned by the U.S. corporation above it in the chain." (U.S. Department of Commerce-Bureau of Economic Analysis 1990b, S. 85). Vgl. hierzu auch Mataloni (1992, S. 61). 
der Stimmrechte bzw. bei nicht-körperschaftlich organisierten Unternehmen eine entsprechende Beteiligung besitzt oder kontrolliert. Als eigentlicher wirtschaftlicher Eigentümer (ultimate benefical owner) einer Tochtergesellschaft in den USA gilt in der US-Statistik das Wirtschaftssubjekt, das nicht im Mehrheitsbesitz eines anderen ausländischen Wirtschaftssubjekts steht. Der eigentliche wirtschaftliche Eigentümer einer US-Tochtergesellschaft kann in demselben Land ansässig sein wie die Muttergesellschaft, in einem Drittland oder auch in den USA. Als Direktinvestitionen werden sämtliche Transaktionen zwischen US-Tochtergesellschaft und verbundenen Ausländern erfaßt. Zu diesen zählen neben der ausländischen Muttergesellschaft und dem eigentlichen wirtschaftlichen Eigentümer alle ausländischen Wirtschaftssubjekte, an denen der eigentliche wirtschaftliche Eigentümer mit mehr als $50 \%$ beteiligt ist; sind diese im Mehrheitsbesitz des eigentlichen wirtschaftlichen Eigentümers stehenden ausländischen Wirtschaftssubjekte selbst an weiteren gebietsfremden Unternehmen mit mehr als $50 \%$ beteiligt, dann zählen auch diese Unternehmen und unter der Voraussetzung von über $50 \%$ igen Beteiligungen alle weiteren ausländischen Unternehmen zu den Mitgliedern der „forcign parent group“, d. h. zu dem ausländischen multinationalen Unternehmen ohne US-Tochtergesellschaften. ${ }^{225}$

Abbildung 4.9 zeigt die Beziehungen zwischen US-Tochtergesellschaft und den Mitgliedern der „foreign parent group“. Unternehmen E ist die ausländische Muttergesellschaft der US-amerikanischen Tochtergesellschaft H. Da kein Investor eine Mehrheitsbeteiligung an Unternehmen A hat, ist diese Gesellschaft der eigentliche wirtschaftliche Eigentümer der US-Tochtergesellschaft $\mathrm{H}$. Zur "foreign parent group" von Unternehmen $\mathrm{H}$ gehören die Unternehmen A, B, C, E und F, nicht aber die Unternehmen D und G. In der USStatistik werden sowohl die Beteiligungen von Unternehmen $\mathrm{E}$ an $\mathrm{H}$ als auch Kredite der Unternehmen A, B, C und $\mathrm{F}$ an die US-Tochtergesellschaft $\mathrm{H}$, nicht aber Kredite der Unternehmen D und $\mathrm{G}$ an Unternehmen $H$ als Direktinvestitionen erfaßt. ${ }^{226}$

Ein Direktinvestitionsunternehmen ist ein gewerbliches Unternehmen ${ }^{227}$, an dem ein Wirtschaftssubjekt eines anderen Landes mindestens $10 \%$ des Stimmkapitals bzw. eine entsprechende Beteiligung bei nicht-körperschaftlich organisierten Unternehmen unmittelbar oder mittelbar hält oder kontrolliert. Als Direktinvestitionsunternehmen gelten in der US-

225 „The foreign parent group ... consists of (1) the foreign parent, (2) any foreign person, proceeding up the foreign parent's ownership chain, that owns more than 50 percent of the person below it up to and including the ultimate benefical owner ..., and (3) any foreign person, proceeding down the ownership chain of each of these members, that is owned more than 50 percent by the person above it. " (U.S. Department of Commerce-Bureau of Economic Analysis 1990b, S. 85).

226 Zur Abgrenzung der ausländischen Muttergesellschaft, des eigentlichen wirtschaftlichen Eigentümers und der "foreign parent group“ sowie zu den Beziehungen zwischen US-Tochtergesellschaft und den Mitgliedern der „foreign parent group“ vgl. z. B. auch Quijano (1990, S. 30).

227 „A business enterprise is any organization, association, branch, or venture that exists for profit-making purposes or to otherwise secure economic advantage“. (U.S. Department of Commerce-Bureau of Economic Analysis 1990b, S. 85). 
Abbildung 4.9: Ausländische Direktinvestitionen in den USA - Beziehungen zwischen den Mitgliedern der ,foreign parent group" und US-amerikanischer Tochtergesellschaft

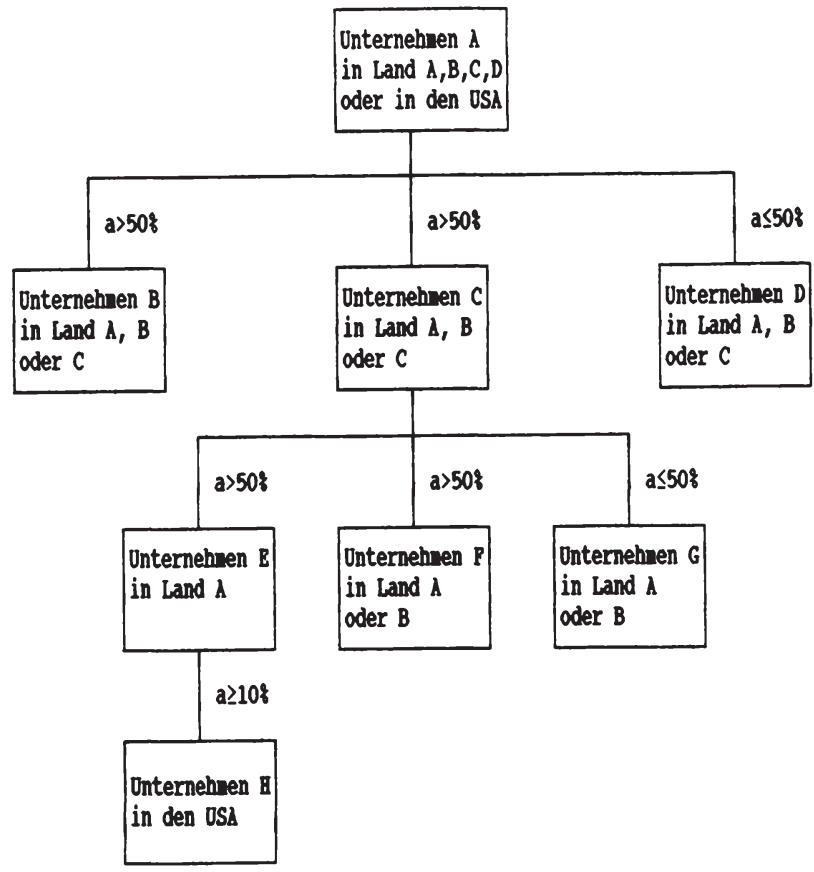

$a=$ Anteil an den Stimmrechten, die die jeweils unmittelbar übergeordnete Gesellschaft an dem ihr direkt untergeordneten Unternehmen hält oder kontrolliert.

Statistik auch unbewegliche oder bewegliche Wirtschaftsgüter, z. B. Ölbohrplattformen oder Pipelines, die die Muttergesellschaft zur Ausübung ihrer Tätigkeit in einem anderen Land einsetzt, sowie Immobilien, sofern sie nicht zum privaten Gebrauch bestimmt sind. Bei Körperschaften, die hauptsächlich in einem anderen Land als dem ihres juristischen Sitzes tätig sind, werden die Geschäftstätigkeiten außerhalb ihres Domizilstaates ebenfalls als nicht-körperschaftlich organisierte Tochtergesellschaften im Ausland behandelt; dies gilt auch dann, wenn die Muttergesellschaft die Aktivitäten als wesentlichen Bestandteil ihrer eigenen Tätigkeiten betrachtet und sie normalerweise konsolidieren würde. ${ }^{228}$

Ausländische Tochtergesellschaften von US-Unternehmen werden in der Regel dem Land

$\overline{228}$ Vgl. U.S. Department of Commerce-Bureau of Economic Analysis (1990b, S. 85 f.). 
ihres Standorts zugeordnet, d. h. „the country in which the affiliate's physical assets are located or where its primary activity is carried out. "229 Stimmen Sitzland und Standort nicht oder nur teilweise überein, dann sind für Unternehmensstandorte außerhalb der USA folgende Fälle zu unterscheiden: ${ }^{230}$ Eine körperschaftlich organisierte Tochtergesellschaft mit Sitz in Land A, die alle materiellen Wirtschaftsgüter oder Geschäftsbereiche in Land B hat, wird als Tochterunternehmen in Land B behandelt; die Briefkastenfirma in Land A wird als nicht existierend betrachtet. Eine in Land A ansässige körperschaftlich organisierte Tochtergesellschaft, die ihre materiellen Wirtschaftsgüter oder Geschäftsbereiche entweder teilweise in mindestens einem anderen Land oder ausschließlich in mindestens zwei anderen Ländern hat, wird als Tochterunternehmen in Land A behandelt; in jedem der anderen Länder wird die Existenz von Zweigniederlassungen unterstellt. Eine körperschaftlich organisierte Tochtergesellschaft mit Sitz in Land A, die materielle Wirtschaftsgüter oder Geschäftsbereiche teilweise oder auch ausschließlich in den USA hat, wird stets als Tochterunternehmen in Land A behandelt. Die Ausfuhr von Direktinvestitionskapital wird auch dann dem Land der ausländischen Tochtergesellschaft zugeordnet, wenn die betreffende Tochtergesellschaft selbst nicht an der Transaktion beteiligt ist, wenn also beispielsweise eine US-amerikanische Gesellschaft eine Tochtergesellschaft im Ausland von einem Wirtschaftssubjekt eines Drittlandes erwirbt. ${ }^{231}$

Seit dem Berichtsjahr 1974 werden die US-Statistiken für Direktinvestitionen in den USA nicht mehr nach dem Grundsatz des eigentlichen wirtschaftlichen Eigentümers erstellt, sondern der Klassifikation der Direktinvestitionen nach Herkunftsländern liegen die Länder der ausländischen Muttergesellschaften und aller weiterer Mitglieder der „foreign parent group“ zugrunde. ${ }^{232}$ Der Wechsel des Zuordnungskriteriums führt für einzelne Länder zu einem Bruch in den Zeitreihen.

Die Gliederung der Direktinvestitionen nach Zielbranchen erfolgt mittels eines dreistufigen Verfahrens auf der Grundlage der Umsätze der Tochtergesellschaften (bzw. der Gesamteinkommen bei Holdinggesellschaften). ${ }^{233}$ Da die Tochtergesellschaften in den USA

${ }^{229}$ U.S. Department of Commerce-Bureau of Economic Analysis (1990b, S. 88).

230 Vgl. U.S. Department of Commerce-Bureau of Economic Analysis (1990b, S. 88).

${ }^{231}$ Zur regionalen Gliederung der Direktinvestitionen der USA vgl. U.S. Department of CommerceBureau of Economic Analysis (1990b, S. 88 und 92).

232 Vgl. z. B. Krägenau (1979, S. 113), U.S. Department of Commerce-Bureau of Economic Analysis (1990b, S. 85 und 88) und U.S. Department of Commerce-The International Investment Division (1976, S. 51). Seit dem Berichtsjahr 1989 werden der Bestand an Direktinvestitionen in den USA und die an das Ausland geleisteten Kapitalerträge für Direktinvestitionen zusätzlich nach dem Land des eigentlichen wirtschaftlichen Eigentümers klassifiziert; vgl. z. B. U.S. Department of CommerceBureau of Economic Analysis (1991b, S. 79 Tab. 18; 1992a, S. 115 Tab. 18). In den US-Statistiken für alle anderen Aktivitäten ausländischer multinationaler Unternehmen erfolgt die Zuordnung nach dem Land des eigentlichen wirtschaftlichen Eigentümers.

${ }^{233}$ Zur Beschreibung des dreistufigen Verfahrens vgl. z. B. U.S. Department of Commerce-Bureau of Economic Analysis (1990b, S. 88 f.) oder Quijano (1990, S. 35). 
- im Unterschied zu den Tochtergesellschaften im Ausland - auf der Basis vollständiger Konsolidierung berichten, ${ }^{234}$ spiegelt die Zuordnung nach dem Wirtschaftszweig, in dem der größte Teil des Gesamtumsatzes erzielt wird, bei diversifizierenden Unternehmen u. U. die Gesamtaktivitäten einer US-amerikanischen Tochtergesellschaft nur unzureichend wider. ${ }^{235}$

\subsubsection{Direktinvestitionskapital in der US-Statistik}

Innerhalb der Kapitalströme für Direktinvestitionen wird in der US-Zahlungsbilanzstatistik zwischen Eigenkapitalströmen, reinvestierten Gewinnen und Veränderungen der konzerninternen Forderungen bzw. Verbindlichkeiten unterschieden. Beim Bestand an Direktinvestitionen umfaßt das Eigenkapital auch die reinvestierten Gewinne.

Erst seit dem Berichtsjahr 1982 (US-amerikanische Direktinvestitionen im Ausland) bzw. 1980 (ausländische Direktinvestitionen in den USA) umfassen die Angaben für alle drei Komponenten des Direktinvestitionskapitals sowohl körperschaftlich als auch nicht-körperschaftlich organisierte Tochtergesellschaften. Die mit den Totalerhebungen dieser Jahre eingeführte Gleichbehandlung beider Formen von Tochtergesellschaften hat keinen Einfluß auf die Gesamthöhe der ausgewiesenen Kapitalströme für Direktinvestitionen, wohl aber auf die Struktur des Direktinvestitionskapitals. In den Jahren vor 1982 bzw. 1980 wurde das gesamte Direktinvestitionskapital nicht-körperschaftlich organisierter Unternehmen in einer einzigen Summe als „Eigenkapital und konzerninterne Nettoforderungen bzw. -verbindlichkeiten“ erfaßt. Die gesamten Gewinne nicht-körperschaftlich organisierter Tochtergesellschaften wurden als transferierte Gewinne betrachtet; tatsächlich reinvestierte Gewinne wurden in der Kapitalbilanz als Transfer von der Muttergesellschaft an die Tochtergesellschaft erfaßt. Die in der Zahlungsbilanzstatistik ausgewiesenen reinvestierten Gewinne früherer Jahre umfassen also nur die von körperschaftlich organisierten Tochtergesellschaften. ${ }^{236}$

234 Infolge der Konsolidierung umfassen beispielsweise die 8577 in der Totalerhebung für das Berichtsjahr 1987 meldepflichtigen Tochtergesellschaften in den USA 23404 US-amerikanische Unternehmen; vgl. Scholl (1991, S. 34 Fn. 11).

235 Vgl. Belli (1984, S. 29 Fn. 5). Ergänzend stehen erstmals für das Berichtsjahr 1987 sehr detaillierte Daten über die Aktivitäten und zur Bedeutung US-amerikanischer Tochtergesellschaften ausländischer Gesellschaften auf dem Aggregationsniveau von Produktionsstätten oder Standorten zur Verfügung; zu diesen Daten vgl. U.S. Department of Commerce-Bureau of Economic Analysis (1992b) und als Überblick Howenstine/Zeile (1992). - Entsprechend ist bei der Interpretation der US-amerikanischen Direktinvestitionen im Ausland nach Herkunftsbranchen zu beriicksichtigen, daB die US-Muttergesellschaften als vollständig konsolierte gewerbliche Unternehmen definiert sind und über die einzelnen US-amerikanischen Untergesellschaften unabhängig von deren Branchenzugehörigkeit aggregiert wird. Zur Aussagekraft der sektoralen Gliederung der Direktinvestitionen der USA vgl. auch Lowe/Mataloni (1991, S. 45).

236 Vgl. Krueger (1984a, S. 40 f.), Howenstine (1984, S. 24 f.), Belli (1984, S. 36) oder U.S. Department of Commerce-Bureau of Economic Analysis (1990b, S. 90 und 93). 
Für Direktinvestitionsunternehmen, die Kreditinstitute sind, ist das Direktinvestitionskapital - den Empfehlungen von IMF und OFCD entsprechend - auf Eigenkapital und langfristige Kreditbeziehungen zwischen Direktinvestor und Tochtergesellschaft beschränkt. Transaktionen, dic nicht im Zusammenhang mit daucrhaften Investitionen stehen, insbesondere Forderungen und Verbindlichkeiten infolge normaler Bankgeschäfte zwischen Mutter- und Tochtergesellschaft, sind nicht in den Direktinvestitionen, sondern in den Portfolioinvestitionen enthalten. ${ }^{237}$

Investitionen einer ausländischen Tochtergesellschaft in ihre US-amerikanische Muttergesellschaft bzw. Investitionen ciner US-amerikanischen Tochtergesellschaft in ihre ausländische Muttergesellschaft, also wechsclscitige Beteiligungen von Tochter- und Muttergesellschaften, werden seit dem Berichtsjahr 1977 (Direktinvestitionen der USA) bzw. 1974 (Direktinvestitionen in den US $\Lambda$ ) nicht mehr mit den jeweiligen Direktinvestitionen der Muttergesellschaften in ihre Tochtergesellschaften saldiert, da dieses Verfahren bei einigen Komponenten der Kapitalbilanz zu Doppelzählungen führte. Seit 1977 (bzw. 1974) werden die Investitionen einer Tochtergesellschaft in ihre Muttergesellschaft als ausländische Direktinvestitionen in den USA (bzw. als US-amerikanische Direktinvestitionen im Ausland) erfaßt, wenn die ausländische Tochtergesellschaft (bzw. die US-Tochtergesellschaft) mit mindestens $10 \%$ am Eigenkapital ihrer US-Muttergesellschaft (bzw. ausländischen Muttergesellschaft) beteiligt ist, und als Portfolioinvestition, wenn die Tochtergesellschaft am Eigenkapital ihrer Muttergesellschaft weniger als $10 \%$ hält. In dem Fall, daß die Investitionen ciner Tochtergesellschaft in ihre Muttergesellschaft als Portfolioinvestitionen klassifiziert werden, werden jedoch alle Forderungen und Verbindlichkeiten zwischen Mutter- und Tochtergesellschaft weiterhin saldiert und unter den Direktinvestitionen der Muttergesellschaft ausgewiesen. Halten dagegen Mutter- und Tochtergesellschaft gegenscitig mindestens $10 \%$ ihrer $\Lambda$ nteile, dann werden die Forderungen bzw. Verbindlichkeiten zwischen Mutter- und Tochtergesellschaft entsprechend entweder den Direktinvestitionen der Muttergesellschaft oder den Dircktinvestitionen der Tochtergesellschaft zugeordnet. ${ }^{238}$

Fremdwährungsbeträge sind von den Meldepflichtigen gemäß den US generally accepted accounting principles (GAAP) in US-\$ umzurechnen. Dies bedeutet:

- Für Kalender- oder Wirtschaftsjahre, die am oder nach dem 15.12 .1982 beginnen, sind $\Lambda$ ktiva, Passiva, Einnahmen und $\Lambda$ usgaben zu laufenden Wechselkursen umzurechnen; ${ }^{239}$ d. h., ktiva und Passiva sind mit dem Wechselkurs am Ende des Kalender- bzw. Wirtschaftsjahres umzurechnen, Einnahmen und Ausgaben mit dem gewichteten Durchschnit.t der Wechselkurse der Periode, die die Gewinn- und Verlustrechnung abdeckt

237 Vgl. U.S. Department of Commerce-Bureau of Economic Analysis (1990b, S. 88).

238 Vgl. hierzu U.S. Department of Commerce-Burealt of Economic Analysis (1990b, S. 92 und 94 f.).

239 Ausgenommen hiervon sind Beträge in Währungen von Ländern mit sehr hoher Inflationsrate; vgl. Howenstine (1981, S. 22 Fn. 1). 
(Financial Accounting Standards Board Statements No. 52 - F $\Lambda$ SB 52). ${ }^{240}$

- In früheren Jahren erfolgte die Umrechnung nach Financial Accounting Standards Board Statements No. 8 (FASB 8). Nicht-monetäre Bilanzposten waren mit dem zum Zeitpunkt des Frwerbs gültigen Wechselkurs umzurechnen, monetäre Bilanzposten mit dem Wechselkurs am Bilanzstichtag und Aufwands- und Ertragsposten, soweit sie nicht durch dic Bilanz bestimmt sind, mit dem gewichteten durchschnittlichen Wechselkurs. ${ }^{241}$

\section{(a) Eigenkapital}

Das Eigenkapital ${ }^{242}$, das einem Direktinvestor an seiner körperschaftlich organisiertcn Tochtergesellschaft zuzurechnen ist, setzt sich zusammen aus dem Grund- bzw. Stammkapital, das der Direktinvestor an dem Tochterunternehmen hält, den sonstigen Kapitaleinlagen der Muttergesellschaft bei dem Tochterunternchmen und den Ansprüchen der Muttergesellschaft auf die einbehaltenen Gewinne ihres Tochterunteruehmens. ${ }^{243}$ Bei nicht-körperschaftlich organisierten Direktinvestitionsunternehmen besteht das einem Direktinvestor zuzurechnende Eigenkapital aus dem Anteil der Muttergesellschaft am gesamten Eigenkapital der Tochtergesellschaft; eine Aufteilung des Eigenkapitals wie bei körperschaftlich organisierten Tochterunternehmen ist nicht möglich.

Eine Zunahme des Eigenkapitals US-amerikanischer (ausländischer) Muttergesellschaften an ihren ausländischen (US-amerikanischen) Tochtergesellschaften ist mit Ausfuhr (Einfuhr) von Eigenkapital verbunden, wenn die US-amerikanische (ausländische) Muttergesellschaft im Ausland (in den USA) eine neue Tochtergesellschaft errichtet, an einem bestehenden ausländischen (US-amerikanischen) Unternchmen erstmals cine mindestens $10 \%$ ige Beteiligung erwirbt, zusätzliche Anteile an einer bestehenden ausländischen (USamerikanischen) Tochtergesellschaft erwirbt oder ihre Kapitaleinlagen erhöht. Entsprechend ist die Liquidation einer ausländischen (US-amerikanischen) Tochtergesellschaft, der Verkauf von Anteilen an einer ausländischen (US-amerikanischen) Tochtergesellschaft und die Rückführung von Kapitaleinlagen mit Einfuhr (Ausfuhr) von Eigenkapital verbunden. In der Veränderung des Eigenkapitals enthalten sind auch die Ansprüche der Muttergesellschaften auf die Erlöse aus Liquidation oder aus dem Verkauf von Aktiva der Tochtergesellschaften (liquidating dividends). Der Saldo zwischen Zunahme und Rückgang des Eigenkapitals bildet die Nettoausfuhr von Eigenkapital (Direktinvestitionen der

${ }^{240}$ Vgl. z. B. Scholl (1986, S. 35 Fn. 7).

${ }^{241}$. Vgl. z. B. Schoenfeld (1981, S. 306).

${ }^{242}$ Zum folgenden vgl. inșbesondere U.S. Department of Commerce-Bureau of Economic Analysis (1990b, S. $90 \mathrm{f}$. und $93 \mathrm{ff}$.)

243 Das Grundkapital umfaßt alle Stamm- und Vorzugsaktien mit oder ohne Stimmrecht. Die sonstigen Kapitaleinlagen der Muttergesellschaft. bestehen aus investiertem oder zugeführtem Kapital, das nicht im Grund- hzw. Stammkapital enthalten ist, und aus Kapitalisierungen von konzerninternen Konten, ohne daB die Umwandlung von Verbindlichkeiten einer Tochtergesellschaft gegenüber ihrer Muttergesellschaft in Eigenkapital mit der Ausgabe von Aktien verbunden ist. 
USA) bzw. dic Nettoeinfuhr von Eigenkapital (Direktinvestitionen in den USA). ${ }^{244}$

Die Stromgrößen für Einfuhr bzw. Ausfuhr von Eigenkapital werden zu Transaktionswerten gemeldet. Sie basieren bei den Direktinvestitionen der USA im Ausland auf den Büchern der US-amerikanischen Muttergesellschaften und bei den ausländischen Direktinvestitionen in den USA in der Regel auf den Büchern der US-amerikanischen Tochtergesellschaften. ${ }^{245}$ Bei Änderungen des Eigenkapitals, die nicht mit Transaktionen zwischen ausländischer Muttergesellschaft und US-Tochtergesellschaft verbunden sind und sich deshalb nur in den Büchern der ausländischen Muttergesellschaft, nicht aber in den Büchern der US-Tochtergesellschaft niederschlagen, ist zu unterscheiden, ob an der Transaktion cin US-Wirtschaftssubjekt beteiligt ist oder nicht. Erwirbt beispielsweise eine ausländische Muttergesellschaft cine Kapitalbeteiligung an einer US-Tochtergesellschaft von einem nicht-verbundenem US-Wirtschaftssubjekt, dann ist diese Transaktion in der Einfuhr von Eigenkapital enthalten; dem U.S. Department of Commerce/BEA ist der Marktwert der Transaktion aus den Büchern der Muttergesellschaft zu melden. Erwirbt dagegen eine ausländische Muttergesellschaft eine Kapitalbeteiligung an einer US-Tochtergesellschaft von einem anderen ausländischen Wirtschaftssubjekt, dann erscheint diese nur zwischen Ausländern stattfindende Transaktion nicht in der Zahlungsbilanzstatistik, und zwar unabhängig davon, ob dic beiden ausländischen Wirtschaftssubjekte zur „foreign parent group“ gehören oder nicht. In diesem Fall werden Zunahme und Rückgang an Eigenkapital jeweils um denselben Betrag unterschätzt; sind die beiden $\Lambda$ usländer in verschiedenen Ländern ansässig und/oder haben sie ihren wirtschaftliche Schwerpunkt in unterschiedlichen Branchen, dann werden die ausländischen Direktinvestitionen in den USA nach Herkunftsländern und/oder -branchen verzerrt wiedergegeben.

\section{(b) reinvestierte Gewinne}

Mit der Revision der US-Zahlungsbilanzstatistik vom Juni 1978 wurden die reinvestierten Gewinne von körperschaftlich organisierten Tochtergesellschaften rückwirkend für die Jahre ab 1960 in das Dircktinvestitionskapital cingerechnet. Dic einbehaltenen Gewinne nicht-körperschaftlich organisierter Tochtergesellschaften sind dagegen erst seit dem Berichtsjahr 1982 (Dircktinvestitionen der USA) bzw. 1980 (Direktinvestitionen in den USA) in den für reinvestierte Gewinne ausgewiesenen Daten enthalten.

Die reinvestierten Gewinne ${ }^{246}$ der Direktinvestitionsunternehmen werden als Residualgrö-

244 Zunahme und Rückgang des Figenkapitals werden auch getrennt ausgewiesen; vgl. hierzu z. B. Murad (1992, S. 100 Tab. 5).

245 Die Transaktionswerte in den Büchern der Muttergesellschaft können sich von denen in den Büchern der Tochtergesellschaft unterscheiden; erstere spiegeln die tatsächlichen Kosten bei Erwerb bzw. die Erlöse bei VeräuBerung von Beteiligungen an Tochtergesellschaften wider.

246 Zum folgenden vgl. - soweit keine anderen Quellen genannt sind - U.S. Department of Commerce- 
Be ermittelt und zwar als Differenz zwischen den Gewinnen und den von den Tochtergesellschaften an die Muttergesellschaften ausgeschütteten Gewinnen vor Abzug der Kapitalertragsteuer auf Dividendenleistungen. ${ }^{247}$ Der Umfang, in dem bei der Gewinnermittlung neben den Anteilen der Muttergesellschaften am Bilanzgewinn ihrer Tochtergesellschaften (nach Abzug der von den Tochtergesellschaften zu leistenden Einkommen- bzw. Körperschaftsteuern) auch die darin nicht enthaltenen Anteile der Muttergesellschaften an den Vermögenszuwächsen bzw. -verlusten berücksichtigt werden, wurde in den letzten drei Jahren mehrfach geändert, und zwar jeweils rückwirkend für alle Berichtsjahre ab 1982:

- Bis zur Revision der US-Zahlungsbilanzstatistik vom Juni 1990 zählten zu den Gewinnen nicht nur die Anteile der Muttergesellschaften an den laufenden Einnahmen ihrer Tochtergesellschaften, sondern auch die Anteile der Muttergesellschaften an allen anderen Einkunftsarten, also auch an den realisierten und nicht-realisierten Vermögenszuwächsen bzw. -verlusten ihrer Tochtergesellschaften, jeweils nach Abzug der von den Tochtergesellschaften zu leistenden Einkommen- bzw. Körperschaftsteuern. Realisierte und nicht-realisierte Vermögenszuwächse bzw. -verluste können „result from the sale or other disposition of affiliates' assets and liabilities, from writeups or writedowns of the book value of assets and liabilities, and from changes in the dollar value of foreign-currencydenominated assets and liabilities or from the translation of the affiliates' financial statements from local currencies into dollars due to changes in exchange rates. ${ }^{\text {}} 248$

- Im Juni 1990 ging das U.S. Department of Commerce/BEA dazu über, bei den Direktinvestitionen der USA die Anteile der US-Muttergesellschaften an den Vermōgenszuwächsen bzw. -verlusten, die entstehen, wenn sich die Wechselkurse, mit denen Fremdwährungsaktiva und -passiva ausländischer Tochtergesellschaften in US-\$ umgerechnet werden, zwischen Beginn und Ende des Meldezeitraums ändern, sog. Fremdwährungsumrechnungsberichtigungen (currency translation adjustments), nicht mehr als Teil der Gewinne zu behandeln; andere Vermögenszuwächse bzw. -verluste wurden weiterhin bei der Gewinnermittlung berücksichtigt. ${ }^{249}$

Bureau of Economic Analysis (1990b, S. 61-63, 91 und 94).

247 Bei den Gewinnausschüttungen von körperschaftlich organisierten Tochtergesellschaften werden die Dividenden auf von den Muttergesellschaften gehaltenen Stamm- und Vorzugsaktien berücksichtigt, nicht aber Ausschüttungen in Form von Gratisaktien und die Ansprüche der Muttergesellschaften auf Erlöse aus Liquidation oder aus dem Verkauf von Aktiva der Tochtergesellschaften.

248 U.S. Department of Commerce-Bureau of Economic Analysis (1990b, S. 61); vgl. auch U.S. Department of Commerce-Bureau of Economic Analysis (1990b, S. 26 f.). Dieses umfassende Konzept für Kapitalerträge und für Gewinne (,all inclusive“ basis) war erst Mitte der 70er Jahre (1977 für Direktinvestitionen der USA bzw. 1974 für Direktinvestitionen in den USA) eingeführt worden; in früheren Jahren blieben nicht-realisierte Vermögenszuwächse bzw. -verluste bei der Ermittlung der Kapitalerträge für Direktinvestitionen und damit bei den reinvestierten Gewinnen unberücksichtigt. Vgl. z. B. Krägenau (1979, S. 111 f.) und U.S. Department of Commerce-The International Investment Division (1976, S. 51).

249 Bei den Direktinvestitionen in den USA enthalten die Gewinne weiterhin die Anteile der ausländischen Muttergesellschaften an allen realisierten und nicht-realisierten Vermögenszuwächsen bzw. 
- Seit der Revision der US-Zahlungsbilanzstatistik vom Juni 1992 werden sowohl bei den Direktinvestitionen der USA als auch bei Direktinvestitionen in den USA bei der Ermittlung der Gewinne keine Vermögenszuwächse bzw. -verluste mehr berücksichtigt. ${ }^{250}$

Zugleich werden seit der Revision vom Juni 1992 die Gewinne rückwirkend für die Berichtsjahre ab 1982 nicht mehr auf der Grundlage der historischen Anschaffungs- bzw. Herstellungskosten berechnet, sondern auf der Grundlage der laufenden Anschaffungskosten (Wiederbeschaffungskosten) nach Berichtigung um die Meldungen für Abschreibungen, für Substanzverzehr und für bestimmte aufgewendete Explorations- und Entwicklungskosten. Diese Marktpreisberichtigung (current-cost adjustment), is made primarily to ensure that these charges reflect current-period prices, as well as to more closely align income earned in a given period with charges against income in the same period, as required by economic accounting principles. "251 Die Höhe der Marktpreisberichtigung ist die Differenz zwischen Abschreibungen, Substanzverzehr und aufgewendeten Explorationsund Entwicklungskosten in den Jahresabschlüssen und deren Werten auf der Basis von Wiederbeschaffungskosten. Die Marktpreisberichtigung ist weder regional noch sektoral aufteilbar.

Da die Gewinne sowohl Bestandteil der Kapitalerträge aus Direktinvestitionen sind als auch in die Ermittlung der reinvestierten Gewinne eingehen, schlagen sich Änderungen in der Erfassung von Vermögenszuwächsen bzw. -verlusten in den Kapitalerträgen aus Direktinvestitionen (Leistungsbilanz) und über die reinvestierten Gewinne in derselben Höhe, aber mit umgekehrtem Vorzeichen in der Stromgröße Direktinvestitionskapital (Kapitalbilanz) nieder. Die Umklassifizierung der Fremdwährungsumrechnungsgewinne bzw. -verluste, der sonstigen Vermögenszuwächse bzw. -verluste und der Marktpreisberichtigung von Kapitalströmen zu Wertberichtigungen hat keinen Einfluß auf die Höhe des ausgewiesenen Bestands an Direktinvestitionen.

Die Anteile der Muttergesellschaften am Bilanzgewinn ihrer Tochterunternehmen basieren auf den unmittelbar gehaltenen Kapitalbeteiligungen der Direktinvestoren. Der Bilanzgewinn der Direktinvestitionsunternehmen wird den Büchern der Tochtergesellschaften entnommen. Die Angaben über die ausgeschütteten Gewinne basieren auf den Büchern der US-amerikanischen Muttergesellschaften bzw. auf denen der US-amerikanischen Tochtergesellschaften. Die reinvestierten Gewinne werden in der Zahlungsbilanzstatistik in der Periode erfaßt, in der die Tochtergesellschaften die Gewinne erzielen. ${ }^{252}$

-verlusten ihrer US-Tochtergesellschaften. Vgl. Nicholson (1990, S. 72 f.) und U.S. Department of Commerce-Bureau of Economic Analysis (1990c, S. 57).

250 Vgl. Murad (1992, S. 73).

251 Murad (1992, S. 72). Zum Konzept und zum Verfahren der Marktpreisberichtigung vgl. Murad (1992, S. 72 f.).

${ }^{252}$ Vgl. hierzu auch U.S. Department of Commerce-Bureau of Economic Analysis (1990b, S. 5). 


\section{(c) konzerninterne Forderungen bzw. Verbindlichkeiten}

Die dritte Komponente des Direktinvestitionskapitals in der Zahlungsbilanzstatistik ist eine Stromgröße für die konzerninternen Forderungen bzw. Verbindlichkeiten (intercompany debt). ${ }^{253} \mathrm{Zu}$ den US-amerikanischen Direktinvestitionen im Ausland zählt die Zunahme der konzerninternen Nettoforderungen der US-amerikanischen Muttergesellschaften gegenüber ihren ausländischen Tochtergesellschaften innerhalb des Berichtsjahres, zu den ausländischen Direktinvestitionen in den USA die Zunahme der konzerninternen Nettoverbindlichkeiten der US-amerikanischen Tochtergesellschaften gegenüber ihren ausländischen Muttergesellschaften. Die konzerninternen Forderungen bzw. Verbindlichkeiten umfassen u. a. Handelskredite, fällige Wechsel, sonstige laufende Verbindlichkeiten (z. B. kurzfristige Kredite) und langfristige Darlehen der Muttergesellschaften an ihre Tochtergesellschaften abzüglich ähnlicher Positionen, die die Muttergesellschaften ihren Tochterunternehmen schulden, sowie den Nettobuchwert von Operational-Leasing, sofern diese Verträge zwischen Mutter- und Tochtergesellschaften für länger als ein Jahr geschlossen werden, und von Finanzierungs-Leasing.

Die Stromgröße konzerninterne Nettoforderungen bzw. -verbindlichkeiten wird jeweils berechnet als Differenz zwischen dem Saldo der konzerninternen Nettoforderungen bzw. -verbindlichkeiten am Ende des laufenden Jahres und diesem Saldo am Ende des Vorjahres. Der Nettosaldo am Jahresende ist bei Direktinvestitionen der USA die Differenz zwischen den Forderungen und den Verbindlichkeiten der US-amerikanischen Muttergesellschaften gegenüber ihren ausländischen Tochtergesellschaften bzw. bei Direktinvestitionen in den USA die Differenz zwischen den Verbindlichkeiten und den Forderungen der US-amerikanischen Tochtergesellschaften gegenüber ihren ausländischen Muttergesellschaften. ${ }^{254}$ Die Stromgrößen für konzerninterne Forderungen bzw. Verbindlichkeiten werden zu Transaktionswerten ausgewiesen. Sie spiegeln nicht immer tatsächliche Mittelströme wider, und sie basieren auf den Büchern der US-amerikanischen Muttergesellschaften bzw. auf den Büchern der US-amerikanischen Tochtergesellschaften. ${ }^{255}$

In der Zunahme der konzerninternen Nettoverbindlichkeiten der US-Tochtergesellschaften sind nicht nur die Transaktionen zwischen ausländischen Muttergesellschaften und US-Tochtergesellschaften enthalten, sondern auch die Transaktionen zwischen anderen

253 Zum folgenden vgl. auch U.S. Department of Commerce-Bureau of Economic Analysis (1990b, S. $91 \mathrm{f}$. und 94).

${ }^{254}$ Veränderungen von Forderungen und Verbindlichkeiten der US-amerikanischen Muttergesellschaften bzw. der US-amerikanischen Tochtergesellschaften werden auch getrennt ausgewiesen; vgl. z. B. Murad (1992, S. 100 Tab. 5).

255 Der Ausweis konzerninterner Forderungen bzw. Verbindlichkeiten in den Büchern der Muttergesellschaften kann sich u. a. wegen unterschiedlicher zeitlicher Erfassung, Rechnungslegung oder Bewertung unterscheiden von den entsprechenden Positionen in den Büchern der Tochtergesellschaften. 
Mitgliedern der "foreign parent group“ und den US-Tochtergesellschaften. Erfaßt sind also beispielsweise auch Kredite, die ein Mitglied der „foreign parent group“ einer USTochtergesellschaft gewährt, ohne daß dieses an dem US-Unternehmen Anteile hält. Im Eigenkapital und in den reinvestierten Gewinnen dagegen schlagen sich nur Transaktionen zwischen ausländischen Muttergesellschaften und US-Tochtergesellschaften oder dritten nicht-verbundenen US-Wirtschaftssubjekten nieder.

Eine Sonderrolle innerhalb der Direktinvestitionen der USA spielen die Finanzierungstochtergesellschaften auf den Niederländischen Antillen. Die meisten dieser Tochtergesellschaften wurden Ende der 70er und Anfang der 80er Jahre gegründet, um bei nichtverbundenen Ausländern Mittel aufzunehmen und diese dann über Finanzierungstochtergesellschaften auf den Niederländischen Antillen den US-Muttergesellschaften zuzuführen. Für die US-Muttergesellschaften hatte diese indirekte Mittelaufnahme im Ausland bis zum 18.7.1984 gegenüber der direkten Mittelaufnahme im Ausland den Vorteil, daß bei einer direkten Mittelaufnahme US-Quellensteuer auf Zinsen aus festverzinslichen Wertpapieren bei Zahlung an Ausländer in Höhe von $30 \% \mathrm{zu}$ entrichten war, während die Zinszahlungen der USA an die Niederländischen Antillen von der US-Quellensteuer freigestellt waren. ${ }^{256}$ Erst seit der Totalerhebung 1977 sind die Kredite dieser Finanzierungstochtergesellschaften an ihre US-Muttergesellschaften im Direktinvestitionskapital enthalten; vor 1977 wurde diese Form der Kreditaufnahme als direkte Mittelaufnahme im Ausland durch die US-amerikanischen Muttergesellschaften behandelt und als Portfolioinvestitionen ausgewiesen.

Tabelle 4.7 zeigt, daß v. a. die insgesamt für Kapitalausfuhr in Form von Zunahme der konzerninternen Nettoforderungen der US-amerikanischen Muttergesellschaften gegenüber ihren ausländischen Tochtergesellschaften in den meisten Jahren dominiert wird von den Kreditbeziehungen zwischen US-Muttergesellschaften und ihren zum Zwecke der indirekten Kreditaufnahme im Ausland gegründeten Finanzierungstochtergesellschaften auf den Niederländischen Antillen. Solange die direkte Mittelaufnahme im Ausland für die USMuttergesellschaften wegen der US-Quellensteuer auf Zinsen aus festverzinslichen Wertpapieren bei Zahlung an Ausländer ceteris paribus mit höheren Kosten verbunden war als bei der Zwischenschaltung von Finanzierungstochtergesellschaften auf den Niederländischen Antillen, wurde die Kapitalausfuhr für Direktinvestitionen der USA teilweise kompensiert durch die Kapitaleinfuhr infolge der Kredite dieser Finanzierungstochtergesellschaften an ihre US-Muttergesellschaften. Nach Abschaffung dieser US-Quellensteuer im Juli 1984 verschob sich die Kreditaufnahme von US-Gesellschaften zugunsten der direkten Mittelaufnahme in Europa bei nicht-verbundenen Ausländern. Diese Transaktionen werden

${ }_{256}$ In den Jahren 1968 bis 1974 wurden Finanzierungstochtergesellschaften auf den Niederländischen Antillen zur Umgehung der US-Kontrollen für Direktinvestitionen errichtet; vgl. U.S. Department of Commerce-Bureau of Economic Analysis (1990b, S. 92). 
jedoch als Portfolioinvestitionen und nicht als Direktinvestitionen erfaßt. Die geringere Kreditaufnahme der US-Muttergesellschaften bei ihren Finanzierungstochtergesellschaften auf den Niederländischen Antillen und die vermehrte Rückzahlung von in früheren Jahren gewährten Krediten führen dazu, daß die Veränderung der konzerninternen Nettoforderungen der US-Muttergesellschaften von Kapitaleinfuhr in Kapitalausfuhr umschlägt. Zugleich wurden einige dieser Finanzierungstochtergesellschaften aufgelöst oder die Kapitaleinlagen in sie reduziert. ${ }^{257}$

Zumindest die Nettoforderungen der US-Muttergesellschaften gegenüber ihren Finanzierungstochtergesellschaften auf den Niederländischen Antillen sollten bei der Interpretation der Direktinvestitionen der USA unberücksichtigt bleiben, und zwar nicht nur aus dem formalen Grund, daß diese Transaktionen vor dem Berichtsjahr 1977 als Portfolioinvestitionen erfaßt wurden, sondern auch, weil die US-Muttergesellschaften in einigen Jahren wegen internationaler Zinssatzdifferentiale v. a. ihre inländische Expansion sowie Unternehmenszusammenschlüsse in den USA durch die Ausgabe von Anleihen über ihre Finanzierungstochtergesellschaften auf den Niederländischen Antillen finanzierten. ${ }^{258}$ Die Klassifikation dieser reinen Finanzierungstransaktionen als Direktinvestitionen liefert für das Volumen an US-amerikanischen Direktinvestitionen im Ausland ein verzerrtes Bild. ${ }^{259}$

\subsubsection{Bestand an Direktinvestitionen in der US-Statistik}

Der Bestand an Direktinvestitionen ist ein Maß für die Nettoansprüche der Direktinvestoren gegen ihre Tochtergesellschaften am Jahresende. ${ }^{260}$ Im Juni 1991 veröffentlichte das U.S. Department of Commerce/BEA erstmals nicht nur Angaben über den Bestand an Direktinvestitionen zu historischen Anschaffungs- bzw. Herstellungskosten (Buchwertmethode), sondern auch Angaben über den Bestand an Direktinvestitionen in Preisen der laufenden Periode, und zwar alternativ zu Wiederbeschaffungskosten und zum Marktwert. ${ }^{261}$

257 Zur Entwicklung der Transaktionen zwischen US-Muttergesellschaften und ihren Finanzierungstochtergesellschaften auf den Niederländischen Antillen nach Abschaffung der US-Quellensteuer auf Zinsen aus festverzinslichen Wertpapieren bei Zahlung an Ausländer vgl. z. B. Bach (1985, S. $30 \mathrm{f}$;; 1986, S. 25 und 32; 1987, S. 41 f.; 1991, S. 47), Dilullo (1984, S. 44 f.; 1985, S. 62; 1986, S. 43 f.), Krueger (1984a, S. 39; 1984b, S. 38; 1985a, S. 38) und Scholl (1985, S. 31; 1986, S. 32; 1987, S. 42; 1988, S. 82; 1989, S. 47; 1990, S. 60; 1991, S. 30). Die Zunahme des Eigenkapitals im Jahr 1986 ist zurückzuführen auf eine ungewöhnlich große Kapitaleinlage einer US-Muttergesellschaft in ihre Finanzierungstochtergesellschaft auf den Niederländischen Antillen; vgl. z. B. Scholl (1987, S. 42).

258 Vgl. z. B. Scholl (1985, S. 30 f.).

259 Julius/Thomsen (1988) bereinigen in ihrer beschreibenden Analyse über die Direktinvestitionen der G-5-Länder die Daten der USA um alle Transaktionen zwischen US-Muttergesellschaften und Finanzierungstochtergesellschaften auf den Niederländischen Antillen.

260 Der Bestand an Direktinvestitionen ist kein MaB für das Gesamtvermögen der Tochtergesellschaften. Zu diesem vgl. z. B. Bezirganian (1991; 1992), Mataloni (1992) und U.S. Department of CommerceBureau of Economic Analysis (1992c; 1992d; 1992f).

261 Zum Konzept und zum Schätzverfahren für den Bestand an Direktinvestitionen in Preisen der laufenden Periode vgl. Landefeld/Lawson (1991). Der Bestand an Direktinvestitionen zu Wiederbe- 
Tabelle 4.7: US-amerikanische Direktinvestitionen im Ausland in Mio. US-\$ (Transaktionswerte) nach Komponenten und ausgewählte Transaktionen zwischen US-Muttergesellschaften und ihren Finanzierungstochtergesellschaften auf den Niederländischen Antillen, 1982 bis 1991

\begin{tabular}{|c|c|c|c|c|c|c|c|c|}
\hline \multirow[b]{5}{*}{ Jahr } & \multicolumn{8}{|c|}{ OS-anerikanische Direktinvestitionen ${ }^{1}$ in Ausland in Mio. OS-\$ (Kapitalausfuhr: + ) } \\
\hline & \multirow[t]{4}{*}{ insgesant } & \multicolumn{3}{|l|}{ davon: } & \multirow{2}{*}{\multicolumn{4}{|c|}{$\begin{array}{l}\text { darunter: } \\
\text { Transaktionen uit Pinanzierungstochter- } \\
\text { gesellschaften auf den Wiederländischen } \\
\text { intillen }{ }^{2}\end{array}$}} \\
\hline & & \multirow[t]{3}{*}{$\begin{array}{l}\text { Eigen- } \\
\text { kapital }\end{array}$} & \multirow{3}{*}{$\begin{array}{l}\text { rein- } \\
\text { vestierte } \\
\text { Gewinne }\end{array}$} & \multirow{3}{*}{$\begin{array}{l}\text { konzern- } \\
\text { interne } \\
\text { Mettofor- } \\
\text { derungen } \\
\text { der US- } \\
\text { Mutter- } \\
\text { gesell- } \\
\text { schaften }\end{array}$} & & & & \\
\hline & & & & & zusannen & davon: & & \\
\hline & & & & & & $\begin{array}{l}\text { Bigen- } \\
\text { kapital }\end{array}$ & $\begin{array}{l}\text { rein- } \\
\text { vestierte } \\
\text { Gewinne }\end{array}$ & $\begin{array}{l}\text { konzern- } \\
\text { interne } \\
\text { Mettofor- } \\
\text { derungen } \\
\text { der oS- } \\
\text { Mutter- } \\
\text { gesell- } \\
\text { schaften }\end{array}$ \\
\hline 1982 & 1078 & 9708 & 4806 & -13436 & -8593 & 4173 & 857 & -13623 \\
\hline 1983 & 6686 & 4903 & 13453 & -11669 & -3128 & 1411 & 1003 & -5542 \\
\hline 1984 & 11649 & 1347 & 17276 & -6973 & -1973 & 982 & 899 & -3855 \\
\hline 1985 & 12724 & -2210 & 13665 & 1269 & 4181 & -864 & 837 & 4208 \\
\hline 1986 & 17706 & 551 & 9048 & 8106 & 4867 & 745 & -401 & 4523 \\
\hline 1987 & 28980 & 4635 & 17650 & 6696 & 2904 & -1422 & 527 & 3799 \\
\hline 1988 & 17871 & -6112 & 13319 & 10665 & 3547 & -2568 & -2 & 6117 \\
\hline 1989 & 30167 & -1755 & 15950 & 15971 & 4489 & -953 & 185 & 5257 \\
\hline 1990 & 34111 & 7455 & 20886 & 5770 & 4775 & -368 & 84 & 5060 \\
\hline 1991 & 28197 & 11650 & 18949 & -2402 & $\begin{array}{ll}-1 & 023\end{array}$ & -262 & 358 & -1119 \\
\hline
\end{tabular}

1 Direktinvestitionskapital und reinvestierte Gewinne ohne Vermögenszuwächse bzw. -verluste sowie ohne Marktpreisberichtigung der Gewinne.

2 Transaktionen mit Tochtergesellschaften, die von den US-Muttergesellschaften $v$, a. zur indirekten Mittelaufnahme im Ausland errichtet wurden.

Quelle: U.S. Department of Commerce-Bureau of Economic Analysis (1992e, S. 120 Tab. 7 und S. 122 Tab. 10).

schaffungskosten wird für die Jahre ab 1976 ausgewiesen. Der Bestand an Direktinvestitionen zum Marktwert wird für die Jahre ab 1982 ermittelt; seit diesem Jahr stehen vollständige Informationen über den Bestand an Eigenkapital und die Kapitalausfuhr bzw. -einfuhr in Form von Eigenkapital zur Verfügung. Vgl. Scholl (1991, S. 26 Tab. 3 Anm. 5 und 6). Seit dem Jahr 1991 wird der Bestand an Direktinvestitionen im Rahmen der Nettoauslandsposition der USA alternativ zu Wiederbeschaf- 
Bei der Buchwertmethode mißt der Bestand an Direktinvestitionen den Buchwert der Beteiligungen der Direktinvestoren an ihren Tochtergesellschaften und des Saldos von Forderungen und Verbindlichkeiten gegenüber ihren Direktinvestitionsunternehmen. Die Buchwerte werden den Büchern der ausländischen bzw. US-amerikanischen Tochtergesellschaften entnommen. ${ }^{262}$

Bei der Wiederbeschaffungskostenmethode (current-cost method) werden die Anteile der Direktinvestoren an den Investitionen ihrer Tochtergesellschaften in Sachanlagen, also die materiellen Wirtschaftsgüter auf der Aktivseite der Bilanz der Tochtergesellschaft, mit ihren Wiederbeschaffungskosten neu bewertet. Die Neubewertung erfolgt für Investitionen in Maschinen und Anlagen unter Verwendung eines perpetual inventory Modells, für Investitionen in Vorräte unter Verwendung des Verhältnisses der zu Wiederbeschaffungskosten und zu ursprünglichen Anschaffungs- bzw. Herstellungskosten in den Volkswirtschaftlichen Gesamtrechnungen der USA erfaßten US-amerikanischen Lagerbeständen bei nichtlandwirtschaftlicher Unternehmenstätigkeit und für Investitionen in Grund und Boden unter Verwendung länderspezifischer impliziter Preisdeflatoren für das Bruttosozialprodukt bzw. das Bruttoinlandsprodukt. Die Finanzanlagen werden nicht neubewertet; es wird unterstellt, daß deren historische Werte den laufenden in etwa entsprechen.

Bei der Marktwertmethode wird der Teil des Direktinvestitionsbestandes, der auf Eigenkapital entfällt, also die Passivseite der Bilanz, unter Verwendung eines gewogenen durchschnittlichen Indexes für die ausländischen Aktienkurse (Direktinvestitionen der USA) bzw. cines umfassenden Indexes für US-Akticnkurse (Direktinvestitionen in den USA) neubewertet. Das neubewertete Eigenkapital spiegelt damit die Aktienkurse am Jahresende wider. Ähnlich wie bei der Wiederbeschaffungskostenmethode werden die Verbindlichkeiten nicht neubewertet; für diese wird unterstellt, daß sie in etwa mit Preisen der laufenden Periode bewertet sind.

Tabelle 4.8 zeigt den Einfluß der Bewertungsmethode auf den ausgewiesenen Bestand an Direktinvestitionen. Ende 1991 hatten die USA Direktinvestitionen im Ausland in Höhe von 450,2 Mrd. US-\$ (historische Anschaffungs- bzw. Herstellungskosten), 655,3 Mrd. US$\$$ (Wiederbeschaffungskosten) bzw. 802,0 Mrd. US-\$ (Marktwert); der Bestand an ausländischen Direktinvestitionen in den USA betrug Ende 1991 407,6 Mrd. US-\$ (historische Anschaffungs- bzw. Herstellungskosten), 487,0 Mrd. US-\$ (Wiederbeschaffungskosten) bzw. 654,1 Mrd. US-\$ (Marktwert). Bei der Buchwertmethode wird der Bestand an Direktinvestitionen wegen der Bewertung mit historischen Anschaffungs- bzw. Herstellungskosten im Verhältnis zum Wert in Preisen der laufenden Periode unterschätzt. Der

fungskosten und zum Marktwert ausgewiesen; vgl. Scholl $(1990 ; 1991)$ und Scholl et al. (1992).

262 Vgl. z. B. Scholl (1990, S. 57). Zu den Gründen für die Anwendung der Buchwertmethode vgl. U.S. Department of Commerce-Bureau of Economic Analysis (1989, S. 40). 
Einfluß der Bewertungsmethode ist auf die Direktinvestitionen der USA größer als auf die Direktinvestitionen in den USA. Dies ist damit zu erklären, daß der kumulative Effekt von Preiserhöhungen auf die zumeist bereits in den $60 \mathrm{er}$ und 70er Jahren getätigten USamerikanischen Direktinvestitionen im Ausland ausgeprägter ist als auf die ausländischen Direktinvestitionen in den USA, deren Volumen erst seit Ende der 70er Jahre stark zugenommen hat. Der Bestand zu historischen Anschaffungs- bzw. Herstellungskosten und der zu Wiederbeschaffungskosten zeigen, wenn auch auf unterschiedlichem Niveau, einen ähnlichen Trend. Die unterschiedliche Entwicklung des Direktinvestitionensbestands zu Wiederbeschaffungskosten und zum Marktwert ist $u$. a. auf die unterschiedliche Entwicklung von Wiederbeschaffungskosten für Sachanlagen und von Aktienkursen zurückzuführen. Bei der Marktwertmethode wird der Nettowert der Tochtergesellschaft geschätzt; dieser umfaßt neben den Wiederbeschaffungskosten für Sachanlagen auch den Marktwert immaterieller Vermögensgegenstände, z. B. gewerbliche Schutzrechte oder den Namen eines Unternehmens. Darüber hinaus spiegelt der Marktwert auch allgemeine oder sektorspezifische wirtschaftliche Erwartungen wider. ${ }^{263}$

Für den Bestand an Direktinvestitionen nach den Komponenten Eigenkapital (einschließlich reinvestierter Gewinne) und konzerninterne Nettoforderungen bzw. -verbindlichkeiten nach Ziel- bzw. Herkunftsländer und nach Wirtschaftszweigen stehen nur die Daten für den Bestand an Direktinvestitionen nach der Buchwertmethode zur Verfügung. ${ }^{264}$

\subsubsection{Schätzverfahren in den USA}

Da die Unternehmen zum einen seit den Totalerhebungen für das Berichtsjahr 1982 (Direktinvestitionen der USA) bzw. 1980 (Direktinvestitionen in den USA) auf der Grundlage von Wirtschaftsjahren melden dürfen, zum anderen in den meisten Jahren nur Stichprobenerhebungen durchgeführt werden, stellen die in der US- Statistik ausgewiesenen Daten für Direktinvestitionen (Stromgrößen und Bestände) nur Schätzwerte dar. Eine Bereinigung der in den Totalerhebungen und in den vierteljährlichen Stichprobenerhebungen gemeldeten Transaktionswerte findet nur in Ausnahmefällen statt. ${ }^{265}$

Das Verfahren, mit dem das U.S. Department of Commerce/BEA die Angaben der rund ein Drittel Unternehmen, deren Wirtschaftsjahre vom Kalenderjahr abweichen, auf Kalenderjahre umrechnet, hängt davon ab, ob sich das Unternehmen im Jahr der Totalerhebung auch an den vierteljährlichen Stichprobenerhebungen beteiligt hat oder nicht. ${ }^{266}$ Bei den

${ }_{263}$ Vgl. Landefeld/Lawson (1991, S. 41). Zu den alternativen Maßen für die Rentabilität von Direktinvestitionen vgl. Landefeld et al. (1992) und U.S. Department of Commerce-Bureau of Fconomic Analysis (1991a).

${ }^{264}$ Vgl. hierzu z. B. Scholl (1991, S. 27 f.), Scholl et al. (1992, S. 53) oder U.S. Department of CommerceBureau of Economic Analysis (1992a; 1992e).

265 Vgl. U.S. Department of Commerce-Bureau of Economic Analysis (1990b, S. 5).

${ }^{266}$ In den Totalerhebungen 1977 bzw. 1974 war auf der Grundlage von Kalenderjahren zu berichten. 
Table 0.1: US-amerikanische Direktinvestitionen im Ausland und ausländische Direktinvestitionen in den ISA in Mio. US-\$ (Bestände nach Buchwert-, Wiederbeschaffungskosten- und Marktwertmethode), 1982 bis 1.991

\begin{tabular}{|c|c|c|c|c|c|c|}
\hline \multirow{2}{*}{$\begin{array}{l}\text { Stand } \\
\text { an } \\
\text { Jahres- } \\
\text { ende }\end{array}$} & \multicolumn{3}{|c|}{ Bestand an Direktinvestitionen } & \multicolumn{3}{|c|}{$\begin{array}{l}\text { Veränderung des Bestands } \\
\text { gegenuber den Vorjahr }\end{array}$} \\
\hline & $\begin{array}{l}\text { Buchwert- } \\
\text { vethode }\end{array}$ & $\begin{array}{l}\text { Wieder- } \\
\text { beschaffungs- } \\
\text { wethode }\end{array}$ & $\begin{array}{l}\text { Marktwert- } \\
\text { methode }\end{array}$ & $\begin{array}{l}\text { Buchwert- } \\
\text { methode }\end{array}$ & $\begin{array}{l}\text { Wieder- } \\
\text { beschaff ungs- } \\
\text { wethode }\end{array}$ & $\begin{array}{l}\text { Marktwert- } \\
\text { rethode }\end{array}$ \\
\hline & \multicolumn{6}{|c|}{ OS-ameritanische Direktimestitionen in Ansland in Mio. of $\$$} \\
\hline $1982^{1}$ & 207752 & 387239 & 226638 & -20596 & -25179 & $\ldots$ \\
\hline 1983 & 207203 & 371667 & 270768 & -549 & -15572 & 44130 \\
\hline 1984 & 211480 & 361588 & 265822 & 1277 & -10079 & -1946 \\
\hline 1985 & 230250 & 387183 & 379108 & 18770 & 25595 & 113286 \\
\hline 1986 & 259800 & 121167 & 518711 & 29550 & 33984 & 139603 \\
\hline 1987 & 314307 & 493341 & 576960 & 54507 & 72174 & 58249 \\
\hline 1988 & 335893 & 515702 & 678614 & 21586 & 22361 & 101654 \\
\hline $1989^{2}$ & 372419 & 552822 & 807896 & 36526 & 37120 & 129282 \\
\hline 1990 & 424086 & 623587 & 716441 & 51667 & 70765 & -91455 \\
\hline \multirow[t]{2}{*}{$1991 \mathrm{p}$} & 450196 & 655260 & 802000 & 26110 & 31673 & 85559 \\
\hline & \multicolumn{6}{|c|}{ ausländische Direktinvestitionen in dea OSA in Mio. OS-\$ } \\
\hline 1982 & 124677 & 176870 & 130428 & 15963 & 16944 & ... \\
\hline 1983 & 137061 & 184394 & 153318 & 12384 & 7524 & 22890 \\
\hline 1984 & 164583 & 211201 & 172377 & 27522 & 26807 & 19059 \\
\hline 1985 & 184615 & 231326 & 219996 & 20032 & 20125 & 47619 \\
\hline 1986 & 220414 & 265833 & 272966 & 35799 & 34507 & 52970 \\
\hline $1987^{3}$ & 263394 & 313451 & 316200 & 12980 & 47618 & 13234 \\
\hline 1988 & 314754 & 374345 & 391530 & 51360 & 60894 & 75330 \\
\hline 1989 & 368924 & 133164 & 534734 & 51170 & 58819 & 143204 \\
\hline 1990 & 396702 & 466515 & 536560 & 27778 & 33351 & 1826 \\
\hline $1991 \mathrm{P}$ & 407577 & 187022 & 654094 & 10875 & 20507 & 117534 \\
\hline
\end{tabular}

$p$ vorläufig

1 Bruch in den Zeitreihen zuischen 1.981 und 1982 uegen limstellung auf die ne ue Basis (Totalerhebung 1.98:).

2 Bruch in den Zeitreihen zuischen 1988 und 1989 wegen l'mstellung auf die neue Basis (Totalerhebung 1989).

3 Bruch in den Zeitreihen zuischen 1986 und 1987 wegen limstellung auf die neue Basis (Totalerhebung 1987).

Quelle: Scholl et al. (1992. S. 4.9 Tab. 3 und S. 5.3 Tab. 5) und L.S. Department of CommerceBureau of Eronomir Analysis (1991b. S. 51 Tab. 9: 19916. S. 85 Tab. 10): cigene Berechnungen. 
Tochtergesellschaften, die an den vierteljährlichen Stichprobenerhebungen teilgenommen haben, werden die Daten der Totalerhebung für jene Quartale des Wirtschaftsjahres, die im Kalenderjahr der Totalerhebung liegen, zu den Daten aus den vierteljährlichen Stichprobenerhebungen für die verbleibenden Quartale des Kalenderjahres addiert. Bei Tochtergesellschaften, die an den vierteljährlichen Stichprobenerhebungen nicht teilgenommen haben, werden bei den Kapitalerträgen aus Direktinvestitionen und deren Komponenten (außer für Vermögenszuwächse bzw. -verluste) die Angaben für das Wirtschaftsjahr als Daten für das Kalenderjahr verwendet. Für Eigenkapital, konzerninterne Nettoforderungen bzw. -verbindlichkeiten sowie für Vermögenszuwächse bzw. -verluste wird ein dem bei den vierteljährlichen Stichprobenerhebungen entsprechendes Verfahren angewendet: In die Kalenderjahrdaten gehen nur die Beträge für Quartale des Wirtschaftsjahrs ein, die auch im Kalenderjahr der Totalerhebung liegen; für die übrigen Quartale werden Beträge in Höhe von Null unterstellt.

In den Jahren zwischen Totalerhebungen müssen die Daten für die Tochtergesellschaften, deren Bilanzsumme, Umsatzerlöse oder Gewinne über der Meldefreigrenze der letzten Totalerhebung, aber unter der Meldefreigrenze der vierteljährlichen Stichprobenerhebungen liegen, geschätzt werden. Das verwendete Verfahren ist für die einzelnen Komponenten des Direktinvestitionskapitals unterschiedlich. Da die Stromgrößen für Eigenkapital und für konzerninterne Forderungen bzw. Verbindlichkeiten durch tendenziell große Unbeständigkeit und relativ häufige Vorzeichenwechsel (von Kapitaleinfuhr zu Kapitalausfuhr und umgekehrt) gekennzeichnet sind, wird für diese beiden Bestandteile des Direktinvestitionskapitals ausschließlich die Summe der gemeldeten Stichprobendaten als Ergebnis verwendet. Durch den Verzicht auf die Schätzung der nicht gemeldeten Transaktionen wird implizit unterstellt, daß diese per Saldo Null sind. Im Zusammenhang mit der regionalen und/oder der sektoralen Gliederung des Direktinvestitionskapitals und seinen Komponenten bedeutet dies die Annahme, daß sich die nicht gemeldeten Kapitalströme in jedem Land und in jedem Wirtschaftszweig ausgleichen, und zwar einerseits für die Direktinvestitionen der USA und andererseits für die Direktinvestitionen in den USA.

Im Gegensatz dazu enthalten die Daten für reinvestierte Gewinne in Berichtsjahren, in denen keine Totalerhebung durchgeführt wurde, sowohl die Angaben der in den vierteljährlichen Stichprobenerhebungen berichtenden Tochtergesellschaften als auch - mit Ausnahme von Vermögenszuwächsen bzw. -verlusten - geschätzte Größen für nicht meldende Tochtergesellschaften. Für letztere werden die Angaben für die Anteile der Mut-

Als Wirtschaftsjahr gilt das Geschäftsjahr, das im Kalenderjahr der Totalerhebung endet. Das Verfahren zur Umrechnung von Daten für Wirtschaftsjahre auf Kalenderjahre beschreibt Belli (1984, S. 33 f.) für Direktinvestitionen in den USA; entsprechendes gilt für Direktinvestitionen der USA. Zum Umrechnungsverfahren vgl. beispielsweise auch Scholl (1991, S. 34) oder U.S. Department of Commerce-Bureau of Economic Analysis (1990b, S. 87). 
tergesellschaften an den Gewinnen ihrer Tochtergesellschaften (ohne Vermögenszuwächse bzw. -verluste) nach Abzug der von den Tochtergesellschaften zu leistenden Einkommenbzw. Körperschaftsteuern, an den ausgeschütteten Gewinnen nach Abzug der Kapitalertragsteuern und an den Quellensteuern auf Dividendenleistungen unter Verwendung der Meldungen in den vierteljährlichen Stichprobenerhebungen der folgenden Jahre abgeleitet mittels Extrapolation der Ergebnisse der jeweils letzten Totalerhebung und der Daten von Tochtergesellschaften, die inzwischen die Meldefreigrenze der letzten Totalerhebung überschritten haben und in den vierteljährlichen Stichprobenerhebungen berichten. Diese Schätzwerte werden dann zu den reinvestierten Gewinnen der berichtenden Tochtergesellschaften addiert. Die Vermögenzuwächse bzw. -verluste nicht meldender Tochtergesellschaften werden seit 1986 bzw. 1984 - rückwirkend für die Berichtsjahre ab 1983 (Direktinvestitionen der USA) bzw. 1981 (Direktinvestitionen in den USA) - nicht mehr geschätzt; in die Ermittlung der Gewinne, und damit in die Kapitalerträge aus Direktinvestitionen, die reinvestierten Gewinne und das Direktinvestitionskapital, gehen - der Vorgehensweise bei Eigenkapital und konzerninternen Nettoforderungen bzw. -verbindlichkeiten entsprechend - seither nur noch die Vermögenszuwächse bzw. -verlustc der in den vierteljährlichen Stichprobenerhebungen berichtenden Tochtergesellschaften ein. ${ }^{267}$

Der Bestand an Direktinvestitionen zu historischen Anschaffungs- bzw. Herstellungskosten (Buchwertmethode) wird in den Jahren, in denen keine Totalerhebung durchgeführt wird, durch Fortschreibung seit der jeweils jüngsten Totalerhebung ermittelt: ${ }^{268} \mathrm{Zu}$ den Beständen am Vorjahresende werden jeweils die für das Berichtsjahr zu Transaktionswerten erfaßte Nettokapitalausfuhr bzw. Nettokapitaleinfuhr für Direktinvestitionen und Wertberichtigungen (valuation adjustments) addiert. Die Wertberichtigungen erfassen Änderungen der Buchwerte, die nicht mit Kapitalströmen verbunden sind, insbesondere

267 Zum Extrapolationsverfahren, das den seit 1986 bzw. 1984 für die Berichtsjahre ab 1983 bzw. 1981 veröffentlichten Daten zugrunde liegt und das sich teilweise von dem in früheren Jahren verwendeten unterscheidet, vgl. Belli (1984, S. 34 f.) und U.S. Department of Commerce-Bureau of Economic Analysis (1990b, S. 89 f., 93 und 95 f.); zu den Berechnungsschemata für reinvestierte Gewinne vgl. Belli (1984, S. 30 Tab. 6), Howenstine (1984, S. 23 Tab. 6) und U.S. Department of Commerce-Bureau of Economic Analysis (1985a, S. 32 Tab. 6; 1986, S. 43 Tab. 7). So wurden beispielsweise früher auch die Vermögenszuwächse bzw. - verluste auf alle Tochtergesellschaften hochgerechnet. Darüber hinaus wurden die Kapitalertragsteuern auf ausgeschüttete Gewinne nicht durch Extrapolation ermittelt, sondern unter Verwendung geschätzter Quellensteuersätze. Bei der Berechnung der Direktinvestitionen der USA in den Jahren 1982 und 1983 wurde zunächst jedoch übersehen, daß nicht-körperschaftlich organisierte Tochtergesellschaften in den meisten Ländern keine Quellensteuer auf transferierte Gewinne zu leisten haben; in beiden Jahren wurden die reinvestierten Gewinne deshalb um jeweils rund 0,6 Mrd. US- $\$$ zu niedrig ausgewiesen. Dieser Fehler wurde erst im Juni 1985 korrigiert. Vgl. Howenstine (1984, S. 25). Die Angaben der OECD (1987, S. 172 Tab. II.1) enthalten diese Korrektur noch nicht. Seit der Revision vom Juni 1992 wird rückwirkend für die Berichtsjahre ab 1982 ein neues Verfahren zur Schätzung der in- und ausländischen Quellensteuern angewendet; vgl. hierzu Murad (1992, S. 73).

268 Die Veränderung des Bestands an Direktinvestitionen gegenüber dem Vorjahr wird jedes Jahr in der Juni-Ausgabe des Survey of Current Business im Rahmen der Nettoauslandsposition der USA analysiert; vgl. hierzu z. B. Scholl $(1990 ; 1991)$ sowie Scholl et al. (1992). 
Fremdwährungsumrechnungsgewinne bzw. -verluste sowie sonstige Vermögenszuwächse bzw. - verluste, soweit diese nicht bereits über die reinvestierten Gewinne in den Kapitalströmen enthalten sind, und sonstige Wertberichtigungen. Letztere sind größtenteils das Nettoergebnis von Veräußerung und Erwerb von Beteiligungen an Tochtergesellschaften zu über die Buchwerte hinausgehenden Preisen. ${ }^{269}$

Bei der Wiederbeschaffungskostenmethode und bei der Marktwertmethode setzen sich Änderungen des Bestands an Direktinvestitionen gegenüber dem Vorjahr zusammen aus Kapitalausfuhr bzw. -einfuhr in Preisen der laufenden Periode und aus Wertberichtigungen. Anders als bei der Buchwertmethode spiegeln die Wertberichtigungen bei diesen beiden Methoden auch Preisänderungen wider. Diese erfassen beim Bestand zu Wiederbeschaffungskosten den Effekt von Änderungen der Preise für Sachanlagen sowie von Änderungen der Struktur der Sachanlagen und beim Bestand zum Marktwert Änderungen der Aktienkurse nach Abzug der Effekte der reinvestierten Gewinne. ${ }^{270}$

Da die Auswertung der Totalerhebungen mehrere Jahre dauert, ${ }^{271}$ werden die Daten für die Berichtsjahre, in denen die Ergebnisse der jüngsten Totalerhebung noch nicht vorliegen, zunächst nach dem oben beschriebenen Verfahren ermittelt, wobei die Schätzung der reinvestierten Gewinne auf der Extrapolation der Ergebnisse der vorletzten Totalerhebung beruht. Nach dem Vorliegen der Ergebnisse der jüngsten Totalerhebung werden die Daten rückwirkend ab dem Berichtsjahr dieser Totalerhebung revidiert; die Daten für die Jahre vor der jüngsten Totalerhebung bleiben dagegen unverändert. ${ }^{272}$ Das bedeutet: Die für US-amerikanische Direktinvestitionen im Ausland ausgewiesenen Daten beruhen für die Berichtsjahre 1958-1965 auf der Fortschreibung der Ergebnisse der Totalerhebung 1957, für 1967-1976 auf der Extrapolation der Totalerhebung 1966, für 1978-1981 auf der Totalerhebung 1977 und seit 1982 auf der Totalerhebung 1982; die Daten für die Jahre ab 1989 werden nach dem Vorliegen der Ergebnisse der Totalerhebung 1989 revidiert. Den für ausländische Direktinvestitionen in den USA ausgewiesenen Daten liegen für die Berichtsjahre 1959-1973 die Ergebnisse der Totalerhebung 1959, für 1974-1979 die der Totalerhebung 1974, für 1980-1986 die der Totalerhebung 1980 und seit 1987 die der To-

${ }_{269}$ Zu den sonstigen Wertberichtigungen vgl. z. B. Scholl (1987, S. 42; 1988, S. 82; 1989, S. 47 ff.; 1990, S. 56 f. und $62 ; 1991$, S. 28 ff.) und Whichard (1983, S. 16 f.).

270 Die sonstigen Wertberichtigungen spiegeln beim Bestand in Preisen der laufenden Periode auch den Interaktionseffekt zwischen Wechselkurs- und Preisänderungen wider. Vgl. Landefeld/Lawson (1991, S. 45).

$271 \mathrm{Zu}$ den Ergebnissen der Totalerhebungen für Wirtschaftsjahre (für 1974 und 1977: Kalenderjahre) vgl. U.S. Department of Commerce (1976, vol. 2) sowie U.S. Department of Commerce-Bureau of Economic Analysis (1981; 1983; 1985b; 1990a); zu den vorläufigen Ergebnissen für die Totalerhebung $1989 \mathrm{vgl}$. U.S. Department of Commerce-Bureau of Economic Analysis (1991d).

272 Nur die Ergebnisse der jeweils ersten Totalerhebung für Direktinvestitionen der USA bzw. in den USA wurden zur Konstruktion von Zeitreihen für die Berichtsjahre 1950 bis 1956 bzw. 1958 in die Vergangenheit extrapoliert. 
talerhebung 1987 zugrunde. Jede Umstellung auf eine neue Totalerhebung führt zu einem Bruch in den Zeitreihen für Direktinvestitionen (Transaktionswerte und Bestandsgrößen).

Die Gegenüberstellung der mittcls Extrapolation der Daten der vorletzten Totalerhebung unter Verwendung der Ergebnisse der vierteljährlichen Stichprobenerhebungen der folgenden Jahre geschätzten Direktinvestitionen mit den Ergebnissen der jüngsten Totalerhebung zeigt, daß die Abweichungen zwischen geschätzten und durch Totalerhebung ermittelten Werten recht groß sein können. Nach dem Vorliegen der Ergebnisse der für das Berichtsjahr 1982 durchgeführten Totalerhebung für Direktinvestitionen der USA im Ausland mußte der für dieses Jahr ausgewiesene Bestand von 221,8 Mrd. auf 207,8 Mrd. US-\$ nach unten und die Kapitalausfuhr von -4,4 Mrd. auf -2,4 Mrd. US-\$ nach oben revidiert werden; die Ausfuhr von Eigenkapital wurde um 5,5 Mrd. US-\$ und die Zunahme der konzerninternen Nettoforderungen der US-Muttergesellschaften gegenüber ihren ausländischen Tochtergesellschaften um 1,9 Mrd. US-\$ nach oben, die im Ausland reinvestierten Gewinne um 5,3 Mrd. US-\$ nach unten korrigiert. ${ }^{273}$ Nach dem Vorliegen der Ergebnisse der Totalerhebung für Direktinvestitionen in den USA wurde der für das Berichtsjahr 1987 ausgewiesene Bestand von 271,8 Mrd. auf 263,4 Mrd. US-\$ nach unten und die Kapitaleinfuhr von 46,9 Mrd. auf 58,1 Mrd. US-\$ nach oben revidiert; die Stromgrößen für Eigenkapital und für konzerninterne Nettoverbindlichkeiten der US-Tochtergesellschaften gegenüber ihren ausländischen Muttergesellschaften sind nach der Datenrevision um 3,7 Mrd. bzw. 9,9 Mrd. US-\$ höher, die in den USA reinvestierten Gewinne um 2,4 Mrd. US-\$ niedriger. ${ }^{274}$

Als Gründe für die Abweichungen zwischen geschätzten und durch Totalerhebungen ermittelten Werten für Direktinvestitionen sind bei unveränderter Definition und Methodologie zur Erfassung von Direktinvestitionen insbesondere zu nennen: ${ }^{275}$

- Transaktionen in Form von Eigenkapital und von konzerninternen Forderungen bzw. Verbindlichkeiten werden in den vierteljährlichen Stichprobenerhebungen weniger urnfassend gemeldet, entweder weil sie in den Stichprobenerhebungen nicht meldepflichtig sind oder weil der Meldepflicht nicht nachgekommen wird.

- Der Anteil der in den vierteljährlichen Stichprobenerhebungen nicht berichtenden Tochtergesellschaften wird über- oder unterschätzt.

- Die Meldungen werden bei den Stichprobenerhebungen zu spät abgeliefert.

${ }^{273}$ Vgl. hierzu Krueger (1985a, S. 57 Tab. 5), Scholl (1986, S. 35 Tab. 5) und U.S. Department of Commerce-Bureau of Economic Analysis (1986, S. 44 Tab. 10). Bei den einzelnen Komponenten des Direktinvestitionskapitals ist zu berücksichtigen, daB für das 1. Quartal 1982 die einzelnen Komponenten des Direktinvestitionskapitals nicht-körperschaftlich organisierter Tochtergesellschaften geschätzt werden mußten; vgl. Scholl $(1986$, S. 35 und 16).

${ }^{274}$ Vgl. hierzu Nicholson (1991, S. 42 Tab. G) und Scholl (1991, S. 35 Tab. 8).

275 Vgl. hierzu u. a. Belli (1984, S. 34), Nicholson (1991, S. 42) und Scholl $(1986$, S. 34 f. und 16; 1991, S. 34). 
- Finige: Unternehmen berichten zwar in den Totalerhebungen korrekt, nicht aber in den vierteljährlichen Stichprobenerhebungen.

- Fine unterschiedliche zeitliche 7uordnung der Transaktionen in Total- und Stichprobenerhebung spiclt v. a. bei den konzerninternen Forderungen bzw. Verbindlichkeiten eine Rolle.

- Im 7eitablauf ändern sich dic Grundsätze des Rechnungswesens. So ist beispielsweise die Bestandsrevision für Direktinvestitionen der USA im Jahr 1982 z. T. auch darauf zurückzuführen, daß einige Unternehmen Fremdwährungsbeträge in den vierteljährlichen Stichprobenerhebungen mit historischen Wechselkursen (FASB 8) und in der Totalerhebung mit laufenden Wechselkursen (FASB 52) umrechneten. Die einmalige Anpassung der Jahresabschlüsse infolge der Umstellung von FASB 8 auf FASB 52 wurde aus den Erträgen für Direktinvestitionen und damit aus den reinvestierten Gewinnen herausgerechnet und als Wertberichtigung des Bestands erfaßt. ${ }^{276}$

Dic Unterschiede bei den Angaben über den Bestand an Dircktinvestitionen ergeben sich aus den seit der jeweils letzten Totalerhebung kumulativen, z. T. einander kompensierenden Fehlern bei der Erfassung der jährlichen Stromgrößen für Direktinvestitionskapital und den Fehlern bei den Wertberichtigungen. ${ }^{277}$

In ihrem quantitativen $\Lambda$ usmaß nicht zu unterschätzen sind auch die Datenrevisionen aufgrund der Berücksichtigung neuer Informationen aus anderen Erhebungen des U.S. Department of Commerce/BEA über die Aktivitäten multinationaler Unternehmen und infolge neuer Schätzverfahren. Im Zusammenhang mit den für Direktinvestitionen ausgewiesenen Daten sind v. a. zwei Methoden zur besseren Erfassung der Transaktionen nicht, meldender Unternehmen zu nennen.

Seit dem Berichtsjahr 1981 sind in den für Direktinvestitionen in den USA ausgewiesenen Da1,en auch Informationen aus den 1979 eingeführten, jährlichen Erhebungen des U.S. Department of Commerce/BE $\Lambda$ über neue Direktinvestitionsunternehmen in den US $\Lambda$ enthalten. ${ }^{278}$ In diesen Erhebungen werden alle US-amerikanischen Unternehmen crfaßt, all denen ein ausländisches Wirtschaftssubjekt im Berichtsjahr unmittelbar oder mittelbar über eine bereits bestehende US-Tochtergesellschaft erstmals eine mindestens $10 \%$ ige Beteiligung erwirbt, sowic alle neuen US-Unternehmen, die im Berichtsjahr von ausländischen Direktinvestoren direkt oder ïber deren bereits bestehenden US-Tochtergesellschaften indirekt errichtet wurden. Das Investitionsvolumen im Zusammenhang

276 Vgl. Scholl (1986, S. 35). Zu der einmaligen negativen Wertberichtigung infolge des neuen Standards zur Umrechnung von Fremdwährungsbeträgen vgl. Whichard (1983, S. 16 f.).

277 Vgl. Scholl $(1986$, S. 34 f.).

278 Die Berïcksichtigung dieser Daten erfolgte im Juni 1984 rückwirkend; vgl. hierzu Belli (1984, S. 35 f.) und Krueger (1984a, S. 11 und 73). 
mit Erwerb oder Errichtung neuer US-Tochtergesellschaften, das hier unabhängig von der Herkunft der Finanzierungsmittel erfaßt wird, ist, im Einzelfall häufig vergleichsweise gering. Die Summe der Transaktionen, die in den im Rahmen der Erstellung der US-7ahlungsbilanzstatistik durchgeführten vierteljährlichen Stichprobenerhebungen nicht meldepflichtig sind, ist insgesamt jedoch nicht $\mathrm{zu}$ vernachlässigen. ${ }^{279}$

Im Juni 1992 wurde, einer Initiative des U.S. Department of Commerce/BE $\Lambda$ folgend, ${ }^{280}$ rückwirkend für die Berichtsjahre ab 1990 eine neue Methode eingeführt, um auch 7unahme und Rückgang des Figenkapitals säumiger Meldepflichtiger zu crfassen. Geschätzt. werden jetzt die Eigenkapitalströme (Zunahme und Rückgang) dieser Tochtergesellschaften, indem die in einem Quartal gemeldeten, um Informationen aus den Erhebungen über Gründung und Erwerb neuer US-Tochtergesellschaften sowie aus anderen Erhebungen ergänzten Eigenkapitalströme multipliziert werden mit dem Verhältnis von Figenkapitalbestand in der Vorperiode von Tochtergesellschaften, die zwar meldepflichtig sind, aber in der laufenden Periode nicht melden, zu Eigenkapitalbestand in der Vorperiode von in der laufenden Periode berichtenden Tochtergesellschaften. Die Schätzung der Eigenkapitalströme säumiger Meldepflichtiger wird nur für aggregierte Daten durchgeführt; die Schätzwerte werden dem, am Eigenkapitalbestand am Ende des Vorjahres gemessenen, größten Land bzw. Wirtschaftszweig zugeordnet. ${ }^{281}$

\subsubsection{Direktinvestitionen der USA im Ausland und ausländische Direktin- vestitionen in den USA in den Jahren 1982 bis 1991 (Transaktions- werte)}

Den Umfang der zwischen Juni 1990 und August 1992 für das Direktinvestitionskapital in den Jahren 1982 bis 1991 durchgeführten Revisionen zeigt Tabelle 4.9. ${ }^{282}$ Die für cin bestimmtes Jahr ausgewiesenen Transaktionswerte für Direktinvestitionen weisen z. T. eine sehr große Spannweite auf; vgl. die Differenzen zwischen den Spalten (1) und (3), (3) und (5) bzw. (1) und (5) sowic zwischen (5) und (7). Dic in den Spalten (1) bis (6) wiedergegebenen Daten für Dircktinvestitionskapital bzw. für reinvestierte Gewinne waren bzw. sind Bestandteil der US-Zahlungsbilanzstatistik. $\Lambda \mathrm{n}$ dieser Stelle sci nochmals

279 Von der Meldepflicht befreit sind alle neuen US-Tochtergesellschaften mit einer Bilanzsumme von höchstens 1 Mio. US- $\$$ und neue US-Tochtergesellschaften, die weniger als 200 Morgen Land besitzen. Der Erwerb zusätzlicher Beteiligungen an und die Erweiterung von bestehenden USTochtergesellschaften sowie der Verkauf bestehender US-Tochtergesellschaften an anderc Dircktinvestoren bleiben in diesen Erhebungen unberücksichtigt. Zu den Ergebnissen dieser Erhebungen vgl. z. B. Fahim-Nader (1992c). Quijano (1990, insb. S. 32) vergleicht die Daten über Erwerb und Frrichtung neuer US-Tochtergesellschaften mit den Direktinvestitionskapitalst.römen der Zahlungsbilanzstatistik.

$280 \mathrm{Vgl}$. U.S. Department of Commerce-Bureau of Fconomic Analysis (1991c).

281 Vgl. Murad (1992, S. 75) f.).

282 Wiedergegeben sind für ein bestimmtes Jahr die jeweils neuesten Daten; vorläufige Ergebnisse bleibcn - außer für 1991 - unberücksichtigt. 
darauf hingewiesen, daß die für die Jahre bis einschließlich 1981 veröffentlichten Daten für Direktinvestitionen nicht revidiert wurden, so daß sowohl die Zeitreihen für Direktinvestitionen der USA als auch die für Direktinvestitionen in den USA zwischen 1981 und 1982 cinen Bruch aufweisen. Bei den Direktinvestitionen der USA wurde darüber hinaus im Jahr 1982 cine neue Totalerhebung durchgeführt; bei den Direktinvestitionen in den USA gibt es infolge der Totalerhebung im Jahr 1987 einen weiteren Bruch in den Zeitreihen zwischen 1986 und 1987.

Dic Unterschicde für das ausgewiesene Direktinvestitionskapital sind in den meisten Jahren ausschließlich auf die im Zcitablauf geänderte Gewinnabgrenzung zurückzuführen. Spalte (1) bzw. (2) zeigt das Direktinvestitionskapital bzw. die reinvestierten Gewinne, wenn bei der Gewinnermittlung sämtliche Vermögenszuwächse bzw. -verluste der Tochtergesellschaften berücksichtigt werden. Seit Juni 1990 werden bei den Direktinvestitionen der USA Fremdwährungsumrechnungsgewinne bzw. -verluste nicht mehr als Teil der Gewinne bchandelt. ${ }^{283}$ Andere Vermögenszuwächse bzw. -verluste sind weiterhin in den Gewinnen und damit über die reinvestierten Gewinne in den Stromgrößen für Direktinvestitionskapital enthalten; vgl. Spalten (3) und (4). Eine entsprechende Vorgehensweise bei den Dircktinvestitionen in den US $\Lambda$ war wegen Datenmangels nicht möglich; in den Stromgrößen reinvesticrte Gewinne und Direktinvestitionskapital sind deshalb die Anteile der ausländischen Muttergesellschaften an allen realisierten und nicht-realisierten Vermögenszuwächsen bzw. -verlusten ihrer US-Tochtergesellschaften noch enthalten. Die asymmetrische Behandlung der Fremdwährungsumrechnungsgewinne bzw. -verluste wird u. a. damit gerechtfertigt, daß diese Vermögenszuwächse bzw. -verluste bei den Direktinvestitionen in den USA eine sehr viel geringere Bedeutung haben als bei den Direktinvestitionen der USA, da die Aktiva und Passiva von US-Tochtergesellschaften zum großen Teil in US$\$$ ausgedrückt sind und deshalb nicht von Fremdwährungsbeträgen in US-\$ umgerechnet werden müssen. ${ }^{284}$

Die IIöhe der Vermögenszuwächse bzw. -verluste infolge Änderungen der zur Umrechnung von Fremdwährungsbeträgen in US-\$ verwendeten laufenden Wechselkurse hängt bei gegebener Entwicklung des Außenwerts des US-\$ ab vom Wert und von der Währungszusammensetzung der in US-\$ umzurechnenden $\Lambda$ ktiva und Passiva. Da die Aktiva der ausländischen Tochtergesellschaften in der Regel ihre Verbindlichkeiten übersteigen, gilt für Direktinvestitionen der US $\Lambda$ tendenzicll: Bei ciner $\Lambda$ ufwertung des US-\$ gegenüber den wichtigsten Währungen sinkt der in US-\$ umgerechnete Wert der Nettoaktiva einer Tochtergesellschaft im Ausland; eine Aufwertung des US-\$ führt also zu nicht-realisierten

\footnotetext{
${ }_{283}$ Wegen Datenmangels mußte bei der Revision bis einschließlich dem 1. Quartal 1990 unterstellt werden, daß alle Vermögenszuwächse bzw. -verluste im Zusammenhang mit Eigenkapital Fremdwährungsumrechnungsgewinne bzw. -verluste sind; vgl. Nicholson (1990, S. 72 f.).
}

284 Vgl. Nicholson (1990, S. 72 f.) 


\begin{tabular}{|c|c|c|c|c|c|c|c|c|c|c|c|}
\hline \multirow[b]{4}{*}{ Jahr } & \multicolumn{2}{|c|}{ 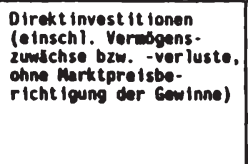 } & \multicolumn{2}{|c|}{ 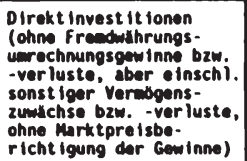 } & \multirow[t]{3}{*}{$\begin{array}{l}\text { Differenz } \\
\text { (1)./.(3) }\end{array}$} & \multicolumn{2}{|c|}{$\begin{array}{l}\text { Oirekt Invest it ionen } \\
\text { (ohne Verndgenszuwatchse } \\
\text { bzw. - vor luste. } \\
\text { nit Marktprelsbe- } \\
\text { richt lgung der Gewinne) }\end{array}$} & \multirow[t]{3}{*}{$\begin{array}{l}\text { Differenz } \\
\text { (3). } / .(5)^{c} \\
\text { bzw. } \\
(1) . / .(5)^{d}\end{array}$} & \multicolumn{2}{|c|}{$\begin{array}{l}\text { Direkt invest it lonen } \\
\text { (ohne Verabgenszuwichse } \\
\text { bzw. -ver luste. } \\
\text { ohne Marktpreisbe- } \\
\text { richt igung der Gew inne) }\end{array}$} & \multirow[t]{3}{*}{$\begin{array}{l}\text { Marktpreis- } \\
\text { bericht igung } \\
\text { Differenz } \\
\text { (5)./.(7) }\end{array}$} \\
\hline & insgesant & $\begin{array}{l}\text { darunter: } \\
\text { re invest. } \\
\text { Gew inne }\end{array}$ & insgesant & $\begin{array}{l}\text { darunter: } \\
\text { re invest. } \\
\text { Gewinne }\end{array}$ & & insgesant & $\begin{array}{l}\text { darunter: } \\
\text { re invest. } \\
\text { Gewinne }\end{array}$ & & insgesant & $\begin{array}{l}\text { darunter: } \\
\text { re invest. } \\
\text { Gew inne }\end{array}$ & \\
\hline & (1) & (2) & (3) & (4) & & (5) & (6) & & (7) & (8) & \\
\hline & \multicolumn{11}{|c|}{ US-anarikanischo Direkt invest it ionen in Ausland in Mio. US-s (Kapita lausfuhr: + ) } \\
\hline $1982 !$ & -2369 & 1359 & 967 & 4695 & -3336 & -991 & 2737 & 1958 & 1078 & 4806 & -2069 \\
\hline 1983 & 373 & 1139 & 6695 & 13462 & -6322 & 4889 & 11655 & 1806 & 6686 & 13453 & -1797 \\
\hline 1984 & 2821 & 8447 & 11587 & 17214 & -8766 & 10948 & 16574 & 639 & 11649 & 17276 & -701 \\
\hline 1985 & 18068 & 19009 & 13162 & $14 \quad 102$ & 4906 & 13401 & 14342 & -239 & 12724 & 13665 & 677 \\
\hline 1906 & 26311 & 17654 & 18679 & 10021 & 7632 & 17090 & 8433 & 1589 & 17706 & 9048 & .616 \\
\hline |997 & 45922 & 34592 & 31045 & 19714 & 14871 & $27 \quad 181$ & 15850 & 3864 & 28980 & 17650 & -1 799 \\
\hline 1800 & 15317 & 11113 & 17879 & 13327 & -2562 & 15448 & 10895 & 2431 & 17871 & 913 & -2423 \\
\hline 1909 & 30256 & 20950 & 33308 & 22370 & $-3 \quad 132$ & 28995 & 14778 & 4393 & $30 \quad 167$ & 15950 & -1172 \\
\hline 1990 & $\ldots$ & $\ldots$ & 33437 & 22250 & $\ldots$ & 32694 & 19468 & 743 & 34111 & 20886 & -1417 \\
\hline \multirow[t]{2}{*}{1991} & $\ldots$ & $\ldots$ & 29497 & 23742 & $\ldots$ & $27 \quad 135$ & 17887 & 2362 & 28197 & 18949 & -1062 \\
\hline & \multicolumn{11}{|c|}{ auslandischo Dirakt investit Ionen in den USA in Mio. US-\$ (Kapitaleinfuhr: +) } \\
\hline 1982 & 13792 & -2379 & $\ldots$ & $\ldots$ & $\ldots$ & 12464 & .3707 & 1328 & 13810 & -2361 & -1346 \\
\hline 1903 & 11946 & 89 & $\ldots$ & $\ldots$ & $\ldots$ & $10 \quad 457$ & -1401 & 1489 & 11518 & .340 & -1061 \\
\hline 1904 & 25359 & 280 & $\ldots$ & $\ldots$ & $\ldots$ & 24748 & 2286 & 611 & 25567 & 3105 & .819 \\
\hline 1905 & 19022 & -1378 & $\ldots$ & $\ldots$ & $\ldots$ & 20010 & -390 & -980 & 20490 & 90 & -480 \\
\hline $19 \%$ & 34091 & -2293 & $\ldots$ & $\ldots$ & $\ldots$ & 35623 & .761 & -1532 & $36 \quad 145$ & .239 & .522 \\
\hline 19876 & 50119 & -803 & $\ldots$ & $\ldots$ & $\ldots$ & 58219 & -783 & -100 & 59581 & 579 & -1362 \\
\hline 1980 & 59424 & 2816 & $\ldots$ & $\ldots$ & $\ldots$ & 57278 & 670 & 2146 & 58571 & 1963 & -1293 \\
\hline 1909 & 10551 & -3844 & $\ldots$ & $\ldots$ & $\ldots$ & 67872 & .8528 & 2679 & 69010 & .7390 & -1138 \\
\hline 1990 & 37213 & -14000 & $\ldots$ & $\ldots$ & $\ldots$ & 45137 & -16287 & -7924 & 46108 & -15316 & .971 \\
\hline 1991 & 22197 & -14801 & $\ldots$ & $\ldots$ & $\ldots$ & 11497 & .20046 & 10700 & 12619 & .18924 & 1122 \\
\hline
\end{tabular}

a De Daten für die Jahro 1983 bis 1991 bagkieren auf der Fortschrelbung der Totalerhebung 1982 unter Vorwendung der frgebnisse der viertel jahrlichen St ich.

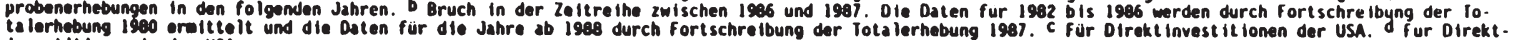
talerhebung 1900 oreittelt

quello: Bach (1992, S. 22 Tab. 5), Murad (1992, S. 78 f. Tab. I und S. 100 Tab. 5) und U.S. Department of Comerce-Bureau of tconomic Analysis (1990,. S. 57.

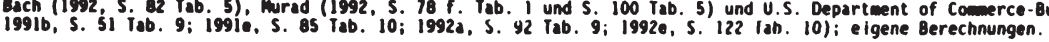


Vermögensverlusten. Umgekehrt sind Abwertungen des US-\$ gegenüber den wichtigsten Währungen tendenziell mit Vermögenszuwächsen verbunden. Nach Bereinigung der Daten um die Fremdwährungsumrechnungsgewinne bzw. -verluste werden bei Aufwertungen des US-\$ dem Betrage nach höhere und bei Abwertungen des US- $\$$ dem Betrage nach niedrigere Werte für Kapitalerträge aus US-amerikanischen Direktinvestitionen im Ausland, für reinvestierte Gewinne und für Direktinvestitionskapital ausgewiesenen.

Die Vermögenszuwächse bzw. -verluste infolge der Umrechnung von Fremdwährungsbeträgen in US-\$ sind in einigen Jahren sehr groß. Die Differenzen zwischen den Spalten (1) und (3) spiegeln in den Jahren 1982 bis 1987 ausschließlich Fremdwährungsumrechnungsgewinne (+) bzw. -verluste (-) wider. In den Jahren 1982 bis 1984 dominieren die durch die Aufwertung des US-\$ gegenüber den wichtigsten Währungen entstandenen Fremdwährungsumrechnungsverluste das ausgewiesene Direktinvestitionskapital. Im Jahr 1984 beispielsweise betrugen die Vermögensverluste infolge der Umrechnung 8,8 Mrd. US-\$; nach Bereinigung um diese Vermögensverluste werden für die Kapitalausfuhr für Direktinvestitionen nicht mehr 2,8 Mrd. US-\$ sondern 11,6 Mrd. US-\$ ausgewiesen und für die reinvestierten Gewinne statt 8,4 Mrd. US-\$17,2 Mrd. US-\$. In den Jahren 1985 bis 1987 wertete der US-\$ gegenüber den meisten ausländischen Währungen ab; die durch die Umrechnung von Fremdwährungsbeträgen in US-\$ entstandenen Vermögenszuwächse erreichten im Jahr 1987 den Betrag von 14,9 Mrd. US- \$. Die Bereinigung der Gewinne um Fremdwährungsumrechnungsgewinne führt zu entsprechend niedrigeren Werten für reinvestierte Gewinne und für Direktinvestitionskapital. Die Differenzen zwischen den Spalten (1) und (3) sind in den Jahren 1988 und 1989 sowohl auf Fremdwährungsumrechnungsverluste als auch auf sonstige Revisionen der Komponenten des Direktinvestitionskapital zurückzuführen.

Seit Juni 1992 werden - rückwirkend für die Jahre ab 1982 - sowohl bei den Direktinvestitionen der USA als auch bei den Direktinvestitionen in den USA bei der Gewinnermittlung keine Vermögenszuwächse bzw. -verluste der Tochtergesellschaften mehr berücksichtigt und die Gewinne einer Marktpreisberichtigung unterzogen; vgl. Spalten (5) und (6). In den Jahren 1982 bis 1988 spiegeln die Differenzen zwischen Spalten (3) und (5) (US-amerikanische Direktinvestitionen im Ausland) bzw. zwischen Spalten (1) und (5) (ausländische Direktinvestitionen in den USA) ausschließlich den Effekt wider, den die Entfernung der Vermögenszuwächse bzw. -verluste (bei Direktinvestitionen der USA ohne und bei Direktinvestitionen in den USA einschließlich Fremdwährungsumrechnungsgewinne bzw. -verluste) und die Marktpreisberichtigung der Gewinne auf die reinvestierten Gewinne und damit auf das Direktinvestitionskapital hat. In den Jahren 1989 bis 1991 
kommen - teilweise einander kompensierende - Revisionen bei allen Komponenten des Direktinvestitionskapitals hinzu. ${ }^{285}$

Da die Marktpreisberichtigung der Gewinne weder regional noch sektoral aufgegliedert werden kann, weist das U.S. Department of Commerce/BEA im August 1992 u. a. die reinvestierten Gewinne und das Direktinvestitionskapital ohne Vermögenszuwãchse bzw. -verluste, aber auch ohne Marktpreisberichtigung aus; vgl. Tabelle 4.9 Spalten (7) und (8). Die Differenzen zwischen den Spalten (5) und (7) geben die Höhe der Marktpreisberichtigung an. ${ }^{286}$

Tabelle 4.9 zeigt aber nicht nur den großen Einfluß, den die Gewinnermittlungsmethode auf die ausgewiesenen reinvestierten Gewinne und damit auf das ausgewiesene Direktinvestitionskapital hat, sondern auch, daß die Direktinvestitionen in Form von reinvestierten Gewinnen bei den Direktinvestitionen der USA von großer Bedeutung sind; dies gilt auch dann, wenn Vermögenszuwächse bzw. -verluste nur teilweise oder gar nicht als Bestandteil der reinvestierten Gewinne, sondern als Wertberichtigungen des Direktinvestitionsbestands erfaßt werden. In den Jahren 1982 bis 1985 sind die reinvestierten Gewinne sogar größer als das Direktinvestitionskapital. D. h., die Kapitalausfuhr in Form von reinvestierten Gewinnen und Eigenkapital wird teilweise kompensiert durch Kapitaleinfuhr infolge der Zunahme der Nettoverbindlichkeiten der US-Muttergesellschaften gegenüber ihren ausländischen Tochtergesellschaften. ${ }^{287}$ Bei den Direktinvestitionen in den USA sind die reinvestierten Gewinne in vielen Jahren negativ, $d$. h., die ausgeschütteten Gewinne der US-Tochtergesellschaften sind größer als ihre in der laufenden Periode erzielten Gewinne.

285 So entfallen beispielsweise für das Jahr 1991 von der Revision der Kapitalausfuhr für USamerikanische Direktinvestitionen im Ausland von 29,5 Mrd. auf 27,1 Mrd. US-\$ auf statistische Änderungen +1 Mrd. US-\$, auf die Entfernung der Vermögenszuwächse bzw. -verluste (ohne Fremdwährungsumrechnungsgewinne bzw. -verluste) $-2,3 \mathrm{Mrd}$. US- $\$$ und auf die Marktpreisberichtigung $-1,1$ Mrd. US-\$; die Kapitaleinfuhr für Direktinvestitionen in den USA wurde von 22,2 Mrd. auf $11,5 \mathrm{Mrd}$. US- $\$$ nach unten korrigiert und zwar um $-7,7 \mathrm{Mrd}$. US-\$ infolge statistischer Änderungen. um -1,9 Mrd. US- $\$$ wegen Entfernung der Vermögenszuwächse bzw. -verluste (einschlieBlich Fremdwährungsumrechnungsgewinne bzw. -verluste) und um $-1,1 \mathrm{Mrd}$. US- $\$$ infolge Marktpreisberichtigung. Vgl. Murad (1992, S. 69 Tab. G). Zum Umfang der Revisionen für die einzelnen Komponenten des Direktinvestitionskapitals in den Jahren 1990 und 1991 vgl. z. B. Bach (1992, S. 82 Tab. 5) und Murad (1992, S. 100 Tab. 5).

286 Da die Marktpreisberichtigung der Gewinne nur die Höhe der reinvestierten Gewinne (und die Kapitalerträge aus Direktinvestitionen) beeinflußt, sind die Differenzen zwischen den Spalten (5) und (7) bzw. (6) und (8) identisch. In der US-Zahlungsbilanzstatistik werden die Direktinvestitionen weiterhin mit Marktpreisberichtigung der Gewinne ausgewiesen. Vgl. hierzu U.S. Department of CommerceBureau of Economic Analysis (1992a, insb. S. 88 Tab. 2; 1992e, insh. S. 117 Tab. 2).

${ }^{287}$ In den Jahren 1983 bis 1985 sind die reinvestierten Gewinne auch dann größer als das Direktinvestitionskapital, wenn man die Transaktionen zwischen US- Muttergesellschaften und deren Finanzierungstochtergesellschaften auf den Niederländischen Antillen aus dem Direktinvestitionskapital herausrechnet. 


\subsubsection{Direktinvestitionen der Bundesrepublik Deutschland in den USA und Direktinvestitionen der USA in der Bundesrepublik Deutschland in bundesdeutscher und in US-amerikanischer Statistik}

Tabelle 4.10 zeigt die in der Transferstatistik des BMWi, in der Zahlungsbilanzstatistik der Deutschen Bundesbank und in der US-Statistik ausgewiesenen Transaktionswerte für deutsche Direktinvestitionen in den USA und für US-amerikanische Direktinvestitionen in der Bundesrepublik in den Jahren 1987 bis $1991 .{ }^{288}$ Diese drei Statistiken weichen in bezug auf Erhebungsmethoden und Schätzverfahren sowie in bezug auf die Abgrenzung von Direktinvestor, Direktinvestitionsunternehmen und Direktinvestitionskapital (teilweise) voneinander ab. Darüber hinaus umfassen die USA in der Zahlungsbilanzstatistik der Deutschen Bundesbank im Gegensatz zur US-Zahlungsbilanzstatistik nicht die US-amerikanischen Gebiete und Besitzungen in Ozeanien; diese werden bei den Entwicklungsländern aufgeführt. Für die Direktinvestitionen der Bundesrepublik in den USA werden in allen Statistiken - ausgenommen für das Jahr 1990 - positive Nettodirektinvestitionen ausgewiesen. Das Volumen der Transaktionen, auch deren Größenordnung, und die Entwicklung gegenüber dem Vorjahr bleibt aber in den meisten Jahren offen. Im Zusammenhang mit den US-amerikanischen Direktinvestitionen in der Bundesrepublik ist in den meisten Jahren nicht eindeutig, ob die Bundesrepublik Deutschland Nettokapitalimporteur oder -exporteur ist. Am größten sind die Unterschiede in den verschiedenen Statistiken für das Jahr 1991: Die Transferstatistik weist -2,1 Mrd. DM, die Zahlungsbilanzstatistik der Deutschen Bundesbank -0,4 Mrd. DM und die US-Statistik $+9,5$ Mrd. DM aus. ${ }^{289}$ Dies hängt u. a. damit zusammen, daß nur die US-Statistik auch mittelbare Direktinvestitionen in der Bundesrepublik erfaßt, also z. B. die Investitionen in den neuen Bundesländern von in Deutschland ansässigen Unternehmen, die Tochtergesellschaften von US-Konzernen sind.

Bei einer Gegenüberstellung der in der Bundesrepublik und in den USA (nach der Buchwertmethode) ermittelten Bestände für deutsche Direktinvestitionen in den USA und für US-amerikanische Direktinvestitionen in der Bundesrepublik hängt die Höhe des Bestands, v. a. aber die der Bestandsänderungen davon ab, ob man die Angaben der Deutschen Bundesbank in US-\$ oder die des U.S. Department of Commerce/BEA in DM umrechnet. Deshalb wird auf die Wiedergabe dieser Daten verzichtet. Durch die - zum Teil wieder-

${ }_{288}$ Die Angaben schließen ab 1.7.1990 bzw. ab 1990 die Transaktionen des Gebiets der ehemaligen DDR mit den USA ein. Diese Änderung hat keinen Bruch in den Zeitreihen zur Folge, denn in den Jahren vor 1990 hatten weder die USA noch die DDR im jeweils anderen Land Tochtergesellschaften; vgl. U.S. Department of Commerce-Bureau of Economic Analysis (1992a, S. 112 Anm. 1 zu Tab. 16; 1992e, S. 142 Anm. 1 zu Tab. 17).

${ }^{289}$ Für das Berichtsjahr 1991 weist die US-Statistik das Direktinvestitionskapital nach Ziel- bzw. Herkunftsländern nur ohne Vermögenszuwächse bzw. -verluste und ohne Marktpreisberichtigung der Gewinne aus. 
Tabelle 4.10: Deutsche Direktinvestitionen in den USA und US-amerikanische Direktinvestitionen in der Bundesrepublik Deutschland in Mio. DM (Transaktionswerte), 1987 bis 1991

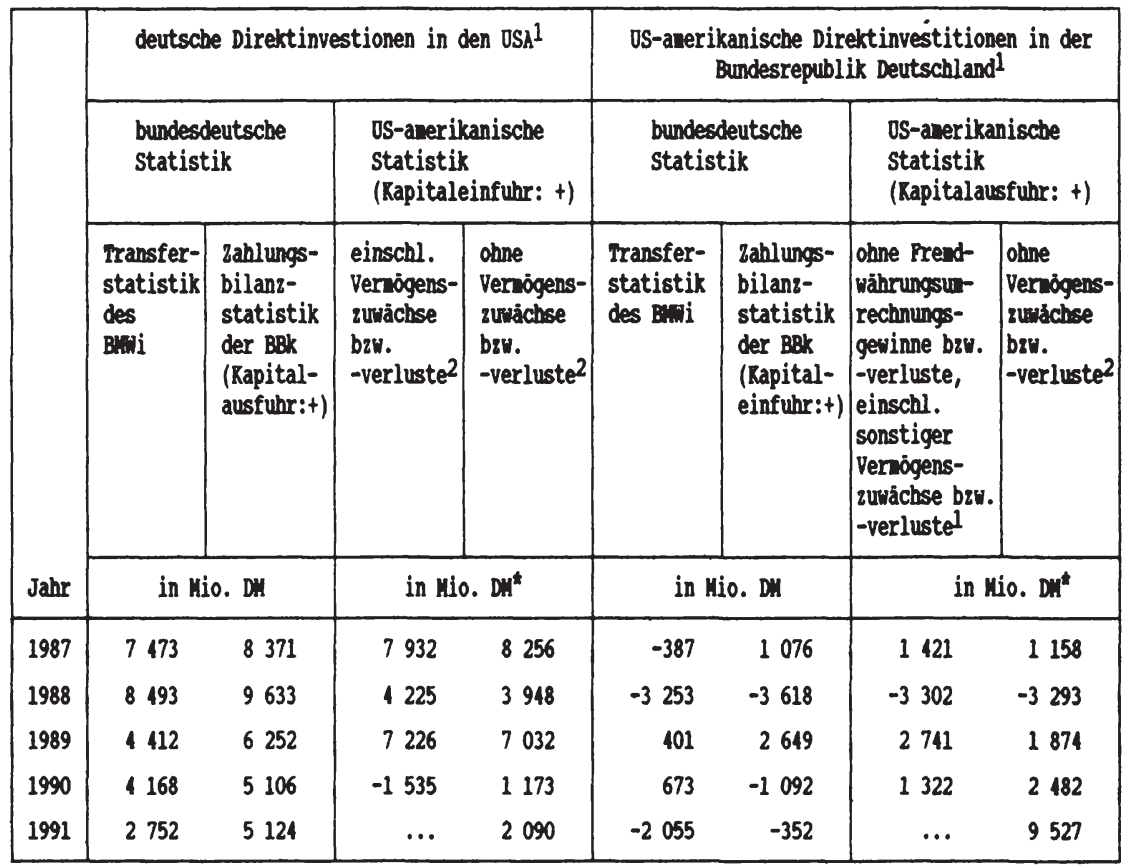

* Umrechnung auf der Basis des jeweiligen jahresdurchschnittlichen Wechselkurses für den US-\$. 1 Ab 1.7.1990 (bundesdeutsche Statistik) bzw. ab 1990 (US-Statistik) einschließlich Transaktionen des Gebiets der ehemaligen DDR mit den USA.

2 Ohne Marktpreisberichtigung der Gewinne.

Quelle: Bundesministerium für Wirtschaft (o.J., S. 100 Tab. 5.5.2.1.2.2 und S. 103, Tab. 5.5.2.1.3.2), Deutsche Bundesbank (1990g, S. 13; 1992b, S. 13; 1992c, S. 8 f. Tab. 5a) und U.S. Department of Commerce-Bureau of Economic Analysis (1991b, S. 75 f. Tab. 16; 1991e, S. 104 f. Tab. 17; 1992a, S. 111 f. Tab. 16; 1992e, S. 141 f. Tab. 17); eigene Berechnungen.

holte - Umrechnung des ausgewiesenen Unternehmensvermögens von DM in US-\$ bzw. von US- $\$$ in DM sind bei Aufwertungen (Abwertungen) der DM gegenüber dem US-\$ die Veränderungsraten der DM-Beträge geringer (höher) als die der US-\$-Beträge. So errechnet man beispielsweise für die Veränderungen der unmittelbaren und mittelbaren deutschen Direktinvestitionen in den USA von Ende 1989 bis Ende 1990 -2,8 Mrd. DM (BBk) bzw. -5,9 Mrd. DM (US-Statistik) oder +2,6 Mrd. US-\$ (BBk) bzw. - 0,1 Mrd. US-\$ 
(US-Statistik); die DM wertete im Vorjahresvergleich gegenüber dem US- $\$$ auf. ${ }^{290}$

\subsection{Weitere Argumente gegen quantitativ-empirische Studien mit aggregier- ten Daten für Direktinvestitionen}

Die bisherigen Ausführungen haben am Beispiel der in der Bundesrepublik und in den USA verwendeten Methoden zur statistischen Erfassung von Direktinvestitionen gezeigt, daß die ausgewiesenen Daten für Direktinvestitionen weder international noch national noch innerhalb eines Landes intertemporal vergleichbar sind. Darüber hinaus gibt es noch eine Reihe weiterer Argumente gegen quantitativ-empirische Studien mit aggregierten Daten für Direktinvestitionen.

Der Behauptung, die Änderungen des Bestands an Direktinvestitionen seien ein besserer Indikator für den „Erfolg der Bemühungen, im Ausland durch eigene Niederlassungen oder Beteiligungen Fuß zu fassen, als die Transaktionswerte der Zahlungsbilanz" ${ }^{\text {291 }}$ ist zuzustimmen - insbesondere wenn man dabei sowohl unmittelbare als auch mittelbare Direktinvestitionen berücksichtigt. Die Bedeutung einzelner Länder als Zielländer deutscher Direktinvestitionen im Ausland bzw. als Herkunftsländer der ausländischen Direktinvestitionen in der Bundesrepublik ist nur den Bestandsdaten zu entnehmen. Für die Frage nach den Determinanten von Direktinvestitionen sind endogene Variablen, die auf dem Bestand an Direktinvestitionen oder auf Bestandsänderungen aufbauen, jedoch ungeeignet. Der Zusammenhang zwischen dem Bestand an Direktinvestitionen zu einem bestimmten Zeitpunkt und internationalen Zinssatzdifferenzen, Profitabilitätsunterschieden, Standortfaktoren, tarifären oder nicht-tarifären Handelshemmnissen, firmenspezifischen Vorteilen, Transaktionskosten oder anderen möglichen Determinanten von Direktinvestitionen zum selben Zeitpunkt dürfte gering sein. Standortentscheidungen sind langfristige Investitionsentscheidungen. Sie werden auf der Grundlage erwarteter, sich im Zeitablauf ändernder Rahmenbedingungen getroffen. Änderungen des nach der Buchwertmethode ermittelten Bestands sind nicht nur abhängig von der Neuanlage in bzw. der Liquidation von Kapitalbeteiligungen, von Errichtung oder Erwerb bzw. Auflösung oder Veräußerung von Zweigniederlassungen und Betriebsstätten, von Gewährung oder $\Lambda$ ufnahme bzw. Rückzahlung von Krediten und von der Nichtausschüttung von Gewinnen. In die Bestandsänderungen gehen auch Wertänderungen des Vermögens ein, die nicht das Ergebnis von Investitions- und Finanzierungsentscheidungen sind. Dem Volumen nach sind in diesem Zusammenhang insbesondere Bestandsänderungen als Folge von sich zwischen den Erhebungszeitpunkten ändernden Wechselkursen hervorzuheben; ein Herausrechnen

290 Umrechnung der Beträge mit dem Wechselkurs am jeweiligen Jahresende. Vgl. Deutsche Bundesbank (1992a, S. 7; 1992c, S. 8 f. Tab. 5a) und U.S. Department of Commerce-Bureau of Economic Analysis (1992a, S. 111 f. Tab. 16).

291 DIW (1992, S. 172 Fn. 1). 
dieser wechselkursbedingten Wertänderungen des Unternehmensvermögens ist im allgemeinen nicht möglich.

Finen Indikator für die Direktinvestitionsintensität, der nicht von Wechselkursänderungen beeinflußt ist und der interindustrielle Unterschiede der Direktinvestitionsintensitäten bei abweichenden sektorspezifischen Kapitalintensitäten erfaßt, sieht Wagner (1991, S. 126 ff.) im Verhältnis der Anzahl der Direktinvestoren in einer Industrie zur Gesamtzahl von Unternehmen in dieser Branche. Da die Anzahl der Direktinvestoren statistisch zu niedrig ausgewiesen wird, ${ }^{292}$ unterschätzt diese endogene Variable die Direktinvestitionsintensität jedoch.

Die statistisch ermittelten Stromgrößen für Direktinvestitionen spiegeln nur begrenzt die Entscheidungen von inländischen (bzw. ausländischen) Unternehmen und Privatpersonen wider, im Ausland (bzw. im Inland) mit der Absicht der Kontrolle Realkapital zu bilden. Einerseits unterschätzen, andererseits überschätzen die in den Zahlungsbilanzstatistiken $^{293}$ ausgewiesenen Direktinvestitionsströme das Ausmaß an Investitionen von Inländern im Ausland (bzw. von Ausländern im Inland). ${ }^{294}$

Da die Stromgrößen für Direktinvestitionen als Bruttodirektinvestitionen nur solche - mit der Absicht, Kontrolle auf das kapitalnehmende Unternehmen auszuüben, durchgeführte - Kapitalanlagen im Ausland berücksichtigen, die mit einem Kapitalexport des kapitalgebenden Landes verbunden sind, wird das Ausmaß an während eines bestimmten Zeitraums tatsächlich durchgeführten Direktinvestitionen unterschätzt. Dies gilt auch dann, wenn für die in den Tochtergesellschaften einbehaltenen Gewinne fiktive Transaktionen unterstellt werden. Zahlungsbilanzdaten für Direktinvestitionen messen grenzüberschreitende Finanzierungsströme. Infolge der einschränkenden Definition von Direktinvestitionen als bestimmte Form internationaler Kapitalbewegungen werden als Direktinvestitionen nur solche Investitionen erfaßt, wenn der Direktinvestor die Finanzierungsmittel selbst aufbringt. Direktinvestitionen, die nicht mit einem grenzüberschreitenden Kapitaltransfer zwischen dem Wohnsitzland der Muttergesellschaft und dem Belegenheitsland des Direktinvestitionsunternehmens verbunden sind, bleiben unberücksichtigt. D. h., in den Stromgrößen für Direktinvestitionen nicht enthalten sind Investitionen, die eine bereits bestehende Tochtergesellschaft durch Kreditaufnahme in ihrem Sitzland, durch Kreditaufnahme bei nicht-verbundenen Ausländern im Wohnsitzland ihrer Muttergesellschaft oder in einem Drittland oder durch Ausgabe von Zusatzaktien selbst finanziert. Zu den Gründen, warum die für die Durchführung einer Direktinvestition erforderlichen Geldmit-

292 Die Begründung für die Bundesrepublik Deutschland (vgl. S. 138 f.) gilt analog für andere Statistiken.

293 Entsprechendes gilt fïr die Transferstatistik des BMWi.

294 Zum folgenden vgl. auch Boskin/Gale (1987, S. 204 f.), Hartman (1981, S. 3 und S. 26 f. Fn. 3; 1984, S. 486 Fn. 1) und Slemrod (1990, S. 83), v. a. aber Jun (1990, S. 62 ff.). 
tel im Zielland der Direktinvestition oder in einem Drittland aufgebracht werden, zählen u. a. Ausnutzung der infolge unvollkommener Kapitalmobilität bestehenden internationalen Zinssatzdifferenzen, Vermeidung des Wechselkursrisikos, steuerliche Gründe und institutionelle Gründe wie nicht bestehende oder nicht funktionsfähige Kapitalmärkte und Kapitalverkehrskontrollen.

Die jährlichen Erhebungen des U.S. Department of Commerce-Bureau of Economic Analysis über Erwerb oder Errichtung neuer Tochtergesellschaften in den USA zeigen: Neue Tochtergesellschaften in den USA werden dem Volumen nach in erster Linie von bereits bestehenden US-amerikanischen Tochtergesellschaften erworben oder errichtet; die Mittel dafür bringen die bereits bestehenden US-Tochtergesellschaften zum großen Teil selbst auf. Im Berichtsjahr 1991 finanzierten die Mitglieder der "foreign parent group“ direkt nur $58 \%$ aller Investitionsausgaben für Erwerb oder Errichtung neuer Tochtergesellschaften in den USA (1990: 49,3\%); die restlichen Mittel brachten die bestehenden USTochtergesellschaften selbst durch Kreditaufnahme im In- und Ausland sowie durch intern erzeugte Mittel auf. Zwischen den Ländern (Zuordnung nach den eigentlichen wirtschaftlichen Eigentümern der US-amerikanischen Tochtergesellschaften), zwischen den Industriezweigen und innerhalb eines Landes bzw. Wirtschaftszweiges im Zeitablauf sind dabei große Unterschiede festzustellen. ${ }^{295} \mathrm{Zu}$ beobachten ist auch, daß Unternehmensübernahmen vollständig oder weitgehend durch im Zielland der Direktinvestition aufgebrachte Mittel finanziert werden. ${ }^{296}$

Darüber hinaus enthalten die Daten für Direktinvestitionen auch nicht die Mittel von Investoren, deren Kapitalbeteiligungen an Unternehmen im Ausland infolge Unterschreitung der zur statistischen Abgrenzung von Direktinvestitionen und Portfolioinvestitionen zugrunde gelegten Mindestbeteiligungshöhe als Portfolioinvestitionen erfaßt werden; diese Investoren können aber durchaus auch, z. B. durch Beteiligung im Vorstand oder im Aufsichtsrat, Einfluß auf die Geschäftstätigkeit des gebietsfremden Unternehmens nehmen.

Die in der Zahlungsbilanzstatistik ausgewiesenen Stromgrößen für Direktinvestitionen überschätzen die von Inländern im Ausland (bzw. von Ausländern im Inland) getätigten Anlageinvestitionen in dem Ausmaß, in dem die Transfers von den Muttergesellschaften an ihre Tochterunternehmen nicht zum Erwerb von Sachkapital verwendet werden.

Die statistisch ermittelten ausländischen Nettodirektinvestitionen im Inland unterscheiden sich von inländischen Nettoanlageinvestitionen im Sinne der VGR auch insofern, als

295 Der von Mitgliedern der „foreign parent group“ zur Verfügung gestellte Anteil an den Investitionsausgaben für Erwerb oder Errichtung neuer Direktinvestitionsunternehmen in den USA von deutschen eigentlichen wirtschaftlichen Eigentümern war im Jahr 1990 mit $48 \%$ durchschnittlich und im Jahr 1991 mit $85 \%$ überdurchschnittlich hoch. Vgl. Fahim-Nader (1992c, S. 76 f.).

296 Vgl. hierzu z. B. Bach (1991, S. 55), Krueger $(1987$, S. 36) und OECD $(1987$, S. 11). 
letztere die Differenz zwischen Bruttoanlageinvestitionen und Abschreibungen sind. Nettodirektinvestitionen dagegen werden berechnet als Neuanlagen abzüglich Liquidationen. Abschreibungen gehen in die Nettodirektinvestitionen höchstens indirekt über die reinvestierten Gewinne ein. Sofern die nicht-ausgeschütteten Gewinne in den Direktinvestitionen enthalten sind, stellen die Nettodirektinvestitionen zwar eine Art von Nettostromgrößen dar, ${ }^{297}$ aber anders als bei den inländischen Nettoanlageinvestitionen werden bei den reinvestierten Gewinnen nicht ökonomische, sondern in den Bilanzen berücksichtigte Abschreibungen zugrunde gelegt. ${ }^{298}$ Die Liquidationen spiegeln in einigen Ländern - so z. B. in den USA - nicht nur den Rückgang oder die Auflösung von Anlageinvestitionen wider, sondern sie enthalten auch die Kredite der Tochtergesellschaften an ihre Muttergesellschaften. Wenn diese Kredite der Direktinvestitionsunternehmen jedoch die Folge mittelbarer Kreditaufnahme der Muttergesellschaften im Ausland sind, dann unterschätzen die ausgewiesenen Nettodirektinvestitionen die inländischen (bzw. ausländischen) Nettoanlageinvestitionen im Ausland (bzw. Inland). Im Unterschied zu inländischen Nettoanlageinvestitionen sind ausländische Nettodirektinvestitionen im Inland nicht unbedingt mit einer Erweiterung des gesamtwirtschaftlichen Produktionspotentials verbunden. Nur bei Errichtung neuer Tochtergesellschaften und bei Erweiterung bestehender Direktinvestitionsunternehmen werden produktive Anlagen aufgebaut. Übernahmen bereits bestehender Unternehmen und Beteiligungserwerb an solchen Unternehmen ändern unmittelbar nur die Eigentumsverhältnisse; sie haben kurzfristig keinen, möglicherweise aber längerfristig einen Kapazitätseffekt. ${ }^{299}$ Aus den genannten Gründen, aber auch wegen Unterschieden in bezug auf Erhebungsmethoden, Bewertungsvorschriften und Einfluß der Wechselkursentwicklung sind die in der Zahlungsbilanzstatistik für ausländische Direktinvestitionen im Inland ausgewiesenen Daten nur begrenzt vergleichbar mit den im Rahmen der VGR für inländische Nettoanlageinvestitionen ermittelten Daten.

Darüber hinaus ist in einzelnen Ländern das Inland in Zahlungsbilanzstatistik und VGR regional nicht einheitlich abgegrenzt. Dadurch entsteht für Zeitreihen- und für Querschnittsanalysen das Problem, daß in den Schätzgleichungen u. U. Daten, die sich auf unterschiedliche Gebiete beziehen, gemischt werden. Denn die exogenen Variablen werden in der Regel der VGR (oder anderer statistischer Quellen, deren Abgrenzung des Inlands

297 Langkau et al. (1989, S. 65 ff.) verwenden in ihrer Querschnittsanalyse zum Einfluß der Besteuerung auf Direktinvestitionen als abhängige Variable den Anteil der Direktinvestitionen des Auslands in einem bestimmten Land an den gesamten Bruttoinvestitionen dieses Landes abzüglich der Investitionen des Staates und des Wohnungsbaus. In bezug gesetzt werden also die ausländischen Nettodirektinvestitionen im Inland nicht mit den inländischen Nettoanlageinvestitionen, sondern mit den inländischen Bruttoinvestitionen.

$298 \mathrm{Zu}$ den Abschreibungen in VGR und Steuerrecht in der Bundesrepublik Deutschland vgl. Wesselbaum-Neugebauer (1992, S. 8 f.).

299 Dieckheuer (1990, S. 12 f.) bezeichnet die Kapitalanlagen, bei denen unmittelbar zusätzliche Investitionsnachfrage im Sinne der VGR entsteht, als additive Direktinvestitionen, die anderen als substitutive Direktinvestitionen. 
derjenigen der VGR folgt) entnommen. Bei normierten Daten für Direktinvestitionen bzw. bei Direktinvestitionsintensitäten stehen in diesen Fällen in Zähler und Nenner Größen, die sich auf unterschiedliche Gebiete beziehen. ${ }^{300}$

Transaktionswerte für Direktinvestitionen in einem einzelnen Jahr sind häufig geprägt durch große Einzeltransaktionen, aber auch durch Sondereinflüsse. Darüber hinaus sind auch die Transaktionswerte nicht unabhängig von der Entwicklung der Wechselkurse. Anders als Erweiterungsinvestitionen, und mit Einschränkung auch der Erwerb zusätzlicher Kapitalanteile an bereits bestehenden Unternehmen, sind Unternehmensübernahmen unteilbar. Da der Kaufbetrag auf einmal anfällt, haben Unternehmensübernahmen, u. U. aber auch der Erwerb zusätzlicher Anteile zur Aufstockung auf 100\%ige Beteiligungen, einen großen Einfluß auf die für Direktinvestitionen ausgewiesenen Kapitalströme. ${ }^{301}$ So entfallen beispielsweise 2,1 Mrd. DM von den in der Zahlungsbilanzstatistik der Deutschen Bundesbank im Jahre 1988 ausgewiesenen Liquidationen von US-amerikanischen Kapitalanteilen in der Bundesrepublik in Höhe von 5,9 Mrd. DM auf die Übernahme der von der US-amerikanischen Texaco gehaltenen 99,1244\%igen Beteiligung an der Deutschen Texaco AG, Hamburg, durch die Rheinisch-Westfälische Elektrizitätswerk AG (RWE), Essen. ${ }^{302}$ Im Jahre 1990 stehen über $37 \%$ aller japanischen Direktinvestitionen in den USA im Zusammenhang mit der bis dahin größten Einzeltransaktion eines japanischen Konzerns in den USA; Matsushita übernahm für 6,5 Mrd. US-\$ das Universal Studio in Hollywood. ${ }^{303}$ Sondereinflüsse - z. B. staatliche Reprivatisierungsprogramme, wie sie Mitte der 80er Jahre in Großbritannien und in Frankreich zu beobachten waren, ${ }^{304}$ oder befristete Steueranreize - können zu einem Aufschub oder zu einem zeitlichen Vorziehen von Investitionsvorhaben führen und (Direkt-)Investitionsströme temporär umlenken. Eine empirische Analyse der Determinanten von Direktinvestitionen müßte auch berücksich-

$\overline{300}$ Die empirischen Studien zum EinfluB der Besteuerung auf Direktinvestitionen, die das Modell von Hartman modifizieren, verwenden - dem Vorgehen von Hartman $(1981 ; 1984)$ folgend - als erklärende Variable das Verhältnis von ausländischen Direktinvestitionen in den USA zum BSP in den USA bzw. das Verhältnis von US-amerikanischen Direktinvestitionen im Ausland zum BSP in den USA. Hartman begründet seine Vorgehensweise mit der besseren Vergleichbarkeit der Ergebnisse mit den empirischen Studien zu den Determinanten von inländischen Investitionen; vgl. hierzu Hartman (1981, S. $13 ; 1984$, S. 479).

301 Das U.S. Department of Commerce-Bureau of Economic Analysis weist in seinen vierteljährlichen bzw. jährlichen Analysen der Entwicklung der US-Zahlungsbilanzstatistik bzw. der Nettoauslandsposition der USA, ähnlich wie die Deutsche Bundesbank, regelmäßig auf große, namentlich allerdings nicht genannte Einzeltransaktionen hin. Vgl. hierzu z. B. Bach (1989, S. 32 f.; 1990, S. 44 ff.; 1991, S. 37 und 47 ff.; 1992, S. 56 und 71), DiLullo (1990, S. 34 f.), Krueger (1989, S. 55 f.), Murad (1989, S. 26 f.), Nicholson (1990, S. 70 f.), Scholl (1990, 62 ff.; 1991, S. 30 ff.), Scholl et al. (1992, S. 56 ff.) und Deutsche Bundesbank (1972, S. 28; 1974, S. 24; 1989a, S. 33; 1991b, S. 34).

302 Die RWE AG brachte im Jahr 1989 diese Beteiligung in eine neugegründete Tochtergesellschaft, die RWE-DEA AG für Mineralöl und Chemie, Hamburg, ein; vgl. o.V. (1988).

303 Zur Übernahme der Music Corporation of America, der Muttergesellschaft der Universal Studios, durch den japanischen Elektronikkonzern Matsushita vgl. Hauch-Fleck (1991).

$304 \mathrm{Vgl}$. hierzu z. B. Erbe et al. (1991, S. 78 ff. und S. 84 ff.) und Julius/Thomsen (1988). 
tigen, daß es für die Direktinvestitionen in Form von Kapitalerhöhungen bei Tochtergesellschaften von Kreditinstituten teilweise auch institutionelle Gründe gibt, und zwar dann, wenn den Kreditinstituten ein bestimmtes Verhältnis zwischen Kreditvolumen und Eigenmitteln vorgeschrieben ist. ${ }^{305}$

Die bei der Rückführung der im Ausland erzielten Gewinne an die Muttergesellschaften anzuwendende Methode zur Vermeidung bzw. Verminderung der Doppelbesteuerung und damit die Gesamtsteuerbelastung hängt u. a. ab von der Rechtsform der Tochtergesellschaft. Die verfügbaren Daten für Direktinvestitionen trennen jedoch nicht zwischen körperschaftlich und nicht-körperschaftlich organisierten Direktinvestitionsunternehmen. Auch aus diesem Grunde ist eine quantitative Analyse des Einflusses der Besteuerung auf internationale Standortentscheidungen auf der Grundlage des verfügbaren, aggregierten Datenmaterials nicht möglich.

Für die Direktinvestitionen nach Ziel- und nach Herkunftsländern werden in der Regel nur Nettostromgrößen ausgewiesen, nicht aber disaggregierte Werte für Neuanlagen und für Liquidationen. $^{306}$ Transaktionen zwischen Ausländern, z. B. die Übernahme eines deutschen Direktinvestitionsunternehmens durch einen Investor aus Land A von einem Investor aus Land B, spiegeln sich nicht in den ausländischen Direktinvestitionen im Inland nach Herkunftsländern wider. Darüber hinaus stehen keine getrennten Daten für die Aktivitäten von Direktinvestoren mit Nettodirektinvestitionen und solchen mit Nettodisinvestitionen zur Verfügung. In den insgesamt für Nettodircktinvestitionen ausgewiesenen Daten werden beide Typen von Investoren saldiert. Durch die Verwendung von Nettostromgrößen als erklärende Variable in Schätzgleichungen unterstellt man, daß dic Determinanten von Neuanlagen und von Disinvestitionen symmetrisch sind. ${ }^{307}$ Es wird also durch diese Annahme von Anfang an ein Teil des Untersuchungszieles als Frgebnis vorausgesetzt. Die Symmetrieannahme impliziert eine hohe Mobilitāt von Direktinvestitionen. Eine bereits umgesetzte Standortentscheidung ist kurzfristig aber nur unter Inkaufnahme von sunk cost revidierbar.

Einer empirischen Überprüfung des Einflusses der Besteuerung auf Direktinvestitionen steht auch entgegen, daß in den ausgewiesenen Daten für Direktinvestitionen teilweise als Herkunfts- bzw. als Zielland Staaten mit unterschiedlichen Steuersystemen zusammengefaßt werden. So wird z. B. Monaco sowohl in der französischen als auch in der bundesdeutschen Zahlungsbilanzstatistik unter Frankreich erfaßt; getrennte Daten für Belgien und

305 Vgl. hierzu Deutsche Bundesbank (1982a, S. 44).

306 In der Zahlungsbilanzstatistik der Deutschen Bundesbank sind die USA das einzige Land, für das Neuanlagen und Liquidationen getrennt ausgewiesen werden; für alle anderen Länder stehen nur Nettostromgrößen zur Verfügung. Vgl. hierzu z. B. Deutsche Bundesbank (1992b, S. 34 ff.).

307 Diese Annahme wird meist nur implizit getroffen; anders z. B. Culem (1988, S. 887). Zur Symmetrieannahme vgl. Boddewyn (1983). 
für Luxemburg werden weder in der bundesdeutschen Zahlungsbilanzstatistik noch in der Zahlungsbilanzstatistik der Belgisch-Luxemburgischen Wirtschaftsunion veröffentlicht; in der bundesdeutschen Zahlungsbilanzstatistik umfaßt die Schweiz auch den badischen Zollausschluß Büsingen und das Fürstentum Liechtenstein.

Der anhand von US-amerikanischen Daten häufig in mehr oder weniger modifizierter Form getestete Ansatz von Hartman (1985) basiert auf der Unterscheidung zwischen Direktinvestitionen, die durch im Ausland einbehaltene Gewinne finanziert werden, und Direktinvestitionen, die durch Transfers von den Muttergesellschaften an ihre Tochtergesellschaften finanziert werden. Dieser Ansatz ist auf der Grundlage von deutschen Daten empirisch nicht überprüfbar. Denn zum einen sind die reinvestierten Gewinne erst seit dem Berichtsjahr 1977 regional aufteilbar, zum anderen werden sie nicht nach Ländern disaggregiert ausgewiesen, so daß für einzelne Länder keine Unterscheidung zwischen den durch Transfers und den durch reinvestierte Gewinne finanzierten Direktinvestitionen möglich ist.

Auffällig an den bisher durchgeführten Zeitreihen- und Querschnittsanalysen zum Einfluß der Besteuerung auf Direktinvestitionen ist der meist äußert geringe Stichprobenumfang. Die Ergebnisse stützen sich beispielsweise bei Langkau et al. (1989) auf 13 und bei Hartman $(1981 ; 1984)$ auf 15 Beobachtungen; auch in den anderen Studien ist der Stichprobenumfang stets kleiner als 30 Beobachtungen. Bei der Interpretation der Ergebnisse bleiben die Auswirkungen des geringen Stichprobenumfangs auf die Aussagekraft der Signifikanztests unberücksichtigt. ${ }^{308}$

Standortentscheidungen beruhen auf den erwarteten Rahmenbedingungen. Da erwartete Größen nicht beobachtbar sind, werden realisierte Größen - in der Regel implizit ${ }^{309}$ - als Proxy für diese verwendet. Ein Versuch, die Erwartungsbildung zu modellieren, ist bisher noch nicht unternommen worden. Für aggregierte Daten wird dies auch nicht gelingen, denn Investitionsentscheidungen dürften auf der Gesamtrentabilität eines multinationalen Unternehmens beruhen, also auf einer unternehmensspezifischen Größe.

Die Umsetzung von Investitionsabsichten in konkrete Investitionspläne und ihre anschlie-

308 Weitgehend unbekannt scheinen den Autoren auch die Verfahren zu sein, mit denen getestet wird, ob die für das verwendete ökonometrische Verfahren erforderlichen Voraussetzungen auch erfüllt sind. Vgl. hierzu z. B. die Auseinandersetzung zwischen Young $(1988 ; 1989)$ und Murthy (1989). Eine ausführliche Darstellung der Testverfahren für mittels der Methode der kleinsten Quadrate geschätzter Modelle geben Krämer/Sonnberger (1986). Zur Bedeutung von Spezifikationstests vgl. Krämer et al. (1985).

309 Young (1988) weist explizit darauf hin, daB er realisierte Größen als Proxy für die nicht beobachtbaren erwarteten Steuersätze und Ertragsraten verwendet. Er begründet diese Vorgehensweise mit dem Argument, "to simplify the analysis and to facilitate comparisons with other studies." (Young 1988, S. 110). 
Bende Realisierung benötigt in der Regel mehrere Jahre. Diese time lags werden in den empirischen Studien entweder gar nicht berücksichtigt oder die zeitliche Verzögerung wird simultan mit dem Schätzansatz durch „trial and error" getestet. Stehn (1992, S. 88 f.) sieht in der Kumulierung von Stromgrößen für Direktinvestitionen über drei bis vier Jahre einen Ausweg. Mit dieser endogenen Variablen würden die Verzerrungen der Schätzergebnisse infolge crratischer Schwankungen der Direktinvestitionen in einem Jahr weitgehend vermieden und der zu erwartende time lag zwischen Änderungen der Rahmenbedingungen und der Durchführung der Investition erfaßt. Im Zusammenhang mit exogenen Variablen. die sich auf einen Zejtpunkt beziehen - wie beispielsweise internationale Körperschafisteuersatzdifferentiale - stellt diese Vorgehensweise keine Lösung dar. Außerdem können sich die Determinanten für Direktinvestitionen in Form von Erweiterungen bestehender Tochtergesellschaften und in Form von Errichtung von Fertigungsstätten. Verkaufs- und Servicebetrieben an einem neuen Standort durchaus unterscheiden, aber dies ist empirisch nicht überprüfbar, denn die hierfür notwendigen disaggregierten Daten stehen nicht zur Verfügung.

Finige empirische Arbeiten zum Finfluß von Steuern auf Direktinvestitionen tragen der Tatsache, daß die statistisch ausgewiesenen Direktinvestitionen wegen Unterschieden in bezug auf Frhebungsmethode, auf dic $\Lambda$ bgrenzung von Dircktinvestor, Direktinvestitionsunternehmen sowic Direktinvestitionskapital und auf die verwendeten Schätzverfahren international und auf nationaler Fbene teilweise auch intertemporär nicht vergleichbar sind Rechnung durch dic Aufnahme von Dummy-Variablen in die Schätzgleichung. Dabei wird in der Regel unterstellt, daß Unterschiede in den Erfassungsmethoden zwischen Ländern bzw. in einem bestimmten Land im Zeitablauf mit einer Niveauverschiel)ung bei Strukturkonstanz verbunden sind.

Auf der Grundlage der zur Verfügung stehenden aggregierten Daten für Direktinvestitionen ist es nicht möglich zu zeigen, ob zwischen internationalen Standortentscheidungen von Unternehmen und der Besteuerung von Unternehmensgewinnen ein Zusammenhang besteht. 
Otto Roloff, Sibylle Brander, Ingo Barens and Claudia Wesselbaum - 978-3-631-75210-4 Downloaded from PubFactory at 01/11/2019 07:04:40AM via free access 


\section{Kapitel 5:}

\section{Steuersätze im internationalen Vergleich}

Prinzipiell können im Rahmen der vorliegenden internationalen Steuerbelastungsvergleiche drei Vorgehensweisen zur Ermittlung von Steuersätzen unterschieden werden:

Die Berechnung auf Basis der Daten der Volkswirtschaftlichen Gesamtrechnung (VGR) betrachtet das Problem der differierenden Steuersysteme in den Mitglicdstaaten der EG aus finanzwissenschaftlicher Perspektive. Anhand der Daten der Volkswirtschaftlichen Gesamtrechnung soll ein Durchschnittsteuersatz aller Unternehmen in cinem Staat als Verhältnis von Unternehmensteucrn zu Bruttoeinkommen aus Unternehmertätigkeit und Vermögen ermittelt werden. Der durchschnittliche Steuersatz gibt danach die Belastung des Unternehmenssektors wieder, d. h. sowohl die Steuerlast der Unternehmen, die steuerpflichtige Gewinne erzielen als auch solcher Unternehmen, die das Wirtschaftsjahr mit Verlusten beenden und keine Ertragsteuern zu leisten haben. Die insbesondere für Investitions- und Standortentscheidungen relevante Steuerbelastung einzelner Unternehmen oder Branchen kann mit Iilfe der Daten der Volkswirtschaftlichen Gesamtrechnung nicht. dargelegt werden. ${ }^{1}$ Hinzu kommt, daß in verschiedenen Ländern die Sozialabgaben nicht gesondert erhoben, sondern durch die direkten und indirekten Steucrn finanzicrt werden. Die für die unternehmerische Investitionsentscheidung relevante $\Lambda$ bgabenbelastung des Unternehmensgewinns kann aufgrund der Interdependenz von direkten und indirekten Steuern sowie staatlichen und unternehmerischen Sozialleistungen nicht für jedes Land bestimmt werden. ${ }^{2}$ Für die unternchmerische Investitionspolitik stellt der gesamtwirtschaftliche Durchschnittsteuersatz daher keine entscheidungsrelevante Größe dar.

Im Rahmen des Tarifvergleichs werden die das Unternehmen belastenden Stcucrarten herausgegriffen ( Unternehmensteuern ${ }^{4}$ ), die sich hierfür aus den nationalen Gesetzen ergebenden Steuersãtze addiert und so die formale Grenzsteucrbelastung für ein Unternehmen und, teilweise, deren Aktionäre des betrachteten Staates ermittelt. Der marginale Steuersatz zeigt an, mit welchem Prozentsatz der Grenzertrag/-verlust be- oder entlastet wird. Dieser Tarif wird daher hauptsächlich bei Investitionsentscheidungen verwendet. ${ }^{3}$ Die Abzugs- bzw. Nichtabzugsfähigkeit bestimmter Steuern als Betriebsausgabr und ihr Finfluß auf dic Grenzsteuerbelastung wird dabei beachtet. Unberücksichtigt bleiben jedoch dic national differierenden Gewinnermittlungsvorschriften zur Frmittlung der steucrpflichtigen Bemessungsgrundlage von Kapitalgesellschaften sowic die bei der Einkommens-

1 Vgl. Inst.itut der deutschen Wirtschaft (1989, S. 4-5).

2 Vgl. Schöne (1976, S. 399).

3 Vgl. Spooner (1986, S. 293). 
beste'uerung der Aktionäre bzw. Eigner zu berücksichtigenden persönlichen Verhältnisse, z. B. Familienstand. ${ }^{4}$

Bei der Vrranlagungssimulation werden neben den formalen Steuersätzen auch die Bemessungsgrundlagen der betrachiteten Länder mit in die Vergleichsrechnungen einbezogen. Dies geschieht durch die Veranlagung eines repräsentativen Unternehmens nach den geltenden Steuergesetzen des Sitzstaates. Die sich aus der Multiplikation der steuerlichen Bemessungsgrundlage mit dem nominalen Steuersatz ergebende inländische Steuerbelastung wird dividiert durch ein korrigiertes Unternehmenseinkommen (ökonomischer Gewinn). ${ }^{5}$ Der ermittelte durchschnittliche effektive Steuersatz gibt für das jeweilige Land die Distribution der steuerlichen Bemessungsgrundlage ${ }^{6}$ und den aus früheren Investitionen resultierenden Liquiditätsentzug durch den Fiskus wieder. ${ }^{7}$ Der auf Vergangenheitsdaten basierende durchschnittliche effektive Steuersatz enthält jedoch keine Information über den Einfluß steuerlicher Vergünstigungen (z. B. erhöhte Abschreibungen, Investitionszulagen) auf zukünftige Investitionsentscheidungen. ${ }^{8}$ Damit allokationsverzerrende Wirkungen des Steuersystems dargelegt werden können, ist es erforderlich, den durchschnittlichen effektiven Grenzsteucrsatz zu ermitteln. ${ }^{9}$ Der Grenzsteuersatz ist definiert, als die Differenz, zwischen der erwarteten marginalen Rendite eines Unternehmens vor St.cucrn und des einem Kapitalgeber nach Abzug aller Steuern verbleibenden Frtrages, dividiert durch die erzielte Rendite vor Steuern eines Unternehmens. ${ }^{10}$ Die Rendite einer Grenzinvestition wird kalkuliert unter Berücksichtigung der ökonomischen Abschreibung, erwarteter Inflationsraten und der Kapitalkosten, welche durch die Finanzierungsform determiniert werden. Der zu berücksichtigende Steuersatz beinhaltet die national und lokal erhobenen Unternehmensteuern sowie die auf Kapitaleinkünfte und Wertzuwächse zu lcistende Steuer eines Kapitaleigners. ${ }^{11}$ Der durchschnittliche effektive Grenzsteuersatz „... measures the combined incentives of all investors to undertake a marginal investment financed by a mix of debt and equity. It can be used to measure misallocations of capital as well as intertemporal distortions. It can be used to isolate the net impact of each tax instrument." 12

In folgenden wird aul die genannten Untersuchungsmethoden näher eingegangen.

\footnotetext{
4 Vgl. Neumark (1969, o. S.).

5 Vgl. Fullerton (1984, S. 25), o. V. (1982, S. 567), Seidel et, al. (1989, S. 79 ff.).

6 Vgl. Gravelle (1985, S. 103 f.), McDaniel (1985, S. 274).

7 Vgl. Spooner (1986, S. 293), Littmann (1989, S. 129).

* Vgl. Fullerton (1984, S. 23), Spooner (1986, S. 294).

9 Vgl. Fullertion et. al. (1982, S. 581).

$10 \mathrm{Vgl}$. Bradford/Stuart (1986, S. 308), Jorgenson/Yun (1991, S. 110), Fullerton (1984, S. 25), King/liullerton (1984, S. 9).

11 Vgl. Foldst.cin rt. al. (1983, S. 135 fr.), Fullert.on (1984, S. 23 f.), Gravelle (1985, S. 104), McDaniel (1985, S. 274 ff.), Spooner (1986, S. 293 ff.).

12 Fullert.on (1985, S. 109).
} 


\subsection{Berechnungen auf Basis der Daten der Volkswirtschaftlichen Gesamt- rechnung ${ }^{13}$}

Bei der Berechnung des Durchschnittsteuersatzes auf Basis der Daten der Volkswirtschaftlichen Gesamtrechnung (VGR) ergeben sich erhebliche methodische Probleme. Die bundesdeutsche Volkswirtschaftliche Gesantrechnung stellt z. B. die zur Durchführung der Berechnung benötigten speziellen Daten über das Bruttoeinkommen aus Unternehmertätigkeit und Vermögen von Kapitalgesellschaften sowie die von ihnen entrichteten Unternehmensteuern nicht zur Verfügung. Das in der Volkswirtschaftlichen Gesamtrechnung ausgewiesene Bruttoeinkommen aus Unternehmertätigkeit und Vermögen beinhaltet die Daten aller Unternehmen, welche vorwiegend Waren und Dienstleistungen produzieren bzw. erbringen und diese gegen Entgelt, veräußern. Hierzu zählen auch landwirtschaftliche Betriebe, Kreditinstitute, Handwerkshetriebe, Praxen der Freien Berufe, die nichtgewerbliche Wohnungsvermietung einschließlich der Nutzung von Eigentümerwohnungen, die Deutsche Bundesbahn, die Deutsche Bundespost und sonstige Unternehmen, die sich im Eigentum des Staates befinden. ${ }^{14}$ Für die Ermittlung des Durchschnittsteuersatzes ist es erforderlich, das Bruttoeinkommen aus Unternehmertätigkeit und Vermögen urn die tatsächlichen und unterstellten Einkommen dieser Unternehmen zu korrigieren und den sich ergebenden Restbetrag auf die der Körperschaftsteuer unterliegenden Gesellschaften mit eigener Rechtspersönlichkeit und die der Einkommensteuer unterliegenden Einzelunternehmen bzw. Personengesellschaften aufzugliedern. Aufgrund des konzeptionellen Aufbaus der Volkswirtschaftlichen Gesamtrechnung kann lediglich der unverteilte Nettogewinn der Unternehmen mit eigener Rechtspersönlichkeit aufgezeigt werden. Die für die Berechnung der Steuerbelastung benötigte Information über den von der Kapitalgesellschaft zu versteuernden Gewinn, kann der Volkswirtschaftlichen Gesamtrechnung nicht entnommen werden. ${ }^{15}$ Die in der Abbildung A 1 genannten Ergebnisse geben daher nicht die durchschnittliche Steuerbelastung von Kapitalgesellschaften sondern des gesamten Unternehmenssektors wieder, d. h. der gewerblich tätigen Einzelunternehmer, der gewerblichen Personengesellschaften und der Kapitalgesellschaften.

Neben der Bereinigung der Ausgangsdaten stellt sich für die Untersuchenden auch das Problem, daß aufgrund der speziellen Aussageziele der Volkswirtschaftlichen Gesamtrechnung die verwendeten Definitionen inhaltlich von den in der Steuerbilanz angewandten Begriffsbestimmungen abweichen. ${ }^{16}$ Bei der Berechnung der Abschreibungen wird in der bundesdeutschen Volkswirtschaftlichen Gesamtrechnung z. B. vom Prinzip der realen Ka-

${ }^{13}$ Dieser methodische Ansatz wurde von Littmann (1988), Matthäus-Maier (1988) und dem Institut der deutschen Wirtschaft (1989) gewählt.

14 Vgl. Statistisches Bundesamt (1990, S. 47).

15 Vgl. Statistisches Bundesamt (1990, S. 32 und 50 f.).

16 Vgl. Institut der deutschen Wirtschaft (1989, S. 4-5). 
pitalerhaltung ausgegangen, d. h. die Abschreibungen werden grundsätzlich linear von den Wiederbeschaffungspreisen ${ }^{17}$ berechnet. ${ }^{18}$ Im Steuerrecht wird hingegen von dem Prinzip der nominellen Kapitalerhaltung (Nominalwertprinzip) ${ }^{19}$ ausgegangen, wobei unterschiedliche Abschreibungsmethoden zulässig sind. ${ }^{20}$ Weitere Differenzen ergeben sich aus der unterschiedlichen Behandlung von geringwertigen Wirtschaftsgütern (GWG), ${ }^{21}$ von umfangreicheren Instandhaltungsarbeiten ${ }^{22}$ sowie der um Scheingewinne und -verluste bereinigten Bewertung der Vorratsänderungen. ${ }^{23}$ Das in der Volkswirtschaftlichen Gesamtrechnung ausgewiesene Bruttoeinkommen aus Unternehmertätigkeit und Vermögen kann somit sowohl positiv als auch negativ von dem in der Steuerbilanz ausgewiesenen Gewinn abweichen.

Fin weiteres methodisches Problem ergibt sich aus dem Tatbestand, daß das im Rahmen der volkswirtschaftlichen Gesamtrechnung ausgewiesene Steueraufkommen nicht identisch ist mit der Steuerbelastung der Unternehmen im Wirtschaftsjahr der Veranlagung. Während die Volkswirtschaftliche Gesamtrechnung das kassenmäßig zugeflossene Steuerergebnis wiedergibt, d. h. Steuervorauszahlungen, - abschlußzahlungen sowie -nachzahlungen beinhaltet, müßte dem Unternehmensgewinn die Steuerzahlung gegenübergestellt werden, die sich aufgrund der Veranlagung berechnet. Für diesen Zweck gliedert die bundesdeutsche Volkswirtschaftliche Gesamtrechnung das Steueraufkommen der Unternehmen jedoch nicht genügend auf. ${ }^{24}$ Des weiteren fehlt eine rechtsformabhängige Spezifizierung der sowohl von den natürlichen als auch juristischen Personen zu leistenden Steuerarten (Gewerbesteuer, Vermögensteuer auf das Betriebsvermögen), so daß sich Schwierigkeiten bei der rechtsformabhängigen Zurechnung des Steueraufkommens ergeben.

Im Rahmen der internationalen Steuerbelastungsvergleiche bestehen aufgrund der national divergierenden Gesetzesbestimmungen hinsichtlich der Körperschaftsteuerpflicht und des bei der Besteuerung einzubeziehenden Einkommens zusätzliche Probleme. In Frankreich können z. B. auch Personengesellschaften für die Körperschaftbesteuerung

17 Die ursprünglichen Anschaffungskosten werden um die zwischenzeitlich eingetretenen Preisveränderungen korrigiert. "Aus volkswirtschaftlicher Sicht sollen die Abschreibungen den Werteverzehr erfassen, der reinvestiert werden müßte, um das Anlagevermögen in seinem realen Wert zu erhalten." Haslinger (1990, S. 60).

18 Vgl. Haslinger (1990, S. 60), Statistisches Bundesamt (1990, S. 53 und 76).

19 Die Abschreibungen können nur von den ursprünglichen Anschaffungskosten berechnet werden.

20 Vgl. Stobbe (1972, S. 40 f.), Perridon/Steiner (1986, S. 296 f.).

21 Im Rahmen der Volkswirtschaftlichen Gesamtrechnung mindern die geringwertigen Wirtschaftsgüter als Vorleistung direkt den Gewinn, während sie in den Handels- und Steuerbilanzen als Anlageinvestition aktiviert und, entweder direkt oder über den Nutzungszeitraum verteilt, abgeschrieben werden können. Vgl. Statistisches Bundesamt (1990, S. 72).

22 Im Rahmen der Volkswirtschaftlichen Gesamtrechnung werden diese Reparaturen zu den Anlageinvestitionen gerechnet, während sie in der Unternehmensbilanz Betriebsausgaben darstellen. Vgl. Statistisches Bundesamt (1990, S. 72).

$23 \mathrm{Vgl}$. Statistisches Bundesamt (1990, S. 72).

24 Vgl. Statistisches Bundesamt (1990, S. 84). 
optieren. ${ }^{25}$ Bei einer Analyse müßte neben den bereits genannten Korrekturen eine weitere Berichtigung um die auf diese Personengesellschaften entfallende Körperschaftsteuer vorgenommen werden. Die bloße Gegenüberstellung des Körperschaftsteueraufkommens in der Bundesrepublik Deutschland und in Frankreich würde ohne Berücksichtigung dieses Punktes zu Fehlinterpretationen führen. Ebenso führt die unterschiedliche Abgrenzung des in einem Staat zur Steuer heranzuziehenden Einkommens nach dem Universal- oder Territorialprinzip ${ }^{26}$ zu einer abweichenden Steuerbemessungsgrundlage. Die sich hieraus ergebenden Differenzen können nur schwer eliminiert werden.

Die in der Abbildung A 1 ausgewiesenen Ergebnisse lassen somit lediglich vermuten, daß die Steuerbelastung der bundesdeutschen körperschaftsteuerpflichtigen Unternehmen nicht identisch ist mit der aufgrund von reinen Tarifvergleichen ermittelten Steuerlast. Daß die im Rahmen der Berechnung des durchschnittlichen Steuersatzes auftretenden methodischen Probleme nicht zu unterschätzen sind, zeigen die unterschiedlichen Ergebnisse.

\subsection{Tarifvergleich ${ }^{27}$}

Im Rahmen des Tarifvergleichs wird angenommen, daß die steuerliche Bemessungsgrundlage in allen betrachteten Nationen identisch ist. Der durch die Addition der gesetzlichen Tarife berechnete Grenzsteuersatz ist im Rahmen einer Investitionsentscheidung nur relevant, falls gewinnsteuerliche Wirkungen auftreten, z. B. zusätzliche Gewinne erwirtschaftet werden, ein Verlustausgleich vorgenommen werden kann oder die Inanspruchnahme von Abschreibungswahlrechten eine Gewinnverlagerung bewirkt. ${ }^{28}$ Beachtet werden muß jedoch, daß die Höhe des Grenzsteuersatzes nicht die Steuerbelastung des Unternehmens widerspiegelt, welche sich aus dem Produkt von Steuersatz und Bemessungsgrundlage ergibt. Unterschiede in der Abgrenzung der Bemessungsgrundlage und, in Systemen mit gespaltenem Körperschaftsteuertarif, alternative Gewinnverwendungsarten nehmen dabei neben dem Grenzsteuersatz einen gravierenden Einfluß auf die Höhe der Unternehmenssteuerbelastung. ${ }^{29}$

Untersuchungen von Hulten und Robertson (1985) haben z. B. gezeigt, daß der ame-

\footnotetext{
25 Vgl. Tillmanns (1989, S. 722).

${ }^{26}$ Im Rahmen des Universalprinzips wird das Welteinkommen bzw. das Weltvermögen des steuerpflichtigen Unternehmens zur Steuer herangezogen. Im Gegensatz hierzu beschränkt sich die Steuerpflicht des Unternehmens unter Anwendung des Territorialprinzips auf das im Inland bezogene Einkommen bzw. das dort belegene Vermögen. Vgl. Fischer/Warneke (1988, S. 40).

27 Dieser methodische Ansatz wurde von Boss (1988), Fuest/Kroker (1988), Fischer (1984) und Jacobs/Spengel (1992) gewählt.

${ }^{28} \mathrm{Vgl}$. Perridon/Steiner (1986, S. 80 f.).

29 Vgl. Perridon/Steiner (1986, S. 81).
} 
rikanische Grenzsteuersatz seit 1952 unter dem Durchschnittsteuersatz liegt. ${ }^{30}$ Der effektive Steuersatz auf den Grenzertrag einer früheren Investition kann über dem zu erwartenden Grenzsteuersatz der geplanten Investition liegen, da für die Neuinvestitionen erhöhte Abschreibungen sowie Investitionsbeihilfen gewährt werden. Gegebenenfalls sind zusätzliche Finanzierungskosten notwendig, welche die steuerliche Bemessungsgrundlage verringern. ${ }^{31}$ Es ist daher zunächst erforderlich, die durch die Investition verursachten Kosten im Hinblick auf ihre steuerliche Abzugsfähigkeit zu betrachten und die anvisierte Ausschüttungsquote des Unternehmens mit in die Berechnung einzubeziehen. Praktische Schwierigkeiten ergeben sich bei der Zuordnung des Beitrages der Investition zu den unterschiedlichen Steuerarten (Ertrag- und Substanzsteuern). ${ }^{32}$ Zur Umgehung dieses Problems behelfen sich die Untersuchenden im Rahmen der Tarifvergleiche mit der hypothetischen Annahme, daß die durch die Investition verursachten Kosten in den betrachteten Staaten eindeutig quantifizierbar sind. Die Auswirkungen auf die steuerliche Bemessungsgrundlage werden in den Ländern als identisch angenommen, wobei davon ausgegangen wird, daß eine einheitliche Definition des zu versteuernden Gewinns existiert. Somit bleiben die in den Mitgliedstaaten der Europäischen Gemeinschaft stark divergierenden steuerlichen Gewinnermittlungsvorschriften unberücksichtigt. Die Nichtbeachtung dieser wichtigen Regelungen wird dabei hauptsächlich mit der Komplexität der nationalen Steuergesetzgebungen begründet. ${ }^{33}$ Durch die Verfolgung einer gezielten Steuerpolitik und die Inanspruchnahme von Bewertungswahlrechten kann die steuerliche Belastung des Unternehmens jedoch ebenso beeinflußt werden wie durch die Höhe der Steuertarife. ${ }^{34}$

Die Ergebnisse der Steuerbelastungsvergleiche basieren zudem auf der Hypothese, daß die Kapitalgesellschaft ihren Gewinn in voller Höhe thesauriert; alternative Gewinnverwendungen werden nicht berücksichtigt. Betrachtet man jedoch das Ausschüttungsverhalten der Kapitalgesellschaften so ist weder die Vollausschüttung noch die Vollthesaurierung, sondern die teilweise Ausschüttung des Gewinns typisch. ${ }^{35}$

Die Anwendung des Schütt-aus-hol-zurück-Verfahrens ${ }^{36}$ kann z. B. in der Bundesrepublik Deutschland aufgrund der Körperschaftsteuersatzdifferenz von 14 Prozentpunkten kostengünstiger sein als die sofortige Gewinnthesaurierung. Aufgrund der Zustimmungspflicht aller Anteilseigner ist die volle Ausschüttung des Gewinns und die anschließende

\footnotetext{
30 Vgl. Fullerton (1984, S. 29 f.), Gravelle (1985, S. 104 f.).

$31 \mathrm{Vgl}$. Fullerton (1984, S. 38).

32 Vgl. Perridon/Steiner (1986, S. 81).

$33 \mathrm{Vgl}$. Fuest/Kroker $(1987$, S. 30).

$34 \mathrm{Vgl}$. Scheibe-Lange (1986, S. 776).

35 Vgl. Scheibe-Lange (1986, S. 775).

36 Der Gewinn wird zunächst in voller Höhe an die Anteilseigner ausgeschüttet, im Rahmen der individuellen Einkommenveranlagung versteuert und anschlieBend durch Wiedereinlage der Kapitalgesellschaft zugeführt.
} 
Rückführung der Dividende jedoch nur bei einer überschaubaren Anzahl von Gesellschaftern durchführbar. Für die Großzahl von Kapitalgesellschaften (insbesondere für Publikumsgesellschaften) ist das Verfahren nicht anwendbar. Die Vorteilhaftigkeit des Verfahrens ist zudem nur dann gegeben, wenn die Belastung der Anteilseigner in Höhe des individuellen Einkommensteuersatzes (plus Kirchensteuer) zuzüglich der durch die Wiedereinlage (Einlagenfinanzierung) entstehenden Kosten ${ }^{37}$ niedriger ist als die Steuerbelastung des Unternehmens bei sofortiger Thesaurierung des Gewinnes. ${ }^{38}$ Erfolgt die Rückführung des Gewinns durch die Gewährung eines Darlehens des Anteilseigners an die Kapitalgesellschaft, so sind die Bestimmungen des Bundesministers der Finanzen zu beachten. ${ }^{39}$

Ein weiterer neuralgischer Punkt ist, daß zur Ermittlung der deutschen Vermögensteuerbelastung der Einheitswert des Unternehmens in Abhängigkeit vom Gewinn festgelegt wird. Da keine Statistiken über das Verhältnis des Einheitswertes zum Gewinn vor Steuern existieren, liegt es im Ermessen der Untersuchenden, dieses Verhältnis festzulegen und somit die Steuerbelastung zu beeinflussen. ${ }^{40}$ Bei den Tarifvergleichen wird die Relation von Gewinn zum Einheitswert des Betriebes mit allgemein 1 : 10 angenommen. Nach Meinung von Littmann (1987) und Scheibe-Lange (1986) dürfte die Realität mit einer Bandbreite von $1: 4$ bis $1: 7$ einigermaßen zutreffend erfaßt sein.

Der anhand der nationalen Steuergesetze ermittelte formale Grenzsteuersatz stellt für den Investor keine Entscheidungshilfe dar, da die individuelle Ertrags- und Aufwandssituation des Unternehmens unberücksichtigt bleibt. Eine Orientierung an dem allgemeinen Grenzsteuersatz kann daher zu Fehlallokationen führen.

\subsection{Veranlagungssimulation}

Im Rahmen einer Veranlagungssimulation werden der nominale Steuertarif, die steuerliche Bemessungsgrundlage und der ökonomische Gewinn eines Unternehmens in den internationalen Steuervergleich einbezogen. Grundsätzlich lassen sich dabei zwei methodische Ansätze unterscheiden. Zum einen wird die Belastung eines repräsentativen Unternehmens betrachtet und dessen durchschnittlicher effektiver Steuersatz ermittelt. Zum ande-

\footnotetext{
37 Dies sind insbesondere die Gesellschaftsteuer ( $1 \%$ der Einlage) sowie die anfallenden Emissionskosten (Gerichts- und Notariatskosten, Börseneinführungsprovision, Konsortialprovision, Druckkosten der Aktien etc.). Vgl. Perridon/Steiner (1986, S. 295).

$38 \mathrm{Vgl}$. Bauer (1988, S. 2576), Perridon/Steiner (1986, S. 293 ff.).

39 Danach wird das einer Kapitalgesellschaft von ihren Gesellschaftern zur Verfügung gestellte Fremdkapital als verdecktes Nennkapital betrachtet, wenn aus rechtlichen Gründen die Zuführung in Form von Gesellschaftskapital zwingend gewesen wäre oder wenn die Vertragsbestimmungen als Gestaltungsmißbrauch im Sinne von $\S 42 \mathrm{AO}$ gesehen werden müssen mit der Folge, daß die für das verdeckte Nennkapital geleisteten Vergütungen nicht als Betriebsausgaben sondern als verdeckte Gewinnausschüttungen anzusehen sind. Vgl. Horlemann (1990, S. 2086 f.).

$40 \mathrm{Vgl}$. Scheibe-Lange (1986, S. 773 f.).
} 
ren wird untersucht, wie hoch die durchschnittliche effektive Grenzsteuerbelastung eines Unternehmens und seines Kapitalgebers ist, wenn eine Einheit zusätzlich investiert wird. Im folgenden werden die beiden Methoden dargestellt.

\subsubsection{Durchschnittlicher effektiver Steuersatz}

Für die Berechnung durchschnittlicher effektiver Steuersätze ${ }^{41}$ in verschiedenen Ländern ist es notwendig, die steuerliche Bemessungsgrundlage, den nominalen Unternehmensbzw. Gesamtsteuersatz und den ökonomische Gewinn zu determinieren. Die bisher detaillierteste Untersuchung hat das Deutsche Institut für Wirtschaftsforschung (DIW) im Rahmen eines Gutachtens für das Bundeswirtschaftsministerium durchgeführt. Ausgangsbasis für die Analyse in sieben Industrieländern ${ }^{42}$ sind Modellunternehmen der Chemischen Industrie, des Maschinenbaus, des Fahrzeugbaus, der Büromaschinenbranche und des Bekleidungsgewerbes. Die Bilanzstruktur des repräsentativen Unternehmens beruht auf Schätzungen des DIW auf der Basis der Statistik der Unternehmen und Arbeitsstätten. ${ }^{43}$ In einem ersten Schritt wird aus dem Bilanzgewinn der „bereinigte“ (ökonomische) Bilanzgewinn abgeleitet, indem der Handelsbilanzgewinn um die Abschreibungen, die Körper-, Gewerbe- und Grundsteuer erhöht und um die Nettozuführung bzw. -auflösung von Rücklagen und Rückstellungen korrigiert wird. Der bereinigte Bilanzgewinn entspricht dem cash flow vor Steuern. ${ }^{44}$ Unter Berücksichtigung spezifischer nationaler Regelungen hinsichtlich der steuerlich zulässigen Normal- und Sonderabschreibungen, der Nettoeinstellungen bzw. -auflösungen steuerbegünstigter Rücklagen sowie Rückstellungen wird der Gewinn vor Steuern berechnet. Der Gewinn vor Steuern wird verringert um die abzugsfähigen Steuern sowie Freibeträge oder andere Abzüge. Der verbleibende körperschaftsteuerpflichtige Gewinn wird unter Berücksichtigung des Ausschüttungsverhältnisses ${ }^{45}$ den aktuellen Steuertarifen unterworfen. Die sich ergebende Gesamtsteuerlast eines Unternehmens wird in Relation gesetzt zu dem bereinigten Bilanzgewinn, d. h. dem cash-flow. ${ }^{46}$

Weicht der durchschnittliche effektive Steuersatz von dem gesetzlichen Tarif ab, so besteht unter dem Gesichtspunkt der Steuerneutralität ein Handlungsbedarf. Übersteigt der ökonomische den steuerpflichtigen Gewinn, z. B. aufgrund der Eliminierung erhöhter Abschreibungen, so liegt der durchschnittliche effektive Steuersatz unter dem nominalen. Für eine steuerliche Entlastung besteht in diesem Fall kein Handlungsbedarf. Übersteigt demgegenüber die steuerpflichtige Bemessungsgrundlage den ökonomischen Gewinn, z. B.

\footnotetext{
${ }_{41}$ Dieser methodische Ansatz wurde von Fuest/Kroker (1989a) und Seidel et al. (1989) gewählt.

42 Dies sind die Bundesrepublik Deutschland, Frankreich, Italien, Großbritannien, Schweden, die USA und Japan.

$43 \mathrm{Vgl}$. Seidel et al. (1989, S. 70 f.).

44 Vgl. Bradford/Stuart (1986, S. 308).

45 Das Ausschüttungsverhalten von Unternehmen ist in Nationen mit gespaltenen Steuertarifen von Bedeutung, d. h. in diesem Fall für die Bundesrepublik Deutschland und Frankreich.

${ }^{46} \mathrm{Vgl}$. Fuest/Kroker (1989b, S. 260 f.), Seidet et al. (1989, S. 79 ff.). 
aufgrund der Auflösung inflationsbedingter Scheingewinne, ${ }^{\mathbf{4 7}}$ so ist der Gesetzgeber gefordert, die auf Unternehmensgewinne und -vermögen lastende Ertrag- und Substanzbesteuerung zu verringern. ${ }^{48}$ Ist der ökonomische Gewinn identisch mit dem steuerlichen, so ist ein steuerlicher Handlungsbedarf nicht gegeben. Die in der DIW-Studie ermittelten durchschnittlichen effektiven Steuersätze unterschreiten in den Ländern und betrachteten Branchen durchgängig die nominale Gesamtsteuerbelastung. In der Tabelle 5.1 werden die von Seidel et al. (1989) ermittelten Resultate auszugsweise wiedergegeben.

Tabelle 5.1: Steuern vom Gewinn, Ertrag und Vermögen insgesamt (Gesamtsteuerlast) im Verhältnis zum bereinigten Bilanzgewinn (cash flow) für Kapitalgesellschaften des Maschinenbaus und Bekleidungsgewerbes bei tatsächlichem Ausschüttungsverhältnis im internationalen Vergleich in $v . H$.

\begin{tabular}{|l|c|c|}
\hline & $\begin{array}{l}\text { Maschinen- } \\
\text { bau }\end{array}$ & $\begin{array}{c}\text { Bek leidungs- } \\
\text { gewerbe }\end{array}$ \\
\hline Bundesrepublik Deutsch land & 34,7 & 51,0 \\
Frankreich & 42,6 & 59,4 \\
Italien & 30,3 & 39,6 \\
Vereinigtes Königreich & 30,6 & 38,5 \\
Schweden & 44,9 & 56,9 \\
Vereinigte Staaten von Amerika & 35,4 & 46,1 \\
Japan & 39,0 & 53,7 \\
\hline
\end{tabular}

Quelle: Seidel et al. (1989, S. 113).

Die Tabelle 5.1 verdeutlicht, daB die nationale Steuerbelastung je nach Branche stark variiert. Die Aussage von Seidel et al., daß in der Bundesrepublik Deutschland kein Handlungsbedarf besteht, die auf Unternehmensgewinne lastenden Steuern zu verringern, ${ }^{49}$ kann aufgrund der hohen Aggregation der Daten und den großen Abweichungen zwischen der Steuerbelastung in den verschiedenen Unternehmensbranchen nicht nachvollzogen werden.

Im Rahmen der steuerlichen Veranlagungssimulation kommen eine Fülle von Einzelre-

47 Ein Scheingewinn ergibt sich aus der ${ }_{n}$ Differenz $\mathrm{zwischen}$ dem Nominalgewinn und dem mit Rücksicht auf die Erhaltungserfordernisse der Unternehmung bestimmten Real- bzw. Substanzgewinn, der die Folgen der Geldwertverschlechterung bzw. der Preissteigerungen berücksichtigt ${ }^{4}$. Grotherr (1987, S. 51).

$48 \mathrm{Vgl}$. Fuest/Kroker (1989a, S. 46).

$49 \mathrm{Vgl}$. Seidel et al. (1989, S, 137). 
gelungen zur Anwendung, z. B. hinsichtlich der Bewertung von Wirtschaftsgütern des Anlage- und Umlaufvermögens, der Rücklagenbildung, dem Umfang der zulässigen Rückstellungen, der Abzugsfähigkeit von Betriebsausgaben sowie des Verlustrück- und -vortrages. Aufgrund der Komplexität der nationalen Steuergesetze beschränken sich die bisher vorliegenden Untersuchungen, ebenso wie die DIW-Studie, bei der Einbeziehung steuerlich relevanter Finflüsse hauptsächlich auf die Abschreibungsvorschriften und die Möglichkeiten der Bildung von Pensionsrückstellungen.

Neben dem Ausweis einer zutreffenden Vermögenslage und der periodengerechten $\mathrm{Zu}$ ordnung von Aufwendungen verfolgt der Steuergesetzgeber außerfiskalische Ziele, z. B. die Förderung von bestimmten Gebieten oder des Umweltschutzes. ${ }^{50}$ Ein in vielen Staaten häufig eingesetztes Mittel für die Realisierung dieser politischen Zielsetzungen ist die Gewāhrung erhöhter Abschreibungsmöglichkeiten. Die Steuerpolitik geht dabei von der Annahme aus, daß bessere Abschreibungsbedingungen Investitionen fördern. „... the tax system enshrined the doctrine that tax allowances encouraged investment. Hence elaborate allowances were given to allow the writing off of capital expenditure far ahead of any real depreciation or obsolescence. " ${ }^{51}$ Werden die unternehmensinternen Investitionsentscheidungen durch steuerliche Anreize beeinflußt, so kann dies dazu führen, daß die zu erwartenden Steuervergünstigungen die Rangordnung bei den Rentabilitäten der Investitionsalternativen sowie den Investitionsumfang verändern. ${ }^{52}$

In Großbritannien werden z. B. seit 1970 für wirtschaftlich bedeutsame Investitionsbereiche (industriell genutzte Gebäude und abnutzbares bewegliches Anlagevermögen) hohe Abschreibungen zugelassen, welche teilweise die sofortige Abschreibung des Vermögensgegenstandes im Jahr der Anschaffung oder Herstellung ermöglichten. Diese steuerlichen Investitionsanreize haben jedoch im Vergleich zu anderen Industrienationen kein höheres Investitionsvolumen bewirkt, sondern zu Fehlallokationen geführt. ${ }^{53}$ "But there is little evidence that these incentives have strengthened the economy or improved the quality of investment.... the evidence suggests that businesses have invested substantially in assets yielding a lower rate of return than the investment made by our principal competitors. Too much of British investment has been made because the tax allowances make it look profitable, rather than because it would be truly productive. We need investment decisions based on future market assessments, not future tax assessments. ${ }^{\omega 54}$

Aufgrund dieser Erfahrungen wurde durch den Finance Act 1984 die Sofortabschreibung

\footnotetext{
${ }^{50}$ Vgl. Biener/Berneke (1986. S. 108 f.).

51 Tiley et al. (1991, S. 333).

52 Vgl. Schneider (1989b, S. 314).

53 Vgl. Grotherr (1987, S. 196 f.).

54 Lawson (1984, S. 179). 
in Großbritannien zunächst stufenweise verringert und ist seit dem 1.4.1986 nur noch in den Fördergebieten ${ }^{55}$ zulässig. Gleichzeitig wurde der Körperschaftsteuersatz schrittweise von $50 \%$ auf derzeit $33 \%$ herabgesetzt. ${ }^{56}$

Tabelle 5.2: Capital allowances and corporation tax rates

\begin{tabular}{|c|c|c|c|}
\hline & Plant \& Machinery & Industrial Buildings & Corporate Pax Pates \\
\hline Expenditure incurred & \multicolumn{2}{|c|}{ initial allowances } & \\
\hline Before 14.3.1984 & $100 \&$ & 758 & $50 \%$ \\
\hline On or after 14.3.1984 & 758 & 508 & $45 ?$ \\
\hline On or after 1.4.1985 & $50 ?$ & 258 & $40 ?$ \\
\hline On or after 1.4.1986 & Mil & Mil & $35:$ \\
\hline On or after 1.4.1991 & Mil & Mil & 348 \\
\hline On or after 1.4.1992 & Nil & vil & 338 \\
\hline
\end{tabular}

Quelle: Vgl. Morgan (1986, S. 9), Lawson (1984, S. 179), Tiley et al. (1991, S. 653).

Infolge der historischen Entwicklung der nationalen Steuersysteme bestehen in den Mitgliedstaaten der EG differenzierte Instrumentarien für die Förderung von Investitionen und der Gründung oder Ansiedlung von Unternehmen. Neben dem Sofortabschreibungswahlrecht ist hier insbesondere die Gewährung staatlicher und regionaler Zuschüsse (die weder steuerpflichtig sind noch die Höhe der Anschaffung- oder Herstellungskosten verringern) und die Bewilligung von Steuergutschriften oder -befreiungen zu nennen. Die Betrachtung der national divergierenden Abschreibungsregeln sagt daher nur begrenzt etwas über die Prioritäten der Regierungen für die steuerliche Förderung von Investitionen aus, zumal die Vorschriften über die Auflösung oder Übertragung der gebildeten stillen Reserven ${ }^{57}$ in den Vergleichen nicht berücksichtigt werden. Daneben bleibt zu

55 Dies sind Tyneside, Hartlepool, Middlesborough, Workington, North East Lancashire, Salford, Trafford, Wakefield, Glanford, Scunthorpe, Rotherham, Speke (Liverpool), Telford, Dudley, Corby, Wellingborough, North Kent und die Isle of Dogs (London) in England; Swansea, Milford Haven und Delyn (Flint) in Wales; Clydebank. Tyside und Invergordon in Schottland sowie Londonderry und Belfast in Nordirland. Vgl. Homburger (1989, S. 24).

56 Vgl. Grotherr (1987, S. 197 f.).

57 Dies sind z. B. die Regelungen über die Reinvestitionsrücklage, die Besteuerung der Veräußerungsge- 
bemerken, daß es im Ermessen des Bilanzierenden liegt, inwieweit die gewährten steuerlichen Abschreibungswahlrechte in Anspruch genommen werden. Dies wird wiederum durch die divergierenden Zielvorstellungen der Bilanzadressaten bestimmt, so daß z. B. in der Bundesrepublik Deutschland, aufgrund der Maßgeblichkeit der Handelsbilanz für die Steuerbilanz, die Aktionärsinteressen (hoher Gewinn) und das Ziel der Steueroptimierung (niedriger steuerlicher Gewinn) gegeneinander abgewägt werden müssen.

Die Förderungsvielfalt hat bei den staatlichen Altersversorgungssystemen zu einem Variantenreichtum an supplementären Sicherungssystemen geführt. Diese reichen von dem die einkommensunabhängigen Leistungen des Regelsystems ergänzenden Pflichtsysteme in Großbritannien über obligatorische betriebliche Systeme in Frankreich bis hin zu völlig freiwilligen betrieblichen Versorgungssystemen in der Bundesrepublik Deutschland, welche die einkommensabhängigen Leistungen des staatlichen Rentensystems ergänzen. Der Bedarf ergänzender Absicherungssysteme wird dabei von dem Absicherungsniveau der staatlichen Regel- und, gegebenenfalls ergänzender, Pflichtsicherungssysteme determiniert. ${ }^{58}$ Bei den freiwilligen Ergänzungssystemen lassen sich in den EG-Ländern drei zulässige Wege einer Vorausfinanzierung unterscheiden:

- Rechtlich selbständige Pensionskassen,

- Gruppenversicherungen sowie

- Pensionsrückstellungen. ${ }^{59}$

Rechtlich selbständige Pensionskassen sowie Gruppenversicherungen findet man in nationaler Ausprägung in praktisch allen Ländern. Die Zahlungen an diese Versorgungseinrichtungen stellen dabei steuerlich abzugsfähige Betriebsausgaben dar. Die interne Mittelverwendung durch die steuerlich zulässige Bildung von Pensionsrückstellungen, wie sie in der Bundesrepublik Deutschland dominiert, bildet bei den Ergänzungssystemen die Ausnahme und wird in Frankreich und Großbritannien steuerlich nicht anerkannt. ${ }^{60}$ Den für Pensionszusagen zu bildenden Rückstellungen wird in der Bundesrepublik Deutschland häufig eigenkapitalähnlicher Charakter unterstellt. Dabei bleibt unberücksichtigt, daß den Rückstellungen ein Aufwand gegenübersteht, der lediglich hinsichtlich der Höhe und des Zeitpunktes der Zahlung nicht exakt bestimmbar ist. Der wirtschaftlich eingegangenen Verpflichtung zur Leistung kann sich das Unternehmen nicht entziehen und muß auch in schwierigen Zeiten eingelöst werden. ${ }^{61}$ Arbeitet ein Unternehmen mit dem zurückgestellten Kapital, so kann es seine Selbstfinanzierungskraft stärken, zeitweilige Liquiditätsvorteile erwerben und Anlagegewinne aber auch -verluste erwirtschaften. Das aus dieser

winne mit einem ermäßigten Steuersatz, die Vorschriften bezüglich des Verlustrück- oder Verlustvortrages sowie die Möglichkeit der Verrechnung von Veräußerungsverlusten mit laufenden Gewinnen.

58 Vgl. Rößler (1990, S. 7).

59 Vgl. RöBler (1990, S. 7).

60 Vgl. o. V. (1989b, S. 8 ff.), Rößler (1990, S. 7), Schneider (1990, S. 573).

61 Vgl. Lubitz/Ploog (1991, S. 7). 
internen Mittelverwendung resultierende unternehmerische Risiko muß dabei von einem Unternehmen getragen werden, wobei von der Kapitalanlage her allerdings ganz andere Bedingungen verlangt werden als beim normalen Geschäft. Die bei einer Innenfinanzierung bestehende Gefahr nicht optimaler Mittelanlage, vorzeitiger Inanspruchnahme oder einer längeren Leistungsdauer kann bei den Altersversorgungspflichten mittel- und langfristig negative Folgen haben. ${ }^{62}$ Die durch den Abschluß einer Direktversicherung mögliche Ausgliederung des Risikos führt in der Bundesrepublik Deutschland allerdings zu einer pauschalen Lohnversteuerung der Beiträge ${ }^{63}$ und somit zu zusätzlichen Lohnkosten. Als ein weiterer Nachteil wird vielfach die Tatsache angesehen, daß dem Unternehmen bei Abschluß einer Versicherung Finanzmittel direkt entzogen werden, die bei der Rückstellungsbildung dem Unternehmen zunächst zur Verfügung stehen. Werden Pensionszusagen neu gebildet, so ist der Finanzierungseffekt über mehrere Jahre hoch, da der Aufwandsverrechnung keine Auszahlung gegenübersteht. In der Periode, in der der Versorgungsfall eintritt, soll die Pensionsrückstellung dem kapitalisierten Wert der zu erwartenden Pensionsleistung entsprechen. Der Teilwert der künftigen Verpflichtung mindert sich ab dem Zeitpunkt der Pensionsleistung laufend, da die Lebenserwartung des Pensionsberechtigten abnimmt. Die Rückstellung ist daher Jahr für Jahr in Iöhe der Differenz zwischen dem versicherungsmathematischen Barwert und der künftigen Pensionsleistung am Schluß des Wirtschaftsjahres sowie am Ende des vorangegangenen Wirtschaftsjahres gewinnerhöhend aufzulösen. Ist der Aufösungsbetrag niedriger als die zu leistende Pensionszahlung des Wirtschaftsjahres, so ergibt sich per Saldo eine laufende Gewinnminderung. Halten sich die $\mathrm{Zu}$ - und Abgänge die Waage, so tritt kein zusätzlicher Finanzierungseffekt auf; übersteigen die jährlichen Zahlungen die Zuführung, so kommt es für ein Unternehmen zu einem Entzug finanzieller Mittel. ${ }^{64}$ Die Abtretung der Risiken an die Versicherung ist aus diesem Grund insbesondere bei klein- und mittelständischen Kapitalgesellschaften kein zu unterschätzender Gesichtspunkt und kann auch bei Kooperationen, Beteiligungen und Unternehmenszusammenschlüssen von Vorteil sein, da die intern finanzierte Altersversorgung bei potentiellen, mit dem nationalen System nicht vertrauten, Partnern zum Stolperstein werden kann. ${ }^{65}$

Im Hinblick auf die national unterschiedlich geregelten Vorschriften zur Förderung von Investitionen und Unternehmensansiedlungen sowie den nur in der Bundesrepublik Deutschland steuerlich anerkannten Pensionsrückstellungen erscheint es fraglich, inwieweit diese Punkte als wesentliche Einflußgröße zur Bestimmung der steuerlichen Bemessungsgrundlage herausgegriffen werden können, um im Rahmen der Steuerbelastungsvergleiche die

62 Vgl. Rößler (1990, S. 7).

${ }^{63}$ Siehe $\$ 40$ b EStG.

64 Vgl. Franke/Hax (1989, S. 1881 f.), Habermann (o. J., S. 4), Littmann/Langmann (1987, S. 7), Perridon/Steiner (1986, S. 301 f.), RöBler (1990, S. 7), Schneider (1989a, S. 889 f.).

65 Vgl. Rößler (1990, S. 7), Fischer (1989a, S. 120 f.). 
aufgrund der nationalen Bestimmungen bestehenden Differenzen exemplarisch aufzuzeigen.

Neben der Komplexität der Steuersysteme ergibt sich für die Untersuchenden das Problem, die für dic Durchführung einer vollständigen Veranlagungssimulation benötigten Steuerbilanzen und Arbeitspapiere zu erhalten. Die Unternehmen sind in aller Regel nicht dazu bereit, die erforderlichen Informationen zur Verfügung zu stellen. Steuerbilanz- oder andere aussagefähige Jahresabschlußstatistiken für Unternehmen aller Rechtsformen existieren in der Bundesrepublik Deutschland aufgrund der strengen Vorschriften des Datenschutzes nicht. Die Institute behelfen sich daher mit Modellannahmen, die auf den veröffentlichten Unternehmensdaten basieren. Die Aussagekraft der Frgebnisse ist stark eingeschränkt, da diese "repräsentativen“ Unternehmen nicht die spezielle Situation des Unternehmens widerspiegeln. Des weiteren geben weder die vom Statistischen Bundesamt publizierten Daten noch die veröffentlichten Handelsbilanzen dem Untersuchenden einen, bzw. nur einen begrenzten, Einblick in die Verhaltensweisen der Unternehmen, ihre Steuerbelastung durch die Inanspruchnahme von Bewertungswahlrechten zu optimieren.

Die Möglichkeiten zur Gestaltung der steuerlichen Bemessungsgrundlage sind allerdings vom Gesetzgeber vorgegeben und sollten daher weder über- noch unterschätzt werden. Vielfach unbeachtet bleibt, daß die eingeräumten Bewertungswahlrechte keine endgültige Steuerminderung darstellen, sondern eine Verlagerung der Steuerzahlung auf spätere Jahre herbeiführen, d. h. eine Steuerstundung bewirken. Diese entspricht einem zinslosen Darlehen, das dem Unternehmen unabhängig von seiner Kreditwürdigkeit gewährt wird. ${ }^{66}$ Steuerlich kürzere Nutzungsdauern, die Möglichkeit der degressiven Abschreibung und die zusätzliche Gewährung von Sonderabschreibungen in Höhe des über die tatsächliche Wertminderung des Wirtschaftsgutes hinausgehenden Abschreibungsbetrages führen zunächst zu einer Verschiebung der Steuerzahlung auf spätere Jahre. ${ }^{67}$ Die Auflösung dieses vom Fiskus gewährten Darlehens und die Nachversteuerung der überhöhten $\mathrm{Ab}$ schreibungsbeträge erfolgt bei einer späteren Veräußerung des Vermögensgegenstandes. In diesem Zusammenhang kommen die in den Staaten geltenden Vorschriften bezüglich der Übertragung eventueller Veräußerungsgewinne auf neue Wirtschaftsgüter (Reinvestition), der Verrechnung von Veräußerungsgewinnen oder - verlusten im Wirtschaftsjahr der Veranlagung mit laufenden Gewinnen sowie die variierenden Regelungen des Verlustrückoder -vortrages zur Anwendung, welche eine Verlängerung des Steuerkredites oder eine begünstigte Besteuerung zur Folge haben können. Bis zu einer Auflösung des zinslosen Steuerkredits kann ein Unternehmen die gestundete Steuer jedoch zinsbringend anlegen,

${ }^{66}$ Vgl. o. V. $(1983$, S. 11).

67 Vgl. Knobbe-Keuk (1989, S. 136).

Otto Roloff, Sibylle Brander, Ingo Barens and Claudia Wesselbaum - 978-3-631-75210-4 
so daß zu dem Liquiditătsvorteil auch ein Zinsvorteil kommt. welcher die Kosten einer Investition verringert und die erwartete Rentabilität erhöht. ${ }^{68}$

Die Vielzahl der für die Berechnung der steuerlichen Bemessungsgrundlage und des ökonomischen Gewinns benötigten Daten sind nur im Finzelfall für zurückliegende 7eiträume vorhanden. ${ }^{69}$ Die Standortwahl eines Unternehmens bezieht sich allerdings auf zukünftige Handlungen und erfaßt die ebenfalls zukünftigen honsequenzen. Unvollkommene Informationen über die Zukunft des Unternehmens und die die Entwicklung der Steuergesetze beeinflussenden Faktoren sowie das fragmentarische Wissen der Unternehmensführung von den Bedingungen ihrer Maßnahmen und den Verlauf dieser Bedingungen in der Zeit. bewirken eine Unsicherheit hinsichtlich der entscheidungsrelevanten Daten. ${ }^{70}$ Mit der Zahl der zu schätzenden Zukunftsdaten steigt die Unsicherheit. Kurzfristig lassen sich dabei die aus den Steuergesetzen ergebenden nominalen Steuersätze planen. ${ }^{71}$

Bei einem Vergleich der von verschicdenen Wissenschaftlern bzw. Instituten veröffentlichten Daten muß beachtet werden. daß der für die Berechnung der Steucrbelastung einzubeziehende Unternehmen- oder Gesamtstcucrsatz weder national noch international einheitlich definiert ist. Daher liegt es im Ermessen des Untersuchenden. eine Abgrenzung vorzunehmen. Im Rahmen der Studic des DIWs wird die Steuerbelastung eines Internehmens definiert als die Körperschaftsteuer auf ausgeschüttete und thesauricrte Gewinne zuzüglich der abzugsfähigen Steuern vom Gewinn, Ertrag und Vermögen ${ }^{72}$ sowie der sonstigen nicht abzugsfähigen Steuern vom Gewinn, Ertrag und Vermögen. ${ }^{73}$ Die Interaktion zwischen den einzelnen Steuerarten ${ }^{74}$ wird dabei berücksichtigt. Außer Acht lassen die Untersuchenden des DIWs dabei die Frage, inwieweit Schuldner und wirtschaftlicher Träger der Steuer identisch sind. In der Bundesrepublik Deutschland verringert z. B. die von einem Unternehmen erhobene lokale Gewerbesteuer als Betriebsausgabe den Ilandels- und Steuerbilanzgewinn. Wird die lokale Steuer über den Preis verdient und die Belastung auf diese Weise auf den Endabnehmer überwälzt, so stellt in diesem Fall die Gewerbesteuer keine Unternehmensteuer dar. Durch die Berücksichtigung der Gesamtsteuerbelastung, d. h. der Differenz zwischen der Rendite eines Unternehmens vor Steuern und der einem Kapitalgeber verbleibenden Rendite nach Abzug sowohl der Unternehmensteuer als auch der persönlichen Steuer, entfällt das Zuordnungsproblem.

\footnotetext{
68 Vgl. Knobbe-Keuk (1989, S. 136).

69 Vgl. Schöne (1976, S. 401), Spooner (1986, S. 294).

$70 \mathrm{Vgl}$. Perridon/Steiner (1986, S. 26), Gutenberg (1983, S. 133).

71 Vgl. Schöne (1976, S. 401)

72 Hierbei handelt es sich um die lokale Gewerbeertrag- und Gewerbekapitalsteuer.

73 Hierzu zählt z. B. die von dem Einheitswert des Betriebsvermögens zu berechnende Vermögensteuer. Vgl. Seidel et al. (1989, S. 80).

74 Die lokale Gewerbesteuer in der Bundesrepublik Deutschland verringert z. B. die körperschaftsteuerliche Bemessungsgrundlagc.
} 
Neben der steuerlichen Bemessungsgrundlage und dem Steuertarif wird bei der Ermittlung eines durchschnittlichen effektiven Steuersatzes der ökonomische Gewinn berücksichtigt. Der ökonomische oder effektive Gewinn soll die von handels- und steuerrechtlichen Bestimmungen unbeeinflußte Rendite eines Unternehmens wiedergeben. Aus diesem Grund ist es erforderlich, die im Rahmen einer Veranlagungssimulation aus der Handelsbilanz abgeleitete steuerliche Bemessungsgrundlage zu korrigieren, ${ }^{75}$ denn sowohl die Handelsbilanz als auch die daraus abgeleitete Steuerbilanz werden nicht nach "rein" wirtschaftlichen Gesichtspunkten erstellt. Bei der Frstellung einer Handelsbilanz müssen die unterschiedlichen Interessen der Adressaten (z. B. Gläubigerschutz) sowie steuerliche Abschreibungsbestimmungen beachtet werden. Auf die abgeleitete Steuerbilanz nehmen zudem außerfiskalische Zielsetzungen einen Einfluß. Die handels- und steuerrechtliche Bewertung der Aktiva und Passiva erfolgt prinzipiell nach dem Nominalwertprinzip. Eine Bereinigung um inflationsbedingte Veränderungen erfolgt nicht. Jede vorgenommene Bewertung müßte demnach hinsichtlich der ökonomisch, ,richtigen“ und handels- bzw. steucrechtlich zulässigen Beurteilung überprüft werden. Die Korrektur der steuerlichen Bemessungsgrundlage erfordert wie die Veranlagungssimulation selbst eine Vielzahl an Informationen, z. B. über die effektive Wertminderung eines jeden Vermögensgegenstandes (true economic depreciation), die richtige Erfassung von Rückstellungen etc. Diese Aufgabe kann aufgrund der benötigten internen Informationen von externen Wissenschaftlern nicht erbracht werden. Die Kapitalgesellschaften selber werden zum einen kein Interesse daran haben, den "richtigen“ Gewinn der Öffentlichkeit, und somit der Konkurrenz, zugänglich zu machen. Zum anderen dürfte es für sie problematisch wenn nicht gar unmöglich sein, für alle Bilanzpositionen den Gegenwartswert zu ermitteln.

Damit Untersuchungen über die durchschnittliche effektive Steuerbelastung von Unternehmen im internationalen Vergleich durchgeführt werden können, ist es daher erforderlich, den ökonomischen Gewinn zu schätzen. Der im Rahmen der Studie von dem DIW verwendete cash flow ist für die Taxierung des ökonomischen Gewinns eines Unternehmens nicht geeignet. Der cash flow wird im allgemeinen als Kennzahl bei der Finanz- und Bilanzanalyse in zwei unterschiedlichen Interpretationen verwendet. Zum einen soll der cash flow es bei ciner externen Analyse ermöglichen, die gegenwärtige und zukünftige tatsächliche Ertragskraft eines Unternehmens zu bestimmen, d. h. den erfolgswirtschaftlichen Ïtberschuß zu ermitteln. Zum anderen wird der cash flow verwendet, um die Innenfnanzierungskraft für Investitionen, Schuldentilgung und Aufrechterhaltung der Liquidität zu überprüfen, d. h., um den finanzwirtschaftlichen Überschuß eines Unternehmens zu bestimmen. Der cash flow kann jedoch nicht als ökonomischer Gewinn interpretiert werden. Abschreibungen und Rückstellungen stellen für cin Unternehmen einen tatsächlichen $\Lambda$ ufwand dar und nur für die Differenz zwischen der effektiven Wertminderung und den

75 Vgl. Fuest/Kroker (1989a, S. 47), Seidel et al. (1989, S. 79). 
handelsrechtlich vorgenommen Wertansätzen muß eine Korrektur vorgenommen werden. ${ }^{76}$ Im Rahmen einer externen Analyse kann diese Aufteilung aufgrund der fehlenden Daten nicht vorgenommen werden. Die von dem DIW ermittelten Resultate können demnach nur als Indiz interpretiert werden, daß die steuerliche Bemessungsgrundlage keinen ökonomischen Gewinn darstellt und somit die von einem Unternehmen an den Fiskus zu leistende Steuerzahlung nicht die effektive Belastung wiedergibt. Aufgrund der hohen Aggregation der Daten und den genannten methodischen Problemen, können die berechneten Steuersätze für eine empirische Studie über den Zusammenhang von Direkinvestitionen und effektiven Steuersätzen nicht herangezogen werden. Für einen cinzelnen Investor stellen die Resultate aufgrund der hohen Aggregation ebenfalls keinen Indikator dar. Inwieweit ein Handlungsbedarf für den nationalen Fiskus besteht, kann anhand der Studie nicht beurteilt werden.

\subsubsection{Effektiver Grenzsteuersatz anhand des Modells von King und Fullerton}

Durch die Berechnung eines effektiven Grenzsteuersatzes soll der Finfluß des von einem Staat kontrollierten Steuersystems auf ökonomische Entscheidungen dargelegt werden. ${ }^{77}$ Die auf die Einkünfte bzw. den Gewinn und das Vermögen erhobenen nationalen und lokalen Steuern nehmen einen Einfluß auf die einem Kapitaleigner verbleibende Rendite. I'nterliegen die verschiedenen Kapitaleinkunftsarten (z. B. Zins- und Dividendeneinkünfte) einer unterschiedlichen Steuerbelastung, kann dic Finanzicrungsstruktur einer Kapitalgesellschaft beeinflußt. werden, d. h. inwieweit cinem Unternehmen durch die Zuführung von Eigenkapital oder durch die Aufnahme von Fremdkapital Mittel bereitgestellt werden. Die Steuergesetzgebung kann in diesem Fall zu ciner Fehlallokation von Kapital führen, welche verstärkt werden kann, wenn der Staat direkte (z. B. Investitionszulagen) oder indirekte (z. B. Sonderabschreibungen) Subventionen für bestimmte Branchen oder Wirtschaftsgüter gewährt und die Unternehmen aufgrund dieser Anreize vermehrt Investitionen in den geförderten Bereichen durchführen, während effizientere, aber nicht zulagefähige Investitionen, unterbleiben. ${ }^{78}$

Für die Ermittlung eines effektiven Grenzsteuersatzes existieren derzeit keine einheitlichen, und vor allen Dingen international anwendbaren, Vorschriften. Bei der Interpretation und Analyse veröffentlichter Resultate muß daher zunächst betrachtet werden, wie der effektive Steuersatz definiert wird und welche Daten bei der Berechnung zugrundegelegt werden. ${ }^{79}$ Die bekannteste und bisher umfangreichste Studie zur Ermittlung eines effektiven Steuersatzes wurde von King und Fullerton (1984) erstellt.

\footnotetext{
76 Vgl. Perridon/Steiner (1986, S. 327 f.).

$77 \mathrm{Vgl}$. Fullerton et al. (1982, S. 580).

$78 \mathrm{Vgl}$. Fullerton et. al. (1982, S. 580 f.).

$79 \mathrm{Vgl}$. Bradford/Stuart (1986, S. 308).
} 


\subsubsection{Theoretische Grundlage}

Der effektive Grenzsteuersatz einer inländischen marginalen Investition wird von King und Fullerton unter Berücksichtigung der Branchenzugehörigkeit des investierenden Unternehmens, alternativer Sachanlageinvestitionsobjekte, unterschiedlicher Finanzierungsarten. verschiedener inländischer Kapitalgeber sowie der national und lokal erhobenen Steuern auf den Ertrag und das Vermögen des Unternehmens und der Anteilseigner berechnet. Die Analyse hatte dabei nicht das Ziel, einen effektiven Grenzsteuersatz für jedes Land zu ermitteln, sondern einen aktuellen Überblick über die von Großbritannien, der Bundesrepublik Deutschland, Schweden und den Vereinigten Staaten von Amerika gewährten steuerlichen Investitionsanreize zu geben. Die komplexen Stcuersysteme der betrachtcten Länder sollten dabei zusammengefaßt und auf eine intuitiv ansprechende Weise dargelegt werden. um eine Ausgangsgröße für weitere ökonomische Analysen über das Investitionsverhalten von Unternehmen bereitzustellen. ${ }^{80}$

Das Steuersystem eines Landes sowie das Investitionsverhalten von Unternehmen und Kapitalgebern ist so komplex und vielfältig, daß es notwendig ist, vereinfachende Annahmen zu treffen, welche die theoretische Grundlage für die Analyse darstellen. Für die Interpretation der von King und Fullerton ermittelten Resultate ist es notwendig, die der Analyse zugrundeliegenden Annahmen zu betrachten. Im folgenden wird die von King und Fullerton verwendete Definition des effektiven Steuersatzes wiedergegeben, die getroffenen Annahmen dargestellt und hinsichtlich ihrer Plausibilität überprüft.

Der effektive Grenzsteuersatz ( $\mathrm{t}$ ) berechnet sich laut King und Fullerton als Differenz zwischen der auf den Gegenwartswert abdiskontierten Rendite einer inländischen Grenzinvestition vor Steuern $(p)$ und der einem inländischen Kapitalgeber verbleibenden Rendite nach Abzug aller Ertrag- und Substanzsteuern (s) im Verhältnis gesetzt zu dem Kapitalwert der Rendite vor Steuern, d. h. ${ }^{81}$

$$
t=\frac{p-s}{p}
$$

In $\Lambda$ bhängigkeit von der Branchenzugehörigkeit des inländischen Unternehmens (verarbeitendes Gewerbe, sonstige Industrieunternehmen, Handel und Dienstleistungen), der Kapitalanlage (Maschinen und Anlagen, Gebäude, Vorräte), der Finanzierungsart (Fremdkapital, Eigenkapital, Gewinnthesaurierung) und dem inländischen Kapitalgeber (privater Haushalt, steuerbefreite Institution, Versicherungsgesellschaften), ergeben sich pro betrachtetem Land 81 effektive Grenzsteuersätze. ${ }^{82}$ Die dabei getroffene Annahme, daß je-

\footnotetext{
$80 \mathrm{Vgl}$. King/Fullerton (1984, S. 9), Schaden (1991, S. 22), Scott (1987, S. 257).

$81 \mathrm{Vgl}$. King/Fullerton $(1984$, S. 9).

82 Die effektiven Grenzsteucrsätze je Land können bei King/Fullerton (1984, Anhang B, o. S.) nachge- 
der Kapitalgeber sein gesamtes Kapital in jenes marginale Projekt investieren wird, das den geringsten effektiven Grenzsteuersatz und somit die höchste Rendite nach Steuern aufweist, impliziert einen Grad der Konzentrierung bei den Portfolios und sonstigen Investitionen, welcher empirisch gesehen nicht sinnvoll ist. Die Begrenzung der Analyse auf diese hypothetischen Fälle ist nach King und Fullerton zu agnostisch. In ihrer Untersuchung gewichten King und Fullerton daher die effektiven Grenzsteuersätze entsprechend der aktuellen Verteilung der durchgeführten Investitionen und des dafür bereitgestellten Kapitals. Dies bietet ihnen gleichzeitig die Möglichkeit, zu analysieren, in welcher Höhe das Steueraufkommen zunehmen würde, wenn alle Vermögensgegenstände einer Wirtschaft, entsprechend der bisherigen Verteilung, um ein Prozent steigen würden. ${ }^{83}$ Der durchschnittliche effektive Grenzsteuersatz $\left(t_{D}\right)$ einer Investition ergibt sich aus der durchschnittlichen Gesamtsteuerbelastung $\left(w_{D}\right)$ dividiert durch die gewichtete marginale Rendite einer inländischen Grenzinvestition vor Steuern $\left(p_{D}\right):^{84}$

$$
t_{D}=\frac{w_{D}}{p_{D}}
$$

Die durchschnittliche Gesamtsteuerbelastung einer gewichteten marginalen Investition berechnet sich aus der Addition aller Differenzen zwischen der Rendite vor Steuern des Unternehmens $\left(\mathrm{p}_{K}\right)$ und der dem Kapitalgeber verbleibenden Rendite nach Steuern $\left(\mathrm{s}_{k}\right)$ gewichtet mit der entsprechenden Verteilung des Anlagevermögens $\left(\alpha_{K}\right)$, d. h. ${ }^{85}$

$$
w_{D}=\sum_{k=1}^{81}\left(p_{k}-s_{k}\right) \alpha_{k} .
$$

k definiert dabei eine spezifische Kombination von Kapitalgeber, Finanzierungsart, Investor und Anlageart. Aufgrund der von King und Fullerton getroffenen Annahme ergeben sich hieraus 81 Kombinationsmöglichkeiten je Land, d. h. $k=1, \ldots, 81$. Die durchschnittliche marginale Rendite des Unternehmens vor Steuern wird definiert durch: ${ }^{86}$

$$
p_{D}=\sum_{k=1}^{81} p_{k} \alpha_{k} .
$$

Die durchschnittlichen effektiven Grenzsteuersätze werden von King und Fullerton für jedes Land ermittelt und in ihrer weitergehenden Analyse miteinander verglichen. Bei den von King und Fullerton veröffentlichten Resultaten muß beachtet werden, daß es sich entgegen der Tabellenbezeichnung nicht um effektive Grenzsteuersätze einer inlāndischen

schlagen werden.

\footnotetext{
83 Vgl. King/Fullerton (1984, S. 14 und 306).

$84 \mathrm{Vgl}$. King/Fullerton (1984, S. 15).

$85 \mathrm{Vgl}$. King/Fullerton (1984, S. 15).

$86 \mathrm{Vgl}$. King/Fullerton (1984, S. 15).
} 
Investition, sondern immer um durchschnittliche, d. h. gewichtete, effektive Grenzsteuersätze handelt!

In ihrer Studie gehen King und Fullerton von einer geschlossenen Volkswirtschaft aus. Die Investitionsprojekte können daher nur im jeweiligen Inland realisiert werden, d. h. Direktinvestitionen und grenzüberschreitende Portfolioinvestitionen bleiben unberücksichtigt. Die Untersuchung von King und Fullerton ist begrenzt auf Investitionen von Kapitalgesellschaften. Außer Betracht bleiben die Investitionen des öffentlichen Haushaltes und von Personengesellschaften. Finanziert wird die inländische Grenzinvestition durch die zusätzlichen Ersparnisse der inländischen privaten Haushalte ${ }^{87}$ Der Finanzierungsbedarf ergibt sich laut King und Fullerton aus der Differenz zwischen den Anschaffungskosten und dem Gegenwartswert der steuerlich zulässigen Abschreibungen, der gewährten Zulagen und Subventionen. ${ }^{88}$ King und Fullerton gehen von der Annahme aus, daß die aus den marginalen Investitionen erzielte Rendite zurück an die Kapitalgeber fließt. ${ }^{89}$ Der Investor verfügt laut Annahme von King und Fullerton über vollkommene Informationen. ${ }^{90}$ Ihre Untersuchung beschränken King und Fullerton auf alternative Investitionen des verarbeitenden Gewerbes, der sonstigen Industrieunternehmen sowie der Handels- und Dienstleistungsunternehmen, welche entweder Maschinen und Anlagen, ${ }^{91}$ Gebäude oder Vorratsvermögen erwerben wollen und diese durch Fremdkapital, durch die Ausgabe neuer Aktien oder aber durch Gewinnthesaurierung finanzieren. ${ }^{92}$

Die Aufnahme von Fremdkapital kann laut King und Fullerton dabei entweder durch die Emission von Schuldverschreibungen oder durch ein Darlehen bei der Bank erfolgen. Anteilseigner der Kapitalgesellschaft sind entweder private Haushalte, ${ }^{93}$ steuerbefreite Institutionen ${ }^{94}$ oder steuerpflichtige Versicherungsgesellschaften. ${ }^{95}$ Die Bewertung der Maschinen und Gebäude erfolgt im Rahmen der Analyse von King und Fullerton

$87 \mathrm{Vgl}$. King/Fullerton (1984, S. 8).

88 "The cost of the project is unity, the initial payment for the asset, minus the present discounted value of any grants or tax allowances given for the asset." King/Fullerton (1984, S. 19).

Der Einfluß der steuerlichen Abschreibungen wird im Kapitel 5.3.2.4 analysiert.

Vgl. King/Fullerton (1984, S. 18 f.).

89 Vgl. King/Fullerton (1984, S. 11).

$90 \mathrm{Vgl}$. King/Fullerton (1984, S. 18 und 28).

91 Hierunter fallen sowohl Anlagen als auch Fahrzeuge. Vgl. King/Fullerton (1984, S. 13).

92 Vgl. King/Fullerton (1984, S. 13 f.).

93 Hierzu zählen King und Fullerton auch die indirekt über Mittelsmänner gehaltenen Aktien bei Banken oder allgemein zugänglichen Fonds. Vgl. King/Fullerton (1984, S. 13), Sievert et al. (1989, S. 150).

94 Dies können je nach nationalen Bestimmungen Pensionsvereine, Lebensversicherungen, Wohlfahrtseinrichtungen etc. sein. Vgl. King/Fullerton (1984, S. 13), Sievert et al. (1989, S. 150).

95 Hierzu zählt laut King und Fullerton auch jenes Kapital, das die privaten Haushalte den Gesellschaften aufgrund von Versicherungsverträgen zur Verfügung stellen, welches diese wiederum anlegen. Die Versicherungsgesellschaften sind im allgemeinen nicht steuerbefreit. Der Körperschaftsteuersatz vermindert sich allerdings je nach nationaler Steuergesetzgebung. Vgl. King/Fullerton (1984, S. 9 und 13). 
Abbildung 5.1: Kapitalgeber, Finanzierungsart, Investor, Anlageart

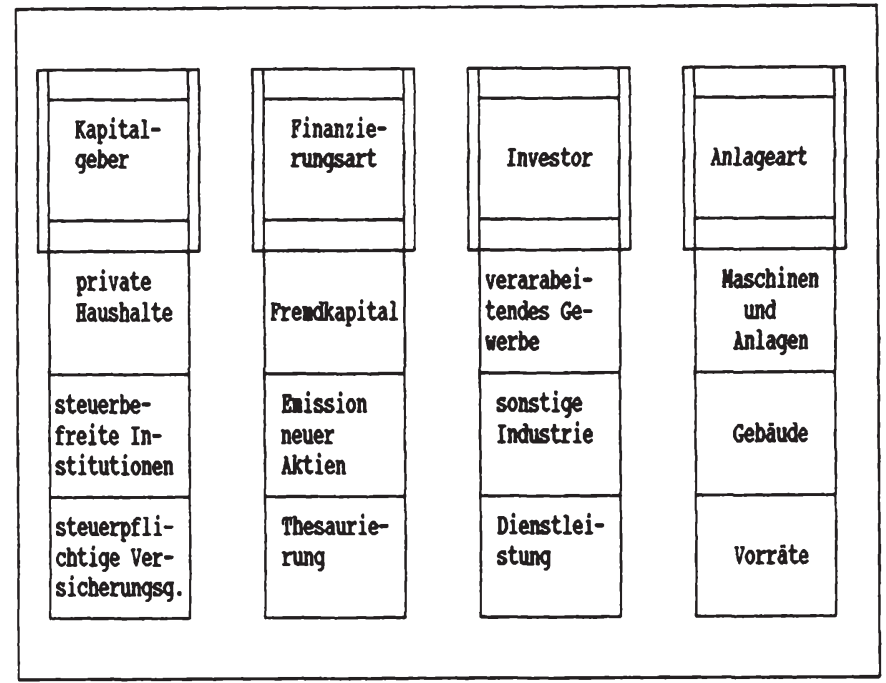

unter Berücksichtigung der wirtschaftlich zutreffenden Abnutzung (true economic depreciation), für die ein exponentieller Verlauf unterstellt wird. ${ }^{96}$ Die „true economic depreciation" entspricht den marktüblichen Wiederbeschaffungskosten für die verbrauchsbedingte Wertminderung. Bei konstanten Preisen stimmt der Abschreibungsbetrag über die gesamte Lebensdauer mit den historischen Anschaffungskosten überein; bei Inflation berechnet sich die wirtschaftlich zutreffende Absetzung anhand der Wiederbeschaffungskosten abzüglich des nominalen Vermögenszuwachses der Wirtschaftsgüter. ${ }^{97}$ Bei der Bewertung des Vorratsvermögens legen King und Fullerton die national divergierende, steuerlich zulässige Bewertungsmethode zugrunde. Werden dabei die am Jahresende noch vorhandenen Bestände mit den historischen Anschaffungskosten angesetzt, so führt c. p. eine durch Inflation verursachte Bestandswerterhöhung zu einem Inflationsgewinn (Scheingewinn), welcher der laufenden Besteuerung unterliegt. ${ }^{98}$

King und Fullerton gehen davon aus, daß das Unternehmen alle relevanten Steuervergünstigungen in Anspruch nehmen kann. ${ }^{99}$ Hierzu zählen sie die steuerlich zulässige Nor-

\footnotetext{
96 Vgl. King/Fullerton (1984, S. 29).

$97 \mathrm{Vgl}$. King (1977, S. 233 und 243 f.).

$98 \mathrm{Vgl}$. King/Fullerton (1984, S. 21).

$99 \mathrm{Vgl}$. King/Fullerton (1984, S. 27).
} 
malabschreibung, ${ }^{100}$ die Sofort- und Sonderabschreibungen ${ }^{101}$ sowie Investitionszulagen und Steuerkredite. ${ }^{102}$ Das betrachtete Unternehmen erzielt laut King und Fullerton generell steuerbare Gewinne, und, äquivalent dazu, Verluste werden mit dem identischen Steuersatz entlastet, mit dem Gewinne besteuert werden. ${ }^{103}$ Neben der inländischen Körperschaftsteuer betrachten King und Fullerton auch die von den Ländern ggf. auf den Unternehmensgewinn oder das -vermögen erhobenen lokalen Steuern ${ }^{104}$ sowie eine betriebliche Vermögensteuer der Kapitalgesellschaft. ${ }^{105}$ Ebenfalls von King und Fullerton berücksichtigt wird eine von dem inländischen Anteilseigner zu zahlende Vermögensteuer auf die Grenzinvestition, eine bei der Veräußerung ggf. zu leistende Steuer auf die Vermögenszuwächse (capital gains tax) sowie eine auf laufende Dividenden- oder Zinseinkünfte zu zahlende persönliche Steuer des Kapitalgebers. Unberücksichtigt bleiben die Schenkungsund Erbschaftsteuer sowie die Kapitalertragsteuer. ${ }^{106}$ Neben den Steuersätzen werden von King und Fullerton sowohl die aktuellen, länderspezifischen Inflationsraten ${ }^{107}$ als auch alternative Preissteigerungsraten $(0$ und $10 \%)$ in die Vergleichsrechnungen einbezogen, da sie den zu versteuernden nominalen Gewinn erhöhen und somit einen Einfluß auf den effektiven Grenzsteuersatz nehmen. King und Fullerton gehen davon aus, daß die Inflationsrate während der Laufzeit der Investition konstant ist. ${ }^{108}$

In einer Welt ohne Steuern entspricht laut King und Fullerton die Rendite eines investierenden Unternehmens (p) der zu leistenden Zahlung an den Kapitaleigner (r), d. h. dessen

100 Hierzu zählt die lineare oder degressive Abschreibung sowie andere planmäßige Absetzungen. King und Fullerton berücksichtigen auch die Möglichkeit des Unternehmens, während der steuerlich unterstellten Nutzungsdauer von der degressiven zur linearen Abschreibung zu wechseln. Vgl. King/Fullerton (1984, S. 19).

101 In Großbritannien konnten z. B. in 1980 Investitionen in Maschinen und Anlagen im Jahr der Anschaffung voll abgeschrieben werden. Für Industriegebäude war eine Sofortabschreibung in Höhe von $50 \%$ und für Hotels in Höhe von $20 \%$ zulässig. In den Folgejahren konnte der nach der Sofortabschreibung verbleibende Betrag mit linear $4 \%$ abgeschrieben werden. Geschäftshäuser und Grundstücke konnten nicht abgeschrieben werden. Der Effekt der großzügigen Abschreibungsregeln war, daB die Unternehmen hauptsächlich in jenen Bereichen Investitionen tätigten, die ihnen eine höchstmögliche Sofortabschreibung garantierten. Vgl. King/Fullerton (1984, S. 42 f.).

102 Diese Zulagen sind gebunden an Investitionen, die in besonderen Regionen (z. B. strukturell schwachen Gebieten mit hoher Arbeitslosigkeit) oder aber in bestimmten Bereichen (z. B. Forschung und Entwicklung, Energiesektor) vorgenommen werden. Vgl. King/Fullerton (1984, S. 19, 48 f. und $166 \mathrm{f}$.).

103 Vgl. King/Fullerton (1984, S. 27).

104 Bei der Berechnung des Steuersatzes für Unternehmen $(\tau)$ wurden für die Bundesrepublik Deutschland die Gewerbe- und die Grundsteuer berücksichtigt. Vgl. King/Fullerton (1984, S. 168 ff.).

$105 \mathrm{Vgl}$. King/Fullerton (1984, S. 20 und 23).

Die in dem Vereinigten Königreich lokal erhobenen Rates werden von King und Fullerton als abzugsfähige Vermögensteuer auf Gebäude erfaBt. Vgl. King/Fullerton (1984, S. 313).

106 Vgl. King/Fullerton (1984, S. 27).

107 Die Inflationsrate betrug für das Jahr 1980 in Großbritannien 13,57 \%, in Schweden 9,4 \%, in der Bundesrepublik Deutschland 4,2 \% und in den Vereinigten Staaten von Amerika 6,77 \%. Vgl. King/Fullerton (1984, S. 313).

$108 \mathrm{Vgl}$. King/Fullerton (1984, S. 17 f. und 313). 
Rendite (s): 109

$$
p=r=s .
$$

Die von einem Kapitalgeber empfangene Zahlung entspricht dabei dem nominalen Zinssatz (i), d. h. für den privaten Haushalt, die steuerbefreite Institution bzw. die steuerpflichtige Versicherungsgesellschaft gilt: ${ }^{110}$

$$
r=i
$$

King und Fullerton gehen davon aus, daß dieser Zinssatz eine bedeutende Rolle sowohl bei der Investitionsentscheidung eines Unternehmens als auch bei dem Sparverhalten eines privaten Haushaltes spielt. ${ }^{111}$

Werden Steuern erhoben, so kann die Rendite eines inländischen Unternehmens (p), die Vergütung eines Kapitalgebers ( $r$ ) sowie die diesem nach Steuern verbleibende Rendite (s) voneinander abweichen. ${ }^{112}$ Ausgangsbasis der Analyse ist für King und Fullerton daher die Frage: „What is the minimum rate of return it must yield before taxes in order to provide the saver with the same net of tax return he would receive from lending at the market interest rate? ${ }^{413}$ Diese Mindestrendite vor Unternehmensteuer wird als Kapitalkosten bezeichnet und ist laut King und Fullerton abhängig von der Branchenzugehörigkeit eines Unternehmens, der Finanzierungsart des hypothetischen Projektes und dem inländischen Kapitalgeber. Für eine gegebene Kombination dieser Faktoren ergibt sich: ${ }^{114}$

$$
p=f(r)
$$

Die Kapitalkostenfunktion, $f(r)$, ist abhängig von den Einzelregelungen des Steuersystems, den Abschreibungsregelungen, den staatlichen Zulagen, der Bewertung des Vorratsvermögens etc. ${ }^{115}$ welche in den folgenden Kapiteln näher analysiert werden.

Die Grenzkosten des Projektes beinhalten laut King und Fullerton in einer Welt mit Steuern sowohl die an den Kapitalgeber zu leistende Verzinsung seines eingesetzten Kapitals als auch die an den Fiskus zu leistende Zahllast. ${ }^{116}$ King und Fullerton nehmen dabei an, daB dem nationalen Investor die für die Berechnung der Grenzkosten benötigten nomina-

\footnotetext{
$109 \mathrm{Vgl}$. King/Fullerton (1984, S. 11).

110 Ohne Berücksichtigung einer Inflationsrate. Vgl. King/Fullerton (1984, S. 10).

$111 \mathrm{Vgl}$. King/Fullerton (1984, S. 10).

112 Vgl. Harberger (1966, S. 108), King/Fullerton (1984, S. 9).

113 King/Fullerton (1984, S. 10).

$114 \mathrm{Vgl}$. King/Fullerton (1984, S. 10).

$115 \mathrm{Vgl}$. King/Fullerton (1984, S. 10).

116 Vgl. King/Fullerton (1984, S. 8, 10 und 14).
} 
len Steuersätze bekannt sind und während des Investitionszeitraumes konstant bleiben. ${ }^{117}$ Die Gesamtsteuerbelastung ist laut King und Fullerton abhängig von der Steuerlast des Unternehmens, der Interaktion des Steuersystems mit Inflation, der steuerlich zulässigen Abschreibung sowie der Bewertung von Vorräten, dem Einkommensteuersatz des privaten Haushaltes, der Versteuerung von Einnahmen aus unterschiedlichen Einkunftsarten, der Existenz von Vermögensteuern etc. ${ }^{118}$

Um die Steuersysteme verschiedener Nationen darstellen zu können, unterscheiden King und Fullerton bei der Berechnung des effektiven und des durchschnittlichen effektiven Grenzsteuersatzes einer geplanten inländischen Investition zwei Fälle. Zum einen gehen sie davon aus, daß in einem Kapitalmarktgleichgewicht der Grenzertrag unterschiedlicher Realinvestitionen, ${ }^{119}$ unter Berücksichtigung alternativer Finanzierungsinstrumente, bei einem den Gewinn maximierenden Unternehmen ( $p$ ) durch den Marktzinssatz ( $r$ ) determiniert wird. Im Rahmen dieses, von King und Fullerton als fixed-p bezeichneten Falles, unterstellen sie daher, daß alle alternativen Grenzinvestitionen eine identische Rendite in Höhe von jährlich real $10 \%$ vor Steuern erzielen. Dies ermöglicht es ihnen, für jedes Projekt den einem Kapitalgeber verbleibenden Ertrag nach Steuern (s) zu berechnen. Aufgrund der Differenz zwischen der Unternehmensrendite vor Steuern und der vom Investor erzielten Verzinsung nach Steuern kann dabei sowohl die Gesamtsteuerbelastung (w) als auch der effektive Grenzsteuersatz $(\mathrm{t})$ ermittelt werden. ${ }^{120}$ Zum anderen gehen King und Fullerton davon aus, daß ein inländischer privater Haushalt unabhängig von der Kapitalanlageart einen identischen Zinssatz nach Unternehmensteuer und vor persönlichen Steuern erzielen will, d. h. sie gehen von einer einheitlichen Rendite eines Kapitalgebers in Höhe des realen Zinssatzes (r) von $5 \%$ für alle zur Wahl stehenden Projekte aus. Dabei nehmen King und Fullerton an, daß der Kapitaleigner eine identische Nettorendite (s) für alle inländischen Anlagearten erzielt. Auf alle Einkünfte aus Kapitalvermögen muß folglich ein einheitlicher Einkommensteuersatz angewendet werden, so daß lediglich die Rendite eines Kapitaleigners vor Steuern in die Betrachtung von King und Fullerton einbezogen wird. Der Ertrag nach Einkommensteuern kann von der Rendite nach Steuern eines anderen Anlegers abweichen, wenn unterschiedliche Einkommensteuersätze erhoben werden. Bei diesem, als fixed-r benannten Fall, variiert laut King und Fullerton die Rendite vor Unternehmensteuern eines Investors bei den verschiedenen Anlagearten, d. h. auf Unternehmensebene werden Eigen- und Fremdkapital unterschiedlich besteuert. ${ }^{121}$

\footnotetext{
117 Vgl. King/Fullerton (1984, S. 18).

118 Vgl. King/Fullerton (1984, S. 9).

119 Das heißt, es werden Maschinen und Anlagen, Gebäude und Vorräte, aber keine Finanzanlagen erworben.

120 Vgl. King/Fullerton (1984, S. 10 f.).

121 Vgl. King/Fullerton (1984, S. 10 und 12).

Otto Roloff, Sibylle Brander, Ingo Barens and Claudia Wesselbaum - 978-3-631-75210-4 
Nicht in die Betrachtung einbezogen wird die steuerliche Bemessungsgrundlage, da diese nach Ansicht von King und Fullerton zum einen die Wechselwirkungen zwischen Personenund Unternehmensteuern ignoriere (z. B. Anrechnungssysteme) und zum anderen lediglich die Steuerrate des realisierten Kapitaleinkommens wiedergeben würde. Angaben über die für zusätzliche Investitionen notwendigen Anreize würden durch den anhand der steuerlichen Bemessungsgrundlage ermittelten Steuersatz nicht gegeben. ${ }^{122}$

Die aufgrund der oben dargelegten Annahmen von King und Fullerton ermittelten Resultate wurden und werden vielfach zitiert und als Grundlage für Steuerwirkungsanalysen verwendet. ${ }^{123}$ Die Vorgehensweise von King und Fullerton ist allerdings in mehreren Punkten nicht plausibel und zum Teil widersprüchlich. Dies, wird im folgenden dargelegt.

Die von King und Fullerton zugrundegelegte Marginalanalyse impliziert, daß die Unternehmen ein Gewinnmaximum und die Haushalte ein Nutzenmaximum anstreben. Dabei verfügen sie über vollkommene Informationen hinsichtlich ihrer Handlungsalternativen und deren Resultate. ${ }^{124}$ Die Güterpreise, der Nominallohn und der Zinssatz werden als gegeben angenommen. Die Marktteilnehmer verfügen weder über räumliche, persönliche noch sachliche Präferenzen und besitzen vollständige Preisinformation. Die Wirtschaftssubjekte verhalten sich auf allen Märkten als Mengenanpasser, d. h. es existiert vollständige Konkurrenz. Damit kurzfristig auftretende Preisdifferenzen immer ausgeglichen werden, ist es erforderlich, daß die Produktionsfaktoren vollständig mobil sind und in jedem Wirtschaftsbereich eingesetzt werden können. ${ }^{125}$ Der Gewinn des Unternehmens entspricht der Differenz zwischen den Umsatzerlösen sowie den Arbeits- und Kapitalkosten und ist im Gewinnmaximum Null, d. h., es wird kein Extraprofit erzielt. Die Gesamtsteuerbelastung ergibt sich aus der Differenz zwischen der Rendite des Unternehmens vor Steuern und der dem Kapitaleigner nach Abzug der Unternehmensteuern sowie der individuellen Steuern verbleibenden Rendite, d. h.

$$
w=p-s
$$

Inwieweit die Gesamtsteuerbelastung (w) für alle inländischen Kapitalgeber bei den von King und Fullerton analysierten Fällen identisch ist, wird im folgenden exemplarisch für

\footnotetext{
122 Vgl. King/Fullerton (1984, S. 7 f.).

King und Fullerton machen dabei keine Angaben darüber, welche Anreize gewährt werden müßten, um zusätzliche Investitionen zu initiieren.

${ }^{123}$ Auf Grundlage des Modells von King und Fullerton haben z. B. Daly et al. (1985) eine vergleichende Studie für Kanada, Schweden, das Vereinigte Königreich, die Vereinigten Staaten von Amerika und die Bundesrepublik Deutschland erstellt. Devereux (1990) sowie Devereux und Pearson (1990) haben unter Zugrundelegung des Modells effektive Grenzsteuersätze für das verarbeitende Gewerbe in verschiedenen OECD Nationen ermittelt. Die Studien für die OECD werden im Kapitel 5.3.3 dargestellt.

$124 \mathrm{Vgl}$. Fullerton et al. (1982, S. 581).

125 Vgl. Fullerton et al. (1982, S. 581), Geigant et al. (1987, S. 472).
} 
die privaten Haushalte analysiert. Eine detailierte Analyse hinsichtlich der Einbeziehung steuerlicher oder ökonomischer Abschreibungen, der Berücksichtigung von inflationsbedingten Scheingewinnen etc. wird nicht vorgenommen, da zunächst überprüft wird, inwieweit es möglich ist, in das Modell der vollständigen Konkurrenz nationale Steuersysteme zu integrieren, um Rückschlüsse auf die gewährten Investitionsanreize und das Verhalten von Unternehmen ziehen zu können.

Bei der Betrachtung wird, entsprechend der Vorgehensweise von King und Fullerton, zum einen unterstellt, daß das Unternehmen eine identische Bruttorendite erzielt, welche sowohl die Steuerbelastung des Unternehmens als auch die des privaten Haushaltes beinhaltet (fixed-p Fall). Zum anderen wird überprüft, wie hoch die Rendite vor Unternehmensteuern in Abhängigkeit von der Finanzierungsart sein muß, um dem privaten Haushalt eine identische Rendite vor persönlicher Steuer zahlen zu können (fixed-r Fall).

Die Analyse begrenzt sich auf die Betrachtung der lokalen und nationalen Steuerbelastung ohne Vermögensteuer ${ }^{126}$ in der Bundesrepublik Deutschland, dem Vereinigten Königreich und den Vereinigten Staaten von Amerika. Außer acht bleibt die Kapitalertragsteuer, da im Rahmen der Analyse von einer geschlossenen Volkswirtschaft ausgegangen wird. Die von der Kapitalgesellschaft ggf. einzubehaltene Quellensteuer ist bei der Ertragsteuer des Kapitaleigners in voller Höhe anrechenbar, so daß die Kapitalertragsteuer einen durchlaufenden Posten darstellt und die Gesamtsteuerbelastung nicht beeinflußt. Als Unternehmensteuer wird in Anlehnung an King und Fullerton die von der Kapitalgesellschaft zu leistende Körperschaftsteuer und die lokal erhobene Ertragsteuer definiert. Die Einkommensteuer der privaten Haushalte beinhaltet die auf die Einkünfte zu leistende persönliche Steuer, vermindert um die anrechenbare Unternehmensteuer.

Hinsichtlich der Finanzierungsform wird zwischen der vollen Fremdfinanzierung sowie der hundertprozentigen Eigenfinanzierung bei Dividendenzahlung und Thesaurierung unterschieden. Im Falle der Gewinneinbehaltung erfolgt die Realisierung der Rendite erst zum Zeitpunkt einer Veräußerung der Aktien, d. h. nicht durch eine spätere Dividendenauszahlung der akkumulierten Beträge. Zinseszinsen werden dabei nicht berücksichtigt. Die aus der inländischen Grenzinvestition erzielte Rendite wird an den Kapitaleigner, d. h. privaten Haushalt, weitergeleitet. Referenzgröße für einen privaten Haushalt ist die für ein festverzinsliches Wertpapier erzielbare Rendite nach persönlicher Einkommensteuer. Das bei dem privaten Haushalt zu versteuernde Einkommen $(G)$ entspricht dem nominalen Zinssatz (i). Die einem Kapitaleigner nach Abzug der Steuer $\left(\mathrm{w}_{H H}\right)$ verbleibende Rendite

$\overline{126}$ Die Vermögensteuer ist nicht nur abhängig von der Finanzierungsart sondern ebenso von der Verwendung des Kapitals. Um die Substanzsteuer mit in die Analyse einzubeziehen wäre es daher erforderlich, weitergehende Annahmen bezüglich der Anlageform zu treffen. In Großbritannien handelt es sich bei der lokalen Steuer um eine Vermögensteuer, die nicht in die Betrachtung einbezogen wird. 
(s) beträgt:

$$
s=i\left(1-t_{I}\right)
$$

Unabhängig von der betrachteten Nation ergibt sich für die Gesamtsteuerbelastung (w):

$$
w=G t_{I}=i t_{I}
$$

Ein privater Haushalt wird sich hinsichtlich seiner Kapitalanlage indifferent verhalten, wenn die aus dem festverzinslichen Wertpapier erzielbare Nettorendite der bei einer Anlage des Kapitals in einem Unternehmen realisierbaren Rendite nach Steuern entspricht.

\subsubsection{2 fixed-p Fall}

Im folgenden wird unter Annahme des fixed-p Falles ${ }^{127}$ untersucht, inwieweit die Belastung mit Unternehmen- und privater Steuer je nach Finanzierungsart variiert oder identisch ist. Bei der Berechnung der Gesamtsteuerbelastung werden in Übereinstimmung mit der Vorgehensweise von King und Fullerton drei Fälle unterschieden und zwar zum einen die Kapitalanlage

a) als Fremdkapital,

b) als Eigenkapital mit Dividendenzahlungen und

c) als Eigenkapital bei Thesaurierung.

\section{a) Fremdkapital}

Erwirbt der private Haushalt eine Schuldverschreibung eines Unternehmens, so muß das Unternehmen eine vertraglich vereinbarte Schuldzinsleistung an den Kapitalgeber zahlen. Neben dem Kapitalgeber muß daher auch das Unternehmen in die Analyse einbezogen werden, um zu überprüfen, inwieweit eine kapitalaufnehmende Gesellschaft steuerlich belastet ist und welche Konsequenzen sich hieraus für die Gesamtsteuerbelastung ergeben.

Die Schuldzinsen sind in den betrachteten Staaten bei der Ermittlung des zu versteuernden Einkommens der Kapitalgesellschaft abzugsfähig. In Großbritannien und den USA wird bei einer Fremdfinanzierung keine Ertrag- oder Substanzsteuer von dem Unternehmen erhoben, d. h. eine Unternehmensteuer entfällt $\left(w_{U N}=0\right)$. Die zu leistenden Zinsen (i) entsprechen laut Annahme der erzielten Rendite, $d . h$. in diesem Fall p. Dem Unternehmen verbleibt kein körperschaftsteuerpflichtiger Gewinn $(\pi), d$. h.

$$
\begin{aligned}
\pi & =p-i \\
& =0 .
\end{aligned}
$$

127 Im Rahmen des fixed-p Falles wird unterstellt, dab die Rendite des Unternehmens vor Steuern (p) für alle Finanzierungsarten identisch ist. 
Der Kapitaleigner muß die erhaltenen Zinserträge seinem persönlichen Ertragsteuersatz unterwerfen, d. h. das marginale Einkommen entspricht:

$$
G=i
$$

In Großbritannien und den USA verbleibt einem Kapitalgeber daher eine Rendite nach Steuern in Höhe von:

$$
s=i\left(1-t_{I}\right) \text {. }
$$

Für die Gesamtsteuerbelastung gilt in Großbritannien und den USA daher:

$$
w_{H H}=i t_{I}=w
$$

Im Gegensatz hierzu wird in der Bundesrepublik Deutschland auf die zu zahlenden Schuldzinsen eine lokale Gewerbeertragsteuer ${ }^{128}$ erhoben. Die von dem Unternehmen zu zahlenden Zinsen sowie die lokale Steuer $\left(t_{L}\right)$ sind bei der Ermittlung des zu versteuernden Einkommens der Kapitalgesellschaft gewinnmindernd zu berücksichtigen. Damit ein Unternehmen die Zins- und Steuerverpflichtungen erfüllen kann, muß die erzielte Rendite neben der Zinszahlung auch die Gewerbeertragsteuer beinhalten, $d$. h.

$$
\begin{aligned}
p & =i+0,5 i t_{L} \\
& =i\left(1+0,5 t_{L}\right)
\end{aligned}
$$

Die Rendite eines Unternehmens vor Steuern weicht somit in der Bundesrepublik Deutschland von den Zinseinkünften eines privaten Haushaltes vor der individuellen Ertragsteuer in Großbritannien und den USA ab, d. h.

$$
p \neq i
$$

Das körperschaftsteuerpflichtige Einkommen eines Unternehmens in der Bundesrepublik Deutschland beläuft sich aufgrund der Abzugsfähigkeit der Zinszahlung und der Gewerbeertragsteuerzahlung auf:

$$
\pi=p-i\left(1+0,5 t_{L}\right)=0 .
$$

$\overline{128}$ Bei dem Gewerbeertrag müssen 50 v. H. der Schuldzinsen dem Gewinn gem. $\S 8$ GewStG hinzugerechnet werden. Die Abzugsfähigkeit der Gewerbeertragsteuer bei der Ermittlung des zu versteuernden Einkommens wird bei der Berechnung des Steuersatzes berücksichtigt. Siehe hierzu auch King/Fullerton (1984, S. 169). Neben der Gewerbeertragsteuer wird eine lokale Gewerbekapitalsteuer berechnet. Diese, von dem Vermögen abhängige Steuer, wird gleichfalls, wie die Vermögensteuer, nicht in die Analyse einbezogen. 
Für die Unternehmensteuerbelastung $\left(w_{U N}\right)$ gilt:

$$
w_{U N}=i 0,5 t_{L}
$$

Bei dem Kapitaleigner unterliegen die Zinseinkünfte der individuellen Ertragsteuer, d. h.

$$
G=i
$$

wobei für die Ertragsteuerbelastung des Haushaltes gilt:

$$
w_{H H}=i t_{I}
$$

Die Rendite eines in der Bundesrepublik Deutschland ansässigen Kapitaleigners beläuft sich demnach auf:

$$
s=i\left(1-t_{I}\right)
$$

Die Gesamtsteuerbelastung in der Bundesrepublik Deutschland beträgt somit:

$$
\begin{aligned}
w & =0,5 i t_{L}+i t_{I} \\
& =i\left(0,5 t_{L}+t_{I}\right)
\end{aligned}
$$

\section{b) Eigenkapital und Dividendenzahlungen}

Erwirbt der inländische Kapitalgeber Aktien eines inländischen Unternehmens, so ist die Dividendenleistung im Gegensatz zu einer Zinszahlung bei der Ermittlung der steuerlichen Bemessungsgrundlage einer Kapitalgesellschaft in keiner der betrachteten Nationen abzugsfähig. Wāhrend der Fremdkapitalgeber sowohl in Falle eines Gewinnes als auch in Verlustjahren des Investors eine Forderung auf die festgelegte Verzinsung seines eingesetzten Kapitals gegenüber der Gesellschaft hat, kann der Aktionär keinen vertraglich geregelten Anspruch auf Dividende geltend machen. Die Steuerbelastung des Unternehmens verringert zudem die Rendite des Anteilseigners. Darüber hinaus unterliegt die erzielte Rendite sowohl bei dem Unternehmen als auch bei dem privaten Haushalt einer Ertragsbesteuerung. Die Nationen wenden unterschiedliche Methoden an, um die hieraus resultierende Doppelbesteuerung ${ }^{129}$ zu vermeiden und die Gesamtsteuerbelastung zu minimieren.

\section{ba) klassisches System}

129 In den von King und Fullerton betrachteten Staaten wird das klassische System (Vereinigte Staaten von Amerika und Schweden), das System der Teilanrechnung anhand eines auf den Ausschüttungobetrag anzuwendenden Satzes (Vereinigtes Königreich) und das Vollanrechnungssystem (Bundesrepublik Deutschland) durchgeführt. Die folgenden Ausführungen beschränken sich daher auf diese Methoden. 
Das klassische System wird derzeit unter anderem in den Vereinigten Staaten von Amerika und Schweden ${ }^{130}$ angewendet. Die Nichtabzugsfähigkeit der Leistung an einen Eigenkapitalgeber führt dazu, daß das körperschaftsteuerpflichtige Einkommen ${ }^{131}$ mit der erzielen Rendite vor Steuer übereinstimmt.

$$
\pi=p
$$

Für die Steuerbelastung des Unternehmens ergibt sich daher:

$$
\begin{aligned}
w_{U N} & =p t_{L}+p\left(1-t_{L}\right) t_{C} \\
& =p\left(t_{L}+t_{C}-t_{L} t_{C}\right)
\end{aligned}
$$

Die bei einem Anteilseigner zugeflossene Dividende $(r)^{132}$ ergibt sich aus der Rendite eines Unternehmens vor Steuern, vermindert um die einzubehaltende nationale und lokale Ertragsteuer:

$$
D_{N}=r=p\left(1-t_{L}-t_{C}+t_{L} t_{C}\right) .
$$

Im Rahmen des klassischen Systems wird die Doppelbelastung von Dividendeneinkünften weder vermindert noch vermieden. Ein Kapitaleigner muß die zugeflossene Dividende seinem persönlichen Ertragsteuersatz unterwerfen; eine Anrechnung der von einem Unternehmen bereits geleisteten Steuer findet nicht statt. Die von einem Aktionär zu versteuernde marginale Bruttodividende $(\mathrm{G})$ ist identisch mit dem zugeflossenen Ausschüttungsbetrag, d. h.

$$
G=r
$$

Für die Steuerbelastung des privaten Haushaltes ergibt sich:

$$
\begin{aligned}
w_{H H} & =G t_{I} \\
& =p\left(1-t_{L}-t_{C}+t_{L} t_{C}\right) t_{I}
\end{aligned}
$$

Die nach Steuern verbleibende Rendite beläuft sich auf:

$$
s=p\left(1-t_{L}-t_{C}+t_{L} t_{C}\right)\left(1-t_{I}\right)
$$

$\overline{130}$ In der weiteren Betrachtung wird auf das Steuersystem von Schweden nicht eingegangen.

131 In den USA wird neben der bundesstaatlich geregelten Körperschaftsteuer eine national geregelte Steuer erhoben, welche die Bemessungsgrundlage für die Bundessteuer verringert. Diese lokale Steuer ist nicht identisch mit der Gewerbesteuer in der Bundesrepublik Deutschland.

132 King und Fullerton bezeichnen die Rendite nach Unternehmensteuer und den realen Zinssatz als r. In der vorliegenden Arbeit wird der reale Zinssatz mit der Variablen $i_{r}$ gekennzeichnet. 
Die Gesamtsteuerbelastung beträgt in diesem Fall:

$$
\begin{aligned}
w & =p\left(t_{L}+t_{C}-t_{L} t_{C}\right)+p\left(1-t_{L}-t_{C}+t_{L} t_{C}\right) t_{I} \\
& =p\left[t_{L}+t_{C}-t_{C} t_{L}+t_{I}\left(1-t_{L}-t_{C}+t_{L} t_{C}\right)\right] .
\end{aligned}
$$

bb) Teilanrechnung

Das Teilanrechnungsverfahren wird innerhalb der betrachteten Staaten in dem Vereinigten Königreich angewendet. Aufgrund der steuerlichen Nichtabziehbarkeit von Dividendenzahlungen ist die erzielte Bruttorendite identisch mit dem körperschaftsteuerpflichtigen Einkommen. Eine lokale Ertragsteuer wird in Großbritannien nicht erhoben. Für die Unternehmensteuerbelastung bedeutet dies:

$$
w_{L^{\prime} N}=p t_{C}
$$

Der Ausschüttungsbetrag beläuft sich auf:

$$
r=p\left(1-t_{C}\right)
$$

Bei dem Teilanrechnungsverfahren erfolgt eine Gutschrift der Unternehmensteuer in Höhe des sich aus der Multiplikation der einem Kapitaleigner nach Unternehmensteuern zufließenden Dividende mit einem im nationalen Steuergesetz festgelegten Anrechnungssatz (c) ergebenden Betrages. Der gewährte Erstattungsbetrag muß bei einem Kapitaleigner der empfangenen Dividende hinzuaddiert werden und unterliegt dem persönlichen Einkommensteuersatz. Für die zu versteuernde Bruttodividende ergibt sich daher:

$$
G=p\left(1-t_{C}\right)(1+c)
$$

Die Ertragsteuerbelastung des privaten Haushaltes berechnet sich aus:

$$
\begin{aligned}
w_{H H} & =p\left(1-t_{C}\right)(1+c) t_{I}-p\left(1-t_{C}\right) c \\
& =p\left(1-t_{i}\right)\left[(1+c) t_{I}-c\right] .
\end{aligned}
$$

Einem Kapitaleigner in Großbritannien verbleibt demnach eine Rendite nach Abzug der Steuern und unter Berücksichtigung der Teilanrechnung in Höhe von:

$$
\begin{aligned}
s & =p\left(1-t_{C}\right)(1+c)\left(1-t_{I}\right)-p\left(1-t_{C}\right) c \\
& =p\left(1-t_{C}\right)\left[(1+c)\left(1-t_{I}\right)-c\right] .
\end{aligned}
$$


Die (resamtsteuerbelastung beträgt. somit:

$$
\begin{aligned}
w & =p t_{C}+p\left(1-t_{C}\right)(1+c) t_{I}-p\left(1-t_{C}\right) c \\
& =p\left[t_{C}+t_{I}\left(1-t_{C}\right)(1+c)-c\left(1-t_{C}\right)\right]
\end{aligned}
$$

bc) Vollanrchnung

1)as Vollanrechnungsverfahren wird derzeit in der Bundesrepublik Deutschland angewendet. Die: steuerliche Nichtberücksichtigung des Entgeltes an inländische Kapitaleigner führt dazu. daß auf die Rendite eines Unternehmens sowohl die Gewerbeertragsteuer als auch eine verringerte hörperschaftsteuer $\left(\mathrm{t}_{C W A}\right) \mathrm{zu}$ leisten ist. Für das körperschaftsteucrpflichtige Einkommen gilt aufgrund der Abzugsfähigkeit der lokalen Steuer:

$$
\pi=p\left(1-t_{L}\right)
$$

I)ic gesamte Unternehmensteuerbelastung beläuft sich auf:

$$
\begin{aligned}
w_{U N} & =p t_{L}+p\left(1-t_{L}\right) t_{C W A} \\
& =p\left(t_{L}+t_{C W A}-t_{L} t_{C W A}\right) .
\end{aligned}
$$

J.)er Dividendenertrag eines inländischen Aktionärs beträgt unter Berücksichtigung der lokalen Steuer:

$$
\begin{aligned}
r & =p\left(1-t_{L}\right)-p\left(1-t_{L}\right) t_{(W A} \\
& =p\left(1-t_{L}-t_{C W A}+t_{L} t_{C W A}\right)
\end{aligned}
$$

Im Rahmen des Vollanrechnungsverfahrens wird einem inländischen Anteilseigner die von einer Kapitalgesellschaft einbehaltene Körperschaftsteuer auf die Dividende in voller Höhe gutgeschrieben. Der Anrechnungssatz (c) ist in diesem Fall gleich eins. Die Steuergutschrift wird der empfangenen Dividende hinzugerechnet und erhöht das steuerpflichtige Einkommen. Die ggf. zusätzlich erhobene lokale Steuer wird nicht angerechnet. Bemessungsgrundlage für die Berechnung der persönlichen Ertragsteuer ist daher:

$$
\begin{aligned}
(\dot{r} & =p\left(1-t_{L}\right)\left(1-t_{C W A}\right)+p\left(1-t_{L}\right)\left(1-t_{C W A}\right) \frac{t_{C W A}}{\left(1-t_{C W A}\right)} \\
& =p\left(1-t_{L}\right)-p\left(1-t_{L}\right) t_{C W A}+p\left(1-t_{L}\right) t_{C W A} \\
& =p\left(1-t_{L}\right) .
\end{aligned}
$$

Die Steuerbelastung eines privaten Haushaltes beläuft sich auf:

$$
\begin{aligned}
w_{I H I} & =p\left(1-t_{L}\right) t_{I}-p\left(1-t_{L}\right) t_{C W A} \\
& =p\left(1-t_{L}\right)\left(t_{I}-t_{\left(W_{A}\right.}\right) .
\end{aligned}
$$


Für die Rendite nach Steuern gilt demnach:

$$
\begin{aligned}
s & =p\left(1-t_{L}\right)-p\left(1-t_{L}\right)\left(t_{I}-t_{C W A}\right) \\
& =p\left(1-t_{L}\right)\left[1-\left(t_{I}-t_{C W A}\right)\right] \\
& =p\left(1-t_{L}\right)\left(1-t_{I}+t_{C W A}\right) .
\end{aligned}
$$

Die Gesamtsteuerbelastung resultiert aus der nicht anrechenbaren lokalen Steuer zuzüglich der von einem privaten Haushalt zu leistenden Einkommensteuer. d. h.

$$
\begin{aligned}
w & =p t_{L}+p\left(1-t_{L}\right) t_{C W A}+p\left(1-t_{L}\right) t_{I}-p\left(1-t_{L}\right) t_{C W^{\prime} A} \\
& =p\left[t_{L}+\left(1-t_{L}\right) t_{I}\right] .
\end{aligned}
$$

Die von einer Kapitalgesellschaft einbehaltene Körperschaftsteuer auf Dividendendenzahlungen stellt im Rahmen des Vollanrechnungsverfahrens somit lediglich einen durchlaufenden Posten dar, entsprechend der Kapitalertragsteuer.

\section{c) Eigenkapital bei Thesaurierung}

Im Gegensatz zu der Gewinnausschüttung erfolgt bei der Thesaurierung kein hapitalfluß von dem Unternehmen zu dem privaten Haushalt in Wirtschaftsjahr der Renditerzielung. Die Einkünfte müssen nur bei einem Unternehmen versteuert werden; eine Besteuerung bei einem Kapitaleigner entfällt zunächst. Gleichzeitig verzichtet dieser allerdings auch auf Liquidität, während er der Gesellschaft Mittel zur freien Verfügung stellt. Das körperschaftsteuerlich zu erfassende Einkommen je Periode (n), ${ }^{133}$ in der ein Kapitaleigner Aktien hält, entspricht in Großbritannien und den Vereinigten Staaten von Amerika der erzielten Rendite eines Unternehmens:

$$
n \pi=n p .
$$

In der Bundesrepublik Deutschland weicht das zu versteuernde Einkommen in jeder Perjode in Höhe der zu leistenden Gewerbeertragsteuer von der Bruttorendite ab:

$$
n \pi=n p\left(1-t_{L}\right)
$$

Die Gesamtsteuerbelastung beläuft sich im Wirtschaftsjahr der Gewinnentstehung in der Bundesrepublik Deutschland und in den USA jeweils auf:

$$
\begin{aligned}
w_{U N} & =n p t_{L}+p\left(1-t_{L}\right) t_{C} \\
& =n p\left(t_{L}+t_{C}-t_{L} t_{C}\right)
\end{aligned}
$$

$\overline{133}$ Laut Annahme von King und Fullerton werden die Aktien im Durchschnitt 10 Jahre gehalten. Eine Verzinsung der einbehaltenen Rendite erfolgt nicht. Vgl. King/ Fullerton (1984, S. 23 f.). 
In Großbritannien muß zusätzlich zu der Körperschaftsteuer keine lokale Ertragsteuer geleistet werden, $d . h$.

$$
w_{U N}=n p t_{C}
$$

Der dem Unternehmen nach Steuern verbleibende Thesaurierungsbetrag $\left(T_{H}\right)$ je Wirtschaftsjahr beläuft sich auf:

$$
T_{H}=n p\left(1-w_{U N}\right)
$$

Im Zeitpunkt des Zuflusses der akkumulierten Rendite ${ }^{134}$ bei dem privaten Haushalt, d. h. bei einer Veräußerung der Aktien nach Ablauf der n-ten Periode, erfolgt je nach Nation eine unterschiedliche Besteuerung. In Großbritannien und den USA unterliegt die realisierte Wertsteigerung einer capital gains tax $(z) ;^{135}$ eine Voll- oder Teilanrechnung der von dem Unternehmen bereits geleisteten Ertrag- und Substanzsteuer unterbleibt. Das zu versteuernde Einkommen eines privaten Haushaltes ist identisch mit der Rendite nach Unternehmensteuer (r), d. h. der Kapitalzufluß beträgt annahmegemäß in Großbritannien:

$$
r=G=n p\left(1-t_{C}\right)
$$

sowie in den Vereinigten Staaten von Amerika:

$$
r=G=n p\left(1-t_{L}-t_{C}+t_{L} t_{C}\right)
$$

Dic sich hicraus ergebende Steuerbelastung eines privaten Haushaltes beläuft sich in Großbritannien auf:

$$
w_{H H}=n p\left(1-t_{C}\right) z
$$

und in den USA:

$$
w_{H H}=n p\left(1-t_{L}-t_{C}+t_{L} t_{C}\right) z .
$$

134 Laut Annahme von King und Fullerton entspricht der akkumulierte Thesaurierungsbetrag dem Wertzuwachs der Aktien, so daß in jedem Fall eine Wertsteigerung gegeben ist. Vgl. King/Fullerton (1984, S. 23 f.).

$135 \mathrm{z}$ entspricht dem effektiven Steuersatz auf entstandene Vermögenszuwächse, welcher die aus der Steuerstundung resultierenden Erträge beinhaltet. Laut King und Fullerton führt der Vermögenszuwachs einer Einheit in der ersten Periode zu einem realisierten (jewinn in Höhe von $\epsilon$ und einem nicht realisierten Frtrag in Höhe von $1-\epsilon$. Unter der Annahme, daß $\epsilon$ konstant ist, ergibt sich fïr $z=\epsilon z_{s} / \epsilon+\sigma$, wobei $\sigma$ dem nominalen Kalkulationssatz des Investors entspricht. Vgl. King/Fullerton (1984, S. 23). 
Dem Kapitaleigner in Großbritannien verbleibt demnach eine Rendite nach Steuern von:

$$
s=n p\left(1-t_{C}\right)(1-z)
$$

und in den Vereinigten Staaten von Amerika in Höhe von:

$$
s=n p\left(1-t_{L}-t_{C}+t_{L} t_{C}\right)(1-z) .
$$

Für die Gesamtsteuerbelastung in Großbritannien gilt:

$$
w=n p\left[t_{C}+\left(1-t_{C}\right) z\right],
$$

während für die Vereinigten Staaten von Amerika sich eine Gesamtsteuerbelastung ergibt in Höhe von:

$$
w=n p\left[t_{L}+t_{C}-t_{L} t_{C}+z\left(1-t_{L}-t_{C}+t_{L} t_{C}\right)\right] .
$$

In der Bundesrepublik Deutschland werden langfristige Vermögenszuwächse ${ }^{136}$ nicht besteuert. Eine Gutschrift der bereits gezahlten Unternehmensteuer erfolgt nicht. Die realisierten Vermögenszuwächse fließen einem inländischen Kapitaleigner ohne individueller Steuerbelastung zu. Für die Rendite eines Aktionärs gilt daher:

$$
s=n p\left(1-t_{L}-t_{C}+t_{L} t_{C}\right)
$$

Die Gesamtsteuerbelastung beträgt somit:

$$
w=n p\left(t_{L}+t_{C}-t_{L} t_{C}\right)
$$

In der folgenden Tabelle 5.3 werden die obigen Ergebnisse zusammengestellt. Bei der Interpretation der Übersicht muß beachtet werden, daß die Zinssätze, die Steuerbelastung und die sich daraus ergebenden Nettorenditen der alternativen Finanzierungsformen nur innerhalb eines betrachteten Landes aber nicht zwischen den verschiedenen Staaten verglichen werden können, da von einer geschlossenen Volkswirtschaft ausgegangen wird!

\subsubsection{3 fixed-r Fall}

Die bisherige Analyse erfolgte unter der Annahme, daß bei allen Finanzierungsformen eine einheitliche Rendite vor Steuer von einem Unternehmen erwirtschaftet wird (fixed-p). Geht man demgegenüber, entsprechend der Vorgehensweise von King und Fullerton, davon aus, daB der inländische Kapitalgeber unabhängig von der Deklarierung des Kapi-

\footnotetext{
${ }^{136}$ In der Bundesrepublik Deutschland müssen private Haushalte Vermögenszuwächse auf Aktien ledig-
} lich versteuern, wenn sie innerhalb einer Spekulationsfrist von sechs Monaten realisiert werden. 
Tabelle 5.3: fixed-p Fall

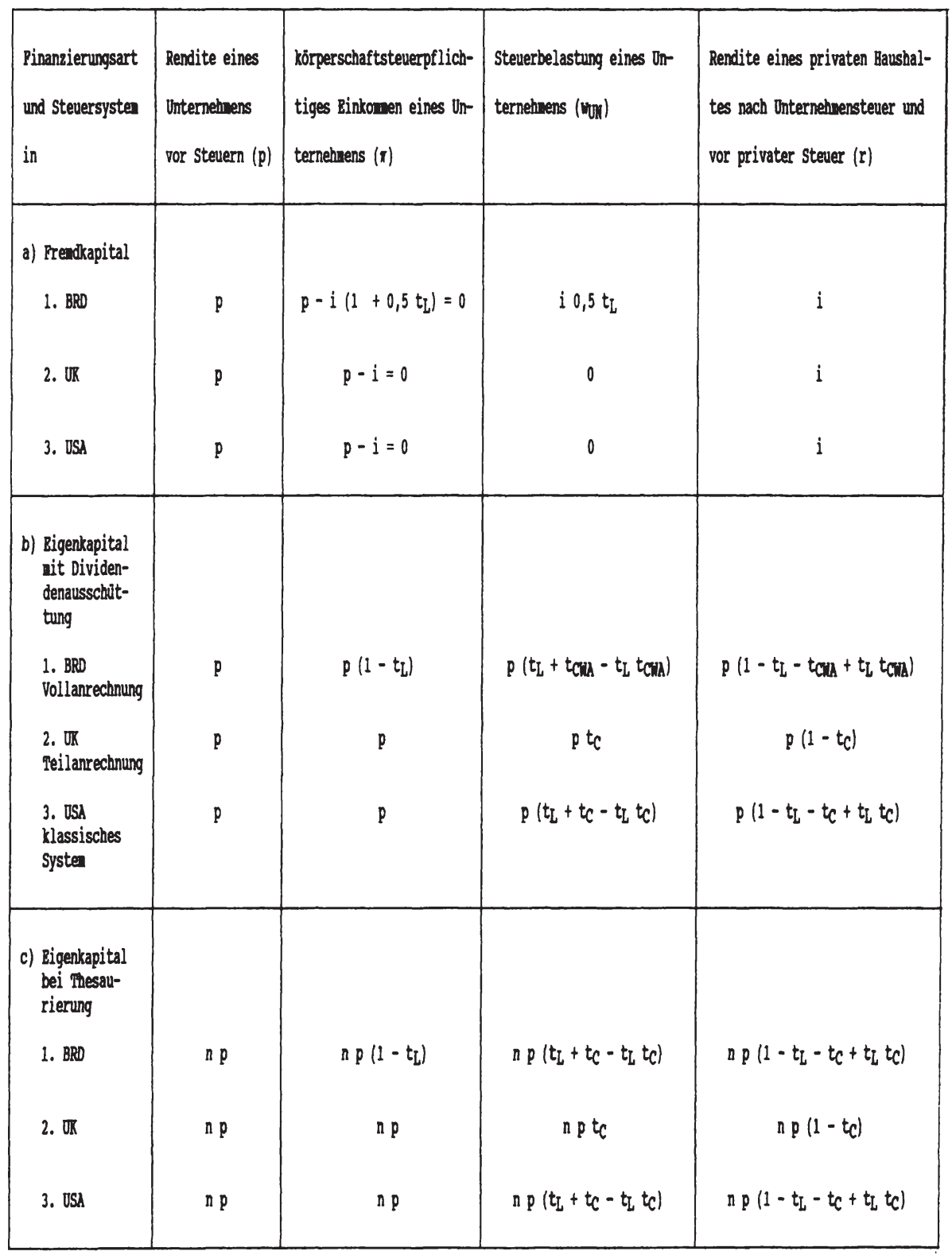




\begin{tabular}{|c|c|c|c|}
\hline $\begin{array}{l}\text { steuerpflichtiges Bin- } \\
\text { kanen eines privaten } \\
\text { Bansbaltes (G) }\end{array}$ & $\begin{array}{l}\text { Steverbel astung eines } \\
\text { privaten Banshal tes (MFir) }\end{array}$ & $\begin{array}{l}\text { Rendite nach abzug der ristrag- } \\
\text { stever eines privaten Fans- } \\
\text { haltes (s) }\end{array}$ & Cesartstenerbelastung (v) \\
\hline$i$ & it tI & $i\left(1-t_{I}\right)$ & $i\left(0,5 t_{i}+t_{I}\right)$ \\
\hline i & i tI & $i\left(1-t_{I}\right)$ & $i t_{I}$ \\
\hline i & i t I & $i\left(1-t_{I}\right)$ & $i t_{I}$ \\
\hline$p\left(1-t_{1}\right)$ & $p\left(1-t_{L}\right)\left(t_{I}-\tan \right)$ & $p\left(1-t_{L}\right)\left(1-t_{I}+t_{\infty}\right)$ & $p\left(t_{2}+t_{I}\left(1-t_{t}\right)\right]$ \\
\hline$p\left(1-t_{c}\right)(1+c)$ & $p\left(1-t_{c}\right)\left[t_{I}(1+c)-c\right]$ & $p\left(1-t_{c}\right)\left[(1+c)\left(1-t_{I}\right)-c\right]$ & $p\left[t_{C}+t_{I}\left(1-t_{C}\right)(1+c)-c\left(1-t_{C}\right)\right]$ \\
\hline$P\left(1-t_{L}-t_{C}+t_{L} t_{C}\right)$ & $P\left(1-t_{L}-t_{C}+t_{L} t_{C}\right) t_{I}$ & $P\left(1-t_{I}-t_{C}-t_{L} t_{C}\right)\left(1-t_{I}\right)$ & $P\left[t_{I}+t_{C}-t_{L} t_{C}+t_{I}\left(1-t_{C}-t_{C}+t_{L} t_{C}\right)\right]$ \\
\hline 0 & 0 & $\Delta p\left(1-t_{c}-t_{c}+t_{t} t_{c}\right)$ & $\operatorname{Pp}\left(\mathrm{t}+\left(1-t_{q}\right) t_{C}\right)$ \\
\hline$\Delta p(1-t c)$ & $a p\left(1-t_{c}\right) 2$ & $a p\left(1-t_{C}\right)(1-8)$ & $\operatorname{lo}\left[t_{c}+2\left(1-t_{c}\right)\right]$ \\
\hline $\operatorname{lp}\left(1-t_{t}-t_{c}+t_{t} t c\right)$ & $\Delta p\left(1-t_{t}-t_{c}+t_{t} t_{c}\right) z$ & $a p\left(1-t_{c}-t_{c}+t_{t} t_{c}\right)(1-z)$ & $D p\left(t_{C}+t_{C}-t_{C} t_{c}+z\left(1-t_{c}-t_{C}+t_{C} t_{c}\right)\right]$ \\
\hline
\end{tabular}


tals (Eigen-/Fremdkapital) eine identische Rendite vor persönlicher Steuer erzielen will (fixed-r Fall), so muß untersucht werden, welchen Ertrag vor Steuern die Kapitalgesellschaft erwirtschaften muß, um dem privaten Haushalt die geforderte Rendite nach Unternehmensteuern und vor privater Ertragsteuer zahlen zu können. Dabei gehen King und Fullerton davon aus, daß die Steuerbelastung des privaten Haushaltes für alle Finanzierungsarten identisch ist, so daß die gleiche Rendite vor Einkommensteuer zu einer übereinstimmenden Nettorendite führt. Die persönliche Ertragsteuer eines privaten Haushaltes wird in die Betrachtung von King und Fullerton daher nicht einbezogen. Inwieweit identische Einkünfte eines privaten Haushaltes äquivalent sind mit einer übereinstimmenden Rendite vor Steuern eines Unternehmens, wird durch den Vergleich des internen Kalkulationssatzes überprüft, wie aus folgender Gleichung (5.59) ersichtlich. Die vorher bereits dargelegten Annahmen werden übernommen.

Der interne Kalkulationssatz eines Unternehmens wird durch die Finanzierungsart bestimmt. Als Referenzgröße wird im allgemeinen der Kapitalkostensatz verwendet, welcher abhängig ist von den effektiven Ausgaben der Finanzierung. ${ }^{137}$ In einer Welt ohne Steuern und Inflation entspricht der interne Kalkulationssatz $(\sigma)$ dem nominalen Marktzinssatz (i), dem Ertrag des Kapitaleigners (r) und seinem zu versteuernden Einkommen (G), ${ }^{138}$ d. h.

$$
\sigma=i=r=G \text {. }
$$

In einer Welt mit Steuern weicht der interne Kalkulationssatz in Höhe der Unternehmensteuerbelastung von dem nominalen Marktzinssatz ab. Werden alle Anlage- und Finanzierungsalternativen steuerlich gleich behandelt, so existiert für den Kapitalmarkt ein Gleichgewichtszinssatz. Aufgrund der übereinstimmenden Steuerbelastung für alle Kapitaleinkünfte können die Kapitaleigner auch bei alternativer Anlage keine höhere Rendite erzielen. Ein privater Haushalt wird sich daher indifferent verhalten. Damit ein Unternehmen einem Kapitalgeber eine identische Rendite nach Unternehmen- und vor Einkommensteuer wie bei einer alternativen Geldanlage leisten kann, muß der interne Kalkulationssatz neben den Finanzierungskosten auch die Unternehmensteuer ${ }^{139}$ beinhalten, d. h. der interne Rechnungssatz entspricht der Rendite einer Kapitalgesellschaft vor Steuern:

$$
\sigma=p
$$

Die beiden Begriffe werden in der weiteren Ausarbeitung synonym verwendet.

\footnotetext{
137 Vgl. Neske/Wiener (1985, S. 610).

138 Vgl. Harberger (1966, S. 108), King/Fullerton (1984, S. 10 und 21).

139 Als Unternehmensteuer wird in Anlehnung an King und Fullerton die von der Kapitalgesellschaft zu leistende Körperschaftsteuer und die lokale Ertrag- und Substanzsteuer verstanden.
} 
Die Kosten der Kapitalaufnahme sind abhängig von der Finanzierungsart, d. h. inwieweit ein Kapitaleigner Fremd- oder Eigenkapital zur Verfügung stellt. Die an einen Kapitalgeber zu leistende Zins- bzw. Dividendenzahlung ist bekannt (fixed-r) und für alle Finanzierungsarten identisch. Inwieweit eine gleiche Rendite nach Unternehmensteuern auch zu einer übereinstimmenden Bruttorendite ( $p$ ) führt, wird im folgenden analysiert. In Erweiterung der Studie von King und Fullerton wird die einem privaten Haushalt nach persönlicher Ertragsteuer verbleibende Rendite (s) in die Betrachtung einbezogen. Die im Rahmen der Analyse einzubeziehenden Unternehmensteuern, die Ermittlung der Rendite nach Steuern eines Unternehmens, die Berechnung des steuerpflichtigen Einkommens eines Haushaltes sowie deren Steuerbelastung und die nach Steuern verbleibende Rendite können bei dem zuvor behandelten fixed-p Fall nachgelesen werden. Auf eine genaue Ausführung dieser Punkte wird bei der folgenden Darstellung des fixed-r Falles verzichtet.

\section{a) Fremdfinanzierung}

Im Rahmen der Fremdfinanzierung wird die erzielte Rendite in Form von Schuldzinsen an den Kapitalgeber weitergeleitet. ${ }^{140}$ Die Zinszahlung stellt bei der steuerlichen Gewinnermittlung eine abzugsfähige Betriebsausgabe dar. Eine nationale sowie lokale Ertragsteuerzahlung entfällt in dem Vereinigten Königreich und den Vereinigten Staaten von Amerika $\left(w_{U N}=0\right)$. Der interne Kalkulationssatz $(\sigma=p)$ entspricht dem an einen Kapitaleigner zu entrichtenden Marktzinssatz (i), d. h.

$$
p=i
$$

Der Kapitaleigner muß die empfangenen Einkünfte (r) aus Kapitalvermögen seiner persōnlichen Ertragsteuer unterwerfen.

In der Bundesrepublik Deutschland wird neben der Körperschaftsteuer eine lokale Gewerbeertragsteuer auf die Schuldzinsen erhoben, welche bei der Berechnung der körperschaftsteuerlichen Bemessungsgrundlage abzugsfähig ist. Die von einer Kapitalgesellschaft zu leistende lokale Ertragsteuer verringert nicht die vertraglich festgelegte Zinszahlung an den privaten Haushalt. Ein Unternehmen muß demnach neben einem bestimmten Zinssatz auch die zu entrichtende lokale Steuer erzielen, d. h. der interne Kalkulationssatz erhöht sich um die zu leistende Gewerbeertragsteuer. Aufgrund der Abzugsfähigkeit der Schuldzinsen sowie der lokalen Steuer bei der Ermittlung der körperschaftsteuerlichen Be-

$140 \mathrm{Vgl}$. King/Fullerton (1984, S. 11). 
messungsgrundlage müssen weitere Ertragsteuern nicht geleistet werden, d. h. die Rendite vor Unternehmensteuern entspricht:

$$
\begin{aligned}
p & =i+i 0,5 t_{L} \\
& =i\left(1+0,5 t_{L}\right)
\end{aligned}
$$

Ein bundesdeutscher Darlehensgeber muß ebenso wie in Großbritannien und den USA den in Höhe des Kapitalmarktzinssatzes zufließenden Ertrag seiner persönlichen Ertragsteuer unterwerfen.

\section{b) Eigenfinanzierung bei Dividendenzahlungen}

Im Falle der Eigenfinanzierung bei Dividendenzahlung unterliegt die Rendite sowohl bei einem Unternehmen als auch bei einem privaten Haushalt einer Ertragsbesteuerung (siehe obige Ausführungen fixed-p Fall). Diese steuerliche „Diskriminierung“ wird von King und Fullerton durch die Variable $\theta$ ausgedrückt. Sie definiert die marginalen Opportunitätskosten für einbehaltene Gewinne als entgangene marginale Bruttodividende (G) eines Kapitaleigners vor Abzug einer persönlichen Ertragsteuer. Folglich ist $\theta$ identisch mit der zusätzlichen Bruttodividende, die ein Anteilseigner erzielen könnte, wenn eine Einheit des Unternehmensgewinns nach Steuern ausgeschüttet würde, d. h. ${ }^{141}$

$$
\theta=\frac{1}{(1-c)}=G
$$

Gegenstand der Untersuchung ist allerdings nicht die Frage nach der zusätzlichen Bruttodividende eines Kapitaleigners, wenn eine Einheit mehr ausgeschüttet wird, sondern vielmehr ist von Interesse, wie hoch die Rendite des Unternehmens vor Steuern ( $p$ ) sein muß, um dem inländischen Kapitalgeber den Kapitalmarktzins (i) vergüten zu können. Unter Beachtung der nationalen Steuergesetzgebung ergeben sich die in der Tabelle 5.4 zusammengefaßten Resultate. Die bei der Berechnung des internen Kalkulationssatzes zu berücksichtigenden Steuerbelastungen können der Tabelle 5.3 entnommen werden.

In den USA erfolgt aufgrund des klassischen Systems keine Anrechnung der Unternehmensteuer bei den Anteilseignern. Der Kapitalzufluß bei einem privaten Haushalt ist identisch mit dem zu versteuernden Einkommen $(G=i)$. Aufgrund der Teilanrechnung ergibt sich in Großbritannien und der Bundesrepublik Deutschland eine Differenz zwischen der erhaltenen Rendite nach Unternehmensteuern (r) und dem bei einem inländischen Kapitaleigner zu versteuernden Einkommen (G) und zwar in Höhe des gesetzlich geregelten Anrechnungsbetrages (siehe vorherige Ausführungen zu dem fixed-p Fall). 
Tabelle 5.4: Interner Kalkulationssatz $(\sigma=p)$ bei einer Ausschüttung in Höhe des Kapitalmarktzinssatzes $(i=f i x)$

\begin{tabular}{|l|c|}
\hline & interner Kalkulationssatz $(0=p)$ \\
\hline Bundesrepublik Deutsch land & $\frac{i}{1-t_{L}-t_{C W A}+t_{L} t_{C} W A}$ \\
Vereinigtes Königreich & $\frac{i}{1-t_{C}}$ \\
Vereinigte Staaten von & $\frac{i}{1-t_{L}-t_{C}+t_{L} t_{C}}$ \\
\hline
\end{tabular}

\section{c) Eigenkapital bei Thesaurierung}

Im Falle der Thesaurierung müssen die Einkünfte im Wirtschaftsjahr der Entstehung nur bei einem Unternehmen versteuert werden. Der Thesaurierungsbetrag ist laut Annahme identisch mit der Rendite eines Unternehmens nach Steuern, die einem Aktionär im Falle der Ausschüttung zukommen würde. Ein Anteilseigner erzielt erst bei einer Veräußerung seiner Aktien in der Periode $\mathrm{n}$ die kumulierte Rendite. Eine Verzinsung der einbehaltenen Rendite erfolgt nicht. Kursschwankungen werden ausgeschlossen und die Aktien im Durchschnitt 10 Jahre gehalten, d. h. $n=10 .{ }^{142}$ Damit ein Kapitaleigner im Falle der Thesaurierung keine geringere Rendite erhält als bei einer direkten Ausschüttung, muß der Wertzuwachs $(\mu)$ mit dem akkumulierten Kapitalmarktzinssatz übereinstimmen, $\mathrm{d}$. $\mathrm{h}$.

$$
\mu=n i \text {. }
$$

Bei der Realisierung des Wertzuwachses wird in der Bundesrepublik Deutschland keine individuelle Ertragsteuer von einem privaten Haushalt erhoben. In Großbritannien und den USA ist demgegenüber auf den Vermögenszuwachs eine capital gains tax zu entrichten. Eine Anrechnung der von einer Kapitalgesellschaft im Zeitpunkt der Thesaurierung bereits geleisteten Ertragsteuer ist in keiner der betrachteten Nation zulässig. Der interne

142 King und Fullerton treffen keine Annahmen hinsichtlich der Verwendung des thesaurierten Gewinnes. Vgl. King/Fullerton (1984, S. 23 f.). 
Kalkulationssatz muß die zum Zeitpunkt der Gewinnthesaurierung zu leistenden Unternehmensteuern beinhalten, um an den Kapitaleigner in dem Zeitpunkt der Realisierung eine Rendite nach Unternehmensteuer in Höhe des Marktzinssatzes leisten zu können. Für die Bundesrepublik Deutschland ergibt sich daraus:

$$
p=n \frac{i}{1-t_{L}-t_{C}+t_{L} t_{C}},
$$

für Großbritannien:

$$
p=n \frac{i}{\left(1-t_{C}\right)},
$$

und für die Vereinigten Staaten von Amerika:

$$
p=n \frac{i}{1-t_{L}-t_{C}+t_{L} t_{C}} .
$$

Die Resultate der obigen Ausführungen werden in der Tabelle 5.5 zusammengefaßt. Ein Vergleich der Ergebnisse zwischen den Nationen ist nicht möglich, da sich die Zinssätze, die Unternehmen- und persönliche Steuerbelastung sowie der sich hieraus ergebende interne Kalkulationssatz nur auf eine geschlossene Volkswirtschaft beziehen.

Die in den Tabellen 5.3 und 5.5 zusammengefaßten Resultate der Untersuchung des fixed-p Falles sowie des fixed-r Falles verdeutlichen, daß die Gesamtsteuerbelastung einer Investition je nach Finanzierungsart stark variiert. Eine identische Rendite vor Steuern eines Unternehmens (fixed-p Fall) führt zu einer abweichenden Rendite nach Steuern eines privaten Haushaltes (s. Tabelle 5.3). Eine übereinstimmende Rendite nach Unternehmensteuern eines Kapitalgebers (fixed-r Fall) setzt eine abweichende Unternehmensrendite vor Steuern voraus und führt außerdem zu einer je nach Finanzierungsart variierenden Rendite nach persönlicher Steuer eines Kapitaleigners (s. Tabelle 5.5). Orientieren sich die privaten Haushalte an der Rendite eines Unternehmens nach Steuern der verschiedenen Anlagemöglichkeiten (fixed-r Fall), so beinhaltet die von King und Fullerton getroffene Annahme, daß die Kapitaleigner einer Steuerillusion unterliegen, weil identische Renditen nach Unternehmensteuern keine übereinstimmenden Nettorenditen implizieren. Da die Wirtschaftssubjekte laut Annahme von King und Fullerton über vollständige Informationen verfügen und frei von räumlichen, persönlichen und sachlichen Präferenzen agieren, wird das Entscheidungskalkül eines Kapitaleigners nicht durch die Rendite nach Unternehmensteuer und vor persönlicher Steuer (r) determiniert, sondern durch die nach Abzug aller Steuern verbleibenden Rendite (s). King und Fullerton beziehen diese Alternative jedoch nicht in ihre Analyse ein.

Die Analyse der obigen Tabellen 5.3 und 5.5 verdeutlicht, daß unter Berücksichtigung der 
von King und Fullerton getroffenen Annahmen ein nutzenmaximierender privater Haushalt in der Bundesrepublik Deutschland sein gesamtes Kapital in inländische festverzinsliche Wertpapiere anlegen wird, weil er dort die höchste Rendite nach Abzug aller Steuern erzielen kann. Kapitalgesellschaften werden bei den getroffenen Annahmen wegen der fehlenden Finanzierungsmöglichkeit in der Bundesrepublik Deutschland nicht gegründet. In Großbritannien und den Vereinigten Staaten von Amerika bewirken die nationalen Steuersysteme ceteris paribus, daß den Kapitalgesellschaften lediglich Fremdkapital von den privaten Haushalten zur Verfügung gestellt wird. Die Fremdfinanzierung wiederum führt in diesen Staaten zu keinen steuerpflichtigen Unternehmensgewinnen, d. h. eine steuerliche Belastung der Unternehmen entfällt.

Die Gesamtsteuerbelastung entspricht in den betrachteten Nationen demzufolge der persönlichen Steuerlast eines privaten Haushaltes. Das nationale Steuersystem beeinfluBt demnach nicht die Investitionsentscheidung eines Unternehmens sondern das Spar- und Anlageverhalten des privaten Haushaltes!

In ihrer Studie haben King und Fullerton eine Vielzahl von effektiven und durchschnittlichen effektiven Grenzsteuersätzen berechnet, welche vielfach zitiert wurden und werden. Neben den bisher genannten Einflußfaktoren (Kapitalgeber, Finanzierungsart, Investor, Anlageart und nominale Steuersätze) werden von King und Fullerton bei der Kalkulation von effektiven Grenzsteuersätzen steuerliche und ökonomische Abschreibungssätze, staatlich gewährte Investitionszulagen, die steuerlich zulässige Bewertung des Vorratsvermögens, eine je nach nationalem Steuersystem zu leistende Vermögensteuer ${ }^{143}$ und variierende Inflationsraten einbezogen. Unter Berücksichtigung der genannten Determinanten kalkulieren King und Fullerton für jedes Land $243^{144}$ effektive Grenzsteuersätze. Inwieweit die Einbeziehung der zusätzlichen Faktoren im Rahmen des Modells der vollständigen Konkurrenz zu einer Kapitalbildung und somit zu einer Unternehmensteuerbelastung führt, wird im folgenden analysiert.

\subsubsection{4 Ökonomische Abschreibung}

Betrachtet man die von King und Fullerton ermittelten Resultate, stellt man fest, daB in Großbritannien und der Bundesrepublik Deutschland die Gesamtsteuerbelastung bei der Gewinnthesaurierung am höchsten ist, während in den Vereinigten Staaten von Amerika

143 Die Vermögensteuer wird im folgenden nicht betrachtet.

144 Die aus der Kombination von Kapitalgeber (private Haushalte, steuerbefreite Institutionen, steuerpflichtige Versicherungsgesellschaften), Finanzierungsart (Fremdkapital, Emission neuer Aktien. Thesaurierung), Investor (verarbeitendes Gewerbe, sonstige Industrie, Dienstleistung) sowie Anlageart (Maschinen und Anlagen, Gebäude, Vorräte) sich ergebenden 81 effektiven Grenzsteuersätze pro Land werden unter Berücksichtigung eines Inflationssatzes von Null, einem angenommenen Inflationssatz von $10 \%$ sowie der aktuell beobachteten Inflationssatz berechnet. Dies führt zu 243 effektiven Grenzsteuersätzen pro Land. 
Tabelle 5.5: fixed-r Fall

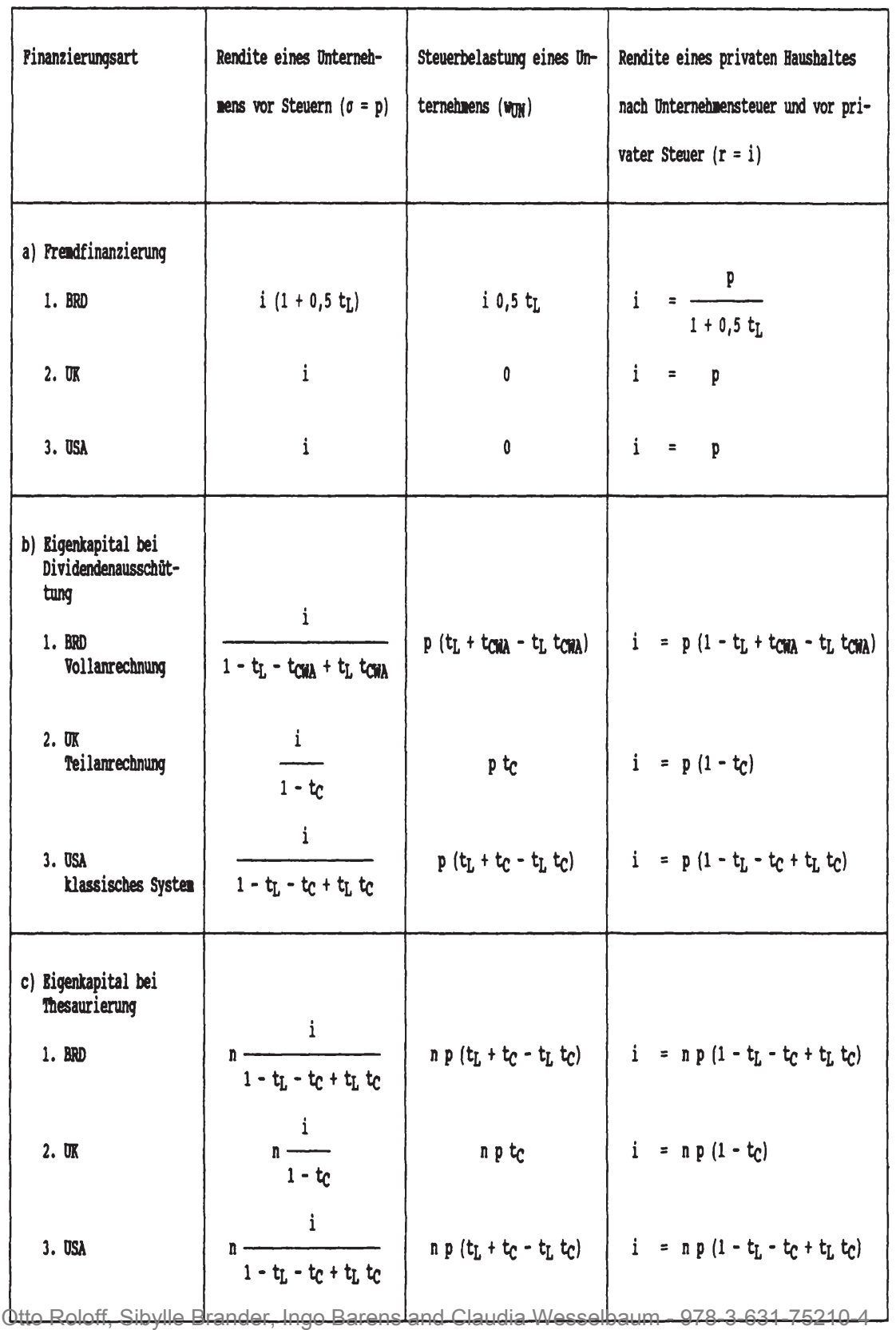




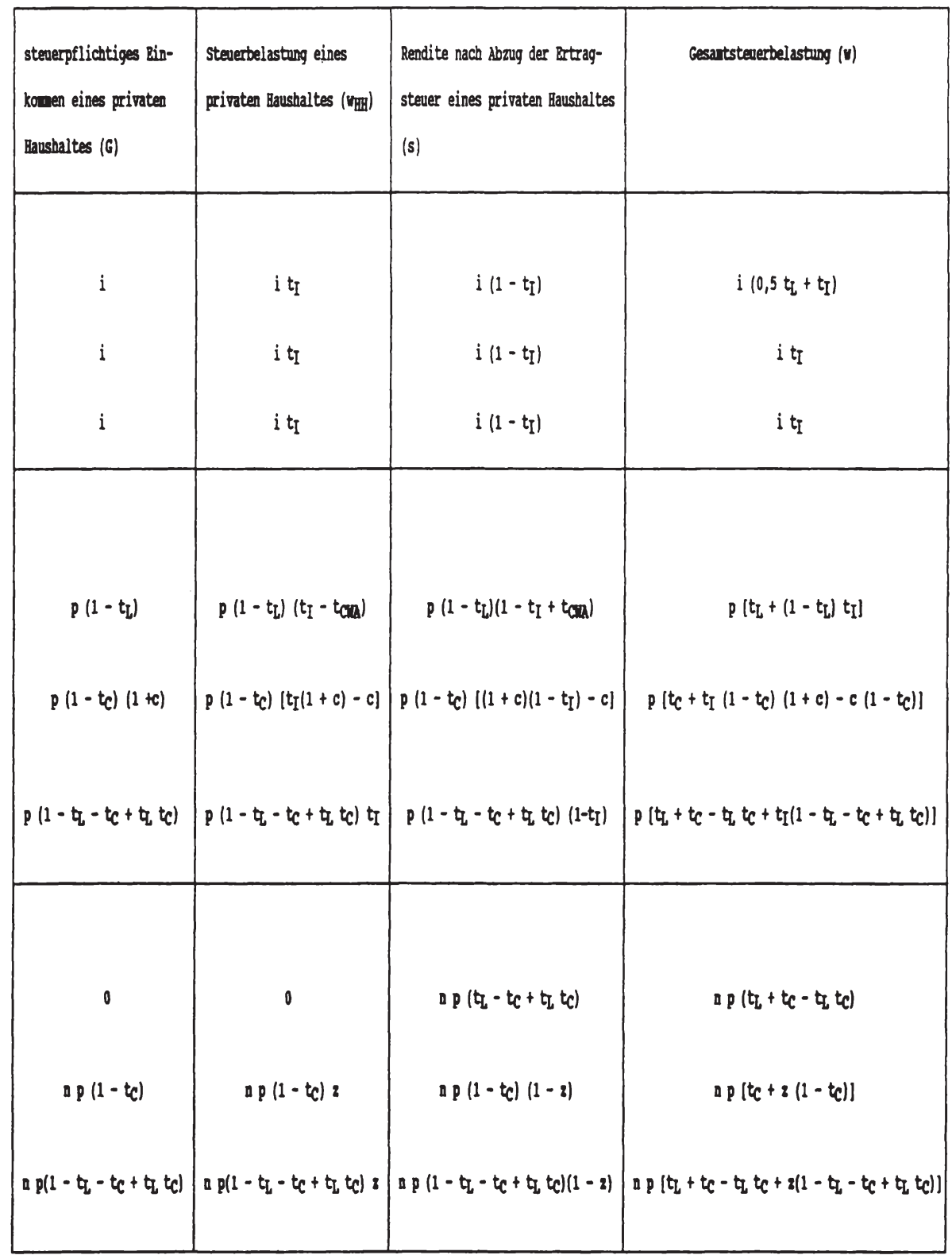


die Dividendenausschüttung die effektiv höchste Grenzsteuerbelastung aufweist. Negative effektive Grenzsteuersätze werden in Großbritannien und den Vereinigten Staaten von Amerika bei einer Fremdfinanzierung von Maschinen und Anlagen realisiert, d. h., im Zusammenhang mit der geplanten Investition übersteigen die staatlich gewährten Zulagen die Gesamtsteuerbelastung. Die staatlichen Vergünstigungen bestehen laut King und Fullerton aus:

- der Steuereinsparung durch die Standardabschreibung,

- der Steuereinsparung durch die Inanspruchnahme der zulässigen Sofortabschreibung und/oder

- den direkten Zulagen,

welche im Zusammenhang mit einer Investitionseinheit gewährt werden. ${ }^{145}$ Inwieweit das nationale Steuersystem Investitionen subventioniert, wird laut King und Fullerton durch das Verhältnis zwischen dem steuerlich zulässigen und dem ökonomisch richtigen Abschreibungssatz wiedergegeben. ${ }^{146} \mathrm{Im}$ folgenden wird daher analysiert, wie die ökonomische und steuerliche Abschreibung definiert ist und welche steuerlichen Effekte aus einer Differenz zwischen dem steuerlichen bzw. ökonomischen Abschreibungssatz resultieren.

In der gegenwärtigen Diskussion über die Steuerpolitik existiert die Ansicht, daß die steuerliche Abschreibung mit der tatsächlichen Wertminderung eines Vermögensgegenstandes übereinstimmen soll. Das Problem der Verwirklichung dieses Grundsatzes besteht darin, daß die Abnutzung der Wirtschaftsgüter durch die unternehmensspezifische Nutzung bestimmt wird. Im Gegensatz zu den Lohnkosten oder anderen Ausgaben existieren im Zusammenhang mit den Wertminderungen keine in Geldeinheiten direkt meßbaren Ausgaben und infolgedessen fehlt es an einer unmittelbaren Kostenerfassung für steuerliche Zwecke. ${ }^{147}$

Die ökonomische Abschreibung erfaßt die tatsächliche Wertminderung eines Vermögensgegenstandes, ${ }^{148}$ während die steuerliche Standardabsetzung für Abnutzung den Zweck hat, die historischen Anschaffungskosten auf die betriebsgewöhnliche Nutzungsdauer zu verteilen. ${ }^{149}$ Neben der Verteilung der ursprünglichen Anschaffungskosten auf den Zeitraum der Nutzung stellen die steuerlich zulässigen Abschreibungssätze für die nationalen Regierungen ein Instrument dar, um außerfiskalische Ziele zu realisieren, z. B. durch hohe Sonderabschreibungen oder auch Sofortabschreibungen Investitionen in bestimmten Regionen oder zu bestimmten Zeiten zu fördern. Während die steuerlichen Abschreibungssätze den nationalen Steuergesetzen entnommen werden können, gelten für die Be-

\footnotetext{
145 Vgl. King/Fullerton (1984, S. xiii und 19).

146 Vgl. King/Fullerton (1984, S. 45).

147 Vgl. Jorgenson/Sullvian (1981, S. 171 f.), Hulten (1981, S. 5).

148 Vgl. Jorgenson/Sullivan (1981, S. 171 f.).

149 Vgl. Wöhe/Bieg (1991, S. 56). 
rechnung der ökonomisch zutreffenden Abschreibung keine allgemein anwendbaren Prinzipien. Es existieren jedoch unterschiedliche Ansätze, ${ }^{150}$ um die tatsächliche Wertminderung eines Wirtschaftsgutes zu erfassen.

King und Fullerton übernehmen in ihrer Studie den Ansatz von Hulten und Wykoff (1981) für die Bestimmung der ökonomischen Abschreibung. Diese definieren die ökonomische Abschreibung als Differenz zwischen den ursprünglichen Anschaffungskosten und dem am Markt für Gebrauchtgüter gehandelten Wert eines Vermögensgegenstandes pro Wirtschaftsjahr. ${ }^{151}$ Ihre empirische Auswertung der vorhandenen Daten ergibt, daß die Wertminderung eines Vermögensgegenstandes geometrisch verläuft und durch die Anwendung degressiver Abschreibungssätze angenähert werden kann. ${ }^{152}$ Die Umsetzung dieses Ansatzes setzt die Existenz von Gebrauchtgütermärkten für alle abnutzbaren Vermögensgegenstände voraus. ${ }^{153}$ Außerdem muß die wirtschaftliche Nutzungsdauer und die Inflationsrate ex ante bestimmt werden. Für die Bestimmung der wirtschaftlichen Nutzungsdauer verwenden King und Fullerton in ihrer Analyse die für einige Länder existierenden Erhebungen über die wirtschaftliche Nutzungsdauer, z. B. Großbritannien. ${ }^{154}$ In anderen Fällen approximieren King und Fullerton die Nutzungsdauer auf der Grundlage veröffentlichter Daten über das Anlagevermögen, z. B. für die Bundesrepublik Deutschland. ${ }^{155}$ Bei der Berechnung der ökonomischen Abschreibungssätze gehen King und Fullerton davon aus, daß die Wertminderung eines Wirtschaftsgutes exponentiell verläuft. ${ }^{156}$

Die ökonomisch erfaßten Wertminderungen bilden die Basis für die Berechnung der Verkaufspreise eines Unternehmens. ${ }^{157}$ Wird die ökonomische Absetzung für Abnutzung über den Umsatz verdient und entspricht die tatsächliche Wertminderung der steuerlich zulässigen Abschreibung, so ist unter der Annahme, daß bei der Bewertung der übrigen Aufwendungen keine Differenzen auftreten, der ökonomische Gewinn identisch mit dem körperschaftsteuerpflichtigen Gewinn. Die nach dem ökonomischen Gewinn zu berechnende Steuerlast entspricht in diesem Fall dem tatsächlich zu leistenden Betrag. Übersteigt die verdiente ökonomische Abschreibung den bei der Ermittlung der steuerlichen Bemessungsgrundlage zu berücksichtigenden Betrag, so überschreitet in dem betrachteten Wirtschaftsjahr der körperschaftsteuerpflichtige Gewinn den ökonomischen. Für ein Unternehmen bedeutet dies, daß die tatsächliche Steuerschuld den aufgrund des ökonomischen Ge-

\footnotetext{
150 Zum Beispiel der Ansatz von Terborgh (1954), Beidleman (1976) und Auerbach/Jorgenson (1980).

$151 \mathrm{Vgl}$. Hulten/Wykoff (1981, S. 85).

152 Vgl. Hulten/Wykoff (1981, S. 112).

$153 \mathrm{Vgl}$. Wetzler (1981, S. 299).

154 „To compute asset lives for the different assets and industries in our classification, we used data on asset lives for a large number of assets both in manufacturing (Griffin 1976) and in nonmanufacturing (supplied by the Central Statistical Office)." King/Fullerton (1984, S. 46).

$155 \mathrm{Vgl}$. King/Fullerton (1984, S. 166).

$156 \mathrm{Vgl}$. King/Fullerton (1984, S. 29).

$157 \mathrm{Vgl}$. Ellinghorst (1989, S. 591).
} 
Tabelle 5.6: Auswirkungen der ökonomischen und steucrlichen Abschreibung auf die Steuerzahllast eines Unternehmens während eines Wirtschaftsjahres

\begin{tabular}{|c|c|c|}
\hline Annahme & $\begin{array}{l}\text { ertragsteuerpflichtiger } \\
\text { Gewinn }\end{array}$ & $\begin{array}{l}\text { Differenz zwischen der } \\
\text { tatsächlichen und ökono- } \\
\text { misch "richtigen" Steuer- } \\
\text { zahlung }\end{array}$ \\
\hline$\delta=\mathrm{at}$ & $\pi_{\mathrm{E}}=\pi$ & 0 \\
\hline$\delta>$ at & $\pi \mathrm{E}>\pi$ & $-(\delta-$ at $) \tau$ \\
\hline$\delta<\mathrm{at}$ & $\pi \mathrm{E}<\pi$ & $(\delta-a t) \tau$ \\
\hline
\end{tabular}

winns zu berechnenden Steuerbetrag übersteigt. In diesem Fall gewährt ein Unternehmen dem Staat ein zinsloses Darlehen. Ïbersteigt die steuerliche zulässige Abschreibung die verdiente ökonomische Absetzung für Abnutzung, so unterschreitet der körperschaftsteuerliche Gewinn den ökonomischen. Die tatsächlich zu leistende Steuerzahlung ist demnach niedriger als die nach dem ökonomischen Gewinn zu berechnende Steuerlast. In Höhe des Differenzbetrages erfolgt eine Verringerung der steuerlichen Belastung während des Wirtschaftsjahres, d. h. eine Steuerstundung wird realisiert. In der Tabelle 5.6 werden die genannten Fälle dargestellt.

Während der Nutzungsdauer eines Wirtschaftsgutes können alle drei genannten Fälle auftreten. Insbesondere in den Anfangsjahren kann aufgrund von zulässigen Sonderabschreibungen die steuerliche Absetzung die tatsächliche Wertminderung übersteigen. Da die insgesamt auf die Nutzungsdauer zu verteilende Summe steuerlich auf die ursprünglichen Anschaffungskosten begrenzt ist, führen überhöhte Absetzungen zu Beginn der Nutzungsdauer eines Wirtschaftsgutes zu einem geringeren zu verteilenden Betrag während der Restnutzungsdauer. Dies wird anhand der Tabelle 5. 7 verdeutlicht. Dabei wird angenommen, daß die ökonomische Abschreibung linear verläuft. Die steuerliche Abschrei- 
Tabelle 5.7: Steuerliche Auswirkungen variierender ökonomischer und steuerlicher Abschreibungsbeträge auf die Steuerbelastung ohn€ Berücksichtigung von Inflation

\begin{tabular}{|c|c|c|c|c|c|c|c|c|c|}
\hline Jahr & $\begin{array}{l}\text { Oesat? } \\
\text { pro } \\
\text { Jahr }\end{array}$ & $\begin{array}{l}\text { Lohn- } \\
\text { kosten }\end{array}$ & $\begin{array}{l}\text { Absch } \\
\text { steuer- } \\
\text { liche }\end{array}$ & $\begin{array}{l}\text { eibung } \\
\text { okkono- } \\
\text { nische }\end{array}$ & $\begin{array}{l}\text { Gewinn p } \\
\text { steuer- } \\
\text { lich }\end{array}$ & $\begin{array}{l}\text { ro Jahr } \\
\text { ökono- } \\
\text { uisch }\end{array}$ & $\begin{array}{l}\text { tatsách- } \\
\text { liche Steu- } \\
\text { erbelastung }\end{array}$ & $\begin{array}{l}\text { okononische } \\
\text { Steuerbe- } \\
\text { lastung }\end{array}$ & $\begin{array}{l}\text { Steuer- } \\
\text { stunoung }\end{array}$ \\
\hline 1 & 1500 & 500 & 1000 & 600 & 0 & 100 & 0 & 200 & 200 \\
\hline 2 & 1500 & 500 & 665 & 600 & 335 & 400 & 167,5 & 200 & 32,5 \\
\hline 3 & 1500 & 500 & 445 & 600 & 555 & 400 & 277,5 & 200 & $-77,5$ \\
\hline 1 & 1500 & 500 & 445 & 600 & 555 & 400 & 277,5 & 200 & $-77,5$ \\
\hline \multirow[t]{2}{*}{5} & 1500 & 500 & 445 & 600 & 555 & 400 & 277,5 & 200 & $-77,5$ \\
\hline & 7500 & & 3000 & 3000 & & & 1000,0 & 1000 & 0 \\
\hline
\end{tabular}

bung verläuft degressiv und beträgt 33,33 v. H.; der Wechsel von der degressiven zu der linearen Abschreibung ist zulässig und wird vorgenommen. Die ursprünglichen Anschaffungsaufwendungen für den Vermögensgegenstand belaufen sich auf 3000 Einheiten. Dic wirtschaftliche Nutzungsdauer beträgt fünf Jahre. Der anzuwendende Steuersatz beläuft sich auf 50 v. H.

Die Analyse der Tabelle 5.7 zeigt, daß über die tatsächliche Wertminderung hinausgehende Standardabschreibung oder staatlich gewährte Sonderabschreibung keine Steuercinsparung sondern lediglich eine Steuerstundung bewirken, wenn

- ein Extraprofit realisiert wird und

- die bei der steuerlichen Gewinnermittlung zu berücksichtigende Abschreibung die tatsächliche Wertminderung zu Beginn der Nutzung übersteigt.

Aufgrund der gesetzlichen Begrenzung des steuerlichen Abschreibungshöchstbetrages auf die ursprünglichen Anschaffungskosten wird der gewährte Steuerkredit während der Restnutzungsdauer des Vermögensgegenstandes aufgelöst. Der Staat verzichtet demnach nicht endgültig auf Einnahmen, so daß von einer indirekten Subvention nicht gesprochen werden kann. Die gestundete Steuer stellt für ein Unternehmen eine Finanzierungs- und Liquiditätshilfe dar. Wird der gestundete Betrag ertragsbringend angelegt, so kann das Unternehmen einen zusätzlichen Gewinn erzielen, welcher wiederum steuerpflichtig ist. Die Auflösung des unabhängig von der Kreditwürdigkeit eines Unternehmens zinslos gewährten Steuerkredites ${ }^{158}$ erfolgt sukzessive während der Restnutzungsdauer eines abschrei-

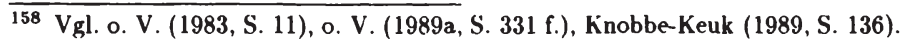


bungsfähigen Wirtschaftsgutes. Wird der Vermögensgegenstand vor der geplanten Nutzungsdauer veräußert. so müssen die national divergierenden Vorschriften über die steuerliche Behandlung von Veräußerungsgewinnen oder -verlusten sowie die Möglichkeiten der Übertragung von stillen Reserven auf neue Wirtschaftsgüter beachtet werden.

Während die steuerliche Abschreibung auf den ursprünglichen Anschaffungsaufwand begrenzt ist, nehmen Preissteigerungen auf die von den Wiederbeschaffungsaufwendungen zu berechnende ökonomische Wertminderung einer Investition einen direkten Einfluß. Wird die ökonomische Abschreibung über den Umsatz verdient, erfolgt eine Besteuerung des inflationsbedingten Gewinnes (Scheingewinn). Das in den nationalen Steuergesetzen fixierte Prinzip der nominalen Kapitalerhaltung ${ }^{159}$ hat demnach bei Inflation einen realen Substanzverlust zur Folge. Durch die ertragsbringende Anlage der aus Extraprofiten sowie überhöhten steuerlichen Abschreibungen resultierenden Steuerstundungsbeträge kann der Substanzverlust gegebenenfalls partiell oder gänzlich kompensiert werden. ${ }^{160}$

In dem von King und Fullerton zugrundegelegten Modell der vollständigen Konkurrenz können über die Normalverzinsung hinausgehende Gewinne von einem Unternehmen nicht realisiert werden. Auch unter Einbeziehung der steuerlichen Standard- und Sonderabschreibung ist es einem Unternehmen daher nicht möglich, Kapital zu bilden, welches Grundlage für die Erzielung steuerpflichtiger Einkünfte ist. Die Ermittlung von effektiven Grenzsteuersätzen beschränkt sich demnach auch unter Einbeziehung von ökonomischen und steuerlichen Abschreibungen auf die Betrachtung privater Haushalte.

\subsubsection{Investitionszulagen}

Bezieht man zusätzlich zu den Abschreibungen staatliche Zulagen in die Analyse ein, resultiert hinsichtlich der Kapitalbildung in einem Unternehmen und der daraus resultierenden Steuerbelastung eine differenziertere Aussage.

Die in Zusammenhang mit der Grenzinvestition gewährten direkten Subventionen reduzieren unter Zugrundelegung der Annahmen von King und Fullerton die Nachfrage eines Unternehmens auf dem Kapitalmarkt und verringern die an einen Kapitaleigner zu leistenden Finanzierungskosten eines Unternehmens. In ihrer Untersuchung gehen King und Fullerton davon aus, daß die Basis für die Berechnung der steuerlichen Abschreibungsbeträge nicht um die empfangenen Beihilfen gemindert wird. ${ }^{161}$ Werden die anhand des ursprünglichen Anschaffungspreises bzw. der erhöhten Wiederbeschaffungskosten kalku-

\footnotetext{
159 Das Prinzip der nominalen Kapitalerhaltung besagt, daß lediglich die ursprünglichen Anschaffungskosten bei der Berechnung der steuerlichen Abschreibungsbeträge berücksichtigt werden dürfen. Preissteigerungen bleiben unberücksichtigt. Vgl. Wöhe (1984, S. 951).

160 Vgl. Grotherr (1987, S. 76).

161 Vgl. King/Fullerton (1984, S. 167).
} 
lierten ökonomischen Abschreibungen und die an Fremdkapitalgeber zu leistenden Zinszahlungen am Markt verdient, verbleibt einem Unternehmen Kapital in Höhe der gewährten Zulagen. Die Subventionen führen demnach zu einer dauerhaften Finanzhilfe in einem Unternehmen. Die aus der zweckgebundenen Anlage der Zulage erzielbaren Einnahmen unterliegen der Steuerpflicht und entsprechen im Modell der vollständigen Konkurrenz der Normalverzinsung des eingesetzten Kapitals. Inwieweit ein Unternehmen das durch die Abschreibung rückgeführte Kapital in Sachanlagen investiert oder festverzinsliche Wertpapiere erwirbt, wird durch die Rendite nach Unternehmensteuern bestimmt.

Die staatlichen Zulagen sind auf spezifische Investitionen in bestimmten Regionen oder auf spezielle Branchen bzw. Wirtschaftsgüter begrenzt. Infolgedessen unterliegen ausschließlich jene Unternehmen einer Steuerpflicht, welche in staatlich geförderten Bereichen oder Gebieten investieren. Durch die Steuerpflicht der erzielten Rendite eines Unternehmens erfolgt eine sukzessive Rückführung der gewährten Subventionen.

\subsubsection{Bewertung des Vorratsvermögens}

Zusätzlich zu Abschreibungen und staatlichen Zulagen beziehen King und Fullerton die steuerliche Bewertung des Vorratsvermögens und dessen Reagibilität auf Inflation in die Untersuchung ein. Inwieweit die Bewertung des Vorratsvermögens zu einer Kapitalbildung in einem Unternehmen führt, wird im folgenden analysiert.

Der Buchwert der Vorräte kann sich am Ende jedes Wirtschaftsjahres aufgrund einer Erhöhung der Bestände oder, bei konstantem Bestand, durch höhere Preise verändern. ${ }^{162}$ Die im Rahmen der Gewinnermittlung zu berücksichtigende nominale Bestandsveränderung wird durch die Differenz des Vorratsvermögens am Ende und am Anfang des Wirtschaftsjahres ermittelt. Je nach anzuwendendem Verbrauchsfolgeverfahren kann die Erfassung eines c. p. durch Inflation verursachten Scheingewinns zu dem Zeitpunkt der Bestandsaufnahme oder aber bei einer späteren Realisierung erfolgen.

Die Anwendung des FiFo-Verfahrens ${ }^{163}$ (first in - first out) führt bei Inflation dazu, daB bei einem gleichbleibenden Bestand der Wert des Vorratsvermögens höher ausgewiesen wird als im Vorjahr. Der ausgewiesene Scheingewinn unterliegt der Besteuerung des

\footnotetext{
162 Vgl. King/Fullerton (1984, S. 21).

${ }^{163}$ Bei Anwendung des FiFo-Verbrauchsfolgeverfahrens wird unterstellt, daB die zuerst erworbenen oder hergestellten Gegenstände auch zuerst wieder veräußert oder verwendet werden. Der am Ende des Jahres vorhandene Bestand an Vorräten stammt demgemäß aus den letzten Einkäufen bzw. der letzten Herstellung und ist daher mit den zu diesem Zeitpunkt geltenden Preisen zu bewerten. Die Differenz zwischen dem Wert des Vorratsvermögens am Anfang- und am Ende eines Wirtschaftsjahres wird bei konstantem Bestand in der Gewinn- und Verlustrechnung als Gewinn erfabt. Vgl. Olfert et al. $(1989$, S. 208 f.).
} 
Wirtschaftsjahres. ${ }^{164}$ Das LiFo-Verfahren ${ }^{165}$ (last in - first out) andererseits führt bei Inflation dazu, daß das Vorratsvermögen mit dem Wert zu Beginn eines Jahres angesetzt wird. Ceteris paribus resultiert aus diesem Verfahren, daß Scheingewinne nicht im Zeitpunkt der Bewertung sondern bei der Realisierung versteuert werden müssen. ${ }^{166}$ Während des von King und Fullerton analysierten Zeitraums erfolgte in der Bundesrepublik Deutschland die Vorratsbewertung nach der Durchschnittsmethode. ${ }^{167}$ Dieses Verfahren führt nicht zu einer Vermeidung sondern lediglich zu einer Verringerung der Scheingewinnbesteuerung in dem Wirtschaftsjahr. ${ }^{168}$

Werden nicht die einzelnen Wirtschaftsjahre sondern die gesamte Laufzeit der Investition betrachtet, bewirken die in den betrachteten Staaten gesetzlich geregelten Verfahren für die Bewertung des Vorratsvermögens, daß durch Inflation verursachte Scheingewinne steuerlich in voller Höhe erfaßt werden. Die unterschiedlichen Verbrauchsfolgeverfahren bewirken lediglich eine Erfassung dieser Scheingewinne in verschiedenen Perioden. Werden Extraprofite und Steuerstundungseffekte von einem Unternehmen verwirklicht, so kann durch die Wiederanlage der gestundeten Steuer der Scheingewinn ganz oder teilweise kompensiert werden. ${ }^{169}$

Im Modell der vollständigen Konkurrenz können Extraprofite von einem Unternehmen nicht realisiert werden, d. h. Steuerstundungseffekte treten nicht auf. Die steuerliche Bewertung des Vorratsvermögens bewirkt demnach keine Kapitalbildung in einem Unternehmen und führt nicht zu einer Unternehmensteuerbelastung.

\subsubsection{Resümee und abschließende Bemerkungen}

Die Analyse von King und Fullerton beruht auf der Annahme einer geschlossenen Volkswirtschaft. Bei den von King und Fullerton für die empirische Studie verwendeten Informationsmaterials handelt es sich demgegenüber um Daten offener Volkswirtschaften. Die von

\footnotetext{
164 Vgl. Grotherr (1987, S. 33).

165 Bei diesem Verfahren wird unterstellt, daß die zuletzt gekauften oder hergestellten Gegenstände auch zuerst wieder verwendet oder verkauft werden. Der am Stichtag der Inventur noch vorhandene Bestand stammt somit aus früheren Lieferungen bzw. Herstellungen, die entweder mit dem Tagespreis oder dem bei Inflation niedrigeren Anschaffungs- oder Herstellungspreis bewertet werden müssen. Dieses Verfahren führt zu einer Unterbewertung des Vorratsvermögens. Vgl. Olfert et al. (1989, S. 207 f.).

166 Vgl. Grotherr (1987, S. 367).

167 Im Rahmen dieses Verfahrens können gleichartige Vermögenswerte zu einer Gruppe zusammengefaßt und mit dem permanenten oder periodisch ermittelten gewogenen Durchschnittswert angesetzt werden. Bei der permanenten Durchschnittsbewertung erfolgt die Ermittlung des Durchschnittspreises nach jedem Zugang, während bei der periodischen Bewertung nur einmal am Ende der Periode der Durchschnittspreis aus allen Zugängen ermittelt wird. Die permanente Durchschnittsbewertung ist dabei zeitnaher und entspricht somit am ehesten den Anschaffungskosten, während die periodische Durchschnittsbewertung praktikabler ist. Vgl. Olfert et al. (1989, S. 203 f.).

168 Vgl. Grotherr (1987, S. 335).

169 Siehe auch Ausführungen zu dem Kapitel 5.3.2.4 Ökonomische Abschreibungen.
} 
King und Fullerton vorgenommene Betrachtung einer geschlossenen Volkswirtschaft ignoriert zudem, dab nicht nur Unternehmen multinational operieren, sondern auch Kapitalgeber international agieren. Eine Reduzierung der persönlichen Ertragsteuer für inländische Anteilseigner kann demgemäß zwar zu einer Erhöhung der Ersparnis im betrachteten Staat führen, ohne jedoch gleichzeitig. steigende Investitionen im Inland nach sich zu ziehen. ${ }^{\mathbf{1 7 0}}$ Andererseits können steuerliche Anreize eines Staates eine Erhöhung inländischer Investitionen bewirken, ohne jedoch simultan zu einem größeren nationalen Sparaufkommen zu führen. Neben den Ertragsteuersätzen auf inländische Kapitaleinkünfte sind in einer offenen Volkswirtschaft daher auch die von ausländischen Kapitaleignern im Quellen- und Wohnsitzstaat zu leistenden persönliche Steuern Bestandteil des effektiven Steuersatzes einer Grenzinvestition. ${ }^{171}$

Für die Einbeziehung der Ertragsteuerbelastung von Kapitaleignern in eine Analyse ist es erforderlich, Daten über die Verteilung der Zins- oder Dividendenleistungen auf die unterschiedlichen privaten Haushalte in verschiedenen Länder auszuwerten. Darüber hinaus müssen die Verfahren für die Vermeidung einer Doppelbesteuerung einbezogen werden, um die einem Kapitaleigner nach Steuern verbleibende Rendite zu ermitteln und den effektiven Grenzsteuersatz berechnen zu können. Bei der empirischen Untersuchung von King und Fullerton werden zwar die Daten von offenen Volkswirtschaften zugrundegelegt, jedoch werden weder Annahmen über den Wohnsitzstaat eines Kapitaleigners noch über die anzuwendenden Verfahren zur Vermeidung der Doppelbesteuerung getroffen.

Die für den fixed-r Fall getroffene Annahme, daß identische Renditen nach Unternehmensteuern zu einer übereinstimmenden Rendite nach persönlicher Ertragsteuer eines privaten Haushaltes führt, wird von King und Fullerton bei der empirischen Analyse aufgegeben. Vielmehr werden je nach Einkunftsart abweichende Ertragsteuersätze unterstellt. Die zugrundegelegten Parameter werden im Anhang in der Tabelle A 1 zusammengefaBt.

King und Fullerton nehmen an, daB die Kapitalanlageentscheidung eines privaten Haushaltes sowie die Investitionsentscheidung eines Unternehmens auf der Basis des derzeitigen Steuersystems getroffen werden. Die einem Unternehmen verbleibende Rendite ist abhängig von zukünftigen Erträgen und Aufwendungen, in der Zukunft eintretender Inflationsraten und der bei Realisierung der Einkünfte geltenden Steuergesetze. ${ }^{172}$ Die gegenwärtigen Entscheidungsparameter sollten nur dann in die Zukunft fortgeschrieben werden, wenn davon ausgegangen werden kann, daß während der Laufzeit der Investition keine gravierenden Veränderungen zu erwarten sind. In Großbritannien wurde durch die Steuerreform 1984 die Bewertung des Vorratsvermögens nach dem FiFo-Verfahren vorge-

170 Vgl. Bradford/Stuart (1986, S. 311).

171 Vgl. Bradford/Stuart (1986, S. 311).

172 Vgl. Devereux (1990, S. 7). 
schrieben, woraus die vollständige Besteuerung von Scheingewinnen bei Entstehung und nicht erst bei Realisierung resultiert, die bis dato steuerlich nicht erfaßt wurden. ${ }^{173}$ Die Gesetzesänderung wird von King und Fullerton nicht berücksichtigt, d. h. Vergangenheitsdaten werden in die Zukunft projiziert.

Die Analyse der Annahmen von King und Fullerton verdeutlicht, daß unabhängig von dem nationalen Steuersystem ausschließlich Kapitaleigner steuerlich belastet werden. Da King und Fullerton in ihrer Studie davon ausgehen, daß Unternehmen nicht über Kapital verfügen, sondern Grenzinvestitionen durch die Aufnahme von Mitteln finanzieren müssen, entfällt demnach eine steuerliche Belastung von Unternehmen. Die Ermittlung von effektiven Grenzsteuersätzen beschränkt sich daher auf die Betrachtung der steuerlichen Belastung von privaten Haushalten, denn sowohl Versicherungsgesellschaften als auch steuerbefreite Institutionen verfügen laut King und Fullerton lediglich über das von privaten Haushalten bereitgestellte Kapital und sind demgemäB nur Kommissionäre. Im Zusammenhang mit der Kapitalvergabe sind laut King und Fullerton keine Kosten zu berücksichtigen. Der effektive Grenzsteuersatz ist demgemäß bei einer Inflationsrate in Höhe von Null identisch mit dem nominalen Ertragsteuersatz eines privaten Haushaltes und divergiert entsprechend einer zu berücksichtigenden Preissteigerungsrate. Die obigen Ausführungen verdeutlichen, daß die von King und Fullerton vorgenommene Einbeziehung der nationalen Steuergesetze in das Modell der vollständigen Konkurrenz keine Aussagen über das real beobachtbare Investitionsverhalten von Unternehmen erlaubt. Das Steuersystem der verschiedenen Nationen wird zu vereinfacht dargestellt, so daB die ermittelten Ergebnisse nicht als Grundlage für komplexe einzelwirtschaftliche Investitionsentscheidungen verwendet werden können. Ein Handlungsbedarf bei der nationalen Steuergesetzgebung kann aufgrund der Studie von King und Fullerton nicht hergeleitet werden. Aufgrund der hohen Aggregation der Daten sowie der methodischen Probleme, können die von King und Fullerton ermittelten Resultate nicht für weitergehende empirische Untersuchungen verwendet werden.

\subsubsection{OECD}

Im Auftrag der OECD hat Devereux in 1989 effektive Grenzsteuersätze für das verarbeitende Gewerbe in 23 Industrienationen ermittelt. Bei der Analyse hat Devereux das von King und Fullerton (1984) entwickelte Gleichungssystem zugrundegelegt. Die

173 Bis zu dem Wirtschaftsjahr 1984 konnten Unternehmen eine den steuerpflichtigen Gewinn mindernde Rücklage in Höhe des Produktes aus dem Buchwert des Vorratsvermögens am Anfang der Periode und der Steigerung eines amtlich veröffentlichten Vorratsgüterpreisindexes bilden. Der Index basierte auf der monatlichen Entwicklung des Preisniveaus der Vorratsvermögens, welche von britischen Unternehmen durchschnittlich gehalten wurden. Eine gewinnerhöhende Auflösung der Rücklage kann im Falle des fortgeführten Geschäftsbetriebes in der Regel unterbleiben. Eine aus der Anwendung des FiFo-Verfahrens resultierende Scheingewinnbesteuerung konnte dadurch vermieden werden. Vgl. Grotherr (1987, S. 364). 
Annahme, daß Maschinen und Anlagen, Vorräte oder Gebäude durch Gewinnthesaurierung, die Ausgabe neuer Aktien oder Fremdkapital finanziert werden, wird von Devereux übernommen. ${ }^{174} \mathrm{Um}$ die Studie zu vereinfachen, konzentriert er sich in seiner Untersuchung auf die Körperschaftbesteuerung in den einzelnen Nationen. Unberücksichtigt bleiben daher sowohl die Substanzsteuern als auch die zusätzlich erhobenen ertragsabhängigen Steuern der lokalen Ebenen. Des weiteren werden Zulagen nicht in die Analyse einbezogen, da diese häufig auf Investitionen in bestimmten Regionen oder auf spezielle Branchen bzw. Wirtschaftsgüter beschränkt sind und zudem von den Regierungen limitiert werden. ${ }^{175}$ Die Ermittlung der Rendite vor Unternehmensteuern erfolgt unter Berücksichtigung der ökonomischen Abschreibung. ${ }^{176}$ Im Rahmen seiner Studie gelangt Devereux nicht zu neuen Erkenntnissen. Die obigen Ausführungen zu der Analyse von King und Fullerton können daher auch auf die aktualisierte Untersuchung von Devereux übertragen werden.

In Erweiterung zu den bisherigen Analysen haben Devereux und Pearson im Jahre 1990 die durchschnittliche Rendite einer ausländischen Tochterkapitalgesellschaft vor Steuern sowie die effektive Gesamtsteuerbelastung einer Mutterkapitalgesellschaft für Direktinvestitionen in 23 OECD Nationen ${ }^{177}$ berechnet. Die Analyse von Devereux und Pearson basiert ebenfalls auf dem Modell von King und Fullerton, welches um die im Ausland zu leistende Steuer ergänzt wird. In die Untersuchung ziehen Devereux und Pearson die Körperschaftsteuer, die Einkommensteuer, die auf Veräußerungsgewinne zu zahlende capital gains tax sowie die Kapitalertragsteuer ein. Bei der Quellensteuer berücksichtigen Devereux und Pearson lediglich die in Doppelbesteuerungsabkommen geregelten Sätze. Wechselkursänderungen sowie die steuerliche Behandlung von hieraus resultierenden Gewinnen oder Verlusten werden von Devereux und Pearson ignoriert. ${ }^{178}$

In die Analyse beziehen Devereux und Pearson Direktinvestitionen einer im jeweiligen Inland ansässigen Mutterkapitalgesellschaft in einer anderen OECD Nation durch eine Tochterkapitalgesellschaft ein; Portfolioinvestitionen bleiben unberūcksichtigt. ${ }^{179}$ Die Gewinne einer Tochterkapitalgesellschaft kōnnen laut Devereux und Pearson dreimal steuerlich erfaßt werden. Zunächst erfolgt die Besteuerung der Einkünfte im Ansässigkeitsstaat

\footnotetext{
174 Vgl. Devereux $(1990$, S. 6).

175 Vgl. Devereux $(1990$, S. 7).

176 Devereux übernimmt im Rahmen seiner Studie ebenfalls die Resultate von Hulten und Wykoff (1981). Maschinen werden demnach mit einem Abschreibungssatz in Höhe von 23,3\% abgeschrieben, während die Wertminderung auf Gebäude mit 3,6\% pro Jahr angenommen wird. Die für steuerliche Zwecke unterstellte Nutzungsdauer beläuft sich bei Maschinen auf 8 Jahre und für Gebäude auf 25 Jahre. Vgl. Devereux (1990, S. 6).

177 Dies sind Australien, Österreich, Belgien, Kanada, Dänemark, Finnland, Frankreich, die Bundesrepublik Deutschland, Griechenland, Irland, Italien, Japan, Luxemburg, die Niederlande, Neuseeland, Norwegen, Portugal, Spanien, Schweden, die Schweiz, das Vereinigte Königreich, die Vereinigten Staaten von Amerika und (teilweise) die Türkei. Vgl. Devereux/Pearson (1990, S. 13).

178 Vgl. Devereux/Pearson (1990, S. 2).

179 Vgl. Devereux/Pearson (1990, S. 2 und 4).
} 
der Tochterkapitalgesellschaft, d. h. im Quellenland. Bei einer Rückführung der Gewinne an die Mutterkapitalgesellschaft kann die zweite Besteuerung eintreten, gesetzt den Fall, daß eine Quellensteuer erhoben wird. Gegebenenfalls werden die ausländischen Einkünfte im Wohnsitzstaat der Mutterkapitalgesellschaft zu einer weiteren Steuer herangezogen, wenn das Anrechnungssystem für die Vermeidung der doppelten Besteuerung verwendet wird. Die Gesamtsteuerbelastung ist in diesem Fall abhängig von der Steuer, welche hätte gezahlt werden müssen, wenn die Dividende im Inland erzielt worden wäre. Wird das Freistellungsverfahren angewendet, erfolgt nach Annahme von Devereux und Pearson keine Besteuerung im Wohnsitzland. ${ }^{180}$

Die Finanzierung der ausländischen Tochterkapitalgesellschaft erfolgt laut Devereux und Pearson durch die inländische Mutterkapitalgesellschaft und zwar entweder durch den Erwerb von neuen Aktien der Tochter, die Vergabe eines Darlehens an die ausländische Gesellschaft oder den Verzicht auf Dividendenausschüttungen. Eine Finanzierung der Tochterkapitalgesellschaft im Quellenstaat schließen Devereux und Pearson aus. Bei der Analyse gehen Devereux und Pearson davon aus, daß sich die Mutterkapitalgesellschaft ausschlieflich im Wohnsitzstaat durch die Emission neuer Aktien, die Aufnahme eines Darlehens oder die Thesaurierung von Gewinnen refinanziert. ${ }^{181}$ Devereux und Pearson nehmen an, daß die Refinanzierungsart im Inland der Mutterkapitalgesellschaft den internen Kalkulationszinssatz determiniert. Der interne Zinssatz ist identisch mit der auf inländische Projekte zu erwirtschaftenden Rendite. ${ }^{182}$ Das Projekt wird laut Devereux und Pearson realisiert, wenn die Rendite eines Unternehmens nach Abzug aller Kosten mindestens den Refinanzierungskosten entspricht. Devereux und Pearson gehen von der Annahme aus, daß die Finanzierungsart der Tochterkapitalgesellschaft die Steuerbelastung und die nach Steuern verbleibende Rendite aus der Investition bestimmt. ${ }^{183}$

Die obige Analyse der Studie von King und Fullerton hat bereits gezeigt, daß in dem Modell der vollständigen Konkurrenz nationale Steuersysteme keine Unternehmensteuerbelastung nach sich ziehen, dagegen private Haushalte als Kapitaleigner zu einer Steuer herangezogen werden. Eine Erweiterung des Modells um Direktinvestitionen führt zwar zu einer Vervielfachung der zu berücksichtigenden Parameter, ohne die Aussagekraft des Grundmodells zu korrigieren. Devereux und Pearson konstatieren selbst, ,that it is rather difficult to draw any general conclusions from such a large quantity of data. ${ }^{184}$ Die von Devereux und Pearson ermittelten Daten können aufgrund ihrer hohen Aggregation nicht für weitergehende Untersuchungen verwendet werden.

\footnotetext{
180 Vgl. Devereux/Pearson (1990, S. 4 und 7 f.).

181 Vgl. Devereux/Pearson (1990, S. 2 und 4).

182 Vgl. Devereux/Pearson (1990, S. 5).

183 Vgl. Devereux/Pearson (1990, S. 7).

184 Devereux/Pearson (1990, S. 19).
} 
Die Analyse der bısher veröffentlichten Steuerbelastungsvergleiche für die Ermittlung von effektiven Durchschnittsteuersätzen bzw. effektiven Grenzsteuersätzen verdeutlicht, daß es zur Zeit keine theoretisch fundierten und empirisch durchführbaren Modelle für die Berechnung der effektiven Steuerbelastung von Unternehmen existieren. Daher ist es nicht verwunderlich, wenn ein Unternehmen sich in erster Linie für die nach Steuern verbleibende Rendite und nur indirekt für den effektiven Grenzsteuersatz interessiert. ${ }^{185}$ 
Otto Roloff, Sibylle Brander, Ingo Barens and Claudia Wesselbaum - 978-3-631-75210-4 Downloaded from PubFactory at 01/11/2019 07:04:40AM via free access 


\section{Anhang Kapitel 5}

Otto Roloff, Sibylle Brander, Ingo Barens and Claudia Wesselbaum - 978-3-631-75210-4 Downloaded from PubFactory at 01/11/2019 07:04:40AM 
Otto Roloff, Sibylle Brander, Ingo Barens and Claudia Wesselbaum - 978-3-631-75210-4 Downloaded from PubFactory at 01/11/2019 07:04:40AM via free access 
Abbildung A 1: Unternehmensteuerbelastungsvergleiche

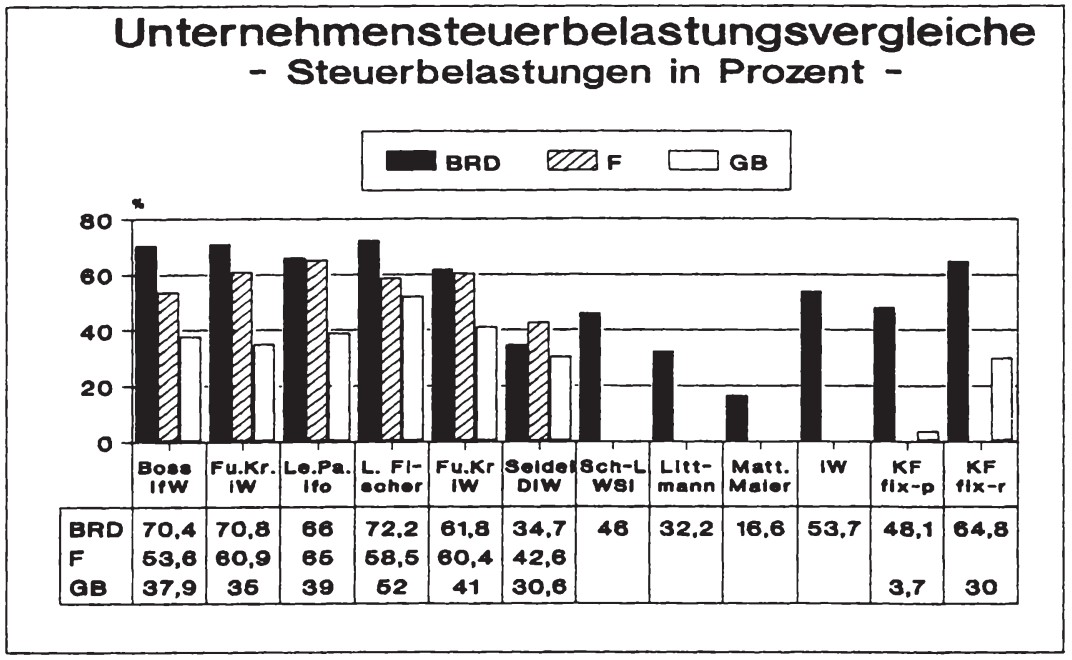

Boss, IfW = Boss, Alfred [1989]; Institut für Weltwirtschaft an der Universität Riel; Steuerbelastung von Rapitalgesellschaften bei cewinnthesaurierung.

Pu.Rr., iw = Puest, Winfried; Rroker, Rolf [1988]; Institut der deutschen Wirtschaft; cesantsteuerbelastung einer Rapitalgesellschaften bei cerinnthesaurierung.

Le.Pa, ifo = Leibfritz, Willi; Parsche, Rüdiger [1989]; Institut für Wirtschaftsforschung; Belastung des steuerpflichtigen Gewinns einer Rapitalgesellschaft der Werkzeugzaschinenindustrie.

L. Pischer = Fischer, Lutz [1984]; Rapitalgesellschaften bei Gewinnthesaurierung.

Pu.Rr., in = Puest, Windfried; Rroker, Rolf [1989 a]; Institut der deutschen Wirtschaft; effektive durchschnittliche Steuerbelastung von Kapitalgesellschaften in der Werkzeuguschinenindustrie 1987 bei einer 208igen Gevinnausschüttung

Seidel, DIW

= Seidel, Bernhard et al. [1989]; Deutsches Institut für Wirtschaftsforschung; Steuern von Cewinn, Rrtrag und Venögen für eine Rapitalgesellschaft des Maschinenbaus bei tatsáchlichen Ausschüttungsverballtnis in Verhảltnis zun bereinigten Bilanzgevinn; Bundesrepublik: goer Steverrecht.

Sch-L, WSI = Scheibe-Lange, Ingrid [1986]; Wirtschafts- und Sorialwissenschaftliches Institut des Deutschen Gerverkschaftsbundes bei voller cevinnthesaurierung in v. I. des tatsảchlichen Gevinns (unter Bericksichtigung der steverlichen abschreibungen).

Littuann

Matt. Maier

= Littwann, Ronrad [1988]; Volkswirtschaftliche Gesantrechnung.

iw

= Matthảus-Haier, Ingrid [1988]; Volksuirtschaftliche Cesantrechnung.

= Institut der deutschen Wirtschaft [1989]; Volksuirtschaftliche Gesantrechnung geväB Bundesbank-Konzept, 1. Bj. 1988.

$K R$, fix-p = King, Mervyn A.; Rullerton, Don [1984]; durchschnittlicher effektiver Grenzsteuersatz unter der Annahre, dab alle Grenzinvestitionen eine identische Rendite in Hobe von real 5 i nach Stevern beziehen bei aktueller Inflationssatz, aktuellen ubschreibungen und aktuellen Gevichtungen für das Jahr 1980.

KP, fix-r

= King, Mervyn A.; Pullerton, Don [1984]; durchschnittlicher effektiver Grenzsteversatz unter der Annabee, daB alle Grensinvestitionen eine identische Rendite in Hôbe von real 10 \& vor Stevern beziehen bei aktueller Inflationsrate, aktuellen ubschreibungen und aktuellen Gevichtungen für das Jahr 1980.

Pundstellen: s. Literaturverzeichnis 
Tabelle A 1: Vermögenssteuer- und Einkommensteuersatz in Abhängigkeit von der Finanzierungsart für Großbritannien, die Bundesrepublik Deutschland und die Vereinigten Staaten von Amerika laut King/Fullerton

\begin{tabular}{|c|c|c|c|c|c|c|c|c|c|}
\hline & $\begin{array}{l}\text { Preadka- } \\
\text { pital }\end{array}$ & $\mid \begin{array}{l}\text { Brission } \\
\text { v.Aktien }\end{array}$ & $\begin{array}{l}\text { Thesan- } \\
\text { rierung }\end{array}$ & $\begin{array}{l}\text { Preadka- } \\
\text { pital }\end{array}$ & r.akstion & Thesau- & $\begin{array}{l}\text { Vereini } \\
\text { Anerike } \\
\text { Prendka- } \\
\text { pital }\end{array}$ & $\begin{array}{l}\text { nigte Staat } \\
\text { | Rission } \\
\text { v.Aktien }\end{array}$ & $\begin{array}{l}\text { ten von } \\
\text { Thesau- } \\
\text { rierung }\end{array}$ \\
\hline 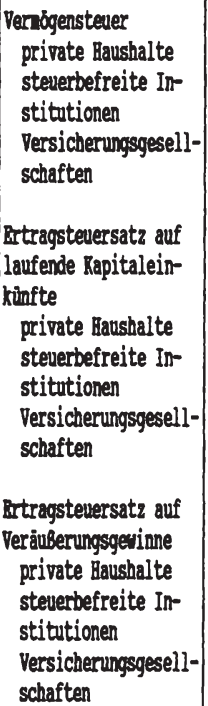 & $\begin{array}{c}0,2382 \\
0 \\
0,1765\end{array}$ & $\begin{array}{c}0,2382 \\
0 \\
0,1765\end{array}$ & $\begin{array}{c}0,2832 \\
0 \\
0,1765\end{array}$ & $\begin{array}{r}0,398 \\
0 \\
0,028\end{array}$ & $\begin{array}{l}0,480 \\
0,4001) \\
0,028\end{array}$ & $\begin{array}{l}0,480 \\
0,4001) \\
0,028\end{array}$ & $\begin{array}{c}0,284 \\
0 \\
(0.149+ \\
3.88 x)\end{array}$ & {$\left[\begin{array}{c}0,475 \\
0 \\
0,069\end{array}\right.$} & $\begin{array}{c}0,475 \\
0 \\
0,069\end{array}$ \\
\hline
\end{tabular}

1) Steuerbefreite bzw. Gereinnùtzige Institutionen kőnnen die einbehaltene Rorperschaftsteuer auf Dividenden nicht anrechnen. Die Rapitalertragsteuer wird in voller Bobe baw. teilweise (50 \%) erstattet.

Quelle: Ring/Fullerton (1984, Appendix A, ohne Seitenangabe und S. 174). 


\section{Literaturverzeichnis:}

Abel, Andrew B. (1979). Investment and the Value of Capital. 1. Aufl., New York/London Abel, Andrew B.; Blanchard, Olivier Jean (1986). The present value of profits and cyclical movements in investment. in: Econometrica, 54. Jg., Heft 2, March, S. 249-273

Abkommen zwischen der Bundesrepublik Deutschland und dem Vereinigten Königreich Großbritannien und Nordirland zur Vermeidung der Doppelbesteuerung und zur Verhinderung der Steuerverkürzung (1966). in: Bundessteuerblatt, 16. Jg., 1966, Teil I, S. 730-744

Adebahr, Hubertus (1981). Direktinvestitionen. Eine Problemskizze. Berlin

Agarwal, Jamuna P. (1980). Determinants of Foreign Direct Investment: A Survey. in: Weltwirtschaftliches Archiv, vol. 116, S. 739-773

Agarwal, Jamuna P.; Gubitz, Andrea; Nunnenkamp, Peter (1991). Foreign Direct Investment in Developing Countries. The Case of Germany. Tübingen

Alworth, Julian S. (1987). Taxation and the cost of capital: a comparison of six EC countries. in: Cnossen, Sijbren (Hrsg.). Tax coordination in the European Community, Series on international taxation Nr. 7, Deventer/Antwerpen, S. 253-283

Alworth, Julian S. (1988). The finance, investment and taxation decisions of multinationals. Oxford

Auerbach, Alan J.; Jorgenson, Dale (1980). Inflation-proof depreciation of assets. in: Harvard Business Review, September-October, S. 113-118

Bach, Christopher L. (1985). U.S. International Transactions, Fourth Quarter and Year 1984. in: Survey of Current Business, vol. 65, Heft 3, S. 29-58

Bach, Christopher L. (1986). U.S. International Transactions, Fourth Quarter and Year 1985. in: Survey of Current Business, vol. 66, Heft 3, S. 24-54

Bach, Christopher L. (1987). U.S. International Transactions, Fourth Quarter and Year 1986. in: Survey of Current Business, vol. 67, Heft 3, S. 32-62

Bach, Christopher L. (1989). U.S. International Transactions, Second Quarter 1989. in: Survey of Current Business, vol. 69, Heft 9, S. 28-52

Bach, Christopher L. (1990). U.S. International Transactions, Fourth Quarter and Year 1989. in: Survey of Current Business, vol. 70, Heft 3, S. 33-66

Bach, Christopher L. (1991). U.S. International Transactions, Fourth Quarter and Year 1990. in: Survey of Current Business, vol. 71, Heft 3, S. 34-68

Bach, Christopher L. (1992). U.S. International Transactions, Fourth Quarter and Year 1991. in: Survey of Current Business, vol. 72, Heft 3, S. 51-93

Barens, Ingo (1992). Investitionen, Marktbewertung und Kapitaltheorie. Eine Studie über neuere investitionstheoretische Ansätze. Unveröffentlichte Habilitationsschrift. Wuppertal

Bauer, Jörg (1988). Steuergestaltung tut not! - Ausgewählte unternehmenspolitische Folgerungen auf der Steuerreform 1990. in: Der Betrieb, 41. Jg., 23.12.1988, Heft 51/52, S. 2573-2577

Bedford, Horst; von Saldern, Sabine (1972). Entwicklung und Förderung der französischen Direktinvestitionen. in: Scharrer, Hans-Eckart (Hrsg.): Förderung privater Direktinvestitionen. Hamburg, S. 321-397

Beidleman, Carl R. (1976). Economic depreciation in a capital goods industry. in: NationalTax Journal, 29. Jg., Nr. 4, S. 379-390 
Belli, R. David (1984). Foreign Direct Investment in the United States in 1983. in: Survey of Current Business, vol. 64, Heft 10, S. 26-48

Beyfuß, Jörg; Kitterer, Bernd H.-J. (1990). Deutsche Direktinvestitionen im Ausland. Bestandsaufnahme und Ergebnisse einer Unternehmensbefragung. Beiträge zur Wirtschafts- und Sozialpolitik, Institut der deutschen Wirtschaft Köln, Nr. 181, Köln

Bezirganian, Steve D. (1991). U.S. Affiliates of Foreign Companies: Operations in 1989. in: Survey of Current Business, vol. 71, Heft 7, S. 72-93; Errata: Survey of Current Business, vol. 71, Heft 8, S. 46

Bezirganian, Steve D. (1992). U.S. Affiliates of Foreign Companies: Operations in 1990. in: Survey of Current Business, vol. 72, Heft 5, S. 45-68

Biener, Herbert; Berneke, Wilhelm (1986). Bilanzrichtlinien-Gesetz. Textausgabe des Bilanzrichtlinien-Gesetzes vom 19.12.1985 (BGBl I S. 2355) mit Bericht des Rechtsausschusses des Deutschen Bundestages, Regierungsentwürfe mit Begründung, EGRichtlinien mit Begründung, Entstehung und Erläuterung des Gesetzes. Düsseldorf

Blankart, Charles B. (1991). Öffentliche Finanzen in der Demokratie, München

Boddewyn, Jean J. (1983). Foreign Direct Divestment Theory: Is It the Reverse of FDI Theory?. in: Weltwirtschaftliches Archiv, vol. 119, S. 345-355

Boeck, Klaus (1972). Entwicklung und Förderung der britischen Direktinvestitionen. in: Scharrer, Hans-Eckart (Hrsg.): Förderung privater Direktinvestitionen. Hamburg, S. $229-319$

von Boehmer, Henning (Hrsg.) (1991). Deutsche Unternehmen in Frankreich. Leitfaden für die Rechts- und Wirtschaftspraxis, Stuttgart

Bolenz, Gerhard (1978). Sequentielle Investitions- und Finanzierungsentscheidungen. Ein kontrolltheoretischer Beitrag. Wirtschaftskybernetik und Systemanalyse. Band 5, Berlin

Boskin, Michael J.; Gale, William G. (1987). New Results on the Effects of Tax Policy on the International Location of Investment. in: Feldstein, Martin (Hrsg.): The Effects of Taxation on Capital Accumulation. Chicago und London, S. 201-222

Boss, Alfred (1988). Unternehmensbesteuerung und Standortqualität. Ein internationaler Vergleich. Institut für Weltwirtschaft Kiel, Kieler Diskussionsbeiträge Nr. 145/146

Bradford, David; Stuart, Charles (1986). Issues in the measurement and interpretation of effective tax rates. in: National Tax Journal, 39. Jg., S. 307-316

Brander, Sibylle (1993). Direktinvestitionen und ihre statistische Erfassung. Unveröffentlichtes Manuskript. Wuppertal

Braun, Gerhard (1988). Die Theorie der Direktinvestition. Köln

Buchner, Robert (1990). Rechnungslegung und Prüfung der Kapitalgesellschaft. Stuttgart

Buckley, Peter J. (1985). Testing Theories of the Multinational Enterprise: A Review of the Evidence. in: Buckley, Peter J.; Casson, Mark (Hrsg.): The Economic Theory of the Multinational Enterprise. London und Basingstoke, S. 192-211

Der Bundesminister für Wirtschaft (1964). Runderlaß Außenwirtschaft 41/63 betreffend: Vierte Verordnung zur Änderung der Außenwirtschaftsverordnung (AWV) vom 17. Dezember 1963 (BGBl. I S. 888) vom 21. Dezember 1963. in: Bundesanzeiger, 16. Jg., Nr. 1 vom 3. Januar 1964, S. 2

Der Bundesminister für Wirtschaft (1981a). Runderlaß Außenwirtschaft Nr. 11/81 betreffend IV 1; Vermögensanlagen Gebietsansässiger in fremden Wirtschaftsgebieten. Vom 31. März 1981. in: Bundesanzeiger, 33. Jg., Nr. 75 vom 22. April 1981, S. 1-3 
Der Bundesminister für Wirtschaft (1981b). Runderlaß Außenwirtschaft, Nr. 12/81 betreffend IV 1; Vermögensanlagen Gebietsfremder im Wirtschaftsgebiet. Vom 31. März 1981. in: Bundesanzeiger, 33. Jg., Nr. 75 vom 22. April 1981, S. 3-1

Der Bundesminister für Wirtschaft (1982a). Runderlaß Außenwirtschaft Nr. 12/82 Vermögensanlagen Gebietsansässiger in fremden Wirtschaftsgebieten. Vom 31. März 1982. in: Bundesanzeiger, 34. Jg., Nr. 74 vom 21. April 1982, S. 1-2

Der Bundesminister für Wirtschaft (1982b). Runderlaß Außenwirtschaft Nr. 1:3/\$2 Vermögensanlagen Gebietsfremder im Wirtschaftsgebiet. Vom 31. März 1982. in: Bundesanzeiger, 34. Jg., Nr. 74 vorn 21. April 1982, S. 2-3

Der Bundesminister für Wirtschaft (1982c). Runderlaß Außenwirtschaft. Nr. 27/82 betreffend VI: Zweiundfünfzigste Verordnung zur Änderung der Außenwirtschaftsverordnung. Vom 13. August 1982. in: Bundesanzeiger, 34. Jg., Nr. 152 vom 19. August $1982, \mathrm{~S} .1-2$

Der Bundesminister für Wirtschaft (1983). Runderlaß Außenwirtschaft $7 / 83$ betreffend VI: Allgemeines Außenwirtschaftsrecht Auslegung der Begriffe „Gebietsansässige" und "Grebietsfremde" (natürliche Personen) nach $\S 4$ hbs. $1 \mathrm{Nr} .3$ und $4 \Lambda W G$. Vom 9. Februar 1983. in: Bundesanzeiger, 35. Jg., Nr. 29 vom 11. Februar 1983, S. 1257

Der Bundesminister für Wirtschaft (1985a). Runderlaß Außenwirtschaft, Nr. 9/85) Vermögensanlagen Gebietsansässiger in fremden Wirtschaftsgebieten. Vom 29. März 1985. in: Bundesanzeiger, 37. Jg., Nr. 75 vom 20. April 1985, S. 1021-4023

Der Bundesminister für Wirtschaft (1985b). Runderlaß Außenwirtschaft Nr. 10/85 .. Vermögensanlagen Gebietsfremder im Wirtschaftsgebiet. Vom 29. März 1985. in: Bundesanzeiger, 37. Jg., Nr. 75 vom 20. April 1985, S. 4023

Der Bundesminister für Wirtschaft (1987a). Runderlaß Außenwirtschaft Nr. 5/87 Vermögensanlagen Gebietsansässiger in fremden Wirtschaftsgebieten. Vom 17. März 1987. in: Bundesanzeiger, 39. Jg., Nr. 66 vom 4. April 1987. S. 3725-3726

Der Bundesminister für Wirtschaft (1987b). Runderlaß $\Lambda$ ußenwirtschaft Nr. 6/87 -- Vermögensanlagen Gebietsfremder im Wirtschaftsgebiet. Vom 17. März 1987. in: Bundesanzeiger, 39. Jg., Nr. 66 vom 4. April 1987, S. 3726

Der Bundesminister für Wirtschaft (1988a). Runderlaß Außenwirtschaft Nr. 11/88 Vermögensanlagen Gebietsansässiger in fremden Wirtschaftsgebieten. Vom 19. Mai 1988. in: Bundesanzeiger, 40. Jg., Nr. 99 vom 28. Mai 1988, S. 2350

Der Bundesminister für Wirtschaft (1988b). Runderlaß Außenwirtschaft Nr. 12/88 Vermögensanlagen (Gebietsfremder im Wirtschaftsgebiet. Vom 19. Mai 1988. in: Bundesanzeiger, 40. Jg., Nr. 99 vom 28. Mai 1988, S. 2350-2351

Der Bundesminister für Wirtschaft (1989). Runderlaß Außenwirtschaft Nr. 19/89 betreffend VI: Fünfte Verordnung zur Änderung der Außenwirtschaftsverordnung. Vom 20. September 1989. in: Bundesanzeiger, 41. Jg., Nr. 184 vom 29. September 1989. S. 4621-4623

Der Bundesminister für Wirtschaft (1991). Runderlaß Außenwirtschaft. Nr. 14/91 betreffend VI: Sechzehnte Verordnung zur Änderung der Außenwirtschaftsverordnung. Vom 18. Juli 1991. in: Bundesanzeiger, 43. Jg., Nr. 133 vom 20. Juli 1991, S. 4744

Der Bundesminister für Wirtschaft (1992a). Runderlaß Außenwirtschaft Nr. 2:3/92 Vermögensanlagen Gebietsansässiger in fremden Wirtschaftsgebieten. Voin 20. Mai 1992. in: Bundesanzeiger, 44. Jg., Nr. 101 vom 2. Juni 1992, S. 4430 
Der Bundesminister für Wirtschaft (1992b). Runderlaß Außenwirtschaft Nr. 24/92 Vermögensanlagen Gebietsfremder im Wirtschaftsgebiet. Vom 20. Mai 1992. in: Bundesanzeiger, 44. Jg., Nr. 101 vom 2. Juni 1992, S. 4430-4431

Der Bundesminister für Wirtschaft (1992c). Runderlaß Außenwirtschaft Nr. 38/92 betreffend I.1 und 2: Auswirkungen des Binnenmarktes ab 1. Januar 1993 auf die Außenwirtschaftsverordnung. Vom 11. Dezember 1992. in: Bundesanzeiger, 44. Jg., Nr. 239 vom 19. Dezember 1992, S. 9505-9506

Bundesministerium für Wirtschaft (1990). Leistung in Zahlen '89. Bonn

Bundesministerium für Wirtschaft (o.J.). Wirtschaft in Zahlen '92. Bonn

Burmeister, Edwin (1987). „Wicksell effects“. in: Eatwell, John et al. (Hrsg.): The New Palgrave. A Dictionary of Economics. Band 4, 1. Aufl., London, S. 910-912

Campbell, John Y. (1991). Aggregate Investment, the Stock Market, and the $Q$ Model: Robust Results for Six OECD Countries: Comment. in: European Economic Review, 35. Jg., Mai, S. 826-830

Casson, Mark (1987). The Market and the Firm. Studies on Multinational Enterprise and the Scope of the Firm. Oxford

Caves, Richard E. (1982). Multinational Enterprise and Economic Analysis. Cambridge Surveys of Economic Literature. Cambridge usw.

Chirinko, Robert S. (1987). Tobin's $Q$ and Financial Policy. in: Journal of Monetary Economics, 19. Jg., S. 69-87

Chirinko, Robert S. (1988). Will „The“ Neoclassical Theory of Investment Please Rise?: The General Structure of Investment Models and Their Implications for Tax Policy. o. $\mathrm{O}$.

Chirinko, Robert S. (1990). Multiple Capital Inputs, Tobin's Q, and Investment Spending. Chicago

Chirinko, Robert S. (1992). „Q“. in: Eatwell, John et al. (Hrsg.): The New Palgrave Dictionary of Money and Finance. Band 3, 1. Aufl., London, S. 245-247

Cnossen, Sijbren (Hrsg.) (1987). Tax coordination in the European Community. Series on international taxation Nr. 7, Deventer/Antwerpen

Coen, Robert M.; Eisner, Robert (1992). „Investment“. in: Eatwell, John et al. (Hrsg.): The New Palgrave Dictionary of Money and Finance. Band 2, 1. Aufl., London, S. $508-514$

Culem, Claudy G. (1988). The Locational Determinants of Direct Investments among Industrialized Countries. in: European Economic Review, vol. 32, S. 885-904

Daly, Michael et al. (1985). The taxation of capital income in canada: a comparison with sweden, the U.K., the U.S.A. and West Germany. Economic Council of Canada, Discussion Paper No. 289, o. O.

Debatin, Helmut; Endres, Dieter; unter Mitarbeit von Roland Maas (1990). Das neue Doppelbesteuerungsabkommen USA/Bundesrepublik Deutschland - The new US/German Double Tax Treaty. München

Debatin, Helmut; Korn, R.; unter Mitarbeit von P. Hellwig und F. Hundt (1989). Doppelbesteuerung. Sammlung der zwischen der Bundesrepublik Deutschland und dem Ausland bestehenden Abkommen über die Vermeidung der Doppelbesteuerung. Kommentar, Stand: November 1989. Band Band IV: Länderteil von Schweiz bis Zypern, München 
Deutsche Bundesbank (1964). Mitteilung Nr. 8002/64 betreffend Meldevorschriften für den Zahlungsverkehr nach $\S \S 59$ bis 69 der Außenwirtschaftsverordnung (AWV). Vom 27. Januar 1964. in: Bundesanzeiger, 16. Jg., Nr. 20 vom 30. Januar 1964, S. 1

Deutsche Bundesbank (1965). Die deutschen Direktinvestitionen im Ausland. in: Monatsberichte der Deutschen Bundesbank, 17. Jg., Nr. 12, S. 19-27

Deutsche Bundesbank (1972). Ausländische Beteiligungen an Unternehmen in der Bundesresrepublik. in: Monatsberichte der Deutschen Bundesbank, 24. Jg., Nr. 1, S. 28-38

Deutsche Bundesbank (1974). Ausländische Beteiligungen an Unternehmen in der Bundesresrepublik. in: Monatsberichte der Deutschen Bundesbank, 26. Jg., Nr. 11, S. 22-33

Deutsche Bundesbank (Hrsg.) (1976a). Deutsches Geld- und Bankenwesen in Zahlen 18761975. Frankfurt am Main

Deutsche Bundesbank (1976b). Mitteilung Nr. 7004/76 betreffend Drittes Gesetz zur Änderung des Außenwirtschaftsgesetzes vom 29. März 1976 (BGBl. I S. 869); hier: Rechtliche Verselbständigung von Zweigniederlassungen und Betriebsstätten im Außenwirtschaftsrecht. Vom 9. April 1976. in: Bundesanzeiger, 28. Jg., Nr. 72 vom 13. April 1976, S. 3

Deutsche Bundesbank (1976c). Mitteilung Nr. 8002/76 betreffend Erläuterungen der Deutschen Bundesbank zu den Meldevorschriften für den Kapitalverkehr nach § 56a und $b$ und 58a und $b$ Außenwirtschaftsverordnung (AWV). Vom 22. Juli 1976. in: Bundesanzeiger, 28. Jg., Nr. 140 vom 29. Juli 1976, S. 3

Deutsche Bundesbank (1976d). Erläuterungen der Deutschen Bundesbank zur Meldung „Vermögen Gebietsansässiger in fremden Wirtschaftsgebieten " - Vordruck Anlage K 3 Blatt 1 und Blatt 2 zur AWV. Vom 22. Juli 1976. in: Bundesanzeiger, 28. Jg., Nr. 140 vom 29. Juli 1976, S. 3-4

Deutsche Bundesbank (1976e). Erläuterungen der Deutschen Bundesbank zur Meldung „Vermögen Gebietsfremder im Wirtschaftsgebiet" - Vordruck Anlage K 4 Blatt 1 und Blatt 2 zur AWV. Vom 22. Juli 1976. in: Bundesanzeiger, 28. Jg., Nr. 140 vom 29. Juli 1976, S. 4

Deutsche Bundesbank (1978). Umschwung in der Bilanz der Direktinvestitionen. in: Monatsberichte der Deutschen Bundesbank, 30. Jg., Nr. 10, S. 31-36

Deutsche Bundesbank (1979). Stand der Direktinvestitionen Ende 1976. Erste Ergebnisse einer neuen Statistik über die deutschen Direktinvestitionen im Ausland und die ausländischen Direktinvestitionen in der Bundesrepublik Deutschland. in: Monatsberichte der Deutschen Bundesbank, 31. Jg., Nr. 4, S. 26-40

Deutsche Bundesbank (1980). Die Auslandsverflechtung der Unternehmen Ende 1977. in: Monatsberichte der Deutschen Bundesbank, 32. Jg., Nr. 4, S. 22-35

Deutsche Bundesbank (1981a). Die Auslandsverflechtung der Unternehmen im Jahre 1978. in: Monatsberichte der Deutschen Bundesbank, 33. Jg., Nr. 1, S. 28-45

Deutsche Bundesbank (1981b). Die Kapitalverflechtung der Unternehmen mit dem Ausland. in: Monatsberichte der Deutschen Bundesbank, 33. Jg., Nr. 10, S. 39-55

Deutsche Bundesbank (1982a). Die Entwicklung der Kapitalverflechtung der Unternehmen mit dem Ausland von 1976 bis 1980. in: Monatsberichte der Deutschen Bundesbank, 34. Jg., Nr. 8, S. $42-59$

Deutsche Bundesbank (1982b). Mitteilung Nr. 8001/82 - Erläuterungen der Deutschen Bundesbank zu den Meldevorschriften für den Kapitalverkehr und für den Zahlungsverkehr nach $\S \S 55$ bis 69 der Außenwirtschaftsverordnung (AWV). Vom 27. August 1982. in: Bundesanzeiger, 34. Jg., Nr. 162 vom 2. September 1982, S. 2 
Deutsche Bundesbank (1983a). Die Kapitalverflechtung der Unternehmen mit dem Ausland nach Ländern und Wirtschaftszweigen 1976 bis 1981. Beilage zu „Statistische Beihefte zu den Monatsberichten der Deutschen Bundesbank", Reihe 3, Zahlungsbilanzstatistik, Nr. 6, Juni 1983

Deutsche Bundesbank (1983b). Struktur der Kapitalverflechtung der Unternehmen mit dem Ausland. in: Monatsberichte der Deutschen Bundesbank, 35. Jg., Nr. 5, S. 32-45

Deutsche Bundesbank (1984a). Die Entwicklung der Kapitalverflechtung der Unternehmen mit dem Ausland im Jahre 1982. in: Monatsberichte der Deutschen Bundesbank, 36. Jg., Nr. 4, S. 22-27

Deutsche Bundesbank (1984b). Statistische Beihefte zu den Monatsberichten der Deutschen Bundesbank, Reihe 3, Zahlungsbilanzstatistik, März 1984, Nr. 3

Deutsche Bundesbank (1985). Die Kapitalverflechtung der Unternehmen mit dem Ausland im Jahre 1983. in: Monatsberichte der Deutschen Bundesbank, 37. Jg., Nr. 3, S. 29 36

Deutsche Bundesbank (1986). Die Zahlungsbilanzstatistik der Bundesrepublik Deutschland mit dem Ausland 1973 bis 1985 sowie mit einzelnen Ländergruppen und Ländern 1982 bis 1985. Beilage zu „Statistische Beihefte zu den Monatsberichten der Deutschen Bundesbank", Reihe 3, Zahlungsbilanzstatistik, Nr. 7, Juli 1986

Deutsche Bundesbank (1987a). Die Entwicklung der Kapitalverflechtung der Unternehmen mit dem Ausland in den Jahren 1976 bis 1985. in: Monatsberichte der Deutschen Bundesbank, 39. Jg., Nr. 3, S. 21-34

Deutsche Bundesbank (1987b). Die Zahlungsbilanzstatistik der Bundesrepublik Deutschland. Inhalt, Aufbau und methodische Grundlagen. Sonderdrucke der Deutschen Bundesbank, Nr. 8, Frankfurt am Main

Deutsche Bundesbank (1987c). Die Zahlungsbilanz der Bundesrepublik Deutschland mit dem Ausland 1974 bis 1986 sowie mit einzelnen Ländergruppen und Ländern 1983 bis 1986. Beilage zu „Statistische Beihefte zu den Monatsberichten der Deutschen Bundesbank", Reihe 3, Zahlungsbilanzstatistik, Nr. 7, Juli 1987

Deutsche Bundesbank (1988a). Die Kapitalverflechtung der Unternehmen mit dem Ausland nach Ländern und Wirtschaftszweigen 1980 bis 1986 . Beilage $\mathrm{zu}$ "Statistische Beihefte zu den Monatsberichten der Deutschen Bundesbank“, Reihe 3, Zahlungsbilanzstatistik, Nr. 3, März 1988

Deutsche Bundesbank (1988b). Die Zahlungsbilanzstatistik der Bundesrepublik Deutschland mit dem Ausland 1975 bis 1987 sowie mit einzelnen Ländergruppen und Ländern 1984 bis 1987. Beilage zu „Statistische Beihefte zu den Monatsberichten der Deutschen Bundesbank“, Reihe 3, Zahlungsbilanzstatistik, Nr. 6, Juni 1988

Deutsche Bundesbank (1989a). Die Kapitalverflechtung der Unternehmen mit dem Ausland - Stand Ende 1987 und aktuelle Entwicklung. in: Monatsberichte der Deutschen Bundesbank, 41. Jg., Nr. 4, S. 23-33

Deutsche Bundesbank (1989b). Mitteilung Nr. 8001/89 - Erläuterungen der Deutschen Bundesbank zu den Meldevorschriften für den Kapitalverkehr und für den Zahlungsverkehr nach den $\S \S 55$ bis 69 der Außenwirtschaftsverordnung. Vom 7. Dezember 1989. in: Bundesanzeiger, 41. Jg., Nr. 236 vom 16. Dezember 1989, S. 5765-5766

Deutsche Bundesbank (1989c). Die Zahlungsbilanz der Bundesrepublik Deutschland mit dem Ausland 1977 bis 1988 sowie mit einzelnen Ländergruppen und Ländern 1985 bis 1988. Beilage zu „Statistische Beihefte zu den Monatsberichten der Deutschen Bundesbank“, Reihe 3, Zahlungsbilanzstatistik, Juli 1989, Nr. 7

Deutsche Bundesbank (1990a). Erläuterungen der Deutschen Bundesbank zur Meldung „Vermögensanlagen Gebietsansässiger in fremden Wirtschaftsgebieten". Vordruck Anlage K 1 zur AWV. Stand: Dezember 1989 
Deutsche Bundesbank (1990b). Erläuterungen der Deutschen Bundesbank zur Meldung „Vermögensanlagen Gebietsfremder im Wirtschaftsgebiet". Vordruck Anlage K 2 zur AWV. Stand: Dezember 1989

Deutsche Bundesbank (1990c). Erläuterungen der Deutschen Bundesbank zur Meldung „Vermögen Gebietsansässiger in fremden Wirtschaftsgebieten “. Vordruck Anlage K 3 Blatt 1 und Blatt 2 zur AWV. Stand: Januar 1990

Deutsche Bundesbank (1990d). Erläuterungen der Deutschen Bundesbank zur Meldung „Vermögen Gebietsfremder im Wirtschaftsgebiet“. Vordruck Anlage K 4 Blatt 1 und Blatt 2 zur AWV. Stand: Januar 1990

Deutsche Bundesbank (1990e). Erläuterungen zum Leistungsverzeichnis der Außenwirtschaftsverordnung. Stand: Januar 1990. o. O.

Deutsche Bundesbank (1990f). Die Zahlungsbilanzstatistik der Bundesrepublik Deutschland. Inhalt, Aufbau und methodische Grundlagen. Sonderdrucke der Deutschen Bundesbank, Nr. 8, 2. Aufl., Frankfurt am Main

Deutsche Bundesbank (1990g). Die Zahlungsbilanz der Bundesrepublik Deutschland mit dem Ausland 1978 bis 1989 sowie mit einzelnen Ländergruppen und Ländern 1986 bis 1989. Beilage zu „Statistische Beihefte zu den Monatsberichten der Deutschen Bundesbank", Reihe 3, Zahlungsbilanzstatistik, Juli 1990, Nr. 7

Deutsche Bundesbank (1990h). Statistische Beihefte zu den Monatsberichten der Deutschen Bundesbank, Reihe 3, Zahlungsbilanzstatistik, November 1990, Nr. 11

Deutsche Bundesbank (1991a). Die Entwicklung der Kapitalverflechtung der Unternehmen mit dem Ausland von Ende 1987 bis Ende 1989. in: Monatsberichte der Deutschen Bundesbank, 43. Jg., Nr. 4, S. 28-36

Deutsche Bundesbank (1991b). Die Zahlungsbilanz der Bundesrepublik Deutschland im Jahre 1990. in: Monatsberichte der Deutschen Bundesbank, 43. Jg., Nr. 3, S. 27-36

Deutsche Bundesbank (1991c). Mitteilung Nr. 8002/91 - Erläuterungen der Deutschen Bundesbank zu den Meldevorschriften für den Zahlungsverkehr mit dem Ausland nach den $\S \S 59$ ff. der Außenwirtschaftsverordnung (AWV). Vom 1. August 1991. in: Bundesanzeiger, 43. Jg., Nr. 147 vom 9. August 1991, S. 5318

Deutsche Bundesbank (1992a). Die Kapitalverflechtung der Unternehmen mit dem Ausland nach Ländern und Wirtschaftszweigen 1984 bis 1990 . Beilage zu „Statistische Beihefte zu den Monatsberichten der Deutschen Bundesbank", Reihe 3, Zahlungsbilanzstatistik, April 1992, Nr. 4

Deutsche Bundesbank (1992b). Die Zahlungsbilanz der Bundesrepublik Deutschland mit dem Ausland 1980 bis 1991 sowie mit einzelnen Ländergruppen und Ländern 1988 bis 1991. Beilage zu ${ }_{n}$ Statistische Beihefte zu den Monatsberichten der Deutschen Bundesbank", Reihe 3, Zahlungsbilanzstatistik, Juli 1992, Nr. 7

Deutsche Bundesbank (1992c). Statistische Beihefte zu den Monatsberichten der Deutschen Bundesbank, Reihe 5, Die Währungen der Welt, November 1992, Nr. 4

Deutsche Bundesbank (1992d). Statistische Beihefte zu den Monatsberichten der Deutschen Bundesbank, Reihe 3, Zahlungsbilanzstatistik, Juli 1992, Nr. 7

Deutsche Bundesbank (1993). Die Entwicklung der Kapitalverflechtung der Unternehmen mit dem Ausland von Ende 1989 bis Ende 1991. in: Monatsbericht, 45. Jg., Nr. 4. S. 33-49

Deutscher Bundestag (1989). Öffentliche Sitzung des Finanzausschusses. Öffentliche Anhörung zur Unternehmenssteuerbelastung. Steuersätze/Bemessungsgrundlage. Stenographisches Protokoll (XI/Az.: 2450, Nr. 64) vom 6.12.1989 
Deutsches Institut für Wirtschaftsforschung (1992). Saldo der Direktinvestitionen: Kein Indikator für Standortschwäche. in: DIW-Wochenbericht, 59. Jg., Heft 14/92, S. 170173

Devereux, Michael (1990). Effective tax rates on domestic investment in OECD countries. OECD, Working Party No. 2 on tax analysis and tax statistics of the Committee on Fiscal Affairs. Paris, April 1990

Devereux, Michael; Pearson, Mark (1989). Corporate Tax Harmonisation and Economic Efficiency. The Institute for Fiscal Studies, ifs Report Series No. 35, London

Devereux, Michael; Pearson, Mark (1990). Effective tax rates on international investments in OECD countries. OECD, Working Party No. 2 on tax analysis and tax statistics of the Committee on Fiscal Affairs. Paris, May 1990

Devereux, Michael; Schiantarelli, Fabio (1990). Investment, Financial Factors, and Cash Flow: Evidence from U.K. Panel Data. in: Hubbard, R. Glenn (Hrsg.): Asymmetric Information, Corporate Finance, and Investment. Chicago, S. 279-306

Dieckheuer, Gustav (1990). Die Bedeutung ausländischer Direktinvestitionen für Beschäftigung, Struktur, Wettbewerbsfähigkeit und Wachstum von Volkswirtschaften dargestellt am Beispiel der Bundesrepublik Deutschland 1950-1990. Westfälische Wilhelms-Universität Münster, Volkswirtschaftliche Diskussionsbeiträge Nr. 131, Münster

DiLullo, Anthony J. (1984). U.S. International Transactions, Third Quarter 1984. in: Survey of Current Business, vol. 64, Heft 12, S. 41-64

DiLullo, Anthony J. (1985). U.S. International Transactions, Third Quarter 1985. in: Survey of Current Business, vol. 65, Heft 12, S. 58-88

DiLullo, Anthony J. (1986). U.S. International Transactions, Second Quarter 1986. in: Survey of Current Business, vol. 66, Heft 9, S. 40-63

DiLullo, Anthony J. (1990). U.S. International Transactions, Third Quarter 1990. in: Survey of Current Business, vol. 70, Heft 12, S. 30-55

Doppelbesteuerung (1961) Gesetz zu dem Abkommen vom 21. Juli 1959 zwischen der Bundesrepublik Deutschland und der Französischen Republik zur Vermeidung der Doppelbesteuerungen und über gegenseitige Amts- und Rechtshilfe auf dem Gebiete der Steuern vom Einkommen und vom Vermögen sowie der Gewerbesteuern und der Grundsteuern. in: Bundessteuerblatt, 11. Jg., Teil I, S. 342-364

Doppelbesteuerung (1970) Gesetz zu dem Abkommen vom 9. Juni 1969 zu dem am 21. Juli 1959 in Paris unterzeichneten Abkommen zwischen der Bundesrepublik Deutschland und der Französischen Republik zur Vermeidung der Doppelbesteuerungen und über gegenseitige Amts- und Rechtshilfe auf dem Gebiete der Steuern vom Einkommen und vom Vermögen sowie der Gewerbesteuern und der Grundsteuern. Vom 10. Juli 1970. in: Bundessteuerblatt, 20. Jg., Teil I, S. 900-903

Dunning, John H. (1988a). The Eclectic Paradigm of International Production: A Restatement and some Possible Extensions. in: Journal of International Business Studies, vol. 19, S. 1-31

Dunning, John H. (1988b). Explaining International Production. London usw.

Dunning, John H. (1988c). The Theory of International Production. in: International Trade Journal, vol. 3, S. 21-66

Ebel, Jörg (1978). Problems of a Keynesian Investment Function. in: Zeitschrift für die gesamte Staatswissenschaft, 134. Jg., Heft 2, S. 261-285 
Eckert, Gerhard (1978). Eine Überprüfung von Ansätzen zur Erklärung von Direktinvestitionen. Dissertation, Universität Mannheim

Einkommensteuer-Richtlinien (1990) (EStR 1990) in der Fassung vom 10. November 1990. in: Amtliche Steuerrichtlinien, Textausgabe mit kommentierenden Hinweisen, Band I, 14. Ergänzungslieferung 1991, Herne/Berlin

Eisner, Robert; Strotz, Robert H. (1963a). Determinants of Business Investment. in: Commision on Money and Credit (Hrsg.): Impacts of Monetary Policy. Englewood Cliffs, N.J., S. 60-337

Ellinghorst, Paul (1989). Abschreibungen als Finanzierungsinstrument. in: Buchführung, Bilanz, Kostenrechnung, 3.11.1989, Heft 21, S. 591-596

Elsing, Siegfried H. (1990). Grundzüge des Rechts- und Regierungssystems, des Gesellschafts- sowie des Trustrechts der Vereinigten Staaten von Amerika. in: Kramer, Jörg-Dietrich (Hrsg.): Grundzüge des US-amerikanischen Steuerrechts. Stuttgart, S. 3-34

Erbe, Susanne; Großmann, Harald; Jungnickel, Rolf; Koopmann, Georg; Scharrer, HansEckart (1991). Drittlandunternehmen im europäischen Binnenmarkt - Zwischen Liberalismus und Protektionismus. Veröffentlichung des HWWA-Instituts für Wirtschaftsforschung, Hamburg, Hamburg

Ernst, Angelika; Hilpert, Hanns-Günther (1990). Japans Direktinvestitionen in Europa Europas Direktinvestitionen in Japan. Bestandsaufnahme und wirtschaftspolitische Empfehlungen. Ifo-Studien zur Japanforschung, Nr. 4, München

eurostat. Statistisches Amt der Europäischen Gemeinschaften (1983a). Balance of Payments Methodology of the United Kingdom. Méthodologie de la balance des paiements du Royaume-Uni. Luxembourg

eurostat. Statistisches Amt der Europäischen Gemeinschaften (1983b). Die Zahlungsbilanzstatistik der Bundesrepublik Deutschland. The Balance of Payments Statistics of the Federal Republic of Germany. Les statistiques de la balance des paiements de la République Fédéral d'Allemagne. Luxembourg

eurostat. Statistisches Amt der Europäischen Gemeinschaften (1984a). La Méthodologie de la balance des paiments de l'Union Economique Belgo-Luxembourgeoise. Methodologie van de Betalingsbalns van de Belgisch-Luxemburgse Economische Unie. Methodology of the Balance of Payments of the Belgo-Luxembourg Economic Union. Luxembourg

eurostat. Statistisches Amt der Europäischen Gemeinschaften (1984b). Méthodologie de la balance des paiments de la France. Balance of Payments Methodology of France. Luxembourg

eurostat. Statistisches Amt der Europäischen Gemeinschaften (1985). Metodologi for Danmarks Betalingsbalance. Balance of Payments Methodology of Denmark. Méthodologie de la balance des paiments du Danemark. Luxembourg

eurostat. Statistisches Amt der Europäischen Gemeinschaften (1986). Balance of Payments Methodology of Greece. Méthodologie de la balance des paiements de la Grèce. Luxemburg

Fahim-Nader, Mahnaz (1991a). Capital Expenditures by Majority-Owned Foreign Affiliates of U.S. Companies, Revised Estimates for 1991. in: Survey of Current Business, vol. 71, Heft 9, S. 32-38 
Fahim-Nader, Mahnaz (1991b). U.S. Business Enterprises Acquired or Established by Foreign Direct Investors in 1990. in: Survey of Current Business, vol. 71, Heft 5, S. 30-39

Fahim-Nader, Mahnaz (1992a). Capital Expenditures by Majority-Owned Foreign Affiliates of U.S. Companies, Latest Plans for 1992. in: Survey of Current Business, vol. 72, Heft 9, S. 48-55

Fahim-Nader, Mahnaz (1992b). Capital Expenditures by Majority-Owned Foreign Affiliates of U.S. Companies, Plans for 1992. in: Survey of Current Business, vol. 72, Heft 3, S. 43-50

Fahim-Nader, Mahnaz (1992c). U.S. Business Enterprises Acquired or Established by Foreign Direct Investors in 1991. in: Survey of Current Business, vol. 72, Heft 5, S. $69-79$

Fazzari, Steven M.; Athey, M.J. (1987). Asymmetric Information, Financing Constraints, and Investment. in: Review of Economics and Statistics, 69. Jg., August, S. 481-487

Fazzari, Steven M. et al. (1988). Investment, Financing Decision, and Tax Policy. in: American Economic Review, Papers and Proceedings, 78. Jg., May, S. 200-205

Fazzari, Steven M. et al. (1989). Financing Constraints and Corporate Investment. in: Brookings Papers on Economic Activity, S. 141-195

Fazzari, Steven M.; Mott, Tracy L. (1986-87). The investment theories of Kalecki and Keynes: an empirical study of firm data, 1970-1982. in: Journal of Post Keynesian Economics, 9. Jg., Heft 2, Winter, S. 171-187

Feichtinger, Gustav; Hartl, Richard F. (1986). Optimale Kontrolle ökonomischer Prozesse. Anwendungen des Maximumprinzips in den Wirtschaftswissenschaften. Berlin/Heidelberg/New York

Feldstein, Martin et al. (1983). The effective tax rate and the pretax rate of return. in: Journal of Public Economics, 21. Jg., S. 129-158

Fels, Gerhard; Vogel, Otto (Hrsg.) (1985). Unternehmensbesteuerung am Standort Bundesrepublik. Köln

Fischer, Lutz (1984). Die steuerliche Belastung der Unternehmensfinanzierung im internationalen Vergleich und ihr Einfluß auf die Wettbewerbsfähigkeit deutscher Unternehmen. in: Der Betrieb, 37. Jg., 17.02.1984, Heft 7, S. 357-364

Fischer, Lutz (1989). Die effektive Steuerbelastung von Unternehmen. in: John, Gerd, (Hrsg.) (1989). Besteuerung und Unternehmenspolitik. Festschrift für Günter Wöhe, München, S. 131-155

Fischer, Lutz; Warneke, Perygrin (1988). Internationale Betriebswirtschaftliche Steuerlehre. 3., überarb. Aufl., Berlin

Fisher, Franklin M. (1969). The Existence of Aggregate Production Functions. in: Econometrica, 37. Jg., Heft 4, October, S. 553-577

Fisher, Franklin M. (1971). Aggregate productions functions and the explanation of wages: a simulation experiment. in: Review of Economics and Statistics, 53. Jg., Heft 4, November, S. 305-325

Franke, Günter; Hax, Herbert (1989). Pensionsrückstellungen und Steuerersparnisse Erwiderung zu dem Beitrag von D. Schneider, DB 1989, S. 889. in: Der Betrieb, 42. Jg., 22.9.1989, Heft 38, S. 1881-1882

Fuest, Winfried; Kroker, Rolf (1987). Irrtümer in der aktuellen Steuerdiskussion. Beiträge zur Wirtschafts- und Sozialpolitik Band 149, Institut der deutschen Wirtschaft, Köln

Fuest, Winfried; Kroker, Rolf (1988). Internationaler Vergleich der Unternehmensbesteuerung. Stand: Ende 1988. in: iw-trends, Nr. 4, S. D-1 bis D-15 
Fuest, Winfried; Kroker, Rolf (1989a). Unternehmensteuerlast: 20 oder 70 Prozent? Beiträge zur Wirtschafts- und Sozialpolitik Band 175, Institut der Deutschen Wirtschaft, Köln

Fuest, Winfried; Kroker, Rolf (1989b). Unternehmensbesteuerung im internationalen Vergleich: Kritische Anmerkungen zum DIW-Gutachten. in: Steuer und Wirtschaft, 66. (19.) Jg., S. 260-266

Fullerton, Don (1984). Which effective tax rate? in: National Tax Journal, 37. Jg., S. 23-41

Fullerton, Don (1985). Which effective tax rate? A reply. in: National Tax Journal, 38. Jg., S. 109-110

Fullerton, Don et al. (1982). Why do varying effective corporate tax rates matter? in: Tax Notes, Effective corporate tax rates in 1981. A special supplement prepared by the editors of tax notes, Arlington, S. 579-584

Funke, Michael; Willenbockel, Dirk (1991/92). Steuerliche Investitionsförderung in den fünf neuen Bundesländern - Maßnahmen und Auswirkungen. in: Finanzarchiv, 49. Jg., Heft 4, S. 457-480

Galeotti, Marzio (1984). Recent develoments in investment theory. in: Giornale degli economisti e Annali di economia, 13. Jg., S. 393-415

Galeotti, Marzio (1984). Recent develoments in investment theory. in: Giornale degli economisti e Annali di economia, 13. Jg., S. 393-415

Gallaway, Lowell; Shukla, Vischnu (1974). The Neoclassical Production Function. in: American Economic Review, 64. Jg., Heft 3, June, S. 348-358

Garegnani, Pierangelo (1976). The Neoclassical Production Function: Comment. in: American Economic Review, 66. Jg., Heft 3, June, S. 424-427

Garegnani, Pierangelo (1989a). Heterogenes Kapital, Produktionsfunktion und Verteilungstheorie. in: ders. (Hrsg.): Kapital, Einkommensverteilung und effektive Nachfrage. Beiträge zur Renaissance des klassischen Ansatzes in der Politischen Ökonomie. 1. Aufl., Marburg, S. 77-124

Garegnani, Pierangelo (1989b). Zwei Wege zum Prinzip der effektiven Nachfrage. in: ders. (Hrsg.): Kapital, Einkommensverteilung und effektive Nachfrage. Beiträge zur Renaissance des klassischen Ansatzes in der Politischen Ökonomie. 1. Aufl., Marburg, S. 179-191

Gertler, Mark L. (1988). Financial Structure and Aggregate Economic Activity: An Overview. in: Journal of Money, Credit, and Banking, 20. Jg., Heft 3, August, S. 559-588

Gould, John P. (1968). Adjustment Costs in the Theory of Investment of the Firm. in: Review of Economic Studies, 35. Jg., Januar, S. 47-55

Graham, Edward Montgomery; Krugman, Paul (1989). Foreign Direct Investment in the United States. Washington D. C.

Gramlich, Ludwig (1991). Außenwirtschaftsrecht. Ein Grundriß. Köln usw.

Gravelle, Jane G. (1985). "Which effective tax rate?" A comment and extension. in: National Tax Journal, 38. Jg., S. 103-108

Grotherr, Siegfried (1987). Die Scheingewinnbesteuerung im internationalen Vergleich. Analyse der steuerlichen Lösungsansätze in der Bundesrepublik Deutschland, Frankreich, Großbritannien, Japan und den USA. hrsg. in den Schriften des Instituts für Ausländisches und Internationales Finanz- und Steuerwesen der Universität Hamburg, Band 12, Baden-Baden 
Gutenberg, Erich (1983). Grundlagen der Betriebswirtschaftslehre. Erster Band: Die Produktion, 24., unveränd. Aufl., Berlin

Haavelmo, Trygve (1960). A Study in the Theory of Investment. Chicago

Habermann, Gerd (o. J.). Steuerliche Überlegungen eines ausländischen Unternehmers bei Investitionen in der Bundesrepublik Deutschland. Vortrag gehalten am 4.12.1987 im Rahmen der Hamburger Tagung zur Internationalen Besteuerung des Instituts für Ausländisches und Internationales Finanz- und Steuerwesen der Universität Hamburg. Hefte zur Internationalen Besteuerung, Heft 40, Hamburg, o. J.

Handelsblatt (1992). Direktinvestitions-Ströme in Mrd. DM. Grafik. in: Handelsblatt, Nr. 5 vom 8. Januar 1992, S. 4

Harberger, Arnold C. (1966). Efficiency effects of taxes on income from capital. in: Krzyzaniak, Marian (Hrsg.). Effects of corporation income tax. Papers presented at the symposium on business taxation Wayne State University. Detroit, S. 107-117

Harcourt, Geoffrey Colin (1972). Some Cambridge Controversies in the Theory of Capital. 1. Aufl., Cambridge

Hartman, David G. (1981). Domestic Tax Policy and Foreign Direct Investment: Some Evidence. National Bureau of Economic Research, Working Paper No. 784, Cambridge/Mass.

Hartman, David G. (1984). Tax Policy and Foreign Direct Investment in the United States. in: National Tax Journal, vol. 37, S. 475-487

Hartman, David G. (1985). Tax Policy and Foreign Direct Investment. in: Journal of Public Economics, vol. 26, S. 107-121

Haslinger, Franz (1990). Volkswirtschaftliche Gesamtrechnung. 5., überarb. und erw. Aufl., München

Haubold, Dietmar (1972a). Direktinvestitionen und Zahlungsbilanz. Wirkungen der USInvestitionen in Europa auf die amerikanische Zahlungsbilanz. Hamburg

Haubold, Dietmar (1972b). Entwicklung und Förderung der amerikanischen Direktinvestitionen. in: Scharrer, Hans-Eckart (Hrsg.): Förderung privater Direktinvestitionen. Eine Untersuchung der Maßnahmen bedeutender Industrieländer. Hamburg, S. 89228

Hauch-Fleck, Marie-Luise (1991). Matsushita übernimmt Universal. Wie im Kino. Mit riesigen Investitionen wirbeln die Japaner Hollywood durcheinander. in: Die Zeit, Nr. 2 vom 2. Januar 1991, S. 17

Helmedag, Fritz (1991). Lohn- und Profitkurven. in: WiSt, Heft 8, August, S. 408-412

Hidien, Jürgen W. (1991). Investieren in Frankreich. Öffentliches Recht für die deutschfranzösischen Geschäftsbeziehungen. Köln

Holthus, Manfred (1972). Entwicklung und Förderung der japanischen Direktinvestitionen. in: Scharrer, Hans-Eckart (Hrsg.): Förderung privater Direktinvestitionen. Hamburg, S. 399-467

Homburger, A. N. (1989). Die Unternehmensbesteuerung im Vereinigten Königreich. hrsg. vom Britischen Generalkonsulat Düsseldorf, London

Horlemann, Heinz-Gerd (1990). Ergänzung des Steuerreformgesetzes 1990 im Bereich der Unternehmensbesteuerung, insbesondere durch das Wohnungsbauförderungsgesetz. in: Betriebs-Berater, 45. Jg., 30.10.1990, Heft 30, S. 2085-2094

Hoshi, Takeo; Kashyap, Anil K. (1990). Evidence on $q$ amd Investment for Japanese Firms. in: Journal of the Japanese and International Economies, 4. Jg., S. 371-400 
Howenstine, Ned G. (1984). U.S. Direct Investment Abroad in 1983. in: Survey of Current Business, vol. 64, Heft 8, S. 18-39

Howenstine, Ned G. (1989). U.S. Affiliates of Foreign Companies: 1987 Benchmark Survey Results. in: Survey of Current Business, vol. 69, Heft 7, S. 116-140

Howenstine, Ned G.; Zeile, William J. (1992). Foreign Direct Investment in the United States: Establishment Data for 1987. in: Survey of Current Business, vol. 72, Heft 10, S. 44-78

Hulten, Charles R. (Hrsg.) (1981). Depreciation, inflation, and the taxation of income from capital. Washington D. C.

Hulten, Charles; Wykoff, Frank C. (1981). The measurement of economic depreciation. in: Hulten, Charles R. (Hrsg.). Depreciation, inflation, and the taxation of income from capital. Washington D. C., S. 81-125

Institut der deutschen Wirtschaft (Hrsg.) (1989). Unternehmensbesteuerung: Nach VGR über 50 Prozent. in: iwd, 16.03.1989, Nr. 11, S. 4-5

Institut der Wirtschaftsprüfer in Deutschland e.V. (Hrsg.) (1992). Wirtschaftsprüferhandbuch 1992. Handbuch für Rechnungslegung, Prüfung und Beratung. Band I. 10. Aufl., Düsseldorf

International Monetary Fund (1960). Balance of Payments Manual. 3. Aufl., Washington D. C.

International Monetary Fund (1977). Balance of Payments Manual. 4. Aufl., Washington D. C. (Reprinted, June 1978, with minor corrections)

International Monetary Fund (1991). Balance of Payments Statistics Yearbook. vol. 42, Part 1. Washington D. C.

Jacobs, Otto H.; Spengel, Christoph (1992). Unternehmensbesteuerung und Finanzierung - Eine vergleichende Analyse der Besteuerungskonzeptionen für Kapitalgesellschaften in Deutschland, Frankreich und Großbritannien. Universität Mannheim und ZEW, Discussion Paper No. 92-03, Juli 1992

Jacobs, Otto H.; Spengel, Christoph (1992). Britische Direktinvestitionen weisen geringe Steuerbelastungen aus. Untersuchung über Steuern in Europa / Wo ist die niedrigste Belastung? in: Blick durch die Wirtschaft, 35. Jg., 10.9.1992, Nr. 175, S. 7

Jaffee, Dwight M.; Stiglitz, Joseph E. (1990). Credit Rationing. in: Friedman, Benjamin M.; Hahn, Frank H. (Hrsg.): Handbook of Monetary Economics. Volume II. Handbooks in Economics, Band 8, Amsterdam/New York, S. 837-888

Jahrreiß, Wolfgang (1984). Zur Theorie der Direktinvestitionen im Ausland. Versuch einer Bestandsaufnahme, Weiterführung und Integration partialanalytischer Forschungsansätze. Berlin

Jarchow, H.-J.; Rūhmann, P. (1991). Monetäre Außenwirtschaft I. Monetäre Außenwirtschaftstheorie, 3. Aufl., Göttingen

Jochum, Dieter (1991). Steuern und Kapitalbildung. Systeme zur Besteuerung von Kapitalerträgen und deren allokative Wirkung. Frankfurt am Main

John, Gerd (Hrsg.) (1989). Besteuerung und Unternehmenspolitik. Festschrift für Günter Wöhe, München

Jorgenson, Dale W. (1963). Capital Theory and Investment Behavior. in: American Economic Review, Papers and Proceedings, 53. Jg., Mai, S. 247-268 
Jorgenson, Dale W. (1965). Anticipations and Investment. in: Duesenberry, James et al. (Hrsg.): The Brookings Quaterly Econometric Model of the United States. New York, S. 35-94

Jorgenson, Dale W. (1967). The Theory of Investment Behavior. in: Ferber, Robert (Hrsg.): Determinants of Investment Behavior. Universities - National Bureau Conference Series No. 18, New York, S. 129-155

Jorgenson, Dale W.; Sullivan, Martin A. (1981). Inflation and corporate capital recovery. in: Hulten, Charles R. (Hrsg.). Depreciation, inflation, and the taxation of income from capital. Washington D. C., S. 171-235

Jorgenson, Dale W.; Yun, Kun-Young (1991). Tax reform and the cost of capital. Oxford Joseph, James P. (1988). Greek Investment Law: An Overview. in: Law and policy in international business, vol. 20, Heft 2, S. 295-313

Julius, DeAnne (1990). Global Companies and Public Policy. The Growing Challenge of Foreign Direct Investment. The Royal Institute of International Affairs. London

Julius, DeAnne; Thomsen, Stephen E. (1988). Foreign Direct Investment among the G-5. The Royal Institute of International Affairs, London, Disussion Paper No. 8

Jun, Joosung (1990). U.S. Tax Policy and Direct Investment Abroad. in: Razin, Assaf; Slemrod, Joel (Hrsg.): Taxation in the Global Economy. Chicago und London, S. 5574

Junankar, P. M. (1972). Investment: Theories and Evidence. Macmillan Studies in Economics, 1. Aufl., London

Kallen, Paul-Bernhard (1987). Direktinvestitionen deutscher Unternehmen in Entwicklungsländern. Theoretische Analyse und empirische Befunde. Frankfurt am Main usw.

Kießling, Heinz; Pelikan, Horst (1991). Körperschaftsteuer. 12. Aufl, Achim bei Bremen

King, M.A. (March 1975). The United Kingdom Profits Crisis: Myth or Reality? in: The Economic Journal

King, Mervyn A. (1977). Public policy and the corporation. London

King, Mervyn A.; Fullerton, Don (1984). The taxation of income from capital. A comparative study of the United States, the United Kingdom, Sweden and West Germany. London

Klein, Martin (1992). Neoklassische und keynesianische Investitionstheorien. Synopse und Synthese. in: Jahrbücher für Nationalökonomie und Statistik, 209. Jg., Heft 3-4, S. 207-222

Knobbe-Keuk, Brigitte (1989). Bilanz- und Unternehmenssteuerrecht. 7., völlig überarb. und erw. Aufl., Köln

König, Heinz (1991). Aggregate Investment, the Stock Market, and the $Q$ Model: Robust Results for Six OECD Countries: Comment. in: European Economic Review, 35. Jg., Mai, S. 830-832

Kopits, George F. (1976). Taxation and Multinational Firm Behavior: A Critical Survey. in: IMF-Staff Papers, vol. 23, S. 624-673

Krägenau, Henry (1972). Entwicklung und Förderung der deutschen Direktinvestitionen. in: Scharrer, Hans-Eckart (Hrsg.): Förderung privater Direktinvestitionen. Hamburg, S. $469-631$

Krägenau, Henry (1975). Internationale Direktinvestitionen 1950-1973. Vergleichende Untersuchung und statistische Materialien. Hamburg 
Krägenau, Henry (1979). Internationale Direktinvestitionen. Ergänzungsband 1978/79. Hamburg

Krägenau, Henry (1982). Internationale Direktinvestitionen. Ergänzungsband 1982. Hamburg

Krägenau, Henry (1987). Internationale Direktinvestitionen. Ausgabe 1987. Hamburg

Krämer, Walter; Sonnberger, Harald (1986). The Linear Regression Model Under Test. Heidelberg und Wien

Krämer, Walter; Sonnberger, Harald; Maurer, Johann; Havlik, Peter (1985). Diagnostic Checking in Practice. in: Review of Economics and Statistics, vol. 67, S. 118-123

Krause-Junk, Gerold (1988). Überlegungen zu einem künftigen europäischen Körperschaftsteuersystem, in: Konjunkturpolitik, Heft 5/6, S. $268 \mathrm{ff}$.

Krist, Herbert (1985). Bestimmungsgründe industrieller Direktinvestitionen. Berlin

Krueger, Russell C. (1984a). U.S. International Transactions, First Quarter 1984. in: Survey of Current Business, vol. 64, Heft 6, S. 35-73

Krueger, Russell C. (1984b). U.S. International Transactions, Second Quarter 1984. in: Survey of Current Business, vol. 64, Heft 9, S. 34-57

Krueger, Russell C. (1985a). U.S. International Transactions, First Quarter 1985. in: Survey of Current Business, vol. 65, Heft 6, S. 34-71

Krueger, Russell C. (1985b). U.S. International Transactions, Second Quarter 1985. in: Survey of Current Business, vol. 65, Heft 9, S. 28-52

Krueger, Russell C. (1986). U.S. International Transactions, First Quarter 1986. in: Survey of Current Business, vol. 66, Heft 6, S. 36-73

Krueger, Russell C. (1987). U.S. International Transactions, Second Quarter 1987. in: Survey of Current Business, vol. 67, Heft 9, S. 32-55

Krueger, Russell C. (1989). U.S. International Transactions, First Quarter 1989. in: Survey of Current Business, vol. 69, Heft 6, S. 50-92

Krzyzaniak, Marian (Hrsg.) (1966). Effects of corporation income tax. Papers presented at the symposium on business taxation Wayne State University. Detroit

Kühn, Klaus-Peter (1991). Rechnungslegungs-, Prüfungs- und Publizitätsvorschriften in Frankreich. in: von Boehmer, Henning (Hrsg.), Deutsche Unternehmen in Frankreich. Leitfaden für die Rechts- und Wirtschaftspraxis, Stuttgart, S. 199-240

Küting, Karlheinz; Weber, Claus-Peter (1990). Handbuch der Rechnungslegung. Kommentar zur Bilanzierung und Prüfung. 3., grundlegend überarb. und wesentlich erw. Aufl., Stuttgart

Landefeld, J. Steven; Lawson, Ann M. (1991). Valuation of the U.S. Net International Investment Position. in: Survey of Current Business, vol. 71, Heft 5, S. 40-49

Landefeld, J. Steven; Lawson, Ann M.; Weinberg, Douglas B. (1992). Rates of Return on Direct Investment. in: Survey of Current Business, vol. 72, Heft 8, S. 79-86

Langkau, Jochem; Napp, Hans-Georg; Rahmann, Bernd; Roloff, Otto (1989). Steuerstandort Bundesrepublik Deutschland. Eine vergleichende Analyse der Unternehmensund Gemeindesteuern vor dem Hintergrund der Vollendung des gemeinsamen europäischen Binnenmarktes. Bonn

Laurin, Benoît (1990). Die neue Rechtsordnung der Auslandsinvestitionen in Frankreich. in: Recht der Internationalen Wirtschaft, vol. 36, Heft 8, S. 618-621 
Lawson, Nigel (1984). Budget 1984-85. Two targets: further reduction of inflation and start of a tax reform. Extracts from the Budget Speech 1984-85 pronounced by $\mathrm{Mr}$. Nigel Lawson, Chancellor of the Exchequer, on 13 March 1984. in: International Bureau of Fiscal Documentation-Bulletin, S. 177-182

Leibfritz, Willi; Parsche, Rüdiger (1988). Steuerbelastung der Werkzeugmaschinenindustrie im internationalen Vergleich. in: ifo-schnelldienst, 41. Jg., Heft 9, S. 9-16

Lenz, Martin; Meyer, Barbara (1991). Besteuerung deutscher Unternehmen in Frankreich. in: von Boehmer, Henning (Hrsg.), Deutsche Unternehmen in Frankreich. Leitfaden für die Rechts- und Wirtschaftspraxis, Stuttgart, S. 173-198

Littmann, Konrad (1988). Die finanzwissenschaftliche Sicht. in: Fels, Gerhard; Vogel, Otto (Hrsg.) (1988). Unternehmensbesteuerung am Standort Bundesrepublik. Köln, S. 1338

Littmann, Konrad (1989). Stellungsnahme zur Anhörung des Finanzausschusses zur Unternehmensteuerbelastung am 6. Dezember 1989. in: Deutscher Bundestag (1989). Öffentliche Sitzung des Finanzausschusses: Öffentliche Anhörung zur Unternehmenssteuerbelastung. Steuersätze/Bemessungsgrundlage. Stenographisches Protokoll (XI/Az.: 2450, Nr. 64) vom 6.12.1989, S. 127-136

Littmann, Konrad; Langmann, Joachim (1987). 70\%-ige Steuerbelastung der deutschen Unternehmen - ja oder nein? Internationales Finanz- und Steuerwesen der Universität Hamburg. Hefte zur Internationalen Besteuerung, Heft 36, Hamburg

Lowe, Jeffrey H.; Mataloni, Raymond J. Jr. (1991). U.S. Direct Investment Abroad: 1989 Benchmark Survey Results. in: Survey of Current Business, vol. 71, Heft 10, S. 29-55

Lubitz, Günther; Ploog, Volkhard (1991). Ein neues Modell für die betriebliche Altersvorsorge? Der Vorschlag einer ergebnisorientierten Kapitaldirektzusage. in: Blick durch die Wirtschaft, 35. Jg., 6.9.1991, Nr. 106, S. 7

Lucas, Robert E., Jr. (1967a). Adjustment Costs and the Theory of Supply. in: Journal of Political Economy, 75. Jg., Heft 4, August, S. 321-334

Lucas, Robert E., Jr. (1967b). Optimal Investment Policy and the Flexible Accelerator. in: International Economic Review, 8. Jg., February, S. 78-85

Mataloni, Raymond J. Jr. (1990a). Capital Expenditures by Majority-Owned Foreign Affiliates of U.S. Companies, 1991. in: Survey of Current Business, vol. 70, Heft 9, S. $30-36$

Mataloni, Raymond J. Jr. (1990b). Capital Expenditures by Majority-Owned Foreign Affiliates of U.S. Companies: Plans for 1990 - Spending Patterns During 1977-89. in: Survey of Current Business, vol. 70, Heft 3, S. 21-32

Mataloni, Raymond J. Jr. (1991). Capital Expenditures by Majority-Owned Foreign Affiliates of U.S. Companies, Latest Plans for 1991. in: Survey of Current Business, vol. 71 , Heft 3, S. 26-33

Mataloni, Raymond J. Jr. (1992). U.S. Multinational Companies: Operations in 1990. in: Survey of Current Business, vol. 72, Heft 8, S. 60-78

Matthäus-Maier, Ingrid (1988). Die siebzigprozentige Besteuerung des Unternehmensgewinns ist eine Legende. in: Handelsblatt, 43. Jg., 31.12.1988, Nr. 251, S. 18

McClintock, Brent (1988). Recent Theories of Direct Foreign Investment: An Institutionalist Perspective. in: Journal of Economic Issues, vol. 22, S. 477-484

McDaniel, Paul P. (1985). Identification of the "tax" in "effective tax rates, "tax reform" and „tax equity“. in: National Tax Journal, 38 Jg., S. 273-279 
Mennel, Annemarie (Hrsg.) (1991). Steuern in Europa, USA, Kanada und Japan. Loseblatt-Ausgabe, Herne/Berlin, 22. Lieferung 1991

Mettelsiefen, Bernd (1991). Dynamic Effects of Tax Policy Instruments in West Germany. in: Schweizerische Zeitschrift für Volkswirtschaftslehre und Statistik, 127. Jg., Heft 2. S. $141-179$

Meyer, John Robert; Kuh, Edwin (1957). The Investment Decision. Cambridge, Massachusetts

Möllering, Jürgen; Mohr, Konrad (1986). Steuerführer Grossbritannien. Darstellung des Steuerrechts und Kommentar zum DBA-Grossbritannien. Teil 2 und 3, Steuerrecht Grossbritannien, Einzelne Einkunftsarten. Sonderfragen der Einkommensbesteuerung. Steuerliche Aspekte von Lebensversicherungen. Herne/Berlin

Morgan, Eleanor J. (1986). Corporate taxation and investment. The implications of the 1984 tax reform. Aldershot.

Müssener, Ingo (1989). Die britische Gemeindefinanzreform 1988. in: Internationale Wirtschafts-Briefe, Gruppe 2, Grossbritannien, 25.1.1989, Nr. 2, S. 269-274

Müssner, Ingo (1991). Grossbritannien. in: Mennel, Annemarie (Hrsg.), Steuern in Europa, USA, Kanada und Japan. Loseblatt-Ausgabe, Herne/Berlin, 22. Lieferung 1991

Müssener, Ingo (1992). Grundzüge des britischen Steuersystems. in: Internationale Wirtschafts-Briefe, Gruppe 2, Grossbritannien, 25.4.1992, Nr. 8, S. 275-286

Munnel, Alicia H. (ed.) (1990). Is there a Shortfall in Public Capital Investment? Federal Reserve Bank of Boston, Conference Series No. 34

Munnell, Alicia H. (Fall 1992). Infrastructure Investment and Economic Growth. in: Journal of Economic Perspectives, vol. 6, No 4, 189-198

Murad, Howard (1989). U.S. International Transactions. Third Quarter 1989. in: Survey of Current Business, vol. 69, Heft 12, S. 22-46

Murad, Howard (1992). U.S. International Transactions - First Quarter 1992. Revised Estimates for 1976-91. in: Survey of Current Business, vol. 72, Heft 6, S. 60-113

Murthy, N. R. Vasudeva (1989). The Effects of Taxes and Rates of Return on Foreign Direct Investment in the United States: Some Econometric Comments. in: National Tax Journal, vol. 42, S. 205-207

Neske, Fritz; Wiener, Markus (1985). Management-Lexikon. Band II. Managementschulen, Augsburg

Neumark, Fritz (1969). Zur Problematik internationaler Steuerbelastungsvergleiche. in: Volkswirtschaftliche Korrespondenz der Adolf-Weber-Stiftung, 8. Jg., Nr. 12, o. S.

Newlon, Timothy Scott (1987). Tax Policy and the Multinational Firm's Financial Policy and Investment Decisions. Dissertation, University of Princeton,

Nicholson, Robert E. Jr. (1990). U.S. International Transactions, First Quarter 1989. in: Survey of Current Business, vol. 70, Heft 6, S. 66-109

Nicholson, Robert E. Jr. (1991). U.S. International Transactions, First Quarter 1991. in: Survey of Current Business, vol. 71, Heft 6, S. 36-73

Nickell, Stephen (1978). The Investment Decision of Firms. Oxford

Olfert, Klaus et al. (1989). Bilanzen. 5., völlig ern. und erw. Aufl., Ludwigshafen (Rhein) 
o. V. (1982). How to read a tax data chart. in: Tax Notes (Hrsg.). Effective corporate tax rates in 1981. A special supplement prepared by the editors of tax notes. Arlington, S. $567-568$

o. V. (1983). Investitionen der Unternehmen und steuerliche und finanzielle Rahmenbedingungen. in: Europäische Wirtschaft, Juli 1983, Nr. 16, S. 9-15

o. V. (1988). RWE kauft Deutsche Texaco für 1,2 (sic!) Milliarden Dollar. in: Süddeutsche Zeitung, Nr. 129 vom 7. Juni 1988, S. 26

o. V. (1989). Die Colonia-Gruppe wird französisch. Victoire übernimmt die Mehrheit/ Neue Holding. in: Süddeutsche Zeitung, Nr. 172 vom 29./30. Juli 1989

o. V. (1989a). Die Besteuerung der Unternehmensgewinne im internationalen Vergleich. in: DIW-Wochenbericht, 56. Jg., Heft 29, S. 329-343

o. V. (1989b). Stellungsnahme der IBM Deutschland GmbH zur Anhörung des Finanzausschusses des Deutschen Bundestages am 6. Dezember 1989. Thema: Unternehmenssteuerbelastung - Steuersätze/Bemessungsgrundlage. Stuttgart

o. V. (1993a). adidas in neuen Händen. Zweiter Rückzug von Bernard Tapie. in: Neue Zürcher Zeitung, Fernausgabe Nr. 38 vom 12. Februar 1993, S. 12.

o. V. (199:3b). Louis-Dreyfus soll neuer adidas-Manager werden. in: Süddeutsche Zeitung, Nr. 28 vom 4. Februar 1993, S. 30

o. V. (1993c). adidas-Verkauf ist so gut wie perfekt. Neue Eigentümer und Manager/Aufsichtsratssitzung. in: Süddeutsche Zeitung, Nr. 29 vom 5. Februar 1993, S. 22

o. V. (1993d). In den USA will adidas jetzt durchstarten. in: Süddeutsche Zeitung, Nr. 30 vom 6./7. Februar 1993, S. 23

o. V. (1993e). adidas: Eine turbulente Zeit geht vorbei. in: Süddeutsche Zeitung, Nr. 38 vom 16. Februar 1993, S. 19

o. V. (1993f). Tapie verkauft seine adidas-Beteiligung. in: Süddeutsche Zeitung, Nr. 38 vom 16. Februar 1993, S. 19

o. V. (1993g). Der adidas-Verkauf wird zum Politikum. in: Süddeutsche Zeitung, Nr. 39 vom 17. Februar 1993, S. 34

o. V. (1993h). Louis-Dreyfus hat die Option auf alle adidas-Aktien. in: Süddeutsche Zeitung, Nr. 52 vom 4. März 1993, S. 27

OE(I) (1983). Detailed Benchmark Definition of Foreign Direct Investment. Paris

OECD (1987). International Investment and Multinational Enterprises. Recent Trends in International Direct Investment. Paris

Olfert, Klaus et al. (1989). Bilanzen. 5., völlig ern. und erw. Aufl., Ludwigshafen (Rhein)

Olle, Werner; Oesterheld, Werner (1985). Tabellen zu Struktur und Größenordnung Multinationaler Konzerne. in: Mettler, Peter H. (Hrsg.): Multinationale Konzerne in der Bundesrepublik Deutschland. Frankfurt am Main, S. A19-A32

Perridon, Louis; Steiner, Manfred (1986). Finanzwirtschaft der Unternehmung. 4., überarb. Aufl., München

Poterba, James M. (1990). Comments and Discussion on The Stock Market and Investment: Is the Market a Side Show?". in: Brookings Papers on Economic Activity, Heft '2, S. 208-12

Poterba, James M.; Summers, Lawrence H. (198:3). Dividend Taxes, Corporate Investment, and ' $Q$ '. in: Journal of Public Economics, 22. Jg., March, S. 135-167 
Pott, Philipp (1983). Direktinvestitionen im Ausland. Investitionsmotive. Standortfaktoren und Hilfsmittel bei der Entscheidung für die optimale Auslandsinvestition. München

Precious, Mark (1985). Demand Constraints, Rational Expectations and Investment Theory. in: Oxford Economic Papers, 37. Jg., S. 576-605

Precious, Mark (1987). Rational Expectations, Nonmarket Clearing, and Investment Theory. Oxford

Presse- und Informationsamt der Bundesregierung (1992). Die Auslandsinvestitionen im Jahre 1991 - Statistik des Bundesministeriums für Wirtschaft. Aktuelle Beiträge zur Wirtschafts- und Finanzpolitik, Nr. 25/1992, 3. August 1992

Quijano, Alicia M. (1990). A Guide to BEA Statistics on Foreign Direct Investment in the United States. in: Survey of Current Business, vol. 70, Heft 2, S. 29-37

Revisionsprotokoll (1971) zu dem am 26. November 1964 in Bonn unterzeichneten Abkommen zwischen der Bundesrepublik Deutschland und dem Vereinigten Königreich Großbritannien und Nordirland zur Vermeidung der Doppelbesteuerung und zur Verhinderung der Steuerverkürzung. in: Bundessteuerblatt, 21. Jg., Teil I, S. 140143

Richter, Wolfram (1992). Kommunale Unternehmensbesteuerung. Grundsätzliche Anmerkungen zur Verwirklichung eines effizienten Systems. in: Zeitschrift für Wirtschaftsund Sozialwissenschaften, Heft 4, S. 567-586.

Roehm, Eberhard H. (1990). Das amerikanische Gesellschaftsrecht. in: Internationale Wirtschafts-Briefe, 8 USA, Gruppe 3, 25.6.1990, Nr. 12, S. 225-242

Rößler, Norbert (1990). Wie in anderen Industrieländern die betriebliche Altersvorsorge gestaltet wird. Ratschläge für betriebliche Versorgungssysteme. Stand der "Harmonisierung" in Europa, Zwischen Zwang und Freiwilligkeit. in: Blick durch die Wirtschaft, 34. Jg., 29.11.1990, Nr. 231, S. 7

Rothschild, Michael (1971). On the Cost of Adjustment. in: Quarterly Journal of Economics, 75. Jg., November, S. 605-622

Rugman, Alan M. (1986). New Theories of the International Enterprise: An Assessment of Internationalization Theory. in: Bulletin of Economic Research, vol. 38, S. 101-118

Sachverständigenrat (1992). Jahresgutachten 1992/93, BT-Drucksache 12/3774, Bonn. Ziffer $360 \mathrm{ff}$.

von Saldern, Sabine (1973). Internationaler Vergleich der Direktinvestitionen wichtiger Industrieländer. Hamburg

Salinger, Michael A.; Summers, Lawrence H. (1983). Tax Reform and Corporate Investment: A Microeconomic Simulation Study. in: Feldstein, Martin (Hrsg.): Behavioral Simulation Methods in Tax Policy Analysis. Chicago, S. 247-281

von Samson-Himmelstjerna, Alexander (1983). Überblick über die Gesellschaftsformen der Vereinigten Staaten von Amerika. in: Recht der International Wirtschaft. 29. Jg., S. $152-159$

Samuelson, Paul Anthony (1962). Parable and Realism in Capital Theory: the Surrogate Production Function. in: Review of Economic Studies, 39. Jg., S. 193-206 
Schaden, Barbara (1991). Die internationale Besteuerung und das Investitionsverhalten einer internationalen Unternehmung. Universität Konstanz Diskussionsbeiträge des Sonderforschungsbereichs 178 „Internationalisierung der Wirtschaft“, Serie II Nr. 135, April 1991

Scharrer, Hans-Eckart (1972). Direktinvestitionen im Ausland - Probleme der Messung und Förderung. in: Scharrer, Hans-Eckart (Hrsg.): Förderung privater Direktinvestitionen. Hamburg. S. 1-8T

Scheibe-Lange, Inge (1986). Zu hohe Belastung der Unternehmensgewinne mit Ertragsteuern? in: WSI Mitteilungen, 39. Jg., 1986, Heft 12, S. 772-781

Schiantarelli, Fabio; Georgoutsos, D. (1990). Monopolistic Competition and the $Q$ Theory of Investment. in: European Economic Review, 34. Jg., June, S. 1061-1078

Schneider, Dieter (1989a). Steuerfreie Kapitalbildung in dreistelliger Milliardenhöhe durch Pensionsrückstellungen? in: Der Betrieb, 42. Jg., 5.5.1989, Heft 18, S. 889-895

Schneider, Dieter (1989b). Sofortabschreibung, sofortiger Verlustausgleich und Marktlenkung von Risikokapital. in: John, Gerd (Hrsg.). Besteuerung und Unternehmenspolitik. Festschrift für Günter Wöhe, München, S. 309-329

Schneider, Dieter (1990). Investition, Finanzierung und Besteuerung. 6., vollständig neu bearb. Aufl., Wiesbaden

Schneider, Dieter; Siegel, Theodor (1988). Marginal effective tax rates as a tool for managerial economics in connection with the german tax reform 1990 . Wirtschaftswissenschaftliche Dokumentation der Technischen Universität Berlin, Diskussionspapier 126

Schöne, Wolf-Dieter (1976). Probleme eines internationalen Steuerbelastungsvergleiches. in: Finanz Rundschau, 23.8.1976, Nr. 16, S. 399-403

Schoenfeld, Hanns-Martin W. (1981). Grundsätze der Rechnungslegung in den USA. in: ZfB - Zeitschrift für Betriebswirtschaft, 51. Jg., Heft 3, S. 290-311

Scholl, Russell B. (1985). The International Investment Position of the United States in 1984. in: Survey of Current Business, vol. 65, Heft 6, S. 25-33

Scholl, Russell B. (1986). The International Investment Position of the United States in 1985. in: Survey of Current Business, vol. 66, Heft 6, S. 26-35 und S. 16

Scholl, Russell B. (1987). The International Investment Position of the United States in 1986. in: Survey of Current Business, vol. 67, Heft 6, S. 38-45

Scholl, Russell B. (1988). The International Investment Position of the United States in 1987. in: Survey of Current Business, vol. 68, Heft 6, S. 76-84

Scholl, Russell B. (1989). The International Investment Position of the United States in 1988. in: Survey of Current Business, vol. 69, Heft 6, S. 41-49

Scholl, Russell B. (1990). International Investment Position: Component Detail for 1989. in: Survey of Current Business, vol. 70, Heft 6, S. 54-65

Scholl, Russell B. (1991). The International Investment Position of the United States in 1990. in: Survey of Current Business, vol. 71, Heft 6, S. 23-35

Scholl, Russell B.; Mataloni, Raymond J. Jr.; Bezirganian, Steve D. (1992). The International Investment Position of the United States in 1991. in: Survey of Current Business, vol. 72, Heft 6, S. 46-59

Scott, M. FG. (1987). A note on King and Fullerton's formulae to estimate the taxation of income from capital. in: Journal of Public Economics, 34. Jg., S. 253-264

Seidel, Bernhard et al. (1989). Die Besteuerung der Unternehmensgewinne - sieben Industrieländer im Vergleich. DIW Beiträge zur Strukturforschung, Heft 111, Berlin 
Seierstad, A.; Sydsæter, K. (1987). Optimal Control Theory with Economic Applications. Amsterdam/New York

Seifert, Hubertus (1967). Die deutschen Direktinvestitionen im Ausland. Ihre statistische Erfassung als Instrument der internationalen technisch-wirtschaftlichen Zusammenarbeit. Köln und Opladen

Sensenbrenner, Gabriel (1991). Aggregate Investment, the Stock Market, and the $Q$ Model: Robust Results for Six OECD Countries. in: European Economic Review, 35. Jg., Mai, S. 769-825

Shaikh, Anwar (1974). Laws of Algebra and Laws of Production: The Humbug Production Function. in: Review of Economics and Statistics, 57. Jg., Heft 1, S. 115-120

Shaikh, Anwar (1980). Laws of algebra and laws of production the humbug production function II. in: Nell, Edward J. (Hrsg.): Growth, Profits, and Property. Essays in the Revival of Political Economy. 1. Aufl., Cambridge

Shaikh, Anwar (1987). „Humbug production function". in: Eatwell, John et al. (Hrsg.): The New Palgrave. A Dictionary of Economics. Band 2, 1. Aufl., London, S. 690-691

Sievert, Olaf et al. (1989). Steuern und Investitionen. Teil 2. Frankfurt am Main

Sinn, Hans-Werner (1985). Kapitaleinkommensbesteuerung. Berlin

Slemrod, Joel (1990). Tax Effects on Foreign Dirct Investment in the United States: Evidence from a Cross-Country Comparison. in: Razin, Assaf; Slemrod, Joel (Hrsg.): Taxation in the Global Economy. Chicago und London, S. 79-116

Snoy, Bernard (1975). Taxes on Direct Investment Income in the EEC. A Legal and Economic Analysis. New York/Washington/London

Spangemacher, Gerd; Spangemacher, Klaus (1986). Gewerbesteuer. 8. Aufl., Bonn/Achim bei Bremen

Spooner, Gillian M. (1986). Effective tax rates from financial statements. in: National Tax Journal, 39. Jg., S. 293-306

Statistisches Bundesamt (Hrsg.) (1990). Volkswirtschaftliche Gesamtrechnungen. Fachserie 18, Reihe 1.3, Konten und Standardtabellen, 1989, Hauptbericht, Wiesbaden

Stawinoga, Rainer (1987). Handbuch der französischen Körperschaftsteuer. Fachbuchreihe der AHK Paris. Paris

Stehn, Jürgen (1992). Ausländische Direktinvestitionen in Industieländern. Theoretische Erklärungsansätze und empirische Evidenz. Tübingen

Stiglitz, Joseph E. (1988). Why Financial Structure Matters. in: Journal of Economic Perspectives, 2. Jg., Heft 4, Fall, S. 121-126

Stiglitz, Joseph (1992). Capital markets and economic fluctuations in capitalist economies. in: European Economic Review, 36. Jg., Heft 2/ 3, April 92, S. 269-306

Stobbe, Alfred (1972). Volkswirtschaftliches Rechnungswesen. 3., rev. und neubearb. Aufl., Berlin

Stone Tice, Helen; Moczar, Louis J. (1986). Foreign Transactions in the National Income and Product Accounts: An Overview. in: Survey of Current Business, vol. 66, Heft 11, S. 23-36

Streck, Michael (1991). Körperschaftsteuergesetz mit Nebengesetzen. 3., neubearb. Aufl., München

Summers, Lawrence H. (1981). Taxation and corporate investment: A q-Theory Approach. in: Brookings Papers on Economic Activity, Heft 1, S. 67-140 
Terborgh, George (1954). Realistic depreciation policy. Machinery and allied products institute, 0.0 .

Tiley, John et al. (1991). Butterworths UK Tax Guide 1991-92. London

Tillmanns, Wolfhard (1989). Das Steuerrecht Frankreichs. in: Internationale WirtschaftsBriefe, Gruppe 2, Frankreich, 25.4.1989, Nr. 8, S. 721-736

Tipke, Klaus; Lang, Joachim (1991). Steuerrecht. Ein systematischer Grundriß. 13., völlig überarb. Aufl., Köln

Tobin, James (1961). Money, Capital and Other Stores of Value. in: American Economic Review, Papers and Proceedings, 51. Jg., May, S. 26-37

Tobin, James (1967). Comment on Crockett-Friend and Jorgenson. in: Ferber, Robert (Hrsg.): The Determinants of Investment Behavior. A Conference, Universities National Bureau Conference Series No. 18, 1. Aufl., New York, S. 156-160

Tobin, James (1969). A General Equilibrium Approach to Monetary 'Theory, in: Journal of Money, Credit and Banking, 1. Jg., Heft 1, February, S. 15-29

Tobin, James (1978). Monetary Policies and the Economy: The Transmission Mechanism. in: Southern Economic Journal, January, S. 421-431

Tobin, James (1982). Money and Finance in the Macroeconomic Process. in: Journal of Money, Credit, and Banking, 14. Jg., Heft 2, May, S. 171-204

Tobin, James; Brainard, William C. (1968). Pitfalls in Financial Model Building. in: American Economic Review, Papers and Proceedings, 58. Jg., May, S. 99-122

Tobin, James; Brainard, William C. (1977). Asset Markets and the Cost of Capital. in: Belassa, Bela; Nelson, Richard (Hrsg.): Economic Progress, Private Values and Public Policy. Essays in Honor of William Fellner. 1. Aufl., Amsterdam, S. 235-62

Tobin, James; White, Philip M. (1981). Comments and Discussion on „Taxation and corporate investment: A q-Theory Approach“. in: Brookings Papers on Economic Activity, Heft 2, S. 132-139

Treadway, Arthur B. (1969). On Rational Entrepreneurial Behavior and the Demand for Investment. in: Review of Economic Studies, 36. Jg., April, S. 227-239

Treadway, Arthur B. (1970). Adjustment Costs and Variable Inputs in the Theory of the Competitive Firm. in: Journal of Fconomic Theory, Heft 2, S. 329-347

U.S. Department of Commerce (1976). Foreign Direct Investment in the United States. Report of the Secretary of Commerce to the Congress in Compliance with the Foreign Investment Study Act of 1974 (Public Law 93-479), vol. 2: Report of the Secretary of Commerce: Benchmark Survey, 1974. Washington D. C.

U.S. Department of Commerce-Bureau of Economic Analysis (1981). U.S. Direct Investment Abroad, 1977. Washington D. C.

U.S. Department of Commerce-Bureau of Economic Analysis (1983). Foreign Direct Investment in the United States, 1980. Washington D. C.

U.S. Department of Commerce-Bureau of Economic Analysis (1985a). U.S. Direct Investment Abroad: Country and Industry Detail for Position and Balance of Payments Flows, 1984. in: Survey of Current Business, vol. 65, No. 8, S. 30-46

U.S. Department of Commerce-Bureau of Economic Analysis (1985b). U.S. Direct Investment Abroad: 1982 Benchmark Survey Data. Washington, D. C.

U.S. Department of Commerce-Bureau of Economic Analysis (1986). U.S. Direct Investment Abroad: Detail for Position and Balance of Payments Flows, 1985. in: Survey of Current Business, vol. 66, Heft 8, S. 40-73 
U.S. Department of Commerce-Bureau of Economic Analysis (1989). Measuring the U.S. International Investment Position. in: Survey of Current Business, vol. 69, Heft 6, S. 40

U.S. Department of Commerce-Bureau of Economic Analysis (1990a). Foreign Direct Investment in the United States: 1987 Benchmark Survey, Final Results. Washington, D. C.

U.S. Department of Commerce-Bureau of Economic Analysis (1990b). The Balance of Payments of the United States: Concepts, Data Sources, and Estimating Procedures. Washington D. C.

U.S. Department of Commerce-Bureau of Economic Analysis (1990c). U.S. Direct Investment Abroad: Detail for Position and Balance of Payments Flows, 1989. in: Survey of Current Business, vol. 70, Heft 8, S. 56-98

U.S. Department of Commerce-Bureau of Economic Analysis (1991a). Alternative Measures of the Rate of Return on Direct Investment. in: Survey of Current Business, vol. 71 , No. 8 , S. $44-45$

U.S. Department of Commerce-Bureau of Economic Analysis (1991b). Foreign Direct Investment in the United States: Detail for Historical-Cost Position and Balance of Payments Flows, 1990. in: Survey of Current Business, vol. 71, No. 8, S. 47-79

U.S. Department of Commerce-Bureau of Economic Analysis (1991c). Improving the Quality of Economic Statistics: The 1992 Economic Statistics Initiative. in: Survey of Current Business, vol. 71, No. 3, S. 4-5

U.S. Department of Commerce-Bureau of Economic Analysis (1991d). U.S. Direct Investment Abroad: 1989 Benchmark Survey, Preliminary Results. Washington, D. C.

U.S. Department of Commerce-Bureau of Economic Analysis (1991e). U.S. Direct Investment Abroad: Detail for Historical-Cost Position and Balance of Payments Flows, 1990. in: Survey of Current Business, vol. 71, No. 8. S. 81-107

U.S. Department of Commerce-Bureau of Economic Analysis (1991f). U.S. Direct Investment Abroad: Operations of U.S. Parent Companies and Their Foreign Affiliates. Preliminary 1989 Estimates. Washington, D. C.

U.S. Department of Commerce-Bureau of Economic Analysis (1991g). U.S. Direct Investment Abroad: Operations of U.S. Parent Companies and Their Foreign Affiliates, Revised 1988 Estimates. Washington, D. C.

U.S. Department of Commerce-Bureau of Economic Analysis (1992a). Foreign Direct Investment in the United States: Detail for Historical-Cost Position and Balance of Payments Flows, 1991. in: Survey of Current Business, vol. 72, No. 8, S. 87-115

U.S. Department of Commerce-Bureau of Economic Analysis (1992b). Foreign Direct Investment in the United States: Establishment Data for 1987. Washington, D. C.

U.S. Department of Commerce-Bureau of Economic Analysis (1992c). Foreign Direct Investment in the United States: Operations of U.S. Affiliates of Foreign Companies. Preliminary 1990 Estimates. Washington, D. C.

U.S. Department of Commerce-Bureau of Economic Analysis (1992d). Foreign Direct Investment in the United States: Operations of U.S. Affiliates of Foreign Companies. Revised 1989 Estimates. Washington, D. C.

U.S. Department of Commerce-Bureau of Economic Analysis (1992e). U.S. Direct Investment Abroad: Detail for Historical-Cost Position and Balance of Payments Flows. 1991. in: Survey of Current Business, vol. 72, No. 8. S. 116-144

U.S. Department of Commerce-Bureau of Economic Analysis (1992f). U.S. Direct Investment Abroad: Operations of U.S. Parent Companies and Their Foreign Affiliates. Preliminary 1990 Estimates. Washington. D. C. 
U.S. Department of Commerce-The International Investment Division (1976). Benchmark Survey of Foreign Direct Investment in the United States, 1974. in: Survey of Current Business, vol. 56, No. 5, S. 35-51

Vogt, Winfried (1992). Über die Rationalität der ökonomischen Theorie. in: Jahrbuch 10: Die ökonomische Wissenschaft und ihr Betrieb, Campus Verlag: Frankfurt am Main/New York, S. 32-59

Wagner, Joachim (1991). Die bundesrepublikanische Industrie auf dem Weltmarkt. Ökonometrische Untersuchungen zu Bestimmungsgründen von Außenhandel und internationaler Produktion. Berlin

Wegener, Ralph (1987). Makroökonomische Investitionsmodelle auf der Grundlage der neoklassischen Theorie. Eine empirische Untersuchung der Bruttoinvestitionen der Wirtschaftssektoren der Bundesrepublik Deutschland. Krefeld

Wesselbaum-Neugebauer, Claudia (1992). Internationale Steuerbelastungsvergleiche. Unveröffentlichte Dissertation, Universität Wuppertal

Wetzler, James (1981). Roundtable Discussion on policy inititateves to stimulate productivity. in: Hulten, Charles R. (Hrsg.). Depreciation, inflation, and the taxation of income from capital. Washington D. C., S. 279-303

Whichard, Obie G. (1983). U.S. Direct Investment Abroad in 1982. in: Survey of Current Business, vol. 63 , No. 8, S. 14-30

Whichard, Obie G.; Shea, Michael A. (1985). 1982 Benchmark Survey of U.S. Direct Investment Abroad. in: Survey of Current Business, vol. 65, Heft 12, S. 37-57

Whitman, Peter G. et al. (1988). Whiteman on income tax. 3. Aufl., London

Wildasin, D.E. (1984). The $q$ Theory of Investment with Many Capital Goods. in: American Economic Review, 74. Jg., March, S. 203-210

Wirtschaftsprüfer-Handbuch (1992). Handbuch für Rechnungslegung, Prüfung und Beratung. 10. Aufl., Band I. Hrsg. vom Institut der Wirtschaftsprüfer in Deutschland e. V., Düsseldorf

Wöhe, Günter (1974). Einführung in die Allgemeine Betriebswirtschaftslehre. unveränderter Nachdruck der 11., neubearb. und erw. Aufl., München

Wöhe, Günter (1984). Einführung in die Allgemeine Betriebswirtschaftslehre. 15., überarb. Aufl., München

Wöhe, Günter; Bieg, Hartmut (1991). Grundzüge der Betriebswirtschaftlichen Steuerlehre. 3., neubearb. Aufl., München

Wöhe, Günter; unter Mitarbeit von Ulrich Döring (1992). Bilanzierung und Bilanzpolitik. Betriebswirtschaftlich - Handelsrechtlich - Steuerrechtlich. 8., völlig neubearb. und erw. Aufl., München

Young, Kan H. (1988). The Effects of Taxes and Rates of Return in Foreign Direct Investment in the United States. in: National Tax Journal, vol. 41, S. 109-121

Young, Kan H. (1989). Reply to Murthy's Comment. in: National Tax Journal, vol. 42, S. 209 


\section{Quellenverzeichnis:}

Außenwirtschaftsgesetz vom 28. April 1961 (BGBl. I S. 481)

Drittes Gesetz zur Änderung des Außenwirtschaftsgesetzes vom 29. März 1976 (BGBl. I S. 869)

Fünftes Gesetz zur Änderung des Außenwirtschaftsgesetzes vom 20. Juli 1990 (BGBl. I S. 1457)

Gesetz zu dem Vertrag vom 31. August 1990 zwischen der Bundesrepublik Deutschland und der Deutschen Demokratischen Republik über die Herstellung der Einheit Deutschlands - Einigungsvertragsgesetz - und der Vereinbarung vom 18. September 1990 vom 23. September 1990 (BGBl. II S. 885)

Gesetz zur Änderung des Finanzverwaltungsgesetzes und anderer Gesetze vom 7. Juli 1992 (BGBl. I S. 1222)

Verordnung zur Durchführung des Außenwirtschaftsgesetzes (Außenwirtschaftsverordnung - AWV) vom 22. August 1961 (BGBl. I S. 1381)

Vierte Verordnung zur Änderung der Außenwirtschaftsverordnung vom 17. Dezember 1963 (BGBl. I S. 888)

Bekanntmachung der Neufassung der Verordnung zur Durchführung des Außenwirtschaftsgesetzes (Außenwirtschaftsverordnung - AWV) vom 31. August 1973 (BGBI. I S. 1069)

Einunddreißigste Verordnung zur Änderung der Außenwirtschaftsverordnung vom 30. Januar 1974 (BGBl. I S. 122)

Fünfunddreißigste Verordnung zur Änderung der Außenwirtschaftsverordnung vom 3. April 1976 (BGBI. I S. 891)

Zweiundfünfzigste Verordnung zur Änderung der Außenwirtschaftsverordnung vom 13. August 1982 (BGBl. I S. 1152)

Vierundfünfzigste Verordnung zur Änderung der Außenwirtschaftsverordnung vom 17. Januar 1983 (BGBI. I S. 29)

Neunundfünfzigste Verordnung zur Änderung der Außenwirtschaftsverordnung vom 10. September 1986 (BGBl. I S. 1494)

Verordnung zur Durchführung des Außenwirtschaftsgesetzes (Außenwirtschaftsverordnung - AWV) vom 18. Dezember 1986 (BGBl. I S. 2671)

Erste Verordnung zur Änderung der Außenwirtschaftsverordnung vom 14. Dezember 1987 (BGBI. I S. 2626)

Fünfte Verordnung zur Änderung der Außenwirtschaftsverordnung vom 20. September 1989 (BGBl. I S. 1749)

Sechzehnte Verordnung zur Änderung der Außenwirtschaftsverordnung. Vom 18. Juli 1991. in: Bundesanzeiger, 43. Jg., Nr. 133 vom 20. Juli 1991, S. 4741

Sechsundzwanzigste Verordnung zur Änderung der Außenwirtschaftsverordnung. Vom 8. Oktober 1992. in: Bundesanzeiger, 44. Jg., Nr. 194 vom 15. Oktober 1992 , S. 8237-8238. 
Otto Roloff, Sibylle Brander, Ingo Barens and Claudia Wesselbaum - 978-3-631-75210-4 Downloaded from PubFactory at 01/11/2019 07:04:40AM via free access 


\section{FINANZWISSENSCHAFTLICHE SCHRIFTEN}

Band 1 Werner Steden: Finanzpolitik und Einkommensverteilung. Ein Wachstums- und Konjunkturmodell der Bundesrepublik Deutschland. 1979.

Band 2 Rainer Hagemann: Kommunale Finanzplanung im föderativen Staat. 1976.

Band 3 Klaus Scherer: Maßstäbe zur Beurteilung von konjunkturellen Wirkungen des offentlichen Haushalts. 1977.

Band 4 Brita Steinbach: "Formula Flexibility" - Kritische Analyse und Vergleich mit diskretionărer Konjunkturpolitik. 1977.

Band 5 Hans-Georg Petersen: Personelle Einkommensbesteuerung und Inflation. Eine theoretisch-empirische Analyse der Lohn- und veranlagten Einkommensteuer in der Bundesrepublik Deutschland. 1977.

Band 6 Friedemann Tetsch: Raumwirkungen des Finanzsystems der Bundesrepublik Deutschland. Eine Untersuchung der Auswirkungen der Finanzreform von 1969 auf die Einnahmenposition der untergeordneten Gebietskörperschaften und ihrer regionalpolitischen Zieladåquanz. 1978.

Band 7 Wilhelm Pfähler: Normative Theorie der fiskalischen Besteuerung. Ein methodologischer und theoretischer Beitrag zur Integration der normativen Besteuerungstheorie in der Wohlfahrtstheorie. 1978.

Band 8 Wolfgang Wiegard: Optimale Schattenpreise und Produktionsprogramme für öffentliche Unternehmen. Second-Best Modelle im finanzwirtschaftlichen Staatsbereich. 1978.

Band 9 Hans P. Fischer: Die Finanzierung des Umweltschutzes im Rahmen einer rationalen Umweltpolitik. 1978.

Band 10 Rainer Paulenz: Der Einsatz finanzpolitischer Instrumente in der Forschungs- und Entwicklungspolitik. 1978.

Band 11 Hans-Joachim Hauser: Verteilungswirkungen der Staatsverschuldung. Eine kreislaurtheoretische Inzidenzbetrachtung. 1979.

Band 12 Gunnar Schwarting: Kommunale Investitionen. Theoretische und empirische Untersuchungen der Bestimmungsgründe kommunaler Investitionstătigkeit in NordmeinWestfalen 1965-1972. 1979.

Band 13 Hans-Joachim Conrad: Stadt-Umland-Wanderung und Finanzwirtschaft der Kernstădte. Amerikanische Erfahrungen, grundsắtzliche Zusammenhănge und eine Fallstudie für das Ballungsgebiet Frankfurt am Main. 1980.

Band 14 Cay Folkers: Vermógensverteilung und staatliche Aktivităt. Zur Theorie distributiver Prozesse im Interventionsstaat. 1981.

Band 15 Helmut Fischer: US-amerikanische Exportforderung durch die DISC-Gesetzgebung. 1981.

Band 16 Günter Ott: Einkommensumverteilungen in der gesetzlichen Krankenversicherung. Eine quantitative Analyse. 1981.

Band 17 Johann Hermann von Oehsen: Optimale Besteuerung. (Optimal Taxation). 1982.

Band 18 Richard Kössler: Sozialversicherungsprinzip und Staatszuschüsse in der gesetzlichen Rentenversicherung. 1982.

Band 19 Hinrich Steffen: Zum Handlungs- und Entscheidungsspielraum der kommunalen Investitionspolitik in der Bundesrepublik Deutschland. 1983.

Band 20 Manfred Scheuer: Wirkungen einer Auslandsverschuldung des Staates bei flexiblen Wechselkursen. 1983. 
Band 21 Christian Schiller: Staatsausgaben und crowding-out-Effekte. Zur Effizienz einer Finanzpolitik keynesianischer Provenienz. 1983.

Band 22 Hannelore Weck: Schattenwirtschaft: Eine Möglichkeit zur Einschrănkung der öffentlichen Verwaltung? Eine ökonomische Analyse. 1983.

Band 23 Wolfgang Schmitt: Steuern als Mittel der Einkommenspolitik. Eine Ergänzung der Stabilitătspolitik? 1984.

Band 24 Wolfgang Laux: Erhöhung staatswirtschaftlicher Effizienz durch budgetäre Selbstbeschrånkung? Zur Idee einer verfassungsmåßig verankerten Ausgabengrenze. 1984.

Band 25 Brita Steinbach-van der Veen: Steuerinzidenz. Methodologische Grundlagen und empirisch-statistische Probleme von Länderstudien. 1985.

Band 26 Albert Peters: Ökonomische Kriterien für eine Aufgabenverteilung in der Marktwirtschaft. Eine deskriptive und normative Betrachtung für den Allokationsbereich. 1985.

Band 27 Achim Zeidler: Möglichkeiten zur Fortsetzung der Gemeindefinanzreform. Eine theoretische und empirische Analyse. 1985.

Band 28 Peter Bartsch: Zur Theorie der längerfristigen Wirkungen 'expansiver' Fiskalpolitik. Eine dynamische Analyse unter besonderer Berücksichtigung der staatlichen Budgetbeschränkung und ausgewählter Möglichkeiten der öffentlichen Defizitfinanzierung. 1986.

Band 29 Konrad Beiwinkel: Wehrgerechtigkeit als finanzpolitisches Verteilungsproblem. Möglichkeiten einer Kompensation von Wehrungerechtigkeit durch monetäre Transfers. 1986.

Band 30 Wolfgang Kitterer: Effizienz- und Verteilungswirkungen des Steuersystems. 1986.

Band 31 Heinz Dieter Hessler: Theorie und Politik der Personalsteuern. Eine Kritik ihrer Einkommens- und Vermögensbegriffe. 1993.

Band 32 Wolfgang Scherf: Die beschäftigungspolitische und fiskalische Problematik der Arbeitgeberbeitrăge zur Rentenversicherung. Eine Auseinandersetzung mit der Kritik an der lohnbezogenen Beitragsbemessung. 1987.

Band 33 Andreas Măstle: Die Steuerunion. Probleme der Harmonisierung spezifischer Gütersteuern. 1987.

Band 34 Günter Ott: Internationale Verteilungswirkungen im Finanzausgleich der Europäischen Gemeinschaften. 1987.

Band 35 Heinz Haller: Zur Frage der zweckmäßigen Gestalt gemeindlicher Steuern. Ein Diskussionsbeitrag zur Gemeindesteuerreform. 1987.

Band 36 Thomas Kuhn: Schlüsselzuweisungen und fiskalische Ungleichheit. Eine theoretische Analyse der Verteilung von Schlüsselzuweisungen an Kommunen. 1988.

Band 37 Walter Hahn: Steuerpolitische Willensbildungsprozesse in der Europäischen Gemeinschaft. Das Beispiel der Umsatzssteuer-Harmonisierung. 1988.

Band 38 Ulrike Hardt: Kommunale Finanzkraft. Die Problematik einer objektiven Bestimmung kommunaler Einnahmemöglichkeiten in der gemeindlichen Haushaltsplanung und im kommunalen Finanzausgleich. 1988.

Band 39 Jochen Michaelis: Optimale Finanzpolitik im Modell überlappender Generationen. 1989.

Band 40 Bernd Raffelhüschen: Anreizwirkungen der sozialen Alterssicherung. Eine dynamische Simulationsanalyse. 1989.

Band 41 Berend Diekmann: Die Anleihe- und Darlehenstransaktionen der Europăischen Gemeinschaften. 1990.

Band 42 Helmut Kaiser: Konsumnachfrage, Arbeitsangebot und optimale Haushaltsbesteuerung. Theoretische Ergebnisse und mikroökonometrische Simulation für die Bundesrepublik Deutschland. 1990. 
Band 43 Rüdiger von Kleist: Das Gramm-Rudman-Hollings-Gesetz. Ein gescheiterter Versuch der Haushaltskonsolidierung. 1991.

Band 44 Rolf Hagedorn: Steuerhinterziehung und Finanzpolitik. Ein theoretischer Beitrag unter besonderer Berūcksichtigung der Hinterziehung von Zinserträgen. 1991.

Band 45 Cornelia S. Behrens: Intertemporale Verteilungswirkungen in der gesetzlichen Krankenversicherung der Bundesrepublik Deutschland. 1991.

Band 46 Peter Saile: Ein ökonomischer Ansatz der Theorie der intermediären Finanzgewalten Die Kirchen als Parafisci. 1992.

Band 47 Peter Gottfried: Die verdeckten Effizienzwirkungen der Umsatzsteuer. Eine empirische allgemeine Gleichgewichtsanalyse. 1992.

Band 48 Andreas Burger: Umweltorientierte Beschåftigungsprogramme. Eine Effizienzanalyse am Beispiel des "Sondervermögens Arbeit und Umwelt". 1992.

Band 49 Jeanette Malchow: Die Zuordnung verteilungspolitischer Kompetenzen in der Europäischen Gemeinschaft. Eine Untersuchung aufgrund einer Fortentwicklung der ókonomischen Theorie des Föderalismus. 1992.

Band 50 Barbara Seidel: Die Einbindung der Bundesrepublik Deutschland in die Europåischen Gemeinschaften als Problem des Finanzausgleichs. 1992.

Band 51 Ralph Wiechers: Markt und Macht im Rundfunk. Zur Stellung der offentlich-rechtlichen Rundfunkanstalten im dualen Rundfunksystem der Bundesrepublik Deutschland. 1992.

Band 52 Klaus Eckhardt: Probleme einer Umweltpolitik mit Abgaben. 1993.

Band 53 Oliver Schwarzkopf: Die Problematik unterschiedlicher Körperschaftsteuersysteme innerhalb der EG. 1993.

Band 54 Thorsten Giersch: Bergson-Wohlfahrtsfunktion und normative Ökonomie. 1993.

Band 55 Li-Fang Chou: Selbstbeteiligung bei Arzneimitteln aus ordnungspolitischer Sicht. Das Beispiel der Bundesrepublik Deutschland. 1993.

Band 56 Harald Schlee: Einkommensteuerliche Behandlung von Transferzahlungen. Zur Neuordnung der Familienbesteuerung sowie der Besteuerung von Versicherungsleistungen und Sozialtransfers. 1994.

Band 57 Alexander Spermann: Kommunales Krisenmanagement. Reaktionen baden-wūrttembergischer Stadtkreise auf steigende Sozialhiffekosten und Einnahmenausfälle (198092). 1993.

Band 58 Otto Roloff / Sibylle Brander / Ingo Barens / Claudia Wesselbaum: Direktinvestitionen und internationale Steuerkonkurrenz. 1994.

Band 59 Claudia Wesselbaum-Neugebauer: Internationale Steuerbelastungsvergleiche. 1994.

Band 60 Stephanie Miera: Kommunales Finanzsystem und Bevölkerungsentwicklung. Eine Analyse des kommunalen Finanzsystems vor dem Hintergrund der sich abzeichnenden Bevőlkerungsentwicklung am Beispiel Niedersachsens unter besonderer Berücksichtigung des Landkreises Wolfenbüttel und seiner Gemeinden. 1994.

Band 61 Wolfgang Scherf: Die Bedeutung des kaldorianischen Verteilungsmechanismus fúr die gesamtwirtschaftlichen Wirkungen der staatlichen Neuverschuldung. 1994.

Band 62 Rainer Volk: Vergleich der Vergünstigungseffekte der verschiedenen investitionsfördernden Maßnahmen. 1994.

Band 63 Hans-Georg Napp: Kommunale Finanzautonomie und ihre Bedeutung für eine effiziente lokale Finanzwirtschaft. 1994. 


\section{Claudia Wesselbaum-Neugebauer}

\section{Internationale Steuerbelastungsvergleiche}

Frankfurt/M., Berlin, Bern, New York, Paris, Wien, 1994. XX, 295 S., zahlr. Tab.

Finanzwissenschaftliche Schriften. Bd. 59

Verantwortlicher Herausgeber: Alois Oberhauser

ISBN 3-631-46837-7

In der Arbeit werden die bisher durchgeführten internationalen Steuerbelastungsvergleiche hinsichtlich ihrer Aussagekraft überprüft. Die Analyse verdeutlicht, daß zur Zeit keine theoretisch fundierten und empirisch durchführbaren Modelle für die Berechnung der effektiven Steuerbelastung von Unternehmen existieren. Unter Berücksichtigung der steuerlichen Gewinnermittlungsvorschriften sowie der anzuwendenden Verfahren zur Vermeidung bzw. Verminderung der Doppelbesteuerung wird eine einzelwirtschafltiche Veranlagungssimulation für ein real existierendes Unternehmen durchgeführt und der Einfluß der Körperschaftsteuer auf das verwendbare Eigenkapital einer Kapitalgesellschaft dargestellt. Die Untersuchung verdeutlicht, daß eine Reduzierung der komplexen Steuersysteme unterschiedlicher Nationen auf eine für alle Unternehmen geltende und miteinander vergleichbare Kennziffer nicht möglich ist.

Aus dem Inhalt: Internationale Steuerbelastungsvergleiche - Steuerliche Gewinnermittlungsvorschriften - Methoden zur Vermeidung der Doppelbesteuerung: Belastungsunterschiede zwischen den alternativen Formen des Auslandsengagements unter Berücksichtigung von DBA - Veranlagungssimulation

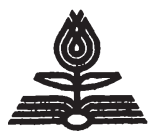

Verlag Peter Lang Frankfurt a.M. $\cdot$ Berlin $\cdot$ Bern $\cdot$ New York $\cdot$ Paris $\cdot$ Wien Auslieferung: Verlag Peter Lang AG, Jupiterstr. 15, CH-3000 Bern 15 Telefon (004131) 9411122, Telefax (004131) 9411131

- Preisăndenungen vorbehalten - 